\title{
ANTHROPOLOGICAL RESEARCHES AND STUDIES
}

No.8, 2018

ISSN 2360-3445

ISSN-L 2360-3445 


\section{Editorial Team:}

Honorary Editor: Gheorghiță Geană

Editor-in-Chief: Cornelia Rada

Assistant Editor: Alexandru Ispas

\section{Specialist Editors:}

Adina Baciu (biomedical anthropology, medicine, psychology)

Cornelia Rada (biomedical anthropology, medicine, psychology)

Gabriel Stoiciu (cultural anthropology, sociology, philosophy)

Corina Bistriceanu Pantelimon (cultural anthropology, sociology, philosophy)

Alexandra Comşa (paleoanthropology)

Alexandra Neagu (cultural and biomedical anthropology, philosophy)

\section{Responsible for final proofreading:}

Alexandra Neagu

Liliana Guran

\section{Technical Editors:}

Alexandra Neagu

Gabriel Stoiciu

\section{Consulting editors and experts:}

- Abdellatif Baali, Cadi Ayyad University, Department of Biology, Morroco; e-mail: abdellatifbaali@hotmail.com

- Adina Baciu, "Francisc I. Rainer" Anthropology Institute of the Romanian Academy, Bucharest, Romania; e-mail: adinabbaciu@ yahoo.com

- Adriana Albu, University of Medicine and Pharmacy, Iasi, Romania; e-mail: adrianaalbu@ymail.com

- Alexandra Comşa, Center of Thracology of the "Vasile Pârvan" Institute of Archaeology, Bucharest, Romania; e-mail: alexcomsa63@yahoo.com

- Alexandra Neagu, "Francisc I. Rainer" Anthropology Institute of the Romanian Academy, Bucharest, Romania; e-mail: alexandra_elena.neagu@yahoo.com

- Antoaneta Pungă, "Carol Davila" University of Medicine and Pharmacy, Discipline of Physiology, Bucharest, Romania; e-mail: antoaneta.punga@yahoo.com

- Arsene Eugen Tarţa, "Carol Davila" University of Medicine and Pharmacy, Bucharest, Romania; e-mail: eugentarta@yahoo.com

- Ciprian Ion Isacu, The Grand Hospital of Charleroi, Belgium; e-mail: ciprian.isacu@ghdc.be

- Consuelo Prado, Department of Biology, Autonomous University of Madrid, Spain; e-mail: consuelo.prado@uam.es

- Corina Bistriceanu Pantelimon, "Spiru Haret" University, Romania; e-mail: corinabistriceanu@yahoo.com

- Cornelia Rada, "Francisc I. Rainer" Anthropology Institute of the Romanian Academy, Bucharest, Romania; e-mail: corneliarada@yahoo.com

- Cristina Faludi, Faculty of Sociology and Social Work, "Babeş-Bolyai" University, ClujNapoca, Romania; e-mail: cristina.faludi@yahoo.com 
- Elena Doldor, Queen Mary University of London, School of Business and Management, United Kingdom; e-mail: e.r.doldor@qmul.ac.uk

- Emma Surman, Keele Management School, Keele University and Research Institute for Social Sciences, United Kingdom; e-mail: e.l.surman@keele.ac.uk

- Françoise Rovillé-Sausse, Muséum national d'histoire naturelle, Paris, France; e-mail: sausse@mnhn.fr

- Gabriel Stoiciu, "Francisc I. Rainer" Anthropology Institute of the Romanian Academy, Bucharest, Romania; e-mail: gabriel.stoiciu@gmail.com

- Konstantin S. Khroutski, Institute of Medical Education, Novgorod State University after Yaroslav-the-Wise, Novgorod the Great, Russia; e-mail: hrucki@mail.ru; hks@ @ novsu.ac.ru

- Laura-Oana Stroică, "Carol Davila” University of Medicine and Pharmacy, Bucharest, Romania; e-mail: joannadean78@yahoo.com

- Luminita Bejenaru, Faculty of Biology, Alexandru Ioan Cuza University of Iaşi, Romania; email: lumib@uaic.ro

- Martin Frisher, School of Pharmacy, Keele University, Staffordshire, UK; e-mail: m.frisher@keele.ac.uk

- Mihaela Kelemen, Keele Management School, Faculty of Humanities and Social Sciences, United Kingdom; e-mail: m.1.kelemen@keele.ac.uk

- Mihaela-Camelia Popa, "Constantin. Rădulescu-Motru" Institute of Philosophy and Psychology, Department of Psychology, Romanian Academy, Bucharest, Romania; e-mail: popa_zaizon@yahoo.com

- Mirko Spiroski, Department of Hematology University Medical Center Skopje, Faculty of Medicine, Skopje, Republic of Macedonia; e-mail: mspiroski@yahoo.com

- Monica Tarcea, University of Medicine and Pharmacy Targu-Mureş, Faculty of Medicine, Romania; e-mail: monaumf2001@yahoo.com; monica.tarcea@umftgm.ro

- Rodney J Reynolds, University College London's Institute for Global Health (IGH), England; email: rodney.reynolds@ucl.ac.uk

- Serghei Suman, State University of Medicine and Pharmacy "Nicolae Testemiţanu”, Chișinău, Republic of Moldova; e-mail: sumanser@yahoo.com; serghei.suman@usmf.md

- Svetoslav Handjiev, Bulgarian Association for the Study of Obesity and Related Diseases (BASORD); Bulgarian Society for the Healthy Foods and Nutrition, Bulgaria; e-mail: svhandjiev@gmail.com

- Tatjana Pavlica, Faculty for Sciences Department for Biology and Ecology, Novi Sad, Serbia; email: tatjana.pavlica@dbe.uns.ac.rs

- Tudor B. Marinescu, "Carol Davila" University of Medicine and Pharmacy, Bucharest, Romania; e-mail: tudorm77@gmail.com

- Victoria Russeva, Institute of Experimental Morphology and Anthropology, Bulgarian Academy of Sciences, Sofia, Bulgaria; e-mail: victoria_russeva@yahoo.com

- Wanda Dressler, Centre National de la Recherche Scientifique, Laboratoire "Dynamique sociale et recompositions des espaces", Paris, France; email: wanda.socio@gmail.com

- Zofia Dworakowska, Institute of Polish Culture, Warsaw University, Poland; e-mail: dworakowska@gmail.com 


\section{Table of Contents}

VALENTINA MARINESCU, IOANA SILISTRARU, Interpersonal communication within Romanian medical field.

ECATERINA BALICA, Young intimate femicide in Romania. Incidence and risk factors.

ANA POPOVA, Risk factors for the safety of the children from transnational families (children left behind)....

DJERDJI ERDES KAVECAN, ANIDA R. FAZLAGIC, Characteristics of psychophysical health, generativity and integrity level in elderly people considering previous and current financial status.

SANTIAGO BOIRA, ANITA NUDELMAN, TINA (TIKO) TSOMAIA, A preliminary analysis of gender violence among migrants and displaced people in Europe.

NINA ERJAVEC, GREGOR ŽVELC, Psychopathology and parent-child relationships in illicit drugs users

SIMONA DE STASIO, BENEDETTA RAGNI, FRANCESCA BOLDRINI, FRANCESCA BEVILACQUA, SIMONETTA GENTILE, Parental stress and bedtime routines in toddlerhood.

ILIYANA KIRILOVA-MOUTAFOVA, The role of psychopathology in social skills training of children with conduct disorder.

CONSTANȚA URZEALĂ, Considerations regarding the risks of obesity and physical inactivity

KRISTINA BRAJOVIC CAR, ALEKSANDRA ĐURIĆ, OANA PĂNESCU, Psychological profiling of participants at the Miss World contest via combined methodology: psychometric assessments and projective drawing. 
ANITA NUDELMAN, DELI TIZE TERI, YAFFLO OUATTARA, Gender and culture-related barriers to access to mother and infant health services in the Far North of Cameroon

SILVA IBRAHIMI, EGLANTINA DERVISHI, VALBONA MUCA, MARIJE DOBRA, Psychodynamic prototype through personality organization chart of educational leaders

CORNELIA RADA, Aging and intergenerational care.

OLUYEMI JOSEPH, YINUSA MOHAMMED, BASHIRU SALAWU, ABDULATEEF RAJI, EMMANUEL ATOLAGBE AND ADEJOKE JOSEPH, Role Conflict among Female medical Career women: who bridges the Gap?.

DIEGO OSWALDO CAMACHO VEGA, Influence of social network sites in healthy behavior related to vigorous recreational physical activity

CONSUELO PRADO, DOLORES MARRODAN, PAULA ACEVEDO, MARGARITA CARMENATE, Girl Body Composition according to pubertal status. Methodology variation.

SVETOSLAV HANDJIEV, ANELIYA KUZEVA, Anthropometric study on the role of yoghurt fermented with Lactobacillus bulgaricus and Bifidobacterium Animalis (subspecies Lactis) in the prevention and treatment of obesity and related diseases.

ALINA FERDOHLEB, Changes in occupational profiles and occupational health service.

ELENA CIOBANU, CĂTĂLINA CROITORU, ANGELA CAZACUSTRATU, SERGHEI CEBANU, OVIDIU TAFUNI, Indoor air pollution associated with population health status

DENIZ YOLDAS, Recreation of personal activist identity in a post-war West Balkan city: Petrinja. 
GÁBOR KOVÁCS, HEALTH OF PUBLIC LIFE IN THE PHILOSOPHY OF HANNAH ARENDT: THE RELATION OF THE PUBLIC AND PRIVATE REALMS IN THE CENTURIES OF MODERNITY

GUDIPATY NAGAMALLIKA, Representation of 'family' in Indian television serials.

YINUSA MOHAMMED, OLUYEMI JOSEPH, BASHIRU SALAWU, ABDULATEEF RAJI, EMMANUEL ATOLAGBE, ADEJOKE JOSEPH, The Family and National Development: How can the Family Forestall Future Insurgency Activities in the Nigerian Society?

BÉLA MESTER, Literati's health and illness as metaphors of the reflections to the modernity in the 19th-century Hungarian intellectual history.

ANTOINE HEEMERYCK, Social Movement and Civil Society in Postcommunist Romania: Local Evolution, Global Comparison

GABRIEL STOICIU, From spontaneous cyber-solidarities to radicalization of protest speech.

ANNA E. KUBIAK, Civilized and wild heterotopia - the case of the Polish cemeteries

ARULCHELVAN SRIRAM, An investigation of television programmes that illustrates superstition and its events on viewers

PETYA PACHKOVA, The Bulgarian family in the early 21st century

BORIS MANOV, VALENTINA MILENKOVA, Students' research activity as a contribution for modern university 


\title{
Interpersonal communication within Romanian medical field
}

\section{DOI: http://doi.org/10.26758/8.1.1}

Valentina Marinescu (1), Ioana Silistraru (1)

Faculty of Sociology and Social Work, Bucharest, Romania

Address correspondence to: Valentina Marinescu, Faculty of Sociology and Social Work, Bd. Schitu Măgureanu, No. 9 - Bucharest, Romania. Ph.: +40720024813; E-mail: vmarinescu9@yahoo.com

\begin{abstract}
Objectives. At present, it is widely recognized that improving quality in healthcare delivery had become an extremely important topic for research. The objective of this study is to compare the types of interpersonal communication between Romanian patients and their general practitioners (GPs) with the discussions between Romanian pharmacists and the patients.

Material and methods. A quantitative method based on a comparative design for analyzing a sample of 199 respondents was conducted. The questionnaire consists of ten open questions plus five socio-demographic items. Descriptive statistics was used in the analysis of the result.

Results. A high percentage of the respondents (35\%) did assess pharmacists as simple dealers and most of them did not communicate with the pharmacists during their encounters. At the same time, only $15 \%$ of the entire sample had discussed more than a half an hour with their GPs, the main subjects of discussions being rather "standardized" (i.e. current treatments and the general health).

Conclusions. Lack of trust in the medical system and medical staff is directly linked not only to the economic and logistic conditions (lack of proper financing, massive migration of doctors, etc.) but it is also a consequence of the "improper" interpersonal communication between the patients and the Romanian medical staff. The basic conclusion of the study is that new strategies and plans for improving interpersonal communication among patients, GPs and pharmacists are needed at present in Romania.
\end{abstract}

Keywords: interpersonal communication; patients; doctors; pharmacists.

\section{Introduction}

Communication between patient and physician is analyzed in order to extract a series of information that will improve the overall medical act designed to heal or alleviate the suffering of the first (i.e. the patient). Doctor-patient bi-directional communication is at the basis of some modern concepts in medical care - patient-centered care or shared decision-making, both designed to significantly improve the quality of the medical act and to limit diagnostic errors and treatment (Stewart, 2005).

\section{Medical narrative - medicine practiced with communication skills}

With the development of the medical narrative study, a new discipline emerged. This is a discipline that analyses the narratives identified during the physician-patient dialogue, especially for decrypting the narrative exposed by the patient, so that the purpose of the medical act is to cure or alleviate suffering. Kathryn Montgomery Hunter (1991) defined medical narrative as an art that 
depends crucially on the ability to say and interpret a story - the story of the patient's illness and suffering.

The medical narrative supports the physician and the patient as the most complex instrument of medicine casuistic that allows practitioners to share diagnosis and vision of the therapeutic act, to circumscribe a single case and, at the same time, to obtain sufficient generalizations which would be useful both in practice and in the improvement of their profession.

The dialogue is at the heart of the medical act due to the fact that medicine is fundamentally narrative, according to Hunter (1991). This is especially true for evidence-based medicine that is usually practiced in university hospitals, and the most important narratives the physician must take into account are those occurring just at the beginning of the interaction with their patient.

Patient narrative recorded inside the medical office or hospital where he or she meets the physician is very different from the vivid color descriptions, the true "war stories" that the patient reports outside of the medical setting. At the first meeting with the doctor, there is the autobiographical narrative that describes a "chronicle" of suffering from a personal perspective, with elements organized sometimes chronologically, with descriptions made in her or his own language of how the disease affects her or him. This is essentially the first narrative that the practitioner receives, and in terms of narrative medicine, it might be one of the most important for the subsequent evolution of his or her relationship with the patient. The structure of the medical narrative is supplemented by the narrative of the doctor or the therapist. He or she (i.e. the practitioner) will use his or her own language and usually will intervene in the patient's narrative to order the useful information for a potential diagnosis in an anamnesis. Hunter $(1991, \mathrm{p} .8)$ uses the concept of "patient as text", which can be understood according to the narrator's skills. The medical profession involves not only a cognitive engagement, as each interaction with the patient brings new information, but also emotional engagement, when the doctor empathizes with his or her suffering. The two levels, cognitive and emotional, are the basis of an intuitive, creative, doctor-specific mechanism that puts together all the information within the interaction with the patient (Stewart, 2005, p.793).

The narrative approach takes into account the patient's narrative and interpretation of the disease. People live in realities they have been symbolically built (Pendelton and Hasler, 1983, p.34) and the symbols used in the disease's narrative are the meanings that the experience of the disease brought to the patients. The only way to decrypt those meanings, writes Pendelton and Hasler (1983), is to examine the narrative of the disease, namely the narrative of the patient.

\section{Patient's expectations of the relationship with his doctor}

According to Stewart (2005), there are two elements needed for the success of doctorpatient communication: the doctor's openness to listen to the patient's story and his or her willingness to learn something new with each narrative run by each patient.

"I have witnessed magical moments during patient meetings with their doctors; I have witnessed the mystery of medical practice and have seen the evolution of patients from sickness to health and vice versa. I have seen many times the way doctors help patients to rebuild their lives for all their lives" (Stewart, 2005, p.793).

The dialogue between physician and patient is the key component of the healthcare system, especially in basic medical care (Beck, Daughtridge and Sloane, 2002, p.25) On the other hand, according to Lipkin, Putnam, and Lazare (1995), it is estimated that a general practitioner performs between 120,000 and 160,000 interviews during a 40-year career. In terms of the quality of physician-patient communication, according to Beck, Daughtridge and Sloane (2002), this has often 
been considered inappropriate. Most patients who were interviewed by Beck, Daughtridge and Sloane assessed that communication skills are among the top three abilities a physician must have, but they have frequently complained that their doctors have less satisfactory communication expertise (Beck, Daughtridge and Sloane, 2002, p.25).

\section{The informed patient}

Medical information is increasingly available from other alternative sources than the medical staff. Since the early 1970's, studies and researches on medical communications have highlighted this quality of the patient, that is, his or her need to be informed and able to ask information specific to him or her (Waitzkin and Stoeckle, 1972). Keating, McDermott, and Montgomery (2014) have shown that there are benefits in the therapeutic process for the patient if he or she is informed and educated and this perspective has become dominant in the research centered on generally improving medical performance. The same researchers are mentioning physician-patient communication as a key element in achieving the goals of the medical act. In this case, physician-patient communication has to involve the assimilation of medical vocabulary and to enable the patient to assign real symptomatology, which becomes a source of relevant information for later diagnosis (Keating, McDermott and Montgomery, 2014, p.14).

\section{Consultation - dialogue between physician and patient}

The definition of consultation, equating with physician-patient dialogue, is that of a "meeting" between two people who usually try to influence one another (Pendelton and Hasler, 1983). Each of them has its own beliefs and ideas, its own feelings and motives, values and needs brought within the consultation. According to Pendelton and Hasler (1983), the key is "mutual understanding". "Understanding", as it is used in "New Consultation - Developing Doctor-Patient Communication", is the result of a process that involves formal learning and information, general and professional socialization, as well as individual experience and education.

"(Consciousness - AN) is a mixture of cognition and affection: the thoughts and feelings that govern the physician's and patient's guidance and which contribute to the modeling of its content" (Pendelton and Hasler, 1983, p.20).

\section{Clinician pharmacist's role in patient compliance with treatment}

The existing literature (Francis and Abraham, 2014, p.600) provides a special role for the clinician in securing that the patient complies with the recommended treatment of the physician. The clinical pharmacist is the specialist who interacts most with the patient to guide, to get medical and therapeutic history, to check for medication errors (including prescribing and administration), to identify possible interactions between prescription drugs, to suggest a personalized dosage and to counsel the patient (Francis and Abraham, 2014, p.600).

In the Romanian medical system, the pharmacist is a relatively new category, and, as such, he or she is little understood, on the one hand. On the other hand, the existing literature and the specialists themselves recognize that the ideal collaboration relationship between the clinician and the patient must be close and in the benefit of the patient (***Pagina Farmaciștilor, 2017).

The clinician should be present at all pharmacies in the community, and any patient may be able to address the side effects he or she may have, ask him or her when and how to contact the doctor if needed. The relationship between the clinician and the patient should be a close one, but for this, the patient must be educated that this specialization exists and that it is something different in the occupational spectrum (***Săptămâna Medicală, 2017). 


\section{Methodology}

In order to study patient-physician and patient-pharmacist communications, an exploratory research project has been made. A quantitative method based on a comparative design for analyzing a sample of 199 respondents has been used. The data were collected in November 2016-March 2017 with the help of an anonymous online questionnaire applied in Bucharest. The questionnaire consisted of ten open questions plus five socio-demographic items.

The method of analyzing the data was an iterative one: the observational codes in the answers have been first identified, then all responses were coded with axial codes, and were transferred to an Excel file. The resulting file was further transformed into an SPSS file, which was analyzed using this statistical package.

\section{Case presentation}

When asked how they can characterize the health system in Romania a huge percentage $(83.4 \%)$ of the respondents used negative statements.

Table 1. How can you characterize the situation of the health system in Romania?

\begin{tabular}{|l|c|}
\hline & $\%$ \\
\hline Positive & 5.5 \\
\hline Middle situation & 7.5 \\
\hline Negative & 83.4 \\
\hline
\end{tabular}

The main arguments used in negative assessments of the Romanian medical system enclosed references to "poverty" (e.g. lack of financial resources and logistic shortages), "corruption", bad management, bureaucracy and lack of understanding from the part of medical staff toward patients' needs. Some examples are below:

"It is poverty in the system. And that is because resources are not well managed, partly due to corruption, partly due to the poor involvement of the Government in the system, and a high degree of bureaucracy. As a result, we have a medical system that does not focus on prevention and where everyone manages on his/her own, either going to the private clinics or avoiding accessing medical services."

"It is a disaster. The medical system is broken primarily due to the attitude of the medical staff, which believed of themselves to be a kind of semi-gods. Secondly, it is due to the attitude of servants that patients have. And, in third place, I should point out the managers of the system who are, in fact, the big thieves who take bribes without worrying to destroy a system, which is already crumbling."

"It is a precarious situation. There is no good communication in the system. What should make ease the lives of doctors and patients in fact put a burden on them. And I refer here at the bureaucracy, at the health cards that do not work, and the payments that are not done in time for the suppliers of different services...".

"There is no concern for the patient's well-being and for the creation of a well-functioning system in which both those who work within it and those who benefit from it to be satisfied. I must add that, 
generally, good health systems are not cheap."

As the data show, in $40.4 \%$ of the cases, the General Practitioners were negatively assessed by the respondents. The situation was mainly due to the direct contact the interviewees had with the doctors. "Lack of empathy", "superficial", "not interested in patients' situation" were only a few characteristics laying at the basis of negative evaluations of GPs relations with respondents, as shown below:

He seems to be nonhuman ... unfortunately! The GP or family medicine should be the most important point for primary prevention.

Oh,...he is superficial. And that's just because he is prescribing my antibiotic on the phone, if you can imagine that.

He is non-existent. He is no longer professing and informs me that he has "passed this dance" to his wife. I never met her. I even wonder if I can be enlisted to another GP without removing the file from where she is now.

He is not serious; his secretary prints you the receipt.

A person who is not at all interested in the patient's situation and offers very strong treatments regardless of the patient's illnesses and symptoms.

At the same time, $35.1 \%$ of the sample equated the pharmacists with shop assistants, as shown in the citations from below:

She is a sales employee who does not know medicine more than me.

He is always in a hurry. He is giving quickly a medicine without listening to all you have to say. And he is insistent with selling non-generic drugs.

He is very helpful! It has never happened to me to enter the pharmacy and not be listened.

I met pharmacists very well trained. Near the block where I live there is a pharmacy with a lab and I often buy products prepared by the pharmacists working there. They're more effective.

Oh, she is a simple seller (I do not trust her advice).

Concerning the last visit to the GPs, $21.3 \%$ of the respondents declared that it was two or three months before, while for $22.8 \%$ of them the visit was made six months before. At the same time, the contacts with the pharmacists were in a shorter time-span: over a half of the respondents $(66 \%)$ declared that they went to a pharmacy the same month and around one-third (23.4\%) a month before. 
Table 2. When did you visit the last time your personal GP and when did you go for the last time to a pharmacy?

\begin{tabular}{|l|c|c|}
\hline & Last visit at the personal GP (\%) & Last visit at the pharmacy (\%) \\
\hline This month & 11.6 & 66 \\
\hline Last month & 16.1 & 23.4 \\
\hline Two or three months ago & 21.1 & 8.1 \\
\hline Six months ago & 22.6 & 2 \\
\hline Last year & 10.6 & - \\
\hline More than a year ago & 18.1 & 0.5 \\
\hline
\end{tabular}

The reasons for visiting the GPs were: to obtain a medical certificate for a specialist doctor $(23.7 \%)$, to make a medical control (34\%), to obtain a general medical certificate $(12.9 \%)$, and to make the personal set of medical analysis $(12.4 \%)$.

In general, the respondents acknowledged that their visit to the GPs lasted between one to twenty minutes (59.4\%) and only $17.8 \%$ declared that their last visit lasted between 20 and 30 minutes.

The main topics of discussion with the GP's were "general personal health status" $(26.2 \%)$, "disease symptoms" (15.4\%), "treatment" (12.8\%) and "interpretation of the analysis and diagnostic" (11.8\%). While only $11.8 \%$ of the respondents did not have any discussion with their GPs, almost one-third of them $(29.2 \%)$ declared that they did not communicate with the pharmacists when they went to the pharmacy.

Table 3. Topic of discussion with GPs vs. topic of discussion with pharmacists

\begin{tabular}{|l|c|l|c|}
\hline \multicolumn{1}{|c|}{ Topic of discussion with GPS } & $\%$ & \multicolumn{1}{|c|}{ Topic of discussion with pharmacists } & $\%$ \\
\hline Disease symptoms & 15.4 & Modes of drug administration & 10.8 \\
\hline General health status & 26.2 & $\begin{array}{l}\text { Recommendations for other drugs than } \\
\text { those prescribed by the doctor }\end{array}$ & 23.8 \\
\hline About the treatment & 12.8 & The price of drugs & 7 \\
\hline Prevention & 6.2 & $\begin{array}{l}\text { Explanation regarding the recipes and } \\
\text { drugs }\end{array}$ & 7.6 \\
\hline $\begin{array}{l}\text { Interpreting the analysis and } \\
\text { diagnosis }\end{array}$ & 11.8 & General topics relating to medicine & 17.3 \\
\hline I have no discussion & 11.8 & I have no discussion & 29.2 \\
\hline Another situation & 15.9 & Another situation & 4.3 \\
\hline
\end{tabular}

Almost a quarter of the total number of respondents $(23.8 \%)$ had communicated with the pharmacists to obtain recommendations for other drugs than those prescribed by their doctors and $17.3 \%$ had a discussion on general topics related to medicine.

When asked about the degree of trust in different occupations within the medical field, the respondents showed that surgeons, specialist doctors, and dentists were credited with relatively high levels of public trust (between 29.6\% for surgeons and $26.1 \%$ for dentists). 
Table 4. What is your degree of trust in ... (\%)

\begin{tabular}{|l|c|c|}
\hline & The lowest (rank 1) & The highest (rank 5) \\
\hline GP & 16.1 & 19.1 \\
\hline Medical assistant & 9.5 & 6.5 \\
\hline Dentist & 3.5 & 26.1 \\
\hline Pharmacist & 12.6 & 9 \\
\hline Specialist doctor & 1.5 & 28.6 \\
\hline Surgeon & 2.5 & 29.6 \\
\hline
\end{tabular}

The results showed that pharmacists and medical assistants had the lowest level of trust among the respondents, with $9 \%$ of the interviewees/respondents highly ranking the pharmacists and only $6.5 \%$ declaring a high trust in medical assistants. With $19.1 \%$ of the total sample assessing a high degree of trust in them, the GPs were placed in the middle position within the respondents' evaluations.

\section{Discussions and conclusions}

Officially, in Romania, primary care, provided through the General Practitioners (Family Doctors), represents the first contact of the population with the health system, both for the diagnosis and treatment of the diseases, as well as for carrying out preventive medical examinations. In 2016, most Romanian GP offices operated in urban areas, 6.7 thousand compared to 4.6 thousand in rural areas, where a family doctor's office has to take care of 1.3 times more inhabitants (belonging to the resident population in the village) compared to an urban one (***Institutul Naţional de Statistică, 2017). Out of the total number of Romanian doctors, $21.5 \%$ were GPs, nearly two-thirds of them practicing in the urban area (***Institutul Național de Statistică, 2017).

In 2016, the discrepancies regarding the access to the medical staff per residential areas are evident. More exactly, in the rural area, 7.9 times more inhabitants do not have access to a doctor as compared with those from the urban areas. Also, in rural areas, 6.1 more times inhabitants do not have access to a dentist as compared with those from the urban areas. Finally, compared with inhabitants from urban areas, 4.0 more times inhabitants from rural areas do not have access to a pharmacist (***Institutul Naţional de Statistică, 2017).

In Bucharest, in May 2016 there were around 977 General Practitioners who had a direct work contract with Bucharest Health Insurance House (***Casa de Asigurări de Sănătate a Municipiului București, 2017). As the statistical data show, in 2015, in Bucharest, for every 100.000 inhabitants, there have been 654 doctors, 90.7 General Practitioners and 563.3 specialist doctors (***Fundația Comunitară București, 2017).

Despite the fact that Bucharest is in a better position than the rest of the country as regards the ratio of medical staff to the number of inhabitants our data reveal that there is a general lack of confidence in the health system a whole, doctors, and pharmacists. The reasons behind this situation comprise not only financial problems, management shortages or out-dated technologies, but also the lack of communication with medical personnel.

The fact that GPs have become a sort of state-bureaucrats (according to our respondents they only write prescriptions or interpret the set of medical analysis) raises serious problems related to their role in the Romanian medical system, as our respondents have also noticed. More than a half 
of the sample declared that they had discussed no more than twenty minutes with their GPs and only for $6.2 \%$ the topic of conversation was prevention for health-related issues.

The higher frequency of visits to the pharmacy seems to confirm the existing data on the high percentage of Romanians practicing self-medication (***Asociaţia Medicilor de Familie Mures, 2016). At the same time, the standard image of the pharmacist as a simple shop assistant makes this problem (e.g. self-medication) difficult to control.

Although this is only an exploratory study one can conclude that the lack of trust in Romanian medical system and medical staff is directly linked to the economic and logistic conditions (lack of proper financing, massive migration of doctors, etc.) and is also a consequence of the "improper" interpersonal communication between the patients and the Romanian medical staff (GPs and pharmacists).

We advocate, as such, that some changes have to be done at different. In our opinion, those new strategies and plans for improving interpersonal communication among patients, GPs and pharmacists have to be based on the active involvement of the three parts in the medical act.

Conflict of interest. The authors of this article do not have any conflict of interests.

\section{Bibliography}

1. Beasley, J.W., Starfield, B., van Weel, C., Rosser, W.W., Haq, C.L., 2007. Global health and primary care research. The Journal of the American Board of Family Medicine, 20(6), pp.518526.

2. Beck, R.S., Daughtridge, R., Sloane, P.D., 2002. Physician-patient communication in the primary care office: a systematic review. The Journal of the American Board of Family Practice, 15(1), pp.25-38.

3. Francis, J., Abraham, S., 2014. Clinical pharmacists: Bridging the gap between patients and physicians. Saudi Pharmaceutical Journal, 22(6), pp.600-602.

4. Hunter, K.M., 1991. Doctors' stories: The narrative structure of medical knowledge. New Jersey: Princeton University Press.

5. Keating, M., McDermott, A., Montgomery, K., 2014. Patient-centred health care: achieving coordination, communication and innovation. Houndsmills, Basingstoke: Palgrave Macmillan.

6. Lipkin, M., Putnam, S.M., Lazare, A., 1995. The medical interview. The medical interview: clinical care, education, and research. New York: Springer-Verlag.

7. Pendelton, D.A. (author), and Hasler, J.D. (editor), 1983. Doctor-patient communication. Theory and Practice. London; New York; Sydney: Academic Press.

8. Waitzkin H., Stoeckle, J.D., 1972. The Communication of Information About Illness: Clinical, Sociological, and Methodological Considerations. Advances in Psychosomatic Medicine, 8, pp. $180-215$.

9. ***Asociația Medicilor de Familie Mureș, 2016. Automedicația este un fenomen îngrijorător, 3 din 4 români se tratează fără a consulta medicul de familie, [online] Available at: http://amfms.ro/automedicatia-este-un-fenomen-ingrijorator-3-din-4-romani-se-trateaza-fara-aconsulta-medicul-de-familie/ [Accessed 19 July 2017]

10. ***Casa de Asigurări de Sănătate a Municipiului București, 2017. Deconturi lunare MF, [online] Available at: http://www.cnas.ro/casmb/page/deconturi-lunare-cabinete-mf.html [Accessed 29 July 2017].

11. ***Fundația Comunitară București, 2017. Raportul Vital Signs 2017 București, [online] Available at: http://bucuresti.vitalsigns.ro/sanatate/ [Accessed 28 July 2017]. 
12. ***Institutul Național de Statistică, 2017. Comunicat de presă - Domeniul: Statisticasănătății 16/30 iunie 2017, [online] Available at: http://www.insse.ro/cms/ro/comunicate-de-presa-view [Accessed 29 July 2017].

13. ***Pagina Farmaciștilor, 2017.Confuzie intre farmacistul generalist de spital si farmacistul clinician, [online] Available at: http://www.paginafarmacistilor.ro/stiri-pharma/confuziefarmacistul-generalist-spital-clinician_5783/ [Accessed 19 July 2017].

14. ***Săptâmăna Medicală, 2017. Necesitatea existenței farmacistului clinician și importanța educației pacientului, printre temele de actualitate dezbătute la FarmaPracticed. 50, [online] Available at: http://www.saptamanamedicala.ro/articole/Necesitatea-existentei-farmacistuluiclinician-si-importanta-educatiei-pacientului-printre-temele-de-actualitate-dezbatute-la-FarmaPractic-ed-50.html [Accessed 18 July 2017]. 


\title{
Young intimate femicide in Romania. Incidence and risk factors
}

\section{DOI: http://doi.org/10.26758/8.1.2}

\author{
Ecaterina Balica
}

Institute of Sociology of the Romanian Academy

Address correspondence to: Ecaterina Balica, Institute of Sociology of the Romanian Academy, Academy House, 13 September Avenue, No.13, 5th District, Bucharest, Romania. Ph.: +400213182448. E-mail: ebalica $\underline{\text { HS@ gmail.com }}$

\begin{abstract}
Objectives. This paper presents the results of the first research made in Romania on young intimate femicide cases committed between 2011 and 2015. The study aims to identify the incidence, risk factors and the particularities of the young intimate femicide from a South-East European country. Material and methods. In the definition area for 'young intimate femicide', there are included all cases of intentional murder of a woman aged between 15-25 years, both the victim and the offender being actual or former intimate partners. Information about the cases of young intimate femicide was extracted from the online media. The registration file for the young intimate femicide cases includes: data regarding the victim, the offender, and the murder.

Results. A number of 184 cases of intimate femicide were committed in Romania between 20112015, out of which 32 cases (17.4\%) were committed against young women aged between 15 and 25 years old. On average, 6 young intimate femicide cases were committed per year. The number of women murdered in urban areas $(59.4 \%)$ was higher than the number of young intimate femicide committed in rural areas $(40.6 \%)$.

Conclusions. This study confirms the results of other studies regarding young intimate femicide. The results of data analysis show that the young intimate femicide is the result of a relationship marked by violence against women. For most of the cases, jealousy associated with the suspicion of infidelity represented the main reasons for young intimate femicide.
\end{abstract}

Keywords: young intimate femicide; risk factors; victims; perpetrators; Romania.

\section{Introduction}

The number of women killed by their partner is still high at the moment, despite the fact that in some regions of the world important steps in fighting violence against women, including intimate femicide, were taken. In the category of 'intimate femicide', all the homicides intentionally committed by the current or former partner (husbands, lovers, concubines) on women were included. A study which analyzed the data regarding intimate partner homicide in 66 countries pointed out that "one in seven homicides (13.5\%) is committed by an intimate partner" (Stockl et al., 2013, p.859). On average, $38.6 \%$ of the total number of femicide cases was committed by the intimate partner. The highest values of intimate femicide were recorded in Southeast Asia (58.8\%), the Americas (40.5\%), and Africa (40.1\%) (Ibidem). The studies focused on the identification of risk factors showed that among risk factors there are: Intimate Partner Violence (Campbell, 1992, 2003; 
Dobash et al., 2004), history of violence, forced sex and threats to harm children (McFarlane et al., 1999), the victim separation from offender (Dobash et al., 2004; Brenan, 2016) associated with "stalking, abuse during pregnancy, forced sex, and previous threat with a weapon" (Campbell et al., 2003b:1089). Other studies pointed out the role of socio-demographical factors (such as the age of aggressor and victim, the poverty, the ethnicity, the type of relationship - Dobash et al., 2004; Campbell et al., 2003b; Wilson et al., 1995).

Some authors drew attention to the fact that offenders who commit femicide are "specialized" in "violence against women" (Dobash et al., 2004). Other authors showed the fact that the offenders were themselves victims of the abuse during their childhood (Aldrige and Browne 2003), they were poor and unemployed (Campbel, 2003, Dobash et al., 2004), have mental health issues (Dobash et al., 2004; Campbell et al., 2001; Belfrage and Rying, 2004), have substance use problems (Dobash et al 2004), a personal criminal history (Belfrage and Rying 2004) and also they have the desire to control women (Dobash et al., 2004; Campbell et al., 2003; Wilson and Daly, 1992). In most of the cases the victims are women who are members of the ethnic groups (Corradi and Piacenti, 2016; Cases et al., 2009; Campbell et al., 2003), have substance use problems (Sharps et al., 2003), and previous experience of Intimate Partner Violence victimization (Abrahams et al., 2000).

The majority of these studies do not differentiate between adult intimate femicide and young or adolescent intimate femicide. So far, few studies have been carried out regarding young intimate femicide and even less were focused on identifying the risk factors that are specific for this type of violence. Nevertheless, some studies highlighted the fact that young femicide cases were committed to a higher extent by intimate partners and family members (Coyne-Beasley et al., 1999), while adolescent femicide cases (11-14 years) were mostly committed by family members (Coyne-Beasley et al., 2003).

Other studies provided information regarding the incidence of femicide for some age groups. Studies carried out in countries from Latin America highlighted the fact that the number of femicide adolescent victims was quite high. In Argentina, the number of female adolescents murdered was of 124 victims aged between 13 and 18 years old within the timeframe 2008-2013 (Zambrano, 2017). On average, 21 female adolescents per year lost their lives in this country. In Mexico, 315 girls and teenagers were killed in 2013 only (Frayssinet, 2015).

In England and Wales, within the timeframe 2009-2015, 3.5\% of the victims of femicide were aged between 14 and 17 years old and 14.8\% were aged between 18 and 25 years old (Brenan, 2016:16). Among the factors which determinate the Intimate Partner Violence evolution towards young femicide there were highlighted the fact that young women tend to consider the partner's violence a sign of love (Roscoe and Callahan, 1983; Roscoe and Kelsey, 1986; Seimer, 2004) and do not evaluate correctly the consequences of violence (Seimer, 2004). Other studies showed that, in general, young intimate femicide is determined by the same risk factors identified among adult intimate femicide. However, the influence of some factors like: jealousy and the partner's desire to control the victim, unemployment and the separation of the victim from the perpetrator are more strongly manifested among cases of young intimate femicide (Glass et al., 2008).

\section{Material and methods}

In this paper, the term 'femicide' was used as it was defined in the Vienna Declaration as "the killing of women and girls because of their gender" (***2013, p.2). In the definition area for „young intimate femicide" there were included all cases of murder intentionally committed on a 
woman aged between 15 and 25 years old, with the victim and the aggressor being actual or former intimate partners (husband, ex-husband, partner, ex-partner, lover, ex-lover). Here there are included all cases committed between Romanians, either in Romania or abroad, regardless of the aggressor's age.

The study presents the results of the analysis of young intimate femicide cases committed between 2011 and 2015. The corpus of the analysis was formed by all the young intimate femicide cases which were identified in the online media $(\mathrm{N}=32)$. In order to obtain information regarding these cases, articles from Romanian media regarding cases of young intimate femicide within the timeframe 2010-2015 ( $\mathrm{N}=569$ articles) were analyzed. These articles were identified using keywords typed in Google Chrome: "murdered his wife/ex-wife", "murdered his girlfriend/exgirlfriend", "murdered his concubinel ex-concubine". In order to identify as many articles as possible, new keywords extracted from the articles found in the first phase were used to find other articles related to the case of young intimate femicide. These keywords were: the name of the aggressor, the weapon used to commit the murder and the place where the murder occurred. The resulting articles were analyzed using a scale divided into four sections: data regarding young intimate femicide, data regarding the victim, data regarding the offender and data regarding media coverage of the case. In order to identify young intimate femicide, all the cases involving victims under the age of 25 and who were either current or former intimate partners when the murder occurred were selected. In the end, $\mathrm{N}=32$ of intimate femicide cases committed by intimate partners on women who were under the age of 25 were identified.

\section{Results}

In the timeframe 2011-2015, in Romania, there were committed 184 intimate femicides. On average, 25.3 women were murdered by their partners per year. In the same timeframe, 54 young femicides took place, 32 cases being committed on young women aged between 15-25 years old. The weight of young intimate femicide in the total amount of intimate femicide cases was $17.4 \%$. , On average, 6 young intimate femicide cases were committed per year. In 2013 values two times higher than the annual average (12 cases) were recorded. The fewest cases were committed in 2015 ( 2 cases). Approximately two-thirds of the cases were committed in the urban area (19 cases) and the rest of them in the rural area (13) (see Table 1).

Table 1. Intimate femicide cases and young intimate femicide cases committed in Romania

\begin{tabular}{|c|c|c|}
\hline Year & Intimate femicide cases & Young intimate femicide cases \\
\hline 2011 & 18 & 5 \\
\hline 2012 & 41 & 6 \\
\hline 2013 & 48 & 12 \\
\hline 2014 & 44 & 7 \\
\hline 2015 & 34 & 2 \\
\hline Total & 184 & 32 \\
\hline
\end{tabular}

\section{Perpetrators' characteristics}

The average age of the perpetrators was 24.7 years old (16-56 years old). More than half of the perpetrators were young people under the age of 25 (16-17 years old - 3 perpetrators; 18-25 
years old -14 perpetrators). A quarter of the perpetrators were young people aged between 26-35 years old, while 5 perpetrators were aged between 36-45 years old. A single perpetrator was above the age of 56. Information about the educational level and profession was rarely mentioned in the articles. Only the professions of one-third of the perpetrators (11) were identified, the majority having a low professional level (9): skilled and low-skilled workers, day laborers, unemployed. Two of the perpetrators were found to have a high professional status: one of them was a well-known businessman and the other was the secretary-general of a county party organization. The great majority of the perpetrators worked in Romania and only four of them abroad ( 2 in Italy, one in the UK and one in Spain).

One-third of the perpetrators were under the influence of alcohol (9) or drugs (1). Health issues were mentioned for only two perpetrators: one of them suffered from depression and the other from a borderline personality disorder. One-third of the perpetrators (11) had criminal records: theft (2), assault and battery (3), rape (1), procuring (2), drug trafficking (1), public order offense (1), and trespassing (1). Three perpetrators were sanctioned for violence acts against the victims that were killed. In one case, the perpetrator had a restraining order and was not allowed to approach the victim.

More than a half of the perpetrators were residents in the urban area (17) and the rest in the rural area (14) (see Table 2).

Table 2. Characteristics of victims and perpetrators

\begin{tabular}{|c|c|c|}
\hline Age & Victims & Perpetrators \\
<17 years & 9 & 3 \\
18-25 years & 23 & 14 \\
26-35 years & - & 9 \\
36-45 years & - & 5 \\
56 years & - & 1 \\
\hline Level of education & - & \\
Low & 5 & 1 \\
Medium & 3 & 1 \\
High & 24 & 29 \\
Unknown & 7 & 8 \\
Occupation level & 1 & 1 \\
Low & - & 2 \\
Medium & 24 & 21 \\
High & 16 & 17 \\
Unknown & 14 & 14 \\
\hline Residence & 1 & $9 / 1$ \\
Urban & & \\
Rural & - & 2 \\
\hline Alcohol/drug & - & 11 \\
consumption & & \\
\hline Health/mental problems & & \\
\hline Criminal records & & \\
\hline
\end{tabular}




\section{Characteristics of the victims}

The victims' average age was 19.9 years old (15-25 years old). Approximately two-thirds were aged between 18 and 25 years old (23 victims), and one third were minors, under the age of 18 (9). It was noticed that the victims' age was younger than the perpetrators'.

The level of education was mentioned for only eight victims. Five of them were high school pupils and three were university students (see Table 2).

More than half of the victims came from the urban area (16) and the rest from the rural area (14). For three of them, the residence was not mentioned. Only one was under the drug influence. The great majority of the victims (23) were clinically healthy people.

\section{Relationship background}

The great majority of the perpetrators were the victims' current partners when the murder occurred (19 were boyfriends and 4 were husbands). Approximately one-third of them were former partners ( 9 former boyfriends). Three of the perpetrators had been separated for maximum 2 weeks and two couples had been separated for 6 months. One victim had just announced the perpetrator that she wanted to break up with him. Most of the actors involved in young intimate femicide cases had been together for maximum 2 years (10). Approximately one third (8) had had a relationship lasting 2-4 years, two couples a relationship longer than 5 years, and one couple a 10-year relationship.

More than a third of the perpetrators (11) were described as jealous (7) or violent (11) individuals. We notice the fact that violence was mentioned for all the 11 perpetrators, while jealousy was indicated only for seven perpetrators. Among them, some perpetrators were both violent and jealous (4) or both jealous and possessive (2). One perpetrator was well known for the jealousy and the threatening towards the victim. For another perpetrator, there were mentioned the jealousy and the fact that he continued to stalk the victim even after they had broken up.

For two-thirds of the relationships (21) frequent verbal conflicts were indicated. One-third of the victims were physically aggressed. Three victims lodged a complaint to the police and seven told the relatives about the violence acts they were undergone to by their partners. A single victim had obtained a restraining order against her perpetrator. One victim was beaten by her former partner even after they had separated. For two victims, there was information that the perpetrators had threatened them to death.

\section{Data regarding young intimate femicide}

The great majority of young intimate femicide (29 cases) were acts of violence involving a single victim. Only three cases involved more victims, one of them being the aggressor's intimate partner (one case had 2 victims, the second 3, and the third 6 victims). Most of the young intimate femicide cases (23) were committed in the evening and at night in the timeframe $6.00 \mathrm{pm}-6.00 \mathrm{am}$. The rest of them were committed during the day, between $6.00 \mathrm{am}$ and $6.00 \mathrm{pm}$. One-third of the young intimate femicide cases were committed at the victim's place ( 3 in the house and 8 in the yard) and only five young intimate femicide cases were committed at the aggressor's place (4 in the house and 1 in the yard). One-third of the murders (11) were committed in the place shared by the victim and the aggressor. Other seven young intimate femicide acts were committed in public places 
(the center of the town, the hospital) or in spaces located at the periphery of the city (abandoned building, parks, a river's shore).

Half of the murders were committed by using a knife and five young intimate femicide acts were committed by hitting the victims with other objects ( 2 with an axe, 2 with a stake/pipe, one with scissors). Approximately one-third of the victims (8) were murdered by hitting them with fists and legs. Eight victims were murdered by strangulation and three were burnt alive. One-third of the young intimate femicide cases (10) were committed in the presence of some witnesses. In four of the cases, the witnesses were members of the family, in other four cases the family's children were present, and in two cases members of the aggressor's family. In almost half of the cases (14) multiple hits on the victims' bodies were identified. In eight cases, the victims were killed by a single hit, in four by 2-5 hits, and in three cases they were killed with 9-14 hits.

Table 3. Motivation of young intimate femicide

\begin{tabular}{|l|c|}
\hline Motivation & Number of cases \\
\hline The aggressor was jealous and thought the victim was cheating on him & 9 \\
\hline The aggressor was jealous & 4 \\
\hline The aggressor did not stand the idea of breaking up with the victim & 4 \\
\hline The victim wanted to end the relationship with the aggressor & 2 \\
\hline $\begin{array}{l}\text { Between the aggressor and the victim conflicts often occurred and following } \\
\text { some contradictions, the situation degenerated }\end{array}$ & 1 \\
\hline $\begin{array}{l}\text { The aggressor was jealous and the victim was often threatened because of } \\
\text { jealousy }\end{array}$ & 1 \\
\hline $\begin{array}{l}\text { The victim ended the relationship with the aggressor. The latter tried to convince } \\
\text { the victim to get back together when she came to his place, but she refused and } \\
\text { the perpetrator became aggressive }\end{array}$ & \\
\hline The victim refused to get back with the partner & 2 \\
\hline $\begin{array}{l}\text { The victim refused to have sexual intercourse with the aggressor and wanted to } \\
\text { go to her parents }\end{array}$ & \\
\hline The aggressor tried to have sexual intercourse with the victim and she refused & 1 \\
\hline $\begin{array}{l}\text { The victim refused to go to France together with the aggressor. He did not have a } \\
\text { permanent job and had gone abroad for } 8 \text { months. At his return, he found the } \\
\text { victim pregnant, which led to the idea he had been cheated on }\end{array}$ & \\
\hline The victims wanted to separate from the partners & 1 \\
\hline $\begin{array}{l}\text { The victim wanted to end the relationship with the aggressor and to abort the } \\
\text { pregnancy }\end{array}$ & \\
\hline The victim and her relatives wanted to throw the aggressor out of the house & 5 \\
\hline $\begin{array}{l}\text { The victim wanted to return to Romania to visit her relatives. The aggressor did } \\
\text { not agree with this - jealous of what the victim could do while she was at home }\end{array}$ & \\
\hline $\begin{array}{l}\text { Between the aggressor and the victim took place conflicts based on alcohol/drugs } \\
\text { consumption }\end{array}$ & 1 \\
\hline The aggressor found out that the victim cheated on him & 2 \\
\hline
\end{tabular}

One-third of the murders were based on jealousy and suspicion of infidelity (9). Other six young intimate femicide cases were committed because of the perpetrators' jealousy. Four of the murderers were generated by conflicts between aggressors and victims and two of them occurred in 
the context of alcohol and drugs consumption. The victims' refusal to get back together with the perpetrators led to killing three young women. A young intimate femicide case was committed because the victim refused to go to France together with the perpetrator, and two cases were committed because the victims refused to have sexual intercourse with the perpetrators. Seven young intimate femicide cases were committed because the victims wanted to separate from the perpetrators (one victim wanted to separate from him and to have an abortion and another victim wanted to throw the aggressor out of the house). For a single young intimate femicide case, there was information that the perpetrator killed his partner because she cheated on him.

\section{Discussions}

The data analysis regarding the young intimate femicide cases in Romania has highlighted the fact that this type of violence seems to align to the patterns of young intimate femicide cases that were analyzed in some European countries (England and Wales). The weight of young intimate femicide cases among the total of intimate femicide cases in Romania was similar to the one recorded in approximately the same timeframe (2009-2015) in England and Wales (Romania 17.4\%; England and Wales - 18.3\%) (Brenan, 2016, p.16).

The number of young intimate femicide cases recorded in Romania was significantly smaller than in countries from Latin America. In Argentina 124 young intimate femicide acts were committed in the timeframe 2008-2013 (Zabrano, 2017) and in Mexico 315 cases were recorded in a single year (Frayssinet, 2015). The average number of young intimate femicide cases per year in Romania was also smaller (6 cases per year) than in countries where this average was calculated (for example Argentina 21 cases per year) (Zabrano, 2017). The small number of young intimate femicide cases identified in Romanian media may be far from being real. Previous studies focused on the analysis of some types of homicide (Balica, 2016a) showed the fact that Romanian media presented approximately half of the homicide - suicides cases committed in the timeframe 20032013. Other studies showed an increase journalists' interest in media coverage of lethal violence in the recent years (Balica, 2016a, Balica, 2016b). Under these circumstances, shown in other papers (Balica, 2018, in press), as the official statistics (of police and justice) do not contain information regarding the victims' gender, the real number of young intimate femicide cases cannot be evaluated.

As it is also presented in the studies carried out in England and Wales (Brenan, 2016, p.16), most of the victims of young intimate femicide cases from Romania were aged between 18-25 years old (two-thirds of the victims). The fact that approximately two-thirds of the young femicide cases $(\mathrm{N}=32)$ were committed by intimate partners confirms the results of other studies which also have shown that young femicide acts with victims aged between 18-25 years old were committed by intimate partners (Coyne-Beasley et al., 1999). At the same time, the results of our study confirm the fact that the age difference between partners represents a risk factor for young intimate femicide. In Romania, the age difference between partners ( 4.8 years) was similar to the age difference identified within research in the USA (4.7 years) (Glass et al., 2008, p.181).

The results of the present study confirm the information highlighted by other studies in Romania and different European countries regarding femicide in general or young intimate femicide. They show the fact that acts of violence have mainly been based on jealousy and the suspicion of infidelity, these two motivations being also identified in young intimate femicide (Glass et al., 2008) and in intimate femicide (Balica, 2018, in press; Balica, 2016a). In this study, unlike intimate femicide, jealousy and suspicion of infidelity seem to be more obvious as main motivations 
of young intimate femicide. The situation is not specific for Romania only, but also for cases committed in other countries (Glass et al., 2008). Taking into account the fact that there is an obvious background of violence between the two partners (although the majority of couples have had a relationship of maximum two years), frequent verbal conflicts, physical aggressions, death threatening and following the victim by the perpetrator were indicated in most of the cases. Information regarding the acts of violence they were undergone to and the lack of police reports can also be interpreted as a sign of tolerance from the victims towards the partners' violence. We can evaluate that there is a high level of interpreting the partner's violence as a sign of love by the young victims (Seimer, 2004; Roscoe and Callahan, 1983).

The way young intimate femicide acts were committed is specific for murderers committed against intimate partners. In most of the cases, the victims were killed using a knife either at their home or at the aggressor's. Using the knife as a murder weapon is a common fact in Romania (Balica, 2016; Balica, 2018, in press). In other European countries, the knife is one of the most frequently used (in Italy, for example, $29 \%$ of femicide acts were committed using a knife) together with the fire weapons (Italy - 31\%) (Corradi and Piacenti, 2016). In the United Kingdom, most of the cases of femicide (45.5\%) and intimate femicide $(48.5 \%)$ were also committed with a sharp object (a knife) (Brenan, 2016, p.26). Strangulating the victim was mentioned in approximately onethird of the young intimate femicide cases in Romania, a fact which confirms the results of international studies regarding femicide (UK - strangulating is the second killing method within intimate femicide) (Brenan, 2016, p.26). On the other hand, the fact that more than half of the victims (17) were murdered by multiple stabs confirms the results of some studies regarding intimate femicide (Mathews et al., 2008; Chan, 2007). The presence of physical and verbal violence acts, but also of threatening and stalking (aggressor following the victim) made us think that the great number of stabs represents the expression of the perpetrator's hostility towards the victim, as it is also shown by Chan in his studies (2007).

\section{Conclusions}

The research regarding young intimate femicide is one of the few studies that have been carried out on this topic at an international level and the first of this kind among countries from the South-East of Europe. Few studies regarding femicide and young femicide were carried out in the European area, although over the past few years the pressure of the European feminist organizations to initiate some measures that would prevent femicide has been felt. The paper brings into the discussion a type of lethal violence whose victims are young women in particular. The present study allows the identification of some risk factors that are specific for young intimate femicide committed in Romania.

The number of the cases analyzed was quite small and the information regarding young intimate femicide was taken from media, therefore the conclusions of this study should be considered with precaution. Nevertheless, the results of our study are similar to the results of international studies. The fact that young intimate femicide (adolescent femicide and young adult femicide) remains quite high in some regions of the world, determines us to suggest the expansion of the analysis of young intimate femicide cases to a greater period of time and the usage of some data regarding this type of femicide which are in the custody of the law system (criminal files from courts, data from police's statistics). The interviews with perpetrators who committed young intimate femicide or with young intimate femicide survivors could be used in order to identify the factors generating intimate partner violence within young short-term couples (as it results/ed from our research). 


\section{Bibliography:}

1. Abrahams, N., Mathews, S., Martin, L.J., Lombard, C., Jewkes R., 2013. Intimate Partner Femicide in South Africa in 1999 and 2009. PLoS Med 10(4): e1001412. Available at: https://doi.org/10.1371/journal.pmed.1001412 [Accessed 22 August 2017].

2. Aldridge, M. L., and Browne, K. D., 2003. Perpetrators of spousal homicide. Trauma, Violence \& Abuse, 4(3), pp.265-276.

3. Balica, E., 2018. Femicidul în comunitățile de imigranți români [Femicide within the Romanian immigrants communities], Revista Română de Sociologie, in press.

4. Balica, E., 2016a. Homicide-Suicide in Romania: Statistical data and Media Representation, Peter Lang Publishing House. Frankfurt am Main

5. Balica, E., 2016b. Homicides-suicides dans la presse roumaine en ligne. In: Dragan, I., Pelissier N\& Frumusani D.R (Eds.). Jurnalisme et transformations sociales: des ancienes aux nouveaux medias. Paris: l'Harmattan.

6. Belfrage, H. and Rying, M. 2004. Characteristics of spousal homicide perpetrators: A study of all cases of spousal homicide in Sweden 1990-1999. Criminal Behaviour and Mental Health, 14(2), pp.121-133.

7. Brennan, D., 2016. Femicide census. Profiles of women killed by men. Redefining an isolated incident. Available at: http://www.northwales-pcc.gov.uk/Document-Library/Advice/FemicideCensus-Report-2016.pdf. [Accesed 22 August 2017].

8. Campbell, J. C., Webster, D., Koziol-Mclain, J., Block, C. R., Campbell, D., Curry, M. A., Gary, F., McFarlane, J., Sachs, C., Sharps, P., Ulrich, Y., Wilt, A.S. 2003a. Assessing risk factors for intimate partner homicide. National Institute of Justice Journal, 250, pp.14-19.

9. Campbell, J. C., Webster, D., Koziol-Mclain, J., Block, C. R., Campbell, D. W., Curry, M. A., et al., 2003b. Risk factors for femicide in abusive relationships: Results from a multisite case control study. American Journal of Public Health, 93(7), pp.1089-1097.

10. Campbell, J. C., 1992. "If I can't have you, no one can": Power and control in homicide of female partners. In: J. Radford and D.E.H. Russell, eds. Femicide: The politics of woman killing. New York: Twayne. pp.99-113.

11. Chan, C.Y. A., 2007. Hostility in Homicide - Suicide Events: A Typological Analysis with Data from a Chinese Society, Hong Kong, 1989-2003. Asian Criminology, 2, pp.1-18.

12. Corradi, C. and Piacenti, F., 2016. Analyzing femicide in Italy. Overview of major findings and international comparisons. Romanian Journal of Sociological Studies, 1, pp.3-17.

13. Coyne-Beasley, T., Moracco K. E., Casteel M. J., 2003. Adolescent Femicide. A populationbased study. Archives of Pediatrics and Adolescent Medicine Journal, 157(4), pp.355-360.

14. Coyne-Beasley, T., Schoenbach, V.J., Herman-Giddens, M.E., 1999. The Epidemiology of adolescent homicide in North Carolina from 1990 to 1995. Archives of Pediatrics and Adolescent Medicine Journal, 153(4), pp.349-356.

15. Dobash, R. E., Dobash, R. P., Cavanagh, K., and Lewis, R., 2004. Not an ordinary killer - Just an ordinary guy. When men murder an intimate woman partner. Violence Against Women, 10(6), pp.577-605.

16. Frayssinet, F., 2015. Teenage Girls in Argentina - Invisible Victims of Femicide. Available at: http://www.ipsnews.net/2015/01/teenage-girls-in-argentina-invisible-victims-of-femicide/. [Accessed 16 August 2017].

17. Glass, N., Laughon, K., Rutto, C., Bevacqua, J., Campbell, J. C., 2008. Young Adult Intimate Partner Femicide. An Exploratory Study. Homicide Studies, 12(2), pp.177-187. 
18. Laurent, C., Platzer, M., Idomir, M., 2013. Femicide: A Global Issue that Demands Action, 1, Vienna: ACUNS.

19. Mathews, S., Naeemah, A., Jewkes, R., Lorna, J. M., Lombard, C., Vetten, L., 2008. Intimate femicide - suicide in South Africa: a cross-sectional, Bulletin of the World Health Organization, 86(7), pp.552-558.

20. McFarlane, J., Campbell, J. C., Wilt, S., Sachs, C., Ulrich, Y., and XU, X., 1999. Stalking and intimate partner femicide. Homicide Studies, 3(4), pp.300-316.

21. Roscoe, B., and Callahan, J. E., 1985. Adolescent's self-report of violence in families and dating relationships. Adolescence, 20(79), pp.545-563.

22. Roscoe, B., \& Kelsey, T., 1986. Dating violence among high school students. Psychology: A Quarterly Journal of Human Behavior, 23(1), pp.53-59.

23. Seimer, B. S., 2004. Intimate violence in adolescent relationships: Recognizing and intervening. MCN, 29(2), pp.117-121.

24. Sharps, P.W., Koziol-McLain, J., Campbell, J., McFarlane, J., Sachs, C., Xu X., 2001. Health care providers' missed opportunities for preventing femicide. Preventive medicine, 33(5), pp.373-80. 25. Stöckl, H., Devries, K., Rotstein, A., Abrahams, N., Campbell, J., Watts, C., Moreno, C. G., 2013. The Global prevalence of Intimate Partner Homicide: a systematic review, The Lancet, 382(9895), pp.859-865.

26. Vives-Cases, C., Gil-Gonzalez, D., Plazaola-Castañ,o J., Montero-Piñar, M.I., Ruiz-Perez, I., Escriba-Agüir, V., Ortiz-Barreda, G., Torrubiano-Domínguez, T., 2009. Violencia de genero en mujeres inmigrantes y españolas: magnitud, respuestas ante el problema y políticas existentes. Gaceta Sanitaria, 23(1), pp.100-106.

27. Wilson, M., Johnson, H., and Daly, M., 1995. Lethal and non-lethal violence against wives. Canadian Journal of Criminology, 37, pp.331-362.

28. Wilson, M. I., and Daly, M., 1992b. Till death us do part. In: J. Radford and D.E.H. Russell, eds. Femicide. New York: Twayne, pp.83-98.

29. Zambrano, A. M., Observatory on Femicides. Available at: http://www.ipsnews.net/2015/01/teenage-girls-in-argentina-invisible-victims-of-femicide/ [Accessed at 16 August 2017].

*** United Nations Economic and Social Council, Commission on Crime Prevention and Criminal Justice, Academic Council on the United Nations System (ACUNS), 2013. E/CN.15/2013/NGO/1 Vienna Declaration on Femicide, Available at: https://www.unodc.org/documents/commissions/CCPCJ/CCPCJ_Sessions/CCPCJ_22/_E-CN152013-NGO1/E-CN15-2013-NGO1_E.pdf [Accessed 20 June 2017] 


\title{
Risk factors for the safety of the children from transnational families (children left behind)
}

\section{DOI: http://doi.org/10.26758/8.1.3}

Ana Popova

Institute for the Study of Societies and Knowledge, Bulgarian Academy of Sciences, Sofia, Bulgaria

Address correspondence to: Ana Popova, Institute for the Study of Societies and Knowledge, Bulgarian Academy of Sciences, 13 A Moskovska Str., Sofia, Bulgaria, Tel: +359 889 874219; Email: popovaani@abv.bg

\begin{abstract}
Objectives. The main objective of this paper is to explore the current situation with the transnational families in Bulgaria and Romania, their profile and the consequences of the transnational way of life for the children left behind.

Material and methods. The paper presents a comparative analysis of the risk factors for the children from transnational families, identified and interpreted in two studies supported by UNICEF in Bulgaria and Romania. Two methods are used in the paper - secondary analysis of existing data and comparative method.

Results. The phenomenon "children left behind in Bulgaria with parents working abroad" affects between 265,102 and 271,782 children at the end of 2012. Among them, there is a growing nuisance. They don't receive the necessary health care, often drop out the school and become dependent on drugs, alcohol, and cigarettes. In Romania, the phenomenon "alone at home" affects about 350,000 children. The risks identified for the Romanian children are: physical, psychological and emotional vulnerability, the risk of sexual abuse and harassment, the risk of trafficking and prostitution, early start of sexual life and others.

Conclusions. The children from transnational families are subject to many risk factors. The responsible institutions are not able to provide the necessary support and the qualified personnel in these institutions is not sufficient. There are many gaps in the national policy in relation to the children of migrant parents.
\end{abstract}

Keywords: transnational families; labor migration; risk factors; children left behind; home alone children; safety.

\section{Introduction}

In the process of globalization, a significant increase of the migration flows can be observed due to the natural human strife for overcoming the poverty and unemployment, as well as because of the interest towards education abroad or the need for a better living standard. One of the newly-appearing phenomena in these conditions is the transnational family - a family unit in which one or both parents become migrants and leave their relatives, mostly children, in the country of origin.

In the context of the Millennium goals of UN and the Strategy 2020 of the European Union, the phenomenon of "transnational families" is increasingly focusing the public opinion and is put in 
the attention of the family policy of the European Union. This issue has been recently introduced and discussed within the framework of the family policy of Bulgaria and Romania not only as member states of the European Union but also as countries which are directly affected by the scale of this phenomenon, having its consequences for the children left behind by their parents.

The concept of "transnational family" is comparatively new. The phenomenon started to attract the attention of migrant researchers in the early 90 s of the $20^{\text {th }}$ century. In the same period, the concept of "transnationalism" was introduced, explaining the migration as multifaceted social space, experienced by the communities across the borders (Glick-Schiller et al., 1999). Unlike traditional migration theories, the transnationalism offers an alternative approach to the exploration of migrants' experience, based on their simultaneous positioning in several social and territorial locations (Glick-Schiller et al., 1999). In the light of the transnationalism, the traditional understanding of the family as a unit for cohabitation at one and the same place is changing towards the perception of the family as territorially scattered and fragmented (Glick-Schiller et al., 1999).

At present, there are a number of terms that essentially refer to the concept of transnational family, such as multi-sited family (Ong and Nonini, 1997), multi-local binational family (Guarnizo, 1997), transcontinental family (Kelly, 1990), international family (Ho, 1993) and others. These terms are used interchangeably although there are differences in the research perspective for defining each concept. The researchers have reached a consensus on the idea about the geographical dispersal of the family, i.e. for a new geography of the family unit (Lam et al., 2002), as well as for the maintenance of close contacts with the relatives in the country of origin. However, the authors put different meanings in the analyzed subject that varies both in terms of family size nuclear/extended - and its composition - uni-national or bi-national (mixed).

The different points of view about the concept of transnational family are reflected in the variety of its definitions. As one of the basic definitions is accepted that of Bryceson and Vuorela, according to which those families whose members are living apart from each other for a shorter or longer time, but maintaining common relationships and a spirit of collective welfare and unity even across the borders of separate countries can be defined as transnational (Bryceson and Vuorela, 2002).

Wiltshire defines the transnational family as a large amorphous structure, consisting of kinship segments, which are scattered across the national boundaries (Wiltshire, 1992).

According to Le Gal, the transnational family is a modernized model of family relations characterized by geographic dispersion due to the migration of one or more of the family members (Le Gal, 2005).

Bjeren interprets the transnational family as collective kinship relations with residence in at least two countries (Bjeren, 1997). These transnational units are not static but may change over time by changing the status of the constituent members - emigrants, immigrants or returning to the country of origin (Zontini, 2007). An important clarification about the transnational families made by Zontini is that their members are separated geographically but maintain social, cultural, reproductive and financial links across the borders (Zontini, 2007).

Despite the fact that the members of the transnational families continue to keep their relations across the borders, the researchers are united around the view that the separated cohabitation affects the fulfilment of the fundamental functions of the family unit, namely: reproductive, socializing, economic, function of primary social control, recreational, protective and hedonistic function (Tolstokorova, 2013). 
Nowadays there is a steady trend of increasing attention towards the phenomenon of the transnational families in a global perspective. The term care drain is used in analogy with brain drain (Rossi, 2008).

In the recent years, the topic has also become sensitive for the countries in Eastern Europe because of the significant migration flows in these countries. Detailed studies on the topic are carried out in Moldova (Cheianu et al., 2011), Romania (Toth et al., 2007), Ukraine (Tolstokorova, 2009) and Bulgaria (Kabakchieva et al., 2016).

The phenomenon of the transnational family scientifically difficult to explore, since different forms and manifestations of it were identified. The most widespread form of its existence is the transnational parenting in which there are four cases of separate cohabitation:

- when the mother works abroad and has left her children and the other members of the family in the country of origin (transnational motherhood);

- when the migrant father is away from his family (transnational fatherhood);

- when the two parents are migrants and they either live abroad with their child/children or have left them to the care of relatives in the country of origin;

- when the child lives abroad and is far from his/her parents, most often by reason of obtaining an education.

There are a number of studies dedicated to the experience of women who have gone abroad to work as support staff. The working conditions, the lack of resources and their low social status make them leave their children in the country of origin. In these situations, defined as "global care chains" (Hochschild, 2000), the women, in addition to fulfilling their role as "mothers from a distance" (Hondagneu-Sotelo and Avila, 2003), provide a financial support for their children left in the care of grandparents or other relatives in the country of origin. This type of family configuration is embedded in many studies for Caribbean women who have gone to work in the United States (Guarnizo, 1997), women from Latin Amerika (Hondagneu-Sotelo and Avila, 2003) and from the Philippines (Parrenas, 2003).

Although fewer in number, there are studies exploring the transnational fatherhood and its impact on the children left in the country of origin. In this relation, the study of Nobles (2011), which explores the effects on children from Mexico, whose fathers have migrated or whose parents are divorced, stands out. Nobles finds that in cases of migration, the interaction with the children is more intensive than in divorce cases, regardless of the geographic distance. Furthermore, the connection with the migrant father positively affects the school results of children (Nobles, 2011).

In the third form of configuration, when both parents are migrants, the researchers explore the role of those who are left to take care of children, most often their grandmothers or aunts. Bernardi (2011) offers a methodological approach, oriented to the social networks, established in connection with the care for the children left at home. The focus on these networks allows the inclusion of units bigger than the nuclear family, e.g. the extended family that is a dominating institution when both parents are abroad (Bernardi, 2011).

Another type of family configuration stems from the migration of the children - alone or accompanied by a parent. In this case, the researchers speak about "astronaut families" or "children paratroopers" (Ho, 2002). Such families are usually rich, most often from Asia, e.g. China, Hong Kong, Taiwan or South Korea.

There are two main approaches to the clarification of the issue about the types of transnational families. In the first one, the transnational family is interpreted as a transnational household, defined as a household where at least one family member lives abroad. Here the 
migration is an opportunity for economic survival of the family as a whole, including its members left in the country of origin (Hondagneu-Sotelo and Avila, 2003).

The second approach focuses on the transnational kinship networks and the existence of many households. Within the frames of this approach, a number of researchers have worked, among which those from the USA - Sutton, 2004; France - Streiff-Fenart, 1999; Canada - Le Gall, 2005; UK - Plaza, 2000, Australia - Hage, 2004 and many others. This phenomenon relates to migrants from many countries around the world, in one or another stage of their history, who are affected by large migratory waves, e.g. from Tunisia, Lebanon, the Dominican Republic, Mexico, in recent times from Syria and others.

The current paper is focusing on the third form from the types of transnational families listed above, that in which both parents are economic migrants and their children are left in the care of relatives, most often grandparents, in the country of origin.

In connection with the clarification of the phenomenon of transnational families, it is also necessary to discuss the concept of the children left by their parents-economic migrants, in the country of origin for a period longer than 3 months. Recently, in relation to this, the term Children Left Behind was introduced as a result of a discussion in the European Parliament in 2009 and one publication of UNICEF (UNICEF Innocenti Research Centre, 2010). The latter argue that the absence of the parents may have a negative effect on the children left behind, including a risk for their physical and mental health, depression, difficulties in the development, passivity at school, dropping-out of the education system, etc. The children left behind in the country of origin belong to the group of vulnerable children at risk. Most of them develop a sense of deprivation and lack of interest, refusal to participate in school and out-of-school activities. A direct consequence of the parents' migration is the fact that the child doesn't receive parental love and the necessary surveillance of his/her development. As a result of this, the physical and mental health of the child is disturbed and, in some cases, he/she starts to demonstrate a non-typical behavior or is exposed to the risk of different types of exploitation and abuse (Minkovski, 2014).

After a study conducted with the support of UNICEF-Romania in 2008 (Toth et al., 2008) about the children from transnational families, the term Home Alone Children was introduced to qualify the group of children left in the country of origin without parental care because of the labor migration of their parents.

In relation to the concepts discussed above, the researchers differentiate a number of phenomena as a result of the appearance of the transnational families and their impact on the children, such as "dead mothers syndrome" in young children, overly-aggressive behavior among adolescents aiming to attract the attention of their parents, social anxiety (avoidance behavior), emotional isolation and others (Kabakchieva, 2009, p.311).

Last but not least, in connection with the problems discussed, the concept Children at Risk has to be clarified. It is interpreted with several meanings: a) a child whose parents are deceased, unknown, deprived of parental rights or with limited parental rights, or the child has been left without their care; b) a child who is a victim of abuse, violence, exploitation or any other inhuman or degrading treatment or punishment within or outside his or her family; c) a child who is in danger of harming his/her physical, mental, moral, intellectual and social development; d) a child, suffering from disability, as well as from diseases difficult to treat and diagnosed by a specialist; e) a child who is at risk of dropping out of school or has dropped out of school (Additional acts to the Child Protection Law, 2009). The paper seeks to answer the question whether the children from transnational families are children at risk by the indicators listed. 
The main objective of this paper is to explore the current situation with the transnational families in Bulgaria, their profile and the consequences of the transnational way of life on the children left behind.

\section{Material and methods}

On the basis of two studies, carried out with the support of UNICEF-Bulgaria "Effects on the children left behind by their parents, working and living abroad" (2016) and UNICEF-Romania "National analysis of the phenomenon "children left at home by their parents migrating abroad for employability" (2008), the current paper explores in a comparative perspective the risk factors for the children from transnational families, as well as the gaps in the national policies in the two countries, in relation to such children. Although covering different periods of time, the cited studies use one and the same methodology and are very close in their final conclusions. That is why the current paper uses the data collected in the two studies for a secondary analysis and, applying the comparative method, looks for similarities and differences in the identified effects and consequences for the children from transnational families.

\section{Results}

The exploration of the situation with the transnational families in Bulgaria gives evidence about the fact, that at the current moment the responsible institutions do not collect systematic information about the number of the children whose parents are labor migrants. In the existing migration studies, this problem is reflected peripherally (Bogdanov and Rangelova, 2012).

The children with parents abroad, left in Bulgaria, are still not in the focus of the information systems of the Agency for Social Assistance, the State Agency for Child Protection, as well as the bodies dealing with the antisocial actions - the Ministry of the Interior and the Commission for Combating Juvenile Delinquency, as these children are not identified by the indicated institutions as children at risk, i.e. the existence of risk is not proven for them. The main bodies for child protection collect information about concrete cases in their work, including family status, but it is not summarized (Kabakchieva et al., 2016).

The situation is similar in Romania where there is only one governmental source of information - the National Authority for the Protection of Children's Rights (NAPCR), which has been collecting data since 2006 (Toth et al., 2008).

The data from the Bulgarian UNICEF study indicate that at least one parent of every fifth child in Bulgaria is abroad. According to the National Statistical Institute (as of 31.12.2012), there are 1,325,511 children in Bulgaria aged 0 to 19 years. One-fifth of them is equal to 265,102, but another study calculates their number at 271,782. The Bulgarian UNICEF study also indicates a break from the classic, nuclear family with children and two parents. The transnational families whose members live in different countries are $26 \%$ from all Bulgarian families, as in $3 \%$ of cases both parents are abroad. Most of the children with both parents abroad are raised by their grandmother $-65.5 \%$; $13,7 \%$ live with relatives, and $5.1 \%$ live in foster families (Kabakchieva et al., 2016).

At the national level in Romania, it is estimated that the phenomenon "alone at home" involves around 350,000 children (about $7 \%$ of the total population aged 0-18 years) having at least one parent abroad. Approximately 126,000 of these children have two parents abroad, and more than a half of all children live in rural areas. 
For all young people aged 0-18 years, another approximately 400,000 children have experienced the absence of one of the parents as a result of his/her labor migration. This means that almost 750,000 children, out of approximately 5 million children in Romania, have been suffered by their parents' migration (Toth et al., 2008).

If we compare the children affected by the phenomenon of transnational families on the basis of the aforementioned numbers, we can argue that it causes negative consequences for about $\mathbf{2 0 \%}$ of the children in Bulgaria and $\mathbf{1 5 \%}$ of the children in Romania.

The authors of the Bulgarian study draw attention to the fact that nearly $6 \%$ of the children placed in boarding schools have parents abroad. Also, about $20 \%$ of the children using the Animus hotline to share their problems have parents abroad.

A similar conclusion is drawn for Romania - by 30 June 2007, 30,757 children were benefiting from the services for prevention of child separation from their parents, e.g. day-care centers, counseling centers, etc.

The two studies also indicate unfavorable facts about the health and well-being of the children with parents abroad. In Bulgaria, these children have more health problems compared to the children whose parents are at home, mostly because they do not go to a doctor when they are ill. With an average of $5.2 \%$ for all children, $12 \%$ of the children with two parents abroad are often hungry. They lack home-made food and their menu includes mainly pasta and potatoes. The absence of both parents working abroad is one of the reasons for the lower success of child at school, for the repetition of class or so-called "hidden dropout of school", especially during the seasonal migration (Kabakchieva et al., 2016).

In $22 \%$ of the Romanian cases when the mother is abroad, the children have taken medications that were not prescribed by a doctor, compared to $15 \%$ of those who live with their parents. There is a higher prevalence of cases of a chronic disease or handicap among the children with both parents abroad (11\%), compared to those who live with their parents $(5 \%)$. $2 \%$ of the families with current migrants report that at least one of the children has dropped out of school, especially in cases where the mothers are abroad (Toth et al., 2008).

Both studies report a higher percentage of anti-social actions and problems with the police among the children with parents abroad. For example, in Bulgaria, the share of the children with both parents abroad who have had problems with a director or deputy director of a school is nearly three times bigger than the children with parents at home. $40 \%$ of the children with both parents abroad ( 5 times more than the children with parents at home) have visited a Pedagogic Room, which is an indicator of antisocial behavior.

\section{Discussions}

On the basis of the quantitative data from UNICEF's studies in Bulgaria and Romania it can be argued that the children from transnational families experience a number of negative effects by the separated cohabitation with their parents - poor health and emotional status, downgrading or dropping out of school, growth of the antisocial actions among them and others.

Both studies try to draw the public attention to the fact that children from transnational families have infringed rights and are at risk. Four out of the 5 characteristics of the concept "children at risk", listed at the beginning of the present study, can be identified for these children. They are the following:

- The children from transnational families are left without parental care. The absence of one or both parents causes a sense of loneliness, anxiety, social isolation and self-closure. 
For example, the Romanian study shows that $10 \%$ of these children become more reserved and start spending more time in front of the TV or computer (Toth et al., 2008). When in trouble, the children from transnational families are trying to cope alone. On the one hand, this fact is positive, as it contributes to the development of qualities such as independence and self-confidence, but on the other hand, such children feel like outsiders and often fall into isolation from their peers. The disturbed communication with the parents abroad forces these children to share with friends, which sometimes prompts the risk of falling into unfavorable influence. In the Romanian study, it is pointed out that in the cases described, the child's right to not be separated from his/her parents, formulated in the Convention on the rights of the child (1990) is infringed. An additional argument is the fact that the cases of divorce in the transnational families are very common (in $43 \%$ of such families) and they cause a mental trauma in the children.

- For the children from transnational families, there is an increased risk of harming their physical, mental, moral, intellectual and social development. As was pointed out above, the children with parents abroad have unsatisfactory health status and need psychological support to overcome the deprivation and mental disorders. However, it is necessary to emphasize the more serious risks for such children, connected with the alcohol abuse, smoking, drug abuse, early onset of sexual life, and the development of deviant or criminogenic behavior. For example, in the Bulgarian study, it is presented that $60 \%$ of the children with both parents abroad smoke in comparison with 39\% smokers among the children with both parents at home. The same is valid for the alcohol abuse $-72 \%$ of the children with both parents abroad drink, compared to an average of $59.6 \%$. The children themselves report that they use the alcohol as a means of coping with the tension. $25 \%$ of the children with both parents abroad have tried marijuana compared to $13 \%$ of the children with parents at home. The children from transnational families have also more liberated views about sexual life. On the question "Who can be your eventual sexual partner", 30\% of the children with both partners abroad have answered "Everyone I like" (Kabakchieva et al., 2016). The alcohol and drug abuse often lead to deviant behavior and problems with the police. As it is argued in the Bulgarian study, this puts the children with parents abroad at a greater risk to be stigmatized as individuals with antisocial behavior, as small criminals. In the Romanian study, it is pointed out that the cases of negative effects on the children from transnational families described demonstrate an infringed children's right to an adequate standard of living and right to health which explicitly puts them in the group of children at risk.

- For the children from transnational families, there exists a serious risk of dropping out from school. As was mentioned above, there is a downgrading of their success at school, repetition of the class and hidden drop-out in the cases of seasonal migration. The Romanian study presents data from a representative study in which more than $60 \%$ of the respondents think that the children with parents abroad perform worse than their peers at school and miss many classes. This means an infringed right to education of these children.

- For the children from transnational families, there is an increased risk of being abused and exploited. Both the Bulgarian and the Romanian study report many cases of such risks for the children left without parental control and raised in the country of origin by relatives: risk of sexual abuse and harassment, trafficking and prostitution, exploitation at work and others. 


\section{Conclusions}

Together with the serious dangers and risks for the safety of children from transnational families indicated above, the Bulgarian and the Romanian studies have also identified many problematic zones in connection with the lack or ineffective policies regarding these families. The more important of them are as follows:

- Lack of synchronized inter-institutional collection of reliable information about the children whose parents work abroad. This fact allows people to draw conclusions about the unreliability of the responsible institutions and the regulatory framework. All institutions for child protection or for combating antisocial actions work with the children from transnational families when they fall into risk, but not before that, by way of prevention.

- Infringed rights of the children, left to be raised by extended family or on their own due to the unsettled guardianship or guardianship status.

- Non-identification of the children with parents working abroad as children at risk.

- Lack of adequate measures and legislative initiatives for improvement of the policies, normative acts and real outcomes for the children from transnational families (Kabakchieva et al., 2016).

The strong evidence in the two studies presented about defining children from transnational families as children at risk justify the recommendations given for attracting the attention of the society and the responsible institutions to this significant social phenomenon. These recommendations are the following:

- Identifying the children from transnational families as potential children at risk with the aim to provide a preventive and timely support according to their specific needs.

- Developing mechanisms for monitoring and assessment of the phenomenon at the local level and collecting reliable data on children left behind because of labor migration of their parents.

- Review of the legislative framework and the good practices in this field.

- Development of community-based services addressing the needs of children of migrant parents - e.g. day-care centers.

- Developing human resources to support the children from transnational families who are excluded or marginalized, especially in the rural areas.

- Introduction of legislative changes connected with the protection of children's rights when one of the parents is abroad and the other one, who is in the country, is unable to provide care and protection for the child/children.

- Participation of all responsible institutions for children's rights protection at the local level in the process of identifying the children with migrant-parents (departments for child protection, schools, police); creation of a coordination mechanism of the process of identification.

- Assessment of the risks for all children with migrant-parents, including the capacity of the person/persons taking care of them in the country of origin.

- Developing the capacity of the public services for social support at national level.

- Raising the awareness of the population about the phenomenon "home alone children" because of labor migration of their parents. 
- Creating of a concrete and clear mechanism of institutional cooperation and interaction in order to guarantee a joint intervention for decreasing the negative effects on the children stemming from the migration of their parents.

- Developing of local networks for supporting local stakeholders who can resolve the complex problems of transnational families and guarantee their support (Toth et al., 2008).

The data presented from the two UNICEF's studies, as well as the identified risks for the children from transnational families demonstrate the seriousness of this problem, generated by the labor migration in Bulgaria and Romania. It is clear that some legislative initiatives and institutional measures have to be undertaken, in order to guarantee the social safety of the children left behind and their adequate socialization, as well as to prevent their possible deprivation and deviant behavior.

\section{Bibliography}

1. Adamson, P., 2010. The Children Left Behind: A league table of inequality in child well-being in the world's rich countries, UNICEF SERIES: Innocenti Report Card no. 9. Available at: https://www.unicef-irc.org/publications/619-the-children-left-behind-a-league-table-ofinequality-in-child-well-being-in-the.html [Accessed 15 June 2017]

2. Additional act to the Child Protection Law. 2009. State Gazette of the Republic of Bulgaria. 14.

3. Bernardi, L., 2011. A mixed-method social networks study design for research on transnational families. Journal of Marriage and Family, 73, pp.788-803.

4. Bjeren, G., 1997. Gender and reproduction. In: T. Hammar et al., eds. International Migration, Immobility and Development. New York: Berg, pp.219-246.

5. Bogdanov, G. and R. Rangelova., 2012. Social impact of emigration and rural-urban migration in Central and Eastern Europe. Final country report Bulgaria. Executive summary. Available at: http://ec.europa.eu/social/BlobServlet?docId=8837\&langId=en [Accessed 24 June 2017]

6. Bryceson D. and U. Vuorela, 2002. Transnational families in the twenty-first century. In: D. Bryceson and U. Vuorela, eds. The transnational family: new European frontiers and global networks. Oxford \& New York: Berg Publishers Ltd, pp.3-30.

7. Cheianu, A., D. R. Gramma, S. Milicenco, V. Pritcan, V. Rusnac, and D. Vaculovschi, 2011. Specific needs of children and elderly left behind as a consequence of migration. Chisinau, Moldova: Ministry of Labor, Social Protection, and Family of the Republic of Moldova. Available at: http://docplayer.net/372862-Specific-needs-of-children-and-elderly-left-behind-asa-consequence-of-migration.html [Accessed 10 June 2017]

8. Glick-Schiller N., Basch, L. and Szanton Blanc, C., 1999. From immigrant to transmigrant: theorizing transnational migration. In: L. Pries, ed. Migration and Transnational Social Spaces. Aldershot, Hants, England; Brookfield, Vt.: Ashgate. pp. 73-105.

9. Guarnizo, L.E., 1997. The emergence of a transnational social formation and the mirage of return migration among Dominican transmigrants. Identities, 4(2), pp. 281-322.

10. Hage, G., 2004. Issues of Structure and Culture in Researching the Lebanese Transnational Family, lecture presented at the Lebanese Emigration Research Center, Université Notre Dame, Beyrouth, 19 May 2004.

11. Ho, E. S., 2002. Multi-local residence, transnational networks: Chinese astronaut families in New Zealand. Asian and Pacific Migration Journal, 11(1), pp.145-164.

12. Hochschild, A. R., 2000. Global care chains and emotional surplus value. In: A. Giddens and W. Hutton, eds. On the Edge: Living with Global Capitalism. London, Sage, pp.130-146. 
13. Hondagneu-Sotelo, P. and Avila, E., 2003. I'm here, but I'm there: the meanings of Latina Transnational motherhood. In: P. Hondagneu-Sotelo, Gender and US Immigration. Contemporary Trends. Berkeley, Los Angeles and London: University of California Press, pp. 317-341.

14. Kabakchieva, P., 2009. Temporary migrants: beyond roles, across identities. In: A. Kiossev and P. Kabakchieva, eds. "Rules"and "Roles". Fluid Institutions and Hybrid Identities in East European Transformation Processes (1989 - 2005). Berlin: Lit Verlag, pp.11-42.

15. Kabakchieva, P., K. Haralampiev, A. Stambolova, E. Stoykova, T. Tomova, S. Popova, V. Garnizov, G. Angelov, R. Smedovska, N. Bozakova., 2016. Effects on the children left behind by their parents, working and living abroad. Paper developed on commission of UN Children's fund (UNICEFF - Bulgaria) by a team from the "Risk - monitor" Foundation. Available from: https://www.unicef.bg/.../Children_left_behind_march_2016.pdf [Accessed 20 June 2017].

16. Kelly, E., 1990. Transcontinental families. Gujarat and Lancashire: A comparative study of social policy. In: S.C. Vertovec and C. Peach, eds. South Asians Overseas: Migration and ethnicity. Cambridge: Cambridge University Press. pp.251-267.

17. Lam, T., Yeoh, B. and Law, L., 2002. Sustaining families transnationally: Chinese-alaysian in Singapore. Asian and Pacific Migration Journal, 11(1), pp.117-143.

18. Le Gall, J., 2005. Familles transnationales: Bilan des recherches et nouvelles perspectives. Les Cahiers du Gres, 5(1), pp.29-42.

19. Minkovski, R., 2014. Support for children left in Bulgaria by parents living and working abroad. The paper has been written under the guidance of "Partners - Bulgaria" Foundation, within the frames of the project "Programme for support of transnational families". Available at: http://partnersbg.org/ver2/wp-content/uploads/2015/01/Children-Left-Behind-in-Bulgaria2015_PBF-study.pdf. [Accessed 10 June 2017].

20. Nobles J., 2011. Parenting from abroad: Migration, nonresident father involvement, and children's education in Mexico. Journal of Marriage and Family. 73, pp. 729-746. https://doi.org/10.1111/j.1741-3737.2011.00842.x

21. Ong, A. and Nonini, D., 1997. The cultural politics of Chinese transnationalism. New York: Routledge.

22. Parrenas, R.S., 2003. The care crisis in the Phillipines: children and transnational families in the new global economy. In: B. Ehrenreich and A.R. Hochschild, eds. Global Woman: Nannies, Maids and Sex Workers in the New Economy. New York: Metropolitan Books, pp.39-54.

23. Plaza, D., 2000. Transnational Grannies: the changing family responsibilities of elderly African Caribbean - born women in Britain. Social Indicators Research, 51(1), pp. 75-105.

24. Rossi, A., 2008. The impact of migration on children left behind in developing countries: outcomes analysis and data requirements. Available at: http://dx.doi.org/10.2139/ssrn.2490380 [Accessed 2 June 2017].

25. Streiff-Fenart, J., 1999. Construction d'un réseau de parenté transnational: une étude de cas d'immigrés tunisiens dans le sud de la France. Revue Européenne des migrations internationales, 15(3), pp.45-61.

26. Sutton, C.R., 2004. Celebrating ourselves: the family reunion rituals of African- Caribbean transnational families. Global Networks, 4(3), pp.243-257.

27. Tolstokorova, A., 2009. Costs and benefits of labour migration for Ukrainian transnational families: connection or consumptions. Cahiers de l'Urmis [on-line journal] Available at: https://urmis.revues.org/868 [Accessed 12 June 2017]. 
28. Tolstokorova, A., 2013. Ukrainian transnational family as a modernized model of family relationships. Journal of sociology, 2. pp. 43-64.

29. Toth, G., Păun, G., Toth, A., Voicu, O. and Ştefănescu, M., 2007. The effects of migration: children left behind. Soros Foundation Romania. Available at: http://www.fundatia.ro/sites/default/files/en_67_studiu\%20eng1\%20miki.pdf [Accessed 01 June 2017].

30. Toth, A., Munteanu, D., Bleanu, A., Tudor, E., Magheru, M., Luca, C., 2008. National analysis of the phenomenon of children left home by their parents who migrate abroad for employment. UNICEF-Romania and Alternative Sociale, pp. 1-59.

31. Wiltshire, R., 1992. Implications of transnational migration for nationalism: The Caribbean Example. In: N. Glick-Schiller et al., eds. Towards a transnational perspective on migration. Race, Class, Ethnicity, and Nationalism reconsidered. New York: New York Academy of Sciences, pp.175-187.

32. Zontini, E., 2007. Continuity and change in transnational Italian families: The caring practices of second-generation women. Journal of Ethic and Migration Studies, 33(7), pp.1103-1119.

33. *** The United Nations Human Rights. 1989. Convention on the Rights of the Child (UNCRC). Available at: http://www.ohchr.org/EN/ProfessionalInterest/Pages/CRC.aspx [Accessed 18 June 2017] 


\title{
Characteristics of psychophysical health, generativity and integrity level in elderly people considering previous and current financial status
}

DOI: http://doi.org/10.26758/8.1.4

Djerdji Erdes Kavecan, Anida R. Fazlagic

State University of Novi Pazar, Department of Psychology, Novi Pazar, Serbia

Address correspondence to: Djerdji Erdes Kavecan, State University of Novi Pazar, Department of Psychology, VukaKaradzica bb, 36600 Novi Pazar, Tel. +381 317 754, E-mail: djerdji.kavecan@gmail.com

\begin{abstract}
Objectives.The aim of the research presented in this paper is to determine characteristics of psychophysical health, the degree of generativity and integrity with respect to the past and current financial condition of the old.

Material and methods. The research sample consisted of elderly persons from the vicinity of Novi Pazar (N=101), whose average age was 71.7 years old. The instruments used for data collection were as follows: The questionnaire for examining sociodemographic characteristics (designed for research purposes), The RAND-36 Health Survey, Loyola Adapted Generativity Scale and Integrity scale. The data analysis used the descriptive statistical methods, t-test and one-way analysis of variance.

Results. The results show that there are statistically significant differences in only one dimension of mental health - emotional well-being, as well as in the degree of generativity and integrity concerning the earlier family material situation in elderly persons. Concerning the current financial status, statistically significant differences were observed in even four dimensions of psychophysical health: emotional well-being, social functioning, physical functioning and general health. Significant differences have also been shown in the dimension of integrity between the groups with the poor and the good economic background.

Conclusions. Elderly in Novi Pazar, mostly assess their earlier and current material status as medium or good. They also link better health state to a better financial situation and assess mental health as better than physical. The respondents in this study report a relatively high degree of generativity, which speaks of an active relationship towards the environment and achieving integrity.
\end{abstract}

Keywords: elderly, health, material status, generativity, integrity.

\section{Introduction}

Old age is the last period of development throughout the life cycle that can be defined according to chronological age, social roles or according to functional status (Despot Lučanin, 2003). According to the WHO criteria, old age is divided into early (65-74 years), middle (75-84 years) and deep old age from 85 and over (Papalia and Wendkos, 1992, in Brajković, 2010). It is 
common to associate reduced body strength and poorer health with this period of human life. According to research by Schaie and Willis (2001), the likelihood of disease is increasing dramatically in the age after 65 , accounting for approximately $12.5 \%$ of the population and for $30 \%$ of the national health costs in America. As the study underlines, the elderly use $25 \%$ of all the total medicines issued and account for $40 \%$ of the total visits to doctors (Schaie and Willis, 2001). In Serbia, the sixth of the population is 65 years old and older, and the number of persons aged 65 or more is expected to increase by a third in 2052 and represent $22.0 \%$ to $27.1 \%$ of the total population (Satarić, Rašević and Miloradović, 2009). The percentage of chronic diseases among the general population of old people age 70 and older is $81 \%$.

It is known that the economic status of an individual is an important micro-determinant of individual health status. Its impact on the disease has been studied in many European countries, and the results of the research showed a clear correlation between the socioeconomic determinants and the health status of the respondents (Kaikkonen et al., 2009). The more difficult socio-economic condition of people, the more likely they are to assess their own health as being worse with the more frequent presence of health symptoms and chronic conditions (Domínguez-Berjón et al., 2006). The impossibility to afford the necessary goods for the daily subsistence for Bulgarian and Romanian elderly are associated with reporting of a poor health status (Faludi, 2015). All European countries are affected by poverty, whether in absolute (inability to meet basic living needs) or relative (economic status of an individual relative to the community in which he lives) sense (***WHO, 2002). The unemployed, uneducated, displaced persons, rural population, disabled people, homeless people, children aged 7-14 are at special risk but also the old persons (65 years and older). In Europe, the percentage of poverty and social deprivation risk in people aged 65 years or more ranges from $6.1 \%$ in the Netherlands to $51.8 \%$ in Bulgaria. In Serbia, the poverty rate is $25.5 \%$ and the oldage poverty rate $19.1 \%$ (***Republic Statistical Office, 2016). The risk of poverty in the elderly is $35.2 \%$ (***Eurostat, 2016).

Talking about the effects of material status on the well-being of the elderly, a poor socioeconomic situation has been proven to cause more concern for their health, and it is quite understandable that it is associated with negative life events, which contribute to poorer welfare (Kahneman and Deaton, 2010). Old people with poor maternal status also prove to have worse health both physical and mental (Franks, Gold and Fiscella, 2003).

Various studies emphasize different dimensions that are of particular importance for health self-assessment. Perhaps the most important dimension of all is the physical health (Bailis et al., 2001), but on the other hand, two others proved to have a potentially important relationship with health self-assessment: mental well-being and general social health (Bambauer et al., 2005; Dunn, Veenstra and Ross, 2006). This study examines the dimensions of physical and mental health that arose from the Medical Outcomes Study (MOS). These dimensions are also a part of the 36-Item Short Form Health Survey (SF-36) (Hays and Shapiro, 1992; Stewart et al., 1992), described in detail in the instruments section.

\section{Generativity and integrity within the Erikson model of psychosocial development of the entire life cycle}

Erikson's concept of generativity at the end of the twentieth century became one of the very often mentioned constructs in the literature on the development of personality in adulthood. His model of psychosocial development seeks to unify psychological and spiritual development by solving the crises of the initially established eight stages of the life cycle. He defined generativity as 
"concern for generating and guiding the next generation" (Erikson, 1984, p. 240, in Lacković-Grgin and Tucak, 2006a). He considered generativity to be the dominant feature of the seventh stage of development (middle adulthood), as well as that resolution of any, even the seventh stage of development is not necessarily limited time-wise, generativity in one of its forms being just as much present in other stages of development. When we talk about generativity in the older age, it is defined as the attitude towards life and the world in terms of understanding our own position in the sequence of generations. The resolution of the crisis of this stage, reaching the ego integrity and the overcoming of despair, implies adequate acceptance of one's own life continuity as unique and unchangeable. Adults who achieve integrity feel calm, peaceful, complete, and satisfied with their achievements (Schaie and Willis, 2001). The evidence of such claims has shown that generativity is positively related to psychological maturity and well-being in adult and also in older age (Stewart, Ostrove and Helson, 2001), the satisfaction with life and the meaning of life (An and Cooney, 2006; Busch and Hofer, 2012; Cox et al., 2010; Grossbaum and Bates, 2002; Hofer et al., 2008; Rothrauff and Cooney, according to Hofer et al., 2016).

\section{Newer models of generativity}

There are many different concepts about the notion of generativity in contemporary theories. One of the more prominent is Bradley's status model of generativity (Bradley, 1997). The model assumes two criteria for finding the generativity status: involvement and inclusivity. Involvement refers to taking care of oneself and the others, while inclusion refers to the breadth of active care for others. By combining these two criteria, there are five status of generativity, as follows: a) generative status (high degree of involvement and inclusivity both for oneself and for others); b) activity status (high degree of involvement and inclusion for one self, but not for others); c) communal status (high involvement for others, but not for one self, which is sometimes perceived as blocking others independence or as intrusiveness); d) conventional status (high involvement rate and low degree of inlcusivity for one self and others; and e) stagnating status (low involvement and low inclusion both for one self and for others). These statuses are analyzed in different areas of life (family, friendship, work, own interests and goals) (Lacković-Grgin, 2014).

Another model of generativity was given by Stewart and Vandewater (1998) and belongs to developmental models of generativity. It refers to three stages: a) a phase of desire for generativity (in early adulthood); b) a phase of feeling generative capacity; and c) a generational achievement phase. Due to the very characteristic of the generativity development model checking, a longitudinal research plan is required, so it is very difficult to trace any research based on this model (Stewart and Vandewater, 1998).

However, the model of McAdams and de St. Aubin (1992) is considered as the most comprehensive model of generativity today. It includes seven interconnected components, gathered around the common goal of promoting the welfare of future generations: cultural requirements; internal desire; care for the next generation; faith in the species; commitment; agency; respectively generative story. They emphasize that generativity is a component of a healthy adult personality, which gradually develops during the adult life, and that the generative process involves the creation of a generative product, i.e. agency, which is one of two general tendencies of human behavior. In her research, Tucak-Junaković (2010) checked the adapted model of McAdams and de St. Aubin (1992), used in our research, and found the high predictive value of several components of generativity on integrity, which Erikson determines as a sense of purpose and meaning of life and which is achieved in the eighth stage of development. 


\section{Materials and methods}

The aim of this paper is to examine the characteristics of psychophysical health, the level of generativity and integrity in the elderly, given the earlier and current material status of the elderly. Below is a description of all the observed variables, as well as the results of the research.

Sample.

The sample of the research consists of elderly people from Novi Pazar $(\mathrm{N}=101)$, whose average age is 71.7 years, with a range from 65 to 85 years. Out of the total number of respondents, $57 \%$ were women, while $43 \%$ were male respondents. The research covered $34 \%$ of the elderly who reside in the Home for the elderly, while $66 \%$ live in their own households.

The research was conducted from September 2015 to January 2016. The questionnaire was used as instrument for data collection. The survey was organized in cooperation with professional associates at the premises of the Home for the elderly in Novi Pazar, as well as in the households of the elderly who were involved in the research. The selection of respondents was random, regardless of the presence of acute or chronic mental and physical illnesses. The survey was anonymous and the process of completing did not last longer than 45 minutes.

\section{Instruments.}

The questionnaire for examining the socio-demographic characteristics was designed for research purposes and intended to collect general data on respondents and socio-demographic information from their families.

The RAND-36 Health Survey (Version 1.0) (Hays and Shapiro, 1992; Stewart, et al., 1992) was designed to assess the physical and psychosocial health of healthy adult individuals as well as chronically ill ones. It consists of eight subscales, and they are grouped in the following way: Dimensions of psychosocial health - emotional well-being, role limitations due to emotional problems, social functioning, energy fatigue; as well as the dimensions of physical health - physical functioning, role limitations due to physical health, physical pain and general health. In addition to demographic data, there is another additional item in the questionnaire, which is an indicator of the perceived change in the health status of the respondents. The scale consists of 36 questions and those are identical to the questions that were applied by Hays and Shapiro in their Medical Outcomes Study MOS (Hays and Shapiro, 1992; Stewart et al., 1992). High scores on all subscales speak of a better health condition of the individual. The reliability of the instruments on our sample is within reasonable limits, with Cronbach's alpha coefficients ranging from 0.78 to 0.95 .

The Adapted Loyola Generativity Scale (ALGS) (McAdams and de St. Aubin, 1992; Lacković-Grgin and Tucak, 2006a) is based on the McAdams and St. Aubin model and is designed to estimate generative cares, which are a key component of generativity. It consists of 12 claims that contain several forms of generativity, such as: transferring knowledge and skills, contributing to the community and society, endeavoring to be creative and productive, and so on. The ALGS is treated as a single-factor scale and, based on a five-step scale, the respondents assess the extent to which the content of a particular claim is characteristic for them. The theoretical minimum on this scale is 12 points, and the maximum is 60 , where the higher score indicates a higher degree of generativity presence. In our research, the scale showed high internal consistency $(\alpha=0.93)$.

The Scale of Integrity (SI) (Lacković-Grgin, Ćubela Adorić and Nekić, 2006b) is intended to measure integrity as an integrated system of all components of personality. It is based on Erikson's theory of psychosocial development, where the eighth stage of development represents the evaluation, summarization, and integration of previous life. The SI is used as a single-factor scale and consists of 11 items, where respondents on a five-step Likert type scale evaluate how each of 
these claims relates to their past life. The theoretical minimum on this scale is 11 points, and the maximum is 55, where the higher score indicates a higher degree of integration of the respondents. The reliability of the scale on our sample is $\alpha=0.85$.

\section{Results}

On the basis of the average values in Table 1, we can see that the lowest values occurred in the dimensions of role limitations due to physical health $(\mathrm{M}=30.42)$, followed by role limitations due to emotional problems $(M=44.33)$ and the dimension general health $(M=45.96)$, This means that the majority of elderly persons had the most problems with these dimensions, while with social functioning $(M=66.50)$ and emotional well-being $(M=60.54)$ they had the least problems. By calculating the total score for the assessment of the psychosocial and physical health of the respondents, the global psychosocial health $(\mathrm{M}=54.65)$ proved to be better than the global physical health $(\mathrm{M}=45.39)$ (data not shown in Table 1).

Table 1. Descriptive data for the dimensions of the psychosocial and physical health of the respondents

\begin{tabular}{|l|c|c|c|}
\hline \multicolumn{1}{|c|}{ Variable } & $N$ & $M$ & $S D$ \\
\hline Physical functioning & 100 & 51.11 & 30.33 \\
\hline Role limitations due to physical health & 100 & 30.42 & 43.23 \\
\hline Role limitations due to emotional problems & 100 & 44.33 & 47.39 \\
\hline Energy fatigue & 97 & 47.23 & 22.19 \\
\hline Emotional well being & 97 & 60.54 & 22.40 \\
\hline Social functioning & 100 & 66.50 & 29.29 \\
\hline Pain & 97 & 54.07 & 28.46 \\
\hline General health & 100 & 45.96 & 21.96 \\
\hline
\end{tabular}

In Table 2, the data reveal that the degree of generativity and degree of integrity in the old ones were estimated as relatively good. The degree of integrity $(M=36.63)$ was slightly higher in relation to the degree of generativity $(\mathrm{M}=35.64)$.

Table 2. Descriptive data for the dimensions of the generativity and integrity of the respondents

\begin{tabular}{|l|c|c|c|}
\hline \multicolumn{1}{|c|}{ Variable } & $N$ & $M$ & $S D$ \\
\hline Generativity & 100 & 35.64 & 12.63 \\
\hline Integrity & 100 & 36.63 & 9.25 \\
\hline
\end{tabular}

Based on the data in Table 3, it is evident that half of the respondents $(53.5 \%)$ considered the former financial situation as medium, 26.7\% thought it was good, while $19.8 \%$ considered that the material situation was worse before. When the current material situation is in question, 55.4\% of the elderly estimated that it was medium, $30.7 \%$ that it was good, and $13.9 \%$ that it was below the average. 
Table 3. The presentation of the previous and current material status of the respondents

\begin{tabular}{|l|c|c|c|c|}
\hline \multicolumn{1}{|c|}{ Material status } & Former & \multicolumn{2}{c|}{ Current } \\
\hline Categories & $N$ & $\%$ & $N$ & $\%$ \\
\hline Bad (mostly we could not afford everything we needed) & 20 & $19.8 \%$ & 14 & $13.9 \%$ \\
\hline $\begin{array}{l}\text { Medium (usually we could afford everything we needed, but it } \\
\text { happened that we did not have enough money) }\end{array}$ & 54 & $53.5 \%$ & 56 & $55.4 \%$ \\
\hline Good (we could afford everything we needed) & 27 & $26.7 \%$ & 31 & $30.7 \%$ \\
\hline
\end{tabular}

The results in Table 4 show statistically significant differences in only one dimension of psychosocial health - emotional well-being $(\mathrm{F}=3.73, \mathrm{p}<0.05)$, as well as in the degree of generativity $(\mathrm{F}=4.20, \mathrm{p}<0.05)$ and integrity $(\mathrm{F}=4.94, \mathrm{p}<0.001)$ when regarding the earlier family financial situation of the elderly. In families of poorer financial background, the lowest levels of emotional well-being $(M=49.26)$ and integrity $(M=32.45)$ were registered, while a reduced level of generativity proved to be specific to the families with middle-income ( $\mathrm{M}=32.75)$.

Table 4. The differences according to the earlier financial status on the dimensions of psychophysical health, generativity and integrity

\begin{tabular}{|c|c|c|c|c|c|c|}
\hline Variable & Earlier material state & $N$ & $M$ & $S D$ & $F$ & $p$ \\
\hline \multirow{4}{*}{$\begin{array}{l}\text { Physical } \\
\text { functioning }\end{array}$} & bad & 20 & 41.25 & 31.49 & \multirow{4}{*}{1.66} & \multirow{4}{*}{0.20} \\
\hline & medium & 54 & 51.03 & 28.82 & & \\
\hline & good & 27 & 57.42 & 31.71 & & \\
\hline & Total & 101 & 50.80 & 30.33 & & \\
\hline \multirow{4}{*}{$\begin{array}{l}\text { Role limitations } \\
\text { due to physical } \\
\text { health }\end{array}$} & bad & 20 & 22.50 & 41.28 & \multirow{4}{*}{1.42} & \multirow{4}{*}{0.25} \\
\hline & medium & 54 & 27.16 & 42.25 & & \\
\hline & good & 27 & 41.67 & 45.47 & & \\
\hline & Total & 101 & 30.12 & 43.12 & & \\
\hline \multirow{4}{*}{$\begin{array}{l}\text { Role limitations } \\
\text { due to emotional } \\
\text { problems }\end{array}$} & bad & 20 & 33.33 & 47.14 & \multirow{4}{*}{1.60} & \multirow{4}{*}{0.21} \\
\hline & medium & 54 & 41.36 & 47.11 & & \\
\hline & good & 27 & 56.79 & 46.97 & & \\
\hline & Total & 101 & 43.89 & 47.36 & & \\
\hline \multirow[t]{4}{*}{ Energy fatigue } & bad & 19 & 40.26 & 24.63 & \multirow{4}{*}{1.18} & \multirow{4}{*}{0.31} \\
\hline & medium & 53 & 47.33 & 21.66 & & \\
\hline & good & 26 & 50.51 & 22.39 & & \\
\hline & Total & 98 & 46.80 & 22.48 & & \\
\hline \multirow{4}{*}{$\begin{array}{l}\text { Emotional } \\
\text { well being }\end{array}$} & bad & 19 & 49.26 & 25.96 & \multirow{4}{*}{3.73} & \multirow{4}{*}{0.03} \\
\hline & medium & 53 & 61.36 & 19.97 & & \\
\hline & good & 26 & 66.92 & 21.75 & & \\
\hline & Total & 98 & 60.49 & 22.29 & & \\
\hline \multirow{4}{*}{$\begin{array}{l}\text { Social } \\
\text { functioning }\end{array}$} & bad & 20 & 53.75 & 32.97 & \multirow{4}{*}{2.99} & \multirow{4}{*}{0.05} \\
\hline & medium & 54 & 66.43 & 27.02 & & \\
\hline & good & 27 & 74.54 & 29.31 & & \\
\hline & Total & 101 & 66.09 & 29.44 & & \\
\hline
\end{tabular}




\begin{tabular}{|c|c|c|c|c|c|c|}
\hline \multirow[t]{4}{*}{ Pain } & bad & 19 & 51.58 & 28.54 & \multirow{4}{*}{0.28} & \multirow{4}{*}{0.75} \\
\hline & medium & 53 & 52.59 & 28.69 & & \\
\hline & good & 26 & 57.21 & 29.50 & & \\
\hline & Total & 98 & 53.62 & 28.66 & & \\
\hline \multirow{4}{*}{$\begin{array}{l}\text { General } \\
\text { health }\end{array}$} & bad & 20 & 40.00 & 22.59 & \multirow{4}{*}{1.04} & \multirow{4}{*}{0.36} \\
\hline & medium & 54 & 46.02 & 22.62 & & \\
\hline & good & 27 & 49.31 & 20.19 & & \\
\hline & Total & 101 & 45.70 & 22.01 & & \\
\hline \multirow[t]{4}{*}{ Generativity } & bad & 20 & 36.53 & 15.48 & \multirow{4}{*}{4.20} & \multirow{4}{*}{0.02} \\
\hline & medium & 54 & 32.75 & 11.20 & & \\
\hline & good & 27 & 41.03 & 11.44 & & \\
\hline & Total & 101 & 35.71 & 12.59 & & \\
\hline \multirow[t]{4}{*}{ Integrity } & bad & 20 & 32.45 & 10.82 & \multirow{4}{*}{4.94} & \multirow{4}{*}{0.01} \\
\hline & medium & 54 & 36.08 & 8.17 & & \\
\hline & good & 27 & 40.56 & 8.72 & & \\
\hline & Total & 101 & 36.56 & 9.23 & & \\
\hline
\end{tabular}

Considering the current material state of the elderly, Table 5 shows that statistically significant differences were observed in four dimensions of psychophysical health: emotional wellbeing $(\mathrm{F}=6.19, \mathrm{p}<0.01)$, social functioning $(\mathrm{F}=4.64, \mathrm{p}<0.01)$, physical functioning $(\mathrm{F}=5.05, \mathrm{p}<0.01)$ and general health $(\mathrm{F}=3.62, \mathrm{p}<0.05)$. In all of these dimensions, poor health status was registered for respondents with poor material status. Significant differences had also been shown in the dimension of integrity between the groups with poor and good material status, as well as between the groups with medium and good material status.

Table 5. The differences according to the current material state on the dimensions of psychophysical health, generativity and integrity

\begin{tabular}{|c|c|c|c|c|c|c|}
\hline Variable & Category & $N$ & $M$ & $S D$ & $F$ & $p$ \\
\hline \multirow{4}{*}{$\begin{array}{l}\text { Physical } \\
\text { functioning }\end{array}$} & bad & 14 & 28.21 & 25.54 & \multirow{4}{*}{5.05} & \multirow{4}{*}{0.01} \\
\hline & medium & 56 & 53.05 & 28.33 & & \\
\hline & good & 31 & 56.94 & 32.05 & & \\
\hline & Total & 101 & 50.80 & 30.33 & & \\
\hline \multirow{4}{*}{$\begin{array}{l}\text { Role limitations } \\
\text { due to physical } \\
\text { health }\end{array}$} & bad & 14 & 17.86 & 37.25 & \multirow{4}{*}{1.55} & \multirow{4}{*}{0.22} \\
\hline & medium & 56 & 27.53 & 42.93 & & \\
\hline & good & 31 & 40.32 & 45.04 & & \\
\hline & Total & 101 & 30.12 & 43.12 & & \\
\hline \multirow{4}{*}{$\begin{array}{l}\text { Role limitations } \\
\text { due to emotional } \\
\text { problems }\end{array}$} & bad & 14 & 19.05 & 38.60 & \multirow{4}{*}{2.69} & \multirow{4}{*}{0.07} \\
\hline & medium & 56 & 44.64 & 47.26 & & \\
\hline & good & 31 & 53.76 & 48.44 & & \\
\hline & Total & 101 & 43.89 & 47.36 & & \\
\hline \multirow[t]{4}{*}{ Energy fatigue } & bad & 13 & 36.92 & 21.27 & \multirow{4}{*}{1.91} & \multirow{4}{*}{0.15} \\
\hline & medium & 54 & 46.60 & 21.29 & & \\
\hline & good & 31 & 51.29 & 24.29 & & \\
\hline & Total & 98 & 46.80 & 22.48 & & \\
\hline
\end{tabular}




\begin{tabular}{|c|c|c|c|c|c|c|}
\hline \multirow{4}{*}{$\begin{array}{l}\text { Emotional } \\
\text { Well being }\end{array}$} & bad & 13 & 41.23 & 25.00 & \multirow{4}{*}{6.19} & \multirow{4}{*}{$\mathbf{0 . 0 C}$} \\
\hline & medium & 54 & 63.33 & 19.62 & & \\
\hline & good & 31 & 63.61 & 22.16 & & \\
\hline & Total & 98 & 60.49 & 22.29 & & \\
\hline \multirow{4}{*}{$\begin{array}{l}\text { Social } \\
\text { functioning }\end{array}$} & bad & 14 & 44.64 & 27.17 & \multirow{4}{*}{4.64} & \multirow{4}{*}{0.01} \\
\hline & medium & 56 & 69.20 & 26.65 & & \\
\hline & good & 31 & 70.16 & 31.90 & & \\
\hline & Total & 101 & 66.09 & 29.44 & & \\
\hline \multirow[t]{4}{*}{ Pain } & bad & 13 & 43.65 & 23.11 & \multirow{4}{*}{1.68} & \multirow{4}{*}{0.19} \\
\hline & medium & 54 & 52.27 & 29.06 & & \\
\hline & good & 31 & 60.16 & 29.32 & & \\
\hline & Total & 98 & 53.62 & 28.66 & & \\
\hline \multirow{4}{*}{$\begin{array}{l}\text { General } \\
\text { health }\end{array}$} & bad & 14 & 31.43 & 20.32 & \multirow{4}{*}{3.62} & \multirow{4}{*}{0.03} \\
\hline & medium & 56 & 47.68 & 20.31 & & \\
\hline & good & 31 & 48.59 & 23.82 & & \\
\hline & Total & 101 & 45.70 & 22.01 & & \\
\hline \multirow[t]{4}{*}{ Generativity } & bad & 14 & 35.93 & 18.82 & \multirow{4}{*}{1.47} & \multirow{4}{*}{0.24} \\
\hline & medium & 56 & 33.97 & 10.78 & & \\
\hline & good & 31 & 38.77 & 12.12 & & \\
\hline & Total & 101 & 35.71 & 12.59 & & \\
\hline \multirow[t]{4}{*}{ Integrity } & bad & 14 & 31.86 & 10.01 & \multirow{4}{*}{5.59} & \multirow{4}{*}{0.00} \\
\hline & medium & 56 & 35.51 & 8.50 & & \\
\hline & good & 31 & 40.58 & 8.89 & & \\
\hline & Total & 101 & 36.56 & 9.23 & & \\
\hline
\end{tabular}

\section{Discussions}

The results of this research show that the old people in Novi Pazar and its surroundings assess their global psychosocial health as better than global physical health. Analyzing the more detailed results of this study, one might come to the conclusion that the greatest dissatisfaction is attributed to two dimensions of physical health (role limitations due to physical health), as well as one dimension of mental health (role limitations due to emotional problems), while social functioning and emotional well-being are described as the most satisfactory. These results coincide with other studies, which show that despite worse physical health, social losses, and increasing dependence on others, the old age is still accompanied by a positive sense of well-being (Myers and Diener, 1995, according to Ranzijn and Luszcz, 1999), thus that the old do not withdraw from social contacts. English (2013) states that participation in social activities positively affects emotional well-being and life satisfaction, while Marmot's (2007) study points to the fact that the ability to engage and participate in social activities is crucial for good health, a feeling of well-being, as well as for the longevity of the elderly. The study of Agnew and South (2014) states that interpersonal relationships in persons of third-age have a beneficial effect on the spiritual health as well. According to the theory of selectivity, social interactions do not fall suddenly in the older age but 
are more selective. Thus, the possible explanation for our results is the fact that, according to this theory, the old ones actually socialize only with those whom they connect pleasant emotions with (Berk, 2008), and there is the explanation for the relatively good social functioning and emotional well-being of the elderly in our sample.

The average scores of the observed respondents tell us about the relatively good integrity and generativity of the elderly. The obtained findings provide support to Erikson's theoretical considerations on the preconditions for successful resolution of the eighth stage crisis, i.e. achieving ego integrity and avoiding despair. Most of our respondents have achieved a sense of integrity on the basis of these results, and they feel complete, full and satisfied (Krstić-Joksimović and Mihić, 2013). Consequently, it does not hurt to mention the studies of Carlson, Seeman and Fried (2000), which indicate the significance of generativity in a healthy aging process, as well as Vaillant's (2007) study, which highlights generativity as a key concept of successful adaptation in the old.

By examining and comparing the earlier and the current material state of the old, the results of our research show that the former material conditions of half of the respondents (53.5\%) are assessed as medium; each fourth respondent estimates that it is good, while the fifth considers the previous material state bad. When the current material situation is in question, the group with good material status increases by almost $2 \%$ compared to the earlier economic status; $4 \%$ of the elderly estimate that they have a better material status than before, while $6 \%$ consider it worse than the past one. These results are somewhat unexpected, having in mind that old people are one of the financially most vulnerable groups both in Serbia and the entire world. However, since it is about the self-assessment of the elderly, as well as the fact that their tendency to account of stressful situations is far lesser as compared to the young adults due to more developed stress management strategies (Paykel, 1983), such an assessment of the financial situation is nevertheless taken with reserve. On the other hand, some authors (Johnson and Barer, 1993) claim that at a high age of life there is a declining interest in material possession. However, there is an indication that the interest in material possession does not go away, but only its manifestation changes. While in the younger age this interest is expressed in the continuous acquisition of material goods, in the old age it changes into the preservation of what was previously acquired (Hellvik, 1996, according to Lacković-Grgin, 2014). A possible explanation is that a number of elderly people live in the care homes for the elderly, and therefore do not feel the daily challenges and difficulties in purchasing drugs, food, etc., which are automatically provided in the home. On the other hand, the wishes of the elderly are generally less expensive compared to active young adults and, therefore, they assess the financial situation as satisfactory. This issue certainly remains to be examined in the subsequent research.

Talking about the health state of the elderly and the differences in relation to the earlier and present material situation, the disparities between groups with good and poor material status have proved to be significant in more dimensions of health. Differences have been shown for the following dimensions: emotional well-being, social functioning, physical functioning and general health. The earlier material situation makes the difference between groups in only one dimension, emotional well-being, but it also makes a difference in generativity and integrity, while the current material situation makes a difference only in the level of integrity of the elderly. This kind of information certainly points to Raphael's statement that the material situation is quite an important health determinant of the degree to which a person has physical, social and personal resources to identify and achieve personal aspirations, and can help satisfy the desire for self-sufficiency and self-integrity (Raphael, 2009). On the other hand, the results of several studies (Keyes and Ryff, 1998) show that generativity grows from the age of thirty to fifty, while being the most developed in middle age. It is possible that our respondents also linked the importance of achieving close 
relations and generative acting as a concern for the benefit of future generations with earlier good material conditions.

\section{Conclusions}

On the basis of all this, it can be concluded that the old people in Novi Pazar mostly assess their earlier and current material status as medium or good. They also link better health state to a better financial situation and assess mental health as better than physical. The respondents in this study report a relatively high degree of generativity achievement, which fits the theory of activity and the model of successful aging, as it speaks of an interaction with their environment and their achieved integrity (Baltes and Baltes, 1990).

This study and its results contribute to the state of the art on this subject, certain limitations and objections should be noted. Firstly, the results of our paper are based on the self-evaluation of the elderly. In order to obtain an adequate picture of the health of third age persons, the next study should include other family members or professionals, to examine the type of material and psychological help that old people receive. On the other hand, the examination of differences among the elderly in view of other socio-demographic variables would be very useful.

It is also very important to develop future programs to reduce socio-economic inequalities in health, so it is necessary to intervene on socially vulnerable groups, especially for elderly people aged 65 years. This means that the health of socially vulnerable groups cannot be improved only by providing health services, but it is necessary to work on other health determinants that are present in their everyday lives.

\section{Bibliography}

1. Agnew, C., South, S., 2014. Interpersonal Relationships and Health Social and Clinical Psychological Mechanisms. Oxford: University Press.

2. Bailis, D.S., Segall, A., Mahon, M.J., Chipperfield, J.G. and Dunn, E.M., 2001. Perceived control in relation to socioeconomic and behavioral resources for health. Social Science \& Medicine, 52(11), pp.1661-1676.

3. Baltes, P.B. and Baltes, M.M., 1990. Psychological perspectives on successful aging: The model of selective optimization with compensation. In: P.B. Baltes and M.M. Baltes, eds. Successful aging: Perspectives from the behavioral sciences. Cambridge: Cambridge University Press. pp. 1-34.

4. Bambauer, K.Z., Aupont, O., Stone, P.H., Locke, S.E., Mullan, M.G., Colagiovanni, J. and McLaughlin, T.J., 2005. The effect of a telephone counseling intervention on self-rated health of cardiac patients. Psychosomatic Medicine, 67(4), pp.539-545.

5. Berk, L., 2008. Exploring lifespan development. Boston, MA: Pearson Allyn and Bacon

6. Bradley, C.L., 1997. Generativity - stagnation: Development of a status model. Developmental Review, 17, pp. 262-290.

7. Brajković, L., 2010. Pokazatelji zadovoljstva životom u trećoj životnoj dobi (Indicators of life satisfaction in the third age). PhD. Sveučilište u Zagrebu: Medicinski fakultet.

8. Carlson, M.C., Seeman, T. and Fried, L.P., 2000. Importance of generativity for healthy aging in older women. Aging Clinical and Experimental Research, 12(2), pp.132-140. 
9. Currey, S.S., Rao, J.K., Winfield, J.B. and Callahan, L.F., 2003. Performance of a generic health-related quality of life measure in a clinic population with rheumatic disease. Arthritis \& Rheumatology, 49(5), pp.658-664.

10. Despot Lučanin, J., 2003. Iskustvo starenja (The experience of aging). Jastrebarsko: Naklada Slap.

11. Domínguez-Berjón, F., Borrell, C., Rodríguez-Sanz, M., and Pastor, V., 2006.The usefulness of area-based socioeconomic measures to monitor social inequalities in health in Southern Europe. European Journal of Public Health, 16(1), pp. 54-61.

12. Dunn, J.R., Veenstra, G. and Ross, N., 2006. Psychosocial and neo-material dimensions of SES and health revisited: Predictors of self-rated health in a Canadian national survey. Social Science \& Medicine, 62(6), pp.1465-73.

13. English, E., 2013. The effect of community participation on subjective well-being in community dwelling elders, [online] Available at: 〈http://digitalcommons.iwu.edu/psych_honproj/161> [Accessed 8 March 2017].

14. Faludi, C., 2015. Aranjamentele de viață, starea de sănătate și singurătatea la vârstnicii din Bulgaria, România și Rusia (Living arrangements, health status and loneliness among the elderly in Bulgaria, Romania and Russia). In: C. Rada and C. Faludi, eds. Funcții și disfuncții ale familiei contemporane. O abordare socio-psiho-medicală (Functions and dysfunctions of the contemporary family. A socio-psycho-medical approach). București: Editura Universitară, pp.84-124.

15. Franks, P., Gold, M.R. and Fiscella, K., 2003. Sociodemographics, Self-Rated Health and Mortality in US. Social Science and Medicine, 56, pp.2505-2514.

16. Hays, R.D., Shapiro, M.F., 1992. An Overview of Generic Health-Related Quality of Life Measures for HIV Research. Quality of Life Research, 1, pp.91-97.

17. Hofer, J., Busch, H., Au, A., Poláčková Šolcová, I., Tavel, P., Tsien Wong, T., 2014. For the benefit of others: generativity and meaning in life in the elderly in four cultures. Psychology and aging, [online] 29(4), pp.764-75. doi: 10.1037/a0037762. Epub 2014 Nov 3. Available at: https://www.researchgate.net/publication/267753293_For_the_Benefit_of_Others_Generativity and_Meaning in_Life in the Elderly_in_Four_Cultures\#pfb [Accessed Nov 12 2017].

18. Hofer, J., Busch, H., Au, A., Poláčková Šolcová, I., Tavel, P. and Tsien Wong, T., 2016. Generativity does not necessarily satisfy all your needs: Associations among cultural demand for generativity, generative concern, generative action, and need satisfaction in the elderly in four cultures. Developmental Psychology, 52, pp.509-519.

19. Johnson, C. I. and Barer, B.M., 1993. Coping and a sense of control among the oldest old: An exploratory analysis. Journal of Aging Studies, 7, pp.67-80.

20. Kahneman, D. and Deaton, A., 2010. High income improves evaluation of life but not emotional well-being. Proceedings of the National Academy of Sciences, 107(38), pp.16489-16493.

21. Kaikkonen R, Rahkonen O, Lallukka T, Lahelma E., 2009. Physical and psychosocial working conditions as explanations for occupational class inequalities in self-rated health. European Journal of Public Health, 19, pp.458-463.

22. Keyes, C.L.M. and Ryff, C.D., 1998. Generativity in adult lives: Social structural contours and quality of life consequences. In: D.P. McAdams \& E. de St. Aubin, eds. Generativity and adult development: How and why we care for the next generation. Washington, DC: American Psychological Association. pp. 227-264. 
23. Krstić-Joksimović, K. And Mihić, Lj.,2013. Developmental processes and mental health in old age: contribution to Erikson's psychosocial theory of Personality development. Primenjena psihologija (Applied psychology), 6(4), pp.423-441.

24. Lacković-Grgin, K. and Tucak, I., 2006a. Adaptirana Loyola Skala generativnosti (Adapted Loyola generativity scale) (ALGS). In: V. ĆubelaAdorić A. Proroković, Z. Penezić K. Lacković-Grgin, ed. Zbirka psihologijskih skala $i$ upitnika. Svezak 3 (Collection of psychological scales and questionnaires. Notebook No.3). Zadar: Sveučilište u Zadru. pp.1-5.

25. Lacković-Grgin, K., Ćubela Adorić, V. and Nekić, M., 2006b. Skala integriteta (Integrity scale). In: V. Ćubela Adorić A. Proroković, Z. Penezić K. Lacković-Grgin, eds. Zbirka psihologijskih skala $i$ upitnika. Svezak 3 (Collection of psychological scales and questionnaires. Notebook No.3). Zadar: Sveučilište u Zadru. pp. 19-23.

26. Lacković-Grgin, K., 2014. Novo u psihologijskim razvojnim teorijama: Modificiranje ranijih, te formuliranje i provjera novih teorija i koncepata (New in psychological development theories: The modification of earlier and formulation and testing of new theories and concepts). Suvremena psihologija (Contemporary psychology), 17(2), pp.199-228.

27. Marmot, M., 2007. Achieving health equity: from root causes to fair outcomes. Lancet, 370(9593), pp.1153-63.

28. McAdams, D. P. and de St. Aubin, E., 1992. A theory of generativity and its assessment through self-report, behavioral acts, and narrative themes in autobiography. Journal of Personality and Social Psychology, 62, pp.1003-1015.

29. Paykel, E.S., 1983. Methodological aspects of life events research. Journal of Psychosomatic Research, 27, pp.341-352.

30. Ranzijn, R. and Luszcz, M.A., 1999. Acceptance: a key to well-being in older adults? Australian Psychologist, 34(2), pp.94-98.

31. Raphael, D., 2009. Social Structure, Living Conditions, and Health. In: D. Raphael, ed. Social Determinants of Health: Canadian Perspectives. 2nd Edition. Toronto: Canadian Scholars' Press. pp. 61-74.

32. Satarić, N., Rašević, M. and Miloradović, S., 2009. Oni ne mogu da čekaju. Studija o siromašnim starijim licima u Srbiji (They cannot wait. A study on poor elderly in Serbia). Beograd: INPRESS.

33. Schaie, K.W., Willis, S.L., 2001. Adult development and Aging. New York: Harper Collins College Publishers.

34. Stewart, A.L., Sherbourne, C.D., Hays, R.D., Wells, K.B., Nelson, E.C., Kamberg, C.J., Rogers, W.H., Berry, S.H. and Ware, J.E.Jr., 1992. Summary and Discussion of MOS Measures, In: A.L. Stewart \& J.E. Ware, Jr., eds. Measuring Functioning and Well-Being: The Medical Outcome Study Approach. Durham, NC: Duke University Press. pp. 345-371.

35. Stewart, A.J., Vandewater, E.A., 1998. The course of generativity. In: D.P. McAdams and E. de St. Aubin, eds. Generativity and Adult Development: How and Why We Care for the Next Generation. Washington, DC: APA Press. pp. 75-100.

36. Stewart, A.J., Ostrove, J.M. and Helson, R., 2001. Middle Aging in Women: Patterns of Personality Change from the 30s to the 50s. Journal of Adult Development, 8(1), pp.23-37.

37. Tucak-Junaković, I., 2010. Skala nade u budućnost čovječanstva (Hope for the future of humanity Scale). In: I. Tucak Junaković, V. Ćubela Adorić, Z. Penezić, A. Proroković, eds. Zbirka psihologijskih skala $i$ upitnika. Svezak 5 (Collection of psychological scales and questionnaires. Notebook No.5). Zadar: Sveučilište u Zadru. pp. 39-45. 
38. Vaillant, G.E., 2007. Generativity: A form of unconditional love. In: S.G. Post, ed. Altruism and health. New York: Oxford University. pp. 219-229.

39. ***World Health Organization. The European health report 2002. Part two - The major determinants of health. 2002 [online] Available at: <http://www.euro.who.int/_data/assets/pdf_file/0007/98296/E76907.pdf > [Accessed 13 May 2017].

40. ***Republic Statistical Office of Serbia, Poverty and social inequality, 2016 [online] Available at:

<http://www.stat.gov.rs/WebSite/repository/documents/00/02/45/24/PD10_087_srb_2016.pdf> [Accessed: 1 July 2017].

41. ***Eurostat, People at risk of poverty or social exclusion. 2016 [online] Available at:http://ec.europa.eu/eurostat/statisticsexplained/index.php/People_at_risk_of_poverty_or_socia 1_exclusion [Accessed: 15 July 2017]. 


\title{
A preliminary analysis of gender violence among migrants and displaced people in Europe
}

\section{DOI: http://doi.org/10.26758/8.1.5}

Santiago Boira (1), Anita Nudelman (2), Tina (Tiko) Tsomaia (3)

(1) University of Zaragoza, Spain

(2) Ben Gurion University, Israel

(3) Georgian Institute of Public Affairs (GIPA), Tbilisi (Georgia)

Address correspondence to: Santiago Boira. Facultad de Ciencias Sociales y del Trabajo. University of Zaragoza. C/ Violante de Hungría, 23, 50009 Zaragoza (Spain). Ph.:+0034976761600; E-mail: sboira@unizar.es

\begin{abstract}
Background. The vulnerability of migrant women, especially those coming from patriarchal societies, leads to the increase of gender violence. This is incremented by a myriad of socioecological determinants related to the immigration process and to the nature of male-female relationships.

Objectives. The main objective is to conduct a preliminary analysis of recent publications dealing with the relations between gender violence and migrant populations in the European Union, including internally displaced people.

Materials and methods. This paper is based on a revision of scientific publications from SCOPUS that relate to migrant women who are victims of gender violence in the European Union. The qualitative thematic analysis was used in order to identify the main issues targeted in the articles.

Results. The thematic analysis of the studies reviewed dealing with migration and gender violence highlighted several important themes, including prevalence of violence against migrant women; the forms and contexts of gender violence; the impact of legal, economic environments and sociocultural barriers; the influence of conflict and war; the impact and consequences of violence, especially on women's mental health, as well as strategies and suggestions for interventions.

Conclusions. Increasing the awareness of migration, regarding the conflicts and problems experienced by migrants (of both genders), could enable health and legal authorities to offer more significant culture and gender sensitive services, thus reducing gender violence.
\end{abstract}

Keywords: migration; gender inequality; violence

\section{Introduction}

During the last few years, the European Union has experienced a constant population flow arriving through different entry points, sometimes after long and difficult journeys. In 2015, there were an estimated 2.7 million immigrants to the EU-28 from non-member countries. The largest total number of immigrants was in Germany, followed by the United Kingdom, France, Spain and Italy (Eurostat, 2016). Many of them came from the Middle East, Asia, Africa and America due to 
prolonged wars and political reasons, as well as economic ones. Nevertheless, it is difficult to determine when the migration process will end for these women, since it implies a vital readjustment process in the host society, which can last for many years and even a lifetime.

Gender violence against immigrant women is at epidemic proportions, but research has only recently begun to address this concern (Raj and Silverman, 2002). Various studies have indicated that migrant women are highly vulnerable to domestic violence in European host countries. The vulnerability of migrant women, especially those coming from patriarchal societies, leads to the increase of domestic violence and abuse. This is incremented by a myriad of socioecological determinants related to the immigration process and to the nature of male-female relationships.

Women's isolation due to language and cultural barriers, as well as legal ones, is often increased by socio-economical dependency on their husbands/partners, thus affecting their ability to lodge complaints (for example, go to the police), as well as their access to support networks and professional assistance (Runner, Yoshihama and Novick, 2009; Rana, 2012; Ingram, 2007).

Women who are not citizens of the country in which they reside were found to have a higher prevalence of physical and sexual violence (European Union Agency for Fundamental Rights, 2014), thus making domestic violence a major force of victimization (Davis, Erez and Avitabile, 2001; Carbajosa, et al., 2011; Hazen and Soriano, 2007; Gracia et al., 2010). It is also important to consider the suffering of some of these women in the context of other critical global issues and processes, such as trafficking of women, the effects of patriarchal culture, as well as intra and intergenerational issues.

Femicide is defined widely as the killing of women because of their gender, although it includes different types of phenomena, such as intimate partner murder and honor killings and is often explained using different models (Corradi et al., 2016). "Failed femicide" attempts (Weil, 2016a) have received little attention across Europe.

A recent study among women who survived a femicide attempt indicates some common characteristics shared by migrant women from different countries, such as having been through a process of increasing violence, the forms of violence experienced and how these affected them. In addition, aggressors were described as "control freaks", very jealous and trying to restrict women's movement and activities. In order to justify their aggression, they tend to falsely accuse their wives of being promiscuous, while children are often used to manipulate and pressure their wives. In addition, these women showed an ambivalent attitude towards security forces and care professionals due to lack of trust. Barriers to access services may also be exacerbated due to pressure from the communities of origin in the host country (Nudelman et al., 2017).

When considering migrant male abusers, Fernández-Montalvo et al. (2011) sustain that they are younger, with more children in common with the victim, with a slightly higher level of education and with a longer history of mental illness than Spanish abusers. Furthermore, migrant abusers have more irrational thoughts about women and the use of violence (Echeburúa y Fernández-Montalvo, 1998), and they have experienced childhood abuse more often than their Spanish counterparts.

The aim of this article was to conduct a preliminary analysis of recent publications dealing with the relation between gender violence and migrant populations, including internally displaced people. This is part of a larger study to assess the impact of different factors related to the migration process and the increase of gender violence, including femicide - while focusing on migrants in the European Union. 
The total number of persons born outside the EU-28 and living in an EU Member State on January 1, 2016 was estimated at 35.1 million, while an additional 19.3 million persons were born in a different EU Member State from the one where they were resident (Eurostat, 2016). When considering internally displaced people (IDPs) mostly due to conflicts, the highest number in the EU can be found in Cyprus 272,000 (IDMC, 2017).

The hypothesis suggested is that migrant women's insecure status in Europe may increase their risk of suffering from severe gender violence, making it more difficult for them to come forward, denounce their aggressors and to access the host country's services, thus decreasing their chances of leaving the cycle of violence. Thus, it is of utmost importance to increase awareness, sensitivity, and knowledge on socio-cultural perspectives which may influence gender violence among migrant women.

\section{Material and methods}

This paper is based on a preliminary revision of scientific articles that relate to the issue of migrant women who are victims of gender violence in countries of the EU. SCOPUS was selected since it is one of the most comprehensive databases, which includes the highest indexed and most representative scientific publications and was accessed in August 2017.

The following strategy was used to identify the relevant publications: the initial search limited the time frame to publications as from 2000, in order to base our analysis on the most recent ones, incorporating all the references found in the database, including research articles, systematic reviews, book chapters or any other kind of reference; the second one focused on publications with key words "migrant", " migration" or "displaced people" combined with the terms "domestic violence", "gender violence", "violence against women", "intimate partner violence" or "femicide". The final search was limited to publications referring to member countries of the European Union, as well as Israel, which is grouped together with the European region by many international agencies.

After identifying the relevant publications, a descriptive analysis was performed. Finally, the preliminary thematic analysis was made, based on the main themes identified in the abstracts.

\section{Results}

The resulting number of publications referring to migrant population or displaced people was 414 . Of these only $70(16.9 \%)$ were situated in the territory of countries of the European Union.

\section{Descriptive analysis of the publications}

In this section, the publications will be described according to the year of publication, type of journal, language and countries.

Considering the year of publication, as years go by, a growing interest in themes focusing on migration and displaced populations can be observed (Figure 1). 


\section{Figure 1. Yearly amount of publications}

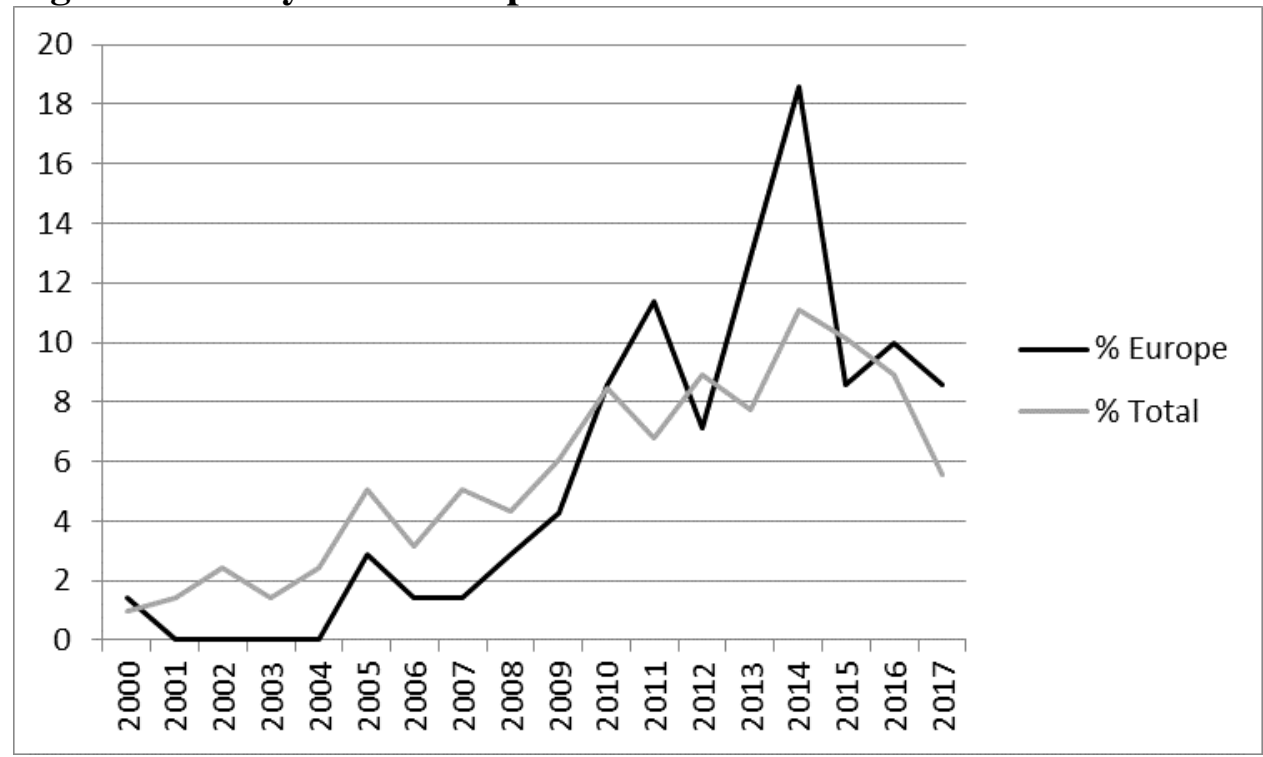

When considering the type of publications, most of them $(\mathrm{N}=62)$ are academic articles representing $89 \%$, followed by reviews $(6 \%)$.

Most of these publications are written in English (54), 12 of them in Spanish, 4 in German, two in Portuguese and one in French.

\section{Figure 2. Publications according to disciplines}

\begin{tabular}{|r|r|r|r|} 
Environmental Science & \\
Economics, Econometrics and... \\
Earth and Planetary Sciences \\
Business, Management and... \\
Arts and Humanities \\
Psychology \\
Social Sciences
\end{tabular}


The main disciplines dealing with issues related to migration, displaced populations, and gender violence are social sciences, medicine, and psychology (Figure 3).

This distribution is similar both among studies focusing on European countries and on the rest of the world.

The countries in Europe where the research took place can be observed in Table 1.

\section{Table 1. Distribution of publications by countries}

\begin{tabular}{|l|c|}
\hline \multicolumn{1}{|c|}{ Country } & References \\
\hline Spain & 26 \\
\hline United Kingdom & 16 \\
\hline Sweden & 6 \\
\hline Germany & 5 \\
\hline Italy & 4 \\
\hline France & 2 \\
\hline Israel & 2 \\
\hline Netherlands & 2 \\
\hline Portugal & 2 \\
\hline Switzerland & 2 \\
\hline France & 2 \\
\hline Belgium & 1 \\
\hline Finland & 1 \\
\hline Ireland & 1 \\
\hline Norway & 1 \\
\hline Poland & 1 \\
\hline Romania & 1 \\
\hline
\end{tabular}

The countries from which most references were found were Spain and the United Kingdom. This is closely related to the professional affiliation of the researchers, who mostly work in Spanish and British Universities.

\section{Thematic analysis}

The main themes that emerged from the analysis of the studies focusing on gender violence and migrants in the European Union related to the increasing prevalence of violence; the forms, causes and contexts of gender violence; the impact of legal, economic environments and sociocultural barriers; the influence of conflict and war; the impact and consequences of violence, especially on women's mental health, as well as strategies and suggestions for interventions. It is important to note that some themes overlap, thus articles may include more than one theme.

Prevalence of violence against migrant women. A group of studies relates to the prevalence of violence among migrant women (Legouge and Pfefferkorn 2011), indicating that it is still one of the most brutal manifestations of the inequalities between men and women. For 
example, in Italy prevalence of abuse is associated with domestic violence among couples in which the mothers are migrants and the fathers Italian (Cammarella et al., 2016). Similarly, violence is considered a frequent problem among both female and male immigrants living in Portugal, with different gender patterns regarding the perpetrators and settings of abuse (Dias, Fraga and Barros, 2013).

The movement towards a real equality is partial and contradictory especially in contexts where immigrants constitute a vulnerable population. Thus, violence may be both higher and underreported among immigrants (Colorado - Yohar et al., 2012).

The forms, causes, and contexts of gender violence. Considering different forms of gender violence, intimate partners committed significantly more homicide-suicides among emigrants than non-emigrants in Romania. Emigrant homicide-suicides also had significantly more reports of prior abuse than non-emigrant homicide-suicides (Balica and Stöck1, 2016).

In Israel, between 1995 and 2007, different characteristics of intimate femicide were identified. Ethiopian immigrants differed significantly from the others due to a pattern of femicide followed by suicide, while among immigrants from the former USSR femicide under the influence of alcohol was prevalent (Sela-Shayovitz, 2010).

Immigrant women also have a higher risk of suffering psychological abuse. In addition, migrant women's awareness of violence differs from native ones: while Spanish women had more difficulty recognizing psychological violence, for Romanian migrants in Spain, it was easier to identify some of the behaviors involving physical or sexual violence (Rabito-Alcón et al., 2013).

Finally, one of the studies identified targeted a specific type of femicide among migrant communities in Europe - honor killings - a culturally specific form of gender-related homicide exacerbated by the migration process. This direct violence against women can be considered a patriarchal backlash in a situation of structural changes in gender relations (Grzyb, 2016).

When focusing on the physical place where gender violence occurs, women victims in Portugal reported that these episodes occurred more often at home $(54.4 \%)$ with the partner as the perpetrator $(43.9 \%)$. Male victims stated that the violent episodes occurred mostly in public spaces (40.8\%), indicating that the perpetrator was frequently a stranger $(28.6 \%)$ or a co-worker $(18.4 \%)$ (Dias, Fraga and Barros, 2013).

Regarding the causes which increase the probability of experiencing intimate partner violence among migrant women, a study conducted in Spain concluded that the variables associated with greater vulnerability are ages lower than 18 years, as well as low socioeconomic status, low social support and having a mother who had experienced intimate partner violence (Sanz-Barbero, Rey and Otero-García, 2014). Intimate partner violence was also associated with factors such as being separated and/or divorced, lack of social support and low religious involvement while varying among immigrants from different countries (Vives-Cases et al, 2014). An additional study in Norway showed that immigrant women had lower income, were less likely to use alcohol and had increased likelihood of having an immigrant partner. While no differences were found between ethnic Norwegian and immigrant women concerning intimate partner violence severity, frequency, guilt, shame, or victimization, immigrants were better at predicting physical violence, but had an increased risk of physical injury related to sexual one (Vatnar and Bjørkly, 2010).

Legal, economic and socio-cultural barriers. The risk of violence can increase among immigrant women due to their legal and economic situation and to different barriers to accessing 
information and support services (Martinez-Roman, Vives-Cases and Pérez-Belda, 2017). Intimate partner violence was found to be higher in physically disordered and decaying neighborhoods and in neighborhoods with low educational and economic status levels, high levels of public disorder and crime, and high concentrations of immigrants (Gracia et al., 2015).

In the United Kingdom, inequalities created by culture, gender, class, and race intersect with state immigration and welfare policies, thereby exacerbating structures of patriarchy within minority communities. It is within these contexts that South Asian women with insecure immigration status experience intensified forms and specific patterns of abuse (Anitha, 2011).

Nevertheless, it is important to be aware of the stigmatizing risks that arise from using culture to frame certain forms of violence against women. Applied uncritically, these approaches risk showing immigrants as powerless women victimized by their non-European cultures and is reminiscent of colonial times (Peroni, 2016).

A study conducted in Spain showed that immigrant women are triply affected: by gender violence, by the economic crisis, and by structural violence. In times of economic crisis intimate partner violence-related policies cease to be a priority, resources are reduced as well as staff and the quality of services, making it even more difficult for migrant women (Briones-Vozmediano et al., 2014a).

Violence against women may be considered one of the most extreme forms of gender inequality. Women are further victimized by the worsening of the job market situation and gender discrimination in employment. For instance, migrant women from poor countries increasingly engage in domestic work and care for dependent people, and their access to certain places of work or to a higher level job is very difficult (Legouge and Pfefferkorn 2011).

At the same time, post-migration sources of stress, social isolation and the absence of the ethnic community among Muslims in Italy are interrelated factors, that contribute to gender violence in the post-migration context. In addition to the social and psychological factors, linguistic and cultural barriers also influence women's capability to leave an abusive relationship (Giuliani and Gennari, 2014).

A fundamental issue for migrant women who are victims of gender violence is being able to obtain professional assistance. Nevertheless, for many of them, the availability, accessibility, and quality of psychosocial and health services pose significant barriers. Other reasons for abandoning the help-seeking process involve structural factors such as economic dependence, loss of social support after leaving their country of origin, and limited knowledge about the resources available. In practice, resources allocated to gender-based violence were insufficient to meet battered immigrant women's needs (Briones-Vozmediano et al., 2014b). In Spain, abused immigrant women require a residence permit as a prerequisite for their access to different services and rights. Since frequently these services are not culturally appropriate, women lose confidence in their effectiveness, which may also reflect the lack of appropriate training among professionals on issues related to intimate partner violence and immigration (Briones-Vozmediano et al., 2015).

Social stigmatization, precarious living conditions, and the climate of fear and suspicion generated by increasingly restrictive immigration policies - hinders undocumented immigrants' access to health care rights in the European context (Larchanché, 2012). Thus, injuries due to domestic violence in Germany are a frequent occurrence in emergency departments, which are usually accessible to all. The victims were predominantly female and were attacked by the (ex) partner, although excessive violence with life-threatening or fatal injuries was not usually observed (Gologan et al., 2014). Nevertheless, foreign women living in Spain are especially vulnerable to death from intimate partner violence (Vives-Cases et al., 2008). 
Conflict and war. A special situation to be considered relates to violence against women in situations of conflict or wars. War-related violence in the community of origin created fear, separation and limited access to reproductive health services, exposing Somali women to nonpartner sexual violence or intimate partner violence. The non-disclosure of this violence due to the risk of shame and stigmatization may explain why their violence-related health issue may be overlooked in the health care system in Sweden. Nevertheless, survival strategies shaped by war such as social networks, stoicism, and faith, contain resources for resilience and enhancement of well-being and sexual and reproductive health and rights in receiving countries after migration (Byrskog et al., 2014).

Besides major international and national advances in gendered legislation, the impacts of sexual violence during and beyond conflict situations are profound, although not adequately recognized or considered during the asylum application process, or, in some cases, in localized communities and organizations in the UK (Canning, 2014).

The impact and consequences of violence. Various studies analyze the impact and the consequences of violence for the victims.

For example, internally displaced women in Britain relocate to escape gender violence, although they had not previously intended to migrate. Journeys are focused on trying to minimize disruption either by staying as close as they can while avoiding friends, family, and known locations, or by traveling to a place similar to the one they left. Their primary concern is safety and their journeys are often complex and segmented into multiple stages over time and space (Bowstead, 2015).

Chan (2000) describes situations of hardship and overwork, poverty and deprivation, poor social support and social isolation, unhappy family relationships, gambling husbands and domestic violence, together with language and cultural difficulties that contributed to poor quality of living standards as well as indirectly caused negative psychosocial health outcomes for Chinese mothers in the UK.

Concomitantly, Martínez and Piqueras (2014) relate to the impact of violence on the identity of women, considering how their different trajectories and webs of violence lead to distinct understandings of the violence they have experienced.

Several studies identified the strong connection between violence and mental health among women migrants. Considering that interpersonal violence is frequently found in relations with the partner, the family, and even outside the family, it seriously affects mental health. Thus, social, cultural and economic factors, particularly gender inequality and women's low status in society, are root causes of violence and affect women's mental health directly. In spite of this evidence, most mental health policies and programmes do not systematically include consideration of violence issues (Alvarez-del Arco et al., 2013). Another study focused on the increased risk for poor mental health among Thai women exposed to intimate partner violence in Sweden, constituting an obstacle for their integration (Fernbrant et al., 2014). countries.

Furthermore, mental health services are sorely lacking in low and middle-income

A significant association between gender violence and depression was found in women (aged >18 years) attending general practice in the Netherlands, where half of the abused women were suffering from depression. Therefore, in order to improve recognition of abused women, doctors should ask depressed women if they ever experienced IPV (Prosman et al., 2011). 
Strategies and suggestions for interventions. Some of the studies contain elements to promote the prevention of violence, improve the care for victims as well as how to work with male perpetrators. Thus, for example, an enabling environment promoted by specific gender-related laws and other specific legislative regulations that address IPV in immigrant populations is considered important (Briones Vozmediano, La Parra and Vives-Cases, 2015).

Targeted interventions were also suggested to deal with mental health. Although poor mental health in Thai women in Sweden represented an obstacle for integration, their potential resilience indicated by high social trust and without exposure to social isolation suggested that such aspects must be included in a program designed to facilitate integration (Fernbrant et al., 2014).

It was suggested that professionals should be targeted and trained in the prevention of violence (including gender violence) and mental health, adding this as part of the official curricula of health providers (Garcia-Moreno and Riechler-Rossler, 2013).

Relating to cultural practices, it is estimated that a third of migrant women from countries where Female genital mutilation (FGM) is practiced may have undergone FGM/cutting in their countries of origin and that girls may be at risk. Thus, both policy and targeted interventions to deal with this practice should be planned in advance (Ortensi and Menonna, 2017). Awareness-raising through the combined efforts of families, communities, and governments, together with the development of health education programs addressing the complications derived from FGM, may help to eradicate this practice (Ruiz, Martínez and del Mar Pastor Bravo, 2016).

Considering suicide prevention, it has been demonstrated that population-based intervention program can reverse this trend among ethnic minority groups with high suicide attempt rates across Europe (Aichberger et al., 2015). Another intervention mentioned is working on the basis of overcoming stereotypes through other women's communicative daily life stories (CDLS) conducted with other women from migrant or ethnic minority descent, which can contribute to dismantle existing sexist and racist stereotypes and prevent gender violence (García-Yeste, 2014).

A study focusing on interventions for male perpetrators found that the effectiveness of psychological treatment programmes for immigrant men who committed a gender-based violent crime in Spain has increased, as well as the number of participants (Echauri et al., 2013).

When addressing future challenges, Torrubiano-Domínguez and Vives-Cases (2013) indicate that the most important goal for future research is the use of Violence Against Women (VAW) scales validated in different languages, which would help to overcome language barriers. They recommend Putting Women First protocol is an ethical guideline for VAW research, which includes recommendations to ensure the safety of the women involved in studies on this subject.

Further research on the causes of gender-based violence among foreign women, as well as additional strategies involving health services are needed (Vives-Cases et al 2008).

In addition, trafficking should also be addressed since it is a health risk related to gender violence, spanning geographical boundaries and involving multiple sectors, including immigration and law enforcement, labor, social and health services. Thus, interventions must be coordinated between nations and across sectors to promote the protection and recovery of people who are trafficked (Zimmerman, Hossain and Watts, 2011). 


\section{Conclusions}

Migration is often accompanied by an increased risk of gender violence due to a myriad of factors, especially among women who continue to be in a socioeconomic disadvantage in their host country (Fernbrant et al, 2011).

The thematic analysis of the studies dealing with migration and gender violence reviewed in this paper highlighted several important themes, including prevalence of violence against migrant women, the forms and contexts of gender violence, the impact of legal, economic environments and socio-cultural barriers, the influence of conflict and war, the consequences of violence, as well as suggestions for intervention strategies.

It is interesting to note the absence of specific studies relating to femicide among migrant populations in the studies sampled, and it is suggested to raise awareness of and to make this phenomenon visible (Weil 2016b). Concomitantly, studies of gender violence among internally displaced people were also found lacking.

On the other hand, it is necessary to beware and make generalizations when addressing groups of women from a specific geographical area (i.e., Anitha, S., 2011; Byrskog et al., 2014), since there will always be differences and characteristics, which must be considered. The same may occur when the terms ethnicity and culture are juxtaposed, since they often do not have the same meaning.

An additional factor to bear in mind is the importance of the team of investigators, which should always include some from the women's countries of origin, thus facilitating an understanding of the native (emic) perspectives.

Considering the vulnerable situation of women on the move, it is important to reflect on the rise of gender violence and of femicide as a result of complex migration processes.

When targeting immigrant women, it is also essential to consider the post-migration context as a risk factor. For these women, the life in the host country is often characterized by difficulties to access crucial services due to language and socio-cultural barriers, as well as their often unclear legal status and their perception of the host society as a threat (Nudelman et al., 2017).

The types of support and assistance available to migrant women, both from organizations and from the different governmental and European official institutions, should be identified and targeted in order to overcome the different barriers to service access and to enhance culture competency (Rana, 2012). Therefore, it is essential to increase the awareness and sensitivity of migration authorities, including police, legal and healthcare professionals regarding the conflicts and problems experienced by migrants of both genders. This would enable them to offer more significant services, thus contributing to the reduction of gender-based violence and the threat of femicide.

Regarding the limitations of this article, we must indicate the difficulty to identify comprehensive categories of analysis, as observed during the presentation of the results of the thematic analysis. This was a direct consequence of the exclusive use of the abstracts in this preliminary study, also allowing for overlapping categories, which may affect future studies.

Future activities should combine research, prevention, and intervention while considering existing promising practices (Runner et al., 2009) and this is also one of the objectives of our future work. We are in the process of developing a broader study on gender violence and femicide among migrants in Europe, including internally displaced people, while especially focusing on groups in movement (in the process itself). This investigation will encompass other countries included in the Council of Europe, where the issue of internally displaced people is acute, such as Ukraine $(1,653,000)$, Turkey $(1,108,000)$, Azerbaijan $(582,000)$, Georgia $(208,000)$ and Bosnia Herzegovina 
$(98,000)$ (IDMC, 2017). It will also address gender violence among refugees, considering that more than a million people from the Middle East and Africa have entered the EU during the past few years, escaping conflicts and dire conditions in their countries of origin.

One of the objectives of our ongoing work is to apply our research findings to enhance capacity building for professionals as well as in interventions focusing on prevention and care among different groups of migrant women.

\section{Bibliography}

1. Aichberger, M. C., Heredia Montesinos, A., Bromand, Z., Yesil, R., Temur-Erman, S., Rapp, M. A., Heinz, A. and Schouler-Ocak, M., 2015. Suicide attempt rates and intervention effects in women of Turkish origin in Berlin. European Psychiatry, 30(4), pp.480-485.

2. Alvarez-del Arco, D., del Amo, J., Garcia-Pina, R., Garcia-Fulgueiras, A. M., RodriguezArenas, M. A., Ibañez-Rojo, V., Diaz-del Peral, D.,. Jarrin, I., Fernandez-Liria, A., Zunzunegi, M.V., Gartiz-Ortozar V., Mazarrasa L and Llacer, A., 2013. Violence in adulthood and mental health: Gender and immigrant status. Journal of Interpersonal Violence, 28(11), pp.2203-2222.

3. Anitha, S., 2011. Legislating gender inequalities: The nature and patterns of domestic violence experienced by south Asian women with insecure immigration status in the United Kingdom. Violence Against Women, 17(10), pp.1260-1285.

4. Balica, E. and Stöck1, H., 2016. Homicide-suicides in Romania and the role of migration. European Journal of Criminology, 13(4), pp.517-534.

5. Bowstead, J. C., 2015. Forced migration in the United Kingdom: Women's journeys to escape domestic violence. Transactions of the Institute of British Geographers, 40(3), pp.307-320.

6. Briones-Vozmediano, E., Agudelo-Suarez, A. A., Goicolea, I. and Vives-Cases, C., $2014 a$. Economic crisis, immigrant women and changing availability of intimate partner violence services: A qualitative study of professionals' perceptions in Spain. International Journal for Equity in Health, 13(1), pp.1-9.

7. Briones-Vozmediano, E., Goicolea, I., Ortiz-Barreda, G. M., Gil-González, D. and Vives-Cases, C., 2014b. Professionals' perceptions of support resources for battered immigrant women: Chronicle of an anticipated failure. Journal of Interpersonal Violence, 29(6), pp.1006-1027.

8. Briones-Vozmediano, E., La Parra, D. and Vives-Cases, C., 2015. Barriers and facilitators to effective coverage of intimate partner violence services for immigrant women in Spain. Health Expectations, 18(6), pp.2994-3006.

9. Byrskog, U., Olsson, P., Essén, B. and Allvin, M. K., 2014. Violence and reproductive health preceding flight from war: Accounts from Somali born women in Sweden. BMC Public Health, 14(1), p.892. doi: 10.1186/1471-2458-14-892.

10. Cammarella, A., Ferracci, A., Gizzi, N. and Menozzi, F., 2016. Genitorialità, dinamiche relazionali ed esiti evolutivi sui figli di coppie miste coinvolti in situazioni di abuso. Maltrattamento e Abuso all'Infanzia, 18(2), pp.119-138.

11. Canning, V., 2014. International conflict, sexual violence and asylum policy: Merseyside as a case study. Critical Social Policy, 34(1), pp.23-45.

12. Carbajosa, P., Lila, M., Negredo, L. and Pérez, M., 2011. El delito de violencia de género y los penados extranjeros. Madrid: Secretaría General Técnica del Ministerio del Interior.

13. Chan, C., 2000. The quality of life of women of Chinese origin. Health and Social Care in the Community, 8(3), pp.212-222. 
14. Colorado-Yohar, S., Tormo, M. J., Salmerón, D., Dios, S., Ballesta, M. and Navarro, C., 2012. Violence reported by the immigrant population is high as compared with the native population in southeast Spain. Journal of Interpersonal Violence, 27(16), pp.3322-3340.

15. Corradi, C., Marcuello-Servos, C., Boira, S. and Weil, S., 2016. Theories of femicide and their significance for social research. Current Sociology, 64(7), pp. 975-995.

16. Davis, R. C., Erez, E. and Avitabile, N., 2001. Access to Justice for Immigrants Victimized by Crime: The Perspectives of Police and Prosecutors. Criminal Justice Policy Review, 12(3), pp.183-196.

17. Dias, S., Fraga, S. and Barros, H., 2013. Interpersonal violence among immigrants in Portugal. Journal of Immigrant and Minority Health, 15(1), pp.119-124.

18. Echauri, J. A., Fernández-Montalvo, J., Martínez, M. and Azkarate, J. M., 2013. Effectiveness of a treatment programme for immigrants who committed gender-based violence against their partners. [Efectividad de un programa de tratamiento con inmigrantes que ejercen violencia de género contra la pareja] Psicothema, 25(1), pp.49-54.

19. Echeburúa, E. and Fernández-Montalvo, J., 1998. Instrumentos de evaluación de maltratadores. In: E. Echeburúa y P. Corral (dirs.), Manual de violencia familiar Madrid: Pirámide. pp.91-129.

20. Fernández-Montalvo, J., Echauri, J. A., Martínez, M. and Azcárate, J. M., 2011. Gender violence and immigration: Differential profile of national and immigrant male abusers. [Violencia de género e inmigración: Perfil diferencial de hombres maltratadores nacionales e inmigrantes] Behavioral Psychology/Psicologia Conductual, 19(2), pp.439-452.

21. Fernbrant, C., Essén, B., Östergren, P. and Cantor-Graae, E., 2011. Perceived threat of violence and exposure to physical violence against foreign-born women: A Swedish population-based study. Women's Health Issues, 21(3), pp.206-213.

22. Fernbrant, C., Emmelin, M., Essén, B., Östergren, P. -., and Cantor-Graae, E., 2014. Intimate partner violence and poor mental health among Thai women residing in Sweden. Global Health Action, 7(1). Available at: <https://www.ncbi.nlm.nih.gov/pmc/articles/PMC4166544/pdf/GHA7-24991.pdf $>$ [Accessed 17 July 2017].

23. García-Moreno, C. and Riecher-Rössler, A., 2013. Violence against women and mental health. Basel: KARGER.

24. García-Yeste, C., 2014. Overcoming stereotypes through the other women's communicative daily life stories. Qualitative Inquiry, 20(7), pp.923-927.

25. Giuliani, C. and Gennari, M., 2014. Intimate male partner violence and Muslim migration. [Intimate male partner violence: Voci dei migranti musulmani] Maltrattamento e Abuso all'Infanzia, 16(1), pp.101-112.

26. Gologan, R., Aziriu, S., Obertacke, U. and Schreiner, U., 2014. Medical and sociodemographic aspects of domestic violence: Systematic evaluation of patient data from the emergency department of a maximum care hospital. [Medizinische und soziodemographische Aspekte häuslicher Gewalt: Systematische Auswertung von Patientendaten einer Notaufnahme eines Krankenhauses der Maximalversorgung] Unfallchirurg, 117(6), pp.528-532.

27. Gracia, E., Herrero, J., Lila, M. and Fuente, A., 2010. Percepciones y actitudes hacia la violencia de pareja contra la mujer en inmigrantes Latinoamericanos en España. Intervención Psicosocial, 19(2), pp.135-144.

28. Gracia, E., López-Quílez, A., Marco, M., Lladosa, S. and Lila, M., 2015. The spatial epidemiology of intimate partner violence: Do neighborhoods matter? American Journal of Epidemiology, 182(1), pp.58- 66. 
29. Grzyb, M. A., 2016. An explanation of honor-related killings of women in Europe through Bourdieu's concept of symbolic violence and masculine domination. Current Sociology, 64(7), pp.1036-1053.

30. Hazen, A. L. and Soriano, F. I., 2007. Experiences with intimate partner violence among Latina women. Violence Against Women, 13(6), pp.562-582.

31. Ingram, E. M., 2007. A comparison of help seeking between Latino and non-Latino victims of intimate partner violence. Violence Against Women, 13(2), pp.159-171.

32. Larchanché, S., 2012. Intangible obstacles: Health implications of stigmatization, structural violence, and fear among undocumented immigrants in France. Social Science and Medicine, 74(6), pp.858-863.

33. Legouge, P. and Pfefferkorn, R., 2011. Inequalities between men and women: Advances and hurdles. [Inégalités hommes - Femmes: Avancées et obstacles]. Pensee, 367, pp.95-103.

34. Martínez, P. R. and Piqueras, C. C., 2014. Analysis of judicial decisions on partner violence among migrant and Spanish population in Almeria and Murcia (2005-2010). [Analisis de resoluciones judiciales sobre violencia en la pareja en la población migrante y española en Almería y Murcia (2005-2010)] Migraciones, 2014(35), pp.99-127.

35. Martinez-Roman, M., Vives-Cases, C. and Pérez-Belda, C., 2017. Immigrant women suffering from IPV in Spain: The perspectives of experienced social workers. Affilia - Journal of Women and Social Work, 32(2), pp.202-216.

36. Nudelman, A., Boira, S., Tsomaia, T., Balica, E. y Tabagua, S., 2017. "Hearing their voices": exploring femicide among migrants and culture minorities. Qualitative Sociology Review, 10(3), pp.49-68.

37. Ortensi, L.E. and Menonna, A., 2017. Migrating with special needs? Projections of flows of migrant women with female genital Mutilation/Cutting toward Europe 2016-2030. European Journal of Population, 33(4), pp. 559-583. |

38. Peroni, L., 2016. Violence against migrant women: The Istanbul convention through a postcolonial feminist lens. Feminist Legal Studies, 24(1), pp.49-67.

39. Prosman, G., Jansen, S. J. C., Lo Fo Wong, S. H. and Lagro-Janssen, A. L. M., 2011. Prevalence of intimate partner violence among migrant and native women attending general practice and the association between intimate partner violence and depression. Family Practice, 28(3), pp.267271.

40. Raj, A. and Silverman, J., 2002. Violence Against Immigrant Women: The Roles of Culture, Context, and Legal Immigrant Status on Intimate Partner Violence. Violence Against Women, 8(3), pp.367-398.

41. Rabito-Alcón, M. F., Puente-García, R., Cámara-Blanco, L., De Frutos-Moneo, E., García-Jorge, S. and Correas-Lauffer, J., 2013. Differential perception of gender violence by Romanian immigrants resident in the metropolitan area of Madrid. [Percepción diferencial de la violencia de género por las inmigrantes rumanas residentes en una zona de la corona metropolitana de Madrid] Semergen, 39(5), pp.247-251.

42. Rana, S., 2012. Addressing Domestic Violence in Immigrant Communities: Critical Issues for Culturally Competent Services. Harrisburg, PA: VAWnet, a project of the National Resource Center on Domestic Violence. Available at: https://vawnet.org/sites/default/files/materials/files/2016-09/AR_DVImmigrantComm.pdf [Accessed 17 July 2017].

43. Ruiz, I. J., Martínez, P. A. and del Mar Pastor Bravo, M., 2016. Key points for abolishing female genital mutilation from the perspective of the men involved. Midwifery, 34, pp.30-35. 
44. Runner, M., Yoshihama, M. and Novick, S., 2009. Intimate Partner Violence in Immigrant and Refugee Communities: Challenges, Promising Practices and Recommendations. Princeton, NJ: Robert Wood Johnson Foundation and Futures Without Violence.

45. Sanz-Barbero, B., Rey, L. and Otero-García, L., 2014. Health status and intimate partner violence. [Estado de salud y violencia contra la mujer en la pareja] Gaceta Sanitaria, 28(2), pp.102-108.

46. Sela-Shayovitz, R., 2010. The role of ethnicity and context: Intimate femicide rates among social groups in Israeli society. Violence Against Women, 16(12), pp.1424-1436.

47. Torrubiano-Domínguez, J. and Vives-Cases, C., 2013. Application of the putting women first protocol in a study on violence against immigrant women in Spain. Gaceta Sanitaria, 27(6), pp.555-557.

48. Vatnar, S. K. B. and Bjørkly, S., 2010. An interactional perspective on the relationship of immigration to intimate partner violence in a representative sample of help-seeking women. Journal of Interpersonal Violence, 25(10), pp.1815-1835.

49. Vives-Cases, C., Álvarez-Dardet, C., Torrubiano-Domínguez, J. and Gil-González, D., 2008. Mortality due to intimate partner violence in foreign women living in Spain [1999-2006]. [Mortalidad por violencia del compañero íntimo en mujeres extranjeras residentes en España (1999-2006)] Gaceta Sanitaria, 22(3), pp.232-235.

50. Vives-Cases, C., Torrubiano-Domínguez, J., Gil-González, La Parra, D., Aqudelo-Suárez, A. A., Davó, M. C., Perez-Belda, M.C. and Martínez-Román, M. A., 2014. Social and immigration factors in intimate partner violence among Ecuadorians, Moroccans and Romanians living in Spain. European Journal of Public Health, 24(4), pp.605-612.

51. Weil, S., 2016a. Failed femicides among migrant survivors. Qualitative Sociology Review, 12(4), pp.6-21.

52. Weil, S., 2016b. Making femicide visible. Current Sociology, 64(7), pp.1124-1137.

53. Zimmerman, C., Hossain, M. and Watts, C., 2011. Human trafficking and health: A conceptual model to inform policy, intervention and research. Social Science and Medicine, 73(2), pp.327335.

54. ***European Union Agency for Fundamental Rights, 2014. Violence against women: An EUwide survey. Luxembourg: Publications Office of the European Union.

55. ***Eurostat, 2016. Migration and migrant population statistics explained. Available at: <http://ec.europa.eu/eurostat/statistics> [Accessed 15 July 2017].

56. ***IDMC - Internal Displacement Monitoring Centre. 2017. GRID 2017 - Mini Global Report on Internal Displacement. Geneva: IDMC. 


\title{
Psychopathology and parent-child relationships in illicit drugs users
}

\section{DOI: http://doi.org/10.26758/8.1.6}

Nina Erjavec (1) and Gregor Žvelc (2)

(1) University Medical Centre Ljubljana, SLOVENIA

(2) University of Ljubljana, Faculty of Arts, Department of Psychology, SLOVENIA

Address correspondence to: Nina Erjavec, University Medical Centre Ljubljana, The Division of Internal Medicine, Zaloška cesta 7, 1000 Ljubljana, Slovenia. Ph: 00386-40-565-085; E-mail: erjavec.na@gmail.com

\begin{abstract}
Objectives: Drug usage represents an important and profound problem, as it can have long-term negative effects on the individual and society. According to previous studies, drug usage is connected to several factors, amongst which we also find psychopathology and the parent-child relationship. The purpose of this study was to explore illicit drug use, as well as to investigate its potential connections to psychopathology and the parent-child relationship of the subject.

Material and methods: There were 475 participants included in the research, all of them young adults from Slovenia. The Drug Usage Questionnaire was used for the drug use assessment, Symptom Checklist-90-Revised was used to assess the psychopathology symptoms, and the Parental Bonding Instrument was used for the assessment of parent-child relationships. The results were gathered in the summer of 2015.

Results: Most participants from the sample have tried marijuana, and the lowest amount have tried heroin. The number of drugs tried and the frequency of drug use is higher for men than for women. A significantly larger percentage of males have tried one or more illicit substances at least once. Drug usage is positively correlated to psychopathology, although correlations are small. Mother and father care are negatively correlated to drug usage, and only a mother's overprotection is positively correlated to the researched variable.

Conclusions: The correlations between variables are small, but statistically significant, which indicates that drug usage is a wide and complex phenomenon. The research has demonstrated that drug use significantly correlates with psychopathology, parental care, and a mother's overprotection. These factors can be considered when designing preventative and therapeutic programs. The research indicated a need for further research in this field.
\end{abstract}

Keywords: drug usage; psychopathology; comorbidity; parent-child relations.

\section{Introduction}

Regular substance use represents an important and profound problem in today's society, as it has short- and long-term consequences for an individual and society. Drug usage can negatively affect mental and physical well-being, criminal behavior, educational achievement, independence, autonomy, and the development of intimate relationships (Newcomb and Bentler, 1988). 
Drug users vary in their drug use patterns, types of used drug, the effect of drugs on their functioning, general personal adaptability, and the presence of personal or family problems. Drug use is not a uni-dimensional problem and is manifested in a wide spectrum of problems. The definition and classification of drug use is a complex challenge (Carr, 2006).

\section{The question of causality}

Most researchers agree that there are complex mechanisms present, not simple linear functions, and that those mechanisms are not sufficiently explored (Demetrovics, 2009). There is an ongoing debate among professionals about the timeline of the emergence of drug use and psychopathology. There are four hypotheses regarding the timeline: 1) drug use can be interpreted as a symptom of some other psychiatric disorder; 2) drug use is developed as a coping mechanism for a psychiatric disorder (self-medication); 3) a psychiatric disorder is developed as a consequence of drug use; and 4) both drug use and psychiatric disorder are parallel processes and emerge from shared etiological factors (Strakowski and DelBello, 2000; Verheul, 2001). However, these four explanations of relations between drug use and psychopathology are not the only ones possible. It is also likely that one disorder develops first, increases risk factors, and contributes to the development of a second disorder (Demetrovics, 2009). None of the models can explain the phenomenon of comorbidity by itself. In some cases, the connections between one substance and a mental disorder can be better explained by one model, and in the case of a different substance and disorder, a different model is more appropriate (Demetrovics, 2009). Several variables are involved in drug use, both hard and soft drugs. For example, alcohol consumption tends to be quite high especially among men, in peer groups, in the case of those who have problems to socialize and correlates with some accentuated personality traits: Demonstrativeness, Hyper-perseverance, Uncontrollability, Hyperthymia, Cyclothymia, Exaltation (Rada and Ispas, 2016).

\section{Comorbidity of drug usage and psychiatric disorders}

The combination of psychoactive substance use and mental disorder leads to worsened prognosis both in youth and adults, so the problem of comorbidity is often researched in drug use/abuse studies (Demetrovics, 2009).

Comorbidity of substance use and other psychiatric disorders is pretty common, as seen in a lot of studies. Lai and Sitharthan (2012) found a significant correlation between drug use and psychopathology, both general psychopathology and the six most common disorders (anxiety, bipolar affective disorder, major depression, personality disorders, severe stress, and schizophrenia). Lev-Ran, Le Foll, McKenzie, and Rehm (2008) found that persons with mental disorders are 10 times more likely to use marijuana than persons without mental disorders, and that prevalence of marijuana use gets higher with the number of psychiatric diagnoses. They found that $79 \%$ of all people with lifelong psychiatric disorders have a comorbid disorder. High prevalence of psychiatric comorbidity (67.1\%) was also observed in young heroin users (Rodriguez-Llera et al., 2006). The most frequent comorbid disorders in heroin users are anti-social personality disorder $(32.9 \%)$, borderline personality disorder (22.1\%), and major depressive disorder (17.4\%). Sareen et al. (2006) found significant connections between anxiety disorders and cocaine, stimulants, hallucinogens, and heroin use. Comorbidity was the highest for panic disorder and hallucinogens use. The use of these drugs also correlates with specific phobias, agoraphobia, generalized anxiety disorder and posttraumatic stress disorder. A total of $20.1 \%$ of the patients diagnosed with bipolar disorder and $10.9 \%$ of patients diagnosed with depressive disorder also have comorbid substance use disorder (Nesvag, 2015). Horwood et al. (2012) found an important linear connection between the frequency 
of marijuana use and the severity of depressive symptoms. Higher marijuana use is connected with a higher severity of depressive symptoms. Ringen et al. (2008a) compared the severity of drug use in patients during the remission phase of a psychotic disorder with the general population sample and found that life-long drug use is significantly higher in psychotic patients than in the general population. This is typical for all drugs, but the biggest difference was found in lifelong amphetamine and cocaine use. Ringen et al. (2008b) found a significant positive connection between the amount of illicit drugs taken at the moment and the severity of psychiatric symptoms in schizophrenia.

As we can see, illicit drug usage is correlated with different psychiatric disorders and comorbidity of substance use disorders, and other psychiatric disorders are pretty common.

\section{Parental bonding and substance use}

Parker et al. (1979) identified four types of parenting that differ by parental overprotection and care. The dimension of care relates to parental warmth against coldness and rejection. The dimension of overprotection describes psychological control against psychological autonomy. Optimal parenting (high care, low overprotection) is a protective factor against substance use (Jurcik, Moulding and Naujokaitis, 2013).

Research shows that extremely overprotective and un-supportive, and also not well-defined parenting full of conflicts are connected to substance use and abuse in young people (Rhodes et al., 2003). Kandel, Kessler, and Margulies (1978) found an important connection between the lack of closeness with parents and a higher probability of substance use. In contrast, a positive family life with an open, trusting, and caring relationship with parents is a factor that protects or delays experimenting with illicit drugs and problematic substance use (Stoker and Swadi, 1990). King and Chassin (2004) showed that parental support is correlated with up to $50 \%$ less risk for the development of substance abuse.

\section{Research problem and hypothesis}

This study aims to explore the connections between three well-studied but not entirely understood psychological phenomenon: substance use/abuse, psychopathology, and parental bonding on a Slovenian sample.

We predict that general and specific substance abuse will correlate positively with different psychopathological symptoms. Furthermore, we predict that parental care will correlate negatively with substance use, whereas parental overprotection will correlate positively.

\section{Material and methods}

\section{Participants}

The study was applied via e-questionnaire and participants from the general public were randomly invited via social media by exposure to researcher's posts about the study, via web portal DrogArt, and via e-mail to members of Society of psychology students at the University of Ljubljana. The invitation clearly stated the aim of the study and that everybody of age 18 to 35 can participate. Data were collected during the summer of 2015.

The total of participants was 475 people, with 137 (28.8\%) males and 337 females (71.2\%). Age range: $12.5 \%$ aged from 18 to $20,60.1 \% 20$ to $25,18.1 \% 25$ to 30 , and $9.3 \% 30$ to 35 . 


\section{Instruments}

Substance Use Questionnaire: For the needs of this study, DrogArt's Mefedron Use Questionaire was adapted. Participants answered questions about drug use: whether or not they use illicit substances, which substance they use (options: marijuana/hashish, cocaine, heroin/other opioid, natural hallucinogens, synthetic hallucinogens, ecstasy, and amphetamines). They also had an option to write other drugs they use which were not on the list. Next, they had to check how often the drug is used.

Symptom Checklist-90-Revised: As a measure of psychopathology, Symptom Checklist90-Revised by Derogatis (1992; Pearson Clinical, 2017) was used. The test is composed of 90 items that are distributed over nine scales (somatization, obsessive-compulsive, interpersonal sensitivity, depression, anxiety, hostility, phobic anxiety, paranoid ideation, and psychoticism).The test also measures the global indicator of distress with the Global Severity Index - GSI (Pearson Clinical, 2017). Participants have to respond to statements about symptoms or general welfare on a scale ranging from 0 (it didn't burden me at all) to 4 (it burdened me a lot). Most people need 12 to 15 minutes to complete it (Pearson Clinical, 2017). The test can be used for evaluating psychopathology on different populations, from a healthy population to patients with a physical illness or psychiatric patients (Pearson Clinical, 2017). Alfa coefficients in our sample ranged from .8 for phobic anxiety to .92 for depression.

Parental Bonding Instrument: The authors of the questionnaire are Parker, Tupling, and Brown (1979). It was translated into Slovenian by Maša and Gregor Žvelc (M. Žvelc, 2006). The Parental Bonding Instrument is a self-assessment questionnaire measuring parental bonding in the first 16 years of life. It consists of 25 items which are completed separately for the relationship with the mother and for the relationship with the father. It measures the basic dimensions of parenting: parental care and parental overprotection. Parental care refers to a loving relationship, warmth, support, and interest in the child. In contrast to the care dimension are rejection and indifference. The dimension of parental overprotection refers to tying the child to oneself, encouraging dependency, overprotection, and having too much control over the child. The opposite is described by encouraging autonomy and independence (Parker, 1979). The alpha coefficients in our sample were .92 for maternal care, .95 for paternal care, .91 for maternal overprotection, and .88 for paternal overprotection.

\section{Procedure}

Participants first answered demographic questions about gender, age, and the questions about substance use. Then, they completed Symptom Checklist-90-revised and the Parental Bonding Instrument.

The collected data was first processed in Excel, and then in SPSS. The reliability of the entire test battery was very high, but the data was not distributed normally, so non-parametric statistical tests had to be used.

\section{Results}

Table 1 shows data regarding general drug use. We can see that the majority of the participants have tried marijuana, but that the usage of other drugs is a lot lower. By its use, ecstasy is next, and then amphetamines, natural hallucinogens, cocaine, synthetic hallucinogens, and other drugs. Heroin was used by the fewest people in the sample. Concerning specific drugs, heroin use is 
the only one where there are no differences between genders. Other drugs have been tried by a significantly higher percentage of men than women.

Table 1. Number, percent of participants, and gender differences regarding usage of listed drug at some point in a participant's life

\begin{tabular}{|l|c|c|c|c|c|c|}
\hline & $\mathrm{N}(\%)$ & Gender & $\%$ & Df & $H^{2}$ & $p$ \\
\hline Marijuana & $384(80.8)$ & $\mathrm{M}$ & 91 & 1 & 11.367 & .001 \\
\hline Cocaine & & $\mathrm{F}$ & 77 & & & \\
\hline & $139(29.3)$ & $\mathrm{M}$ & 47 & 1 & 25.541 & .000 \\
\hline Heroine & $25(5.3)$ & $\mathrm{M}$ & 8 & 1 & 2.873 & .112 \\
\hline & & $\mathrm{F}$ & 4 & & & \\
\hline Natural hallucinogens & $144(30.3)$ & $\mathrm{M}$ & 47 & 1 & 24.049 & .000 \\
\hline & & $\mathrm{F}$ & 24 & & & \\
\hline Synthetic hallucinogens & $75(15.8)$ & $\mathrm{M}$ & 26 & 1 & 13.497 & .000 \\
\hline & & $\mathrm{F}$ & 12 & & & \\
\hline Ecstasy & $177(37.3)$ & $\mathrm{M}$ & 52 & 1 & 15.338 & .000 \\
\hline & & $\mathrm{F}$ & 32 & & & \\
\hline Amphetamine & $158(33.3)$ & $\mathrm{M}$ & 50 & 1 & 20.772 & .000 \\
\hline & & $\mathrm{F}$ & 28 & & & \\
\hline Other drugs & $45(9,5)$ & $\mathrm{M}$ & 13 & 1 & 2.99 & .118 \\
\hline & & $\mathrm{F}$ & 8 & & & \\
\hline
\end{tabular}

Table 2. Frequency of general drug use

\begin{tabular}{|l|r|r|}
\hline & $N$ & \multicolumn{1}{|c|}{$\%$} \\
\hline Never & 96 & 20.2 \\
\hline I stopped using it & 85 & 17.9 \\
\hline Less than once a year & 29 & 6.1 \\
\hline Once a year & 20 & 4.2 \\
\hline A couple of times a year & 87 & 18.3 \\
\hline Once a month & 22 & 4.6 \\
\hline 2-3 times a month & 32 & 6.7 \\
\hline Once a week & 19 & 4.0 \\
\hline A couple of times a week & 47 & 9.9 \\
\hline Daily & 17 & 3.6 \\
\hline A couple of times a day & 21 & 4.4 \\
\hline
\end{tabular}


Table 2 shows the frequency of general drug use. One-fifth of the sample has never tried drugs, but a very similar percentage of the sample has stopped their drug abuse and uses drugs a couple of times a year. There are some differences concerning gender. There are $91 \%$ of at least one-time drug users among men, and 77\% among women $(\mathrm{H} 2=12,558 ; \mathrm{df}=1 ; \mathrm{p}<.001 ; \mathrm{w}=.17 ; 1$ $\beta=.95)$.

The frequency of general drug use is significantly correlated to some psychopathological symptoms (Table 3). The correlations with obsessive-compulsive symptoms, anxiety, phobic anxiety, paranoid ideation, psychoticism, and the Global Severity Index are low but statistically significant. The correlation with obsessive-compulsive symptoms is the highest, and the correlation with psychoticism follows. Table 3 shows that the use of different substances correlates with different psychopathological symptoms in a similar fashion as the frequency of general drug use. The frequency of amphetamine use correlates with most psychopathology symptoms, and the correlations are the highest. However, we have to interpret the results carefully, because it seems that the use of heroin does not correlate with psychopathology. When we look at the sample, we see that there are so few heroin users that we cannot draw conclusions from these results regarding heroin use. The frequency of use of all drugs (except heroin) correlates with obsessive-compulsive symptoms, and most are correlated to psychotic symptoms.

Table 3. Correlations between the frequency of substance use and psychopathology scales on Symptom Checklist-90-Revised

\begin{tabular}{|l|r|r|r|r|r|r|r|r|}
\hline & $\begin{array}{c}\text { General } \\
\text { substance } \\
\text { use }\end{array}$ & Marijuana & Cocaine & Heroine & $\begin{array}{c}\text { Natural } \\
\text { hallucino- } \\
\text { gens }\end{array}$ & $\begin{array}{c}\text { Synthetic } \\
\text { hallucino- } \\
\text { genes }\end{array}$ & Ecstasy & $\begin{array}{c}\text { Amphe- } \\
\text { tamines }\end{array}$ \\
\hline SOM & .060 & .036 & .066 & -.016 & -.001 & -.025 & .031 & .045 \\
\hline O-C & $.186^{* *}$ & $.164 * *$ & $.140^{* *}$ & .017 & $.113 *$ & $.093 *$ & $.184 * *$ & $.198^{* *}$ \\
\hline I-S & .074 & .062 & .032 & -.018 & .022 & .006 & .079 & $.108^{*}$ \\
\hline DEP & .082 & .069 & .053 & -.003 & .029 & .025 & $.100^{*}$ & $.106^{*}$ \\
\hline ANX & $.109^{*}$ & .090 & $.115^{*}$ & .021 & .046 & 066 & .091 & $.135^{* *}$ \\
\hline HOS & .060 & .041 & .087 & .020 & .018 & .035 & .072 & $.109 *$ \\
\hline PHOB & $.095^{*}$ & .087 & $.115^{*}$ & .039 & $.121 *$ & .085 & $.111^{*}$ & $.126^{* *}$ \\
\hline PAR & $.150^{* *}$ & $.132^{* *}$ & $.140^{* *}$ & .057 & .084 & .053 & $.135^{* *}$ & $.139 * *$ \\
\hline PSY & $.168^{* *}$ & $.153^{* *}$ & $.102^{*}$ & .058 & $.103 *$ & .087 & $.133^{* *}$ & $.141^{* *}$ \\
\hline GSI & $.101^{*}$ & .082 & $.104 *$ & .013 & .062 & .008 & .093 & $.139 * *$ \\
\hline
\end{tabular}

Note. $\mathrm{SOM}=$ somatisation; O-C = obsessive-compulsive; I-S = interpersonal sensitivity; DEP = depression; ANX = anxiety; $\mathrm{HOS}=$ hostility; $\mathrm{PHOB}=$ phobic anxiety; $\mathrm{PAR}=$ paranoid ideation; $\mathrm{PSY}=$ psychoticism; $\mathrm{GSI}=\mathrm{Global}$ Severity Index. $* * p<.01 ; * p<.05$. Spearman's $\rho$.

Table 4 shows correlations between parental bonding and the frequency of drug use. The correlations between general drug use frequency and parental care are negative and statistically significant, but small. This means that participants who had warmer, more caring relationships with parents use drugs less frequently than participants with parents who were rejective and indifferent. Participants with mothers who were warm and caring, use amphetamines, ecstasy, marijuana, and cocaine less frequently. Paternal care correlates negatively to ecstasy, cocaine, amphetamine, and marijuana use frequency. All the correlations are small. 
The correlation between parental overprotection and general drug use frequency is statistically significant only in the case of maternal overprotection and not paternal overprotection (Table 4). This means that participants with mothers who were overprotective, controlling, and encouraged dependency, use drugs more frequently than people with mothers who encouraged autonomy and independence. However, paternal overprotection is not correlated with general drug use frequency. The use of amphetamines, marijuana, cocaine, and ecstasy is more frequent with participants whose mothers were more overprotective and encouraged dependence, than with participants whose mothers encouraged independence. All the correlations are small. Paternal overprotection is positively correlated only with amphetamine and ecstasy use.

Table 4. Correlation between parental bonding and drug use frequency

\begin{tabular}{|l|r|r|r|r|}
\hline & \multicolumn{2}{|c|}{ Parental care } & \multicolumn{2}{c|}{ Parental overprotection } \\
\hline & Mother & Father & \multicolumn{1}{c|}{ Mother } & \multicolumn{1}{c|}{ Father } \\
\hline General drug use & $-.162^{* *}$ & $-.146^{* *}$ & $.178^{* *}$ & .04 \\
\hline Marijuana & $-.147^{* *}$ & $-.131^{* *}$ & $.163^{* *}$ & .03 \\
\hline Cocaine & $-.148^{* *}$ & $-.144^{* *}$ & $.136^{* *}$ & .08 \\
\hline Heroin & -.07 & -.04 & .10 & .06 \\
\hline Natural hallucinogens & -.06 & -.07 & .08 & .01 \\
\hline Synthetic hallucinogens & -.09 & -.04 & .08 & -.01 \\
\hline Ecstasy & $-.175^{* *}$ & $-.172^{* *}$ & $.129 *$ & $.097 *$ \\
\hline Amphetamines & $-.182^{* *}$ & $-.132^{* *}$ & $.176^{* *}$ & $.126^{* *}$ \\
\hline
\end{tabular}

Note. $* * p<.01 ; * p<.05$. Spearman's $\rho$.

\section{Discussions}

Concerning the demographic data, the results showed that drug use varies by gender. A significantly larger percentage of males have tried one or more illicit substances at least once, and significantly more men have tried all of the listed drugs except heroin, where the sample was too small to draw any conclusions. Recent studies show that respecting the values of participants in such scientific research is an essential condition, to the detriment of obtaining some spectacular results (Baciu and Pungă, 2017). These findings are consistent with previous studies showing that men use drugs more frequently than women (Newcomb et al., 2014).

It was expected that drug use would correlate significantly to psychopathology. The results showed small, but significant connections between drug use and psychopathology both in general drug use and use of specific drugs. This is consistent with previous studies, where it was found that psychiatric symptoms are more common in populations with substance use problems than with healthy populations (Lai and Sitharthan, 2012; Lev-Ran, Le Foll, McKenzie, and Rehm, 2008; Rodriguez-Llera et al., 2006; Sareen et al., 2006, etc.). The correlations were small, which can be explained by the sample, which was non-clinical. Demetrovics (2009) found that the prevalence of comorbidity is a lot higher in clinical than non-clinical samples. He also found a connection between drug use and psychotic symptoms, which was confirmed in this study, where a correlation between drug use (general and specific) and psychoticism and paranoid ideation was found. Other studies discovered connections between substance use and anxiety disorders (Sareen et al., 2006), which is consistent with our findings of small correlations between general and specific drug use and 
obsessive-compulsive, anxiety, and phobic anxiety symptoms. Connections between general drug use and specific drug use with depressive symptoms have been found. This is consistent with findings of Neswag et al. (2015), who found high comorbidity of substance use in a sample with bipolar disorder and depression.

The correlations can be explained by different theories. Psychopathology could be a consequence of substance use, as drugs can cause epigenetic changes in the brain, which alter the memory functions, executive functions, cognition, behavior, and lower the worth of natural, nondrug related awards (Madras, 2012). Conversely, drug use can also be a form of self-medication of different psychopathological symptoms (Wurmser, 1974; Khantzian, 1985, 1997). Subclinical substance use and negative emotional symptoms can contribute to the development of each other (Valentiner et al., 2004). The connections can also be explained by shared etiological factors that make psychopathology and substance use parallel processes (Demetrovics, 2009).

Based on the literature, we expected correlations between parental bonding and substance use, and the results partially confirmed our predictions. Higher drug use frequency correlates negatively with parental care. Participants, whose mother and father had a more loving relationship, helped them when needed and expressed interest in them, and used illicit substances less frequently than participants whose parents rejected them. Lack of parental care was positively correlated with the frequency of stimulant and marijuana use. Kandel, Kessler and Margulies (1978) got similar results in their study: unsupportive parenting styles are connected with substance use and abuse of young people. Stoker and Swaldy (1990) marked a caring relationship as a protective factor, which protects from or delays drug use.

Maternal overprotection correlates positively with more frequent drug use, but paternal overprotection has no connection to general drug use. Maternal overprotection is correlated to more frequent use of stimulants and marijuana, paternal overprotection correlates only to use of amphetamines and ecstasy. Correlations between highly overprotective parenting and higher substance use were also found in previous studies (Rhodes, 2003).

The results can be explained by various theories. From a psychodynamic point of view, people with substance use problems often had disturbed early object relations (Woollcott, 1981; Johnson, 1993; Krystall, 1993). Drug use can be seen as compensation for lack of quality interpersonal experience (Žvelc, 2011). By Ackard et al. (2006), a quality child-parent relationship is connected to lower risk for development of a substance use problem. Allen and Land (1999) have found that young people, who have a better relationship with their parents, turn to them for information, and they internalize their advice, most likely even concerning drug use.

\section{Conclusions}

This study includes a rather large sample of young people. We sampled people who don't use drugs, some recreational drug users, and even regular drug users, which helped to highlight the problem of substance abuse among young people in Slovenia. We got some interesting information about the popularity of drug use. Marijuana is by far the most used drug in the sample, and heroin the least. We have discovered differences concerning gender, as men have tried more drugs than women on average. Significant correlations between psychopathology and the frequency of drug use were found. Higher results on psychopathology scales are positively correlated with the frequency of general and specific drug use; the first hypothesis was confirmed. Significant correlations between parental bonding and frequency of drug use were also found. Both maternal and paternal care are negatively correlated with drug use, but only maternal overprotection is positively 
correlated to drug use, so the second hypothesis was partially confirmed. Research findings may be useful for designing preventative and therapeutic programs. It is important to consider comorbidity when dealing with different mental disorders. We need to be cautious about the presence of other mental disorders when working with drug users and about drug use when we are working with other psychiatric illness.

The study had some shortcomings which could be eliminated in future studies. Most are concerned with the sample, which is not representative for the Slovenian population. The results were gathered via web survey on social media, and via a website which is mainly visited by drug users that seek help or information, so the sample is specific. Furthermore, there are a lot more women included than men. Even though the sample is pretty big, the groups of some specific drug users were too small to draw any conclusions. The samples of specific drug users should be bigger in future studies. The frequency of drug use and whether or not a person has used a certain drug was used as a criterion. This may not be the best criterion for drug use, so in future studies, criteria like the amount of consumed substance or simultaneous consumption of various substances could be used. The study should be repeated on a clinical sample of people with substance abuse diagnosis and people with other psychiatric diagnoses, and be compared to a general, non-clinical sample.

\section{References}

1. Ackard, D., Neumark-Sztainer, D., Story, M., and Perry, C., 2006. Parent-Child Connectedness and Behavioral and Emotional Health among Adolescents. American Journal of Preventive Medicine, [online] 30(1), pp.59-66. Available at: National and University Library website, Ljubljana, Slovenia. 〈http://dx.doi.org.nukweb.nuk.uni-lj.si/10.1016/j.amepre.2005.09.013> [Accessed 13 June 2017].

2. Allen, J. and Land, D., 1999. Attachment in adolescence. In: J. Cassidy, P.R. Shaver, eds. Handbook of attachment: Theory, research, and clinical applications. New York, NY, US: Guilford Press. pp.319-335

3. Baciu, A., Pungă, A., 2017. Ethical implications of a quantitative study that analyzes the drug consumers from a Bucharest neighborhood. Romanian Journal of Legal Medicine, 25(1), pp.113-119. DOI: 10.4323/rjlm.2017.113

4. Carr, A., 2006. The Handbook of Child and Adolescent Clinical Psychology: A Contextual Approach, 2nd Edition. New York, NY, US: Routledge/Taylor and Francis Group.

5. Demetrovics, Z., 2009. Co-morbidity of drug addiction: An analysis of epidemiological data and possible etiological models. Addiction Research and Theory, [online] 17(4), pp.420-431. Available at: National and University Library website, Ljubljana, Slovenia. <http://web.b.ebscohost.com.nukweb.nuk.uni-lj.si > [Accessed 4 June 2017].

6. Derogatis, L.R., 2017. Symptom Checklist-90-Revised (SCL-90-R®). Available at: <http://www.pearsonclinical.com/psychology/products/100000645/symptom-checklist-90revised-scl-90-r.html\#tab-details> [Accessed 30 June 2017].

7. Horwood, L., Fergusson, D., Coffey, C., Patton, G., Tait, R., Smart, D., Letcher, P., Silins, E., and Hutchinson, D., 2012. Cannabis and depression: an integrative data analysis of four Australasian cohorts. Drug and Alcohol Dependence, [online] 126(3), pp.369-378. Available at: National and University Library website, Ljubljana, Slovenia. <http://web.b.ebscohost.com.nukweb.nuk.uni-lj.si > [Accessed 28 June 2017].

8. Johnson, B., 1993. A developmental model of addictions, and its relationship to the twelve step program of Alcoholics Anonymous. Journal of Substance Abuse Treatment, 10(1), pp.23-30. 
9. Jurcik, T., Moulding, R. and Naujokaitis, E., 2013. How do drug and alcohol use relate to parental bonding and risk perception in university students? Journal of Substance Use, [online] 18(4), pp.254-261. Available at: National and University Library website, Ljubljana, Slovenia. <http://web.b.ebscohost.com.nukweb.nuk.uni-lj.si > [Accessed 13 June 2017].

10. Kandel, D., Kessler, R. and Margulies, R., 1978. Antecedents of adolescent initiation into stages of drug use: A developmental analysis. Journal of Youth and Adolescence, [online] 7(1), pp.1340. Available at: National and University Library website, Ljubljana, Slovenia. <http://web.b.ebscohost.com.nukweb.nuk.uni-lj.si> [Accessed 28 June 2017].

11. Khantzian, E. J., 1985. The self-medication hypothesis of addictive disorders: focus on heroin and cocaine dependence. The American Journal of Psychiatry, 142(11), pp.1259-1264.

12. Khantzian, E. J., 1997. The self-medication hypothesis of substance use disorders: reconsideration and recent applications. Harvard Review of Psychiatry, 4(5), pp.231-244.

13. King, K., and Chassin, L., 2004. Mediating and moderated effects of adolescent behavioral undercontrol and parenting in the prediction of drug use disorders in emerging adulthood. Psychology of Addictive Behaviors: Journal of The Society of Psychologists in Addictive Behaviors, [online] 18(3), pp.239-249. Available at: National and University Library website, Ljubljana, Slovenia. <http://web.b.ebscohost.com.nukweb.nuk.uni-lj.si> [Accessed 28 June 2017].

14. Krystal, H., 1977. Self-and object-representation in alcoholism and other drug-dependence: implications for therapy. NIDA Research Monograph, 12, pp. 88-100.

15. Lai, H. and Sitharthan, T., 2012. Exploration of the comorbidity of cannabis use disorders and mental health disorders among inpatients presenting to all hospitals in New South Wales, Australia. American Journal of Drug and Alcohol Abuse, [online] 38(6), pp.567-574. Available at: National and University Library website, Ljubljana, Slovenia. <http://web.b.ebscohost.com.nukweb.nuk.uni-li.si > [Accessed 28 June 2017].

16. Lev-Ran, S., Le Foll, B., McKenzie, K., George, T., and Rehm, J., 2013. Cannabis use and cannabis use disorders among individuals with mental illness. Comprehensive Psychiatry, [online] 54(6), pp.589-598. Available at: National and University Library website, Ljubljana, Slovenia. <http://web.b.ebscohost.com.nukweb.nuk.uni-lj.si> [Accessed 28 June 2017].

17. Madras, B.K., 2012. Unique consequences of addiction, In: H.J. Shaffer, ed. APA addiction syndrome handbook, Vol. 1: Foundations, influences, and expressions of addiction. [online] Washington, DC, US: American Psychological Association. pp. 317-328. Available at: National and University Library website, Ljubljana, Slovenia. <http://dx.doi.org.nukweb.nuk.unilj.si/10.1037/13751-016> [Accessed 30 June 2017].

18. Nesvåg, R., Knudsen, G., Bakken, I., Høye, A., Ystrom, E., Surén, P., Reneflot, A., Stoltenberg, C. and Reichborn-Kjennerud, T., 2015. Substance use disorders in schizophrenia, bipolar disorder, and depressive illness: A registry-based study. Social Psychiatry and Psychiatric Epidemiology, [online] 50(8), pp.1267-1276. Available at: National and University Library website, Ljubljana, Slovenia. <http://dx.doi.org.nukweb.nuk.uni-lj.si/10.1007/s00127-015-10252> [Accessed 28 June 2017].

19. Newcomb, M. and Bentler, P., 1988. Impact of adolescent drug use and social support on problems of young adults: a longitudinal study. Journal of Abnormal Psychology, [online] 97(1), pp.64-75. Available at: National and University Library website, Ljubljana, Slovenia. <http://dx.doi.org.nukweb.nuk.uni-lj.si/10.1037/0021-843X.97.1.64> [Accessed 4 June 2017].

20. Newcomb, M., Birkett, M., Corliss, H. and Mustanski, B., 2014. Sexual orientation, gender, and racial differences in illicit drug use in a sample of US high school students. American Journal of 
Public Health, [online] 104(2), pp.304-310. Available at: National and University Library website, Ljubljana, Slovenia. $\quad$ http://dx.doi.org.nukweb.nuk.unili.si/10.2105/AJPH.2013.301702 > [Accessed 30 June 2017].

21. Parker, G., Tupling, H. and Brown, L., 1979. A parental bonding instrument. British Journal of Medical Psychology, 52(1), pp.1-10.

22. Rada, C., and Ispas A.T., 2016. Alcohol consumption and accentuated personality traits among young adults in Romania: a cross-sectional study. Substance Abuse Treatment, Prevention, and Policy, $\quad 11: 36 \quad$ DOI: 10.1186/s13011-016-0080-3, Available at :http://www.substanceabusepolicy.com/content/11/1/36 [Accessed 30 June 2017].

23. Rhodes, T., Lilly, R., Fernández, C., Giorgino, E., Kemmesis, U., Ossebaard, H., Lalam, N., Faasen, I. and Spannow, K., 2003. Risk factors associated with drug use: the importance of 'risk environment'. Drugs: Education, Prevention and Policy, [online] 10(4), pp.303-329. Available at: National and University Library website, Ljubljana, Slovenia. <http://web.b.ebscohost.com.nukweb.nuk.uni-lj.si > [Accessed 28 June 2017].

24. Ringen, P., Melle, I., Birkenæs, A., Engh, J., Færden, A., Jónsdóttir, H., Nesvåg, R., Vaskinn, A., Friis, S., Larsen, F., Opjordsmoen, S., Sundet, K. and Andreassen, O., 2008. Illicit drug use in patients with psychotic disorders compared with that in the general population: a crosssectional study. Acta Psychiatrica Scandinavica, [online] 117(2), pp.133-138. Available at: National and University Library website, Ljubljana, Slovenia.

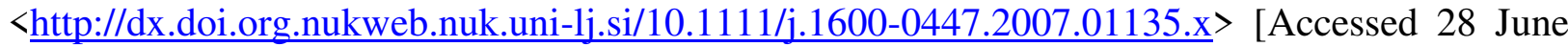
2017].

25. Ringen, P., Melle, I., Birkenaes, A., Engh, J., Faerden, A., Vaskinn, A., Friis, S., Opjordsmoen, S. and Andreassen, O., 2008. The level of illicit drug use is related to symptoms and premorbid functioning in severe mental illness. Acta Psychiatrica Scandinavica, [online] 118(4), pp.297304. Available at: National and University Library website, Ljubljana, Slovenia. <http://web.b.ebscohost.com.nukweb.nuk.uni-lj.si> [Accessed 28 June 2017].

26. Rodríguez-Llera, M., Domingo-Salvany, A., Brugal, M., Silva, T., Sánchez-Niubó, A. and Torrens, M., 2006. Psychiatric comorbidity in young heroin users. Drug and Alcohol Dependence, [online] 84(1), pp.48-55, Available at: National and University Library website, Ljubljana, Slovenia. 〈http://web.b.ebscohost.com.nukweb.nuk.uni-lj.si> [Accessed 28 June 2017].

27. Sareen, J., Chartier, M., Paulus, M. and Stein, M., 2006. Illicit drug use and anxiety disorders: findings from two community surveys. Psychiatry Research, [online] 142(1), pp.11-17, Available at: National and University Library website, Ljubljana, Slovenia. <http://web.b.ebscohost.com.nukweb.nuk.uni-lj.si> [Accessed 28 June 2017].

28. Stoker, A. and Swadi, H., 1990. Perceived family relationships in drug abusing adolescents. Drug and Alcohol Dependence, 25(3), pp. 293-297.

29. Strakowski, S. and DelBello, M., 2000. The co-occurrence of bipolar and substance use disorders. Clinical Psychology Review, [online] 20(2), pp.191-206, Available at: National and University Library website, Ljubljana, Slovenia. <http://web.b.ebscohost.com.nukweb.nuk.unilj.si> [Accessed 30 June 2017].

30. Valentiner, D., Mounts, N. and Deacon, B., 2004. Panic attacks, depression and anxiety symptoms, and substance use behaviors during late adolescence. Journal of Anxiety Disorders, [online] 18(5), pp.573-585, Available at: National and University Library website, Ljubljana, Slovenia. <http://web.b.ebscohost.com.nukweb.nuk.uni-lj.si> [Accessed 30 June 2017]. 
31. Verheul, R., 2001. Co-morbidity of personality disorders in individuals with substance use disorders. European Psychiatry, [online] 16(5), pp.274-282, Available at: National and University Library website, Ljubljana, Slovenia. <http://web.b.ebscohost.com.nukweb.nuk.unilj.si> [Accessed 30 June 2017].

32. Woollcott, P., 1981. Addiction: Clinical and theoretical considerations. The Annual of Psychoanalysis, 9, pp.189-204.

33. Wurmser, L., 1974. Psychoanalytic considerations of the etiology of compulsive drug use. Journal of the American Psychoanalytic Association, 22(4), pp.820-843.

34. Žvelc, G., 2001. Odvisnost kot poskus samoregulacije (sodobne psihoanalitične teorije odvisnosti). = Addiction as an attempt at self-regulation: Contemporary psychoanalytic theories of addiction. Psihološka Obzorja / Horizons of Psychology, 10(3), pp.57-74.

35. Žvelc, M., 2003. Razvoj slikovnega testa separacije in individualizacije (Development of Pictorial test of Separation and Individuation) Unpublished MsC thesis, University of Ljubljana, Faculty of Arts, Department of Psychology, Slovenia. 


\title{
Parental stress and bedtime routines in toddlerhood
}

\section{DOI: http://doi.org/10.26758/8.1.7}

Simona De Stasio (1), Benedetta Ragni (1), Francesca Boldrini (2), Francesca Bevilacqua (3), Simonetta Gentile (3)

(1) Dep. Human Studies, "Lumsa” University, Rome, Italy

(2) "Sapienza" University of Rome, Italy

(3) Children’s Hospital "Bambino Gesù”, Rome, Italy

Address correspondence to: Simona De Stasio, Dep. Human Studies, “Lumsa” University, Rome, Piazza delle Vaschette, 101 - 00193 Italy; E-mail: $\underline{\text { s.destasio@lumsa.it }}$

\begin{abstract}
Objectives. Main purposes of our study were to explore: a) the relationship between paternal and maternal perceptions of their interactions with the child during bedtime routines; b) the possible relationship among context dimensions (social support, marital satisfaction, parenting stress and bedtime routines). We examined both parents' subjective experience toward children's bedtime routines and their personal relationship with going to sleep.

Material and methods. 41 parents (34\% fathers) of toddlers 18 to 36 months old took part in this study. All parents completed Parent-Child Sleep Interaction Scale (PSIS; Alfano et al., 2013), Parent-Stress Index-Short Form (PSI-SF; Abidin, 1995), Social Provisions Scale (SPS; Cutrona and Russell, 1987), Dyadic Adjustment Scale (DAS-4; Sabourin et al., 2005) and ad-hoc semi-structured interview.

Results. Correlations outcome evidenced positive relationships between maternal PSIS global score and paternal PSI "Difficult Child" $(r=.31 \mathrm{p}=0.05)$, maternal subscale PSIS, "Sleep Reinforcement" score and maternal PSI "Parental distress" $(r=.38 \mathrm{p}=0.05)$ score, paternal PSIS "Sleep Conflict" and maternal PSI "Difficult Child" score $(r=.47 \mathrm{p}=0.05)$, maternal PSIS "Sleep Conflict" score and PSI "Difficult Child" reported by both parents (mothers $r=.40 \mathrm{p}=0.01$; fathers $r=.47, \mathrm{p}=0.05$, respectively). Examining parent's answers to the brief semi-structured interview, putting children to sleep is considered a positive and intimate moment (mothers $=80 \%$; fathers $=$ $46 \%$ ) and children's sleep doesn't represent a problem (mothers $=76 \%$; fathers $=61 \%$ ). $56 \%$ of mothers and $38 \%$ of fathers wrote about their bedtime routines as a positive and relaxed moment spent with parents.

Conclusions. A good concordance between mothers' and fathers' perceptions about children's bedtime routines was detected. Proximal context can influence bedtime routine, specifically parental stress can lead to critic bedtime routines. Primary care practitioners can play an instrumental role in helping families institute positive sleep practices and improving sleep in toddlers.
\end{abstract}

Keywords: bedtime routines, parent-child interactions, father's involvement. 


\section{Introduction}

The evolution of adequate sleep-wake regulation patterns is a complex developmental process, challenging parents during the first years of children's life. Sleep disturbances such as bedtime resistance, prolonged night awakenings or nighttime fears are frequently brought to the attention of pediatricians or other child-care professionals (Mindell et al., 2009). Nevertheless, the origin of sleep disturbances in infancy is still unclear; early in life, the comprehension of factors contributing to the disruption of sleep patterns has implications for both research and clinical practice (Alfano et al., 2013). Variability of sleep-wake patterns is conditioned by the interaction of numerous elements (Galland et al., 2012) such as child's temperamental patterns, cultural, social, and familial factors. Parental routine practices and their expectations about bedtime strongly influence sleep, establishing with it a bidirectional link (Sadeh et al., 2010; Galland et al., 2012).

To date, research highlights connections between these variables, analyzing the patterns of children's sleep in the familiar context; the parent-child relationship is described as one of the main determinants of children's quality of sleep. Thus, children's sleep disturbances acquire social correlations, such as other behavioral problems (Dahl and El-Sheikh, 2007; El-Sheikh, 2011).

Large theoretical framework suggests that onset and maintenance of adequate periods of sleep require an environment free of threat, with a decrease of attentiveness and responsiveness (Dahl, 1996); according to the emotional security model (Cummings and Davies, 1996), the feelings of safety and emotional security, conditioning the quality of infant sleep, stems from stable family relationships. Children react with emotional distress to familiar disturbances and parental personal difficulties, suggesting that parents may induce feelings of stress and anxiety, unfavorable to a good quality of sleep (El-Sheikh et al., 2007; Dahl, 1996). As reported by Alfano et al. (2013), an important feature of sleep-wake patterns, is the establishment and maintenance of regular sleep routines; Mindell (2009) defines "bedtime routine" a daily familiar attitude according to which parents, before turning off the lights, engage their children in similar activities, in the same order; the author suggests their advantage in promoting a good quality of infant sleep. Parent-child interaction shows a regulatory effect on child sleep patterns, acting as an external moderator of biological rhythms, as well as infantile self-regulation (Erath and Tu, 2011).

Recent literature underlines that positive children adjustment to the environment, as well as the amount and quality of infant sleep, are related to parental features such as emotional availability, warmth, and sensitivity. By contrast, negative parent-child relationships produce a condition of arousal and vigilance creating psychological discomfort and disrupted children's sleep. In particular, negative parent-child interactions at bedtime may induce feelings of guilt, threat, anger and sadness that may result in serious obstacles to adequate infant sleep (ibidem). Prior research evidenced that proximal context and parental psychosocial functioning are strictly related to child's sleeping patterns.

To date, maternal psychopathology received great attention (anxiety and depression) (Keller, Buckhalt, and El-Sheikh, 2008): the authors reported that children's sleep difficulties are related to psychological distress in mothers (Martin et al, 2007) and they are connected with an increase of marital conflict (Kelly and El-Sheikh, 2011) and of parenting stress (Morrell and Cortina-Borja, 2002).

High levels of stress are negatively related to parents' warmth and reciprocity (Haskett et al., 2006); these factors are essential for a good quality of child's sleep and they are related to the parental perception of their own children's sleep. Mothers and fathers, who describe their child's sleep as more problematic, refer higher levels of stress (Sinai and Tikotzky, 2012). It is not well 
established if these associations are parent or child-driven; probably these effects are bidirectional. Sleep can alter child's attitude to regulate emotions and behaviors (Erath and Kelly, 2011).

This observation is especially true when marital satisfaction is taken into account. Marital conflict can produce physiological arousal, vigilance, and insecurity interfering with child's sleep. Child's emotional stability develops from supportive relationships; therefore, a hostile and aggressive familiar environment may induce psychological distress, interfering with child's feeling of security and sleeping attitude (El-Sheikh, Hinnant and Erath, 2015).

Recognizing the influence of proximal context, we suppose that also the parental perception of social support could impact on child's sleep. Global perception of social support is related to mental and physical health and promotes adaptation to a variety of life stressors (Cutrona and Russell, 1987). According to Bernier and colleagues (2013) maternal perceived social support predicts child sleep consolidation at 2 years, as well as changes in sleep between 18 months and 2 years of age; higher paternal and maternal perceived social support is related to higher sleep consolidation and great enhancement in sleep consolidation for children living in lower socioeconomic conditions.

Maternal role on child sleep has been deeply evaluated in literature; contrariwise, paternal involvement has been scarcely investigated. Features of fathers' and father-child relationship show a connection with developmental outcomes throughout childhood (Barker, Iles and Ramchandani, 2017). Several authors underlined that a few paternal-specific aspects may influence children's sleep patterns (Tikotzky, Sadeh and Glickman-Gravieli, 2010; Sadeh, Tikotzky and Scher, 2010; Palmstierna, Sepa and Ludvigsson, 2008). For example, Titotzky and Glickman-Gavrieli (2010) found that higher paternal involvement was related to fewer night walkings at 1 and 6 months; Bell and Belsky (2008) find greater mother-reported sleep problems for children with absent fathers.

These findings appear of great interest. Most studies examined sleep in early infancy or middle childhood, not considering the child's sleep development occurring in the second year of life (Bernier et al., 2013). Later in childhood parents meet new challenges, such as organizing consistent sleep routines or alleviating bedtime resistance; thus, their involvement in childcare show a significant increase (Bernier et al., 2013).

Toddlerhood is the age of exploration; toddlers, increasing their own motion skills and language abilities, may develop bedtime resistance, as coming to their parents' room in the middle of the night or in the early morning (Johnson and Mindell, 2011). Along toddlerhood, child's rapid cognitive development may lead to changes in bedtime habits: in this period, nighttime fears may increase and, consequently, children may refuse to go to sleep alone. Furthermore, social and emotional development, at this age, leads to a natural desire for independence and autonomy, which may be also accompanied by difficulties in remaining alone, but, when toddlers are stressed, they regress behaviorally probably showing a desire for co-sleeping.

On the basis of ecological research perspective, the main aim of our study was to explore parental perceptions of parent-child interactions at bedtime. In order to verify the possible role of proximal context in child sleep, some variables such as parenting stress, perceived social support and marital satisfaction were considered, evaluating their connection with the bedtime routines. By the employment of ad hoc semi-structured interview, both maternal and paternal perceptions of the children bedtime routines were taken into account; parents were asked to recall and describe their own personal sleep habits during childhood, in order to enlighten possible connections between the two over mentioned dimensions. 


\section{Materials and Methods}

Forty-one parents of toddlers 18 to 36 months old $(M=25.8$ months), (17 boys and 24 girls) living in Rome participated in this study. Criteria for participation were: full-term pregnancy and the absence of any known physical or mental disability. Mothers were between 24 and 44 years old $(M=35.8)$ and fathers between 27 and 53 years old $(M=37)$. As regards the education level, $63.4 \%$ of mothers and $60 \%$ of fathers hold a college degree, while $29.3 \%$ of mothers and $27.4 \%$ of fathers hold a bachelor degree.

All parents completed a questionnaire pertaining to the demographic characteristics of the family (birth rank, mother's age, father's age marital status and parental education, etc.) as well as the child's medical and developmental history. The questionnaire included a dichotomous-scored item assessing whether the child had sleeping problems during the first 2 years of life.

The Parent-Child Sleep Interaction Scale (PSIS; Alfano et al., 2013), a 12-item parent report, was completed by both parents in order to assess parental behaviors and parent-child interactions related to sleep that might induce problematic sleep patterns/disorders in young children. PSIS is formed by three subscales, each consisting of 4 items: Sleep Reinforcement, Sleep Conflict and Sleep Dependence; a Likert-type response format require parents to indicate how frequently each behavior/interaction occurred during the past month: $0=$ never; $1=$ rarely; $2=$ sometimes; 3 = frequently; 4 = always/almost always. Moreover, a "Total Score" index represents the parental perception of hyper-involvement in sleep routines, children's non-independent sleep patterns and need to be reassured and praised at bedtime; the abovementioned variables can represent meaningful elements that lead to the stabilization of dysfunctional sleep-wake patterns.

Parents' individual degree of satisfaction with their current romantic relationship was assessed by the Dyadic Adjustment Scale (DAS; Spanier, 1976; DAS-4; Sabourin, Valois, and Lussier, 2005), a 4-item questionnaire with a 1-6 Likert scale. Total scores can vary from 4 to 24.

The Parenting Stress Index (PSI-Short Form; Abidin, 1995) assessed parents' subjective level of stress perceived toward their child and their parenting role. Its 36 items are rated on a $0-5$ Likert scale. PSI yields a Total Parenting Stress Score from three subscales, each consisting of 12 items: Parental Distress, Parent-Child Dysfunctional Interaction, and Difficult Child. The subscale scores range from 12 to 60, and the total score from 36 to 180. High scores on the subscales and high PSI-SF total score indicate greater levels of stress.

The 24-item self-report Social Provisions Scale (SPS; Cutrona and Russell, 1987) was used to assess individuals' global perceptions of social support. Parents were asked to indicate, on a 1-4 Likert scale, the extent in which they agreed with items describing the social support available to them.

A brief semi-structured interview examined fantasies, fears, anxieties and, more in general, the subjective experience of parents who are putting their child to sleep. It takes about 10 minutes to be completed and it is composed of three questions: 1. "What is like for you putting your child to sleep?"; 2. "Can you remind how it was going to bed when you were a child?"; 3. "Do you consider your child's sleep a problem?".

Data were analyzed using PASW Statistic version 17.0 (SPSS, Chicago, IL). Spearman correlations were performed to examine associations between parent-child sleep interaction at bedtime (PSIS total score and subscales scores), parenting stress (PSI-SF total score and subscales scores), marital satisfaction, perceived social support in both parents. 


\section{Results}

Intercorrelations among the key variables are displayed in Table 1. Results indicate that maternal and paternal scores for bedtime routines, perceived social support, marital satisfaction, parenting stress show small to moderate correlations $(r=.71, r=.28, r=.69$ and $r=.79$, respectively).

Table 1. Bivariate correlations between paternal and maternal PSIS total scores, SPS total scores, DAS total scores and PSI total scores.

\begin{tabular}{|l|l|l|l|l|l|l|l|l|}
\hline & 1 & 2 & 3 & 4 & 5 & 6 & 7 & 8 \\
\hline 1.Pat.PSIS_Tot & 1 & & & & & & & \\
\hline 2.Mat.PSIS_Tot & $.71^{* *}$ & 1 & & & & & & \\
\hline 3.Pat.SPS_Tot & -.06 & .11 & 1 & & & & & \\
\hline 4.Mat.SPS_Tot & -.03 & -.07 & $.28^{*}$ & 1 & & & & \\
\hline 5.Pat.DAS_Tot & -.17 & -.10 & $.23^{*}$ & -.02 & 1 & & & \\
\hline 6.Mat.DAS_Tot & -.20 & -.13 & .15 & 0.18 & $.69^{* *}$ & 1 & & \\
\hline 7.Pat.PSI_Tot & .20 & .09 & -.14 & -.10 & $-.22^{*}$ & $-.36^{* *}$ & 1 & \\
\hline 8.Mat.PSI_Tot & .13 & .08 & .03 & $-.31^{* *}$ & -.14 & $-.28^{* *}$ & $.79^{* *}$ & 1 \\
\hline
\end{tabular}

Table 2. Bivariate correlations between paternal and maternal PSIS scales scores and paternal and maternal PSI scales scores.

\begin{tabular}{|c|c|c|c|c|c|c|c|c|c|c|c|c|c|c|}
\hline & 1 & 2 & 3 & 4 & 5 & 6 & 7 & 8 & 9 & 10 & 11 & 12 & 13 & $\begin{array}{lll}14 & 15 & 16 \\
\end{array}$ \\
\hline 1.Pat.PSIS_Tot & 1 & & & & & & & & & & & & & \\
\hline 2.Mat.PSIS_Tot & $.70^{* *}$ & 1 & & & & & & & & & & & & \\
\hline 3.Pat_PSIS_SR & $.86^{* *}$ & $.57^{* *}$ & 1 & & & & & & & & & & & \\
\hline 4.Mat_PSIS_SR & $.53^{* *}$ & $.77^{* *}$ & $.58^{* *}$ & 1 & & & & & & & & & & \\
\hline 5.Pat.PSIS_SC & $.68^{* * *}$ & $.70^{* * *}$ & $.42^{*}$ & $.48^{*}$ & 1 & & & & & & & & & \\
\hline 6.Mat.PSIS_SC & .34 & $.70^{* *}$ & .22 & $.38^{*}$ & $.79^{* *}$ & 1 & & & & & & & & \\
\hline 7.Pat.PSIS_SD & $.60^{* *}$ & .31 & .36 & .22 & -.02 & -.32 & 1 & & & & & & & \\
\hline 8.Mat.PSIS_SD & $.46^{*}$ & $.58^{* *}$ & .28 & .26 & -.06 & .00 & $.88^{* *}$ & 1 & & & & & & \\
\hline 9.Pat.PSI_PD & -.08 & .01 & .28 & .21 & -.16 & -.04 & -.17 & -.18 & 1 & & & & & \\
\hline 10.Mat.PSI_PD & .02 & .19 & .35 & $.38^{*}$ & -.10 & .20 & -.11 & -.19 & $.88^{* * *}$ & 1 & & & & \\
\hline 11.Pat.PSI_PCDI & -.04 & -.01 & .38 & .19 & -.05 & .02 & -.24 & -.29 & $.88^{* * *}$ & $.81^{\text {** }}$ & 1 & & & \\
\hline 12.Mat.PSI_PCDI & -.13 & .05 & .29 & .16 & -.13 & .13 & -.26 & -.20 & $.87^{* *}$ & $.76^{* *}$ & $.96^{* *}$ & 1 & & \\
\hline 13.Pat.PSI_DC & .08 & $.31^{*}$ & -.01 & .28 & .27 & $.47^{* *}$ & -.11 & -.16 & -.04 & .30 & -.06 & .09 & 1 & \\
\hline 14.Mat.PSI_DC & .25 & .11 & .17 & -.03 & $.47^{*}$ & $.40^{*}$ & -.20 & -.24 & -.19 & -.05 & -.07 & -.11 & $.59^{* *}$ & 1 \\
\hline 15.Pat.PSI_Tot & -.00 & .02 & .38 & .20 & .00 & .08 & -.26 & -.31 & $.92^{* * *}$ & $.85^{* *}$ & $.96^{* *}$ & $.92^{* *}$ & .07 & .091 \\
\hline 16.Mat.PSI_Tot & -.03 & .21 & .30 & $.34^{*}$ & -.03 & $.31^{*}$ & -.23 & -.24 & $.84^{* *}$ & $.91^{* * *}$ & $.86^{* * *}$ & $.86^{* *}$ & $.50^{* *}$ & $\begin{array}{lll}.08 & .09 & 1 \\
\end{array}$ \\
\hline
\end{tabular}

Table 2 indicates that several indicators of parenting stress were related in consistent ways to problematic bedtime routines with the child. 
We found positive relationships between maternal PSIS global score that reassumes sleeprelated behaviors and parent-child interactions that may promote problematic sleep patterns, and paternal PSI "Difficult Child" $(r=.31, \mathrm{p}=0.05)$, maternal subscale PSIS, "Sleep Reinforcement" score and maternal PSI " Parental distress" $(r=.38, \mathrm{p}=0.05)$ score, paternal PSIS "Sleep Conflict" and maternal PSI "Difficult Child" score $(r=.47, \mathrm{p}=0.05)$, maternal PSIS "Sleep Conflict" score and PSI "Difficult Child" reported by both parents (respectively mothers $r=.40, \mathrm{p}=0.01$; fathers $r$ $=.47, \mathrm{p}=0.05)$.

Examining parent's answers to the brief semi-structured interview (Figs. 1-2), putting children to sleep is considered a positive and intimate moment (mothers $=80 \%$; fathers $=46 \%$ ) and children's sleep doesn't represent a problem (mothers $=76 \%$; fathers $=61 \%$ ). $56 \%$ of mothers and $38 \%$ of fathers wrote about their bedtime routines as a positive and relaxed moment spent with parents.

Fig. 1 - Percentages of mothers' and fathers' answers to the brief semi-structured interview

Question n. 1: "What is like for you putting your child to sleep?"
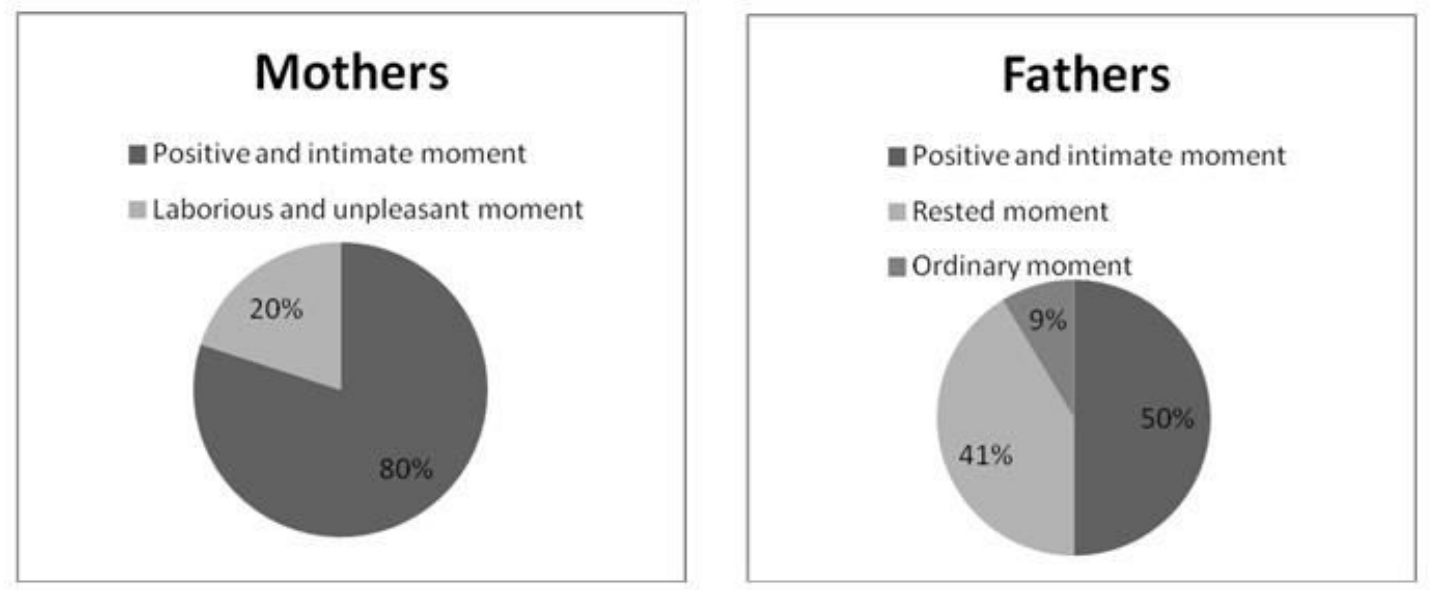

Fig. 2 - Percentages of mothers' and fathers' answers to the brief semi-structured interview

Question n. 3: "Do you consider your child's sleep a problem?"
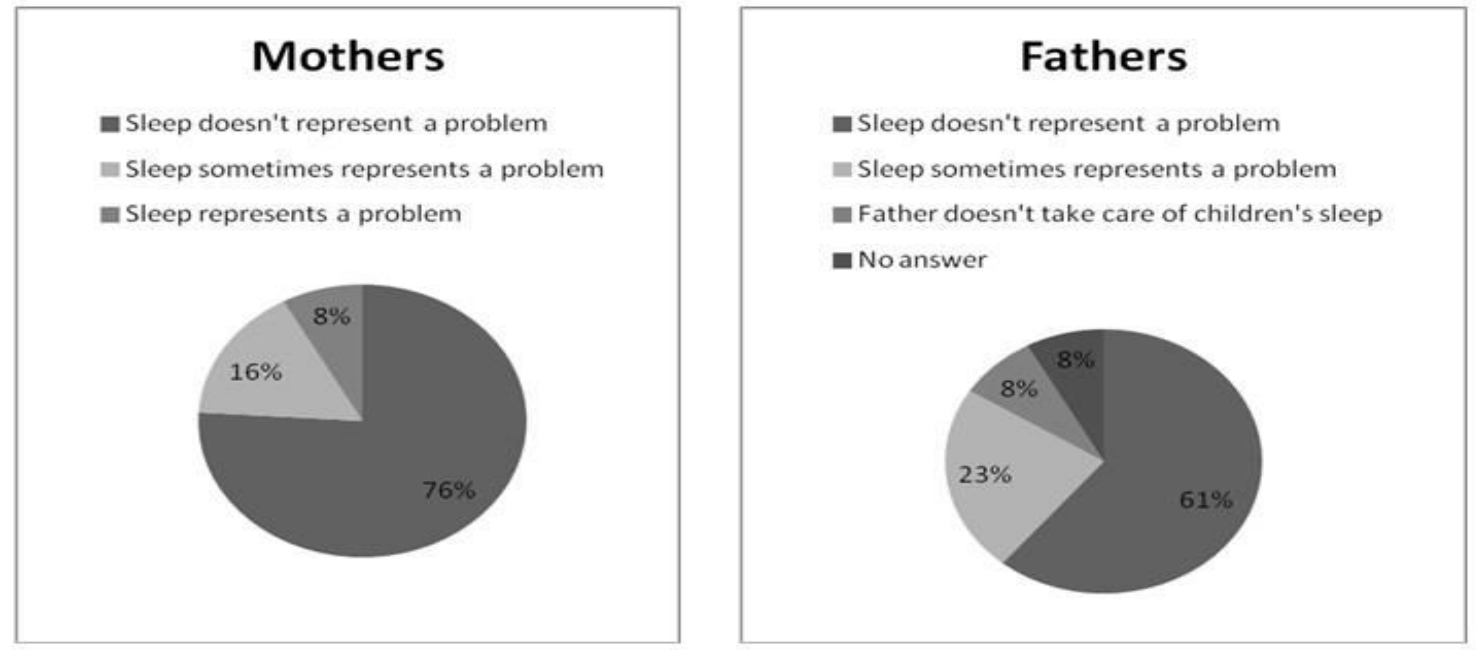


\section{Discussions}

In the current study, we aimed to contribute to the growing field of knowledge about connections between parenting dimensions and toddlers' sleep, notably by studying a non-clinical sample, including both parents, and examining the conditions under which parental psychosocial functioning was related to bedtime routines in toddlerhood. Lower parental functioning (higher parenting stress reported by both parents) was generally related to more critical bedtime routines in toddlers and this result emerged across different indices of functioning. Mothers and fathers who report higher levels of parenting stress were more likely to rate their infants' bedtime routines as more problematic. These findings suggest that the parenting stress reported by both parents may contribute to more critical bedtime routines with their children. Sleep scholars have often noted that the direction of associations between child sleep and family factors was unclear (Keller and ElSheikh, 2011; Meltzer and Mindell, 2007). However, because of the correlational nature of our study, it is impossible to infer about the direction of these links. The findings suggest that at least some of the associations are probably due to family processes influencing children's bedtime routines and consequently their sleep. How, precisely, parental psychosocial functioning may impact young children's sleep consolidation remains a matter for further investigation.

Analyzing parental psychological functioning, we also found a negative relationship between parenting stress and marital satisfaction. The results showed that mothers and fathers with a higher level of stress also reported a lower level of marital satisfaction. Considering this variable, a parent finding gratification in the parental role, perceiving a supportive environment, and living a satisfying marital relationship appears able to create a stable and emotional secure family environment, often considered leading to quality sleep in children (Dahl, 1996). Children's emotional security derives from relationships perceived by them as secure, predictable and stable; therefore, we can expect that marital conflict related to increased psychological distress may interfere with children's sense of security and consequently to sleep consolidation (El-Sheikh, Hinnant and Erath, 2015).

In line with our initial purpose to verify the possible role of proximal context in child sleep, the influence between the above-mentioned links has been recently evaluated and described by ElSheikh and colleagues (2015). More in-depth, authors illustrated as in families where levels of marital conflict were low, children's sleep appeared to be more stable; by contrast, a hostile and aggressive familiar environment induced psychological distress, interfering with child's feeling of security and sleeping attitude. These results relate to conceptual frameworks which proposes that secure family conditions, in contrast to threatening ones, enable children sleep (Dahl, 1996) and that feelings of emotional security derive from safe and supportive perceived family relationships. Children experiencing marital conflict and threats to security may show arousal and vigilance, conditions proposed to be conducive to disrupted sleep (El-Sheik et al., 2015), confirming the need of considering parenting dimensions in relation to toddlers' sleep.

Simultaneously, children's sleep problems can negatively influence marital relationship. Meijer and van den Wittenboer (2007) examined interactions between parental self-efficacy, couple's problem-solving ability and children's sleep and crying in 107 first-time parent couples in the Netherlands: crying of the child would affect couple's relationship and marital satisfaction. This study also shows that increase of paternal self-efficacy contributed to the more marital satisfaction of mothers, confirming that husband's involvement in childcare may improve couple's relationship and marital satisfaction (Meijer and van den Wittenboer, 2007). Considering marital satisfaction and 
parent-child sleep interactions, Smith and colleagues (2014) found correlations between parental report of high "sleep conflict" and lower levels of perceived marital satisfaction.

Examining parent's answers to the brief semi-structured interview, to the questions "What is like for you to put your child to sleep?" and "Do you consider your child's sleep a problem?" the $80 \%$ of mothers and $46 \%$ of fathers described the bedtime moment as a positive and intimate one and for the $76 \%$ of mothers and $61 \%$ of fathers children's sleep doesn't represent a problem. By the question "Can you remind how it was going to bed when you were a child?", instead, the semistructured interview investigated parents' memories about their own experience about bedtime routines: the $56 \%$ of mothers reminded it as a positive experience, while $12 \%$ of them described it as negative; the $38 \%$ of the fathers interviewed described it as positive situation whereas the $8 \%$ of them, as negative. Referring to the Transactional Model (Sadeh and Anders, 1993; De Stasio and Traverso, 2014), parents' memories may modify parental beliefs on children's sleep habits, which show a direct effect on parent-child interactions at bedtime. To date, research showed how the internal working models, shaped by the attachment bond with the caregiver, may be passed down between different generations. Attachment and sleep are two complex systems and their development proceeds simultaneously; the interaction between them lasts throughout the entire life (Adams, Stoops, and Skomro, 2014). As reported by Dahl (1996), individuals need to perceive a sense of protection and safety in order to fall asleep, reducing their responsiveness to external environment; According to Bronfenbrenner's Ecological Perspective (with reference to the incisive role recognized to the immediate context) and according to others well-known developmental researchers, children's sense of safety takes origin from both familial context and parent-child relationship (Bélanger et al.., 2015). Even if this subject has to be still thoroughly examined, the strong link between parental beliefs and children's disrupted sleep-wake patterns is well described in literature (Sadeh, 2010); Morrell and Steele (2003) suggest that children's sleep problems reported by parents may be specifically related to the maternal perception of the setting as fixed, to a decrease of mother's self-efficacy and to the amount of anger shown against child's solicitations.

\section{Conclusions}

Overall, this study evidenced a good concordance between the perceptions of mothers and fathers about bedtime routines with their children.

We found that the different dimensions of proximal context can influence bedtime routine specifically parental stress can lead to critic bedtime routines. Primary care practitioners can play an instrumental role in helping families institute positive sleep practices and improving sleep in infants and toddlers.

\section{Bibliography}

1. Abidin, R.R., 1995. Parenting Stress Index. 3rd edition. Odessa, FL: Psychological.

2. Adams G.C., Stoops M.A., Skomro R.P., 2014. Sleep tight: exploring the relationship between sleep and attachment style across the life span. Sleep Medicine Review, 18(6), pp.495-507.

3. Alfano C.A., Smith V.C., Reynolds K.C., Reddy R., Dougherty L.R., 2013. The Parent-Child Sleep Interactions Scale (PSIS) for preschoolers: factor structure and initial psychometric properties. Journal of Clinical Sleep Medicine, 9(11), pp.1153-1160. 
4. Barker, B., Iles, J.E., and Ramchandani, P.G, 2017. Fathers, fathering and child psychopathology. Current opinion in psychology, 15, pp.87-92. https://doi.org/10.1016/j.copsyc.2017.02.015.

5. Bélanger M.Ė., Bernier A., Simard V., Bordeleau S., Carrier J., 2015. Attachment and sleep among toddlers: disentangling attachment security and dependency. Monographs of the Society for Research in Child Development, 80(1), pp.125-40.

6. Bell, B.G., and Belsky, J., 2008. Parents, parenting, and children's sleep problems: Exploring reciprocal effects. British Journal of Developmental Psychology, 26(4), pp.579-593.

7. Bernier, A., Bélanger, M.È., Bordeleau, S., and Carrier, J.2013. Mothers, fathers, and toddlers: Parental psychosocial functioning as a context for young children's sleep. Developmental Psychology, 49(7), pp.1375-84.

8. Cummings, E.M., and Davies, P., 1996. Emotional security as a regulatory process in normal development and the development of psychopathology. Development and Psychopathology, 8(1), pp.123-139.

9. Cutrona, C.E., and Russell, D.W., 1987. The provisions of social relationships and adaptation to stress. Advances in personal relationships, 1(1), pp.37-67.

10. Dahl, R.E., 1996. The regulation of sleep and arousal: Development and psychopathology. Development and Psychopathology, 8(1), pp.3-27.

11. Dahl, R.E., and El-Sheikh, M., 2007. Considering sleep in a family context: Introduction to the special issue [Special issue]. Journal of Family Psychology, 21(1), pp.1-3.

12. De Stasio, S. and Traverso, P., 2014. Il sonno e le routine di addormentamento nei primi anni di vita di un bambino: la prospettiva interattiva genitore- bambino. Corpo Narrante, 7, pp. 1-9.

13. El-Sheikh, M., Buckhalt, J.A., Cummings, E.M., and Keller, P., 2007. Sleep disruptions and emotional insecurity are pathways of risk for children. Journal of Child Psychology and Psychiatry, 48(1), pp.88-96.

14. El-Sheikh, M., 2011. Sleep and development: Familial and socio-cultural considerations. New York, NY: Oxford University Press.

15. El-Sheikh, M., Hinnant, J.B., and Erath, S.A., 2015. Marital Conflict, Vagal Regulation, And Children's Sleep: A Longitudinal Investigation. Monographs of the Society for Research in Child Development, 80(1), pp.89-106.

16. Erath, S.A., and Tu, K.M., 2011. The parenting context of children's sleep. In: M. El-Sheikh, ed. Sleep and development: Familial and sociocultural considerations. New York, NY: Oxford University Press. pp.29-47.

17. Galland, B.C., Taylor B.J., Elder D.E., Herbison P., 2012. Normal sleep patterns in infants and children: a systematic review of observational studies. Sleep Medicine Reviews, 16(3), pp.21322.

18. Haskett, M.E., Ahern, L.S., Ward, C.S., and Allaire, J.C., 2006. Factor structure and validity of the parenting stress index-short form. Journal of Clinical Child and Adolescent Psychology, 35(2), pp.302-312.

19. Johnson, C. and Mindell, J.A., 2011. Family based interventions for sleep problems of infants and children. In: M. El-Sheikh, ed. Sleep and development: Familial and sociocultural considerations. New York, NY: Oxford University Press. pp.373-395.

20. Keller, P.S., Buckhalt, J.A., and El-Sheikh, M., 2008. Links between family functioning and children's sleep. In: A. Ivanenko, ed. Sleep and psychiatric disorders in children and adolescents. New York, NY: Informa Health Care. pp.49-59. 
21. Kelly, R.J., and El-Sheikh, M., 2011. Marital conflict and children's sleep: Reciprocal relations and socioeconomic effects. Journal of Family Psychology, 25(3), pp.412-422.

22. Martin, J., Hiscock, H., Hardy, P., Davey, B., and Wake, M., 2007. Adverse associations of infant and child sleep problems and parent health: An Australian population study. Pediatrics, 119(5), pp.947-955.

23. Meijer A.M. and van den Wittenboer G.L.H., 2007. Contribution of infants' sleep and crying to marital relationship of first-time parent couples in the 1st year after childbirth. Journal of Family Psychology, 21(1), pp.49-57.

24. Meltzer, L.J., and Mindell, J.A., 2007. Relationship between child sleep disturbances and maternal sleep, mood, and parenting stress: A pilot study. Journal of Family Psychology, 21(1), pp.67-73.

25. Mindell, J.A., Telofski L.S., Wiegand B., Kurtz E.S., 2009. A nightly bedtime routine: impact on sleep in young children and maternal mood. Sleep, 32(5), pp.599-606.

26. Morrell, J., and Steele, H., 2003. The role of attachment security, temperament, maternal perception, and care-giving behavior in persistent infant sleeping problems. Infant Mental Health Journal, 24(5), pp.447-468.

27. Morrell, J., and Cortina-Borja, M., 2002. The developmental change in strategies parents employ to settle young children to sleep, and their relationship to infant sleeping problems, as assessed by a new questionnaire. Infant and Child Development, 11(1), pp.17-41.

28. Palmstierna, P., Sepa, A. and Ludvigsson, J., 2008. Parent perceptions of child sleep: a study of 10000 Swedish children. Acta Padiatrica, 97(12), pp.1631-1639.

29. Sabourin, S., Valois, P., and Lussier, Y., 2005. Development and validation of a brief version of the dyadic adjustment scale with a nonparametric item analysis model. Psychological Assessment, 17(1), pp.15-27.

30. Sadeh, A., and Anders, T. F., 1993. Infant Sleep Problems: Origins, Assessment, Interventions. Infant Mental Health Journal, 14(1), pp.17-34.

31. Sadeh, A., Flint-Ofir, E., Tirosh, T., and Tikotzky, L., 2007. Infant sleep and parental sleeprelated cognitions. Journal of Family Psychology, 21(1), pp.74-87.

32. Sadeh, A., Tikotzky, L., and Scher, A., 2010. Parenting and infant sleep. Sleep Medicine Reviews, 14(2), pp.89-96.

33. Sinai, D., and Tikotzky, L., 2012. Infant sleep, parental sleep and parenting stress in families of mothers on maternity leave and in families of working mothers. Infant Behavior and Development, 35(2), pp.179-186.

34. Smith, V. C., Leppert, K. A., Alfano, C. A., and Dougherty, L. R., 2014. Construct validity of the Parent-Child Sleep Interactions Scale (PSIS): associations with parenting, family stress, and maternal and child psychopathology. Sleep Medicine, 15(8), pp.942-951.

35. Spanier, G.B., 1976. Measuring dyadic adjustment: New scales for assessing the quality of marriage and similar dyads. Journal of Marriage and the Family, 38(1), pp.15-28.

36. Tikotzky, L., Sadeh, A., and Glickman-Gavrieli, T., 2010. Infant sleep and paternal involvement in infant caregiving during the first 6 months of life. Journal of Pediatric Psychology, 36(1), pp.36-46.

37. Troxel, W.M., Robles, T.F., Hall, M., and Buysse, D.J., 2007. Marital quality and the marital bed: Examining the covariation between relationship quality and sleep. Sleep Medicine Reviews, 11(5), pp.389-404. 


\title{
The role of psychopathology in social skills training of children with conduct disorder
}

\section{DOI: http://doi.org/10.26758/8.1.8}

Iliyana Kirilova-Moutafova

Medical Institute, Ministry of Interior of Bulgaria, Sofia

Address correspondence to: Iliyana Kirilova-Moutafova, Email: ilianskk@abv.bg

\begin{abstract}
Objectives. This paper deals with the relationship between the degree of behavioral problems, including the presence of symptoms like anxiety and depression, the efficiency of a conducted training in social skills by using mind mapping techniques, and recording the most frequent display of behavioral problems in children such as running away.

Material and methods. In a period of two years, 100 children, diagnosed with conduct disorder, have been examined. All of them have been accommodated in Correctional Boarding Schools (CBS), Social-Educational Boarding Schools (SEBS), and crisis centers. Clinical semi-structured interviews have been used, Hamilton Anxiety Rating Scale (HAM-A), Beck Depression Inventory (BDI), and Buss-Durkee Hostility Inventory (BDHI). Two groups of children were randomly formed (according to the principle of a sex balance only). Only one of the groups received training in social skills, and skills on how to solve a problem on the basis of a mind mapping card and on the escape situation.

Results. The results show that the average numbers of runaways, in the group of children with mild symptoms that have received training, are significantly lower in the six months period after conducting the study compared with the six months period before. The largest number of escapes, not changing as a result of the intervention, is present in the children with severe symptoms.

Conclusions. This study shows once again the need for an individualized approach to the work with children having behavioral problems, that are accommodated in Correctional Boarding Schools (CBS), Social-Educational Boarding Schools (SEBS), and crisis centers, an approach oriented towards the specific needs of each child.
\end{abstract}

Keywords: depression, anxiety, behavioral problem, mind map.

\section{Introduction}

Conduct disorder is a recurrent and persistent behavioral model, where aggression toward humans and animals, damaging property, frauds or thefts, and blatant breaches of the rules are displayed. To identify and diagnose conduct disorder, three of the above criteria are supposed to have persisted over the previous 12 months or at least one over the previous six months. According to the Diagnostic Statistical Manual (DSM)-IV classification, there are three subtypes of conduct disorder with regard to behavioral problems. DSM-IV-TR (text revision) also allows identifying the condition as mild, moderate or severe (DSM-IV-TR, 2009). The diagnostic record of the conduct disorder in DSM-V has not changed but for the inclusion of the DSM-V specifier "with limited prosocial emotions' (DSM-V, 2014). Although it seems contradictory, anxiety and mood disorders 
are found in many youths with conduct disorder, especially in girls, at increased rates after puberty (Dulcan and Lake, 2012). Irritability, anxiety, and aggression may be the main features with sadness and inability to experience pleasure being less prominent (Moore and Carr, 2000).

Children and adolescents with conduct disorder suffer from such a myriad of biopsychosocial vulnerabilities that it would be amazing to find any single effective treatment modality. Nevertheless, single procedures continue to be developed and tested (Lewis, 1996). The need for an individualized approach, oriented towards the specific need of each of the children, to the work with kids placed in Correctional Boarding Schools (CBS), Social-Educational Boarding Schools (SEBS) and crisis centers, displaying behavioral problems, ought perhaps to be underscored for the umpteenth time. The effective care for children with behavioral problems is at "the stage of pre-criminal status" (Mutafov, Shosheva and Gospodinova, 2000). The aggressive behavior that appears for the first time in the adolescence period is with a better prognosis, with better possibilities for correction and for building good social skills (Polnareva, 2013).

This scientific statement links the severity of the behavioral problems, including anxiety and depressed mood, to the effectiveness of the training in social skills through using suggestopedic techniques, i.e. mind mapping, and recording the most frequent display of children with behavioral problems, i.e. running away.

\section{Material and methods}

One hundred children aged between 15 and 17 years, placed at Correctional Boarding Schools (CBS), Social-Educational Boarding Schools (SEBS) and crisis centers in conditions of detention after running away, have been studied in a two-year period. All of them were diagnosed with conduct disorder and their general physical and mental state was examined. The group did not include children with ADHD and with mental retardation. Semi-structured interviews were conducted with all the members of the group. Data about each child's condition (as regards past diseases, present use of drugs, family constellation, criminogenic environment, period spent in the institution, reasons for placing the child at a residential home - the type of offences committed in the past, arson offences in the past and displayed aggression toward animals and people, use of alcohol, psychoactive substances or combined use, i.e. polysubstances, violence against the child in the past, number of runaways in the recent six months) were collected from the reports of the social services and the Ministry of Interior. The children were given a battery of tests for depression, anxiety, and aggression (Hamilton Anxiety Rating Scale (HAM-A), Beck Depression Inventory (BDI) and BussDurkee Hostility Inventory (BDHI).

The tests applied in this study are widely used in clinical practice and for research aims in Bulgaria. The use of these tests is evident in studies by several authors, published recently (Shumkova, 2006; Krastev, 2011; Temanova, 2011; Stoyanova, 2003; Dimitrov, 2010; Papazova, 2012). They were used with children aged between 13 and 18 years, including with groups of children in institutions (Papazova and Antonova, 2012).

After the tests and semistructured interviews, the group of 100 children was divided for the second stage of the study. Two groups of children were formed randomly to be relatively equally divided in terms of their sex. Each group contained 19 girls and 31 boys. One of the groups received social skills training: skills to solve a problem, using mind mapping, and a situation of running away. The training by using mind map techniques in this study is based on an objective assessment of the real needs of a child, and the goal is to translate the acquired social skills into real-life situations. The method based on using the mind map techniques is easily applicable and pragmatic, 
not requiring the engagement in a particular paradigm or therapeutic theory. It seems to provide a child with the opportunity to receive efficacious interventions and hopefully obtain something tangible and resultative (Kirilova-Moutafova, 2018).

When examining the entire sample of 100 children the Ethics Code for Work with Children was strictly followed and a double informed consent was secured, because minors were studied. All children were informed that they were part of a study, an agreement being concluded on noncommitting offenses while staying at a residential home. Data about runaways have been collected in the next six months by the offices of the Ministry of Interior (launching the search for a missing child, placed in CBS, SEBS or a crisis center). The study was conducted at the Shelter for Temporary Accommodation of Minors and Under-aged, Sofia Directorate of Interior.

\section{Results}

The results obtained from the questionnaires for anxiety, depression and aggression of the entire group of children are given below in Tables 1, 2 and 3.

Table 1. Surveyed individuals according to their level of depression (\%)

\begin{tabular}{|l|c|c|c|c|c|}
\hline Depression (BDI) & Normal & $\begin{array}{c}\text { Mild } \\
\text { depression }\end{array}$ & $\begin{array}{c}\text { Mild to } \\
\text { moderate } \\
\text { severe }\end{array}$ & $\begin{array}{c}\text { Moderate } \\
\text { severe to } \\
\text { severe }\end{array}$ & Severe \\
\hline $\begin{array}{l}\text { Level of } \\
\text { depression }\end{array}$ & 38 & 49 & 8 & 4 & 1 \\
\hline
\end{tabular}

Table 2. Surveyed individuals according to their level of anxiety (\%)

\begin{tabular}{|l|l|l|l|l|}
\hline Anxiety (HAM-A) & Normal & Mild & Moderate & Severe \\
\hline Level of anxiety & 51 & 27 & 20 & 2 \\
\hline
\end{tabular}

Table 3. Surveyed individuals according to their level of aggression (\%)

\begin{tabular}{|l|l|l|l|}
\hline Aggression (BDHI) & Low & Normal & High \\
\hline Level of aggression & 2 & 60 & 38 \\
\hline
\end{tabular}

The results obtained from the tests and semi-structured interviews of all children provided a basis to form three groups. The children with severe symptoms are $7 \%$ of the total of children included in the study; $10 \%$ of the sample has milder symptoms. Those with severe symptoms have higher scores on the Beck Depression Inventory (moderately severe depression and severe depression); on the Hamilton Rating Scale for Anxiety - moderate and severe anxiety, they were aged under 10 at the onset of behavioral disorders; there is information about them suffering violence in the family and misusing several psychoactive substances. The Buss-Durkee aggression level is higher in this group than the total scores.

$10 \%$ of the sample has milder symptoms - these are the children who have mild depression according to Beck Inventory, mild anxiety according to Hamilton, and low scores according to Buss-Durkee. They misuse psychoactive substances, mostly alcohol and marijuana, exhibiting behavioral disorders after turning 10 .

The rest of the children in the sample formed the third group. 
The assumption that the children with severe symptoms would be less influenced by the provided intervention (the training) in comparison with those with relatively milder symptoms was put to the test using the differences in the number of runaways in the six-month period prior to and after conducting the study.

Given the small number of subjects within the studied groups with mild and severe symptoms who have or have not received training (7, and 3, and 3, and 4 children, respectively), Kruskal-Wallis nonparametric tests were performed. The rest of the children in the sample were included in the analysis. Those were the children with various challenging demographic indicators and/or problematic scores in the questionnaires used, considered outside the typical profile configuration of children exhibiting milder or severer behavioral problems. The results of the test are given below in Table 4.

Table 4. Running away rates in the period of six months prior to and after conducting the study on the children with milder or severer symptoms who have received and who have not received training

\begin{tabular}{|c|c|c|c|c|c|}
\hline & \multirow[t]{2}{*}{$\begin{array}{l}\text { Type of } \\
\text { symptoms }\end{array}$} & \multirow[t]{2}{*}{$N$} & $\begin{array}{l}\text { Number of } \\
\text { runaways }\end{array}$ & \multirow[t]{2}{*}{$\begin{array}{l}\text { Chi- } \\
\text { Square }\end{array}$} & \multirow[t]{2}{*}{ Sig. } \\
\hline & & & $\begin{array}{l}\text { Average } \\
\text { rate }\end{array}$ & & \\
\hline \multirow{3}{*}{$\begin{array}{l}\text { Six months prior (the children who } \\
\text { have received training) }\end{array}$} & Mild & 7 & 20 & \multirow[t]{3}{*}{8.98} & \multirow[t]{3}{*}{$.01^{1}$} \\
\hline & Severe & 3 & 46.50 & & \\
\hline & Other & 40 & 24.89 & & \\
\hline \multirow{3}{*}{$\begin{array}{l}\text { Six months after (the children who } \\
\text { have received training) }\end{array}$} & Mild & 7 & 9.14 & \multirow[t]{3}{*}{17.26} & \multirow[t]{3}{*}{$.000^{2}$} \\
\hline & Severe & 3 & 47.00 & & \\
\hline & Other & 40 & 26.75 & & \\
\hline \multirow{3}{*}{$\begin{array}{l}\text { Six months prior (the children who } \\
\text { have not received training) }\end{array}$} & Mild & 3 & 10 & \multirow[t]{3}{*}{12.79} & \multirow[t]{3}{*}{.002} \\
\hline & Severe & 4 & 45.50 & & \\
\hline & Other & 43 & 24.72 & & \\
\hline \multirow{3}{*}{$\begin{array}{l}\text { Six months after (the children who } \\
\text { have not received training) }\end{array}$} & Mild & 3 & 13 & \multirow[t]{3}{*}{3.20} & \multirow[t]{3}{*}{$.20^{3}$} \\
\hline & Severe & 4 & 31 & & \\
\hline & Other & 43 & 25.86 & & \\
\hline
\end{tabular}

${ }^{1 .} \mathrm{p} \leq .05 ;{ }^{2 .} \mathrm{p} \leq .001 ;{ }^{3 .}$ The difference between the average rates of the number of runaways in this group is statistically insignificant

The assumption that children displaying a pronounced inclination to aggression would be less influenced by the training in comparison with those who do not exhibit such inclination was also tested using the differences in the number of runaways prior to and after the study. The average rates of runaways were studied and compared with those of the children who have or have not shown physical aggression and have or have not received training. T-tests were once again conducted for the purpose with one sample tested twice (repeated measures) (Paired-samples TTest). Given the small number of subjects in the studied samples, the Wilcoxon Signed-Rank Test was conducted, i.e. the nonparametric equivalent of the paired t-test (Table 5). 
Table 5. Running away rates in the periods of six months prior to and after conducting the study on the children with aggressive and with non-aggressive behaviors, who have received and who have not received training

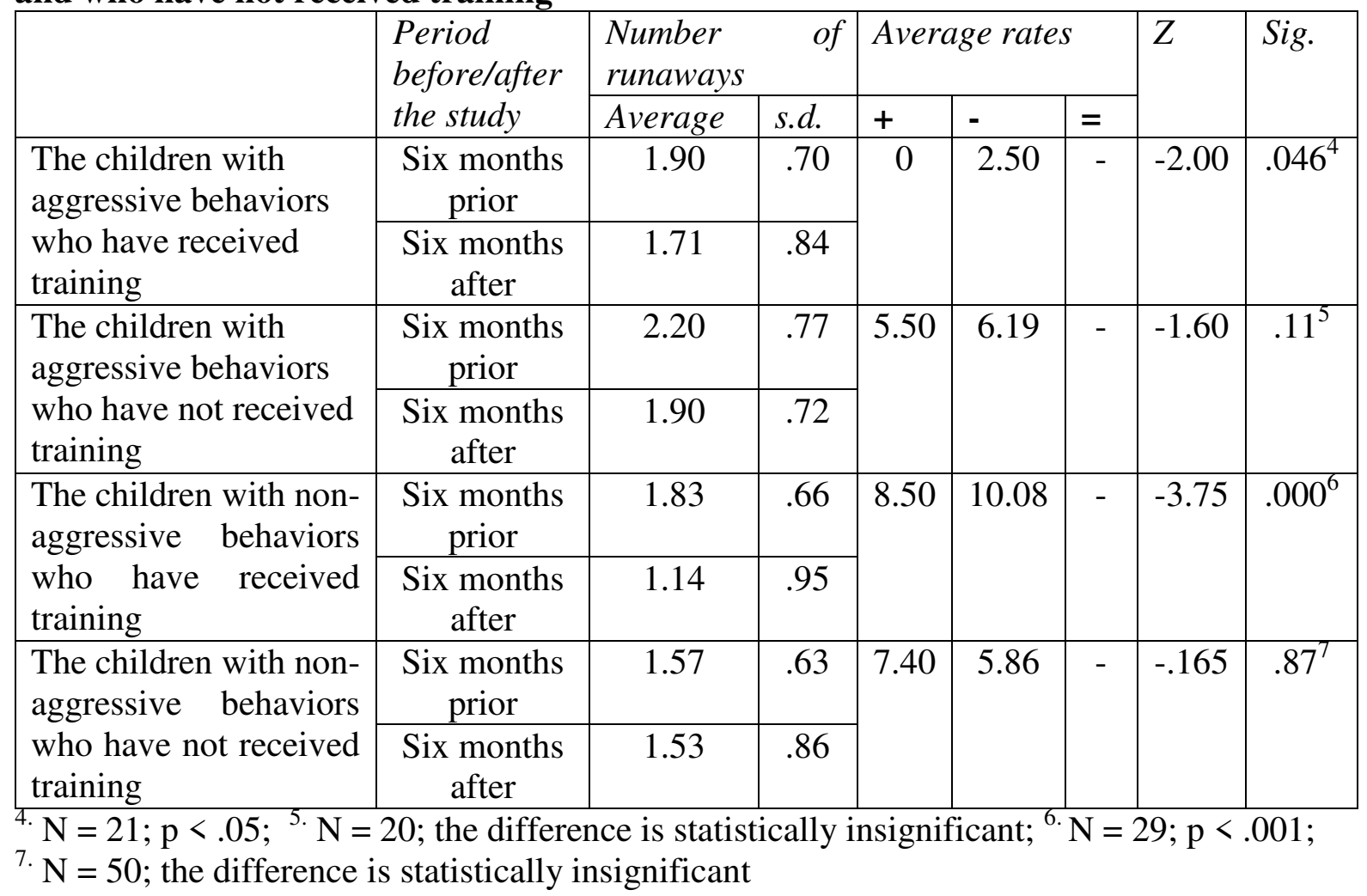

\section{Discussions}

The survey shows relatively high levels of depression and anxiety in children placed in institutions. The result obtained by using self-evaluation questionnaires for exhibiting aggression is impressively similar to the data presented in other sources: episodes of physical aggression performed by the child appeared from the records about the child and the children themselves in the semi-structured interview (41\%). This percentage is very important because approximately $40 \%$ of the children with conduct disorder as adults have violations on Axis II - Antisocial personality disorder (Onchev, 2012). A. Slavtchev (2002) gives similar rates for depression, anxiety, and aggression in mistreated children: $70 \%$ for depression, $67 \%$ for anxiety and $40 \%$ aggressive behavior respectively (Slavtchev, 2002). It is important to note that a very high percentage of children $(75 \%)$ reported experiencing violence in the past and the rest of the children $(25 \%)$ mentioned having witnessed physical aggression towards others (Kirilova-Moutafova, 2014).

The results obtained and presented in the tables above show that the average number of runaways among the children exhibiting no aggression has dropped significantly after receiving the training (See Table 5). Compared with this group, the average number of runaways exhibiting aggression remains much larger after the training, not tangibly changing from the number of runaways prior to conducting the study. Though this group is also influenced by the training, this is to a much lesser degree in comparison with the children who were not inclined to display aggression. It should also be noted here that the difference with the children displaying aggression, 
who have received training, borders on the statistical significance ( $\mathrm{p} \leq .05$; See Table 5), while the one with the non-aggressive children who have received training is within the optimal range ( $\mathrm{p} \leq$ .001; See Table 5). This shows more credibility of the achieved results with this last group.

The results above show that the average rates of the number of runaways in the group of children with mild symptoms that have received training are significantly lower in the period of six months after conducting the study compared with the of six months prior period (See Table 4). The differences for both periods are statistically significant $(\mathrm{p} \leq .05$ and $\mathrm{p} \leq .001$ respectively): what draws attention here is the fact that the rates for the period after the training are higher. The higher level of statistical significance of the results also means more credibility. This is further beefed up by the fact that Chi-Square values are greater here.

The lack of changes in those children who fit neither into the group with mild symptoms nor into that with severe ones is probably due to the fact that the respective group is not homogenous in terms of defined specific characteristics (personal, demographic, psychosocial, etc.). In other words, both children influenced by the training (or have been influenced if receiving training), and those who have not been influenced by the training (or would not have been influenced) may happen to fall in this group and their results neutralize each other.

Multimodality treatment programs that use all of the available family and community resources are likely to bring about the best results in efforts to control conduct disordered behavior (Sadock and Sadock, 2009).

Unfortunately, work with institutionalized children who use psychoactive substances is not performed yet in Bulgaria, while precise diagnostics and therapy of anxiety and depressive disorders, concomitant with a display of behavioral problems, seem to be underestimated. The findings regarding the antisocial trend suggest that hope exist, its real treatment is not psychoanalysis, but an appropriate attitude, welcome and respond to moments of hope (Winnicott, 2008).

\section{Conclusions}

The obtained results confirm the assumption that children with severe symptoms would be less influenced by the provided intervention (the training) in comparison with those exhibiting milder symptoms. The latter are influenced by the training to the greatest degree compared with the other two groups. The children who, after receiving training, can't be classed with any of the two specific groups (with mild or severe symptoms) come second. And last, come the children with severe symptoms, the largest number of runaways that do not change as a result of the intervention.

The results obtained in this survey illustrate a negative tendency and could become a basis for changing the working practices of different institutions that accommodate children with behavioral problems. In order to avoid hypodiagnostic errors in children with anxiety and depression, when they are about to be accommodated in institutions for their status assessment, a meeting with a psychologist and with a child psychiatrist is highly recommended, if necessary. If severe psychopathology is attested, and when it is complicated by the use of substances, an expert in drug dependencies has to participate in the admission team.

\section{Bibliography}

1. Dulcan, M.K., Lake, M.B., 2012. Concise Guide to Child and Adolescent Psychiatry, 4th edition, Arlington: American Psychiatric Publishing, Inc. 
2. Kirilova-Moutafova, I., 2014. За-щита на Егото или дисоциативна симптоматика при деца с екстернализирани поведенчески проблеми (About the shield of Ego or about Dissociative Symptoms in Children with Externalized Behavioral Problems). In: Сборник научни доклади VII национален конгрес по психология, Sofia, Bulgaria, 30 October-2 November 2014, pp.1285-1289. Available at: https://ncp2014.files.wordpress.com/2014/10/sbornik_nauchni_dokladi-isbn-978-954-91472-92.pdf [Accessed 24 June 2017].

3. Kirilova-Moutafova, I., 2018. Application Possibilities of Mind Map in Social Skills Education of Children with Behaviour Problems. In: Trakia Journal of Sciences Stara Zagora (in print).

4. Lewis, D.O., 1996. Conduct Disorder. In: Lewis's Child and Adolescent Psychiatry. A Comprehensive Textbook, 2nd Edition, Williams and Wilkins, p.572.

5. Moore, M., Carr, A., 2000. Depression and Grief. In: A. Car, ed., What Works for Children and Adolescents? A critical review of psychological interventions with children, adolescents and their families, London and New York: Routledge, p.205.

6. Mutafov, S., Shosheva, V., Gospodinova, E., 2000. Етопедия (Ethopedia). Тракийски Университет, Stara Zagora: изд. Кота, p.182.

7. Onchev, G., 2012. Личностова абнормност в клиничната практика (Personal Abnormality in Clinical Practice). 2-ро преработено издание, Sofia: изд. Контекст, p.82.

8. Papazova, E., Antonova, R., 2012. Проблемно поведение и училищна и/или социална среда в юношеска възраст (Problem behavior and school and/or social environment at adolescence). Психологични изследвания, 2, БАН, ИИНЧ. 18-26.

9. Polnareva, N., 2013. Разстройства на детската и юношеската възраст (Child and Adolescent Disorders). In: Психиатрия (под ред. на В. Миланова), Sofia: изд. Медицина и физкултура, pp. 442-445.

10. Sadock, B.J., Sadock, V.A., 2009. Kaplan and Sadock's Concise Textbook of Child and Adolescent Psychiatry, Lippincott Williams and Wilkins, p.99.

11. Slavtchev, A., 2002. Насилие, физическо малтретиране и сексуална злоупотреба с детето (Violence, Physical Abuse and Sexual Abuse of a Child). Sofia: изд. Дидакта консулт, pp.198199.

12. Winnicott, D., 2008. Антисоциалната тенденция (Antisocial Trend (in Bulgarian translation). In: Антисоциална тенденция - теория и терапия. Sofia: Център за психосоциална подкрепа, pp.46-47.

13. *** American Psychiatric Association, 2009. Справочник за диагностичните критерии на ДCH-IV-TP (Diagnostic Statistical Manual of Mental Disorders DSM-IV-TR) Sofia: изд. ИзтокЗапад.

14. ***American Psychiatric Association, 2013. Diagnostic and Statistical Manual of Mental Disorders, Fifth Edition (DSM-5).Washington, DC: American Psychiatric Publishing. 


\title{
Considerations regarding the risks of obesity and physical inactivity
}

\section{DOI: http://doi.org/10.26758/8.1.9}

\section{Constanța Urzeală}

National University of Physical Education and Sports from Bucharest, Romania

Address correspondence to: Constanța Urzeală, Sports and Motor Performance Department, UNEFS, 140 Constantin Noica Street, 6th District, Bucharest, Romania, Ph.: +40/21 3164107, Fax: +40/21 3120400; E-mail: constanta.urzeala@unefs.ro

\begin{abstract}
This paper aims to emphasize the risks of obesity and physical inactivity, knowing that an unhealthy lifestyle based on sedentariness, a chaotic rhythm of work programmes and sleeping hours, and inappropriate food ingestion in terms of quality and regularity of meals is a major factor in disturbing the individual's well-being. Evidence shows that physical activity can be used as a preventive measure or a secondary care standard for chronic health issues related to obesity, such as cardiovascular disease, type 2 diabetes mellitus, colon cancer and stroke. Recent studies are focused on the efficiency of different obesity management strategies in order to avoid obesity-related comorbidities. Physical activity fosters the mental and functional balance of the individual, ensures good body weight control, improves and contributes to maintaining the health status, satisfies the need for movement, responds to the need for group affiliation and social interaction, and provides contexts for personal communication. Despite the people's awareness of the statistics, their involvement in physical activity is low. Physical exercise programmes should be approached as medical prescriptions for an optimal state of health, being a medicine with no negative effect if properly applied, but with many health benefits. Changes in a person's lifestyle related to physical exercise, diet and harmful leisure result from the congruence of several political, economic, ideological and educational factors.
\end{abstract}

Keywords: health, physical inactivity, well-being.

\section{Introduction}

An unhealthy lifestyle based on physical inactivity, a chaotic rhythm of work programmes and sleeping hours, inappropriate food ingestion in terms of quality and regularity of meals is a major factor in disturbing the individual's well-being. Moreover, vicious habits like smoking, alcohol, drugs, gambling cause a decrease in the quality of life. In this context, all people's actions are reflected in their health status, which makes it imperative to promote a balanced way of living since early ages.

In 2016, the World Health Organization (WHO) has highlighted once again that obesity is an alarmingly increasing disease. According to statistics, more than 1.9 billion adults (39\%) were overweight, and of these, over 650 million (13\%) were obese worldwide (***WHO, 2017).

In 2014, across all EU Member States, $51.6 \%$ of the adult population was estimated to be overweight and obese. In Romania, the proportion of women considered to be overweight was 
almost $50 \%$, and of these, $9.7 \%$ were obese, while for the male adult population, more than $60 \%$ was overweight and $9.1 \%$ was obese (***Eurostat Statistics, 2017).

The classification for overweight and obese adults is made by calculating their Body Mass Index (BMI), knowing that an index $\geq 25$ corresponds to overweight, while a BMI $\geq 30$ shows obesity (Katzmarzyk et al., 2000). The most common cause of obesity and overweight is an energy imbalance between ingested calories and consumed calories, but other genetic and environmental causes can be investigated. Also, recent studies are focused on the efficiency of different obesity management strategies designed not to regain weight after losing it (Rogge \& Gautam, 2017).

Obesity is associated with comorbidities such as cardiovascular disease, type 2 diabetes mellitus, musculoskeletal disorders and certain cancers (Fruh, 2017).

Various epidemiologic studies have revealed that physical activity is inversely linked to cardiovascular morbidity and mortality (Koolhaas, 2016). Recent meta-analyses support the benefits of regular physical activity on the coronary heart disease. Moderate-to-high levels of physical activity can reduce the risk of this heart disease by up to $27 \%$ (Sofi, 2008).

Obese people, who have a genetic predisposition for type 2 diabetes and are physically inactive, can develop this metabolic disease as they grow older (Nielsson, 2017). The progression from prediabetes to type 2 diabetes depends on the obesity management (*** American Diabetes Association, 2017), including the involvement of patients in physical exercise programmes. In the United States, evidence suggests that 1 in 3 adults have prediabetes, more than 1 in every 10 adults being diagnosed with diabetes (Santos-Longhurst, 2017). In addition, diabetes is considered to become the $7^{\text {th }}$ leading cause of death at a global level in 2030 (*** WHO, 2017). From another perspective, people diagnosed with type 2 diabetes can balance their blood glucose levels and not develop type 1 diabetes if they follow the medical prescription, the diet and change their lifestyle into a physically active one (Rothberg, 2014).

Hidayat et al. (2017) demonstrate that body fatness at an early age may affect colon cancer risk later in life. The authors support the idea of preventing overweight and obesity in young people to avoid the early onset of colon cancer caused by excess body fatness.

It is known that the regular practice of physical activity reduces the risk of obesity by lowering fat mass and positively influencing lean mass in older adults (Bann et al., 2014). Instead, specialists identify a potentially vicious cycle including weight gain, obesity, and complications associated with a sedentary lifestyle (Golubic et al., 2013).

\section{Issues addressed}

Evidence shows that physical activity can be used as a preventive measure or a secondary care standard for chronic health issues related to obesity, such as cardiovascular disease (Daren, 2013; Go, 2013; Pagac, 2008), type 2 diabetes mellitus (Colberg, 2010; Dharmastuti et al., 2017;

***American Diabetes Association, 2017), colon cancer and stroke (Brown, 2017; Adamsen, 2017). Moreover, specialists have demonstrated that physical inactivity also increases the risk of osteoporosis (Dolan, 2017; Watson, 2017; Mack, 2017). Lack of physical activity is an important modifiable risk factor for bone mineral density. Time spent in sedentary behavior or in nonexercising seated and reclining postures has recently emerged as a new public health risk, independent of the amount of time someone spends being active (Chastin et al., 2017).

Psychologically, obesity can be related to low self-esteem, lack of self-confidence, embarrassment in various social contexts etc. Thus, discrimination, labeling, rejection, and self- 
victimization can exert a strong emotional pressure on an overweight or obese person (Milici, 2015, p.64).

Nowadays, social relationships are influenced by the somatic appearance of the individual. Being "too fat" attracts negative consequences and leads to serious emotional scars. Nuttall (2015, p.117) states that "societal discrimination limits career choices, and indeed many career paths are closed to those considered to be too fat. Also, societal stigma often impairs a person's ability to express his/her intellectual and other talents; that is, they become underachievers".

Sociologists highlight the fact that some individuals choose to practice physical activities for their somatic appearance, for having a body that matches the aesthetic social rigors, in order to align with the lifestyle of those in the group to which they belong, to keep up with what is fashionable or what the society claims to be beneficial to its members. This interest in one's appearance may lead to the choice of less beneficial physical activities, in sanogenetic terms. We refer here to situations where gym or fitness centers are attended only to meet certain social needs, without understanding the principles of exercising, the advantages of systematically practicing physical exercise and adopting a healthy lifestyle. Few people are aware that they engage in movement for their own development and the health-related benefits, thus choosing physical activities with low efficiency for them. We can also add here situations where individuals use drastic measures to lose weight in order to match social norms in the shortest possible time, adopting unhealthy diets and physical exercise programmes that are inappropriate for their bodies.

With age, people's interest in physical activity changes, the main reason being their desire to stay young as long as possible, with no health problems. Constrained by his/her own fears, the individual may adhere to physical activity, but without necessarily seeking its recreational, playful and energy balancing sides. The functional limitations that accompany degenerative processes will influence the engagement in physical activities and their choice. These issues may exert a strong psychological pressure on the person, requiring intense processes of accepting one's own physical capabilities and their downward curve after adulthood.

In recent studies, physical exercise is addressed as a bio-medicine associated with optimal health (Orgeret, 2008, p.52). In Canada and the United States, a new concept has been developed, namely "Exercise is Medicine", according to which physical activity has a major integrative role in the prevention and treatment of diseases, being necessary to include it as part of all healthcare (***Exercise is Medicine, 2017).

The challenge of living with a chronic disease makes people with health-related problems a disadvantaged population, their treatment exerting a high pressure on their lifestyles. Any chronic disease that affects the health status will keep the individual away from physical activity. There may be cases where only certain exercises are allowed or situations where effort is completely forbidden. Physical inactivity and health problems may increase the risks to which the individual is exposed due to possible complications. In terms of social integration, there are situations where individuals suffering from chronic diseases are often marginalized, excluded, isolated, avoided.

Physical activity fosters the mental and functional balance of the individual, ensures good body weight control, improves and contributes to maintaining the health status, satisfies the need for movement, responds to the need for group affiliation and social interaction, provides contexts for personal communication and expression. Overall, physical activity combats the stress of everyday life and increases the quality of life for those who practice it (Dragnea \& Teodorescu, 2002, p.42). The benefits of the exercise are directly related to the individual's movement capabilities, which in turn will condition the performance of daily activities, whether they are professional, administrative and/or domestic. The development of fitness components and the formation of motor skills have 
positive effects on the functional, physiological and psychological levels, acting on the individual's state of health. The indissoluble connection between the motor, functional, biological, psychological and social sides of the individual will condition the optimal development of his/her body and its evolution. For elderly people, the objectives of practicing motor activities are related to slowing down degenerative processes, increasing socialization for those retired, combating anxiety and the feeling of worthlessness or depression. Table 1 shows a synthesis of the functional adaptations and prophylactic effects induced by the regular practice of physical exercise (Dumitru, 1997, p.17).

Table 1. Functional adaptations and prophylactic effects due to physical activity

\begin{tabular}{|c|c|c|}
\hline $\begin{array}{l}\text { System or } \\
\text { function }\end{array}$ & Functional adaptations & Prophylactic effects on: \\
\hline Cardiovascular & $\begin{array}{l}\text { Increased amount of blood pumped by the heart } \\
\text { Increased amount of blood existing in the vessels } \\
\text { Blood becomes more fluid and flows more easily } \\
\text { through arteries and veins }\end{array}$ & $\begin{array}{l}\text { Arteriosclerosis } \\
\text { Ischemic heart disease } \\
\text { Hypertension }\end{array}$ \\
\hline Pulmonary & Increased pulmonary ventilation & $\begin{array}{l}\text { Chronic pulmonary } \\
\text { disease }\end{array}$ \\
\hline $\begin{array}{l}\text { Skeletal } \\
\text { muscles }\end{array}$ & $\begin{array}{l}\text { Increased muscle mass and muscle tone } \\
\text { Increased muscle strength and local muscle } \\
\text { endurance }\end{array}$ & $\begin{array}{l}\text { Lumbar disease } \\
\text { Fractures that frequently } \\
\text { occur in the elderly }\end{array}$ \\
\hline Adipose tissue & $\begin{array}{l}\text { Decreased fat mass and adipose tissue around } \\
\text { the organs }\end{array}$ & $\begin{array}{l}\text { Obesity } \\
\text { Metabolic disease }\end{array}$ \\
\hline $\begin{array}{l}\text { Carbohydrate } \\
\text { metabolism }\end{array}$ & $\begin{array}{l}\text { Increased ability of the muscle to extract blood } \\
\text { glucose }\end{array}$ & Diabetes \\
\hline Fat metabolism & $\begin{array}{l}\text { Increased ability to use lipids as an energy } \\
\text { substrate }\end{array}$ & Arteriosclerosis \\
\hline Immunity & $\begin{array}{l}\text { Increased ability of the immune system to } \\
\text { respond to microbial aggression and resist illness }\end{array}$ & $\begin{array}{l}\text { Infection, virus disease, } \\
\text { flu }\end{array}$ \\
\hline Digestion & Improved intestinal transit & Colon disease \\
\hline $\begin{array}{l}\text { Nervous } \\
\text { system }\end{array}$ & Increased coordination and balance & $\begin{array}{l}\text { Fractures caused by } \\
\text { domestic accidents }\end{array}$ \\
\hline $\begin{array}{l}\text { Cognitive } \\
\text { function }\end{array}$ & Increased reaction speed & Injuries \\
\hline $\begin{array}{l}\text { Psychosocial } \\
\text { behavior }\end{array}$ & $\begin{array}{l}\text { Improved self-image, professional efficacy, } \\
\text { harmonious family behavior, zest for life }\end{array}$ & $\begin{array}{l}\text { Depression, anxiety, } \\
\text { emotional disorders, } \\
\text { social integration } \\
\text { difficulties }\end{array}$ \\
\hline
\end{tabular}

\section{Discussions}

Despite the people's awareness of the statistics and the dynamic evolution of the fitness industry, the individuals' involvement in physical activity does not record the same ascending rate, most of them being inactive from this point of view (Janssen, 2017; Thanamee, 2017). Golubic et al. (2014) conducted a research on British people aged 60-64, demonstrating that their physical activity involvement was generally low. Milosević et al. (2009) studied the physical inactivity level in 
Croatia, emphasizing that, in Zagreb, 39.6\% men and $43.6 \%$ women had a sedentary lifestyle. In Romania, it is noticed that people are physically inactive from early ages, and the habit of being sedentary tends to extend throughout their lifetime (Albu et al., 2016; Neagu, 2016). Studies reveal that most adults often spend their leisure time watching TV, rented movies, listening to music (Rada, 2017), while children are attracted to electronic devices and playing computer games.

It is difficult to attract to physical exercise programmes the adults who have not had contact with sport but understand the necessity of practicing it and want to change their lifestyle into an active, dynamic, healthy one. Knowing that the habit of practicing physical activity is formed at young ages, physical exercise should be an integral part of the educational act so as to stimulate the desire for movement and maintain the individual's motivation for a regular exercise regime. Socially speaking, the education level is given by the family members. Building an active lifestyle depends on the education level of parents, who in turn have to be engaged in physical exercise programmes both for their own well-being and to be a model for their children. Romanian specialists demonstrate that there are significant differences in the way leisure time is spent based on environment, gender, education level and age (Rada, 2015). The adult's openness to the physical activity valences will be directly reflected in the child's level of involvement in physical exercise programmes. Thus, in the long run, the risk of illness and health disorders decreases as a result of fighting sedentary lifestyle.

The socio-economic conditioning, that influences people's participation in physical activities (Teodorescu \& Popescu, 2016), is equally important. Considering the large number of children who do not attend primary education, it is easy to understand that pupils from socially disadvantaged environments do not even participate in the compulsory physical education and sports (PES) lessons to which they would have free access. The access to sports halls, sports clubs or wellness centers for children is often hampered by poor transport and infrastructure. With the exception of large cities, where the children's clubs for physical activities as leisure have constantly grown in recent years, in many other localities, the only opportunity to do sports is within the PES lesson or the professional sports clubs. Although, at the European level, the emphasis is put on physical activity as a pillar of optimal health, in Romania, performance sport is brought to the forefront. Even if statistics indicate a major drop in the number of children choosing performance sports activities, specialized sections within the school sports clubs do not organize leisure activities and do not include groups of children willing to practice sports for all. Therefore, if children are not talented for performance sport and/or do not wish to engage in this form of physical exercise, they have few opportunities to engage in leisure physical activities.

In addition, the lack of a sports culture and of healthy attitude of the society toward continuing education (Bota, 2006, p.123) is emphasized by the poor participation in the current physical education curriculum and the time budget management so that to provide available resources for extracurricular physical activities. The importance given to the PES subject, as compared to other study subjects focused on developing the child's cognitive processes, is reflected in the large number of children who are medically exempt from physical exercise, not always for justified reasons, but also in the small number of those practicing extracurricular sports activities. The busy schedules of both the pupils and their parents are other factors that may lead to the child's physical inactivity. Doing homework, taking private lessons in various school subjects that mainly stimulate the child's cognitive development and the time spent in traffic to go to school and come back home are the most common reasons given by parents to justify the reduced participation of their children in physical activities. From the adult's perspective, the alert pace of daily life, the unbalanced distribution of leisure and work time, the double workload of women often generated by the low economic level and unequal gender division of household chores are strong arguments that 
cause physical inactivity and implicitly the exposure of their health to the risks of obesity and sedentariness.

\section{Conclusions}

The WHO statistics are alarming, indicating numerous cases of illness caused by physical inactivity in people of any age. Regardless of the country, both physicians and specialists in physical education and sport recommend the practice of physical exercise to counteract the effects of a sedentary lifestyle, fight obesity and mitigate the effects of mental and social pressures due to daily stress in order to replace harmful, self-destructive habits in the individuals' lifestyles.

Physical activities emerge as a powerful link between the real significance of the individual's health status and his/her optimal functioning, between the integrity of the body and the expression of its maximum potential, between existing and living.

Physical exercise programmes should be approached as medical prescriptions for an optimal state of health, being a medicine with no negative effect if properly applied, but with many sanogenetic benefits.

Changes in a person's lifestyle related to physical exercise, diet and harmful leisure result from the congruence of several political, economic, ideological and educational factors. In this context, the risk of chronic diseases and mental disorders can be diminished by conjugating the powerful actions undertaken by decision-makers at the level of national and European systems.

\section{References}

1. Adamsen, L., Andersen, C., Lillelund, C., Bloomquist, K., Møller, T., 2017. Rethinking exercise identity: a qualitative study of physically inactive cancer patients' transforming process while undergoing chemotherapy. British Medical Journal Open, 23, 7(8):e016689, doi: 10.1136/bmjopen-2017-016689.

2. Albu, A., Onose, I., Negrea, M., Cracana, I. and Hodorca, R.M., 2016. Correlation between physical diagnostic and exercise in a group of teens from Garabet Ibrăileanu High School of Iași. The European Proceedings of Social \& Behavioural Sciences, vol XI, pp.273-279.

3. Bann, D., Kuh, D., Wills, A.K., Adams, J., Brage, S., Cooper, R., 2014. Physical activity across adulthood in relation to fat and lean body mass in early old age: findings from the Medical Research Council National Survey of Health and Development, 1946-2010. American Journal of Epidemiology, 179, pp.1197-1207. doi: 10.1093/aje/kwu033.

4. Bota, A., 2006. Exerciții fizice pentru viața activă. București: Cartea Universitară.

5. Brown, J.C., Zemel, B.S., Troxel, A.B., Rickels, M.R., Damjanov, N., Ky, B., Rhim, A.D., Rustgi, A.K., Courneya, K.S., Schmitz, K.H., 2017. Dose-response effects of aerobic exercise on body composition among colon cancer survivors: a randomized controlled trial. British Journal of Cancer Online Publication, 21, doi: 10.1038/bjc.2017.339.

6. Chastin, S.F., Mandrichenko, O., Helbostadt, J.L., Skelton, D.A., 2014. Associations between objectively-measured sedentary behaviour and physical activity with bone mineral density in adults and older adults, the NHANES study. Bone, 64, pp.254-262, doi: 10.1016/j.bone.2014.04.009.

7. Colberg, S.R., Sigal, R.J., Fernhall, B., Regensteiner, J.G., Blissmer, B.J., Rubin, R.R.,ChasanTaber, L., Ann, L., Albright, A.L., Braun, B., 2010. Exercise and Type 2 Diabetes. The 
American College of Sports Medicine and the American Diabetes Association: joint position statement. Diabetes Care, 33(12), pp.147-167, doi: 10.2337/dc10-9990.

8. Darden, D., Richardson, C., Jackson, E.A., 2013. Physical activity and exercise for secondary prevention among patients with cardiovascular disease. Current Cardiovascular Risk Report, 7(6), pp.411-416, doi: 10.1007/s12170-013-0354-5.

9. Dharmastuti, D.P., Agni, A.N., Widyaputri, F., Pawiroranu, S., Sofro, Z.M., Wardhana, F.S., Haryanto, S., Widayanti, T.W., Kotha, S., Gupta, P., Sasongko, M.B., 2018. Associations of physical activity and sedentary behaviour with vision-threatening diabetic retinopathy in Indonesian population with type 2 diabetes mellitus: Jogjakarta eye diabetic study in the community (joged.com). Ophthalmic Epidemiology, 25(2), pp.113-119. doi: 10.1080/09286586.2017.1367410. Epub 2017 Oct 12.

10. Dolan, E., Swinton, P.A., Sale, C., Healy, A., O'Reilly, J., 2017. Influence of adipose tissue mass on bone mass in an overweight or obese population: systematic review and meta-analysis. Nutrition Reviews, 75(10), pp.858-870. doi: 10.1093/nutrit/nux046.

11. Dragnea, A. and Teodorescu, S., 2002. Teoria sportului. București: FEST.

12. Dumitru, Gh., 1997. Sănătate prin sport pe înțelesul fiecăruia. București: Federația Română Sportul pentru toți.

13. Fruh, S.M., 2017. Obesity: Risk factors, complications, and strategies for sustainable long-term weight management. Journal of American Association Nurse Practitioners, 29(S1), pp.3-14. doi: 10.1002/2327-6924.12510.

14. Go, A.S., Mozaffarian, D., Roger, V.L. et al., 2013. Heart disease and stroke statistics--2013 update: a report from the American Heart Association. Circulation, 127(1):e6-e245. Available at: https://www.ncbi.nlm.nih.gov/pmc/articles/PMC5408511/ [Accessed 24 October 2017]

15. Golubic, R., Ekelund, U., Wijndaele, K., Luben, R., Khaw, K.T., Wareham, N.J., Brage, S., 2013. Rate of weight gain predicts change in physical activity levels: a longitudinal analysis of the EPIC-Norfolk cohort. International Journal of Obesity, 37(3), pp.404-409. doi: 10.1038/ijo.2012.58.

16. Golubic, R., Martin, K.R., Ekelund, U., Hardy, R., Kuh, D., Wareham, N., Cooper, R., Brage, S., 2014. Levels of physical activity among a nationally representative sample of people in early old age: results of objective and self-reported assessments. International Journal of Behavioral Nutrition and Physical Activity, 3(11), p.58. doi: 10.1186/1479-5868-11-58. Available at: https://www.ncbi.nlm.nih.gov/pmc/articles/PMC4038114/ [Accessed 24 October 2017]

17. Hidayat, K., Yang, C.M., Shi, B.M., 2017. Body Fatness at an Early Age and Risk of Colorectal Cancer. International Journal of Cancer, doi: 10.1002/ijc.31100, Available at: http://onlinelibrary.wiley.com/doi/10.1002/ijc.31100/abstract;jsessionid=FC9437DA624429FF0 80F989C185BE55C.f04t03 [Accessed 24 October 2017].

18. Janssen, E., Ruiter, R.A.C., Waters, E.A., 2017. Combining risk communication strategies to simultaneously convey the risks of four diseases associated with physical inactivity to sociodemographically diverse populations. Journal of Behavioral Medicine, 5, pp. 1-15. doi: 10.1007/s10865-017-9894-3.

19. Katzmarzyk, P., Pérusse, L., Rao, D.C., Bouchard, C., 2000. Familial Risk of Overweight and Obesity in the Canadian Population using the WHO/NIH Criteria. Obesity Research \& Clinical Practice, 8(2), pp.194-197. 
20. Koolhaas, C.M., Dhana, K., Golubic, R., Schoufour, J.D., Hofman, A., van Rooij, F.J.A., Franco, O.H., 2016. Physical Activity Types and Coronary Heart Disease Risk in Middle-Aged and Elderly Persons: The Rotterdam Study. American Journal of Epidemiology, 183(8), pp.729738, https://doi.org/10.1093/aje/kwv244.

21. Mack, D.E., Wilson, P.M., Santos, E., Brooks, K., 2017. Standards of reporting: the use of CONSORT PRO and CERT in individuals living with osteoporosis. Osteoporosis International, 10, pp.1-19, doi: 10.1007/s00198-017-4249-z.

22. Milici, N., 2015. Sindromul metabolic şi obezitatea. Perspective antropologice (Metabolic syndrome and the obesity. Anthropological perspectives), București: Editura Academiei Române.

23. Milosević, M., Golubić, R., Mustajbegović, J., Jelinić, J.D., Holcer J.N., Kern, J., 2009. Regional pattern of physical inactivity in Croatia. Collegium Antropologicum, 33(1), pp.35-38.

24. Neagu, A., 2016. Les pressions liées à l'apparence et la gestion du poids dans un échantillon des adolescents de Bucarest (Appearance-related pressures and weight management in an adolescent sample from Bucharest). In: III Colloque International Francophone "Mondialisation des comportements alimentaires et facteurs de risques pour l'obésité et le diabète”, Sofia: Simel Press Edt. pp.81-92.

25. Nilsson, E., Ling, C., 2017. DNA methylation links genetics, fetal environment, and an unhealthy lifestyle to the development of type 2 diabetes. Clinical Epigenetics Online, 9, p.105, doi: $\quad$ 10.1186/s13148-017-0399-2.

Available at: https://clinicalepigeneticsjournal.biomedcentral.com/articles/10.1186/s13148-017-0399-2, [Accessed 24 October 2017]

26. Nuttall, F.Q., 2015. Body Mass Index: Obesity, BMI, and Health: A Critical Review. Nutrition Today, 50 (3), pp.117-128, doi: 10.1097/NT.0000000000000092.

27. Orgeret, G., 2008. Le sport est un médicament bio. Trouver le sport adapté à son état de santé. Paris: Ed. J. Lyon, pp.9-62.

28. Rada, C., 2015. How is leisure time spent in Romania, factors involved, Revista de Psihologie, 61(2), pp.85-96.

29. Rada, C., 2017. Impact of some demographic parameters on leisure time and body weight. Anthropological Researches and Studies, 7, pp.111-121.

30. Rogge, M.M., Gautam, B., 2017. Biology of obesity and weight regain: Implications for clinical practice. Journal of the American Association Nurse Practioners, 29(S1), pp.15-29. doi: 10.1002/2327-6924.12504.

31. Rothberg, A.E., McEwen, L.N., Kraftson, A.T., Fowler, C.E., Herman, W.H., 2014. Very-lowenergy diet for type 2 diabetes: an underutilized therapy?, Journal of Diabetes Complications, 28, pp.506-510.

32. Santos-Longhurst, A., 2017. Type 2 Diabetes Statistics and Facts. Health line. Available at: https://www.healthline.com/health/type-2-diabetes/statistics [Accessed 16 October 2017].

33. Sofi, F., Capalbo, A., Cesari, F. et al. 2008. Physical activity during leisure time and primary prevention of coronary heart disease: an updated meta-analysis of cohort studies. European Journal of Cardiovascular Prevention and Rehabilitation, 153, pp.247-257.

34. Teodorescu, S., Popescu, L., 2016. Considerations about equal opportunities in sport. Discobolul-Physical Education, Sport and Kinetotherapy Journal, Vol. XII no.2(44), pp.13-16.

35. Thanamee, S., Pinyopornpanish, K., Wattanapisit, A., Suerungruang, S., Thaikla, K., Jiraporncharoen, W., Angkurawaranon, C., 2017. A population-based survey on physicalinactivity and leisure time physical activity among adults in Chiang Mai, Thailand, 
2014. Archive of Public Health, 75(41), doi: 10.1186/s13690-017-0210-z. Available at: https://archpublichealth.biomedcentral.com/articles/10.1186/s13690-017-0210-z [Accessed 24 October 2017].

36. Watson, S.L., Weeks, B.K., Weis, L.J., Harding, A.T., Horan, S.A., Beck, B.R., 2018. HighIntensity Resistance and Impact Training Improves Bone Mineral Density and Physical Function in Postmenopausal Women with Osteopenia and Osteoporosis: The LIFTMOR Randomized Controlled Trial. Journal of Bone and Mineral Resources, pp.211-220, doi: 10.1002/jbmr.3284. Epub 2017 Oct 4. Available at: http://onlinelibrary.wiley.com/wol1/doi/10.1002/jbmr.3284/full [Accessed 24 October 2017].

37. *** American Diabetes Association, 2017. Physical Activity. What can physical activity do for me? Available at: http://www.diabetes.org/are-you-at-risk/lower-your-risk/activity.html [Accessed 16 October 2017].

38. *** American Diabetes Association.2017. Obesity Management for the Treatment of Type 2 Diabetes. Diabetes Care, 40(S1), pp.57-63. https://doi.org/10.2337/dc17-S010

39. ***European Commission. 2017. Eurostat Statistics Explained. Overweight and obesity - BMI statistics. Available at: http://ec.europa.eu/eurostat/statisticsexplained/index.php/Overweight_and_obesity___BMI_statistics [Accessed 16 October 2017].

40. *** Exercise is Medicine. 2017. Available at: http://exerciseismedicine.org/. [Accessed 24 October 2017].

41. *** Physical Activity Guidelines Advisory Committee. 2008, Physical activity guidelines advisory committee report. Washington DC: US Department of Health and Human Services Available at:https://health.gov/paguidelines/report/pdf/CommitteeReport.pdf [Accessed 24 October 2017].

42. *** World Health Organization (WHO), 2017. Diabetes. Fact sheet. Available at: http://www.who.int/mediacentre/factsheets/fs312/en/ [Accessed 16 October 2017].

43. *** World Health Organization (WHO), 2017. Obesity and overweight. Fact sheet. Available at: http://www.who.int/mediacentre/factsheets/fs311/en/ [Accessed 16 October 2017]. 


\section{Psychological profiling of participants at the Miss World contest via combined methodology: psychometric assessments and projective drawing}

DOI: http://doi.org/10.26758/8.1.10

Kristina Brajovic Car (1), Aleksandra Đurić (2), Oana Pănescu (3)

(1) Faculty for Media and Communication, Department for Psychology, Belgrade, Serbia; email: kristina.brajovic.car@fmk.edu.rs

(2) Belgrade business school - Higher education institution for applied studies, Department for Social studies, Belgrade, Serbia; email: aleksandra.djuric@bbs.edu.rs

(3) Spiru Haret University, Faculty of Psychology and Educational Sciences, Bucharest, Romania; email: oanamadeleine@yahoo.com

Address correspondence to: Kristina Brajovic Car; E-mail: kristina.brajovic.car@fmk.edu.rs

\section{Abstract}

Objectives. We are discussing psychological consequences of consequences of embracing dominant cultural values.

Among them, beauty and its constant visual (and superficial) presentation become imperative criteria for self-evaluation during the growing up process for young girls. Visual criteria are more strongly connected to the perception of self-image compared to the self-evaluation criteria that was relevant for adolescents in the recent past.

Material and methods. On the sample of 20 young women, in the process of competition for Miss World their individual aspirations and profiles were analyzed and compared with the cultural trend. Profiling was done via Machover test and diagnostic interview in line with the drawing output as well as the psychometric evaluation based on the Driver test (35Q) dominant defense mechanisms of personality. Comparative analysis of cultural trends and individual profiles was conducted through interpretative analysis of results collected during psychological profiling of contestants through the theoretical model of Transactional analysis. Transactional analysis of the famous fairy tale Cinderella was reinterpreted in the classical Berne approach in order to make it more relevant for the current problems and issues of young girls.

Results. The central theme is the self-image that is not matching calendar age. Graphical and phenomenological self-reports show that many participants perceived themselves as a child. Selfvalidation and social context interpretation come from the regressive frame of reference.

Conclusions. The results strongly support the hypothesis that beauty contestants need to be carefully selected, motivated and supported in this personality challenging qualification and evaluation process based on one dimension.

Keywords: self-image, injunctions, drivers, beauty pageant, adolescent

\section{Introduction}

Contemporary use of the term star does not have a long history. The emergence of a modern concept and the phenomenon of stars were influenced by the occurrence of mass media, as well as the development of consumer culture in the Western capitalist societies of the twentieth 
century. The term "star" refers to a person who has a set of characteristics that distinguish him/her from the general population. In describing the stars, adjectives such as fame, glamor, spectacular, respectable, famous, popular and similar are most often used.

A complex categorization of celebrities was given by sociologist Chris Rojek (2001). He refers to three types of celebrities categorized according to the status of accomplished fame: status is assigned by a blood link (royal family, powerful families of politicians or business people); status is acquired by work or talent (athletes, artists, successful business people, all those with a rare talent or skill); status is attributed thanks to the media and the public's attention, whereby a person may and may not have a specific talent and quality (Graeme, 2004). This category also includes participants of beauty pageants, as well as the Miss World contestants.

Celebrities who have gained fame through the attention of the media and the public, including the participants of the beauty pageants (even for a short time) have mythological figures of contemporary culture. According to German sociologist Leo Lowenthal, this transition from the "idol of production" to the "idols of consumption" marked a change in the moral and value system those are the contents that the audience can easily adopt by reading magazines and watching entertainment shows (Schmid, 2014). This kind of shows enables escapism to the audience, encourages and offers an illusion of participation in this glamorous world that brings satisfaction. On the other hand, the difficulties through which people pass, for example, at the Miss World contest, provide consolation and facilitate the identification process for the audience. At one level, participants in beauty pageants are unrealistic ideals, and at the second level - faults and weaknesses can be found in them. In this way, the media create the impression that there is actually no difference between "us and them," celebrities are the same ordinary people, with the same problems as everyone else. Becoming a celebrity is, therefore, a choice available to each of us. This is one of the key factors of the prevalence and intensity of the tendency towards media glory. "The idea that someone can build an identity by depicting someone else has created particular problems in contemporary society. The message that everyone can achieve a life of glamour and fame, if they choose, and make an effort, led countless people to neglect the essential elements of their lives searching for unattainable fantasy" (Salecl, 2014, p.51).

Consumer culture in many respects is referring to technology. Based on that fact consumer culture is also promoting the ability to quickly reject "the old" (goods, values, friends etc.) and even faster to accept "the new ones". According to Teodor Adorn and Max Horkheimer, culture is now subject to exchange, it is fully commodified, it has no longer usable value, and only the exchange value remains (Adorno and Horkhajmer, 1989).

Lifestyles are based on the social organization of consumption. In the contemporary culture of celebrities, dominant values and lifestyles are imposed through the media. We are living in a worldwide community made possible by media and internet, who influences the way we view men, women and family (Rada and Pănescu, 2016). Take, for example, competition for the Miss World, which offers a unique way of life and lifestyle, namely it provides accurate Instructions how people should look, behave, what kind of career they should have. This form of unification undermines the individual's identity and uniqueness.

The Miss World competition manipulates the lifestyle that relates to the exterior. Everything is spectacular, glamorous, but a certain pattern of appearance and behavior is imposed, and distributed through the media mostly to young girls, who then adopt and strive towards such a lifestyle. Today, in the culture of spectacle, instead of increasing the diversity of media content, uniformity is pursued according to the dominant form of sensationalism that gathers the widest audience. The world of spectacle has become a substitute for the grim reality that stuns people by 
keeping them in a state of passivity. The spectacle, which relies on the material-hedonistic value orientation, where conformity, orientation to the outward appearance, leisure life, entertainment and unrealistic desires are the basis of reality, has accomplished the tactics of its domination. It is precisely this form of cultural values that contribute to the development of narcissism (or reinforcing narcissistic predisposition) and pseudo identity in celebrities and people who look up to them and adopt their identity as their own. As for the beauty contests, the ones who look up to contestants are mostly young girls. Sigmund Freud (2011) distinguished primary and secondary narcissism. Primary narcissism is a normal development stage during childhood. Secondary narcissism occurs in adulthood. This narcissism is more of a pathological nature, because it refers to the conditions in which people are self-absorbed, incapable of empathy and interpersonal relationships, and approach people as means of meeting their needs. Narcissism is a love for oneself, for one's own personality. A moderate dose of self-love is necessary for a person to have a positive image of himself/herself. However, excessive self-esteem is considered a psychopathological phenomenon. The characteristic of pathological narcissism is that a person creates a grand self that characterizes omnipotence, expressed perfectionism, a strong motive for achievement, maintaining self-esteem by manipulation, exploitation, and underestimation of others. This self is merely a compensation for a genuine self of a narcissist personality that features a negative image of itself and the abundance of narcissistic injuries from childhood, a sense of emptiness, low self-esteem, a sense of pain, and fragmentation of a false image of oneself, which is built as a defensive mechanism.

Narcissism in the light of game analysis (Cinderella example). Here, as a symbolic illustration, we will show intrapsychic developmental challenges in the process of psychological development of the girl in the light of dynamic psychology and transactional analysis of the popular fairy tale - Cinderella. The analysis was carried out by the authors of the research as an additional qualitative research contribution and support to the interpreted conclusions of this paper.

The beginning of the drama starts with a psychological auto manipulated game "Poor me". Cinderella unquestioningly accepts her difficult fate by believing in her inferiority in relation to other family members. The way others treat her will determine her inner experience of her own value. In order to remain persistent in the role she has accepted, she must isolate all those needs that she acquired by birth - to be important to herself, to know what she feels, to openly seek and take what she needs. Fortunately, growing up and maturing nevertheless spontaneously inflict damage on her wrong decisions and negative adjustment of her personality to the unfavorable living condition. She begins to realize that a different life story, no matter how far from her, is still possible. There are "happy princes" but also "happy princesses" who do not hide in the ashes behind those whom they leave the role of "flamboyant villains" in order to preserve their innocent face and the public presentation of "martyrs". Those same villains do not lack initiative or willpower to live their lives according to their own choices. However, they are really the first to be criticized by the critics who watch the drama from the side. In spite of that, all villains are wholeheartedly accepted in the life of a Cinderella. They help her define and shape her weaknesses, fears, and insecurities, turning them into real virtues compared to the "bad" features of the people she is surrounded by. First of all, in her own eyes, she receives recognition of the identity of a "goody-good" and ceases to believe that she herself is not Ok, although others do not treat her well. I am Ok - others are not Ok, is the motto which she uses to protect herself against deeper injuries. Thanks to that, she has steadily built the identity of a "good girl" in her own eyes, but also in the eyes of the selected audience by the script. Regardless of the fact that those are birds, horses, dogs, and mice, as it is said in fairy tales, it is important that they are from the same story and share her viewpoint. After that, Cinderella is ready for new challenges of social reality. Finally, tired of the game "Poor me", she decides to take risks 
and openly seeks what she wants out of life: fun, opportunity, joy, play, pleasure, and related psychological needs in accordance with the development stage. Of course, she does not get what she seeks right away. Nothing new. "Cannot", "Not now", "Why you," "I won't," "I can't," "I don’t know" are just some of the frequent answers when a person needs the cooperation of others to realize his own intentions and ideas. Nevertheless, being free does not mean that the plan would be accomplished in any case. Even the refusal does not mean that "it shouldn't have been asked for". Anyone who is aware of what he really wants and believes he is entitled to it will find a way to get it. Even if it was with the help of the pumpkin, mice, and villas, as it is described in a fairy tale. Of course, leaving a bad life pattern does not mean jumping straight to autonomy. This is simply not the case, not even in fairy tales. So Cinderella withdrew from the game of "victim" for one night to experience how it is to be a "peasant woman". This is a metaphor, and the name of the psychological game designed by Eric Berne, not a derogatory word for a woman who is engaged in agriculture work. "Peasant Woman" has no confidence in herself, uncritically believes people of high status, keeps asking for advice of people who she believes are better and smarter than her, but in the end never listens or applies this advice, she doesn't even remember it, but instead she finds a way to quickly replace them with other eminent advisers or to discredit them as ignorant, even if she doesn't understand or listen to them (Berne, 1996). In the same manner, Cinderella celebrates the importance and significance of the success and value of the people who organize the event and come to such parties. She gives herself the right only to passively observe how others enjoy. And superficially, by her appearance, fits into society, but retains the feeling that she essentially does not belong to the world she admires the most. Today, Instagram would be a lot of help for her to build an image faster and easier to fit in wherever she wants, not even having to be exposed to the challenge of personal confrontation, or conversation.

Subsequently, there is another trap of the new script and dramatic turnaround. The Cinderella has succeeded much more than her original role of the Bystander imposed upon her (Clarkson, 1996). She managed to be noticed and chosen. It was for her capacities and experiences of herself a bit too much at the time, and she avoided a spontaneous and free encounter with the prince, saving herself from the risk of intimacy by the script of Almost. He almost met her and her truth instead of the Instagram picture, but she skillfully managed to escape. There was just one shoe left but it was not enough to know who she really was and to what extent she really was not what she represented.

A persistent prince does not stop here and does not agree to the game. Love pushes him to seek life more than a game. He conducts extensive research, after which, all false arguments and false representations dissipate. Simply, advertising is not sufficient, nor necessary, when we know exactly what we want, and what we do not want. And it is confirmed in the end, regardless of the fact that the sweat, blood, and tears are spilled on the advertisement, just like in the original fairy tale. This is the painful truth of advertisers in today's marketing perspective of all-pervasive digital communications and complete control of users over media and the growing control of consumers over purchasing choices. The one who has the ability to see and to know what he wants is inspiring enough to add to the confidence of those who do not have enough of it as well. There is no ash that could hide quality, nor deception that could mask a bad offer. Cinderella, therefore, reveals her noble person and interest, accepts the risk of intimacy, leaves the game, gives up Cinderella and Instagram beauty as well, and for now, there seems to be no objection.

Narcissism and the public self. After the transaction analysis of Cinderella, a popular narrative that is still developmentally relevant, especially in the psychological development of women, we return to a wider picture. Famous persons have dual aspects of identity - personal and 
public, or private and social. The difference between the individual and social identity can be explained as a distinction between the private and public sphere. The problem is that changes in the content, character and expression of one sphere leave the consequences in the way of expressing another sphere. A celebrity, in order to become one, often has to look and behave in a certain way, which is culturally defined, and media support and broadcast it all for the sake of profit. This uniformity is part of the social identity, that is, the public sphere of celebrities. When this sphere becomes dominant, and when individuality is suppressed, personality problems occur, or pseudoidentity is formed, which in the material-hedonistic value orientation and culture of spectacle is often shown through narcissism and self-absorption. The prescribed rules of public life are not authentic; an individual can achieve self-actualization only through personal experience, personal growth and development. Suffocating freedom in this way, cause or open repressed impulses of hatred and aggression that affect the creation of uniformed and unhappy people, who have suppressed their individualities and the need for personal growth and development, autonomy, firm identity, and integrity. Young people, especially girls, who look up to models, who are also very young themselves, rarely realize that their sense of self-confidence is conditioned by the opinions of others about them, and the behavior of others as well. Their self-respect is conditioned by the success in "managing the image others have about them" and that is the reason why fame is so important to them. It is not only a practical means of acquiring material profit, which may have been a primary motive, but also a means of confirming the importance and value of a person, first of all in their own eyes.

\section{Methodology}

\section{Objectives}

The general goal of this research was to explore in depth motivation and expectations among adolescent girls (from the age 16 to 21) that have chosen to enter a beauty pageant. Competing in sports is normally accompanied by psychological evaluation and preparation for any outcome, winning or losing. This is not the case with beauty competitions, generally speaking, at least not as a part of a standard protocol. We could say that during beauty contest, in particular where high stakes are involved (i.e. national ambassador of beauty), girls are exposed to situations which represent a stressor for them, without undergoing proper preparations or support procedures. In order to better understand the specific needs of a typical contestant, and for the purpose of proposing and developing an adequate response and support network, psychological testing was organized for the finalist, during the last phase of the competition. By that time, they all overcame the initial anxiety and adapted themselves adequately to the role.

\section{Material and methods}

Testing was performed through the application of the projective technique Human figure drawing - Machover test, followed by the semi-structured interview on the meaning presented in the drawing. Various projection drawings have been designed for assessing children's personality and psychological disorders including the tests of drawing a person (DAP). The validity and reliability of the DAP test are satisfactory (Rawley, 2005). This research protocol aimed at assessing the nature and quality of self-perception and self-awareness from the perspective of dominant life goals and values. The projective kind of technique is chosen due to the fact that it bypasses conscious resistance and does not provoke giving of socially preferred response. In addition, candidates were profiled on the basis of the two theoretically similar personality tests, based on the theory of the 
Transactional analysis, one of which was intended to measure dominant defense mechanisms of the personality (test Driver - 35Q), while the other test, Drego Injunction scale (Drego, 1994), was intended to measure a developmental deficit in terms of accurate self and others perception, social skills, and affective fluency and stability. Transactional analysis theorists and researchers consider five such clusters are universally present regardless of gender and national identification (Stewart \& Joines, 1987). In his empirical efforts to develop a scientifically valid driver instrument, Sandström (2015) created a test with the following psychometric characteristics: the values of Cronbach's alpha for the drivers as a measure of reliability for each individual sub-scale are: Hurry Up - 0.83; Be Strong - 0.80; Please Me - 0.82; Try Hard - 0.77; Be Perfect - 0.73. Study of these concepts in Serbia and Croatia gave results that indicate the need for further development of the psychometric characteristics of the Drivers test (Pejić et al., 2015). Drego's scale is a descriptive clinical inventory that is often used by transactional analysis clinicians as a naturalistic method for client assessment, with strong clinical and conceptual validity in quick client description, treatment orientation and understanding based on theory. Empirical validity of Drego's scale is yet to be psychometrically tested and improved by research and clinical application in different cultures, especially outside of the Western world.

As stated above, both tests have been administered previously on the Serbian sample where this research is conducted. Joint administration of these two instruments increased the validity of each of the tests used individually and added to the possibility of a broader understanding of participants' capacity to overcome stress, their dominant interpersonal style and grounding for the sense of self. A total of 20 subjects completed all questionnaires.

Research protocol. Testing was carried out in the presence of psychologists and other subjects, that is, in a group context. The time they needed to complete the tests was 80 minutes, since they were interacting with the examiner so that all the uncertainties related to certain questions and instructions were clarified. This ensured the quality (credibility) of the obtained results and their further usability in the analysis of individual differences, as well as the similarities in the personality profile among the participants.

\section{Results}

The results are given in the form of the narrative summary, containing the crossinterpretation of the results obtained with all three psychometric tools. The reason for the application of combined methodology and narrative analysis of results was to better describe and explain the individual differences between the tested subjects, while, at the same time, narrative analysis provided an insight into some common themes and trends in all the answers given by the participants that came from the same sample group.

In what follows, we will present two illustrative narratives, from a sample of 20 participants, contestants of the Miss World Competition, as a support to the conclusions drawn on the basis of the thematic and interpretive analysis of all the profiles obtained.

Profile of the participant A.Ć. in a narrative form:

High expectations of herself have been taken over by others. The basic motive is to get approval and acceptance from her environment. The participant is not set up independently in her plans. Her success and engagement are conditioned by the circumstances, permissions and encouragement that she seeks of others. Contact with reality is not her strong side; she rather leaves the assessment to others. In trying to respond successfully to others' expectations of herself, she may seem false, 
alienated, rude, distanced or uninterested. As for her authentic expression of personality, the drawing reveals a sense of herself as an "awkward child, stopped in the game".

Profile of the participant T.P. in a narrative form:

Extremely high ambition, as well as expectations from herself. She is strict towards herself, with strong self-criticism. With this profile of personality, responsibility and reliability go together as related characteristics. She does not forget her own failures, nor does she like to be seen and treated as if she were a child (a girl). Self-perception of herself is ahead of her years (she considers herself a "powerful woman", as she states). There is a noticeable conflict within her personality at the level of self-image. On one hand, there is a vision of a powerful woman, and on the other hand, a graphic representation and an accompanying interview show the perception of herself as a playful, carefree and lazy child. It could be assumed that this is exactly the side of her personality she is trying to hide in self-representation. The closeness with others is not valued as a quality, nor is it initiated. She relies more on herself.

Profile of the participant A.Z. in narrative form:

Anxiety and mistrust dominate above other personality traits in this particular psychological profile. In the first place because of other people opinion and acceptance, the interviewee wants to be successful (even perfect, as she claims). It is noticeable that she appreciates the efforts more than the results, which diminishes her ambition on the long run. Self-perception is such that she sees herself as an immature person. From the drawing, we can see that human figure corresponds to the girl's appearance, without any signs that the figure would indicate the self-perception as a girl who is growing into adulthood. The primary criterion in perception and evaluation of oneself is aesthetic in nature. In relations with others, she is presenting her flexibility, poor self-confidence, and unclear personal goals.

Profile of the participant M.N. in a narrative form:

Results point to Introversion in social situations and avoidance of self-analysis and critical review of herself. Primarily, what is important to interviewee is that her performance helps her in seeking of love and acceptance from the people that are close to her. On the other hand, it seems that she does not give herself the right or permission to be open and spontaneous in social situations. Selfconfidence is unstable, "shaky" because it strongly depends on "how others see me." This is not seen in the initial impression based on her appearance by which she is trying to control and hide emotions and strives toward perfectionism. Female figures from her immediate social environment are perceived as the most important role models and support. Striving toward perfection is the dominant defense mechanism reflected in her answers and self-presentation.

Profile of the participant A.S. in a narrative form:

The interviewee has not developed autonomous motivation or her own assessment criteria. She is directed toward others in that sense, which is in accordance with her adolescent phase (being the youngest among the contestants). Analysis of the drawings shows the active interpersonal conflict between two dimensions of the identity (pupil versus professionally engaged individual). In her drawing, she presented herself as an older girl, with a book in one hand and a purse in the other (the symbols of two different tendencies). Motivation is partly irrational ("to be memorable"), especially after comparative analysis of the different results (DAP, Driver and Injunction tests), which point to insecurity and low self-esteem. 
The central theme dominating the majority of answers is the self-image that is not in line with the actual age. Graphical and phenomenological self-report indicates that almost all participants (16 out of 20) perceived themselves as children. That means that self-validation, as well as social context interpretation, is oriented within the regressive frame of reference. In most of the cases, "others" are perceived as threats, while also being granted more power and control compared to the control function attributed to oneself. The results of the interviews show high level for the injunctions - Don't grow up, Don't be you and Don't think. Also, dominant drivers observed are Be perfect, Please others and Try hard. The results clearly support the initial hypothesis that beauty contestants, still in their adolescent and post-adolescent years, need to be carefully selected, motivated and supported in these psychologically provocative situations, such as evaluation and qualification in one-dimensional perspective.

\section{Discussions}

Fame gives the participants of beauty contests (which include Miss World competition) the illusion of being in the center of the world, but, in fact, they are being alienated from the world and themselves as well. The material and hedonistic system of values, the culture of spectacle, the orientation to the exterior, the tendency to fulfill the abundance of desires and desires without delay, media exposure and loss of privacy in order to gain and maintain fame are dominant. All this leads to narcissism or intensifies the already existing narcissistic predisposition in which case identity is connected with the fact to what degree they are accepted by the public and exposed in the media. Here we can speak of the functions of the internalized psychological injunction "Don't Be Important", because people with expressed narcissism as a characteristic (or mechanism of defense in this case) view their sense of identity and values through the prism and opinion of others. For this reason, they are often surrounded by people who would confirm ideas about their "Grand Self". In addition to transactional analysis with interpretation based on concept of Drivers as irrational motivators developed during formative years in reaction to a persistent exposure to social stressors and psychological challenges, we can found theoretical base for associations between sociopsychological deficit, fear of rejection and development of "Grand Self" also in the theory of interpersonal psychoanalysis (Horney, 1937; Sullivan, 1953.). Horney's classification of intrapersonal defense mechanisms, as reactions to an early experience of hostility and threat of rejection, names "self-investment into status and material profit" as one of four different ways to adapt in situations where lack of trust and hope are experienced by a person during developmental years (Chang \& James, 1987).

Money and fame are social, external motives, but there are other, deeper, psychological reasons that lie at the basis of their desire for media exposure. A histrionic personality disorder is closely linked with narcissism. A histrionic personality wants to be always at the center of attention, these individuals often act aggressively and egocentrically and need to feel that "everything revolves around them." They want everyone to love them, to admire and to adore them. They really want recognition. They handle situations in which they do not get what they want with difficulty. These people are too social, often seductive, everything around them is exaggerated, especially emotions. They change their mood often; from the greatest euphoria they fall into the deepest depression. The authors of personal adaptations concept in transactional analysis (Joines and Stewart, 2015) argue that at the basis of this structure of personality lays the fear of rejection that is deeply hidden from self-awareness by intrapersonal dynamics. As children, these people did not get enough love and attention. Here you can recognize a psychological ban, do not be what you are, but be what others expect from you, because this is the only way that this person thinks he can get love and attention. 
Based on the theory of life script analysis, we can say that, in time, these people create beliefs about themselves and others that only if they are liked by everyone, they would be loved. Growing up, their fears have reinforced, as well as the need to impress others. It has become the only way to avoid what they are most terrified of - to be alone and unloved.

The assumption is that one of the main motives that famous people have is the strong psychological need for attention. The need for provoking attention that some famous people have is almost pathological, and their symbiosis with the media is a way to get that attention. Due to the introjected "Don't Be Important" ban, attention is being sought and obtained in an inauthentic way, and thus it is not valued by the person who seeks it pathologically.

Drivers are also important concepts of Transaction Analysis in work with celebrities. Drivers are visible in behavior and represent a certain, predictable behavioral pattern adopted in childhood that has adaptive function for the personality, but inhibits authentic reactions. By conducting Driver Test 35Q, we examined the dominant drivers among the respondents. Driver "Be perfect" can be perceived through focus on appearance and obsession with oneself. The most common attributes of the "Be perfect" driver have to do with performance and appearance; being spotless, clean, with a perfect presentation for others. Narcissistic and histrionic people often manifest this driver, which they project on the outside environment. Striving for perfection or showing the person as perfect is closely linked with the phenomenon of selfie. As for selfie, actor James Franco says: "Selfie is an avatar, a mini version of us, a way to let others know who we are. At a time when the sea of information is available only with a mouse click, the power of attracting the audience is a real power. Selfie attracts attention, and attention is the key word. It is a kind of pseudo-privacy. Selfie is in the era of social networks a way to say - hey this is me" (Džejms, 2014, p.45). The results show that's exactly the same psychological effect the respondents from the sample are trying to reach, only in the traditional way (such as the Miss World competition).

\section{Conclusion}

By analyzing the professional texts (Đurić, 2015) one can conclude that the pseudo identity celebrities build provides a false and ephemeral feeling of security, value, and self-confidence. The psychological need for growth and development and the realization of all the potentials that a person possesses can be suppressed, and the need for love, attention and personal worth can be achieved in an unauthentic manner through symbiosis with the media, success can be equated with fame, but in spite of this, basic needs cannot disappear because they are immanent to human nature.

Numerous studies, as this one, suggest that this kind of pseudo-identity among famous

people can cause the appearance of narcissism or reinforce the already existing narcissistic and/or histrionic personality structure, since narcissism has the character of a defensive mechanism. Transactional concepts, such as bans, drivers, psychological games, and life script analysis, aim to uncover the mechanisms of personality dysfunctions in order to provide incentives for the development of authentic forces in person. According to Eric Berne (Berne, 1996), consciousness, spontaneity, and intimacy are basic forces of the autonomous personality.

Advisory and if necessary psychotherapeutic, the strategy for the psychological problems that this research has dealt with, regarding the developmental and psychological vulnerability of young adult women in the light of the popular culture and its negative impacts on personality, implies that in addition to working on the raising the awareness of psychological bans, it is also necessary to perform the analysis of life script, as well as the decontamination of the ego state Adults. The functionality of the ego state Adults is significantly reduced under the influence of life script that is detected as a pattern within the sample, the participants of the study. Then, a therapy 
that follows involves working on a new decision as the antithesis of the script beliefs along with the strengthening of Nursing Parent, who should support a new decision and strengthen the ego state Child by functioning in accordance with the new decisions about a change (Erskin and Morsund, 2015).

As a reminder, all aspects, such as socio-economic, cultural and educational, are inseparable from the individual and vice versa. Personality cannot be developed in isolation, and therefore communication is a basic condition for the development of personalization. Social existence and activity are a necessary precondition for the realization of one's personal life. Therefore, the private and public sphere of personality should not be in dichotomy. Personality achieves its integration when it succeeds in developing its specific abilities and autonomy.

\section{Bibliography}

1. Adorno, T. and Horkhajmer, M., 1989. Dijalektika prosvetiteljstva (Dialectics of Enlightenment), Sarajevo: Veselin Masleša

2. Berne, E., 1996. Games People Play: The Basic Handbook of Transactional analysis. New York: Ballantine Books.

3. Chang, V. and James, M., 1987. Anxiety and projection as related to games and scripts. Transactional Analysis Journal. 17(4), pp.178-184.

4. Clarkson, P., 1996. Bystander games. Transactional Analysis Journal, 23(3), pp.158-172.

5. Erskin, G.R., and Morsund, P.Dž., 2015. Integrativna psihoterapija na delu (Integrative psychotherapy at work), Translation from English by Milan Djurisic, Novi Sad: Psihopolis Institut.

6. Drego, P. 1994. Changing systems through correlations of injunction inventories with analyses of myths and songs. In P. Lapworth, ed. The Maastricht papers: Selections from the 20th EATA Conference, 10-1 July 1994. Amersfoort, Netherlands: Yvonne van Praag. pp. 5-19.

7. Freud, S., 2011. Kompletan uvod u psihoanalizu (A complete introduction to psychoanalysis), Prosveta, Beograd.

8. Graeme, T., 2004. Understanding celebrity. London: Sage.

9. Horney, K. 1937. The neurotic personality of our time. New York: Norton \&Co.

10. Rada, C. and Pănescu, O.M., 2016. Psihologia, psihoterapia familiei şi cuplului. Teorii, cercetări, intervenţii (Psychology, psychotherapy of family and couples. Theories, research, interventions), Bucureşti: Editura Universitară.

11. Pejić. M., Brajović Car, K. and Ellersich, P. 2015. The Psychometric Properties of the Driver test Q 35 in Serbian and Croatian Sample (Poster). University of Zagreb, Faculty of Humanities and Social Sciences, Department of Psychology, 22 ${ }^{\text {nd }}$ International Scientific Meeting in Psychology "Ramirez and Zoran Bujas'days", Zagreb, Croatia.16-18 April 2015.

12. Rawley S. 2005. Aggression and depression assessed through art: Using draw-a-story to identify children and adolescents at risk. New York and Hove: Brunner-Routledge.

13. Rojek, C., 2001. Celebrity, London: Reaktion Books

14. Salecl, R., 2014. Tiranija izbora (The tyranny of choice), Beograd: Arhipelag.

15. Sullivan, H.S., 1953. The interpersonal theory of psychiatry. New York, NY, US: W.W. Norton \& Co.

16. Čejni, D., 2003. Životni stilovi (Lifestyles), Beograd: Clio Publisher.

17. Džons, V., Stjuart, I., 2015. Tipovi ličnosti (Types of personality), Novi Sad: Psihopolis Institut.

18. Đurić, A., 2015. Medijasfera u zagrljaju Velikog brata (Media-embraced Big Brother), Beograd: Čigoja štampa. 
19. Džejms, F., Selfi kaže ovo sam ja (Selfie says this is me). Available at: $\langle$ http://www.politika.rs/rubrike/spektar/digitalnisvet/selfi-kaže-hejovosamja.It.html > [Accessed 22 February 2017].

20. Schmid, D., 2004. Murderabilia: Consuming Fame. M/C Journal, 7(5), Available at: <http://journal.media-culture.org.au/0411/10-schmid.php> [Accessed 14 April 2017].

21. Sandström, S., 2015. Transactional Analysis Driver Test, Available at: $\langle$ http://tadrivertest.com/en/page/13 > [Accessed 10 February 2015]. 


\title{
Gender and culture-related barriers to access to mother and infant health services in the Far North of Cameroon
}

DOI: http://doi.org/10.26758/8.1.11

Anita Nudelman (1), Deli Tize Teri (2) and Yafflo Ouattara (3)

(1) Ben Gurion University, Israel

(2) University of Yaounde I, Cameroon

(3) Joint United Nations Programme on HIV and AIDS (UNAIDS)

Address correspondence to: Anita Nudelman, Ben Gurion University, Israel, e-mail: anitanudelman@gmail.com

\begin{abstract}
Objectives. The Far North region of Cameroon has one of the highest neonatal, child mortality and poverty rates in the country. The aim of this study was to understand the gender and culture-related barriers to women's utilization of RMNCH (reproductive, maternal, neonatal and child health), including HIV services.

Material and methods. A participatory qualitative Rapid Assessment Process (RAP) was used and team members included women from the communities involved.

Results. Diseases affecting infants are explained by causes ranging from bad nutrition to sorcery and angry ancestors' spirits and traditional treatments are often preferred over medical services. Pregnancy is considered a natural state and a "women's issue", which is accompanied by cultural and religious norms that protect mother and fetus. Many women give birth at home with traditional birth attendants, who are trusted and follow accepted practices. Pregnant women living with HIV fear disclosing their status since this may lead to stigma and discrimination. Unequal gender power relations - including financial dependency on the husband - pose an additional barrier to service uptake, further enhanced by low male involvement in pregnancy-related health services. Lack of respect and confidentiality by health providers, associated with low-level availability and accessibility of services may also discourage their uptake.

Conclusions. The implementation of the RAP findings may enable innovative ways to increase culture and gender sensitivity of RMNCH services, including prevention of vertical transmission of HIV, in communities in Far North of Cameroon.
\end{abstract}

Keywords: RMNCH; culture; gender inequality; HIV; barriers to health services

\section{Introduction}

In many countries, especially in the developing world, women and children do not utilize available and essential health services due to a myriad of gender and socio-cultural barriers (Grieg et al, 2008).

Cultural perceptions, traditions and gender norms are an integral part of communities' way of life. They shape and influence daily activities, including accepted behaviors related to diseases, pregnancy, and childbirth as well as the selection of health care providers and treatment (Lori and Boyle, 2011). In some societies, unequal gender power relations reflect accepted gender roles that, 
combined with economic, political, and social factors, may pose serious barriers to access infant, child and maternal health services, including HIV related ones. For people living with HIV and AIDS (PLWHA), cultural barriers are further enhanced by the fear of stigma due to HIV disclosure and concomitant lack of support by partners, family, and community (Elwell, 2016; Gourlay et al, 2013).

Additional barriers to health services may arise from patient and provider's different cultural backgrounds, socio-economic and educational levels, and disrespectful attitudes and lack of confidentiality of some health providers (Karamagi et al, 2006). Among women living with HIV, these barriers are increased by the fear being stigmatized and discriminated against, thus deterring them from accessing specific health services (Painter et al, 2004; Reis et al, 2005). Furthermore, access to health services may also be influenced by their availability and accessibility, as well as by the quality of services available.

Maternal and infant mortality remain highest in developing countries due to barriers to utilization of health care (Cheptum et al, 2014), having hindered the Millenium Development Goals 4, 5 and 6, as well as mother to child transmission of HIV (United Nations, 2016).

This study was initiated by UNAIDS for the Sida/H4+ project (WHO, 2015) to accelerate the reduction of maternal, neonatal and infant mortality, as well as eliminating vertical transmission of HIV and reducing AIDS-related maternal deaths by half (UNAIDS, 2011). It focuses on the gender and culture related barriers to uptake of Maternal and Child Health services in the Far North Province of Cameroon, which holds a population of 3.8 million (approximately $18 \%$ of the national population), encompassing more than 50 different ethnic groups and religions such as Christianity, Islam, and Animism. The local economy is agro-pastoral, based in sustenance farming, with an incipient tourism industry which has decreased since 2014, due to the Boko Haram insurgency spilling into Cameroon from neighboring Nigeria (Rackley, 2017).

The study focuses on five-high need health districts in the Far North region: Maroua rural, Maroua urban, Guidigis, Moulvoudaye and Koza. These districts were selected due to their low coverage in health interventions, high proportion of home deliveries, low contraceptive prevalence rate, high neonatal and child mortality rates, and the highest prevalence of poverty in Cameroon (INS, 2011).

Maternal, infant and child health services are highly underused in this region, not only due to objective reasons but because they are often not gender and culture friendly (Bonono and OngoloZogo, 2012). Thus, the exploration of culture and gender barriers to services could contribute to a more context-sensitive healthcare enhancement, as well as to the decrease of maternal and infant morbidity and mortality, including prevention of mother-to-child transmission (PMTCT).

\section{Material and methods}

The Rapid Assessment Process (RAP) was the methodological approach chosen to understand the gender and culture related barriers to women's use of maternal and child services (including HIV ones) in three representatives sites within the selected health districts in the Far North region of Cameroon: Maroua (both urban and rural), Guidiguis and Koza. This method had previously been used in a similar study initiated by UNAIDS in specific sites in five high burden countries, most of them in Africa (Nudelman, 2013). The Rapid Assessment Process is an intensive team-based qualitative technique to quickly develop an understanding of a situation from the insiders' perspective (Beebe, 2004). Instead of extended fieldwork, it is based on intensive and participatory team interaction and multiple cycles of data collection followed by analysis (Scrimshaw et al, 1991). Therefore, the team trained for the project was entirely composed of 
members native to the Far North, and although some did not currently reside in the region, they had close ties to the communities assessed since they had all grown up there and returned frequently to see their families. The team included community women from the different sites whose insight and participation proved to be invaluable.

The ethnicity of the participants - including key informants and Focus Group Discussion members - varied across the RAP sites. In urban Maroua, the RAP included participants from heterogonous ethnic groups such as Peul, Kapsiki, Mousgoum, Guizigua, Kanouri and Moufou. In rural Maroua, the ethnicity of most participants was Guizigua and Moufou. In Guidiguis, participants were Toupouri and Massa, while the participants in Koza belonged to the Mafa ethnic group (Boutrais 1984).

The study focused on the barriers to services in selected sites and not on an in-depth study of specific ethnic groups since access to services was similar across them.

The purpose of the Rapid Assessment Process was to explore the barriers from women's and communities' perspectives in order to promote gender and culture-sensitive health services. Fieldwork was conducted in April 2014, encompassing 132 participants who were interviewed either in-depth or in focus group discussions. It included key informants (community leaders and health providers), pregnant women, mothers of small children (some living with HIV), male partners as well as other men from the community. The interview guides were culturally adapted by the research team and translated into Fulfulde, the local language in most of the rapid assessment sites. An additional 18 community members were interviewed informally.

\section{Results}

\section{Barriers to the use of maternal and infant health services, including PMTCT}

The access and utilization of health services were influenced by different barriers, which resulted from a combination of factors, such as poverty, a weak health system and socio-cultural barriers, including fear of stigma and discrimination related to HIV. In addition, certain traditional cultural perceptions may influence a woman's decision to attend a health facility for an antenatal visit or for childbirth (i.e. considering that it is natural to deliver at home), while gender also plays an important role in some of the aforesaid factors. For example, women may not disclose their HIV status for fear of abandonment, loss of economic support, emotional and physical abuse, and discrimination (Medley et al., 2004). The findings will be presented in 5 categories: (1) Barriers related to socio-cultural perceptions; (2) Barriers related to gender roles and low male involvement; (3) Barriers related to perceptions of health services and providers; (4) Fear of disclosure, stigma, and discrimination and (5) Lack of resources, poor infrastructure, and poverty

\section{Barriers related to socio-cultural perceptions Barriers related to the perception of diseases}

The rapid assessment's findings indicate that wide-spread diseases affecting infant morbidity and mortality are often explained by causes that range from bad nutrition to sorcery. In general, treatments for these diseases in the different communities range from auto-medication to traditional practices, according to the perceived illness causation, with official health services as the last option.

Some diseases, such as tandaw (a type of mycoses) and bedel (a stomach disease), are believed to be caused by angry ancestors' spirits due to lack of sacrifices in their honor nowadays: 
"Before, we used to sacrifice cocks (roosters) next to the water source in the mountain so that it would not dry up; or we cracked eggs instead. But, for a few years already, this rite has not been kept." (Male FGD, rural Maroua)

Therefore, it is believed that if children suffering from bedel go to a hospital, the disease may get worse and even cause death, since according to the community's perceptions, bedel does not like injections or white man's treatment and only requires sacrifices or scarification.

Among some of the communities assessed, malaria is believed to be caused by eating raw vegetables, millet stems, and sour milk:

"At the beginning of harvest season, the children here eat many millet stems. There is a type of wild millet which has a sweet stem-like sugar cane, called "tchibe" or "lewlewa" amomg the Kapsiki. Parents cultivate them and often sell them in the village or the market. Among us, the harvest season of these stems is always accompanied by malaria epidemics." (Woman, urban Maroua)

Considering the aforesaid, malaria is often perceived as a regular seasonal disease that can be treated and will eventually pass, and thus it is not considered necessary to access a health facility:

"In this village, there are traditional healers who are very efficient; if you have simple malaria, they give you a medicine and you are cured." (Male FGD, rural Maroua)

Although many participants are aware that malaria is transmitted by mosquitoes, nets may not be used due to the belief that they are sprayed with toxic materials or that they are distributed by the white man to kill black people, a belief which is also common to some perceptions of the origin of HIV in Africa (Rodlach, 2006).

"What is given free of charge, is surely harmful (so beware and do not use it)." (Woman living with HIV, Maroua)

Knowledge and perceptions of HIV/AIDS vary across the different sites, and this disease was practically unknown in some remote rural areas. Nevertheless, local names for the disease both reflect and influence cultural perceptions of HIV. For example, it is often referred to as "plastique", which is also an incurable disease that kills animals (through slow waste and diarrhea) that is believed to be caused by eating plastic or "leda". In addition, beliefs about HIV's origins and modes of transmission, such as being caused by sorcery or a punishment from God, tend to reinforce fears and stigma, while posing barriers to service access:

"The disease is the consequence of the sins and the sign of the end of the world. In fact, diseases and disasters are an announcement or the signal of Islam's prophecy. Allah will not change as long as the community does not change its ways." (Imam, Maroua)

These beliefs also pose barriers to attending an antenatal consultation or "kilo", which participants usually equal to testing for HIV since it is a standard practice to test all women during antenatal consultations (ANC).

Considering the widespread perceptions and beliefs related to HIV, culturally-appropriate treatments are often preferred over the modern anti-retroviral one and may include Christian and Muslim prayers, as well as the use of traditional medicine. 
For some Christian revival Churches, the treatment is through prayers. Thus, the faithful can obtain a cure to HIV through their belief and confidence in God:

"I know two sisters in Christ who were found to be HIV positive. They belong to our Church. The Church's faithful fasted and prayed for them for days. After that, they were tested again three times, and at the end the result became negative." (Female FGD, urban Maroua)

\section{Barriers related to perceptions of pregnant women and childbirth}

Pregnancy is viewed as a natural state, a "benign disease", and considered a women's issue. Many cultural and religious norms must be kept during pregnancy in order to protect the mother and the fetus from dangers, mostly concerning nutrition and behavioral taboos. Such practices do not necessitate the use of health services:

"A pregnant woman should not eat large lizards (varanus), locusts and certain other animals such as rabbits. According to the tradition, the newborn child can look like the animal the mother ate or it will make the child very thin." (Woman, Guidiguis)

Regarding pregnant women living with HIV, some of them felt ashamed and feared to disclose their status since they may be considered immoral and irresponsible by community members because their babies will inevitably be born HIV positive and will probably die soon after birth:

"A pregnant woman who is seropositive is a criminal because her days are numbered. She will die and abandon her baby." (Man, rural Maroua)

In addition, women living with HIV are often rejected and even isolated, especially in polygamist families:

"People keep away from me. When I prepare food, the neighbors and even my brothers tell their children not to eat my food." (Woman living with HIV, Guidiguis)

Modern family planning is not a developed maternal service in the region, with the exception - to a limited extent - of Maroua city. In a society where children (especially boys) are highly valued and considered a sign of richness, it is usually the man's prerogative to decide on this issue. Nevertheless, traditional ways of spacing children exist, involving "marabous" (traditional healers) and some traditional birth attendants:

"I can hinder a woman from (getting pregnant) giving birth for some years, but it depends on couple agreeing to this. If a woman comes to see me with her husband to space out their children, I will do it! '”(Traditional birth attendant, Koza)

\section{Gender roles and low male involvement}

In line with culturally accepted gender role norms and expectations, a woman is expected to be subservient, and socially and financially dependent on her husband and in-laws. Thus, unequal gender power relations can pose a significant barrier to maternal health services, considering that the husband is traditionally the main decision-maker in the family and his consent is required for a woman to access them. Men may oppose antenatal visits due to a combination of factors, such as 
lack of gender and culture-appropriate treatment at a health facility, where male nurses treat Muslim women (and may also see them naked):

"Yes some Muslims do not accept that the men (male nurses) handle their wives. But it is not the religion or the Islam which forbids, it is the men themselves who are against it. In order to solve this problem, we have created a maternity clinic here in Bamaré quarter and we have female nurses." (Religious authority, Maroua)

These barriers can be further reinforced by lack of trust in the efficacy of the services, as well as the unwillingness to spend money on transport, which is a husband's prerogative in the patriarchal family structure in this region:

"...for example, I asked my husband for money, he refused. I wanted to trade (in order to get money for transport) he also refused. So with what can I go to the antenatal consultation?" (Pregnant woman, urban Maroua)

If a woman disobeys her husband, she may be at risk of physical or emotional abuse and even abandonment:

"One night, I was beaten by my husband because I had suggested going to the kilo (antenatal consultation). As my husband knew that I would then ask him for money for the kilo, he began to beat me." (Female FGD, rural Maroua)

HIV was also found to have a gender connotation, since it is considered a female disease, mostly transmitted by women:

"Women refuse to get tested here in the Far North because they are afraid to find out their status. Women are often accused of being the vector that transmits the disease. Therefore, if a woman decides to be tested, she will be afraid of stigma. If she finds out that she is seropositive, she is forced to hide her status to avoid being divorced." (Woman living with HIV, urban Maroua)

Male partners' limited participation in issues related to pregnancy and childbirth, both at home and during women's visits to health facilities, poses an additional barrier that may discourage service uptake - including PMTCT. This is strengthened by the widespread perception that issues related to pregnancy and childbirth are "women's business" (which is an accepted gender role). Furthermore, some men refuse to get involved due to fear of social embarrassment, since a man who accompanies his wife may be viewed in a negative way by the community and considered "a man dominated by a woman". Thus, men often discourage maternal and HIV service uptake or do not provide their wives with the necessary emotional and logistical support.

A different view was expressed by a health provider in urban Maroua, who suggested that if men got involved, maternal health service utilization might increase:

"Men should become aware that the hospital is a good thing, otherwise the women will not change. It is the man who decides and if he asks his wife do some thing or other, she will do it (related to pregnancy, etc.). If men join women, things will work out”. 


\section{Barriers related to perceptions of health services and providers}

The adherence to cultural norms and beliefs that may conflict with medical treatment is sometimes reinforced by mistrust of health providers, further discouraging visits to healthcare facilities. Thus, women often prefer to continue with traditional birth practices:

"Women are used to delivering their babies well at home; so, the community does not see the importance of going to a hospital." (Health provider, Koza)

"I never go to the hospital for delivery. I do it like going to the toilet (squatting) and I deliver. Why is it important to go to the hospital?" (Woman, Guidiguis)

"A long time ago, a 'Mitsekar' Mafa clan ancestor declared that the (clan's) daughters must give birth at home; following the death of a pregnant woman due to exhaustion on the long way to give birth in the hospital. Since his message, some families continue to give birth at home to avoid a curse (from the ancestors) to befall their families." (Female FGD Koza)

Although sometimes antenatal services were encouraged by providing incentives and small gifts to women, they are not consistently used, except in case of emergencies. Even women who attend antenatal consultations tend to give birth at home, assisted by traditional birth attendants (TBA), who are familiar and well-respected members of the communities, follow socio-cultural norms, and are trusted.

Health services in some rural areas are almost inexistent or can be very distant. In urban areas, many women prefer private facilities to government ones because of the quality of services and the friendlier attitudes of the health providers:

"At the central hospital, there are no chairs for us to sit on! The women are (waiting) in the sun and nurses do not even look at you!'” (Woman, urban Maroua)

This is further compounded by previous experiences of being badly treated while accessing modern maternal services. Some pregnant women indicated that they were not treated respectfully or were often insulted, increasing the barriers to services:

"Nurses mock women here in Koza. They often say: 'we are going to operate a bull' to describe a pregnant woman who has a big body or 'we are going to operate a goat' to describe a pregnant woman with complications." (Traditional village chief, Koza)

"Male nurses sometimes laugh (mock) at the nudity of the women who come to give birth in the hospital. After the delivery, they stay to discuss and to describe what her genitalia looks like. The professional secrecy is not guaranteed! They report everything they see in the village. That is why some women do not go to the hospital." (Woman, Guidiguis)

Thus, negative attitudes furthered by lack of respect and confidentiality by certain health providers - mainly in public health facilities - pose a major barrier to maternal services in some communities. Naturally, women turn to traditional birth attendants, who are more familiar and supportive.

Although antenatal and natal services have a low utilization rate in the Far North Region, postnatal ones are accessed more frequently. These services enable mothers to obtain vaccination 
carnets, as well as birth certificates for their babies (necessary for benefits and bureaucratic issues, such as registration for school).

\section{Fear of disclosure, stigma, and discrimination}

Women usually become aware of their HIV status when they attend antenatal consultations or give birth since testing for HIV is a standard procedure. The test results are sometimes disclosed without counseling or in insensitive ways, by informing a woman: "You have AIDS", which can further increase her fears and distress.

Social stigma is the main cause due to which participants living with HIV failed to disclose their status to their partners, families and other community members. Women living with HIV generally faced more barriers to treatment than males, due to cultural perceptions of gender roles that tolerate male, but not female infidelity:

"If a man gets infected with AIDS, the community considers he did it because he succumbed to temptation. But if it is a woman, it is a sin because she does not have the right to do things out of wedlock." (Religious Authority, urban Maroua)

The fear of gossip and disclosure is particularly difficult for women, who may fear violence or abandonment by their partners if their HIV status is revealed:

"A woman is much more exposed (than men) to the whispers (gossip) of the people around her." (Woman, urban Maroua)

This barrier is further enhanced since pregnant women living with HIV-as well as their male partners - fear that their status may be revealed if they are seen attending a specific health facility that is associated with HIV. For instance, in some health districts, maternal services are exposed to the public, so women who come to be tested for HIV are received in groups in open spaces, without respecting their privacy:

"When we pass on the road, we see the women under the shed in the hospital. The women don't want people to know that they came for the "kilo" (testing) in a place like an ANC or a health center that symbolize HIV positive." (Woman, Koza)

Women living with HIV are sometimes also stigmatized by health providers. A few were offensive towards people living with HIV who came to collect their antiretroviral medicines:

"Because patients get impatient while waiting for services, she (a nurse) told us in a loud voice: 'it is not me who sent you to get AIDS: That shamed us and discouraged others to come and get their medicine. Fortunately, she was chased away from the hospital." (Woman. urban Maroua)

Thus, negative attitudes and the breaches of confidentiality by some health providers can pose a strong barrier for women living with HIV to attend health facilities. Furthermore, the distribution of antiretroviral medicines often tends to be irregular, with people living with HIV being shuffled from one health center to another. This results in a loss of time and resources while increasing the visibility of women living with HIV (and concurrently their stigmatization), as well as their negative perception and their utilization of HIV services. 
In many communities, there was little information about vertical transmission of HIV or PMTCT treatment, with most exceptions in Maroua city.

\section{Lack of resources, poor infrastructure, and poverty}

Participants' financial constraints pose a barrier to access maternal and HIV health services and are also associated with the low level of services available and the shortage of trained personnel and medicines. Some women complained of visits to undersized, underequipped, and understaffed health facilities, in which services were not adequate. In certain remote areas, the complete lack of availability of services led to increased difficulties in travel and additional expenses:

"The reason people refuse to go to the hospital is the lack of financial means ... the high cost of the antenatal consultation limits their attendance, since here women are not emancipated enough to create jobs and provide for their own needs." (Female FGD, woman, urban Maroua)

For women in some villages in rural areas, the distance to the nearest basic health facility ranged from $15 \mathrm{~km}$ to $35 \mathrm{~km}$, posing an objective barrier that is further enhanced by poverty (estimated at $41 \%$ of the population in this region):

"Here in Ngarmace, we are $10 \mathrm{~km}$ away from Torock, $24 \mathrm{~km}$ from Guereme and $19 \mathrm{~km}$ from Guidiguis. Do you realize that a pregnant woman risks giving birth on the way! So why not use a traditional midwife (instead)?" (Pregnant woman, Guidiguis)

When considering HIV health services, availability, and accessibility is often critical for testing and treatment, including PMTCT:

"(HIV) tests are not always available... And when we got the tests they were already outdated. When the woman you advised to do the screening finds that the test is not available, it becomes difficult for her to come back tomorrow and she will not come... and many women who attend ANC remain in the village without being tested." (Health provider, Koza)

Some participants recalled better times, when mobile services outreached their distant communities and they did not have to walk or to travel long distances:

"In the past, there were doctors who came to do the kilo (antenatal consultation) for the women here in the village. They used to do it in my house; but for a long time now, they are not coming anymore." (Village chief, rural Maroua)

In addition, people are often faced with the dilemma of having to choose between allocating funds for basic food or for covering travel expenses to a health facility, which can result in an additional barrier to service utilization.

"Instead of spending more than $10000 \mathrm{~F}$ in the hospital, we can give birth for 1500 or $2000 \mathrm{~F}$. The rest of money can help us to feed them." (Woman, Koza) 


\section{Discussions}

Cultural perceptions, beliefs, and practices, as well as gender inequality, still pose a challenge to child, maternal, and HIV services in many African countries (Cheptum, 2014), notwithstanding the advances made by Millennium Development Goals (United Nations, 2016). These are further compounded by socio-economic factors and others related to health facilities factors, posing significant barriers to service utilization.

In the Far North of Cameroon, some diseases that affect children are considered seasonal or related to supernatural causes and are treated at home or by traditional healers, sometimes delaying essential medical treatment, as in the case of malaria (Makundi et al, 2006).

Pregnancy and childbirth are often managed at home (USAID and MCHIP, 2012) since they are considered natural processes of the life cycle. Thus, traditional birth attendants are often preferred since they are respected members of the community, share cultural norms and beliefs, and are considered more supportive than providers in health facilities (Lori and Boyle, 2011; Kaombo, 2013). In addition, beliefs related to HIV (Dickinson, 2013), such as it being caused by witchcraft or divine punishment, are still widespread (Rodlach, 2006). Considering the aforesaid, access to maternal health services in general, as well as to specific HIV ones, such as prevention of vertical transmission, may often be discouraged (USAID and MCHIP, 2012; Ganlel et al, 2015).

Gendered roles regarding maternal health are clear-cut (Godlove et al, 2010). However, although pregnancy and childbirth are perceived as women's responsibility, usually a woman must obtain her partner's consent in order to access maternal and HIV care, due to traditional social structures that reinforce gender inequality (Grieg et al, 2008). Considering that partner support is essential for antenatal consultations and especially for prevention of vertical transmission, low male participation continues to pose a serious barrier to the utilization of these health services (Gourlay et al, 2013).

Women living with HIV experience higher levels of stigma than men and may be blamed for bringing the disease into the family, as they are usually the first person in a family to find out their status when tested during ante-natal consultations. Many women fear disclosing their HIV status to their husbands since this may lead to violence, abandonment and divorce (One in nine Campaign, 2012), thus affecting their access to services (Moges, 2009). In addition, some women indicated that if they were seen at a facility with HIV services, community members would suspect them of living with HIV, which could lead to gossip and discrimination, thus further discouraging them from accessing services, including PMTCT.

Lack of trust of health services was attributed to a combination of factors. Health providers are often identified with modern medicine, which is not widely used in some communities that still foster traditional perceptions and beliefs. Consequently, misunderstandings, wariness, and mistrust are inevitable (Bohren et al, 2014). This can be enhanced by the negative attitudes and behavior of some health providers, as was noted by women living with HIV, who suffered from discriminatory treatment and breaches of confidentiality, thus increasing their fear of disclosure through service utilization (Famaroti, Fernandes and Chima, 2013; Karamagi et al, 2006).

In addition to the barriers mentioned, objective factors such as poverty, availability, and accessibility to the child, maternal, and HIV health services contribute to their low uptake in the region. Concurrently, the distance to these facilities may be aggravated by bad infrastructure, lack of transport, and the costs and time involved in traveling (Tize Teri, 2016), further affecting women's mobility, which is already limited by accepted cultural norms and gender power relations (Grieg et al, 2008). 


\section{Conclusions and recommendations}

The study highlighted the need for gender and culture transformative approaches to overcome barriers to maternal and child services in the Far North Region of Cameroon, including prevention of vertical transmission (Nudelman, 2013). Sensitization and awareness campaigns should target the main diseases that affect maternal and infant health. Issues related to pregnancy, childbirth and gender equality, as well as stigma and discrimination, may be better addressed through innovative techniques while encouraging active community participation. These may include: community theatre, peer training, activities in churches and football clubs, as well as interactive radio programs in local languages.

At the same time, ongoing health provider sensitization is essential to enhance culture and gender sensitive health care. Implementing a task shifting process (WHO, 2008) could reduce the overburden of health providers and extend health services to more remote areas. Thus, training of and collaboration with traditional birth attendants could have a significant impact on maternal health in the region (Kaombo, 2013), in addition to a more active involvement of community health liaisons (Nudelman and Tezi Teri, 2014).

Male engagement in maternal and HIV services should also be encouraged, while taking into account traditional gender and socio-cultural issues (Godlove et al, 2010). Finally, empowering women from the different communities in the region - including women living with HIV - through capacity building, could enable their participation in health care services, while fostering gender equality and contributing to stigma reduction and to health service uptake (Mothers-to-mothers Uganda, 2016). Considering the objective barriers mentioned such as accessibility, reinstatement of mobile clinics could bring the maternal and HIV services closer to remote communities.

The implementation of the findings and recommendations of this rapid assessment may contribute to the enhancement of health care in culture-specific contexts in the Far North province of Cameroon. Consequently, it may reduce morbidity and mortality, as well as eliminate new HIV infections among children in the region while also sustaining their mothers' health and well-being (UNAIDS, 2015).

\section{Bibliography}

1. Beebe, J., 2004. Rapid Assessment Process, Encyclopedia of Social Measurement, SOME00562, pp.1-7.

2. Bohren, M.A., Hunter, E.C., Munthe-Kaas, H., Souza, J.P., Vogel, J.P., and Gülmezoglu, A.M., 2014. Facilitators and barriers to facility-based delivery in low- and middle-income countries: a qualitative evidence synthesis. Reproductive Health, 11(1), pp.71. Available at: http://www.reproductive-health-journal.com/content/11/1/71 [Accessed 18 August 2017].

3. Bonono, R.C. and Ongolo-Zogo, P., 2012. Optimizing the use of antenatal care services in Cameroon. Centre for Development of Best Practices in Health-Central Hospital Yaoundé, Cameroon.

4. Boutrais, J., 1984. Le Nord du Cameroun: des hommes, une région. Paris: ORSTOM.

5. Cheptum, J., Gitonga, M., Mutua, E., Mukui, S., Ndambuki, J. and Koima, W., 2014. Barriers to Access and Utilization of Maternal and Infant Health Services in Migori, Kenya, Developing Country Studies 4 (15), pp.48-52.

6. Dickinson, D., 2013. Myths or theories? Alternative beliefs about HIV and AIDS in South African working class communities, African Journal of AIDS Research, 12(3), pp.121-130, DOI: 10.2989/16085906.2013.863212. 
7. Elwell, K., 2016. Facilitators and barriers to treatment adherence within PMTCT programs in Malawi. AIDS Care, 28(8), pp.971-975.

8. Famaroti, T.O., Fernandes, L., and Chima, S.C., 2013. Stigmatization of persons living with HIV/AIDS by healthcare workers at a tertiary hospital in Kwazulu-Natal, South Africa: a crosssectional descriptive study. BMC Medical Ethics, 14(Suppl. 1), pp.56. Available at: https://doi.org/10.11.86/1472-6939-14-51-56

9. Ganle1, K.J., Otupiri., E., Parker, M. and Fitzpatrick, R., 2015. Socio-cultural Barriers to Accessibility and Utilization of Maternal and Newborn Healthcare Services in Ghana after Userfee Abolition. International Journal of Maternal and Child Health, 3(1), pp.1-14.

10. Gourlay, A., Birdthistle, I., Mburu, G., Iorpenda, K. and Wringe, A., 2013. Barriers and facilitating factors to the uptake of antiretroviral drugs for prevention of mother-to-child transmission of HIV in sub-Saharan Africa: a systematic review. Journal of the International AIDS Society, 16(1):18588.

11. Grieg, A., Peacock, D., Jewkes R., and Msimang, S., 2008. Gender and AIDS: Time to Act. AIDS 22 (Suppl. 2 2), S35-S43. Available at: https://journals.1ww.com/aidsonline/fulltext/2008/08002/Gender_and_AIDS time_to_act.7.asp $\underline{x}$ [Accessed 10 July 2017].

12. Kaombo, A.J., 2013. Impact of training traditional birth attendants on maternal mortality and morbidity in Sub-Saharan African countries. Tanzania Journal of Health Research, 15(2), pp.134-142.

13. Karamagi, C.A.S., Tumwine, J.K., Tylleskar, T., and Heggenhougen, K., 2006. Antenatal HIV testing in rural eastern Uganda in 2003: incomplete rollout of the prevention of mother-to-child transmission of HIV programme, BMC International Health and Human Rights, 6(6), doi:10.1186/1472-698X-6-6.

14. Lori, J. R., and Boyle, J.S., 2011. Cultural Childbirth Practices, Beliefs, and Traditions in Postconflict Liberia. Health Care for Women International, 32(6), pp.454-473.

15. Makundi, E.A., Malebo, H.M., Mhame, P., Kitua, A.Y. and Warsame, M., 2006. Role of traditional healers in the management of severe malaria among children below five years of age: the case of Kilosa and Handeni Districts, Tanzania. Malaria Journal, 5:58. Available at: http://www.malariajournal.com/content/5/1/58 [Accessed 12 July 2017].

16. Medley, A., Garcia-Moreno C., McGill, S. and Maman, S., 2004. Rates, barriers and outcomes of HIV serostatus disclosure among women in developing countries: Implications for prevention of mother-to-child transmission programmes, Bulletin of the World Health Organization, 82(4), pp.299-307.

17. Moges, G., 2009. Factors Influencing Utilization of PMTCT Services in Addis Ababa, Ethiopia, $45^{\text {th }}$ International Course in Health Development, KIT (Royal Tropical Institute), Free University, Amsterdam. Available at: http://www.bibalex.org/search4dev/files/351971/185326.pdf [Accessed 15 July 2017].

18. Nkuoh, G.N., Meyer, D.J., Tih, P.M. and Nkfusai, J., 2010. Barriers to Men's Participation in Antenatal and Prevention of Mother-to-Child HIV Transmission Care in Cameroon, Africa. Journal of Midwifery \& Women's Health, 55(4), pp.363-369.

19. Nudelman, A., 2013. Gender-related barriers to services for preventing new HIV infections among children and keeping their mothers alive in high-burden countries. UNAIDS: Discussion Paper. Available at: http://www.unaids.org/en/media/unaids/contentassets/documents/unaidspublication/2013/20131 2_discussion-paper_Gender-HIV-services_PMTCT_en.pdf 
20. Nudelman, A. and Tize Teri, D., 2014. Evaluation des obstacles liés au Genre dans l'accès aux soins de santé maternelle et infantile y compris la PTME dans les districts de santé de Maroua urbain/rural, Koza, Moulvoudaye et Guidiguis à l'Extrême-Nord du Cameroun. Rapport prépare pur CASSRT et ONUSIDA.

21. Painter, T. M., Diaby, K.L., Matia, D.M., Lin, L. S., Sibailly, T.S., Kouassi, M.K., Ekpini, E.R., Roels, T.H., \& Wiktor, S.Z., 2004. Women's reasons for not participating in follow up visits before starting short course antiretroviral prophylaxis for prevention of mother to child transmission of HIV: qualitative interview study. BMJ,329(7465), pp.543. doi: $10.1136 / \mathrm{bmj} .329 .7465 .543$.

22. Rackley, E.B., 2017. Cameroon's Far North: Responding to Boko Haram Edward B. Rackley. Oxford Research Group Briefing. Available at: http://www.oxfordresearchgroup.org.uk/publications/briefing_papers_and_reports/cameroon\%E 2\%80\%99s_far_north_responding_boko_haram [Accessed 17 September 2017].

23. Reis, C., Heisler, M., Amowitz, L., Moreland, R.S., Mafeni, J.O., Anyamele, C. and Iacopino, V., 2005. Discriminatory Attitudes and Practices by Health Workers toward Patients with HIV/AIDS in Nigeria. PLoS Medicine, 2(8) e246.| www.plosmedicine.org 0752.

24. Rödlach, A., 2006. Witches, Westerners and HIV: AIDS and Cultures of Blame in Africa. Walnut Creek, CA: Left Coast Press.

25. Scrimshaw, S.C.M., Carballo, M., Ramosand, L. and Blair, B.A., 1991.The AIDS rapid anthropological assessment procedures: A tool for health education planning and evaluation. Health Education Quarterly, 18(1), pp.111-123.

26. Tize Teri, D., 2016. Le recours à l'accouchement à domicile à l'Extrême-Nord du Cameroun: une logique prédisposant aux soins de santé parallèles. Offres, recours et accès aux soins de santé parallèles en Afrique. Des acteurs en quête de légitimité sociale, médicale et institutionnelle. Éd. Différance Pérenne, pp.257-269.

27. *** Mothers-to Mothers, Uganda, 2016. Available at: https://www.m2m.org/where-wework/uganda/[Accessed 17 July 2017].

28. ***Institut National de la Statistique - INS, 2011. 4eme Enquête Démographique et de Santé et a indicateurs Multiples EDS-MICS4, Yaoundé, Cameroon.

29. ***One in nine Campaign, 2012. We were not meant to survive: Violence in the Lives of HIV Positive Women in South Africa. Available at: htpp://www.oneinnine.org [Accessed 10 August 2017].

30. ***UNAIDS, 2011. Countdown to zero: Global plan towards the elimination of new HIV infections among children by 2015 and keeping their mothers alive. Available at: http://www.unaids.org/en/media/unaids/contentassets/documents/unaidspublication/2011/20110 609 jc2137_global-plan-elimination-hiv-children_en.pdf [Accessed 15 June 2017].

31. ***UNAIDS, 2015. UNAIDS Strategy 2016-2021: On the Fast Track to end AIDS. Available at: http://www.unaids.org/en/resources/documents/2015/UNAIDS_PCB37_15-18 [Accessed 15 August 2017].

32. ***United Nations, 2016. The Millennium Development Goals Report 2015, New York.

33. ***World Health Organization, 2015. The H4+ partnership joint support to improve women's and children's health: progress report 2014. Available at: http://www.who.int/iris/bitstream/10665/134746/1/WHO_RHR_14.27_eng.pdf [Accessed 10 May 2016].

34. *** World Health Organization, 2008. Taskshifting: Global Recommendations and Guidelines. Available at: http://www.who.int/healthsystems/TTR-TaskShifting.pdf [Accessed 15 December 2015]. 


\title{
Psychodynamic prototype through personality organization chart of educational leaders
}

\section{DOI: http://doi.org/10.26758/8.1.12}

Silva Ibrahimi (1), Eglantina Dervishi (2), Valbona Muca (3), Marije Dobra (4)

(1) Department of Psychology, "Albanian University", Tirana, Albania

(2) Department of Psychology and Pedagogy, Faculty of Social Sciences, University of Tirana, Tirana, Albania

(3) Department of Social Work, Faculty of Education “Aleksander Xhuvani”, University of Elbasan, Albania

(4) Local Police Department of Tirana, Albania

Address correspondence to: Silva Ibrahimi, Departament of Psychology, "Albanian University", Tirana, Albania, e-mail: silva.ibrahimi@yahoo.it

\begin{abstract}
Objectives. The present study aims to explore the problematic situation of Personality Organization and Behavioral Tendency in the target group of school leaders and to highlight the need of a qualitative change and organizational structures of the preventive evaluation of mental health in school. We aim to describe the utility of a novel Mental Health Taxonomy as the Psychodynamic Manual as an overall taxonomy rather than the DSM or ICD.

Material and methods. The research was conducted through the interweaving of literature with the context operationalization. In its initial phase of the study, we considered a wide range of classic literature and contemporary updates on elements of human personality, maladaptive or adaptive structures, educational leadership and their typologies. Through a quantitative and qualitative methodology as Q methodology, we reached to fulfill the presented aims and goals. Supporting instruments for the operationalization of the method were: Psychodiagnostic Chart, Mental Functional Level Questionnaire, Object Relations Inventory and the Functional Assessment of Ego. Results. The study showed that there is not only a strong positive relationship between Pathogenic Beliefs and Personality Organization (but also that teachers and school principals display increasing symptoms of "maladaptive behavioral tendency". Leaders with high levels of Neurotic Personality Organization, which has the highest frequency in the factor weight of the mental component have also higher chances for coercive behavior than leaders with Borderline Personality Organization. Results were analyzed with PQMethod software processor.

Conclusions. At the end of the article, we outline some suggestions for formation of a structured based assessment of psychological problems supporting leaders in schools, the function role style and leadership in supporting education and health.
\end{abstract}

Keywords: psychodynamic prototype, personality organization, psychodiagnostic chart; continuing education. 


\section{Introduction}

Psychoanalysis is probably one of the most important theories and methods of approaching, understanding and analyzing the development of emotional functions, motivation, and drives in the human psychology. Endeavors to define a normal and abnormal personality have not set a distinction between what is a tendency of a personality illness state and a clear mental illness. Approaching psychoanalysis to schools as a denotative of problems or conflict resolution, between self and others, was early defined in the literature.

Dynamic forces in the cases where a greater psychic engagement is required are more unconscious than conscious.

The advantage of evaluating a suitable personality level (healthy) of a/the leader is, of course, one of "the bells falling harder" in terms of a progressive adaptation of our transitional society to globalization and changing contexts.

For a scientific clinical screening and prevention of events when maladaptive behavior as violence, persecution and abuse cacturn in prevailing and on hard consequences for the future, it is important to have a clear view of the situation. It helps in this context the supporting evidence-based psychodynamic literature on "Objects Relations", "Personality Pattern and Organization" and "Personality Prototype". Researchers and clinicians from all over the world who contributed in collecting data for instrument validation and their impressions were very important in realizing a database for the newest version of the Psychodynamic Diagnostic Chart -2 (Gordon and Bornstein, 2015; Gordon and Bornstein, 2017). At the center of the concept of classical psychoanalysis in the organization of psyche is the existence of an energetic principle, id, in which is required an immediate dismissal of inner satisfaction and evolution of a well-structured ego. The ego, appropriately, has come as a result of contact between the energy of the id psyche and external realities (Freud, 1900, 1923, 1933).

It is very important for researchers to implement innovative methodologies in order to not reinforce positively the same opinion more than twice and to not affect subjects with controversary dichotomic statements (McKeown and Thomas, 1988).

Ego drives interact in a dynamic mode with each other and defense mechanisms as repression lay to defend infantile satisfaction that the drives unconsciously carry. Unconscious mental life is regulated automatically by the pleasure and desire of pain principle beyond the control of Ego and away from thoughts, beliefs or reality. Ego-repression in the unconscious terms could be adjusted by the assessment of danger and safety. This adjustment is not automatic but is carried out by the high mental functions (thoughts, anticipations, and judgments).

The powerful feelings of fear, anxiety or guilt are also displayed. The experiences from which a child acquires unconscious beliefs are in themselves traumatic.

Such experiences might be objectively unresponsive (the case of little Hans - Freud, 1909) and subjectively traumatic. In the late theory, psychopathology arises from unconscious beliefs to infantile traumatic experiences. Thus, the later adult represses libidinal impulses and then fixes them. Repression is regulated unconsciously by the criteria of safety and risk and the person decides if he could experience freely a component by the whole content of repressed cognitions and further adjust it bringing into conscience. The censor ego regulates the expression of impulses by the criteria of safety and danger and other pulsions manifested in dreams as the power of the dreamer is closed when he/she is sleeping. According to Freud's late papers, psychopathology derives by pathogenic beliefs and the castration anxiety in cathexis (Freud, 1914). 
The consequences of unconscious conflicts demand the analysis of the wholeness withn the three specific parts. In the theory of Object Relations, implications of the structural theory (dissolving unconscious conflicts among impulses and mechanisms of defense) have changed as unconscious conflicts are internalized into objects relations.

Such relations define the nature of defensive actions and impulses toward objects or other relations. Internalized object relationships are the foundation of the tripartite patterns as id, ego, and superego. In a deeper research for the development of the pattern of relations between the individual and others, the Kleinian fellows argued some other viewpoints concerning object-relations model (Klein, 2002)

The core unit was the self in relation to another - and the nature of the relationship between them. Human unit in the external world, involve essentially, relations with other. In the psychology of inner dynamics, self must be understood as always existing and according to relationships it has, remembers, wishes or creates. In the relational and structural model, the shape of self grows and changes from the experiences in their relations, whereas, the nature of the relations is developed and altered by the self.

The unit of self, other and relation turn into a model for the comprehension of shape in every subsystem within the self. Neuroses are seen as related to the poor resolution of the Oedipal Complex. Freud (1917-1957) argued that object relations are a mean of continuing to receive gratification by internalizing images of love after a loss. In the field of personality pattern and organization, defense mechanisms to distortion and the Overall Defense Function have an alternation in the depressive episodes, self-destructing symptoms, and the reversible suicide ideation.

The combination between idealization and disintegration of a given structure makes leader find new alternative models to avoid the threat. The invested energy directs toward the antilibidinal object, destruction in another time of this antilibidinal self by the internal pathogenic patterns.

If we recall the psychosocial phenomena of verbal, physical, emotional or psychological abuse reported in the media throughout this time, the school and community were often encountered students abuse. In a broader view, we could imply that the role of school as an instructive and organizational institution has changed with time either from the mental representation, which has been offered to students in these transition years, or by the internalization of the leader role. At this point the student manifest his or her antilibido in relation to the teacher; teacher attracts the antilibidinal energy and based on his/her personality patterns derives it to the director and then to community shaping a cyclic behavioral tendency.

If this behavioral tendency is placed for instance, in the parameters of a personality affected by stress or neurotic, the resultant will develop a leader personality with a neurotic level that under the influence even of a small stimulus will generate violence or dysphoric outburst.

It is important therefore to understand, monitor and prevent the maladaptive behavioral tendency since its beginning and to avoid an internalization that could forward ego at an earlier state of "trans". The creation of structures involves the separation of self and repression of that part which dissolves from the whole.

Repression is the key component in the endopsychic structure as it represents the mechanism of self -division. The experience integrated within self may be manifested in memory or in a gradual alternation of the wholeness self. Unless the experience is not integrated when it is so not well tolerated to come into awareness, it may be a subject or repression.

Seeking for a maladaptive behavioral trend is surely an endeavor but also crucial for prevention and intervention in the clinical context. The more predictable a behavior, the greater the 
prevention. Since the early writings of Freud, maladaptive behavior took a special attention as it is the prelude of "all sins"(Freud, 1930).

\section{Material and methods}

The method used in the present study aimed to reach a validation since the preliminary assessment of Q method and its suitability to the context with 100 participants. Q methodology was scientifically introduced in 1935 by the British psychiatrist and psychologist William Stephenson and is often associated with a quantitative analysis toward factorial analysis. What is referred today as a Q methodology was introduced for the first time in the Journal "Nature" by the physician and psychologist William Stephenson in 1935. Stephenson served at the time as the assistant of Charles Spearman, the inventor of factorial analysis. The term Q methodology to Brown is further explained in the article "Q Technique and Questionnaires". In recent days, Q methodology is widely used in social sciences, nursing and medical sciences, behavioral medicine and especially in psychology (Stainton Rogers et al., 1995).

For the first in Albania, as a mixed research methodology, Q-sort was used in the research study "Q-sort and Study Case Psychoanalysis" (Ibrahimi \& Qirjako, 2011). In the present research, we were based on the empirical data revealed in the 2011 and the preliminary data collected in the pre-test conducted in Albania, in 2015 by Ibrahimi and Gordon. Our core research question focused on a definition of a trending behavior and personality organization level of School Leaders in Albania. Data of significance alpha $(\mathrm{n}=100 ;=.835)$ revealed a strong correlation between the assessment of viewpoints for personality and leadership in Q method. Correlations between Pearson variables revealed a positive correlation among variables (teachers and directors) and statements related to the personality and leadership style (Q.2, Q.5, Q.24).

In the present study, we have designed a starting concourse of 100 statements in the preliminary phase that were reduced to 77 in the final phase of the test. As Q is focused on the correlation of responses of the individual, statements were designed for both categories of leaders "teachers" and "directors of educational institution" in a tot of 154 statements. Each test holds statements constructed to measure Personality Level, the Influence of School Environment and Community and Leadership Style of the individual according to their functions. Selection of the participants in the study was conducted according to the evidence for the geographic and school population distribution by the Institute of Developing Education with School Directories and the pedagogical staff. We cared that the aging, gender, demographic, education experience of the participants to be very different even within schools of the same city.

Collected data were initially added to the dataset of $\mathrm{Q}$ divided for each unit. Further, through Q software, there were designed the orthogonal variables and matrices among subjects.

Records of statements constructs were gathered by the literature review of "Object Relations" and "Personality Level", research and scientific articles on the practices of teaching and learning, resource data from chronicles related to school leadership and records widely reported in media for school situation and teachers in the Albanian context.

\section{Results}

In both extremities of distribution, there was a position of statements from the most characteristic (on the right) to the least characteristic (to the left). The data gathered on stability and significance in test helped us in designing the final test $\mathrm{Q}$ in two versions, for teachers and school directors with a definitive number of statements 77. In the present study (preliminary phase) 
participants chose statements in a distribution of $3,5,8,12,16,18,16,12,8,5,3$.As the subject had compiled the Q-sort, we recorded the number of ranked statements in a matrix.

Data of significance alpha $(\mathrm{n}=50 ;=.835)$ revealed a strong correlation between the assessment of viewpoints for personality and leadership in Q method. Correlations between Pearson variables revealed a positive correlation among variables (teachers and directors) and statements related to the personality and leadership style (Q.2, Q.5, Q.24). Factorial analysis for all 50 subjects reported the creation of 17 factors from which 4 were considered stable on a level of 0.75 0.85.These factors were considered significant and were reported for the further pyramidal distribution Q.

Sample selection in $\mathrm{Q}$ is not contained to random but some defined criteria as it is linked to the aim and statements introduced in Q (McKeown and Thomas, 1988, pp.37). Significant data were revealed by the comparison of P-model, which represents the Personality Pattern and Disorders of each participant in a study. Every single individual in the P-pattern holds a personal experience or view related to the matrix of Q-sort combination (Brown, 1980).

Participants in the study, who were first contacted in the preliminary phase in March 2014, were introduced with the possibility to participate in the full testing in 2015.

We could detect various types of personality organization, maladaptive behavioral tendency, emotional-behavioral reactions, relatedeness to other, the level of affect and attachment for every personality prototype.

According to the PQMethod, statements related to the element of "Maladaptive Behavior" have obviously a prevailing place over other statements as they carry the greatest weight in the aim of the present study. Descriptive data revealed an altered medium in our cities. Thus, for instance, in Shkoder the highest rank (z-score) is achieved in the statement no.67 of the Q-test "When others gaze me, I flush and think..."with a scoring of 1,819.

Weighting variable matrices and ranking of rotated factors were conducted for each respondent. A relatively small portion of respondents $(14 \%)$ expressed a neutral attitude in characterizing behavior (assessed 0) whereas the majority of them referred significant differences in behavioral trend. From testing the reliability of participants, validation for the Overall Personality Organization scale was $.92(\mathrm{p}<.001)$; for the Overall Severity and Personality Disorder was .89 ( $\mathrm{p}<.001$ ); for the 9 capacities of Mental Functioning ranges from .77 to .89 ( $\mathrm{p}<.001$ ); and for Severity of Symptoms was .87 ( $\mathrm{p}<.001)$. All the PDC constructs revealed strong correlations with MMPI-2 scores (Gordon and Stoffey, 2016). The MMPI-2 scales for Schizophrenia (Sc), Hysteria (Hy) and Ego Strength (Es) revealed a good validity for categorical components of the levels of Psychotic, Borderline and Neurotic Personality Organization.

These categorical components were collected by dividing in 10 points the scale of Personality Organization: psychotic (ratings 1-3, no. = 13), borderline (ratings 4-6, no. = 52) and neurotic (ratings $7-10$, no. $=33$.For the psychotic level scale, authors predicted a significantly higher mean than both $\mathrm{Hy}$ and Es scales. From the pairwise comparison data was revealed that Sc is significantly higher than Es $(\mathrm{M}=85.77, \mathrm{SD}=19.55$ vs. $34.31, \mathrm{SD}=6.78, \mathrm{p}=.001)$ and slightly higher than Hy $(\mathrm{M}=85.77, \mathrm{SD}=19.55$ vs. $72.69, \mathrm{SD}=18.46, \mathrm{p}=.017)$.

For the borderline level scale, authors predicted that the means of the scales Sc and Hy should not be significantly different but both should be significantly higher than the mean of Es.

$\mathrm{Sc}$ and Hy are not very different but $\mathrm{Sc}$ is much higher than $\mathrm{Es}(\mathrm{M}=62.21, \mathrm{SD}=12.31$, vs. 43.58, $\mathrm{SD}=10.25, \mathrm{p}=.001)$ and $\mathrm{Hy}$ is much higher than Es $(64.21, \mathrm{SD}=12.31$ vs. 43.58, $\mathrm{SD}=10.25, \mathrm{p}=$ .001). For the neurotic level scale, it was predicted that the scales Es, Sc and Hy had an average distribution and that Ego Strength was oriented to the normal distribution. 
We can define in this line the strength of Ego functioning in terms of a tendency of Personality towards illness. If, for example, a leader with a Depressive Personality would live in an isolated social environment for a certain time, he/she is more likely to develop the complete range of symptoms of Major Depression.

Table.1. Correlations for the 7 Elements of the Overall Personality Organization Scale.

\begin{tabular}{|l|c|c|c|}
\hline Components & $\boldsymbol{r}$ & $\boldsymbol{M}$ & $\boldsymbol{S D}$ \\
\hline Identity & $.84^{*}$ & .5 .50 & .1 .68 \\
\hline Object Relations & $.83^{*}$ & $.4,85$ & $.1,75$ \\
\hline Affect Tolerance & $.85^{*}$ & .5 .40 & .1 .59 \\
\hline Affect Regulation & $.86^{*}$ & .4 .91 & .1 .63 \\
\hline Superego Integration & $.80^{*}$ & .6 .22 & .2 .00 \\
\hline Reality Testing & $.90^{*}$ & .6 .84 & .1 .93 \\
\hline Ego Resilience & $.69^{*}$ & .5 .83 & .1 .87 \\
\hline Overall Scale & $.92^{*}$ & .5 .50 & .1 .68 \\
\hline
\end{tabular}

$* \mathrm{p}<.001$ Source: Gordon and Stoffey, 2014.

As we could reveal by the data displayed on literature, we developed a deep research in the Albanian context. It is very important for further studies, to research into differences of the behavioral "restrained" and "direct" trend between the participants from south-east city of Korca and those from north of Shkodra, which also present significant difference in choosing their ideal leadership form. The combination of correlations and overlapping of z-scores for all three categories gave us important indexes over the characteristics of ideal leadership and the prevalence of leadership in Albanian school leaders institutions.

\section{Discussions}

The main aim of this study was to explore the problematic situation of Personality Organization and behavior tendency of Educational Institutions through their leadership style. In the goals of the study was involved either the role of internal and external factors in a healthy behavior Prototype. We have developed a voluminous research in the metanalytical, empirical and situational spectrum and were defined the variables which would be employed in the profound analysis of the present study.

The core variables of the study were as follow:

a. Pathogenic beliefs

b. Relationship with self and the Significant Other

c. Leader behavior in the classroom

d. Leader behavior in the community

e. The impact of the environment on the school leader.

Relating to the main concern of the present article, of this study relating the trending behavior of the educational leaders in Albania, we were based on the first "drive" of Personality organization in the Psychodynamic Manual. The unit for measuring " Maladaptive Behavior 
Tendency "included the following statements: 1, 3, 16, 21, 22, 23, 28, 43, 45, 49, 52, 54, 60, 64, 76 and 77 of the test. Statements related to this element have had obviously a prevailing place over other statements as they carried the greatest weight in the aim of the present study.

Descriptive data revealed an altered medium in our cities. Thus, for instance, in Shkoder, that is located on the North-side of the country, the highest rank (z-score) is achieved in the statement no.67 "When others gaze me, I flush and think..." with a scoring of 1,819, while in Vlora, which is located in the South, at the test for directors of educational institutions, the highest rank is the statement no.35 "I long to expect changes" with a score of 1,44.

Likewise, the lowest rank in Shkoder results in the statement no.21 "I am an anti conformist" with a score of 0,3 whilst in Vlore, the statement no. 6 with a score of 0,04 . There is also a similarity in the assessment ranking between Tirana, as the capital city, and Elbasan, a centeredlocated city. A relatively small portion of respondents $(14 \%)$ expressed a neutral attitude in characterizing behavior (assessed 0 ) whereas the majority of them referred significant differences in behavioral trend.

Longitudinal researches of Tanabaum and Schmidt (1958) revealed that the dependence of leader from the dependent lead to disorganization whereas the freedom of participation for the dependent lead to diffusion of role and breaking boundaries. It is very important for further studies, to research into differences of the behavioral "restrained" and "direct" trend between the south-east city of Korca and the north of Shkodra which also present a significant difference in choosing their ideal leadership form.

It is also suggested for authors that either directors or school teachers to develop collegial relations with a vertical decision making, thus, collecting the opinion of all on the decision of one (1958). All is naturally more than the sum of each of its parts!!

\section{Conclusions}

Research for a Prototypical Identity is of great importance in understanding depthy and prevent difficulties later in life. Finding an identity that could establish a consistent development in prototype represents a long and hard journey for the clinical science. Every category of population is affected at different degrees by stressing events and the psychological and social consequences it provides. The relation with the other object-subject is equally important in defining one's psychological outlook.

Educational leaders are probably the part of the public in Albania least studied in the context of mental health and improvement of psychopathologic parameters for raising efficiency and efficacy not only for the individual but also for the entire society. Their perceptions of personality, behavioral trend and leadership style, are significant for a comprehension of these parameters but also to outline some points from which to develop a strategic middle or long-term plan.

The present study highlight some significant views for the educational system in Albania:

1.School teachers and directors show an increased rate of symptoms for "the maladaptive behavioral tendency" for the conditionality of inner and outer factors.

2.There is a strong relation between pathogenic beliefs of school Leaders and maladaptive behavior as a result of it.

3.It prevails a strong positive correlation between the element of personality and maladaptive behavioral tendency.

Results reveal that a leader with a high level of Neurotic PO, have higher chances for a violent tendency behavior than another with a borderline PO. Thus, individuals with high levels of Neurotic PO should be put in the first line of psychological based intervention. 
Relationship with the significant other, internal mental functioning (M), symptomatic patterns $\mathrm{PO}(\mathrm{P})$ and subjective experience toward these relations $(\mathrm{S})$ are the most powerful predictors of prototype organization and maladaptive behavior.

Research of Fisherbein and Ajzen on the perceptions and concepts (1975) revealed that attitudes and behaviors might change through education.

The results of the present study will help the involved parties, educational system and society to develop a framework for monitoring and implementing them in order to prevent or intervene in the risky or deviant potential situations.

As fore, conducting an ad-hoc working group for translating and adapting the psychodynamic clinical instruments in Albanian language, Implementing a $Q$ methodology in several areas of science and research, studying other affecting variables in the development of Prototype, healthy Personality and Psychological Welfare in society and developing a profound research regarding Personality Organization and Patterns in other areas of Clinical Psychology are the fundamental lines for a structuring and prospective progress in the society.

\section{Acknowledgments:}

For the realization of the present study "The Psychodynamic Prototype of Leadership Styles through the Personality Organization Chart - a neo prospects of $Q$-sort" there have been engaged and have provided their precious contribution many people, researchers, respondents, Ministry of Education and Sports of Albania, Educational Directorates and School Directories of all participating cities and fellows in this present work.

\section{Bibliography}

1. Balint, M., 1936. The final goal of psychoanalytic treatment. International Journal of Psychoanalysis, 17, pp.206-216.

2. Balint, M., 1968. The Basic Fault: Therapeutic Aspects of Regression. London: Tavistock.

3. Blatt, S. J., Auerbach, J. S. and Levy, K. N., 1997. Mental representations in personality development, psychopathology and the therapeutic process. Review of General Psychology, 1(4), pp.351-374.

4. Blatt, S. J., Stayner, D., Auerbach, J. S. and Behrends, R. S., 1996. Change in object and selfrepresentations in long-term, intensive, inpatient treatment of seriously disturbed adolescents and young adults. Psychiatry, 59, pp.82-107. https://doi.org/10.1080/00332747.1996.11024752.

5. Block, J., 1961. The Q- Sort Method in Personality Assessment and Psychiatric Research. Springfield Illinois USA: Charles C. Thomas Publisher.

6. Brown, S.R., 2002. Q Technique and Questionnaires. Operant Subjectivity, 25(2), pp.117-126.

7. Brown, S.R., 1980. Political subjectivity: Applications of $Q$ methodology in political science. New Haven: Yale University Press.

8. Fairbairn, W.R.D., 1952. Psychoanalytic studies of the personality. Oxford, England: Routledge \& Kegan Paul.

9. Fairbairn,W.R.D., 2011. Steps in the Development of an Object-Relation Theory of Personality. British Journal of Medical Psychology, 22(1-2), pp.26-31. https://doi.org/10.1111/j.20448341.1949.tb02880.x

10. Fishbein, M. and Ajzen, I., 1975. Belief, attitude, intention and behavior: An introduction to theory and research. Reading, MA: Addison-Wesley. 
11. Freud, A., 1930. Quattro conferenze di psicoanalisi per insegnanti e genitori [Four psychoanalytic conferences for teachers and parents] In: A. Freud, Scritti, Vol I: 1922-1943. Torino: Boringhieri, 1978.

12. Freud, A., 1960. Psychoanalysis for Teachers, Teachers and Parents-Introductory Lectures, Boston, USA: Beacon Press.

13. Freud, S. 1914. Remembering, repeating and working through (Further Recommendations in the Technique of Psychoanalysis II). S.E., 12, pp.147-156.

14. Gordon, R. M., and Stoffey, R.W 2014. Operationalizing the Psychodynamic Diagnostic Manual: a Preliminary Study of the Psychodiagnostic Chart (PDC). Bulletin of Menninger Clinic, 78(1), pp.1-15. https://doi.org/10.1521/bumc.2014.78.1.1

15. Gordon, R.M, Lingiardi, V., Bornstein, R.F and McWilliams, N, 2015. The Psychodynamic Diagnostic Manual Version 2 (PDM-2): Assessing Patients for Improved Clinical Practice and Research, Psychoanalytic Psychology, 32(1), pp.94-115.

16. Gordon, R.M and Gosgrove, L., 2013. Ethical Considerations in the Development and Application of Mental and Behavioral Nosologies: Lessons from DSM-5. Psychological Injury and Law, 6, pp.330-335.

17. Ibrahimi, S. and Qirajako, E. 2011. Q-sort and the Case-Study Psychoanalysis (unpublished research)

18. Klein, M., 1931. Contributo alla teoria dell'inibizione intellettiva. In: M. Klein, Il nostro mondo adulto e altri saggi (Our adult world and other sages), Italian translation by Alberto Ponsi, G. Martinelli \& C. Firenze, 2002.

19. McKeown, B.F. and Thomas, D.B. 1988. Q methodology. Quantitative Applications in the Social Sciences, Series: Quantitative Applications in the Social Sciences (Book 66), Newbury Park, CA: Sage Publications.

20. Stainton Rogers, R. 1995. Q methodology. In: J.A. Smith, R. Harré, and L. Van Langenhove, eds. Rethinking methods in psychology. London and Thousand Oaks, CA: Sage. pp.178-192.

21. Stephenson, W. 1935. Correlating persons instead of tests. Character and Personality, 4(1), pp.17-24. https://doi.org/10.1111/j.1467-6494.1935.tb02022.x.

22. Tannenbaum, A.S. and Schmidt, W.H, 1958. How to choose a leadership pattern, Harvard Business Review, 36(2), pp.95-105. 


\title{
Aging and intergenerational care
}

\section{DOI: http://doi.org/10.26758/8.1.13}

\author{
Cornelia Rada
}

'Francisc I. Rainer' Anthropology Institute of the Romanian Academy, Bucharest, Romania

Address correspondence to: Cornelia Rada, Biomedical Department, 'Francisc I. Rainer' Anthropology Institute of the Romanian Academy, Academy House, 13 September Avenue, No.13, 5th District, Bucharest, Romania, Zip Code 050711, tel. +40728824852; fax +4021.3175072; Email: corneliarada@yahoo.com

\begin{abstract}
Objectives. The evaluation and identification of support flows within the family, and the people involved in helping the elderly.

Material and methods. Between 2016-2017 multiple questionnaires were applied to a total of 601 patients aged 55-93 years. In addition, between 2015-2017, face-to-face interviews with 50 subjects were organized on 4 themes, one on intergenerational support.

Results. The main beneficiaries of the respondents' support were children and parents (over 80\%). The main providers of support to the respondents were children and parents (over 60\%). Another major provider of support was the partner. Helpers were other relatives, but also religious community or clubs for the elderly. More than three-quarters declared that the most upsetting problems in the last year were those related to health, the lack of money and, at a great distance, the family tensions. Most mentioned that the greatest joys were the children, grandchildren, the family, followed at a great distance by travels. The type of support was based on age-specific needs. Individuals with bidirectional support, with the sense of usefulness, with a positive view of life, the extraverted and the sociable were better positioned.

Conclusions. In Romania, the family is preferred as concerns the care for the elderly. The most vulnerable elderly people are those with health problems and low incomes. Social isolation must be prevented through the civic and cultural participation of the elderly in society. The encouragement of people to monitor and improve their health should be constantly promoted.
\end{abstract}

Keywords: aging, intergenerational care, elderly, loneliness, solidarity

\section{Introduction}

Taking into account the growing aging of the population, the United Nations Organization launched in Madrid in 2002 the invitation of "building a society for all ages". The Madrid International Plan of Action on Ageing was initiated, and a Political Declaration was adopted at the Second World Assembly on Ageing (Political Declaration and Madrid International Plan of Action on Ageing, 2002). This involves the integration and participation of the elderly in society, the adoption of measures to promote successful aging, the promotion of intergenerational relations based on co-operation. Romania had representatives at this meeting.

In 21 st century Europe, especially in countries with a high standard of living, the existence of great-grandparents and of 3-4 generations at the same time is common. Demographically speaking, the phenomenon is quite recent. For example, before the Second World War, life 
expectancy at birth was 42.0 years in Romania. Then the decrease to about half of the mortality rate per 1,000 inhabitants led to an increased life expectancy at birth of 63.2 years calculated in 1956 . Then the increase was lower, reaching 67.33 years between 1968 and1970.

Some important indicators for the elderly population registered in 2014 are summarized in the data provided by the National Institute of Statistics (National Institute of Statistics, 2016).

Life expectancy at birth in 2014 in EU-28 member countries was 83.6 years for males and 78.1 for males. In Romania, it was 4.9 years less for females and 6.7 years less for males.

Elderly people have less good health and higher mortality so that a good indicator of longevity is life expectancy at the age of 65. Life expectancy at 65 years in EU-28 member countries in 2014 was 21.6 years for women and 18.2 for men. In Romania, it was 3.5 years lower for both sexes. Knowing the number of years that a person can live is important for shaping policies related to pensions and elderly care, and largely reflects the living conditions of the population.

A subtler indicator, which Romania has calculated after the EU joining in 2007, is the healthy life expectancy that measures on the average period a person is expected to live at a certain age in good health, taking into account the specific rates of mortality, morbidity, and disability risk for that year. It is used to monitor the functional changes in the elderly population, aiming at ensuring and promoting active aging. It is estimated that at the EU level of life expectancy at 65, women and men can expect to have a healthy life of 8.6 years. In Romania, out of the life expectancy of 18.02 years for 65-year-old women, 5.7 years are expected to be lived in good health; as concerns the 65-year-old men, out of 14.68 years of life expectancy, 5.9 years are expected to be lived in good health (National Institute of Statistics, 2016).

The increase of life expectancy, of longevity, makes most people more or less in need to receive help. In the USA and Europe, it has not been identified a law obliging adult children to care for and support their elderly parents, as there is one according to which parents have to take care of their minor children, and yet most elderly people receive help from their children. Altruism and reciprocity are involved in these support flows.

Life expectancy increase makes most of the people to be more or less in need for support (Künemund, Motel-Klingebiel and Kohli, 2005).

Three main types of intergenerational support can be distinguished (Morelli, Lee, Arnn and Zaki, 2015): instrumental, practical support in the form of services, such as caring for parents when they are ill and disabled, caring for grandchildren, great-grandchildren by parents, respectively grandparents. social, emotional support such as visits, phone calls, attention, etc. Financial support, such as money given to children by their parents when they buy a house, or money given to parents by their children when they retire and their income is reduced or when they need health care.

In the context of the above-mentioned ideas, this study aims to evaluate and identify the support flows within family members, the people involved in helping the elderly, and their most recent problems and joys.

\section{Material and methods}

\section{Design and sampling}

This article is based on a quantitative cross-sectional study carried out (2016-2017) on a total of 601 patients aged between 55-93 years old without apparent problems regarding family. Patients were treated within Ana Aslan National Institute of Gerontology and Geriatrics. Table 1 displays the basic sociodemographic variables of the sample population. 
Table 1. Sociodemographic and family characteristics of the participants

\begin{tabular}{|c|c|c|}
\hline Sociodemographic data & $\mathrm{N}$ & $\%$ \\
\hline \multicolumn{3}{|l|}{ Gender } \\
\hline Female & 492 & 81.9 \\
\hline Male & 109 & 18.1 \\
\hline \multicolumn{3}{|l|}{ Age groups (years) } \\
\hline $55-64$ & 224 & 37.3 \\
\hline $65-74$ & 272 & 45.3 \\
\hline $75-84+$ & 105 & 17.4 \\
\hline \multicolumn{3}{|l|}{ Place of residence } \\
\hline Urban & 445 & 74.0 \\
\hline Rural & 156 & 26.0 \\
\hline \multicolumn{3}{|l|}{ Marital status } \\
\hline Married & 318 & 52.9 \\
\hline Widowed & 202 & 33.6 \\
\hline Divorced & 55 & 9.2 \\
\hline Consensual union over 1 year & 19 & 3.2 \\
\hline Unmarried (single) & 7 & 1.2 \\
\hline \multicolumn{3}{|l|}{ Employment status } \\
\hline $\begin{array}{l}\text { Not working (pensioners (retired), } \\
\text { housewife) }\end{array}$ & 574 & 95.5 \\
\hline Working & 27 & 4.5 \\
\hline \multicolumn{3}{|l|}{ Education } \\
\hline $\begin{array}{l}\text { Elementary/high school (up to } 12 \\
\text { years of school) }\end{array}$ & 167 & 27.8 \\
\hline $\begin{array}{l}\text { Lyceum/ school of foreman in a } \\
\text { profession }\end{array}$ & 305 & 50.7 \\
\hline University degree & 129 & 21.5 \\
\hline \multicolumn{3}{|l|}{ Children in the family } \\
\hline 0 & 57 & 9.5 \\
\hline $1+$ & 544 & 90.5 \\
\hline \multicolumn{3}{|c|}{ The number of family members living with the respondent including himself } \\
\hline 1 & 175 & 29.1 \\
\hline 2 & 278 & 46.3 \\
\hline 3 & 58 & 9.7 \\
\hline 4 & 34 & 5.7 \\
\hline $5+$ & 56 & 9.2 \\
\hline
\end{tabular}


Based on the doctor's recommendation and diagnosis, up to 15 blood tests were performed (usual clinical parameters) on the patients. Several questionnaires on personality, depression, memory, quality of life, family, and an omnibus-type questionnaire with 36 items collecting sociodemographic data, data on behaviors harmful for health, opinions, and attitudes relevant to the health of the elderly were applied. The questionnaires were completed in the form of a face-to-face interview conducted by a psychologist with each patient. The response rate was $100 \%$. In addition, between 2015-2017, face-to-face interviews with 50 subjects were organized on 4 themes, one on intergenerational support.

This paper explores some fragments of the interviews concerning the help received within the family as well as the answers from 5 items in the omnibus questionnaire, namely: 1. To what extent do you help (did you help) your close relatives (financially, emotionally, with cleaning or shopping, etc.)? 2. To what extent did your close relatives help you (financially, emotionally, with cleaning, shopping, etc.)? Variants of answer: grandchildren, children, parents, grandparents, brothers, sisters. 3. What other people help you in case you need it? Variants of answer: partner, friends, neighbors, other people namely... With the degrees of intensity: a lot, a little, almost not at all, it is not the case. Open questions: 4. What is the biggest problem in the last year that upsets you? 5. What are the greatest joys of the last year?

\section{Results}

The option "it is not the case" was eliminated from the analyses.

Table 2 shows that the main beneficiaries of the respondents' support were children and parents. More than $80 \%$ of the respondents helped "a lot" their children and parents.

Table 2. The distribution of the respondents according to the intensity of their support to the relatives

\begin{tabular}{|l|c|c|}
\hline $\begin{array}{l}\text { Beneficiaries of the } \\
\text { respondents' support \% }\end{array}$ & A little, almost not at all & A lot \\
\hline Grandchildren & 27.5 & 72.5 \\
\hline Children & 18.5 & 81.5 \\
\hline Parents & 21.4 & 78.6 \\
\hline Grandparents & 53.4 & 46.6 \\
\hline Brothers, sisters & 49.1 & 50.9 \\
\hline
\end{tabular}

The main support providers to the respondents were their children and parents. Over $60 \%$ received "a lot" of support from their children and parents (table 3 ).

Table 3. The distribution of the respondents according to the intensity of the relatives' support

\begin{tabular}{|l|c|c|}
\hline $\begin{array}{l}\text { The support that the relatives } \\
\text { granted to the respondent \% }\end{array}$ & A little, almost not at all & A lot \\
\hline Grandchildren & 52.8 & 47.2 \\
\hline Children & 32.8 & 67.2 \\
\hline Parents & 39.3 & 60.7 \\
\hline Grandparents & 58.1 & 41.9 \\
\hline Brothers, sisters & 59.0 & 41.0 \\
\hline
\end{tabular}


Another major support provider was the partner (table 4).

Table 4. The distribution of the respondents according to the intensity of the support received from other people

\begin{tabular}{|l|c|c|}
\hline $\begin{array}{l}\text { The support received by the } \\
\text { respondent from other people } \\
\%\end{array}$ & A little, almost not at all & A lot \\
\hline Partner & 17.9 & 82.1 \\
\hline Friends & 62.5 & 37.5 \\
\hline Neighbors & 69.1 & 30.9 \\
\hline
\end{tabular}

The respondents mentioned other support providers, mainly relatives, such as daughters-inlaw, sons-in-law, godchildren, godparents, brothers-in-law, sisters-in-law, uncles, aunts, and also communities like religious ones, or elderly clubs.

Asked about the biggest problems in the last year that upset them, over three-quarters of the respondents specified health problems related to themselves, to the spouse or to another family member, followed by the lack of money and at a great distance by the tense relationships within the family.

Asked about the greatest joys of the last year, most of the respondents indicated children, grandchildren, family, followed at a great distance by travels.

Below are some fragments of interviews, performed in 2015-2017, with suggestive life situations as concerns the intergenerational support flows.

"On a Friday afternoon, I met at the train station the parents of a former high school classmate (author's note: the generation of 1976). They were beautifully dressed, they looked happy, and had some luggage. We greeted, exchanged a few words about myself and my parents, and asked them where they were going. They answered: "we are going to the children, as they celebrate 10 years since their marriage." I asked them to send their daughter and their son-in-law my best regards and I wished them to have a nice time. They got on their train carriage and I got on mine. They had transmitted me a positive emotion. During the trip, I nostalgically remembered the high school years, the party for my classmate's wedding, and other things of my youth. Then I thought that my mother told me when she saw me, "welcome my little girl," though I was almost 40 years old. I found it interesting that they talked about their son-in-law as if he was their son. My parents, though they liked and accepted my husband, have never perceived him so close.

I turned on my laptop to write an article I was going to send to a magazine, as I had two hours of travel when I could do something. Yet, I could not do much, though it was necessary because I had a deadline for submitting the proofed document. I was visiting my mother's house for the second annually almsgiving celebration since my father had died. I felt a mixture of annoyance and sadness because only three years ago, with the same train, they both had come to me and my husband to help us with the renovation of our house. Although my father was 72 years old and my mother 61 years old, they were pretty vigorous and energetic to get involved in the supervision of workers, cleaning, and other household chores and everything involved by those three weeks of renovation chaos. I had lived with my parents until I was 32 years old, in S (a small town), and I got married and moved to a distance of $150 \mathrm{~km}$ in B town (a big city). Almost always I felt and enjoyed the support of my parents in any form: money, advice, care, even after I had my own family. I was somehow annoyed by my selfishness because they were truly listening and helping me almost every time, while I did not manage to fulfill their needs. I was so caught up with the professional 
development that I did not allow myself time for anything else. I often told them of my dissatisfactions, my efforts at work, and they used to encourage me and talk to me about patience, diplomacy, emotional intelligence, and so on.

In the year my dad died I spent a week of holidays with my parents in their house in my hometown. I noticed that my father was eating very little and had lost weight, but I did not insist enough that he came with us to take him to a good hospital for investigations. When they accompanied me to the train station, my luggage was full of good food made by them, and my soul was filled with the energy they had inspired me. It did not cross my mind that only a few months later my dad would die in his sleep because of a cardiac arrest. I'm almost sure my dad did not come for the investigations because he did not want to be a burden for me. I still do not know whether the reason I did not insist that he should come was not to disturb my career plans; it is difficult to integrate the feelings of embarrassment and guilt that activate from time to time. This was the situation with intergenerational support: only from them to me." (P.C., 44 years old, female, psychologist, registered in 2016)

"Before my graduation and many years after began to work, my parents helped me constantly with money. At the time when food was rationalized (author's note: before 1989) and it was hard to find anything to buy, I went home during holidays with college mates, and then with my colleagues, and my parents did their best so that we had all comfort. They also paid the first and all the following installments for the apartment where I live. My first piece of furniture was bought entirely by them. Then I had my own salary, but whenever I went to visit them they gave me some money. After I got married, we started to meet only at Easter and Christmas, when I visited them with my wife. At a certain moment, my mother asked my wife to tell me to come for a weekend visit because they had something to talk to me. I was worried a little believing there was some health issue. My mother told me that their pensions were no longer enough for them to live up to the desired standard and asked me to support them financially. Since then I have sent them a sum of money every month. Then, one year after my father had been diagnosed with Alzheimer's disease, he had to be hospitalized in a private specialized home, which costs I paid for a full year. My mother had a lot of trouble with my father as he had become dangerous and aggressive, but she opposed his hospitalization. She always said that she would be ashamed and that the world would say she abandoned him.

My mother is 88 years old and I have been sending her money monthly for 15 years. I am pleased that my income allows me to help her. For about two years, since she was diagnosed with diabetes, she has been complaining that she cannot handle household cleaning and shopping anymore, so we pay weekly a lady who helps her with these activities. Even at this age, she invites friends to coffee or dinner, they talk and listen to music." (R.A.O., 64 years old, male, engineer, registered in 2016)

"Until two years ago I worked full-time, but my colleagues from the Institute used to say that I should have allowed the younger people to be promoted. As I can still work it would be a pity to stay at home, and the money I earn is used to pay for my granddaughter's private lessons. I have been writing a book and, at the end of the year, I am going to send it to the publishing house. I think it will be the last one; in fact, I would have another theme to develop in a smaller volume, but I believe that the Institute will no longer approve my request to prolong my activity. Besides, I have noticed that many young people look at me tacitly and I even heard them saying behind my back that I'm outdated and tired.

My wife is also strong, but she has not been working for more than 15 years since our granddaughter was born. As a professor, she could have continued her work, but we discussed with 
our son and we decided that it was better than sending her to nursery, and institutions that offer after-school programs or hiring a babysitter. We live on the same street and it was easy. My granddaughter even now, when she returns from high-school, she comes to our house, eats and does her homework. I have taught her to drive a motorcycle, of course not on public roads, and she's looking forward to turning 18 years old so that she could have a license. In the city I have not been driving the car and the motorcycle for four years and not because I cannot do it as psychomotricity, coordination, reflexes, and vision are good, but I am afraid of these reckless young people who drive carelessly at high speed, like madmen.

I have a good genetic background, my wife has some heart problems and some knee pains, but I hardly catch any cold. My maternal grandparents were 80 years old at a time when life expectancy did not even reach 60 years old. So did my parents. In autumns we used to go to the country, and with them, my son, his wife, my brother, my sister-in-law and my grandchildren harvested the grapes and made wine. Then we recollected youth memories, laughed, sang, and played Moldavian traditional dances. Now that they have died, a cousin takes care of the house and every autumn we all meet there at the parental home, we talk and have fun." (C.V., 79 years old, male, biologist, works part-time in research, registered in 2017)

"For me, every day means a victory against the disease. For over 15 years I have been struggling with an autoimmune disease that does not heal, and science cannot do much. I make efforts so that I do not retire because without my husband's income I could hardly manage. We do not have children, I am his support, and he is mine. I cultivate a positive attitude, I believe in the power of the mind, but sometimes I feel overwhelmed by this permanent, invalid physical sufferance.

At some distance, my relationships with relatives are on the phone, more from politeness. As regards my neighbors I greet them, but I would not want anything more. I hardly used to accept someone in my life and at the same time I did not like to meet a group, I preferred to meet only one friend. Now I do not even do that anymore and I have a sense of loneliness. For some time, I have begun to enjoy the idea of the spiritual support within the religious community or sharing cultural spiritual moments in a group I have something in common with." (R.C., 65 years old, female, doctor, works in a private clinic, registered in 2016)

\section{Discussions}

Similar to other studies, it was highlighted that most of the caregivers of the elderly are the adult children (Silverstein 2016).

Most of the parents contribute to the support of their children as young adults, living together in a common residence and providing parental transfers. At least in this stage of their life cycle, the young people do not have the proper financial resources without the support of their parents. Consequently, in some studies there were no answer options regarding the level of the respondents' help to their children, considering that parents naturally help their children. This was the case in the 2011-2012 Romanian research, on a randomly selected sample of 1,215 subjects aged between 18 and 74 and based on 100 face-to-face individual interviews in urban and rural areas. The results showed a strong intergenerational support between children and parents and vice versa, and that grandparents helped grandchildren more often than their grandchildren helped (Rada, 2014). By comparing the current sample with the above-mentioned one it can be considered that between the elderly parents and their adult and even elderly children were similarly good relationships (the average age of the subjects was 67.35 years and the average age at the birth of the first child was 
24.18 years). At the same time, the current study also revealed that grandparents helped grandchildren more often than their grandchildren did.

The support from children to parents and vice versa tends to be different. For example, Brandt, Haberkern, Szydlik using data from The Survey of Health, Ageing and Retirement, 2004 (28,517 people older than 50 years from Sweden, Denmark, Holland, Belgium, France, Austria, Switzerland, Spain, Italy, Greece, and Germany) found that especially in the Mediterranean countries, then in Austria and Switzerland, more children take care of their own parents, while in the Scandinavian countries, France, and Germany the care is lower (Brandt, Haberkern and Szydlik 2009). The current study shows that in Romanian family is preferred to take care of the elderly like in the Mediterranean model and unlike the northern one in which state support is preferred. Different factors are involved, such as geographical distance, workplace, education level, health perception, age, family structure, cultural context, social services, specialized institutional assistance, state support, the economic level of the family and of the country, etc. The transfer of elderly care to the state makes the generations more independent, but it is recognized that solidarity between generations in the care of the elderly is significant in the modern welfare states both in the north and in the south (Daatland and Lowenstein 2005). In the case of the elderly, the situational loneliness may happen after satisfactory relationships when specific stress-generating events occur, such as withdrawal from the working group through retirement, death of the partner, disease (Peplau, 1985).

A recent study showed that living as a single person, dissatisfaction with the status of retired, and problems encountered in obtaining the basic daily living resources were associated with a higher level of perceived loneliness among the elderly from Romania, Bulgaria, and Russia" (Faludi, 2015).

In the interview with the RC, of 65 years old, retirement and disease determined the strengthening of the less sociable pattern of the person. A poor satisfaction of the social relationships over a longer period has made loneliness to become chronic, an aspect that RC tried to overcome by choosing a spiritual group or similar values.

Personal health and well-being are positively influenced by the existence of social, friendship. An American study of 7,638 people, over 50 years, which analyzed national data from 1996, 1998, 2000 and 2004, identified both situational loneliness and chronic loneliness as risk factors for mortality (Shiovitz-Ezra and Ayalon, 2010). The good quantity and especially the quality of the social relations, the contact with neighbors, friends, and mainly with family members decrease the risk of sentimental loneliness (Pinquart and Sorensen, 2001). This is the case of the 79year-old CV, whose account reveals a good, genuine, natural, and optimistic spirit, and cooperation between the members of the family of origin and between the members of the family of procreation, vertically and horizontally. The future plans for professional achievements and for the granddaughter, the absence of chronic disabling illnesses, due to the good genetic background, the sociable nature, the cheerful, optimistic way of looking at the future, the good family relationships, the sufficient income and the sense of usefulness have been mutually reinforced. This case can be considered as one of successful aging.

Similar to other studies (Silverstein and Giarrusso, 2010) the interviews revealed that the type of support was based on the needs specific to the age and the stage in the life cycle. For instance, parents offered money to the adult children with poor economic resources, and the adult children offered social support and care to the parents with health problems.

Similar to other studies (Heylen, Mortelmans, Hermans and Boudiny, 2012) interviews showed that family proximity was important in exchanging help, but families offered support if needed, even if they were at a distance. 


\section{Conclusions}

This study shows that family members have good co-operation resources, and practical, emotional, and financial support are present to a large extent. Children and grandchildren have been identified as important resources of joy which shows good family relationships. The study has highlighted that the most vulnerable elderly are those with health and low-income issues, and these aspects are mentioned by most respondents. At the same time, the accounts have emphasized the fact that people with bidirectional support, with a sense of usefulness, with a positive view on life, the extraverts and the sociable ones have a better life.

Social isolation must be prevented through the civic and cultural participation of the elderly in society. The encouragement of people to monitor and improve their health should be constantly promoted.

At society's level, it is essential to develop strategies, programs for stimulating elderly and young people to cooperate and to support each other with resources such as volunteering. On the one hand, the children and young people need models and mentors to share them their life experience, and, on the other hand, the elderly need support from young people.

Education is important in order to avoid age-related negative stereotypes, both because they have the potential to strengthen the prejudices or discrimination of the elderly, and because they influence the person to develop patterns of behavior, thinking, and emotions that confirm that negative stereotype.

\section{Acknowledgements}

The quantitative data of this study were based on the project Quantitative and qualitative study on successful aging, a psycho-socio-medical approach on third age, made by "Francisc I. Rainer" Anthropology Institute of the Romanian Academy (No. 691/12.08.2015) and "Ana Aslan" National Institute of Gerontology and Geriatrics (No. 10413/01.09.2015) from Bucharest. The topic was approved by the Scientific Council of the "Francisc I. Rainer" Anthropology Institute of the Romanian Academy (No. 1021 / 04.11.2015). Project Managers Rada C., Drăghici R. Participants: Ispas A.T., Baciu A.B., Prada G.I., Pena C., Vârtan I., Stan P., Lazăr C.

\section{Ethical considerations}

Written informed consent was obtained from each participant at the time of recruitment. The subjects were informed that they could withdraw from the study at any stage, and confidentiality was assured. The study was approved by the Ethics Commission of the "Francisc I. Rainer" Anthropology Institute of the Romanian Academy, (No. 153/01-03-2016).

\section{Bibliography}

1. Brandt, M., Haberkern, K. and Szydlik, M., 2009. Intergenerational Help and Care in Europe, European Sociological Review, 25(5), pp.1-17, DOI:10.1093/esr/jen076, Available at: <www.esr.oxfordjournals.org> [Accessed 4 August 2017].

2. Daatland, S.O. and Lowenstein, A., 2005. Intergenerational solidarity and the family - welfare state balance, European Journal of Ageing: Social, Behavioural and Health Perspectives, 2(3), pp.174-182, doi: 10.1007/s10433-005-0001-1. 
3. Faludi, C. 2015. Aranjamentele de viață, starea de sănătate și singurătatea la vârstnicii din Bulgaria, România și Rusia (capitol) [Living arrangements, health status and loneliness among the elderly from Bulgaria, Romania and Russia]. In: C. Rada și C. Faludi (coord.), Funcții și disfuncții ale familiei contemporane. O abordare socio-psiho-medicală [Functions and dysfunctions of the contemporary family. A socio-psycho-medical approach], București: Editura Universitară. pp.84-124.

4. Heylen, L., Mortelmans, D., Hermans, M. and Boudiny, K., 2012. The intermediate effect of geographic proximity on intergenerational support: A comparison of France and Bulgaria. Demographic Research, 27(17), pp.455-486, doi: 10.4054/ DemRes.2012.27.17, Available at: <http://www.demographic-research.org/Volumes/ Vol27/17/, [Accessed 10 July 2017].

5. Künemund, H, Motel-Klingebiel, A. and Kohli, M. 2005. Do intergenerational transfers from elderly parents increase social inequality among their middle-aged children? Evidence from the German Aging Survey. Journal of Gerontology: Social Sciences, 60(1), S30-S36, Available at: <https://doi.org/10.1093/geronb/60.1.S30> [Accessed 19 September 2017].

6. Morelli, S.A., Lee, I. A., Arnn, M.E. and Zaki, J., 2015. Emotional and instrumental support provision interact to predict well-being. Emotion, 15(4), pp. 484-493, doi: 10.1037/emo0000084.

7. Peplau, L.A. 1985. Loneliness Research: Basic Concepts and Findings. In: I.G. Sarason, B.R. Sarason, eds. Social Support: Theory, Research and Applications. NATO ASI Series (D: Behavioural and Social Sciences), vol. 24. Springer, Dordrecht.

8. Pinquart, M. and Sorensen, S., 2001. Influences on Loneliness in Older Adults: A MetaAnalysis. Basic and Applied Social Psychology, 23(4), pp.245-266.

9. Rada C., 2014. Intergenerational family support in Romania. Revista de Psihologie, 60(4), pp.293-303.

10. Shiovitz-Ezra, S. and Ayalon, L., 2010. Situational versus chronic loneliness as risk factors for all-cause mortality. International Psychogeriatrics, 22(3), pp.455-462, doi: $10.1017 / \mathrm{S} 1041610209991426$.

11. Silverstein, M. and Giarrusso, R., 2010. Aging and Family Life: A Decade Review. Journal of Marriage and Family, 72(5), pp. 1039-1058, doi: 10.1111/j.1741-3737.2010.00749.x.

12. Silverstein, M.1, 2016. Adult Children Providing Support to their Aging Parents: Mixed Motives over the Family Life Course, Presented at the Oxford Martin School, Available at: <https://www.ageing.ox.ac.uk/download/166> [Accessed 22 June 2017].

13. ***Institutul Naţional de Statistică, Speranţa de viaţă sănătoasă, (National Institute of Statistics, Healthy life expectancy) Bucureşti, Editura Institutul Naţional de Statistică, 2016. Available at: 〈http://www.insse.ro/cms/sites/default/files/field/publicatii/_ speranta_de_viata_sanatoasa.pdf> [Accessed 19 October 2017].

14. ***Political Declaration and Madrid International Plan of Action on Ageing, Second World Assembly on Ageing, Madrid, Spain 8-12 April 2002, United Nation, New York, 2002, Available at: <http://www.un.org/en/events/pastevents/pdfs/Madrid_plan.pdf>[Accessed 10 September 2017]. 


\title{
Role Conflict among Female medical Career women: who bridges the Gap?
}

\section{DOI: http://doi.org/10.26758/8.1.14}

Oluyemi Joseph (1) Yinusa Mohammed (1) Bashiru Salawu (1) Abdulateef Raji (1) Emmanuel Atolagbe (1) and Adejoke Joseph (2)

1. Department of Sociology, University of Ilorin, Ilorin, Nigeria

2. Department of Medical Microbiology and Parasitology, Bowen University, Iwo, Nigeria.

Address correspondence to: Joseph Oluyemi, Department of Sociology, Faculty of Social Sciences, University of Ilorin, Kwara State Nigeria. Phone number: +234/018034205013. Email: josepholuyemi1@gmail.com.

\begin{abstract}
Objectives. This study investigates the conflicting roles of female medical career women in Nigeria. The objectives of the study include: to know who fills the gap as a mother and wife while they are away at work; to know if they provide the needed emotional and psychological support for their families?; to determine if these conflicting roles affect their health and who is to blame?

Materials and Methodology. The study was conducted among married female medical doctors in three Tertiary Hospitals in Nigeria. The study employed qualitative research method in which data was retrieved through in-depth interviews with 15 participants selected through multi-stage sampling method.

Results. Findings revealed that relatives, the school, and caregivers play the role of the female medical career women when they are at work while communication by career women with their families when they are not at home is done through phone calls, text messages, video calls, WhatsApp chats. The majority of the participants is unable to meet up with the role of providing emotional and psychological support for their families because of their busy schedules at work, which also affects their health adversely.

Conclusion and Recommendation. Most of the participants interviewed were found unable to effectively occupy their roles as mothers and wives in the family because of their career. The study recommends that, since the role of women in the family cannot be overemphasized and at the same time women are expected to pursue careers of their own choice, women in Nigeria should endeavor to maintain a balance in their roles as career women at work and as wives in the family.
\end{abstract}

Keywords: caregivers, relatives, female medical doctors, career women, role conflict

\section{Introduction}

The family is the smallest unit of a society and the connection between individuals, the family, and the society cannot be over-emphasized. Historically, the family was typified by gender roles, where men were breadwinners engaged in paid labor work and women specialized in unpaid domestic work and caring for the family (Crompton, 1999). But in recent time, the story has changed as more women are becoming breadwinners in families and women are no longer housewives but work alongside their husbands in the labor market (Lewis, 1997; Rubery et al., 1998). Undeniably, the participation of women in the labor force is now a global phenomenon that 
has developed significantly over the past several decades such that, the majority of women including those with toddlers now work as paid labor in previously male-dominated jobs (Kroska, 2004).

The story is not different in Nigeria. From time immemorial, the Nigerian society has been a patriarchy society (Aina, 1998), where men dominated women (Stacey, 1993; Kramarae, 1992; Lerner, 1986; Humm, 1989; Aina, 1998), and do not participate in domestic work since such tasks are considered to be the exclusively reserved to women (Bernard, 1981; Aweda, 1984; Carrigan, Connell and Lee, 1987; Stocvk, 1995; Silberschmidt, 1999). According to Makama (2015), women constitute about half of the population in Nigeria and are known to play vital roles in the family and the society at large, which cannot be undermined. Men were the main breadwinners, while women were saddled with domestic responsibilities and the socialization and monitoring of young children (Adepoju and Mbugua, 1997). But in recent time, the division of labor in the family in terms of gender roles is gradually disappearing. Women educational attainment has soared over the years and as such, gender inequality in formal employment has drastically declined (Wusu and Abanihe, 2007).

The economic hardship prevailing in the country is also gradually making it a norm for women to make a substantial contribution to family income in order to cater adequately for family needs, and thus, women are increasingly taking up roles that were traditionally reserved for men (Odunaike, 2012). A number of studies have attempted to downplay the magnitude of the contributions of wives earnings to family income (Hansen, 1991). Nevertheless, wives' incomes are seen as benefiting the family in many ways. As such, women now play multiple roles in the society since women are the significant agent of household chores, socialization, and childbearing and have to still carry out their economic roles as formal employees. Therefore, due to the rising number of mothers now in paid employment, the demands at workplaces are increasingly harming the wellbeing of their children (Ering, Akpan and Echiegu, 2014).

Today, educated women are found in virtually all professions, including medicine, and, as such, the care of young children is now being transferred to the larger society (Fapounda, 2014). Women have begun to experience conflict with the competing roles they play at their workplaces and that of the family (Lussier, 2002). Balancing work and family life is increasingly becoming an issue because the family is negatively affected (Aaron-Corbin, 1999; Gryzwacz and Carlson, 2007), as these two domains, though different, are sometimes interdependent and strongly influences each other (Odle-Dusseau, Britt and Bobko, 2012). Both men and women may be said to experience inter-role between work and family (Walker, Wang and Redmond, 2008), women typically assume more family responsibilities than men (Pilinger, 2002). Managing these roles in a patriarchal society like Nigeria may, however, be difficult (Rehman and Roomi, 2012).

According to Okonkwo (2012), in Nigeria for example, the domestic duties of tidying home, cooking for the family, laundry work, and childcare are exclusively women's job, many of whom are also engaged in full-time paid employment. The psychological consequences of combining these roles squarely fall on women (Jacobs and Gerson, 2004), as the Nigerian society still places a premium on the traditional female role with the cultural approval of qualities such as submissiveness, subservience, and supportiveness (Kitching and Woldie, 2014). In particular, women are faced with the problem of multiple role conflict when conflicting demands of marriage, children and work impinge on their work (Aaron-Corbin, 1999). Research has shown that coordinating work and family life is quite difficult for women (Emslie and Hunt, 2009), but married women find it even more problematic (Dyrbye et al., 2014). Therefore, failure to achieve a balance between the work and family domain might have on health, general wellbeing on women (Emslie, Hunt and Macintyre, 2004). 
Research has also shown that finding an acceptable balance between career and family life is a difficult challenge for many female doctors (Verlander, 2004). The medical profession has commonly been characterized by long working hours and the obligation to put patient welfare above personal needs and family responsibilities Gjerberg (2003), which is considered a challenge, especially for a practicing female doctor. It is against the background that this study is being conducted.

\section{Theoretical Orientation}

The study was explained with the Role theory. Role Theory was postulated by Ralph Linton, an American Anthropologist, in the 1930s (Gordon, 1998). The theory was a means for analyzing social systems, in which, roles were conceived as the dynamic aspects of societally recognized social positions or statuses. Role theory argues that human behavior is guided by expectations held both by the individual and by others in the community. It assumes that individuals are members of social positions and hold expectations for their own behaviors and those of other persons. According to the theory, people take distinct positions in the groups they form; these positions are roles, with a set of functions that are molded by the expectations of others. The theory emphasizes on role conflict, which occurs when a person is expected to simultaneously act out multiple roles that carry contradictory expectations. The theory states that role conflict occurs when there are incompatible demands placed upon an individual, such that compliance with all these demands would be difficult. Individuals thus experience role conflict when they find themselves pulled in various directions, as they try to respond to the many statuses they occupy.

Resting on the theory, it can be assumed that female married medical doctors would experience role conflict in the process of occupying various statuses. For instance, role conflict would occur while trying to be a mother and a wife in the family and a doctor at work.

Doctors generally experience a high level of stress as a result of the increased workload with low control over the job (Fuß al., 2008). As a result, a number of doctors experience psychological problems like anxiety, depression, irritability, fatigue, sleep deprivation and substance abuse (Nogueira-Martins, Stella and Nogueira, 1997; Levey, 2001). Often, doctors have to attend to emergency cases and patients with life-threatening illnesses which are usually complicated by their ever busy schedules and disproportionate doctor-patient ratios. The Nigerian health care system is no exception to this. The system is bedeviled with underfunding, dilapidated structures, poor staffing, and inadequate equipment thereby complicating the ordeals of doctors in the system (Onasoga, Ogbebor and Ojo, 2013; Etim, Bassey and Ndep, 2015).

Female doctors have been recognized as core professionals everywhere they are found, whether married or single (Amazu, 1995). However, these conflicting roles have been found to be more demanding for women (Wolfe, 2017). Though both men and women usually experience role conflict between work and family (Walker, Wang and Redmond, 2008), it is assumed that women typically assume more family roles than men (Pillinger, 2002). Research has shown that combining work and family obligations could be difficult for female medical doctors in a patriarchal society like Nigeria (Rehman and Roomi, 2012). In Nigeria, for example, the domestic chores of cooking, tidying up of the house, laundry, and childcare fall basically on women who need to combine these with their career and when a balance cannot be struck between both roles as a mother and a career woman, one suffers at the expense of the other, thus constituting a conflict between their role at home and in their chosen career. In the same time, men take up more masculine roles, thus generating role conflict for those that are working like female medical doctors. 


\section{Materials and Methodology}

This study employed the qualitative method of inquiry, which includes an exploratory and explanatory case study approach to unravel the difficulties confronted by the Nigerian female medical doctors in their attempt to occupy the roles of wives and mothers in the family as well as pursuing their career as Doctors.

The particular choice of a qualitative approach was informed to gain insight into the reality of the role conflict experienced among female doctors in the Nigerian context. According to De Ruyter and Scholl (1998), qualitative research method provides researchers with knowledge of what people think about a particular subject and what makes their thinking differ from other people's thoughts.

The study focused on a group of participants, which were married female medical doctors. The study was conducted among female medical doctors in three tertiary hospitals in Nigeria, which include: Bowen Teaching Hospital, Ogbomoso, Oyo State, Nigeria; Ladoke Akintola University of Technology, Ogbomoso, Oyo State, Nigeria; and University of Ilorin Teaching Hospital, Ilorin, Kwara State, Nigeria. The study population was purposively selected in order to have a spread of doctors in various cadres and specialties.

15 married female medical doctors, selected through multi-stage sampling method, were involved in the study cutting across House officers, Medical Officers, Residents, Senior Residents, and Consultants, while information was retrieved from participants through unstructured in-depth interviews. Participants' consent was sought before the interview was conducted and informants' identities were treated with anonymity to gain the participants' confidence. The participants were given the opportunity to opt out of the research before or during the interview; therefore, they were given free will to participate in the research. To protect the confidentiality of the participants, the identities of the participants were identified with their position in the hospital.

\section{Results}

\section{Who Bridges the Gap?}

Most of the participants in the study had one person or another who stood in for them to cater for their children and husbands when they were away at work. Findings revealed that, because of the conflicting role of doctors at work which afforded them very little time to attend to the family responsibilities, many of the participants had to employ the service of caregivers, relatives like mothers-in-law, sisters-in-law and their mothers, to fill the gap and play their role in their absence as mothers and wives at home. Some participants had this to say.

"Raising up children as a doctor is not easy at all.... I had my first child as a house officer. My child was just three weeks old when I took up the job and it wasn't easy at all. I had to bring in my sister to come and stay with me until the child was six months because I had to do exclusively for six months breastfeeding so most time I had to do breast expression because I couldn't go to feed my baby myself. When my sister left for school, my mother in law came in to stay for a while but because she is a civil servant she had to also go back to work, so, I had to rely on the services of caregivers. As for my husband, he is a teacher so he has all the time; he does all the house chores and takes care of the children and the home when I am not there..." (Senior Registrar, LAUTECH). 
Another female medical doctor has this to say:

"Being a doctor, a wife and mother at home has been very difficult and very challenging. The late nights, there are times you have to travel, go for conferences, you have to read for exams, you really don't have the time for the children and the family, you have to depend on house helps, family members to help you care for the children and the family generally. So it's not been easy ... it's really difficult, at the initial stage it was much more difficult but as you go higher in the profession and become more senior you have more time to yourself and the family. When my children were growing up, I wasn't there at all, my mother had to stand in for me, I was never around, in fact, some of my children's teachers do not know me, they hardly ever see me, sadly my children refer to my mother as their own mother...."(Consultant, UITH).

Another participant also had this to say:

"Unfortunately for us female doctors, our reproductive age coincides with the prime years of our career period and you cannot leave one or another. At times my children come home with assignments that as a mother, I should be able to put them through but I am not always there. Recently, my child had an exam and I just couldn't help. I work for more 70 hours per week, especially when I am on call, where on earth will I have the time to attend to my family, my husband plays my role at home (laugh), he bath the children, feed them and take them to school. At times when I get home late in the night, my children would have slept, it's really sad..... Although anytime I am at home, I make up for the time I have not been around. I will ask my kids how has been your school. What has been happening to you and for my husband I ensure I give him all my time, the little time I spend at home with him, I don't do any other thing than to face my husband and children......"(Senior Registrar, LAUTECH).

\section{Do you Provide Emotional and Psychological Support for the Family?}

The majority of the participants could not provide their children and husbands the necessary emotional and psychological support because they are hardly there. Although they claimed that the bond is there, other mediums such as telephone call, text messages WhatsApp chats were employed in providing these roles while their physical presence at home was lacking Take a look at this:

"...Well am trying my best, my child is still a young child growing, when am around I do my best to make up for the lost time, like today am not working at the moment as it were, we have played football to make up for those times am not around and when he sees me, he runs to me so I think the emotional bond is there. As for my husband, he is also a doctor and he is also not always around but we try to communicate often through WhatsApp, video calls, text messages and emails to ensure that the emotional and psychological support is not lacking, hmmm.... Although the physical presence is not there, they say «out of sight is not out of mind» ... laugh" (Resident, BUTH).

Similarly, another participant has this to say:

"If not for my present posting that takes me out of town, I would have been able to meet up with this obligation. But at the moment, I can say that am lacking in this regard, especially to my child. 
Similarly, to my husband, I can equally say that I am lacking, although I am trying, whenever I am around, to make up for the time I am not around" (Resident BUTH).

\section{Does this Role Conflict affect your Health?}

The majority of the participants experience adverse health effects as a result of the conflicting roles. Some complained of the stress involved, while some others confessed that combining this role affected them both psychologically and physically. This is the experience of some of the participants:

"Yes...the work is quite demanding and stressful, especially when you have to combine it with family responsibilities. Balancing the two could be hectic, you know nobody wants to know that you are married or you have children and so you cannot live up to your responsibilities at work. Sometimes, it could bring emotional challenges, mood change, depression and all that. I work like .....60 hours per week, when you are on weekend call for example, it starts Saturday morning and ends 7:59 on Monday morning and you are expected to be at work again, so maybe the only time you have to stay off work is when you have to go freshen up and eat. It comes with dull headache sometimes, body aches and all that ....uhhh" (Senior Registrar, LAUTECH).

Another participant has this to say:

"Combining the role of a doctor at work and as a mother and wife at home is quite stressful, teaching medical students and also trying to attend to patients is time consuming and then coping with the home front is not easy. At times, I get back home very tired.... Despite this, I still have to play my role as a mother and as a wife; no matter how tired I am, I still have to prepare the meal for my children.... Hmmm, it could be quite stressful" (Consultant BUTH).

In the same vein, see what this participant had to say:

"Well...at the initial stage of my training as a resident, it wasn't easy combining the roles, it affected me psychologically, it was too demanding, I didn't even have time for myself. Unfortunately nobody cares you are married or you have children, everybody just wants the work done, except maybe when you drop down sick that is when people will say,..... ahhh you should have talked .... Ok go on two days leave and come back and finish the job, it's really crazy you know...." (Resident BUTH).

\section{Who is to Blame?}

Although some of the participants see themselves in this conflicting role because they chose to follow a career path to improve their status in the society, some other saw it as a calling. Above all, the majority sees this conflicting role as a means of complimenting family income. Here are some opinions that participants expressed:

"As a working mother, I think it is a choice that I have made as a child, I have always wanted to be a doctor and work as a wife in the future, although being a career mother and wife affords me the opportunity to add to the income of the family. If I wasn't working my husband salary would have been able to cater for the family needs" (Resident BUTH). 
Another participant with a similar view declared:

"...Actually, I believe medicine is a calling; since I was a child it has always been medicine, medicine, if I wasn't a doctor or working, I will not be fulfilled, so I love medicine. I love to work, that is why I am doing medicine. If I am not working, my husband salary would have just been ok for us but because I am working, I am complimenting the family income. I am working to buffer the family income so that we can enjoy the best of life as a family" (Consultant, BUTH).

Also, another participant had this to say:

"Hmmm... I am working to further support my family, my husband, his family, and mine. We have a lot of people to care for from both me and my husband's family, $80 \%$ of our younger ones are still in school and they depend on us for their upkeep, which we have to support. At the end of the day, it's not my income but basically "our income". Although, as a doctor, it's more of a calling and capacity building as well as to improve my status and esteem as a woman." (Resident, BUTH).

\section{Discussions}

The study has been able to explore the conflicting roles of female doctors in Nigeria as professionals and wives and mothers in the family. This study, thus, illuminates the dilemma of Nigerian female doctors in their efforts to achieve work-family balance. The findings revealed that, as a result of the role conflict, the majority of female doctors is not able to effectively occupy their role as mothers and wives in the family. Findings revealed that for most of them, the domestic role is being played by their relatives, i.e. mothers, mothers-in-law and sisters; sometimes this is done by caregivers, the school and even by their husbands. This is consistent with the previous study conducted by Fapounda (2014) who opined that the care of young children does not take place exclusively within the family group, but it is now being transferred to the larger society.

Further findings from the study revealed that participants are unable to provide emotional and psychological support for their children and their husbands, perhaps because medical doctors have the obligation to put their work duties, such as patients' care, above their families' responsibilities (Gjerberg, 2003). Most times of the day they are away at work and such role is played by teachers and the significant others. Unfortunately, some professions like medicine do not fit the typical work pattern of 9pm-5pm (Burke, 2009); the work pattern in the medical profession is characterized by long working hours (Gjerberg, 2003), and sometimes they work during vacations and holidays (Perlow and Porter, 2009), all of which further make achieving this very difficult (Johnson, 1991). Although some participants claimed they make the best use of the limited time at their disposal to catch up with what they have lost, this may not be sufficient to meet the psychological and emotional needs required for the bonding and attachment expected in the family.

Furthermore, findings from the study revealed that the conflicting is detrimental to their health. Health issues like fatigue, depression and psychological trauma resulting from the stress involved in combining the two roles were noted in the study. This is in line with previous studies conducted by Firth-Cozens (2003), Keene and Quadagno (2004), and Wong (2008), which suggested that the occupational workload of the medical profession is huge and thus female doctors become fatigued and drained and unable to perform their roles in the family at the end of their daily shifts. This finding also resonates with Noor (2002), on the argument that when people devote too much time to work, there is every likelihood that other function would be negatively affected. 
Above all, while some participants see their role of doctor as a calling, others see it as a means to raise their status as women. Nevertheless, the majority of the participants confessed that they actually engage in the dual role to help increase the family income. These findings rest on the view of Choji (2012), regarding the changing role of the woman in the family.

\section{Conclusion and Recommendations}

The study explored the conflicting role of female doctors as mothers and wives in the family. The objectives of the study included: to know if female doctors provide psychological and emotional support for their families, to know who fills the gap, to know if the dual role affects their health and to determine who is to blame for their predicament. This study used the traditional qualitative method of inquiry which includes an exploratory and explanatory case study approach to unravel the difficulties confronted by the Nigerian female medical doctors in their attempt to balance their work and family lives obligations.

The study focused on a group of participants, which were married medical doctors. The study was conducted among doctors in three tertiary hospitals in Nigeria: Bowen Teaching Hospital, Ogbomoso, Oyo State; Ladoke Akintola University of Technology, Oyo State and University of Ilorin Teaching Hospital, Kwara State. 15 married doctors were involved in the study cutting across House officers, Medical Officers, Residents, Senior Residents and Consultants, while information was retrieved from participants through unstructured in-depth interviews.

Findings revealed that many female doctors in Nigeria are not able to effectively occupy their role as a mother and wife in the family as a result of the role conflict with their professional status. The study recommended that, since women have vital roles to play in ensuring the continued existence of the family and the society at large, and at the same time pursue careers of their choice, women in Nigeria should endeavor to balance their roles as career women at work and wives in the family.

\section{References}

1. Aaron-Corbin, C., 1999. The Multiple role balancing act. Management Review, 88(9), pp. 6270.

2. Adepoju, A. and Mbugua, W., 1997. The African Family. An overview of changing forms. In: A. Adepoju, ed. 1997. Family, population and development in Africa. London: Zed Books. pp.41-59.

3. Aina, I. O., 1998. Women, culture and society. In: A. Sesay \& A. Odebiyi, eds. 1998. Nigerian women in society and development. Ibadan, Nigeria: Dokun Publishing House/INTEC. pp. 3-33.

4. Amazu, A. in dialogue with Fr. Omexiri. Nigeria: Female Doctors, Indefatigable. Copyright (C) 2008 Daily Champion. January 25, 2008. Available online from: http://allafrica.com/stories/200801250261.html [Accessed 22 January 2018]

5. Aweda, A. D., 1984. Sex-Role Inequalities in the African Family: Contemporary Implications. Ife Social Sciences Review, 7(1 \& 2), pp.188-197.

6. Bernard, J., 1981. The Good-Provider role: Its rise and Fall. American Psychologist, 36(1), pp.112.

7. Burke, R. J., 2009. Cultural values and women's work and career experiences. In: R. Steers and R. Bhagat, R., eds. Handbook of cross-cultural research. Cambridge: Cambridge University Press, pp.442-461. 
8. Carlson, D.S, Kacmar, K. and Stephina, L.P., 1995. An examination of two aspects of workfamily conflict: Time and identity. Women in Management Review, 10 (1), pp.17-25.

9. Carrigan, T., Connell, B. and Lee, J., 1987. The 'Sex-Role' Framework and the Sociology of Masculinity in G. Weiner and M. Arnot, eds. Gender Under Scrutiny: New Inquiries in Education. London: Hutchinson in association with the Open University.

10. Choji, R., 2012 Nigeria: Women Are Taking Over the Role of Bread Winner in Nigeria., Copyright (c) 2012 Leadership, July 24. Available from: http://allafrica.com/stories/201207250512.html. [Accessed 17 July 2017].

11. De Ruyter, K., and Scholl, N., 1998. Positioning qualitative market research: reflections from theory and practice. Qualitative Market Research, 1(1), pp.7-14.

12. Dyrbye, L. N., West, C. P., Satele, D., Boone, S., Tan, L., Sloan, J., Shanafelt, T. D., 2014. Burnout among U.S. Medical Students, Residents, and Early Career Physicians Relative to the General U.S. Population. Academic medicine , 89(3), pp.443-451.

13. Emslie, C., Hunt, K. and Macintyre, S., 2004. Gender, work-home conflict, and morbidity amongst white-collar bank employees in the United Kingdom. International Journal of Behavioral Medicine. 11(3), pp.127-134.

14. Emslie, C. and Hunt, K. 2009. Live to work or work to live? A Qualitative study of gender and work-life balance among men and women in midlife. Gender work and Organization, 16 (1), pp.151-172.

15. Ering, S. O., Akpan, F. U., and Emma-Echiegu, N., 2014. Mothers Employment Demands and Child Development: An Empirical Analysis of Working Mothers in Calabar Municipality. American International Journal of Contemporary Research, 4(4), pp.184-191. Available from: http://www.aijcrnet.com/journals/Vol_4_No_4_April_2014/24.pdf.[Accessed 11 July 2017].

16. Etim, J. J., Bassey, P. E., Ndep, A. O., Iyam, M. A., Nwikekii, C. N, 2015. Work-related stress among healthcare workers in Ugep, Yakurr Local Government Area, Cross River State, Nigeria: a study of sources, effects, and coping strategies. International Journal of Public Heath, Pharmacy and Pharmacology, 1(1), pp.23-34. Available from: http://www.eajournals.org/wpcontent/uploads/Work-----Related-Stress-among-Healthcare-Workers-in-Ugep-Yakurr-LocalGovernment-Area1.pdf. [Accessed 23 January 2018].

17. Fapounda, T.M., 2014. A Comparative Study of Work-Family Balance of Female Journalists and Nurses. International Journal of Research in Humanities and Social Studies, 1(1), pp.77-82. Available from: http://www.ijrhss.org/pdf/v1-i1/10.pdf. [Accessed 12 July 2017].

18. Firth-Cozens, J., 2003. Doctors, their wellbeing, and their stress. BMJ , 326, pp.670-671.

19. Gjerberg, E., 2003. Women doctors in Norway: the challenging balance between career and family life. Social science \& medicine, 57(7), pp.1327-1341.

20. Gordon, M., 1998. Role Theory. In: Oxford Dictionary of Sociology. Oxford, New York: Oxford University Press.

21. Gryzwacz, J. G. and Carlson, D. S., 2007. Conceptualizing work-family balance: Implications for practice and research. Advances in Developing Human Resources, 9(4), pp.455-471.

22. Hansen, S. L. and Ooms ,T., 1991. The Economic Costs and Rewards of Two-Earner, TwoParent Families, Journal of Marriage and Family, 53(3), pp.622-634.

23. Humm, M.,1989. The Dictionary of Feminist Theory. London: Harvester Wheatsheaf.

24. Fuß, I., Nübling, M., Hasselhorn, H.-M., Schwappach, D. and Rieger, M. A., 2008. Working Conditions and Work-Family Conflict in German Hospital: Physicians Psychosocial and Organizational Predictors and Consequences. BioMed Central Public Health, 8, pp. 353.

25. Jacobs, J. and Gerson, K., 2004. The time divide work, family and gender inequality. Cambridge, MA: Harvard University Press. 
26. Johnson, W. D., 1991. Predisposition to emotional distress and psychiatric illness among doctors: The role of unconsciousness and experimental factors. British Journal of Medical Psychology, 64(4), pp.317-329.

27. Keene, J. R. and Quadagno, J., 2004. Predictors of perceived work-family balance: gender difference or gender similarity. Sociological Perspectives, 47(1), pp.1-23.

28. Kitching, B. and Woldie, A. 2004. Female Entrepreneurs in Transitional Economies: a comparative study of Businesswomen in Nigeria and China. In: 4th annual Hawaii International Conference on Business, 21-24 June 2004, Honolulu, Hawaii. Available from: http://eprints.qut.edu.au/1168/. [Accessed 12 July 2017].

29. Kramarae, C., 1992. The condition of Patriarchy. In: Kramarae Cheris and D. Spender Dale, eds. The Knowledge Explosion: Generation of Feminist Scholarship. Athen Series, London: Teachers College Press.

30. Kroska, A., 2004. Divisions of domestic work: Revising and expanding the theoretical explanations. Journal of family issues, 25(7), pp.900-932.

31. Lerner, G., 1986. The Creation of Patriarchy. Oxford: Oxford University Press.

32. Lewis, J., 1997. Lone Mothers in European Welfare Regimes: Shifting Policy Logics. London, Philadelphia: J. Kingsley Publishers.

33. Levey, R. I., 2001. Sources of Stress for Residents and Recommendations for Programs to assist them. Academic Medicine, 70(20), pp.142-150.

34. Nogueira-Martins, L. A., Stella, R. C., Nogueira, H. E., 1997. A pioneering experience in Brazil: the creation of a center for assistance and research for medical residents (NAPREME) at the Escola Paulista de Medicina, Federal University of São Paulo. Sao Paulo Medical Journal, 115(6), pp.1570-1574.

35. Lussier, G., 2002. Support Across two Generations Children's Closeness to Grandparents following Parental Divorce and Remarriage, Journal of Family Psychology, 16(1), pp.363-376.

36. Makama, G. A., 2013. Patriarchy and gender inequality in Nigeria: the way forward. European Scientific Journal, 9(17), pp.115-144. Available from: www.eujournal.org/index.php/esj/article/download/1161/1177. [Accesssed 17 July 2017].

37. Noor, N., 2002. Work-family conflict, locus of control, and women's well-being: test of alternative pathways. The Journal of Social Psychology, 142(5), pp.645-66.

38. Odle-Dusseau, H. N., Britt, T. W., and Bobko, P., 2012, Work-family balance, wellbeing, and organisational outcomes: investigating actual versus desired work/family time discrepancies. Journal of Business and Psychology, 27(3), pp.331-343.

39. Odunaike, B. A., 2012. Role Conflict among Women in Intercontinental Bank Plc, Lagos State. Global journal of human social science sociology, economics \& political science, 12(9), pp.2328. Available from: https://socialscienceresearch.org/index.php/GJHSS/article/view/457/408 [Accessed 10 January 2018].

40. Okonkwo, A. E., 2012. Strain-based family interference with work and feeling of reduced personal accomplishment among mothers in human service profession. In: Work and Family Researchers Network Conference, 12-16 June 2012, New York, USA. Available from: https://workfamily.sas.upenn.edu/wfrn-repo/object/d0ee5zl2yj0qq0he [Accessed 19 November 2017].

41. Onasoga, O. A., Ogbebor, S. O. and Ojo, A. A., 2013. Occupational Stress Management among Nurses in Selected Hospitals in Benin City, Edo State, Nigeria. European Journal of Experimental Biology, 3(1), pp.473-481. 
42. Perlow, L. A and Porter, J., 2009. Making time off predictable and required. Harvard Business, 87(10), pp.102-110. Available from: http://hbr.org/2009/10/making-time-off-predictable-andrequired [Accessed 17 July 2017].

43. Pilinger, J., 2002. The politics of the time: can work-life balance work? Equal Opportunities Review, 107(2), pp.18-21.

44. Rehman, S., and Roomi, M. A., 2012, Gender and work-life balance: A phenomenological study of women entrepreneurs in Pakistan, Journal of Small Business and Enterprise Development, 19(2), pp.209-228.

45. Rubery, J., Smith, M., Fagan, C., and Grimshaw, D., 1998. Women and European Employment. London: Routledge.

46. Silberschmidt, M., 1999. Women Forget that Men are the Masters Gender Antagonism and socio-economic change in Kisii District, Kenya. (C) The author and Nordiska Afrikairstitutet, Stockholm: Elanders Gotab.

47. Stacey, J., 1993. Untangling Feminist theory. In: D. Richardson and V. Robinson, eds. Introducing women's Studies: Feminist Theory and Practice. $1^{\text {st }}$ Edition, London: Macmillan. pp.49-73.

48. Stocvk, R., 1995. Africa South of the Sahara: a Geographical Interpretation. New York: Guilford Press.

49. Verlander, G., 2004. Female Physicians: Balancing Career and Family. Academic psychiatry, 28(4), pp. 331- 336.

50. Walker, E., Wang, C., and Redmond, J., 2008. Women and work-life balance: Is home based business ownership the solution? Equal Opportunities International, 27(3), pp. 258-275.

51. Wolfe, L., 2017. How Women Overcome Challenges in Business. Available from: https://www.thebalance.com/challenges-facing-business-women-working-moms-3514902. [Accessed 22 January 2018].

52. Wolfe, L., 2017. How Women Overcome Challenges in Business. The Balance. Make money personal., 17 July. Available from: https://www.thebalance.com/challenges-facing-businesswomen-working-moms-3514902. [Accessed 22 January 2018].

53. Wong, G. S. W. J., 2008. Doctors and Stress. Medical Bulletin, 13(6) Available from: http://www.fmshk.org/database/articles/03mb1_3.pdf. [Accessed 17 July 2017].

54. Wusu, O. and Abanihe, U. C., 2007. Interconnections of Changing Gender Role, Socialization and Youth Sexual Behaviour in Badagry: Youth's View. Lasu Journal of Social Sciences, 6(1), pp.244-261. 


\title{
Influence of social network sites in healthy behavior related to vigorous recreational physical activity
}

DOI: http://doi.org/10.26758/8.1.15

Diego Oswaldo Camacho Vega

Faculty of Medicine and Psychology, Universidad Autónoma de Baja California,

Address correspondence to: Diego Oswaldo Camacho Vega, Email: diego.camacho@uabc.edu.mx

\begin{abstract}
Objectives. Social network sites have become the web applications most used in Mexico facilitated by the use of smartphones and laptops. They have shown influence in the acquisition of healthy behaviors. The objective of this study is to determine if the use of social networking sites helps to improve vigorous recreational physical behavior.

Material and methods. In order to achieve this objective, it was necessary a systematic cluster sampling from 1927 higher education students resulting in 62 subjects who were studying sports in the largest university in Baja California, Mexico in 2017. A questionnaire based on the socialcognitive theory (eHealth Literacy Scales, developed by Norman and Skinner in 2016) was translated into Spanish and adapted to measure the consumer comfort and skill in using social network sites for improving vigorous recreational physical behavior.

Results. An excellent internal reliability of .958 was obtained for the applied test. Regarding the research question about if the use of social networking sites for the improvement of the vigorous recreational physical activity, this study can reject the null hypothesis and conclude that there are statistically significant differences in the response Agree (4) compared to either Strongly Disagree (1), Disagree (2), Undecided (3), and Strongly Agree (5) for items 21, 22, 23, 24, 25, 26, and, 27.

Conclusions. Students who do vigorous exercise are paying attention to the health-related resources available on the SNS and are using them critically to find help related to their recreational activity (sports). Thus, from the perspective of the eHealth Literacy, SNS could be considered as a media that could provide important information to promote healthy behavior regarding the vigorous physical activity.
\end{abstract}

Keywords: social network sites; healthy behavior; physical activity.

\section{Introduction}

Physical inactivity has been identified as the fourth leading risk factor for global mortality causing an estimated 3.2 million deaths globally, according to the World Health Organization (WHO, 2017, p.1). The same source reports that physical activity improves cardiorespiratory and muscular fitness, bone health, reduces the risk of no communicable diseases and their risk factors (NCDs) and depression. Doing regular to moderate physical exercises like sports or fitness bring more benefits for health: "regular moderate intensity physical activity - such as walking, cycling, or participating in sports - has significant benefits for health. For instance, it can reduce the risk of cardiovascular diseases, diabetes, colon and breast cancer, and depression. Moreover, adequate 
levels of physical activity will decrease the risk of a hip or vertebral fracture and help control weight”(WHO, 2107, p.1).

Nonetheless, access to the information through the Social networking sites, with around 2.46 billions of worldwide users in 2017 (***statista, 2017), involves different responsibilities and opportunities to develop healthy behaviors (Norman and Skinner, 2006). Thus, social networking sites (SNS) have become an important media based on Internet, Facebook being the most popular of them, with 1.8 billion monthly active users: "if the social media giant were a country, it would be much bigger than China" (***World Economic Forum, 2017). SNS have become important applications for sharing personal issues, getting improvement and motivation in the realization of physical activity like exercise (Boonwattanopas, 2016).

Thus, the eHealth literacy understood as "the degree to which individuals have the capacity to obtain, process, and understand basic health information and services needed to make appropriate health decisions" (Ratzan and Parker, 2000, p.vi) - in this case, exercise - is a topic that need attention in order to generate health education, "to influence not only individual lifestyle decisions, but also raises awareness of the determinants of health, and encourages individual and collective actions which may lead to a modification of these determinants" (WHO, 2017, p.1).

Looking for a better compression of the social networking sites and applications and eHealth, the main objective of this study is to determine if the use of social media helps to improve vigorous recreational physical behavior.

\section{Theoretical framework}

\section{The physical activity, sport and exercise}

This paper focuses on the study of exercise related to SNS. Nonetheless, the definition of exercise should be differentiated from those of physical activity and sport. First, according to the World Health Organization (WHO, 2017, p.1), physical activity is defined as "any bodily movement produced by skeletal muscles that require energy expenditure". The benefits of physical activity depend on the intensity and time. For adults, WHO recommends the following levels of intensity and duration:

"1. Adults aged 18-64 should do at least 150 minutes of moderate-intensity aerobic physical activity throughout the week or do at least 75 minutes of vigorous-intensity aerobic physical activity throughout the week or an equivalent combination of moderateand vigorous-intensity activity.

2. Aerobic activity should be performed in bouts of at least 10 minutes duration.

3. For additional health benefits, adults should increase their moderate-intensity aerobic physical activity to 300 minutes per week, or engage in 150 minutes of vigorous-intensity aerobic physical activity per week, or an equivalent combination of moderate- and vigorous-intensity activity.

4. Muscle-strengthening activities should be done involving major muscle groups on 2 or more days a week." (WHO, 2017, p.1)

Meanwhile, sport comprises "a range of activities that are highly organized and involve rules, complex skills, and tactics, physical exertion and competition between participants" (O'Keeffe et al., 2016, p.5).

Exercise, for its parts, is a "physical activity that is planned or structured. It involves repetitive body movement done to improve or maintain one or more components of fitness" 
(O'Keeffe et al., 2016, p.5). In short, sports and exercise are included in the physical activity but differentiated by the goal of the activity as well as the level of organization, planning, and structuring. Physical activity is defined as "any activity that involves or requires some form of physical exertion. It includes sport, play, active transport, chores, games, fitness activities, recreation and some forms of work" (O'Keeffe et al., 2016, p.4).

The physical activity has various influences translated into enablers and barriers: social, cultural and environmental. The social enablers and barriers are represented by friends, parents, siblings, neighbors, etc. For its part, the cultural enablers and barriers refer to ethnicity, religion, belief, and values. Last, the environmental enablers and barriers are the climate, location, safety features, etc. this study focused in social influencers, for this reason, they have been defined widely in relation to social networking sites and the human behavior.

Based on the beforehand mentioned considerations, the present study considered the category of recreational physical activity so as to include sports.

\section{eHealth literacy}

In order to understand how the use of technology could facilitate healthy behaviors such as exercise, social cognitive theory looks like adequate theoretical framework due to definition of health literacy: "the cognitive and social skills which determine the motivation and ability of individuals to gain access to, understand and use information in ways which promote and maintain good health" (WHO, 2017).

The foundations of the eHealth literacy concept are based in part on social cognitive theory and self-efficacy theory (Bandura, 1997), which promote competencies and confidence as precursors to behavior change and skill development" (Norman and Skinner, 2006).

Norman and Skinner's eHealth literacy model is comprised of six core skills or literacies: (1) traditional literacy, (2) health literacy, (3) information literacy, (4) scientific literacy, (5) media literacy, and (6) computer literacy (Norman and Skinner, 2006, p.2). For the purposes of this study, the health literacy related to technologies is considered. For instance, the eHealth literacy refers to "the capacity to use and understand the content of interactive health information technologies" (Gilstad, 2014, p.1).

Nonetheless, promoting and maintaining good health through technology requires the development of skills in using technology as a tool.

The Social networking sites era equivalent to health literacy is eHealth literacy, which includes basic literacy as well as information, media, health, computer and scientific literacies (Norman, \& Skinner, 2006). For this reason, youth can serve as an ideal group to test a measure of eHealth literacy given this population's high familiarity with technology (Gilstad, 2014). Thus, the adequate development of eHealth tools could protect consumers from harm and empower them at the same time, because "regardless of the population of interest, the need to navigate the Social networking sites with confidence is particularly important for health issues in which the consequences of using low quality, misleading, or false information are great" (Gilstad, 2014, p.2)

\section{Research question} activity?

Does the use of social networking sites help to improve the vigorous recreational physical 


\section{Hypothesis} activity.

The use of social networking sites helps to improve the vigorous recreational physical

\section{Material and Methods}

A transactional descriptive study involving one sample selected from a statistical population was conducted.

The systematic sampling was conducted considering a sizeable population of 1927 students, with a confidence level of 90 percent and a margin of error of 10\%. 62 students enrolled in the Faculty of Sports in the largest university in Baja California, Mexico, participated voluntarily in the study, male $(\mathrm{N}=50)$ and female $(\mathrm{N}=12)$. Originally, there were 67 students in the sample, but five students were excluded because they did not fulfill the main characteristic of the study population, which was to perform vigorous physical activity.

To achieve the purposes of the study, an adaptation and Spanish translation of the eHEALS scale (eHealth Literacy Scales) developed by Norman and Skinner (2016) was realized. The adaptation consisted of changing all general items that ask for the use of Internet in a general sense to address specifically the use of social networking sites (all the items). From the Global Physical Activity Questionnaire (GPAQ), elaborated by the World Health Organization (2010), five questions were selected for assessing the level of intensity (moderate or vigorous) and duration (hours per day, days per week) of the reported physical recreational activity.

The statistical procedure for the data set has been as follows: 1) the internal consistency of the scale was determined; 2) considering $\mathrm{p}>.05$ level of significance, the Kolmogorov-Smirnov $\mathrm{Z}$ test to assess the normality of variances was calculated; 3) according to the result of the normality test, it was not necessary to calculate a homogeneity test; 4) Non parametric analysis for all items was calculated, according to the results of the Kolmogorov-Smirnov $\mathrm{Z}$ test.

\section{Results}

The internal consistency reliability of the overall scale, as measured by the Cronbach Alfa coefficient, was very high $(\alpha=.958)$.

Regarding the results of the Kolmogorov-Smirnov $\mathrm{Z}$ test, this revealed not normally distributed data for all the items of the instrument; therefore, a nonparametric analysis of the dataset was necessary, considering $\mathrm{p}>.05$ level of significance. For this reason, the Chi-Square nonparametric test, mean, standard deviation, and percentages were calculated for the scale.

The Chi-Square results show significance for items $\mathrm{Nr}$. 21 (MD=3.3387; Std. Deviation=1.21390; $\mathrm{p}<0.001)$, Nr. 22 (MD=3.3387; Std. Deviation=1.21390; $\mathrm{p}<0.001)$, Nr. 23 $(\mathrm{MD}=3.3387$; Std. Deviation=1.21390; p < 0.000), Nr. 24 (MD=3.3387; Std. Deviation=1.21390; $\mathrm{p}$ $<0.000)$, Nr. 25 (MD=3.3387; Std. Deviation=1.21390; p < 0.000), Nr. 26 (MD=3.3387; Std. Deviation=1.21390; $\mathrm{p}<0.000)$, Nr. 27 (MD=3.3387; Std. Deviation=1.21390; $\mathrm{p}<0.000)$.

Regarding the research question, if the use of social networking sites helps or not to improve the vigorous recreational physical activity, this study can reject the null hypothesis - based on the items mentioned beforehand - and conclude that there are statistically significant differences in the response Undecided (3) for most items. 
Table 1. Mean, Standard Deviation (std), Chi-Square, and frequencies overall the scale.

\begin{tabular}{lllllllll}
\hline Item & 21 & 22 & 23 & 24 & 25 & 26 & 27 & 28 \\
\hline Mean & 3.3387 & 3.4839 & 3.5161 & 3.3710 & 3.4355 & 3.3710 & 3.4194 & 3.1613 \\
Std. & 1.21390 & 1.31501 & 1.25112 & 1.19059 & 1.13976 & 1.07481 & 1.20855 & 1.23067 \\
Deviation & & & & & & & & \\
Chi- & $19.774^{\mathrm{a}}$ & $18.484^{\mathrm{a}}$ & $23.806^{\mathrm{a}}$ & $25.903^{\mathrm{a}}$ & $39.452^{\mathrm{a}}$ & $33.000^{\mathrm{a}}$ & $27.839^{\mathrm{a}}$ & $9.290^{\mathrm{a}}$ \\
Square & & & & & & & & \\
Asymp. & 0.001 & 0.001 & 0.000 & 0.000 & 0.000 & 0.000 & 0.000 & 0.054 \\
Sig. & & & & & & & & \\
Scale & Frequencies & & & & & & \\
$\mathbf{1}$ & 9.7 & 12.9 & 9.7 & 11.3 & 9.7 & 9.7 & 12.9 & 12.9 \\
$\mathbf{2}$ & 17.7 & 11.3 & 14.5 & 11.3 & 11.3 & 6.5 & 6.5 & 16.1 \\
$\mathbf{3}$ & 16.1 & 12.9 & 11.3 & 19.4 & 16.1 & 30.6 & 21.0 & 25.8 \\
$\mathbf{4}$ & 41.9 & 40.3 & 43.5 & 45.2 & 51.6 & 43.5 & 45.2 & 32.3 \\
$\mathbf{5}$ & 14.5 & 22.6 & 21.0 & 12.9 & 11.3 & 9.7 & 14.5 & 12.9 \\
\hline
\end{tabular}

\section{Discussion and Conclusions}

This research has found that social networking sites have not a clear influence on Health behaviors, supporting partially the suggestion made by Latking \& Knowlton (2015) that social media has been successfully used for online self-help to promote health behaviors, mainly for the ease of accessibility for many individuals.

More information is necessary to affirm a positive influence of SNS on health behaviors. Our results showed that higher percentages were obtained for the undecided options, indicating that students are not sure with regards to a series of issues: about what health resources are available on the social networking sites (item 21), where to find helpful health resources on the social networking sites (item 22), how to find helpful health resources on the social networking sites (item 23), how to use the social networking sites to answer their questions about health (item 24), how to use the health information that they find on the social networking sites to help themselves (item 25). At the same time, they hesitate to assert the confidence about the skills they need to evaluate the health resources they find on the social networking sites (item 26), and the capacity to discriminate highquality from low-quality health resources on the social networking sites (item 27).

Thus, persons who do vigorous exercise are paying attention to the health-related resources available on the SNS and are using them critically to find help related to their recreational activity (including sports), but it is not clear if they are getting basic health information (health literacy) from SNS. 
Other topics that should be evaluated are whether social networking sites provide a significantly greater source of social incentives for increasing physical activity in addition to social support (Zhang et al., 2016) and the critical use of information provided by SNS about health.

Finally, it is important to note that the main social network site mentioned by the students has been Facebook (32\%), followed by Twitter (24\%), which indicates the necessity of considering the characteristics of the sample, the context and the own characteristics of the social networking site in future research.

\section{Research limitations and future research directions}

For a better understanding of the impact of SNS on eHealth Literacy, it is necessary to conduct supplementary research, based on empirical data, considering experimental conditions and increasing the sample size, and to compare low, moderate, and vigorous recreational physical activity. Additionally, the context and specific characteristics of the recreational activities should be analyzed.

\section{References}

1. Bandura, A., 1997. Self-efficacy: the exercise of control. New York: W.H. Freeman.

2. Boonwattanopas, N., (n.d.). Use of Online Social Media and eHealth Literacy of Urban Youth in Phuket Province, Thailand, 48-62. Available at: https://www.tcithaijo.org/index.php/EAUHJSci/article/download/52898/45632 [Accessed 18 January 2018].]

3. Boyd, N., and Ellison, N., 2008. Social Network Sites: Definition, History, and Scholarship. Journal of Computer-Mediated Communication, 13, pp.210-230.

4. Gilstad, H., 2014. Toward a comprehensive model of eHealth literacy. In: 2nd European Workshop on Practical Aspects of Health Informatics (Pahi). Trondheim, Norway, 19-20 May. CEUR Workshop Proceedings, 1251(Pahi), pp.63-72. https://doi.org/10.13140/2.1.4569.0247

5. Latkin, C. A., and Knowlton, A. R., 2015. Social Network Assessments and Interventions for Health Behavior Change: A Critical Review. Behavioral Medicine, 41(3), pp.90-97. https://doi.org/10.1080/08964289.2015.1034645.

6. Norman, C. D., and Skinner, H. A., 2006. eHealth Literacy: Essential Skills for Consumer Health in a Networked World. Journal of Medical Social networking sites Research, 8(2), e9. http://doi.org/10.2196/jmir.8.2.e9

7. O'Keeffe, M., Walsh, K., Cleary, V., Millar, S., \& Quinlan, M., 2016. Live it Up 1 VCE Units $1 \& 24 e$ eBookPLUS \& Print + studyON. Richmond, Vic. John Wiley \& Sons Australia, Ltd. Available at: https://www.wiley.com/en-

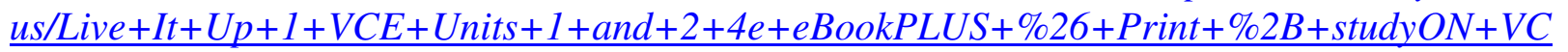
E + Physical + Education + Units $+1+$ and $+2+2 e-p-9780730329374$ [Accesed 24 January 2018]

8. Ratzan, S.C., and Parker, R.M., 2000. Introduction. In: C.R. Selden, M. Zorn, S. Ratzan, R.M. Parker, eds. National Library of Medicine Current Bibliographies in Medicine: Health Literacy. Bethesda, MD: National Institutes of Health.

9. World Economic Forum, 2017, The world's most popular social networks, mapped. [online] Available at: https://www.weforum.org/agenda/2017/03/most-popular-social-networks-mapped/ [Accessed 27 July 2017].

10. World Health Organization, 2017. Health topics. Physical activity [online] Available at: http://www.who.int/topics/physical_activity/en/ [Accessed 24 July 2017].

11. World Health Organization, 2017, Global Strategy on Diet, Physical Activity and Health: 
Physical Activity and adults. [online] Available at: http://www.who.int/dietphysicalactivity/factsheet_adults/en/ [Accessed 24 July 2017].

12. World Health Organization, 2017. Health Promotion: Health literacy and health behavior. [online] Available at: http://www.who.int/healthpromotion/conferences/7gchp/track2/en/ [Accessed 26 July 2017].

13. World Health Organization, 2010. Global Physical Activity Questionnaire. [online] Available at: http://www.who.int/ncds/surveillance/steps/GPAQ/en/ [Accessed 24 July 2017].

14. Zhang, J., Brackbill, D., Yang, S., Becker, J., Herbert, N., and Centola, D., 2016. Support or competition? How online social networks increase physical activity: A randomized controlled trial. Preventive Medicine Reports, 4, pp.453-458. https://doi.org/10.1016/j.pmedr.2016.08.008

15. ***statista, 2017 Number of social network users worldwide from 2010 to 2021 (in billions). Available at: https://www.statista.com/statistics/278414/number-of-worldwide-social-networkusers/ [Accesed 27 March 2018] 


\title{
Girl Body Composition according to pubertal status. Methodology variation
}

\section{DOI: $\underline{\text { http://doi.org/10.26758/8.1.16 }}$}

Consuelo Prado (1), Dolores Marrodan (2), Paula Acevedo (1), Margarita Carmenate (1)

(1) Department of Biology, University Autónoma of Madrid

(2) Department of Zoology and Anthropology, University Complutense of Madrid

Address to correspondence: Consuelo Prado, Departamento de Biología. Facultad de Ciencias. Darwin s/n. Campus de Cantoblanco. Universidad Autónoma de Madrid. 28049 Madrid, Spain. Ph: 34-914972611; Fax: 34-914978344; mail: consuelo.prado@uam.es

\begin{abstract}
Objectives. During puberty, important somatic changes that alter body composition take place. In girls, the production of ovarian estrogen generates an important metabolic change. The objective of the present paper is to analyze the differences in body composition among pre and post-menarche girls of the same chronological age, studying the variations with different methodologies.

Material and methods. The representative sample was composed of 249 schoolgirls, aged 12-13 years, who studied in "Tres Cantos" (Madrid). Two groups were formed with and without menarche (160 and 89). Body composition has been analyzed, using different methodologies: anthropometry and tetrapolar bioelectrical impedance. Population belongs to middle and upper middle class and there are no differences attributable to socio-economic situation.

Results. The analysis shows significant differences in weight and height between pre or postmenarche girls, $41.2 \pm 4.6 \mathrm{Kg}$ versus $52.0 \pm 6.6 \mathrm{Kg}$ and $154.7 \pm 6.4 \mathrm{~cm}$ versus $161.7 \pm 5.4$. According to Cole classification, both groups show a normal level of BMI, but the BMI of menarche girls was $19.89 \pm 2.0$ while that of no menarche girls was $17.21 \pm 1.9$. Body composition shows dramatically differences, the fat percentage was $13.8 \pm 2.7$ and $22.6 \pm 5.9$ in pre and post-menarche girls, with a decline of body water at the same age, water percentage being $64.7 \pm 3.0$ in premenarche subjects versus $57.7 \pm 4.4$ in those with menarche.

Conclusions. The use of biological instead of chronological age is more useful in morphological studies and classifications among the pubertal stage population. The present study shows good correlation between the anthropometric method and bioimpedance to determine fat body composition.
\end{abstract}

Keywords: Bioelectrical impedance, puberty, body composition, anthropometry, girls.

\section{Introduction}

Adolescence is a stage between childhood and the adult phase. It is a critical phase of the vital process where great variability occurs, in terms of shape and body composition. The growth process, which had been more or less constant during the ages of 3-9 years, suffers an important acceleration that gives rise to the so-called growth spurt, manifested very clearly in stature and in the somatic individuals' setup. In girls, this stage of intense changes is marked by the revival of the hypothalamus-hipofisio-gonadal axis (Prado et al., 2009). As a result of these processes, the body 
suffers a major refurbishment and change in its composition. After this stage, the young adults of both sexes have higher mineral bone content and a lower proportion of water. Subsequently, a clear sexual dimorphism is reflected, which entails the acquisition of secondary sex characteristics for each gender and a near final size. The anthropometric assessment is the study of shape, size, composition and proportionality of the individual that allows defining variations of the complex processes such as human growth (Torres et al., 2006; Milici, 2015). Nevertheless, in physical anthropology, there is a general consensus about the desirability of new techniques to supplement the traditional anthropometric methods for a better estimation of body composition. The electrical bioimpedance is among these new techniques aimed to assess the body composition more accurate, less invasive and less expensive. For anthropometric characterization of the female youth population, this study aims to identify the impact of the new hormonal context after ovarian follicular activation and the production of estrogen in girls' body composition and to objectify the changes occurred in different body compartments, in which the mere balance size/weight is insufficient. The new somatic situation is predictive of adult health, indicating the risk of developing pathologies linked to undesirable nutritional status in the medium term.

This study's working hypothesis is that all the methods to study the girls' infanto-juvenile transition are able to effectively reveal the changes in body composition.

\section{Material and methods}

This work is part of a larger study among the adolescent population of the Tres Cantos municipality, situated at the northern periphery of Madrid City. The research was conducted between 2010 and 2016 in all the public secondary schools in this satellite city and, for the present study, all the girls of 12 and 13 years of age $(\mathrm{N}=249)$ were included.

The project resulted from signing a collaboration agreement between the departments of health and education of Tres Cantos' City Hall and the General Foundation of the University Autónoma of Madrid, Department of biology, anthropology unit. Signing the agreement called for the strict monitoring of the bioethical protocol of Helsinki (2008), by obtaining parents' informed consent for all the subjects included in the study.

Once the planned activities were carried out in each of the centers, a custom report of each student was delivered to the participants and their parents or guardians. This report included an anthropometric assessment as well as recommendations to improve their current health status.

Following the International Biological Program protocol (Weiner and Lourie, 1981), the measurements were carried out by the UAM research team with the approved and previously calibrated equipment. The tetrapolar bioimpedance of double sweep (longitudinal-transverse) model 609 of Tanita has been used. Skinfolds measurements were taken with a skinfold caliper - model Holtain (with $1 \mathrm{~mm}$ precision).

Menarcheal status was reported according to status-quo method. If the answer was positive, we asked for the age and the month when first menstruation occurred. Among the subjects of the same chronological age, the menstrual status was the classification criterion in two groups: with and without menarche.

From biceps, triceps, subscapular and suprailiac skinfolds the body density was estimated (Durning and Ramahan, 1967) and, subsequently, the fat percentage of each subject was calculated by Siri Equation. With this data, we have estimated the fat mass and fat-free mass (anthropometric method). Tetrapolar impedance gave evaluations on muscle, fat, water, basal metabolism and biological age. 
The Kolmogorov-Smirnov test was applied to find out if the variables follow a normal distribution. After that, parametric tests (t Student, ANOVAS) were used for cases in which the variable is adjusted to normal and non-parametric tests (Mann-Whitney U, Kruskal-Wallis $\mathrm{H}$ ) otherwise. Tables of contingency, correlations, and $\chi^{2}$ test were also used. The degree of significance of the tests was of $p \leq 0.05$.

\section{Results}

The studied population lives in the municipality of Tres Cantos, in the north area of Madrid and at a distance of $20 \mathrm{~km}$ from the capital. It is an area that includes science parks, technology industry and university population. It represents a fairly uniform environment in term of education and economic status, corresponding to middle and upper middle class. The level of education is very high among the fathers of the girls $(66 \%$ parents and $62 \%$ of the mothers having a third level education), while the occupational categories can be considered high in $57 \%$ of parents and $42 \%$ of the mothers. Generally, the family size corresponds to a nuclear family, consisting of the parents and two children. At the economic level, there was no kind of situation unfavorable for growth and development.

The Bern study $(* * * W H O, 2010)$ for the practice of physical activity of children and adolescents has observed that $21 \%$ of the girls do not practice any physical activity and that in addition, among those who do, only $29 \%$ make it often referred to in the report: 1 hour/ day.

Tobacco use is higher in comparison with male subjects of the same study (Prado et al., 2012), $82 \%$ of young women are declared non-smoker, and among those who smoke 10 cigarettes is the most frequent category $(9.4 \%)$. Alcoholic beverages are consumed primarily during weekends, although $73 \%$ declare not to consume alcohol. Analyzing the hours of rest, a deficit of 5 hours/week of sleep has been observed in the case of adolescent girls, compared to the recommended duration for children aged 12-13 years, which is 9 hours. This deficit is mainly produced during the working days of the week.

Tobacco and alcohol use is more common among girls who have already had the menarche and conversely a decline is observed among those who practice sport; a negative correlation with the hours of sleep is noted, without reaching levels of significance.

The weight status of the population corresponds to the category of normal weight (79\%), although improved situations in overweight (14\%) and low weight (7\%) were detected. The obesity was low represented (1\%) (Cole et al., 2000).

Cole classification evaluated the weight according to the chronological age. However, at puberty, in same chronological age, early and late pubertal maturity coexist, while the weight situation differs noticeably in the mentioned categories. This situation advocates the importance of analyzing somatic features by taking into consideration the status of ovarian maturation of the girls of the same chronological age.

The Kolmogorv-Smirnov test and a series of parametric tests were used to show important differences between girls with and without menarche (Table 1). A statistically significant difference of $7 \mathrm{~cm}$ in height is observed ( $\mathrm{T}$ - independent samples Student, $\mathrm{t}=8.88 ; \mathrm{gl}=247 ; \mathrm{p}<0.001$ ). Similarly, the differences in weight, of $11 \mathrm{~kg}$, are highly significative $(\mathrm{t}=15.82 ; \mathrm{gl}=247 ; \mathrm{p}<$ 0.001). There are not only differences in the direct variables, but also in the proportions. Indeed, it is interesting to note that the BMI of the girls with the menarche is statistically higher $(\mathrm{t}=3.13 ; \mathrm{gl}=$ 247; $\mathrm{p}$ < 0.05). Waist to hip ratio has been widely used in the field of epidemiology since it relates to the content of visceral fat in the body (Milici, 2015). The range suitable for women is from 0.71 to 0.85 . Both groups, with or without menarche, are in the appropriate range, but there is a significant 
difference between the values of this index, which increases in girls with menarche $(\mathrm{t}=7.14 ; \mathrm{gl}=$ 247; $\mathrm{p}<0.001)$.

Table 1. Girls' height, weight, body mass index and waist-hip index according to menarcheal status (mean and standard deviation)

\begin{tabular}{|c|c|c|}
\hline VARIABLE & NON-MENARCHE GIRLS & MENARCHEAL GIRLS \\
\hline HEIGHT $(\mathrm{cm})$ & $154.68(\mathrm{SD} \pm 6.3)$ & $161.66(\mathrm{SD} \pm 5.3)$ \\
WEIGHT $(\mathrm{Kg})$ & $41.33(\mathrm{SD} \pm 4.6)$ & $52.77(\mathrm{SD} \pm 6.5)$ \\
BMI $\left(\mathrm{kg} / \mathrm{m}^{2}\right)$ & $17.21(\mathrm{SD} \pm 1.9)$ & $19.89(\mathrm{SD} \pm 2.0)$ \\
CCI $(\mathrm{cm} / \mathrm{cm})$ & $0.76(\mathrm{SD} \pm 0.07)$ & $0.82(\mathrm{SD} \pm 0.05)$ \\
\hline
\end{tabular}

The significant increase in weight in the menarche transition has been pointed out for decades (Frish and Revelle, 1970). However, this increase in weight may not be harmonious with respect to all the components that comprise the weight status of individuals. Certainly, when the fatty component variation is analyzed, it highlights a statistically significant decrease in body density $(\mathrm{t}=2.34, \mathrm{gl}=247, \mathrm{p}<0.05)$. This decrease in body density is partly due to the significant increase of fatty tissue. There is a difference of fat (not visceral) more than $5.2 \mathrm{~kg}(\mathrm{SD} \pm 1.48$ ) among girls with menarche and without $(\mathrm{t}=8.93$, gl. $=247, \mathrm{p}>0.001)$ (Table 2$)$.

Table 2. Mean values of Siri body density and fat percentage assessed by anthropometric method and tetrapolar impedance (mean and standard deviation) in pre and post-menarche girls.

\begin{tabular}{|c|c|c|}
\hline VARIABLE & NON-MENARCHE GIRLS & MENARCHEAL GIRLS \\
\hline BODY DENSITY & $1.035(\mathrm{SD} \pm 0.009)$ & $1.032(\mathrm{SD} \pm 0.010)$ \\
Kg of FAT & $7.23(\mathrm{SD} \pm 4.1)$ & $12.44(\mathrm{SD} \pm 4.9)$ \\
\% FAT (skinfolds) & $17.51(\mathrm{SD} \pm 3.9)$ & $23.58(\mathrm{SD} \pm 4.2)$ \\
\% FAT (bioimpedance) & $15.83(\mathrm{SD} \pm 2.7)$ & $22.84(\mathrm{SD} \pm 5.3)$ \\
\hline
\end{tabular}

Both percentages (estimated by skinfold thickness and by bioimpedance) show statistically significant differences between the two groups considered $(t=11.33, g l=247, p>0.001)$. The values obtained by bioimpedance are slightly lower than those obtained by anthropometrical measurements, but there are no significant differences between the two methodologies when comparing the pre and post-menarche groups. Deviations from these percentages are always higher in the group with menarche, especially with the bioimpedance determination, which could be due to the effect of variation in body composition, in particular water variation that is experienced during the menstrual cycle in women (Table 2).

If a dual-component model is considered (fat and fat-free mass, assessed by bioimpedance), the study shows that there is more fat-free mass in girls with menarche, but to relativize this percentage of body component in girls without menarche the fat-free mass represents a big fraction of the body weight (Table 3). The differences in the absolute values of fat-free mass are significant $(\mathrm{t}=9.53, \mathrm{gl}=247, \mathrm{p}>0.001)$, as well as the percentages of fat-free mass $(\mathrm{t}=12.0, \mathrm{gl}=247, \mathrm{p}>$ $0.001)$. 
Table 3. Mean values of fat free mass in $\mathrm{kg}$. and percentage of fat-free mass of total body weight assessed by tetrapolar impedance (mean and standard deviation) in pre and postmenarche girls.

\begin{tabular}{|c|c|c|}
\hline VARIABLE & NON-MENARCHE GIRLS & MENARCHEAL GIRLS \\
\hline Fat free mass $(\mathrm{Kg})$ & $33.77(\mathrm{SD} \pm 3.47)$ & $38.70(\mathrm{SD} \pm 2.87)$ \\
& $81.70(\mathrm{SD} \pm 4.2)$ & $74.78(\mathrm{SD} \pm 4.9)$ \\
\hline
\end{tabular}

Within the free body fat fraction, an analysis of greater precision is also possible. Thus, the content of water, bone, and muscle in the two groups of girls has been analyzed. The results of this analysis are summarized in table 4 . The free-fat body mass component has been considered as a whole $(100 \%)$ and the respective percentages that represent the bone, muscle, and water within this component have been established. All results were obtained using tetrapolar bioimpedance, same apparatus and in identical circumstances. The body composition of the girls after menarche is different in all components. It is not just a change in weight (Frish \& Revelle, 1970), or an increase in adipose tissue (Frish, 1987), it is also important to consider a decrease in water content and a logical increase in bone and muscle.

Table 4. Mean values of percentage of fat-free mass and relative percentage of water, bone, and muscle within the fat-free mass assessed by tetrapolar impedance in pre and postmenarche girls.

\begin{tabular}{|c|c|}
\hline Girls without Menarche & Girls with Menarche \\
\hline \% Fat Free Mass $=81.70(\mathrm{SD} \pm 4.2)$ & $\downarrow$ \\
$\downarrow$ & \% Fat Free Mass $=74.78(\mathrm{SD} \pm 4.9)$ \\
\hline of free mass & \% of free mass \\
Water: $64.7(\mathrm{SD} \pm 3.01)$ & Water: $57.2(\mathrm{SD} \pm 4.51)$ \\
Bone: $1.88(\mathrm{SD} \pm 0.18)$ & Bone: $2.08(\mathrm{SD} \pm 0.15)$ \\
Muscle: $33.42(\mathrm{SD} \pm 3.40)$ & Muscle: $40.52(\mathrm{SD} \pm 2.87)$ \\
\hline
\end{tabular}

Generally, in comparison with girls without menarche, those with menarche but of same chronological age present statistically significant diferences in body composition and among various components of fat-free mass: a higher percentage of bone $(\mathrm{t}=9.09, \mathrm{gl}=247, \mathrm{p}>0.001)$ and muscle mass $(\mathrm{t}=15.58, \mathrm{gl}=247, \mathrm{p}>0.001)$ but a lower percentage of water $(\mathrm{t}=14.43, \mathrm{gl}=247, \mathrm{p}>0.001)$.

\section{Discussions}

As we said when introducing the present work, the pubertal transition is characterized by major physical alterations: sexual maturation, changes in body composition, and rapid skeletal growth (Martos et al., 2010). Breast development is the first manifestation of puberty in approximately $85 \%$ of girls; the normal age for initial breast development is between ages 8 and 13 . Menarche generally occurs within 2 years from the onset of breast development (Prado, 2003). Skeletal growth is one of the most striking characteristics of puberty. Linear-growth velocity begins to increase and the peak height velocity is not attained until age 12 in girls. Lean body mass, which 
primarily reflects muscle mass, begins to increase during early puberty in both boys and girls. Fat mass increases during the late stages of puberty in girls. Sex differences in the adolescent growth spurt produce the characteristic sexual dimorphism in shape and proportions seen in young adults (Prado et al., 2014). Of course, sex differences in body composition exist before puberty, but the reason for this phenomenon is unknown (Adams Hillard, 2002). The physical changes that occur during puberty are mediated, in part, through sex steroids, insulin-like growth factor I (IGF-I), and leptin. However, data that address the extent to which concentrations of these hormones influence body composition, bone mass, and density in prepubertal girls are lacking (Chan et al., 2005).

Currently, the relationship between body composition of girls and the necessary changes for the establishment of the ovarian menstrual cycles seems undeniable. It is also a simplistic reductionism to mention critical weight, that of $47 \mathrm{~kg}$. (Frish and Revelle, 1970). Obviously, the association found between menarche and BMI is described in the revised bibliography (Kaplowith et al., 2005; Parent et al., 2003). It has been observed that girls who have an early menarche, before the age of 12, have a higher BMI, and an increased tendency to overweight or obesity. The mentioned studio of Kaplowitz points out that girls who have begun their puberty have a higher BMI than those who have not started it, and that these girls would have an increased tendency to get insulin resistance. The reproductive status is extremely sensitive to the metabolic status and to the amount of stored energy that women have. In effect, it is now well known that the adipose tissue is important to acquire and maintain the reproductive ability, a body fat percentage of 22 being critical for the maintenance of menstrual cycles (Frisch, 1987). Adipose tissue is also a source of no ovarian estrogen production by aromatization of testosterone. But other pubertal changes that occur in the body composition are less known. In the present study, by limiting the concomitant factors such as temporal variation, different ages or different environmental conditions, it has been possible to evaluate what happens in the body composition of girls with the beginning of their ovarian cycles. This study has shown that, apart from any sanitary or economic limitations, girls with menarche have different anthropometric parameters in comparison to others of the same chronological age but without menarche.

In several studies, the associating of obesity with the age of menarche has been discussed. In fact, in a longitudinal study in the Finnish population, it was revealed that a higher BMI among precocious girls remained until the age of 31 (Laitinen et al., 2001). The present work may not endorse this possibility since the significantly higher value of BMI in girls aged 12-13 and with menarche in comparison with their non-menarcheal peers is due to a more advanced global somatic status. It is noteworthy that both groups of girls are in the category of normal weight for their age. The classification of Cole et al. (2000) and Cole et al. (2007) was used to characterize the subjects' weight status. However, this classification takes into account only age intervals, disregarding the differences that pubertal stages generate within body mass components; when discussing the issue of weight standards according to age, this represents a serious limitation that needs to be addressed. The study shows a good correlation between methodologies employed to assess body composition. Although both methods recorded significant differences in body fat percentage between girls with and without menarche, bioimpedance indicated slightly lower values than the anthropometric method. Studies based on bioimpedance during the menstrual cycle have shown that this method provides different estimates along the different phases of the menstrual cycle (Prado and Delgado, 2001). This study has not taken into account the phase of the menstrual cycle in which the girls were at the time of measurement. Maybe if it had, the differences between the two methods would not have been significant. The next step of the study will be the follow-up, in their final stages of adolescence, of the most precocious girls at the onset of menstruation and the evaluation of their 
weight status and body composition to detect the persistence of an increased amount of fat or lack thereof.

\section{Bibliography}

1. Adams Hillard, P.J., 2002. Menstruation in young girls: a clinical perspective. Obstetrics and gynecology, 99(4), pp.655-62.

2. Baker, E.R., 1985. Body weight and the iniciation of puberty. Clinical Obstetrics and Gynecology, 28(3), pp.573-579.

3. Chan, J.L., Mantzoros, C.S., 2005. Role of leptin in energy-deprivation states: normal human physiology and clinical implications for hypothalamic amenorrhoea and anorexia nervosa. Lancet, 366(9479), pp.74-85.

4. Cole, J.T., Bellizzi, M.C., Flegal, M.K., Dietz, W.H., 2000. Establishing a standard definition for child overweight and obesity worldwide: international survey. British Medical Journal, 320(7244), pp.1240-3. https://doi.org/10.1136/bmj.320.7244.1240.

5. Cole, J.T, Flegal, M.K., Nicholls, D., Jackson, A.A., 2007. Body mass index cut offs to define thinness children and adolescents international survey. British Medical Journal, 335, pp.194-201 https://doi.org/10.1136/bmj.39238.399444.55.

6. Comninos, A.N., Jayasena, C.N., Dhillo, W.S., 2014. The relationship between gut and adipose hormones, and reproduction. Human Reproduction Update, 20(2), pp.153-74. https://doi.org/10.1093/humupd/dmt033.

7. Durnin, J. V. and Rahaman, M. M., 1967. The assessment of the amount of fat in the human body from measurements of skin fold thickness. British Journal of Nutrition, 21, pp.681-689.

8. Freedman, D., Kettel. K.L., Serdula, M.K., Dietz, W., Srinovasan, S.R., Berenson, G.S., 2003. The relation of menarcheal age to obesity in childhood and adulthood: the Bogalusa heart study. BMC Pediatrics, 3:3. https://doi.org/10.1186/1471-2431-3-3 @ Freedman et al; licensee BioMed Central Ltd. 2003

9. Frisch, R.E., Revelle, R., 1970. Height and weight at menarche and a hypothesis of critical body weights and adolescent events. Science, 169, pp.397-399.

10. Frisch, R.E., McArthur, J.W., 1974. Menstrual cycles: fatness as determinant of minimum weight for height necessary for their maintenance or onset. Science, 185, pp.949-951.

11. Frisch, R.E., 1987. Body fat, menarche, fitness and fertility. Human Reproduction, 2(6), pp.521533.

12. Kaplowitz, P.B, Slora, E.J., Wasserman, R.C., Pedlow, S.E., Herman-Giddens, M.E., 2005. Earlier onset of puberty in girls: relation to increased body mass index and race. Pediatrics, 108(2), pp.347-53.

13. Laitinen, J., Power, C., Järvelin, M. R., 2001. Family social class, maternal body mass index, childhood body mass index, and age at menarche as predictors of adult obesity. The American journal of clinical nutrition, 74(3), pp.287-294.

14. Martos-Moreno, G.A, Chowen, J.A., Argente, J., 2010. Metabolic signals in human puberty effects of over and undernutrition. Molecular and cellular endocrinology, 324(1-2), pp.70-81.

15. Milici, N., 2015. Sindromul metabolic şi obezitatea. Perspective antropologice (Metabolic syndrome and obesity. Anthropological perspectives). Bucureşti: Editura Academiei Române.

16. Parent, A.S., Teilmann, G., Juul, A., Skakkebaek, N.E., Toppari, J., Bourguignon, J.P., 2003. The timing of normal puberty and the age limits of sexual precocity: variations around the world, secular trends, and changes after migration. Endocrine reviews, 24(5), pp.668-93. 
17. Prado, C., Delgado, E., 2001. Un problème pour la biométrie: la variation de la composition corporelle pendant le cycle menstruel après la puberté. Biométrie humaine et anthropologie, 19(1-2), pp.71-76.

18. Prado C., 2003. La puberté: Une période de crise. In: C. Susanne, E. Rebato \& B. Chiarelli, eds. 2003. Anthropologie biologique. Evolution et biologie humaine. Bruxelles: De Boeck. pp. 503512.

19. Prado C, Marrodan M.D, Valle A., 2009. Growth and maturation. In: M.D. Cabañas, F. Esparza, eds., 2009. Compendio de Cineantropometría, Madrid: CTO. pp .243-247.

20. Prado, C., Marrodan, M.D, Calabria, V., Mendez, B., Arechiga, J., 2012. Nutritional status, variation in body composition, body water, fat and muscle in adolescents of Madrid (Spain). International Conference on Nutrition \& Growth, Paris. Web: www2.kenes.com/nutritiongrowth/pages/

21. Torres, M.A., Braga, J.A., Taddei, J.A., Nóbrega, F.J., 2006. Anemia in low-income exclusively breastfed infants, Jornal de pediatria, 82(4), pp.284-7. https://doi.org/10.2223/JPED.1511

22. Weiner, J.S., and Lourie, J.A., 1981. Practical Human Biology. London; New York: Academic Press.

23. ***World Health Organization. 2010. Global Recommendations on Physical Activity for Health. Geneva: WHO Press. Available at: http://apps.who.int/iris/bitstream/10665/44399/1/9789241599979_eng.pdf [Accessed 12 September 2017]. 


\title{
Anthropometric study on the role of yogurt fermented with Lactobacillus bulgaricus and Bifidobacterium animalis subsp. lactis in the prevention and treatment of obesity and related diseases
}

\section{DOI: http://doi.org/10.26758/8.1.17}

Svetoslav Handjiev (1), Aneliya Kuzeva (2)

(1) Medical University of Sofia; Bulgarian Association for the Study of Obesity and Related Diseases, Bulgaria

(2) Medical University of Sofia, Bulgaria, e-mail: aneliyakuzeva@gmail.com

Address correspondence to: Svetoslav Handjiev, e-mail: svhandjiev@ gmail.com

\begin{abstract}
Objectives. The role of yogurt, respectively probiotics, in the treatment and prevention of obesity has been discussed. The aim of our study was to investigate the effect of yogurt fermented with Lactobacillus bulgaricus and Bifidobacterium animalis subsp. lactis ( $0.5 \%$ fat) in the treatment of patients with obesity.

Material and methods. A total of 57 subjects with central type obesity (21 men and 36 women) were enrolled in the study. The baseline characteristics of the sample (average values) were the following: age -46.2 years, body mass index $(\mathrm{BMI})-35.4$, fat mass $-39.4 \%$, visceral fat -14.1 , waist circumference $-109 \mathrm{~cm}$, hip circumference -120.2 , and sagittal diameter $-27 \mathrm{~cm}$. All these obese patients underwent a dietary regimen, included $290 \mathrm{~g}$ yogurt fermented with Lactobacillus bulgaricus and Bifidobacterium animalis subsp. lactis for dinner during a 6-month period. The product consisted of proteins $-4.3 \mathrm{~g}$, carbohydrates (lactose) $-3.9 \mathrm{~g}$, fat $-0.5 \mathrm{~g}$, and 37 kilocalories per $100 \mathrm{~g}$ product. At the beginning and at the end of the study, several anthropometric parameters have been measured using a bioimpedance device (Tanita 420).

Results. The study demonstrated the decrease of BMI with $9.8 \%$, of fat mass with $9.6 \%$, of visceral fat with $14 \%$, as well as a decrease in waist circumference by $11.9 \%$, of hip circumference by $5.8 \%$, and of sagittal diameter by $10.3 \%$.

Discussion: Probiotics are substances that regulate the normal intestinal flora, influence metabolism and have an effect on various diseases. Our studies were performed on the effect of Lactobacillus Bulgaricus and Bifidobacterium animalis subsp. lactis on carbohydrate and lipid metabolism in obesity. The results indicated that the probiotics improved the impaired glucose and lipid metabolism. The probiotics affected the concentration of free radicals in the blood. Taken together, the results give a reason to assume that the effect of probiotics on oxidative stress in the mechanism of influence on the metabolism is important.
\end{abstract}

Conclusion. The regular consumption of yogurt fermented with Lactobacillus bulgaricus and Bifidobacterium animalis subsp. lactis $(0.5 \%$ fat $)$ in the diet of obese patients leads to improvement of the studied anthropometric parameters as well as to significant decrease in the cardiovascular risk.

Keywords: anthropometric study; yogurt; probiotics; metabolic syndrome. 


\section{Introduction}

Obesity is a chronic metabolic disease that leads to many co-morbidities and high prevalence of mortality (Yumuk et al., 2015; WHO, 2018). The incidence of obesity and related diseases increases constantly (see Figs. 1-4). The role of dairy products in the treatment and prevention of obesity has been discussed (Bogdanov, 2014; Martinez-Gonzalez et al., 2014; Ahn et al., 2015; Handjieva-Darlenska et al.,-2015; Handjieva-Darlenska et al., 2016; Lamarche et al., 2016; Beck et al., 2017). The literature also highlighted the effect of yogurt, respectively probiotics, in the treatment and prevention of obesity (Bogdanov, 2014; Handjieva-Darlenska and Minkova, 2016; Santiago et al., 2016; Karimi et al., 2017).

Figure 1. Expected increase in the incidence of obesity.

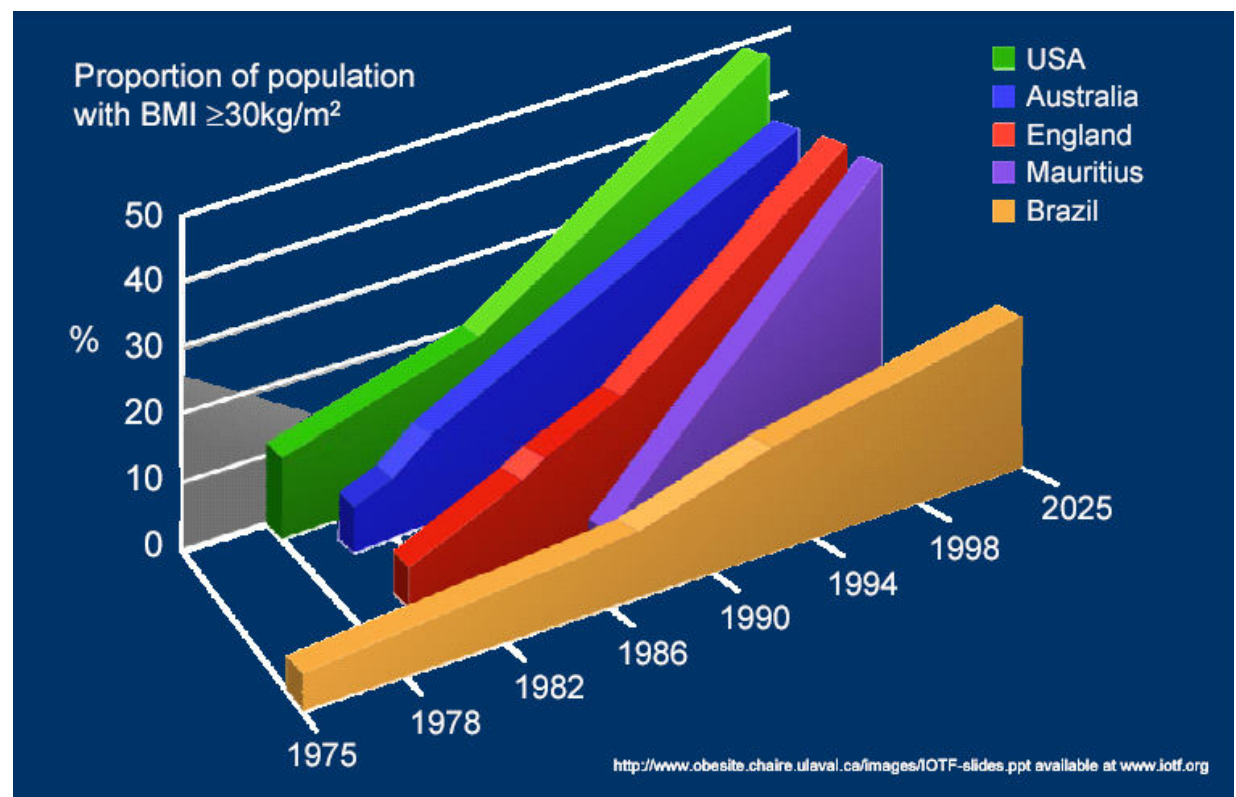

Figure 2. Expected increase in the incidence of diabetes

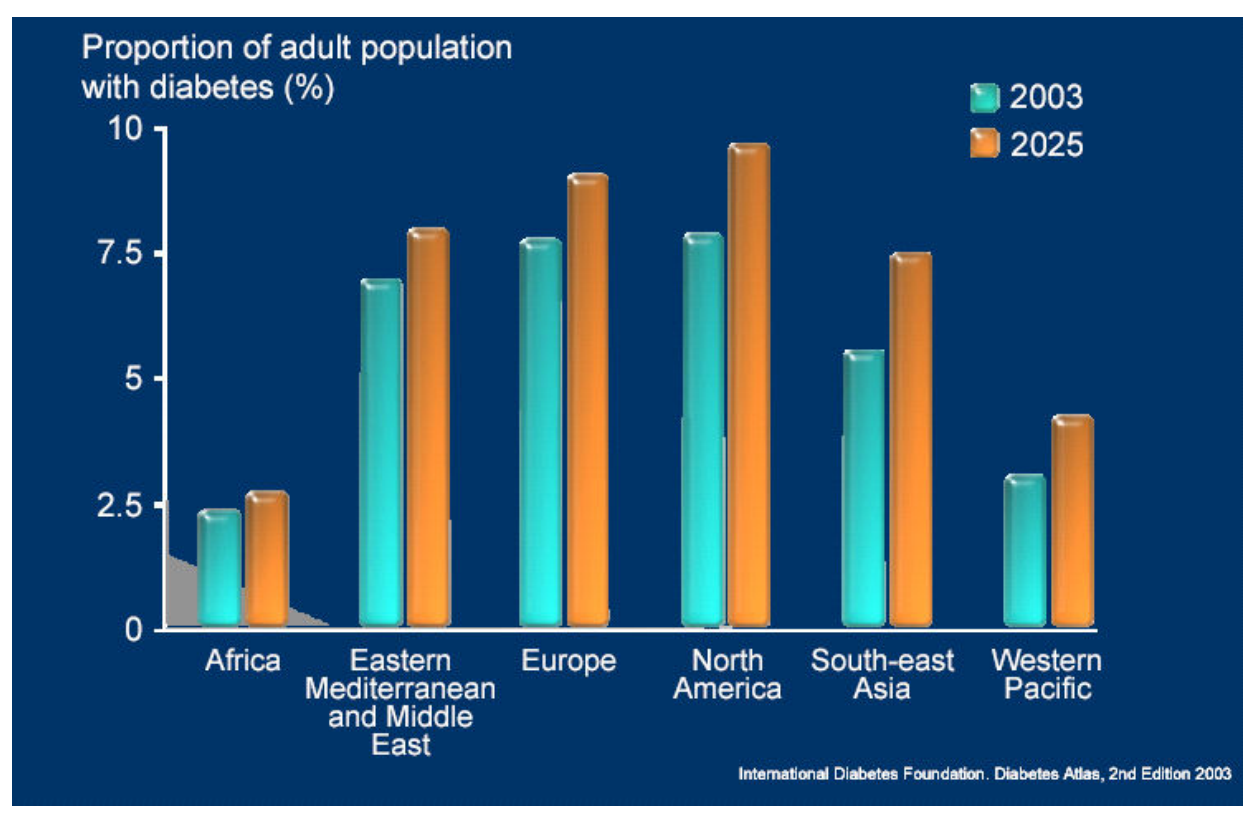


Figure 3. Overweight and obesity prevalence in schoolchildren. National survey on nutrition and nutritional status of schoolchildren in Bulgaria -1998, 2010-2011 (Source: Dimitrova, 2012).

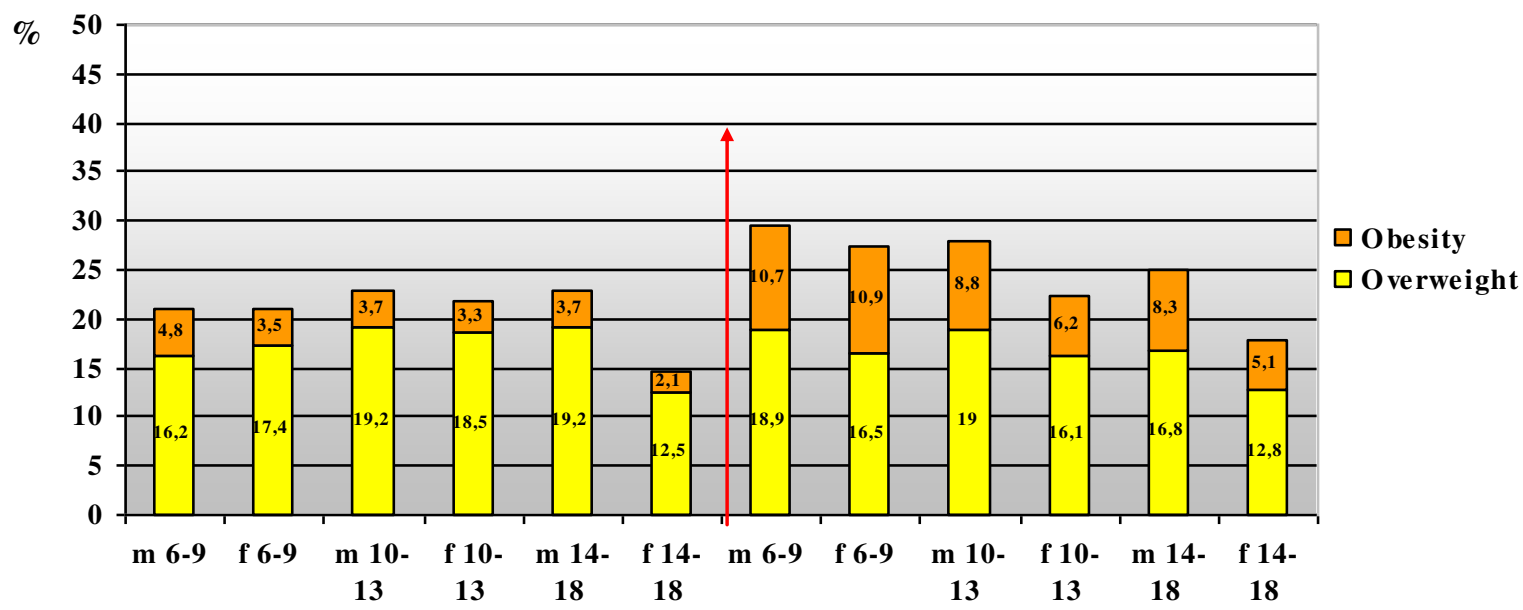

Figure 4. Prevalence of Overweight and Obesity among adults (19-60 years old). National Monitoring of Dietary Intake and Nutritional Status, 1998, 2004 (Source: Dimitrova, 2012).

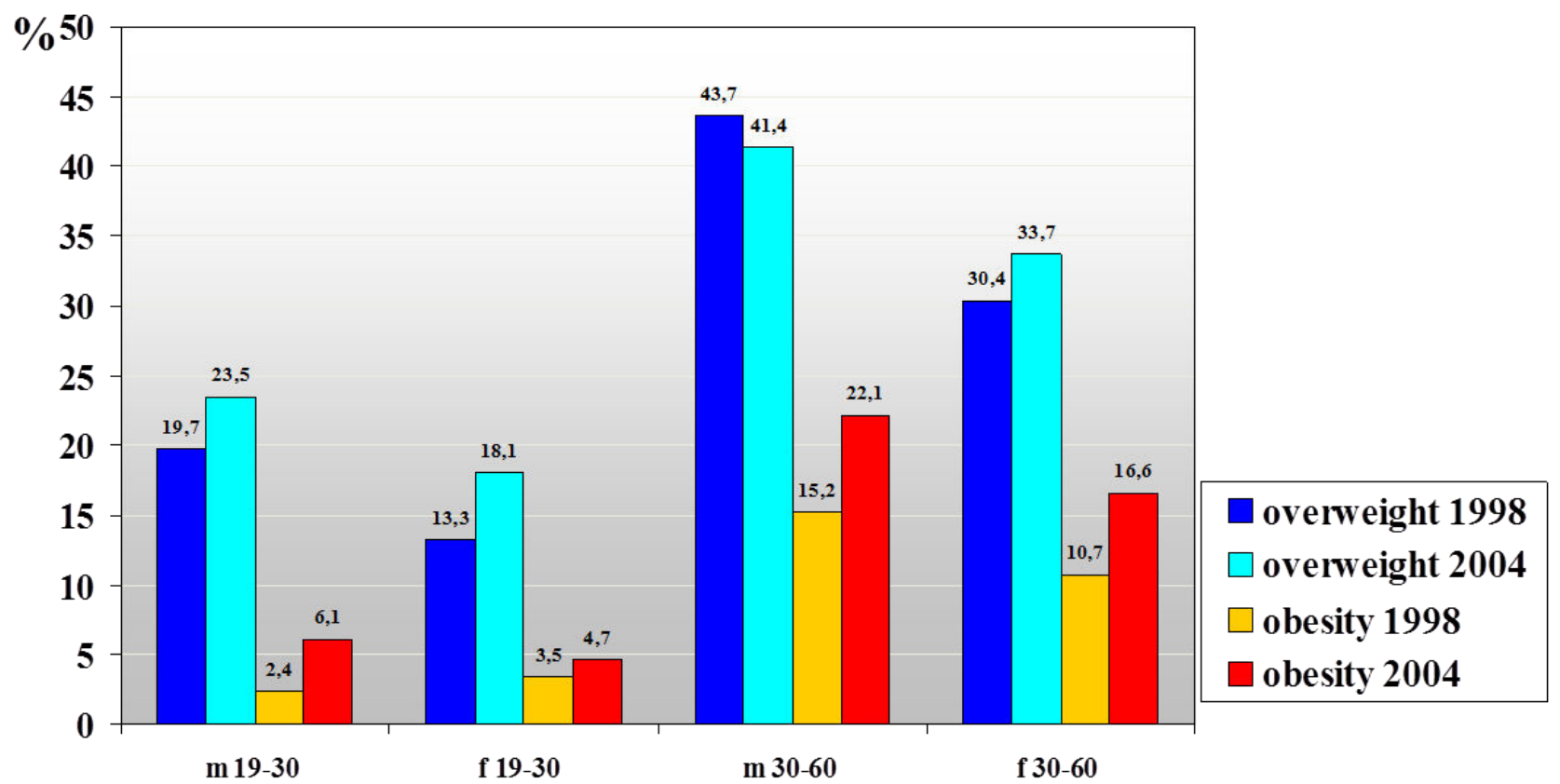

Age (years) 


\section{History}

Even since the end of $19^{\text {th }}$ century, the Russian scientist and pioneer immunologist Ilya Ilyich Mechnikov (or Elie Metchnikoff, as his name is often written), investigating the factors that could enhance or decrease health and longevity, advanced the idea of the harmful intestinal bacteria as the source of the inflammatory process; the thermal preparation of all fruits and vegetables and the regular consumption of yogurt or other types of sour milk were proposed as solutions for the intestinal putrefaction that precipitated the aging process. He emphasized, in particular, the positive, neutralization effect of the so-called Bulgarian Bacillus from the Bulgarian yogurt upon intestinal microbiome, as proven by the health and longevity of the highlanders who include large amounts of soured milk in their diet.

The actual discovery of the Lactobacillus bulgaricus is due to Stamen Grigoroff, a Bulgarian student who studied medical science in Geneva, Switzerland. Immediately after he identified the bacteria that cause the milk to curdle, his professor, Léon Massol wrote to Prof. Ilyja Mechnikoff at the Institut "Louis Pasteur", announcing the great scientific results. His discovery was presented in the paper entitled "Etude sur le lait fermenté comestible: le "Kissélo-mléko" de Bulgarie" and published in Revue médicale de la Suisse romande: organe officiel de la Société médicale de la Suisse romande, issue 10, dated 20.10.1905, Genève, Georg \& G., Libraries-Éditeurs. Librairie de L'Université. Then, it was validated by Metchnikoff, who invites the young scientist to Paris; his assistants, Luerssen and Kuhn, were those who in 1908 gave to this microorganism the designation of Lacto bacterium Bulgaricum - the Bulgarian lactic bacteria.

Subsequently, the benefits of yogurt consumption have been the subject of numerous studies, eventually leading to the establishment of a Bulgarian school. For obtaining his medical degree of Doctor of Medicine in Toulouse, Radush Titkov defended in 1905 a thesis regarding the healthy properties of yogurt. Prof. Assen Zlatarov, who got his Ph.D. in Chemistry and Physics at the prestigious Grenoble University, called the yogurt "an elixir of long-life".

Academician Tasho Tashev, the dean of Bulgarian nutrition science, and his school (19802001) investigated the role of dairy foods in the prevention and treatment of the gastrointestinal and metabolic diseases (von Sanchsen, 2006; Handjieva-Darlenska, 2016).

\section{Aim}

The aim of our study was to investigate the effect of yogurt fermented with Lactobacillus bulgaricus and Bifidobacterium animalis subsp. lactis $(0.5 \%$ fat $)$ in the treatment of patients with obesity and related diseases.

\section{Material and methods}

A total of 57 subjects with central type obesity (21 men and 36 women) were enrolled in the study. The study took place in the National Transport Medical Hospital as part of the BARORD's (Bulgarian Association for Study of Obesity) activities. The participants were volunteers who took part in the study for 6 months and were consulted every 2 weeks throughout the study as part of the outpatient clinics.

The methods involved anthropometrical measurements to determine the initial status of patients and to evaluate the results of the dietary regimen imposed to all the obese patients.

All obese patients underwent a dietary regimen, included 290g yogurt fermented with Lactobacillus bulgaricus and Bifidobacterium animalis subsp. lactis for a 6-month period which 
replaced their regular dinner. The product consisted of proteins $-4.3 \mathrm{~g}$, carbohydrates (lactose) $3.9 \mathrm{~g}$, fat $-0.5 \mathrm{~g}$, and 7 kilocalories per $100 \mathrm{~g}$ yogurt product.

The classification of patients in the obesity weight classes was made considering the body mass index developed by Adolphe Quetelet and recommanded by WHO for estimating body fat mass. It is calculated by dividing the subject's mass by the square of his or her height. Any BMI $\geq$ 35 or 40 signals severe obesity; a BMI of $\geq 35$ or $40-44.9$ or 49.9 represents morbid obesity; a BMI of $\geq 45$ or 50 indicates a super obese. However, since the BMI does not reveal the body fat distribution, other measurements regarding body fat percentage had to be done.

Body height was measured using an anthropometer in the upright position.

Some parameters such as body weight, body mass index, body fat mass, visceral fat, lean body mass were assessed using a bioimpedance device (Tanita 420).

Sagital diameter was measured using a caliper.

\section{Results}

The baseline characteristics of the sample (average values) were the following: age -46.2 years, body mass index (BMI) - 35.4, fat mass $-39.4 \%$, visceral fat -14.1 , waist circumference $109 \mathrm{~cm}$, hip circumference $-120.2 \mathrm{~cm}$, and sagittal diameter $-27 \mathrm{~cm}$.

The study demonstrated the decrease of BMI with $9.8 \%$, of fat mass with $9.6 \%$, of visceral fat with $14 \%$, as well as a decrease in waist circumference by $11.9 \%$, of hip circumference by $5.8 \%$, and of sagittal diameter by $10.3 \%$ (see Table 1 ).

Moreover, at the end of treatment, we observed an improvement trend in the values of blood sugar, total cholesterol, triglycerides as well as of the systolic and diastolic blood pressure.

Table 1. Changes in physical parameters following treatment

\begin{tabular}{|c|c|c|c|c|c|c|c|c|c|}
\hline Parameter & $B M I$ & $\begin{array}{c}F M \\
(\%)\end{array}$ & $\begin{array}{c}L B M \\
(\%)\end{array}$ & $L B M / F M$ & $V F$ & $\begin{array}{c}W \\
(\mathrm{~cm})\end{array}$ & $\begin{array}{c}H \\
(\mathrm{~cm})\end{array}$ & $\begin{array}{c}\text { Sag. } \\
\text { diameter }\end{array}$ \\
\hline $\begin{array}{c}\text { Before } \\
\text { treatment }\end{array}$ & 36.1 & 40.7 & 59.3 & 1.45 & 13 & 109.5 & 122.6 & 0.90 & 24.7 \\
\hline $\begin{array}{c}\text { After } \\
\text { Treatment }\end{array}$ & 32.2 & 36.2 & 63.8 & 1.80 & 11 & 98 & 114.6 & 0.87 & 22.8 \\
\hline
\end{tabular}

\section{Discussions}

Probiotics are substances that regulate the normal intestinal flora, influence metabolism and have an effect on various diseases. Our studies were performed on the effect of Lactobacillus bulgaricus and Bifidobacterium animalis subsp. lactis on carbohydrate and lipid metabolism in obesity. The results indicated that the probiotics improved the impaired glucose and lipid metabolism. The probiotics affected the concentration of free radicals in the blood. Taken together, 
the results demonstrate the effect of probiotics on oxidative stress in the mechanism of influencing carbohydrate and lipid metabolism.

Our study emphasizes the significance of yoghurt and other diary product in the prevention and management of metabolic and cardiovascular diseases, which is in concordance with other results found in the literature (Dimitrova, 2012; Milici and Neagu, 2014; Borys et al., 2015; Ivey et al., 2015; Pashova-Baltova et al., 2015; Santiago et al., 2016; Mohammadi-Sartang et al., 2018).

The production of fermented foods is based on the use of starter cultures, for eg. lactic acid bacteria, which initiate the rapid acidification of the raw material, i.e. the milk. A series of studies on the properties of lactic acid producing bacteria have reported suitable strains for inclusion in functional (starter) cultures and fermented products; among them we list L. bulgaricus strains with established in-vitro immunomodulatory effect, L. helveticus - producer of bioactive peptides with ACE-inhibitory activity, L. Gasseri - with a strong adhesion to the epithelial cells of the gastrointestinal tract and cholesterol-lowering effect.

Recently, new starter cultures of lactic bacteria are developed, which may contribute to microbial safety or provide one or more organoleptic, technological, nutritional or health benefits. Examples are the lactic acid bacteria that produce antimicrobial substances, sugar polymers, sweeteners, aromatic compounds, vitamins or enzymes useful or having probiotic properties (Leroy and De Vuyst, 2004).

\section{Conclusion}

The regular consumption of yogurt fermented with Lactobacillus bulgaricus and Bifidobacterium animalis subsp. lactis $(0.5 \%$ fat $)$ in the diet of obese patients leads to improvement of the studied anthropometric parameters as well as to significant decrease in the cardiovascular risk.

\section{References}

1. Beck, A.L., Heyman, M., Chao, C., Wojcicki, J., 2017. Full fat milk consumption protects against severe childhood obesity in Latinos. Preventive medicine reports, 8, pp.1-5. https://doi.org/10.1016/j.pmedr.2017.07.005

2. Lamarche, B., Givens, D.I., Soedamah-Muthu, S., Krauss, R.M., Jakobsen, M.U., BischoffFerrari, H.A., Pan, A., Després, J.P., 2016. Does Milk Consumption Contribute to Cardiometabolic Health and Overall Diet Quality? The Canadian journal of cardiology, 32(8), pp.1026-32. https://doi.org/10.1016/j.cjca.2015.12.033

3. Dimitrova, D., 2012. Overweight and obesity prevalence in Bulgaria. In: the EPODE INTERNATIONAL NETWORK, Global obesity Forum, New York, U.S., 27-29 June 2012.

4. Bogdanov, G., 2014. Probiotic as antioxidant in juvenile rats' fat-rich diet, Obesity facts, 7(supp.1), pp.66-67. Available at: https://bib.irb.hr/datoteka/703185.obesity_facts_2014.pdf [Accessed 26 June 2017]

5. Karimi, G., Jamaluddin, R., Mohtarrudin, N., Ahmad, Z., Khazaai, H., Parvaneh, M., 2017. Single-species versus dual-species probiotic supplementation as an emerging therapeutic strategy for obesity. Nutrition, metabolism, and cardiovascular diseases : NMCD, 27(10), pp.910-918. https://doi.org/10.1016/j.numecd.2017.06.020

6. Ahn, H.Y., Kim, M., Ahn, Y.T., Sim, J.H., Choi, I.D., Lee, S.H., Lee J.H. 2015. The triglyceride-lowering effect of supplementation with dual probiotic strains, Lactobacillus curvatus HY7601 and Lactobacillus plantarum KY1032: Reduction of fasting plasma lysophosphatidylcholines in nondiabetic and hypertriglyceridemic subjects. Nutrition, 
metabolism, and cardiovascular diseases: NMCD, 25(8), pp.724-33. https://doi.org/10.1016/j.numecd.2015.05.002

7. Borys, J.-M., Graça, P., Gregorio, M.J., Handjiev, Sv., Mantziki, K., Moreno, L.A., du Plessis, H.R., Seidell, J.C., Vassilopoulos, A., Visscher, T.,eds. 2015. EPODE for the Promotion of Health Equity, Cachan Cedex, France: Lavoisier Publishing.

8. Pashova-Baltova, K., Minkova, Sv., Dimitrov, Zh., Mihaylova, M., Spasova, M., Panayotova, T., Ninova, N., 2015. LB fermented functional foods - contributing to the prevention of obesity. In: BASORD (Bulgarian Association for Study of Obesity and Related Diseases), 14th International Symposium „Acad. Tasho Tashev”-“Nutrition and Obesity”, Albena, Bulgaria, 4-6 Septembrie 2015.

9. Ivey, K.L., Hodgson, J.M., Kerr, D.A., Thompson, P.L., Stojceski, B., Prince, R.L., 2015. The effect of yoghurt and its probiotics on blood pressure and serum lipid profile; a randomised controlled trial. Nutrition, metabolism, and cardiovascular diseases: NMCD, 25(1), pp.46-51. https://doi.org/10.1016/j.numecd.2014.07.012.

10. Leroy, F. and De Vuyst, L., 2004. Lactic acid bacteria as functional starter cultures for the food fermentation industry. Trends in Food Science \& Technology, 15(2), pp.67-78.

11. Mohammadi-Sartang, M., Bellissimo, N., Tötösy de Zepetnek, J.O., Brett, N.R., Mazloomi, S. M., Fararouie, M., Bedeltavana, A., Famouri, M., Mazloom, Z., The effect of daily fortified yogurt consumption on weight loss in adults with metabolic syndrome: a 10-week randomized controlled trial, Nutrition, Metabolism and Cardiovascular diseases, 2018, in press, Available online 10 March 2018. https://doi.org/10.1016/j.numecd.2018.03.001.

12. Martinez-Gonzalez, M.A., Sayon-Orea, C., Ruiz-Canela, M., de la Fuente, C., Gea, A., BesRastrollo, M., 2014. Yogurt consumption, weight change and risk of overweight/obesity: the SUN cohort study. Nutrition, metabolism, and cardiovascular diseases: NMCD, 24(11), pp.1189-96, https://doi.org/10.1016/j.numecd.2014.05.015.

13. Milici, N. and Neagu, A., 2014. La consommation de produits laitiers et l'état pondéral chez les adolescents de Bucarest, In: Mondialisation des comportements alimentaires et facteurs de risques pour l'obésité et le diabète, Sofia: Simel Press Edt. pp.101-115.

14. Santiago, S., Sayón-Orea, C., Babio, N., Ruiz-Canela, M., Martí, A., Corella, D., Estruch, R., Fitó, M., Aros, F., Ros, E., Gómez-García, E., Fiol, M., Lapetra, J., Serra-Majem, L., BecerraTomás, N., Salas-Salvadó, J., Pinto, X., Schröder, H., Martínez, J.A., 2016. Yogurt consumption and abdominal obesity reversion in the PREDIMED study. Nutrition, metabolism, and cardiovascular Niseases: NMCD, $\quad$ 26(6), pp.468-75. https://doi.org/10.1016/j.numecd.2015.11.012.

15. Handjieva-Darlenska T., Fr. Roville-Sausse, Sv. Handjieva. 2016. Le yaourt- la diete balkanique. In: Nutrition et Sante. Sofia: Simel Press. pp.52-53.

16. Handjieva-Darlenska, T., Handjiev, Sv., Bogdanov, G., Lazarov, L., Getova, D., Stavreva, G., Boyadjieva, N., 2015. Characteristics of the low calorie diet with Probiotic for prophylaxis of diabetes mellitus type 2 in subjects with obesity and prediabetes. In: BASORD (Bulgarian Association for Study of Obesity and Related Diseases), $14^{\text {th }}$ International Symposium Acad. Tasho Tashev "Nutrition and Obesity", Albena, Bulgaria, 4-6 Sep 2015.

17. Handjieva-Darlenska, T. and Minkova, Sv., 2016. Clinico-Pharmacological, anthropological and technological study on the effect of new Bulgarian probiotic producs, In: A. Cosma si C. Glavce, eds. Antropologie şi sănătate (Anthropology and Health), Bucureşti: Editura Academiei Române. pp. 108-110. 
18. von Sanchsen, Th., The Balkan diet - Western Medicine Point of View. In: BASORD (Bulgarian Association for Study of Obesity and Related Diseases), $2^{\text {nd }}$ Balkan Congress on Obesity, Albena, Bulgaria, 19-21 May 2006, Abstract Booklet p. 70.

19. Yumuk, V., Tsigos, C., Fried, M., Schindler, K., Busetto, L., Micic, D., Toplak, H., Obesity Management Task Force of the European Association for the Study of Obesity, 2015. European Guidelines for Obesity Management in Adults. Obesity facts, 8(6), pp.402-24. https://doi.org/10.1159/000442721.

20. ***World Health Organization, 2018. Global Health Observatory (GHO) data. Overweight and obesity. Available at: http://www.who.int/gho/ncd/risk factors/overweight_obesity/obesity_adolescents/en/ [Accessed 20 March 2018] 


\title{
Changes in occupational profiles and occupational health service
}

\section{DOI: $\underline{\text { http://doi.org/10.26758/8.1.18 }}$}

\author{
Alina Ferdohleb
}

Nicolae Testemitanu State University of Medicine and Pharmacy, Department of Management and Psychology; National Center of Public Health, Scientific laboratory of Occupational health; Chisinau, Republic of Moldova

Address correspondence to: Alina Ferdohleb, bld. Stefan cel Mare si Sfant 196-B, Chisinau, Republic of Moldova; e-mail: alina.ferdohleb@gmail.com

\begin{abstract}
Objectives. Changes in the economy and occupational profile, implementation of new technologies and fragmentation of tasks and work processes justify the urgent needs in specialized occupational health and basic services. The national economy of the Republic of Moldova used to be based on the agricultural sector, two-thirds of the workers being employed in agriculture, while at present this country is undergoing changes in the occupational profile of the agricultural workers. As the total number of employees was reduced twice, the office workers, public workers, and others experienced a growing trend.

Material and methods. Cross-descriptive, retrospective, sociological (questionnaire for hygienist doctors from territorial public health centers), and analytical-descriptive research of national occupational profile in the dynamics of 15 years was conducted. Approval of the ethics committee and informed respondent consent were obtained. There are presented the remote results of 61 hygienist doctors and 53 expert doctors who activated in the security and health services from the Republic of Moldova.

Results. A demographic decline among the working age population was registered (from $63.78 \%$ in 2000 to $59.58 \%$ in 2015); there was also a decrease in the diagnosis of occupational diseases at early stages (0 cases 2014, 2015, 2016), which caused a 1.5-time increase of disabilities in the working population during the last years. We should also mention the 2.5 times rise of the percentage of employees working in harmful and inadequate sanitary conditions. The results of the inquiring the occupational health specialists justified the necessity: to categorize the place of work depending on the branch of the national economy; to elaborate tools to supervise and monitor the occupational health services; to strengthen medical statistical tools in occupational health care; to show the main causes of illness.

Conclusions. Currently, the results of changes in the occupational profile are caused by: the absence of an interdepartmental strategic plan in the field of occupational health; the small number of businesses where health services are provided; lack of specialized indicators for monitoring occupational health; a low number of doctors specializing in occupational medicine; lack of motivation from the employer and the employee to establish the diagnosis of occupational disease; the phenomenon of high migration of the working-age population; the lack of a national electronic medical register for medical examination of the employees with occupational diseases.
\end{abstract}

Keywords: occupational profile; occupational disease; performance indicators; working age population. 


\section{Introduction}

Occupational Health Services (OHS) developed alongside with other social protection measures as a response to provocations of the industrial revolution and demographic changes associated with XXI century (Rantanen and Kim/WHO, 2012). These were perceived as necessary and often initiated by industry. Their organization and tasks are defined tripartite international labor law (employee, employer and syndicates/patronages).

The practice of $\mathrm{OH}$ appeared from the social changes of the industrial revolution and in some cases, is seen as an integral component of a successful business. Still, the access to specialized advice from OHS is mostly limited to employees from big enterprises. Challenges associated with Public Health because of a growth of non-communicable diseases and aging of population will lead to changes in national health systems and integration of new $\mathrm{OH}$ systems (Michalak, 2002).

The growth of world commerce and concurrency based on new technologies changed not only the professional dangers but also lead to the considerate fortification of the subject in the legislation. Implementation and adaptation of these acts need a change from occupational health services, as well from employer/boss. As a result, the current changes in the occupational profile make a beneficial contribution to the development of healthy and productive work conditions and social-economic stability of the country (Godderis, et al., 2004).

Moldova continued on large-scale the socioeconomic reform since the declaration of independence. Despite major changes, which happened during the transition period, of more than 25 years, the economic stability was achieved, GDP growth is moderate, with a reasonable level of unemployment $(4.2 \%)$. Long-term prospects are, however, affected by/correlated with the economic income of migrant workers (which leads to high economic consumption and trade imbalance) but this does not affect the national occupational profile/structure (structures in the national economy, labor productivity in Moldova).

At present, the health of employees working in unfavorable and harmful working conditions is not sufficiently monitored by the occupational health services system in the Republic of Moldova. It is one of public health specialists' concerns in the context of the assessment of occupational risk factors and their influence on the state of health. Despite the progress made in many branches of the Moldavian national economy (agriculture, construction, transport, furniture industry, etc.), the occupational environment continues to present a real danger to the health of employees.

The health assessment does not take into account the employee's daily occupational exposure to the workplace, but only the current situation. The lack of a specialized system in studying and evaluating the relationship between occupational risk factors in the occupational environment and workers' health at the initial/pre-morbid stage allow neither to monitor the health status and the conditions and harmful factors to which workers are exposed, nor, as a result of these investigations, to elaborate the intersectoral prevention measures.

On the other hand, one of the objectives of similar research is to describe opportunities for national profiles supervision (Godderis et al., 2014). Consolidation of occupational health services system will have an important impact not only on public health but also on national economy (Harrison and Dawson, 2016). 


\section{Materials and methods}

In the present research, a transversal-descriptive, sociological analysis of the population able to work was performed. The employees were analyzed depending on their status: official employees, independent workers, unpaid family workers, employers and cooperative members, occupied branch of national economy, as a part of the analytical-descriptive research of occupational national profile in the dynamics of 15 years.

The paper's aim is to describe the "update" of occupational safety and health profile in the Republic of Moldova (***International Labour Organization \& Ministry of Labour, Social Protection and Family of the Republic of Moldova, 2011). The study involved a broad literature research combined with an investigation of the existing methods of reporting and description of the occupational profiles, depending on the country. The field of occupational health takes priority both in the national economy as well in the health of the nation (Macdonald and Sanati 2010). From the literature review, 27 occupational profiles were obtained. Feasibility studies were performed in the same manner in the developed countries, EU countries, neighboring countries, and post-soviet countries: Albania, 2007; Armenia, 2007; Azerbaijan, 2002; China, 2012; India, 2011; Montenegro, 2007; Romania, 2007; Serbia, 2007; the Federation of Bosnia and Herzegovina, 2007; the former Yugoslav Republic of Macedonia, 2008; the Kyrgyz Republic, 2008; the Leningrad Region, 2008; the Murmansk Region, 2009; the Republic of Bulgaria, 2007; the Republic of Croatia, 2007; the Republic of Georgia, 2003, 2008; the Republic of Karelia, 2009; the Republic of Kazakhstan, 2008; the Republic of Tajikistan, 2008; the Republic of Uzbekistan, 2008; the Republika Srpska, 2007; Ukraine, 2007, 2010, 2012.

Our paper is based on the method of describing the occupational profile used in Finland (***Ministry of Social Affairs and Health of Finland, 2006) and Germany (Froneberg and Timm/WHO, 2012). The reasoning behind the selection was the high-ranking positions of these countries in the lists, taking into account the organization of occupational health services, and because of the similarity in health insurance system with the Republic of Moldova.

Additionally, the sociological - qualitative stage (questionnaire for hygienist doctors from territorial public health centers) was also performed as part of the research.

The results of the inquiring were processed with Microsoft Excel and SPSS-21; arithmetic mean $(\mathrm{M})$, the weighted average $(\mathrm{P})$, mean arithmetic error $(\mathrm{m})$, non-parametric tests $(\mathrm{t}, \mathrm{p}, \mathrm{SD}$ and soon) were calculated for validation and according to the advanced hypothesis.

In this research, the fundamental ethical research principles of the Helsinki Declaration have been respected. The hygienist doctors/respondents gave informed consent for enrollment in the study.

\section{Results}

Determination and systematization of a set of epidemiological and performance indicators in the anthropological research are very up-to-date. Electronic report of data can be used by OHS with the aim of supervision and prevention (Michalak J., 2002; Macdonald and Sanati 2010). Afterward, the selected data can serve as indicators for the exposure and prevention of risks and contribute to the evaluation of the performance of occupational health services providers (Turcanu et al., 2012).

According to the database of the National Bureau of Statistics of the Republic of Moldova (available at: www.statistica.md ), on January 1, 2017, the entire population was 3,550,852, out of 
which: $48.08 \%$ were men $(1,707,363$ million $)$ and $51.92 \%$ women $(1,843,486) ; 42.72 \%(1,516,813)$ urban inhabitants and $57.28 \%(2,034,039)$ rural inhabitants, respectively.

The "life expectancy" index in 2016 was 72.17 years, depending on sex -68.14 years for men and 76.15 years for women - and on the place of residence - 75.00 years for the urban population and 70.34 years for the rural population. In contrast, the "demographic burden" index in 2016 was 49.6 persons per republic, indicating a decrease in the working age population and a growth of population besides the working age.

Thus, at 1 January 2017, the working-age population was 2,313,927, which represents $65.17 \%$ of the country's population.

And the population that is economically active and of working age is $35.84 \%(1,272,800)$, of which: $50.33 \%$ men $(640,600)$ and $49.67 \%$ women $(632,200)$. The total adult, working-age population in 2012 was 243.2 million. Out of this total population, 142.4 million were classified as employed and 12.5 million were classified as unemployed.

The remaining the population economically active is $35.84 \%$ cases. On the other hand, the population economically inactive is $48.24 \%(1,712,700)$ (see Figure 1).

Figure 1. Occupational profile of the Republic of Moldova on January 1, 2017.

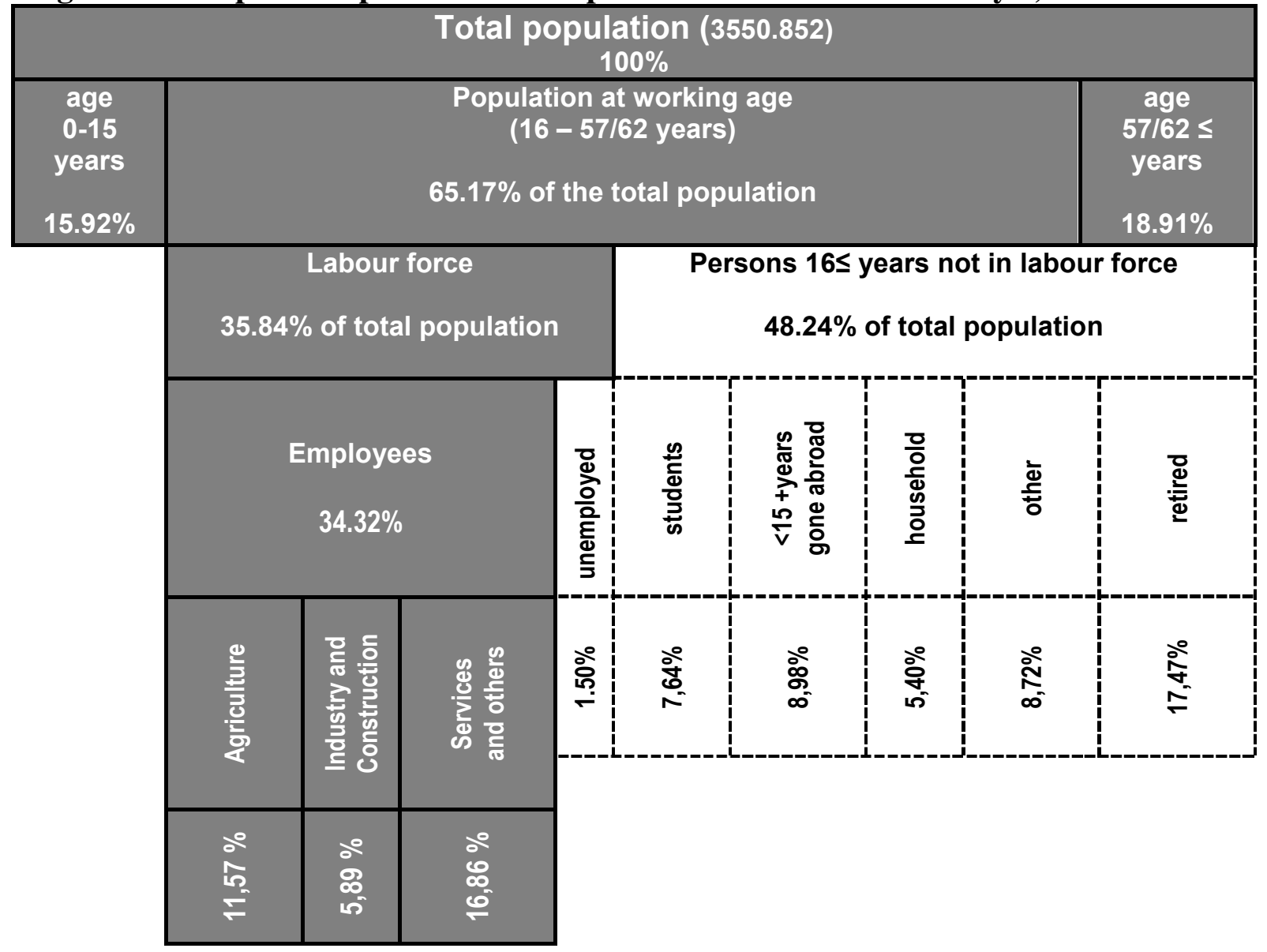

Thus, the share of the unemployed in the country is $4.2 \%(53,300$ of persons), and $1.5 \%$ of the economically active population, respectively. On the other hand, the share is higher $-6.0 \%$ in urban localities compared to rural localities - 2.6\%. Subsequently, we analyzed the unemployment phenomenon by sex, where men's share is $5.5 \%$ and women's $-2.9 \%$, respectively. 
The distribution of the occupational profiles by economic branch is as follows:

- Agriculture, hunting economy and fish farming - $11.57 \%$ of the population $(410,900)$;

- Industry $-4.17 \%$ of the population $(148,100)$;

- Construction $-1.72 \%$ of the population $(60,900)$;

- Wholesale and retail trade; Hotels and restaurants - 6.29\% $(223,500)$;

- Transport and Communications $-2.15 \%$ of the population $(76,200)$;

- Public administration; Education; Health and social assistance - $6.29 \%$ of population $(223,500)$;

- Other activities $-2.82 \%$ of the population $(100,300)$.

It is important to note the significant decrease in number of the working age population over the past 15 years (from $63.78 \%$ in 2000 to $59.58 \%$ in 2015). Promoting 'worthy work for all ages' policy and a gradual increase in the retirement age for men and women might have helped to avoid or minimize the shortages in human resources in some areas of the national economy.

When analyzing absolute data, in the agricultural sector, the number of employees has decreased twice (from 770.4 thousand in 2000 to 381.9 thousand in 2015). Similarly, the number of employees in the industry decreased 1.14 times (from 166.1 thousand in 2000 to 145.6 thousand in 2015). On the other hand, we see some 1.5 times increase in construction field (from 44.4 thousand in 2000 to 65.4 thousand in 2015), as well as in the "wholesale and retail, hotels, restaurants" sector (from 165.3 thousand in 2000 to 189.6 thousand in 2015).

Figure 2. Occupational profile depending on national economy field, \%.

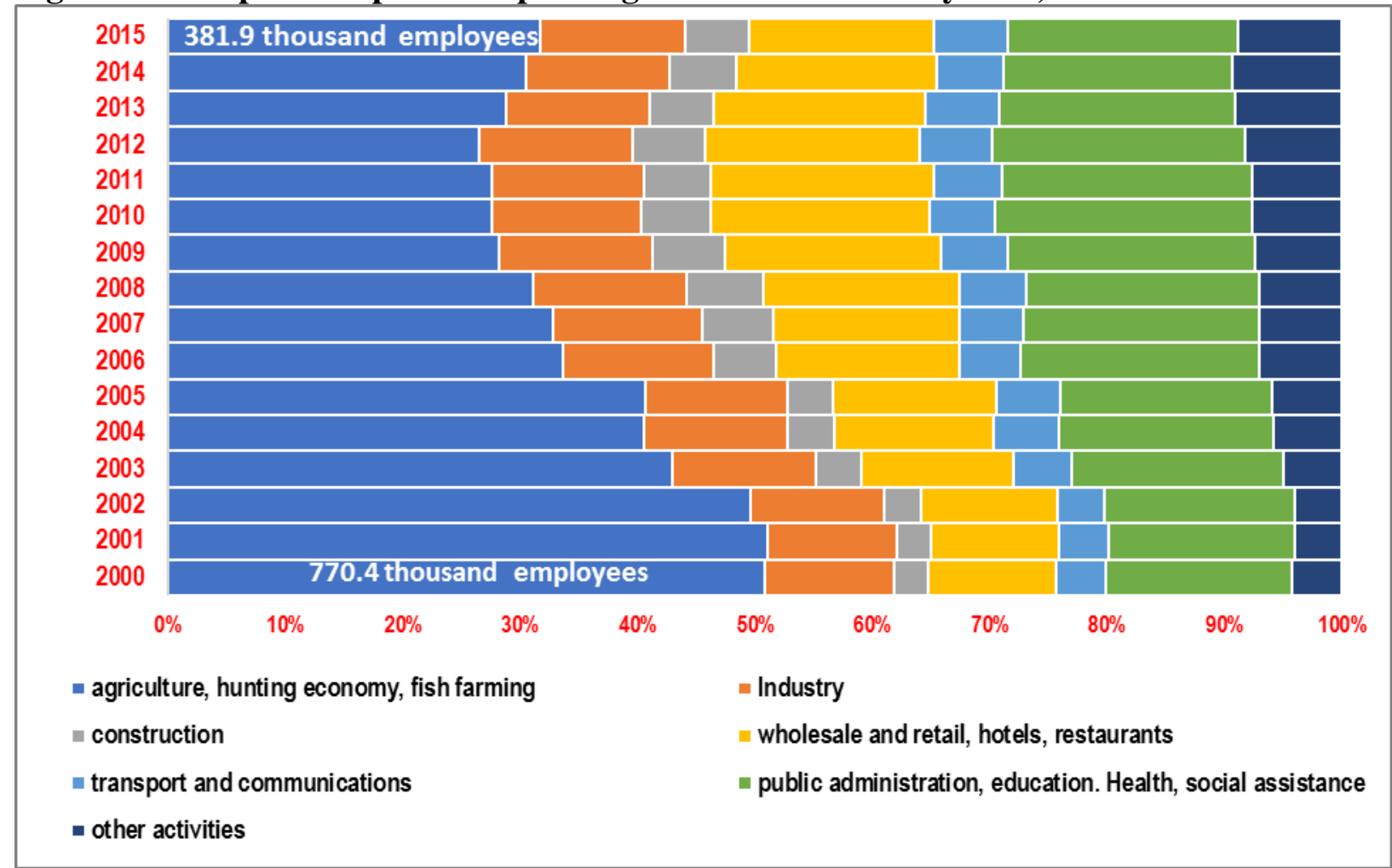

In the next stage, the analysis of the occupational profile was carried out according to the distribution quotas of employees in the national economy.

The trend shows an increase in the former and a steady decline in the latter. Industry $(13.0 \%)$ is in slight growth and construction $(5.7 \%)$ relatively stable. The proportion of public sector employment is relatively high but declining. The share of informal employment is officially $28 \%$, 
but there are estimates referring to as high as 30-50\% share of informal employment if all people participating in work life are counted (Figures 2 and 3). The informality may also explain partly the low formal labor participation rate figures.

The occupational structures are determined by the size of the economic sectors. A series of job sectors - agriculture, forestry, manufacturing, and construction - that absorb almost half of the entire workforce continue to represent high-risk areas regarding the traditional occupational safety and health.

The other half of workforce, such as health workers, workers in trade, hotel, and restaurant occupations, is exposed to the typical occupational health problems of service occupations, ergonomic problems, psychological stress and time pressure and sometimes violence caused by clients. Thus, the Moldavian occupational health services have to be able to respond to both the risks of traditional work and stresses of the so-called new work life.

The distribution of the occupational profiles by the status of the working person (employee, self-employed, unpaid family worker, business owner, member of an agricultural cooperative society) is graphically represented in Figure 3.

Figure 3. Occupational profile according to the employees' statute, $\%$.

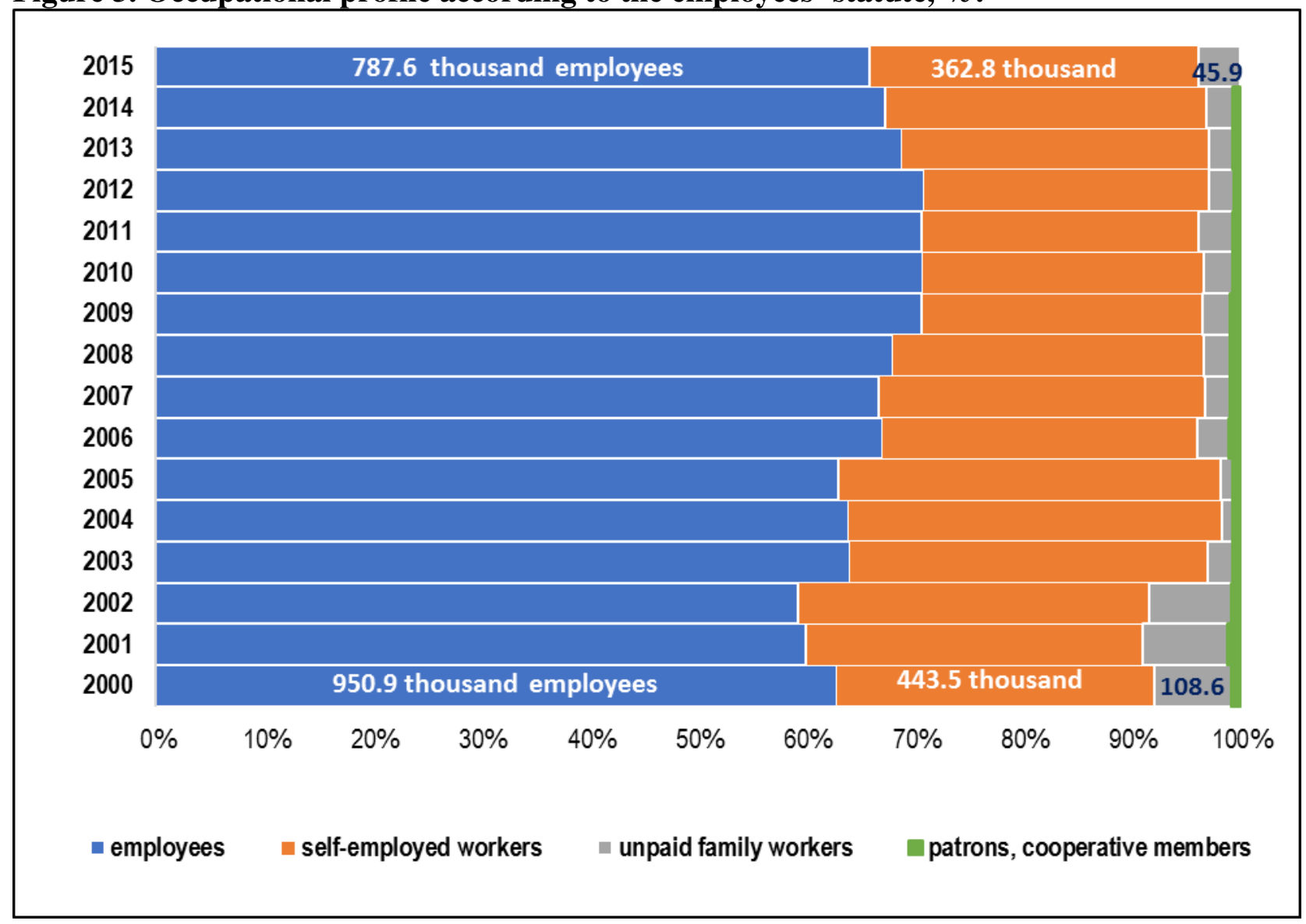

According to the distribution of persons employed in economic activities, 441.0 thousand persons (34.7\% of the total number of employed persons) are employed in the agricultural sector. Of these, $46 \%$ (or $16.1 \%$ of the total number of employed persons) are those engaged in the production of agricultural products exclusively for their own consumption. As compared to 2016, the number of employees in agriculture decreased by 56.5 thousand, or by $11.4 \%$. 
829.2 thousand persons were employed in non-agricultural activities, $2.3 \%$ more than in 2016. The share of persons employed in industry constituted $11.9 \%(11.3 \%$ - 2016) and construction - 5.4 (5.1\% - 2016). The number of persons employed in industry increased by $2.8 \%$ compared to the same quarter of the previous year, and in construction by $2.2 \%$. There were $48.0 \%$ of all employed persons in the services sector, their share recording an increase compared to 2016 $(45.6 \%)$.

By ownership criteria, $75.9 \%$ of the employed population worked in the private sector and $24.1 \%$ in the public sector. The structure of the employed population, according to the professional status, reveals that the share of the employees constituted $63.0 \%$ of the total.

Undeclared work among employees constituted 6.5\%, recording a decrease compared to the second quarter of the previous year (7.8\% in 2016). The employment practice without the completion of individual employment contracts (based on verbal agreements) is more common among male employees $(8.0 \%)$ than female employees $(5.0 \%)$. The largest shares of employees working only on verbal understanding are estimated to be in agriculture $(38.4 \%)$ and trade $(16.1 \%)$.

Each service system must be provided not only material - economically but also with wellprepared human resources. We find that, generally, the health services in the country are affected by the great mobility/exodus and the shortage of medical staff. In the past twenty years, more than $40 \%$ of health workers have left the health system. At national level, the number of doctors decreased from 16,199 in 1996 to approximately 10,397 in 2015. The same phenomenon is found among the doctors of the Public Health Surveillance Service, in the case of hygienist doctors in the Occupational Health Service.

For a deeper understanding of this phenomenon, our study included the use of a qualitative questionnaire and in-depth interviews with hygienist doctors from the territorial public health centers. The interview data from the full research sample of 35 hygienist doctors in the district public health centers was structured according to: the age of the respondents (under 35, 35-60 and over 60); the length of their service (under 5, 5-35 and over 35); grade of specialization (superior, first category, second category and without category).

As a result of the analysis, the age of doctors from district PHC is $50.77 \pm 1.98$ years, Min $=27.0$ years and $\operatorname{Max}=70.0$ years $(S D=11.76)$, the length of service is $24.97 \pm 2.24$ years, Min $=$ 1.0 years and Max $=45.0$ years, $(S D=13.27)$. Regretfully, doctors under the age of 35 were a minority $(14.3 \%)$, while the number of people of retirement age $(22.9 \%)$ is high. Doctors were asked if "the occupational health vision has changed following the workshop": those under 35 years responded positively in $80.0 \%$ of cases, those over 60 years - 75.0\% of cases and those between 35 60 years $-27,3 \%$ of cases. The current situation confirms the responsibility of the specialists for the daily problems encountered in the service of occupational health (see Figure 4).

The affirmative responses to the questions regarding the usefulness of knowledge for practical work were distributed as follows (see Figure 5):

- basic notions in occupational health $(\mathrm{OH}): 74.3 \%$ of cases $(60 \%$ among doctors aged $<35$ years, $62.5 \%$ among doctors aged $>60$ years, and 81.8\% among those aged 35-60 years);

- OH legislation: $62.9 \%$ of cases $(40 \%$ among doctors aged $<35$ years, $75 \%$ among doctors aged $>60$ years, and $63.6 \%$ among those aged $35-60$ years);

- components of the $\mathrm{OH}$ structure: $37.1 \%$ of cases (40\% among doctors aged <35 years, $25 \%$ among doctors aged $>60$, and $40.9 \%$ among those aged $35-60$ years);

- $\mathrm{OH}$ tasks: $54.3 \%$ of cases $(60 \%$ among doctors aged $<35$ years, $37.5 \%$ among doctors aged $>$ 60 , and $59.1 \%$ among those aged $35-60$ years);

- OH activities: $51.5 \%$ of cases (80\% among doctors aged $<35$ years, $25 \%$ among doctors aged $>$ 60 , and $54.5 \%$ among those aged $35-60$ years); 
Analyzing the answers, we found the responsibility (in the anonym questionnaire) of the doctors in the 35-60 age group with valid statistical representation.

Figure. 4. The distribution of the answers to the first question, "the occupational health vision has changed following the workshop" and the respondents' age, $\%$.

\begin{tabular}{|c|c|c|c|}
\hline $20.0 \%$ & & & \\
\\
\end{tabular}

Figure 5. Distribution of responses on utility and information needs following training courses and approached items, \%.

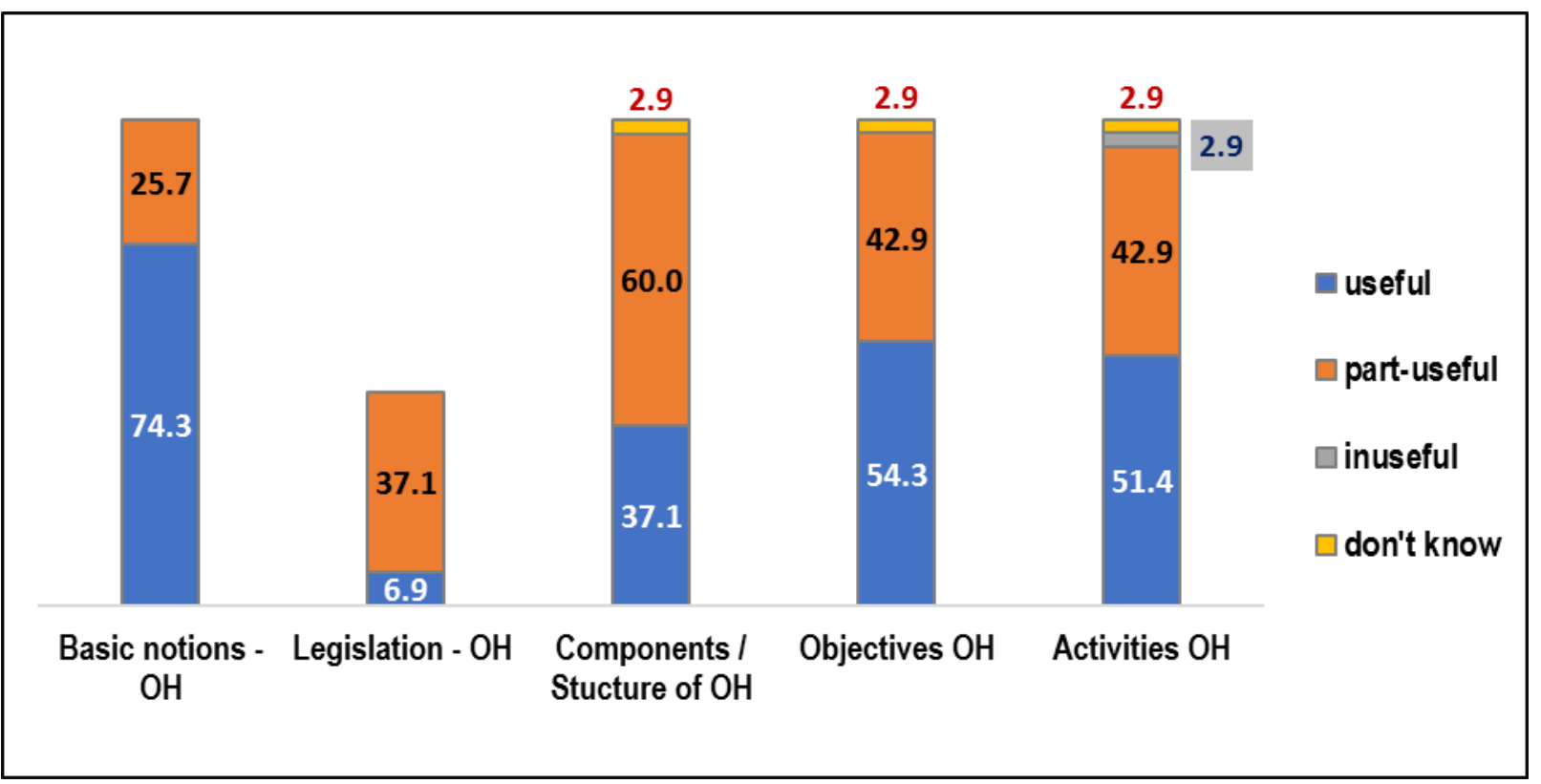

On the other hand, to the question about "the usefulness of information for international law", the answers were distributed in the following way: useful - 48.6\%; partially useful - 42.9\%; useless $-5.7 \%$ and do not know $-2.9 \%$ of cases. 
Further to the "usefulness of the information for national legislation", the answers were as follows: useful - 65,7\%; partially useful - 34,3\%. The objectivity of these questions was presented by the respondents aged 35-60, with representative statistical validity.

The survey also included the identification of those services that intersect/interfere with the work of medical hygiene specialist at the local level. According to their frequency, these were reported as follows: ecologic inspectorate - 34.3\%; labor inspection -14.3\%; agricultural department - 11.4\%; local public administration - 8.3\%, etc.

Regretfully, doctors specialized in occupational diseases, doctors/physicians working in companies or medical examination committees of employees, physicians and others were not mentioned. As it is known, professional diseases have not been diagnosed for three years, in the republic.

In this context, we investigated what training topic (which requires a more detailed or indepth preparation) would be more welcomed among the specialists (see Figure 5).

The first place was shared by the national legislation and normative acts (nominated by 91.4\% of the respondents) and the risk factors in the occupational environment (nominated by an equal percentage). The second place was occupied by the stress at work (topic advanced by $85.7 \%$ of the respondents). The third priority, with an insignificant difference, was the organization of occupational health service (chosen by $82.9 \%$ ) and familiarization with ergonomic methods in OHS (indicated by $82.4 \%$ ).

According to priorities the topics have been hierarchized as follows: experiences and international normative acts (68.6\%); supervision of enterprises where a diagnosis of occupational disease is suspected (74.3\%); research of occupational diseases (77.1\%); medical-professional rehabilitation of employees $(80.0 \%$ ) (see Figure 6).

Figure. 6. Distribution of responses on the usefulness and necessity of information following training courses and addressed items, $\%$.

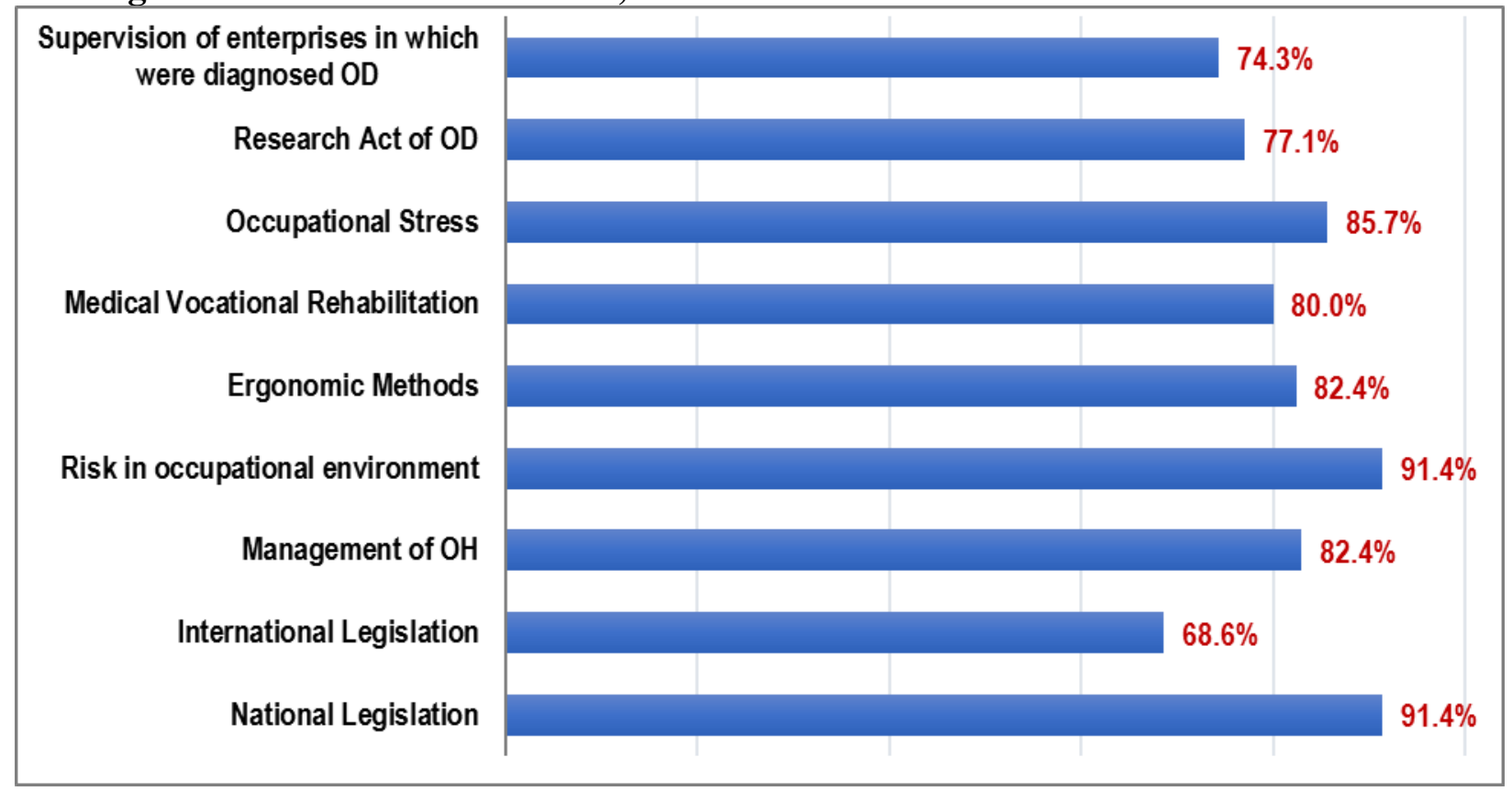


The participants to study were also questioned about their interests in dedicated workshops. Their suggestions include interactive dialogue (submitted by $74.3 \%$ of the respondents); distribution of didactic materials (expressed by $71.4 \%$ ); the utility of the material in practice (supported by $65.7 \%)$.

Today, the welfare of industrialized and developing countries is based on technologies that require chemicals in the occupational environment. While these chemicals are extremely valuable and useful, their production, use, and disposal can be dangerous to human health and the environment. In spite of stringent legislative controls in the EU-27, and the implementation of many voluntary measures by enterprises, annual appraisals indicate that 167,000 workers die due to working conditions. More than $95 \%$ of these deaths are caused by occupational diseases, and half of these deaths are attributable to exposure to chemical and toxic chemicals. Among the main causes are long-term exposures that lead to the development of work-related cancers.

According to EU-OSHA, chemicals products and hazardous chemicals or other materials used in the workplace can cause up to 70,000 deaths per year in the EU. Most of them are from long-term exposure and asbestos still contributes significantly.

Occupational health services confront important changes as a result in the occupational environment, in the health and security concepts, in legislation. In order to achieve a high quality of OHS at a reasonable cost, it is important to prepare a "National Occupational Profile", which will systematize the occupational concept with the help of standard indicators and present them with regularity (5 years, 10 years, 15 years, etc.).

National Occupational Profile is often performed based on the concept of critical thinking. The concept of preventive thinking is presented to manage health services at the workplace (Godderis et al., 2012).

\section{Conclusions}

The findings reveal a stringent need to develop a new strategy on the health and safety of employees at the workplace. This reform will have to consolidate the given area, to harmonize the Internal Legislation with International Labor Organization and World Health Organization conventions in the given field, and to rely on the main directions set by the International Commission on Occupational Health (ICOH).

The achievement of the objectives of occupational medicine is based on the predominant prophylactic feature of this complex discipline, which will be carried out through the systematic supervision with adequate means of the working conditions and health status of the employees in order to identify the new professional risks and methods of combating them. The Occupational Medicine/Occupational Health Services requires the orientation towards teamwork of the specialists in the field of health and safety at work; it is necessary to coordinate well all the services responsible for the health status of the working age population.

The creation of the Occupational Medicine/Occupational Health Service will contribute to improvement of health-care assistance to workers, working conditions, health of employees and of working-age population, by diminishing occupational diseases, morbidity with temporary incapacity to work, general morbidity, work trauma, working-age mortality, and therefore it will contribute to the essential growth of the national economy.

The creation and implementation of the Occupational Medicine/Occupational Health Service will allow in perspective that the policy and the strategy of health and safety at work will no longer present separate activity fields but a whole one, which, within the framework of national policy and strategy, will bring together intersectoral efforts both in legislative and institutional plans. 


\section{References}

1. Froneberg, B. and Timm, S. (CWorld Health Organization Regional Office for Europe, 2012. Country Profile of Occupational Health System in Germany. Available at: <http://www.euro.who.int/_data/assets/pdf_file/0010/178957/OSH-Profile-Germany.pdf?ua=1 $>$ [Accessed 19 October 2017]

2. Godderis, L., Johannik, K., Mylle, G., Bulterys, S., Moens, G., 2014. Epidemiological and performance indicators for occupational health services: a feasibility study in Belgium. BMC health services research, 14, pp.410-419, [online] Available at: <https://bmchealthservres.biomedcentral.com/articles/10.1186/1472-6963-14-410> [Accessed 19 October 2017].

3. Godderis, L., Vanhaecht, K., Masschelein, R., Sermeus W., Veulemans H., 2004. Prevention pathways: application of the critical path methodology in occupational health services. Journal of occupational and environmental medicine, 46(1), pp.39-47. Available at: <https://pdfs.semanticscholar.org/4152/0bca779b45a22beaf5d69d104b538462ed91.pdf> [Accessed 19 October 2017].

4. Harrison, J., Dawson, L., 2016. Occupational Health: Meeting the Challenges of the Next 20 Years. Safety and health at work, 7(2), pp.143-149. Available at: <https://www.ncbi.nlm.nih.gov/pmc/articles/PMC4909849/> [Accessed 19 October 2017].

5. Macdonald, E., Sanati, K., 2010. Occupational health services now and in the future: the need for a paradigm shift. Journal of occupational and environmental medicine, 52(12), pp.12731277. Available at: <https://www.ncbi.nlm.nih.gov/pubmed/21750477> [Accessed 19 October 2017].

6. Michalak J., 2002. Quality assessment in occupational health services: a review. International journal of occupational medicine and environmental health, 15(2), pp.165-171. Available at: <https://www.ncbi.nlm.nih.gov/pubmed/12216774> [Accessed 19 October 2017].

7. Rantanen, J., Kim R. OWorld Health Organization Regional Office for Europe, 2012. Situation Analysis and Recommendations for Stewardship on Workplace Health Promotion in Poland. [online] Available at: <http://www.euro.who.int/en/countries/poland/publications/situationanalysis-and-recommendations-for-stewardship-on-workplace-health-promotion-in-poland > [Accessed 19 October 2017].

8. Turcanu, G., Domente, S., Buga, M., Richardson, E., 2012. Republic of Moldova: health system review. Health systems in transition, 14(7), pp. 1-151. [online] Available at: <https://www.ncbi.nlm.nih.gov/pubmed/23211662> [Accessed 19 October, 2017].

9. ${ }^{* * *}$ International Labour Organization \& Ministry of Labour, Social Protection and Family of the Republic of Moldova, 2011. National Occupational Safety and Health Profile Republic of Moldova. Available at: <http://www.ilo.org/wcmsp5/groups/public/---ed protect/---protrav/--safework/documents/policy/wcms_208206.pdf> [Accessed 19 October 2017].

10. ${ }^{* * * *}$ Ministry of Social Affairs and Health of Finland, 2006. National Occupational Safety and Health Profile of Finland. Helsinki: Helsinki University Printing House. Available at: $<$ http://www.ilo.org/wcmsp5/groups/public/---ed_protect/---protrav/--safework/documents/policy/wcms_179869.pdf> [Accessed 19 October 2017]. 


\title{
Indoor air pollution associated with population health status
}

\section{DOI: $\underline{\text { http://doi.org/10.26758/8.1.19 }}$}

Elena Ciobanu (1), Cătălina Croitoru (1,3), Angela Cazacu-Stratu (2, 4), Serghei Cebanu (2, 4), Ovidiu Tafuni (1)

(1) State University of Medicine and Pharmacy "Nicolae Testemiţanu", Chisinau, Republic of Moldova, General Hygiene Department

(2) State University of Medicine and Pharmacy "Nicolae Testemiţanu", Chisinau, Republic of Moldova, Hygiene Department

(3) National Centre of Public Health, Chisinau, Republic of Moldova, Scientific Laboratory of Occupational Health

(4) National Centre of Public Health, Chisinau, Republic of Moldova, Teenager and Child Health Laboratory

Address correspondence to: Elena Ciobanu; Phone: +37379399610; E-mail: elena.ciobanu@usmf.md

\begin{abstract}
Objectives. The estimation of correlative connections between the harmful factors present on the premises, where meals are cooked and certain diseases of the respiratory system are conditioned by indoor air quality.

Material and methods. Three areas of the Republic of Moldova have been selected for research (North, Center, and South). 150 resident persons from the selected areas participated in the study, and they were invited to answer a series of questions. The air temperature, relative air humidity, and carbon dioxide were measured on the premises in which meals were cooked.

Results. The air pollution in kitchens correlates more essentially when using the bottled gas as fuel $(0.18 \leq \mathrm{r} \leq 0.44, \mathrm{p}<0.001)$ and has an influence of $37.5-41.5 \%$ as compared to natural gas. In case of cooking meals in the dwelling room using bottled gas, an average correlation was established with bronchitis $(\mathrm{r}=0.48, \mathrm{p}<0.01)$, pneumonia $(\mathrm{r}=0.56, \mathrm{p}<0.001)$, obstructive bronchitis $(\mathrm{r}=$ $0.54, \mathrm{p}<0.01)$ and very strongly with bronchial asthma $(\mathrm{r}=0.84, \mathrm{p}<0.01)$. In case of cooking meals in summer kitchens, the average correlation was recorded between the use of peasant stoves and the installation of bronchitis, pneumonia, obstructive bronchitis and a especially bronchial asthma.

Conclusion. The need is imposed to develop certain mechanisms of supervision of the indoor air quality. People responsible for the construction, furnishing and equipping the kitchens should fulfill certain rules that would not only relate to the architectural aesthetics, comfort or benefits implied, but also to the health of the people who will work on such premises with special destination.
\end{abstract}

Keywords: indoor air pollution, cooking, correlation coefficient, health status.

\section{Introduction}

The human beings can be affected by their own habitat. The World Health Organization (WHO) considers that approximately $30 \%$ of the dwelling premises present danger to human health. 
The exposure to polluted air leads to harmful effects on health, varying from respiratory diseases to chronic diseases, cancer, pregnancy complications, and premature death. Many studies show that the level of pollution of the indoor air positively correlates with the perceived health risks (Egondi et al., 2013; Leem et al., 2006; Simon et al., 2014; Uzoigwe et al., 2013).

According to the data presented by WHO (2014), more than $50 \%$ of the premature deaths caused by pneumonia in children under 5 years old are caused by the inhalation of particles polluting the air in households. Annually, between 3.3 and 4.3 million people prematurely die due to certain diseases relating to the pollution of air in households, as a result of cooking meals using solid fuel (Dickinson et al., 2015; Egondi et al., 2013; Simon et al., 2014; ***WHO, no.292, 2014). The biomass as fuel is largely recognized as an important source of pollution that affects human health, air quality at the local and regional level, and also has an impact on climate changes at the global level. All over the world, approximately three billion people use the biomass and coal as a fuel for cooking meals and heating the houses (***WHO, no.313, 2014). In rural areas, they often burn biomass in traditional stoves, with open fire, in low ventilated premises with smoke emissions. The released smoke contains high quantities of pollutants which have severe consequences for the health of the exposed persons. Women are involved in cooking meals and their small children pass the time together with them in such premises. Many studies have shown strong associations between burning biomass and increased incidence of chronic bronchitis in women and acute respiratory infections in children (Măruşteni 2006; Moshammer et al., 2010; Sharma et al., 1998). Significant connection with bronchial asthma, tuberculosis, low birth weight, cancer of the upper respiratory tract was also emphasized (Balakrishnan et al., 2004; WHO, no.292, 2014).

No such research was ever performed in the Republic of Moldova and the real situation concerning the discussed issue is not known. Although this topic was approached in the literature from the point of view of various physical factors and chemical substances, we have initiated our study from simple to complex, with clear perspectives of research for the future. This paper presents a wide evaluation of the conditions of cooking meals in the rural area of the Republic of Moldova and the analysis of the air in such premises in the presence of carbon dioxide and the variation of microclimate factors.

\section{Material and methods}

\section{Period and place of the research}

During the summer period of 2015, a poll was conducted in three areas of the Republic of Moldova (North, Center, and South), and certain physical parameters of the microclimate (temperature and relative humidity of the air) and chemical parameters (carbon dioxide) were measured in the premises were meals were cooked. The measurements were performed in the places where people were cooking meals: kitchens, dwelling premises, summer kitchens, with the aid of Air Quality Monitor 500 device. The stages of data collection were the following: before cooking meals (stage I of measurements), one hour after the beginning (stage II), at the end of the cooking (stage III), and one hour after the end (stage IV), during summertime. 11 questions were included in a questionnaire, and the answers were collected through the direct interview method. The questions referred to the place of cooking meals, types of fuel used by the population in the process of cooking meals, the complaints and suffered diseases. 


\section{Subjects and groups}

150 people were included in the study (50 persons from each of the North, Center, and South regions of the Republic of Moldova). Out of the total number of participants, $6 \%$ were men and $94 \%$ women, a fact explained by the national habits and traditions which assign to women the role of preparing the food for their family. In $99 \%$ of the cases, diseases of the respiratory system were found in the interviewed persons. The subjects were selected according to the following criteria: acceptance to participate in the study, age above 18 years old, responsibility and participation in the process of cooking meals.

\section{Methods applied}

A transversal study with analytic component was designed, using the following methods: observational, sociological, epidemiological and experimental.

\section{Statistical processing}

The results were analyzed by calculating intensive indices. The Student significant test was used for the specification of the degree of significance in comparing the mean values. The statistical connection between the factors was established using the correlation analysis. For determining the direction and strength of the relation between the studied indices, the Bravais-Pearson coefficient of simple and multiple linear correlations ( $r)$ and the determination coefficient $\left(\mathrm{r}^{2}\right)$ were used. The correlation coefficient measures the degree of proximity of the linear association between two variables, and the determination coefficient shows the proportion of variability in the model for the dependent variable. The degree of statistical significance of the correlation was established based on ANOVA test in the Statgraphics Plus 2.1 software. The ANOVA test measures whether a factor contributes significantly to the variation of the answer and determines the extent of variation which is due to a pure error. If the $p$-value in the ANOVA table is $0.05-0.001$, we may affirm that there is a statistically significant connection between the variables at a confidence level of $95.0-99.9 \%$.

\section{Results}

In case of the households where people complained of bronchitis and obstructive bronchitis, the mean values of the temperature (Table 1) for the three types of premises showed the following pattern: after one hour from the beginning of the cooking process (stage II), the air temperature increased by $1.8^{\circ} \mathrm{C}$ as compared to the beginning moment (stage I), and, at the end of cooking (stage III), the temperature increased by $3.6^{\circ} \mathrm{C}$ as compared to stage I. After one hour from the moment of finishing the cooking process (stage IV), the air temperature was higher by $0.7^{\circ} \mathrm{C}$ as compared to stage I.

In the premises in which people suffering from pneumonia were cookeding meals, the mean temperature of the air (the mean value in the three types of premises) increased by $2.0^{\circ} \mathrm{C}$ one hour from the starting moment of the cooking process (stage II) as compared to the initial value (stage I), and, at the end (stage III), the air temperature increased by $5.5^{\circ} \mathrm{C}$ as compared to stage I. One hour after (stage IV), the air temperature was higher by $3.3^{\circ} \mathrm{C}$ as compared to stage I.

The air temperature in the premises where people suffering from bronchial asthma were cooking meals increased by $5.6^{\circ} \mathrm{C}$ in the first hour (stage II) and by $5.5^{\circ} \mathrm{C}$ at the end of the process (stage III) as compared to stage I. One hour after the cooking (stage IV), the air temperature was higher by $1.8^{\circ} \mathrm{C}$ as compared to stage $\mathrm{I}$.

In all the analyzed cases, the air temperature one hour after the end of the cooking process did not return to the initial level, as it was recorded. 
Table 1. Values of air temperature, ${ }^{\circ} \mathrm{C}$

\begin{tabular}{|l|l|c|c|c|c|}
\hline \multicolumn{2}{|c|}{} & Stage I & Stage II & Stage III & Stage IV \\
\hline \multirow{3}{*}{$\begin{array}{l}\text { Bronchitis } \\
\text { and } \\
\text { obstructive } \\
\text { bronchitis }\end{array}$} & kitchen & 27.5 & 29.1 & 31.1 & 28.9 \\
\cline { 2 - 5 } & dwelling room & 26.8 & 29.1 & 30.7 & 27.8 \\
\cline { 2 - 5 } & summer kitchen & 28.5 & 29.9 & 31.9 & 28.1 \\
\cline { 2 - 5 } & average & $27.6 \pm 0.49$ & $29.4 \pm 0.27$ & $31.2 \pm 0.35$ & $28.3 \pm 0.33$ \\
\hline \multirow{4}{*}{\begin{tabular}{l} 
Pneumonia \\
\cline { 2 - 5 }
\end{tabular}} & kitchen & 28.6 & 31.4 & 37.9 & 34.4 \\
\cline { 2 - 5 } & dwelling room & 28.2 & 29.7 & 31.3 & 30.1 \\
\cline { 2 - 5 } & summer kitchen & 28.1 & 29.7 & 32.1 & 30.3 \\
\cline { 2 - 5 } & average & $28.3 \pm 0.15$ & $30.3 \pm 0.57$ & $33.8 \pm 2.08$ & $31.6 \pm 1.40$ \\
\hline \multirow{4}{*}{ Asthma } & kitchen & 27.8 & 30.7 & 33.4 & 29.8 \\
\cline { 2 - 5 } & dwelling room & 27.0 & 39.3 & 34.8 & 29.9 \\
\cline { 2 - 5 } & summer kitchen & 28.6 & 30.3 & 31.6 & 29.2 \\
\cline { 2 - 5 } & average & $27.8 \pm 0.46$ & $33.4 \pm 2.94$ & $33.3 \pm 0.93$ & $29.6 \pm 0.22$ \\
\hline
\end{tabular}

The value of the relative humidity of the air, in the premises where people suffering from bronchitis and obstructive bronchitis were cooking meals (Table 2), had the same dynamics as the air temperature: one hour from the beginning (stage II), it increased by $1.8 \%$, at the end (stage III) by $3.5 \%$, and one hour after (stage IV) by $0.7 \%$ as compared to stage I.

In the premises in which people frequently suffering from pneumonia were cooking meals, the relative humidity (the average of recorded values) increased by $5 \%$ one hour after starting the cooking process (stage II), and by $12.7 \%$ at the end of the process (stage III) as compared to stage I. The relative humidity was higher by $7.0 \%$ one hour after the end (stage IV) as compared to the beginning of the cooking.

In the premises where people complaining of bronchial asthma were cooking meals, the relative humidity of the air increased in the first hour (stage II) by $1.7 \%$ and by $4.8 \%$ at the end (stage III) as compared to stage I. One hour after finishing the cooking process (stage IV), the relative humidity of the air was higher by $2.5 \%$ as compared to the beginning moment.

In all the analyzed cases, the relative humidity of the air one hour after finishing meal cooking has not exceeded the normed level.

Table 2. Values of the relative humidity of the air, \%

\begin{tabular}{|c|c|c|c|c|c|}
\hline & Stage I & Stage II & Stage III & Stage IV \\
\hline \multirow{4}{*}{$\begin{array}{l}\text { Bronchitis } \\
\text { and } \\
\text { obstructive } \\
\text { bronchitis }\end{array}$} & kitchen & 49.5 & 50.6 & 52.9 & 50.6 \\
\hline & dwelling room & 50.2 & 52.7 & 53.5 & 53.5 \\
\hline & summer kitchen & 47.7 & 49.4 & 51.4 & 45.2 \\
\hline & average & $49.1 \pm 0.74$ & $50.9 \pm 0.96$ & $52.6 \pm 0.62$ & $49.8 \pm 2.43$ \\
\hline \multirow{4}{*}{ Pneumonias } & kitchen & 49.2 & 57.6 & 69.7 & 63.4 \\
\hline & dwelling room & 48.4 & 53.4 & 60.3 & 52.3 \\
\hline & summer kitchen & 47.7 & 49.2 & 53.3 & 50.4 \\
\hline & average & $48.4 \pm 0.43$ & $53.4 \pm 2.42$ & $61.1 \pm 4.75$ & $55.4 \pm 4.05$ \\
\hline \multirow{4}{*}{ Asthma } & kitchen & 48.1 & 49.8 & 52.0 & 49.1 \\
\hline & dwelling room & 48.1 & 51.0 & 55.7 & 52.8 \\
\hline & summer kitchen & 48.0 & 48.6 & 50.9 & 49.9 \\
\hline & average & $48.1 \pm 0.03$ & $49.8 \pm 0.69$ & $52.9 \pm 1.45$ & $50.6 \pm 1.12$ \\
\hline
\end{tabular}


In the premises where people suffering from bronchitis and obstructive bronchitis were cooking meals, the average of values of the carbon dioxide concentration showed the following pattern (Table 3): the concentration of carbon dioxide increased in stage II by $0.1 \%$ and by $0.2 \%$ in stage III as compared to stage I. And one hour after finishing the process, it returned to the value of $0.1 \%$.

In the premises in which people frequently suffering from pneumonia were cooking meals, the concentration of carbon dioxide (the mean value for all three types of premises) increased by $0.1 \%$ in stage II and at the end of the cooking process the concentration of carbon dioxide increased by $0.2 \%$ as compared to stage I. One hour after the end, the concentration of carbon dioxide returned to the value of $0.1 \%$.

In the premises in which people suffering from bronchial asthma were cooking meals, the mean values of carbon dioxide increased by $0.1 \%$ one hour after the beginning (stage II) and by $0.2 \%$ at the end of the process (stage III) as compared to stage I. One hour after the finishing moment, the mean value of carbon dioxide concentration was higher by $0.1 \%$ as compared to stage I.

The analysis of the mean values of carbon dioxide concentration in the premises in which the meals were cooked, highlights the fact that the monitored values returned to the initial level and did not exceed the normed levels, except those in which people suffering from bronchial asthma were cooking meals, where the mean value of carbon dioxide concentration was higher than the initial value and exceeded the normed value by $0.1 \%$.

Table 3. Values of carbon dioxide, $\%$

\begin{tabular}{|l|l|c|c|c|c|}
\hline \multicolumn{2}{|c|}{} & Stage I & Stage II & Stage III & Stage IV \\
\hline \multirow{3}{*}{$\begin{array}{l}\text { Bronchitis } \\
\text { and } \\
\text { obstructive } \\
\text { bronchitis }\end{array}$} & kitchen & 0.1 & 0.2 & 0.2 & 0.1 \\
\cline { 2 - 6 } & dwelling room & 0.1 & 0.2 & 0.3 & 0.1 \\
\cline { 2 - 6 } & summer kitchen & 0.1 & 0.2 & 0.3 & 0.1 \\
\cline { 2 - 5 } & average & 0.1 & 0.2 & $0.3 \pm 0.03$ & 0.1 \\
\cline { 2 - 6 } Pneumonias & kitchen & 0.1 & 0.1 & 0.3 & 0.1 \\
\cline { 2 - 6 } & dwelling room & 0.1 & 0.3 & 0.5 & 0.2 \\
\cline { 2 - 6 } & summer kitchen & 0.1 & 0.1 & 0.3 & 0.1 \\
\cline { 2 - 6 } & average & 0.1 & $0.2 \pm 0.07$ & $0.4 \pm 0.07$ & $0.1 \pm 0.03$ \\
\hline \multirow{4}{*}{ Asthma } & kitchen & 0.1 & 0.1 & 0.1 & 0.1 \\
\cline { 2 - 6 } & dwelling room & 0.1 & 0.3 & 0.4 & 0.3 \\
\cline { 2 - 6 } & summer kitchen & 0.1 & 0.1 & 0.4 & 0.1 \\
\cline { 2 - 6 } & average & 0.1 & $0.2 \pm 0.07$ & $0.3 \pm 0.10$ & $0.2 \pm 0.07$ \\
\hline
\end{tabular}

The performed research showed that the indoor air is more polluted in case of cooking meals in the dwelling premises, influencing thus the health status of the dwellers. It was found that in the events when the population had premises specially equipped as kitchens - the cooking conditions were not favorable because these did not fully correspond to the requirements. When cooking meals in summer kitchens, the physical and chemical parameters of the air were relatively closer to the normed values. The values of the researched parameters also depend on the type of cooking installation and the fuel used by the population. The research showed that the air was more polluted when traditional stoves were used. The bottled gas used for cookers polluted the air more than the natural gas. Among the types of fuel used for traditional stoves, some crop residues and the biomass polluted the air the most. 
The pollution of air in kitchens, in case of cooking on cooker, slightly but significantly correlates with the onset of bronchitis $(\mathrm{r}=0.19, \mathrm{p}<0.001)$ and pneumonia $(\mathrm{r}=0.37, \mathrm{p}<0.001)$, while moderately correlates with the onset of obstructive bronchitis and bronchial asthma $(0.48 \leq \mathrm{r} \leq$ $0.57, \mathrm{p}<0.01)$. This factor has an influence of $22.0-31.1 \%$. A more essential correlation was recorded when bottled gas was used as fuel $(0.18 \leq \mathrm{r} \leq 0.44, \mathrm{p}<0.001)$ and an influence of 37.5 $41.5 \%$, which is higher as compared to the use of natural gas $\left(0.12 \leq \mathrm{r} \leq 0.45, \mathrm{p}<0.001 ; 21.5 \leq \mathrm{r}^{2} \leq\right.$ 28.7). Due to the incorrect and insufficient ventilation, significant increases of temperature and relative humidity of the air were recorded during meal cooking, and the measurements one hour after finishing the cooking process showed that the values of such parameters did not return to the norm in most of the cases. The absence of ventilation strongly correlates with all nosologic forms mentioned by the respondents $(0.73 \leq \mathrm{r} \leq 0.96, \mathrm{p}<0.01)$ and influences the onset of diseases to the extent of $34.6 \%$.

In the case of cooking inside the dwelling room, a slight correlation with all the nosologic forms was recorded both when cooking on cooker $(0.22 \leq \mathrm{r} \leq 0.31, \mathrm{p}<0.01)$ and on traditional stove $(0.31 \leq \mathrm{r} \leq 0.38, \mathrm{p}<0.001)$. Cooking on cooker has a rate of influence of $27.6 \%$ while cooking on a stove of $38.4 \%$ on the development of diseases of which the respondents suffer from. The use of bottled gas during cooking on cooker has an average correlation with bronchitis $(\mathrm{r}=0.48, \mathrm{p}<0.01)$, pneumonia $(r=0.56, p<0.001)$, obstructive bronchitis $(r=0.54, p<0.01)$, and a strong correlation with bronchial asthma $(\mathrm{r}=0.84, \mathrm{p}<0.01)$, while the use of natural gas shows a low correlation $(0.12$ $\leq \mathrm{r} \leq 0.22, \mathrm{p}<0.01)$. When the population used wood as fuel for the peasant stove, a slight correlation was recorded with bronchitis $(\mathrm{r}=0.31, \mathrm{p}<0.001)$, pneumonia $(\mathrm{r}=0.35, \mathrm{p}<0.05)$, and an average correlation with obstructive bronchitis $(\mathrm{r}=0.52, \mathrm{p}<0.01)$ and bronchial asthma $(\mathrm{r}=$ $0.63, \mathrm{p}<0.01)$. All the researched nosological forms have proven an average correlation with the use of the biomass $(0.49 \leq \mathrm{r} \leq 0.66, \mathrm{p}<0.001)$ and crop residues $(0.44 \leq \mathrm{r} \leq 0.58, \mathrm{p}<0.001)$. Out of all the types of fuel used by the population for cooking, the highest share of influence is held by the crop residues $\left(r^{2}=48.4\right)$ and biomass $\left(r^{2}=45.0\right)$, a lower influence being held by the faggots $\left(r^{2}=\right.$ $37.6 \%)$ and bottled gas $\left(r^{2}=35.3\right)$, while the lowest share by the wood $\left(r^{2}=27.6\right)$ and natural gas $\left(r^{2}\right.$ $=22.4)$. The absence of an adequate ventilation system slightly but significantly correlates with the onset of bronchitis $(r=0.32, p<0.001)$, pneumonia $(r=0.29, \mathrm{p}<0.001)$, obstructive bronchitis $(\mathrm{r}=$ $0.37, \mathrm{p}<0.001)$ and strongly correlates with the installation of the bronchial asthma $(\mathrm{r}=0.88, \mathrm{p}<$ $0.001)$.

In the summer kitchens, the cooking process recorded a lower correlation with the pollution-induced diseases as compared to the cooking in the dwelling room. At the same time, as most of the premises have no windows, the pollution of air is maintained by a low ventilation.

For the cooking process, the population uses the cooker/natural gas stove, the traditional stove/cook stove and/or the electrical cooker. Cooking the meals on the cooker slightly correlates with the bronchitis $(\mathrm{r}=0.22, \mathrm{p}<0.05)$, pneumonia $(\mathrm{r}=0.26, \mathrm{p}<0.01)$, obstructive bronchitis $(\mathrm{r}=$ $0.31, \mathrm{p}<0.001)$, and bronchial asthma $(\mathrm{r}=0.25, \mathrm{p}<0.001)$. Moderate correlation was recorded between the use of traditional stoves and the onset of bronchitis $(r=0.44, p<0.001)$, pneumonia $(r$ $=0.49, \mathrm{p}<0.01)$, and obstructive bronchitis $(\mathrm{r}=0.65, \mathrm{p}<0.001)$, while strong correlation between it and bronchial asthma $(\mathrm{r}=0.84, \mathrm{p}<0.001)$. Cooking on the cooker influenced the development of diseases to the extent of $23.4 \%$, while cooking on a traditional stove at the extent of $29.7 \%$.

Wood, raw and processed coal, natural gas supplied through centralized pipeline or bottled gas, biomass, crop residues, etc. are used as fuel. The research showed a strong correlation $(0.74 \leq \mathrm{r}$ $\leq 0.80, \mathrm{p}<0.01)$ when using bottled gas, with a share of influence of $38.0 \%$ and a slight correlation when using natural gas $(0.11 \leq \mathrm{r} \leq 0.34, \mathrm{p}<0.001)$ with a share of influence $23.6 \%$. The use of wood and faggots moderately correlates with obstructive bronchitis $\left(r=0.63, p<0.01 ; r^{2}=31.4\right)$ and 
bronchial asthma $\left(\mathrm{r}=0.54, \mathrm{p}<0.001 ; \mathrm{r}^{2}=43.6\right)$. The use of agricultural waste has an average correlation with bronchitis $\left(r=0.63, p<0.01 ; r^{2}=46.1\right)$, pneumonia $\left(r=0.59, p<0.001 ; r^{2}=36.1\right)$, obstructive bronchitis $\left(r=0.64, p<0.001 ; r^{2}=39.2\right)$ and strongly correlates with bronchial asthma $\left(\mathrm{r}=0.90, \mathrm{p}<0.01 ; \mathrm{r}^{2}=42.3\right)$. The insufficient ventilation in these premises slightly correlates with bronchitis $(\mathrm{r}=0.28, \mathrm{p}<0.001)$ and pneumonia $(\mathrm{r}=0.33, \mathrm{p}<0.05)$, while it has an average correlation with obstructive bronchitis $(r=0.47, \mathrm{p}<0.01)$ and strongly correlates with bronchial asthma $(r=0.91, p<0.01)$. This factor influences the development of the mentioned diseases to the extent of $37.6-45.9 \%$.

An important aspect in the indoor pollution is the area of premises. The area inversely correlates with air pollution and development of diseases. A moderate correlation was recorded between the area of premises and bronchitis $S(r=0.58, p<0.05)$, pneumonia $(r=0.45, p<0.01)$ and obstructive bronchitis $(\mathrm{r}=0.52, \mathrm{p}<0.001)$, and a strong correlation with bronchial asthma $(\mathrm{r}=$ $0.85, \mathrm{p}<0.001)$.

Very important in the development of diseases is the duration and frequency of the cooking process. A slight direct correlative connection was established with bronchitis $(\mathrm{r}=0.18, \mathrm{p}<0.001)$, a strong correlation with pneumonia $(\mathrm{r}=0.74, \mathrm{p}<0.01)$, obstructive bronchitis $(\mathrm{r}=0.87, \mathrm{p}<0.01)$, and bronchial asthma $(\mathrm{r}=0.84, \mathrm{p}<0.01)$. The correlation between the frequency of meal cooking and nosological forms was moderate $(0.38 \leq \mathrm{r} \leq 0.63, \mathrm{p}<0.05)$. The duration of the cooking process explains approximately $18.4 \%$ of the variability of nosological forms.

The smokers are exposed to additional pollutants. The fact that people smoke presents a slight correlative connection with the development of pneumonia $(r=0.26, p<0.05)$, a moderate correlation with bronchitis $(\mathrm{r}=0.42, \mathrm{p}<0.001)$ and obstructive bronchitis $(\mathrm{r}=0.51, \mathrm{p}<0.01)$, and a strong correlation with bronchial asthma $(r=0.83, p<0.001)$. The number of cigarettes smoked per day strongly and directly correlates with the nosological forms present in the respondents $(0.76 \leq \mathrm{r} \leq$ $0.89, \mathrm{p}<0.01)$.

The diseases of the respiratory system strongly correlate with the relatively increased humidity of the air $(0.78 \leq \mathrm{r} \leq 0.94, \mathrm{p}<0.001)$ and concentration of carbon dioxide $(0.70 \leq \mathrm{r} \leq 0.82$, $\mathrm{p}<0.01)$ and moderately correlate with the air temperature $(0.43 \leq \mathrm{r} \leq 0.68, \mathrm{p}<0.001$. The modifications of the relative humidity of the air and of the concentration of carbon dioxide explain approximately $30.6 \%$ and respectively $34.5 \%$ of the variability of respiratory diseases.

For assessing the complex influences of the cooking conditions, multiple correlation analysis was applied, taking into consideration the following factors: type of premises, the area of premises, type of installation and type of fuel. The multiple influences explain $61.3-76.6 \%$ ( $\mathrm{p}<$ 0.01) of action of the above factors in the development of the nosological forms recorded in the respondents. The combined influences of insufficient ventilation and indoor smoking are responsible for up to $57.3 \%$ of the population health problems ( $<<0.05)$. Researching the complex action of the physical and chemical factors, created during the cooking process, on the mentioned diseases, a statistically significant $(\mathrm{p}<0.001)$ coefficient of determination was established $(62.3-76.1 \%)$.

\section{Discussions}

In the opinion of Moshammer et al. (2010), the problem of emissions resulting from burning bottled gas, biomass and other types of fuel used in the household for meal cooking is not enough studied. The emissions from the cooker create conditions of air pollution inside the premises, directly contributing to the pollution due to the inefficient ventilation system (exchange of air between indoors and outdoors), and the lack of means and technologies for the elimination of the polluted air outside. According to the research performed by Balakrishnan et al. (2002) and Bruce et 
al. (2000), the products of burning gas and biomass ejected directly in the interior environment increase the concentration of various substances in the air, which negatively affects the health of people participating in the cooking process. Currently, the studies performed in this direction are of interest to the public health and it is worth continuing them in various countries with different levels of development. The analysis of various substances in kitchens is necessary for the evaluation of their impact on population health and the effective reduction of morbidity and mortality from pollution-induced diseases.

The study performed by a group of researchers from California, USA, (Logueet al., 2014), proved that the use of cooking installations fueled with natural gas without vapor hoods for the aspiration of the polluted air directly influences the health status of the resident people and increase the concentration of harmful chemical substances, such as $\mathrm{CO}, \mathrm{NO}_{2}$ as compared to the standardized values for the atmosphere air in 55-70\% and 7-8\% of houses during one typical week in winter.

Our research emphasizes the impact of gas emissions in kitchens not only on the health of adult people involved in the process of cooking meals but also on children who, for various reasons, are present in such premises. Such studies were also carried out by Marks et al. (2010) in Australia, where, in the classrooms equipped with gas cookers, children complained of cough intensification in the morning and during the day, and inflammation of the respiratory tract was noticed in children suffering from bronchial asthma.

As we have already mentioned in the "Materials and methods" section, comparative analysis has been performed between various types of fuel used for the purpose of cooking meals and cooking installations, as well as their degree of technical failure. The degree of gas use was higher as compared to other fuels, for example to biomass. Some studies, such as those performed by Mutlu et al. (2016), showed that there is a strong correlation between the type of fuel used (in that case, wood) and the mutagenic factors.

Consequently, all the people, including healthy adults, could suffer from respiratory diseases caused by the loss of pulmonary function, development of bronchitis, bronchial asthma, etc., till the onset of chronic pulmonary diseases, because the impact of the exposure may have a cumulative effect in time.

According to the research performed by Lupulescu et al. (2008), the sources of air pollution in dwelling premises are relatively numerous and may be classified as permanent, temporary, and accidental. The over-agglomeration and increased humidity in the dwelling premises represent aggravating factors for the onset of dampness and development of fungus, as well as the increased frequency of some respiratory tract diseases, allergic diseases, etc.

The study performed on a sample of 2123 people from 830 dwelling houses in Romania had the purpose of evaluating the dwelling conditions and state of health. The research proved that the non-corresponding thermal environment is a favorable factor in the onset of the condensate and mold, and also a risk factor in the onset of recurrent infections, especially in children. These conditions are associated with the decrease of ventilation in the dwelling premises, including kitchens, in order to increase the energy efficiency. Special attention was paid to the parents' habit of smoking in the housing premises, which is an important risk factor for bronchial asthma in children, since blood eosinophilia and a higher total serum immunoglobulin $\mathrm{E}$ ( $\mathrm{IgE}$ ) level is associated with smoking. The frequency of respiratory tract infections is higher in these children.

To a great extent, the same objectives were also followed by Dasgupta et al. (2013) from Madagascar. A regression analysis was performed to investigate the basic determinant factors, such as various types of fuel (coal, wood, ethanol), ovens (traditional, improved), dimension of the kitchen, type of kitchen (opened, ventilated), construction materials for the kitchen (permeable roof and walls) and environmental factors. The results show that the type of fuel, types of cooker, and the 
kitchen dimension play an important role in the onset of various diseases. In comparison, the air quality is better in case of using ethanol than biomass. Finally, a large kitchen and adequate ventilation in the cooking areas will produce a healthier environment and decrease harmful emissions.

Another study, performed by Sussan et al. (2014) in India shows that the use of the biomass (wood, dung) could increase the risk of chronic respiratory diseases by activating the TLR and IL$1 \mathrm{R}$ receptors (experiment on mice).

In the context of fundamental research concerns towards the actions of the atmosphere pollutants on the nervous system, the scientists from the Center for Research in Environmental Epidemiology (CREE), Barcelona, Spain (2012), studied the relation between the pollutants emanated in the indoor air from the cooker and the development of neural diseases in children and pregnant women. This study emphasizes a decreased adverse effect of indoor air pollution from the cooker on the mental development of small children, the cooker being considered the main source of pollution of the indoor air, including nitrogen dioxide and emanated particles (Vrijheid et al., 2012).

\section{Conclusions}

In light of the above, it is necessary to develop some mechanisms for controlling indoor air quality.

The people responsible for the construction, furnishing and equipping the kitchens should meet certain rules which would not only relate to the architectural aesthetics, comfort or carried benefits, but also to the health of those who will work in such premises with special destination.

The cooking process should be performed in optimal sanitary-hygienic conditions, under rigorous surveillance of the personal hygiene rules and safety requirements, which involves the installation and maximal use of the artificial ventilation installations, for example vapor hoods, aspiration ventilators, etc.; the replacement of some types of fuel (biomass, coal etc.) by natural gas, which is less toxic.

Acknowledgment. The research reported in this publication was supported by the Fogarty International Center of the National Institutes of Health under Award Number R24TW009568. The content is solely the responsibility of the authors and does not necessarily represent the official views of the National Institutes of Health.

Conflict of interest. The authors of this article do not have any conflict of interests.

\section{References}

1. Balakrishnan, K., Mehta, S., Kumar, P., Ramaswamy, P., Sambandam, S., Kumar, K. and Smith, K., 2004. Indoor Air Pollution Associated with Household Fuel Use in India: An exposure assessment and modeling exercise in rural districts of Andhra Pradesh, India. Washington DC, USA: The International Bank for Reconstruction and Development/The World Bank.

2. Balakrishnan, K., Sankar, S., Parikh, J., Padmavathi, R., Srividya, K., Venugopal, V., Prasad, S. and Pandey, V., 2002. Daily average exposures to respirable particulate matter from combustion of biomass fuels in rural households of southern India. Environ. Health Perspect, 110(11), p.1069. 
3. Bates, M., Ram, K. Chandyo, R., Valentiner-Branth,P., Pokhrel, A., Mathisen, M., Basnet, S., Shrestha, P., Strand, T. and Smith, K., 2013. Acute Lower Respiratory Infection in Childhood and Household Fuel Use in Bhaktapur, Nepal. Environmental Health Perspectives, 121(5), pp.637-642.

4. Bruce, N., Perez-Padilla, R. and Albalak, R., 2000. Indoor air pollution in developing countries: a major environmental and public health challenge. Bull. World Health Organ, 78(9), pp.10781092.

5. Dasgupta, S., Martin, P. \& Samad, H., 2013. Addressing household air pollution: a case study in rural Madagascar. The World Bank, Africa Region, Sustainable Development Department \& Development Research Group, Environment and Energy Team. Available at: <http://wwwwds.worldbank.org/external/default/WDSContentServer/IW3P/IB/2013/10/09/000158349_2013 1009092916/Rendered/PDF/WPS6627.pdf. > [Accessed 4 May 2017].

6. Dickinson, K., Kanyomse, E., Piedrahita, R., Coffey, E., Rivera, I., Adoctor, J., Alirigia, R., Muvandimwe, D., Dove, M., Dukic, V., Hayden, M., Diaz-Sanchez, D., Abisiba, A., Anaseba, D., Hagar, Y., Masson, N., Monaghan, A., Titiati, A., Steinhoff, D., Hsu, Y., Kaspar, R., Brooks, B., Hodgson, A., Hannigan, M., Oduro, A. R. and Wiedinmyer, Ch., 2015. Research on Emissions, Air quality, Climate, and Cooking Technologies in Northern Ghana (REACCTING): study rationale and protocol. BMC Public Health, 15:126, https://doi.org/10.1186/s12889-0151414-1.

7. Egondi, T., Kyobutungi, C., Ng, N., Muindi, K., Oti, S., Vijver, S., Ettarh, R. \& Rocklöv, J., 2013. Community Perceptions of Air Pollution and Related Health Risks in Nairobi Slums. $J$ Environ Res Public Health, 10(10), pp.4851-4868.

8. Leem, J., Kaplan, B., Shim, Y., Pohl, H., Gotway, C., Bullard, S., Rogers, J., Smith, M. \& Tylenda, C., 2006. Exposures to Air Pollutants during Pregnancy and Preterm Delivery. Environmental Health Perspectives, 114(6), pp.905-910.

9. Logue, J., Klepeis, N., Lobscheid, A. \& Brett, C., 2014. Pollutant Exposures from Natural Gas Cooking Burners: A Simulation-Based Assessment for Southern California. Environmental Health Perspectives, 122(1), pp.43-50.

10. Lupulescu, D., Fulga, M. \& Iancu, M., 2008. Factori alergizanţi prezenţi în mediul de locuit. [Allergic factors present in the living environment] Revista de Igienă şi Sănătate Publică, 58(1), pp.22-28.

11. Marks, G., Ezz, W., Aust, N., Toelle, B., Xuan, W., Belousova, E., Cosgrove, C., Jalaludin, B. \& Wayne, T., 2010. Smith Respiratory Health Effects of Exposure to Low-NOx Unflued Gas Heaters in the Classroom: A Double-Blind, Cluster-Randomized, Crossover Study. Environmental Health Perspectives, 118, pp.1476-1482.

12. Mărușteni, M., 2006. Noţiuni fundamentale de biostatistică: note de curs [Fundamental notions of Biostatistics: Course Notes]. Târgu-Mureş: University Press.

13. Moshammer, H., Fletcher, T., Heinrich, J., Hoek, G., Hruba, F. \& Pattenden, S., 2010. Gas cooking is associated with small reductions in lung function in children. European Respiratory Journal, 36(2), pp.249-254.

14. Mutlu, E., Warren, S., Ebersviller, S., Kooter, I., Schmid, J., Dye, J., Linak, W., Gilmour, I., Jetter, J., Higuchi, M. \& DeMarini, D., 2016. Mutagenicity and Pollutant Emission Factors of Solid-Fuel Cookstoves: Comparison with Other Combustion Sources. Environmental Health Perspectives, 124(7), pp.974-982.

15. Sharma, S., Sethi, G., Rohtagi, A., Chaudhary, A., Shankar, R. \& Bapna, J., 1998. Indoor air quality and acute lower respiratory infection in Indian urban slums. Environmental Health Perspectives, 106, pp.291-297. 
16. Simon, G., Bailis, R., Baumgartner, J., Hyman, J. \& Laurent, A., 2014. Current debates and future research needs in the clean cookstove sector. Energy for Sustainable Development, 20, pp.49-57.

17. Sussan, T., Ingole, V., Kim, J., McCormick, S., Negherbon, J., Fallica, J., Akulian, J., Yarmus, L., Feller-Kopman, D., Wills-Karp, M., Horton, M., Breysse, P., Agrawal, A., Juvekar, S., Salvi, S. \& Biswal, S., 2014. Source of biomass cooking fuel determines pulmonary response to household air pollution. American Journal of Respiratory Cell and Molecular Biology, 50(3), pp.538-548.

18. Uzoigwe, J., Prum, T., Bresnahan, E. \& Garelnabi, M., 2013. The Emerging Role of Outdoor and Indoor Air Pollution in Cardiovascular Disease. North American Journal of Medicine \& Science, 5(8), pp.445-453.

19. Vrijheid, M., Martinez, D., Aguilera, I., Bustamante, M., Ballester, F., Estarlich, M., FernandezSomoano, A., Guxens, M., Lertxundi, N., Martinez, M., Tardon, A. \& Sunyer, J., 2012. Indoor air pollution from gas cooking and infant neurodevelopment. Epidemiology, 23(1), pp.23-32.

20. ***WHO, 2014. Ambient (outdoor) air quality and health. Fact sheet N313. Available at: <http://www.who.int/mediacentre/factsheets/fs313/en/. > [Accessed 10 May 2017].

21. ***WHO, 2014. Household air pollution and health. Fact sheet N292, 2014. Available at: <http://www.who.int/mediacentre/factsheets/fs292/en/.> [Accessed 10 May 2017]. 


\title{
Recreation of personal activist identity in a post-war west Balkan city: Petrinja
}

\section{DOI: http://doi.org/10.26758/8.1.20}

Deniz Yoldas

Communication Studies graduate, 2013, Istanbul/Turkey

Address correspondence to: Deniz Yoldas; E-mail: denizyoldas@mail.ru

\begin{abstract}
Objectives. Civil Society is the most important instrument to obtain democratic transformation and get EU membership in post-Yugoslav countries. Activism in post-war West Balkan cities, especially in border cities like Petrinja, has communication difficulties with the local communities. The aim of this study was to determine the source of the difficulties by carrying out an analysis on the evolution of personal activist identity in Petrinja as an example.

Material and methods. Between September 2016 - April 2017, data were obtained from 40 urban and rural respondents aged 17-55 in Petrinja. Speech analysis method was used on depth-interviews. The interviews focused on topics related to activism topics: active citizenship, multiculturalism, local development, ecology, LGBT rights, Activists' and associations' daily practices.

Results. These face-to-face in-depth interviews were conducted on the question of property, veteran status, and unemployed (socio-economic) problems. At the time the interviews were carried out, 25 years after the war, nearly $50 \%$ of the real estates in the city were abandoned (vacant estate); a feeling of powerlessness is shared by the youth, in general, voting rates nearly attain $15 \%$. Young people find local development perspective less popular than immigration tendency. The "strange"/ "foreign" image of activists limits their social integration capacity in the local community.

Conclusions. A new activist policy of EU is needed regarding the integration of veterans and local communities, which would facilitate positive change and development for the area.
\end{abstract}

Keywords: Post-War, West Balkans, activism, vacant estate, NGO-mafia.

"Counting other people's sins does not make you a saint" "Entre le choléra et la peste, on ne choisit pas." Maurice Thorez.

\section{Introduction}

Petrinja is a small city/town in the central part of Croatia. It's an inheritor of a difficult history. Even today the town faces unsupportable difficulties: alcoholism, deindustrialization, emigration, demographic crisis, right-wing movements and ethnic-religious hate. 25 years after the war, in this European Union (EU) member country's post-war border city, being an activist for defending the values like multiculturalism, active citizenship, feminism, LGBTI rights is still difficult and activists stay in an isolated position out of the local community.

Petrinja had several rich natural stone sources during the period of the Roman Empire, it was a buffer zone between Ottoman Empire and Austria-Hungary Empire as "war front" in 17-18th centuries, it was a highly industrialized zone in Socialist Yugoslavia times, it's the city also of the genocidal massacres in WW2 and 1991 Yugoslavian civil war periods and currently, the city of 
unemployment, alcoholism, emigrations, deindustrialization, hopeless youth and the minority activists with their exaggerated hopes about European Union EU.

The city is founded by the Roman Empire. The origin of the name comes from Petra (Greek) or Petrus (Latin), it means stone. The historical region of Banovina, the current name SisakMoslavina County of which Petrinja is a part, it has rich natural stone sources. The city was controlled by the Roman Empire, the Ottoman Empire, Napoleon's France, Austria-Hungary Empire, Yugoslavia Kingdom, Nazi Germany, Socialist Yugoslavia, Republic of Serbian Krajina and currently it's controlled by Croatia. Croatia is an EU member since 2013.

Petrinja's people are like general Balkan geography, it is separated by different sects and religions and each religion and sect have a real or supposed relationship with an empire/post-empire state. The real or supposed supporter of Catholicism is Italy and Austria (as the inheritors of Roman and Austria-Hungary Empire), for Islam, it's Turkey (as the inheritor of Ottoman Empire), for Orthodoxy, it's Russia (as the inheritor of Russian Empire) and for new small Protestant communities it's USA and Germany. Islam is accepted mainly by Bosnians, Orthodox by Serbs and Catholicism by Croats. Protestant missioners try to share their faith with social help campaigns in disadvantaged social groups. The identity of "Bosnian" "Serbs" and "Croats" come from these differentiations: Bosnians, Serbs, and Croats are all Slaves and they speak the same language.

Petrinja was/is a small but multicultural city. Orthodox Serbs, Catholic Croats, and Muslim

Bosnians live together in the city. The massacres (Čačić-Kumpes and Nejašmić, 1999, pp.253-275) imprisoned the multicultural life but was not enough to kill it. The first genocidal massacre claim in the modern times for Petrinja comes from the WW2 period. By the claim, Pro-Nazi Croatian paramilitary organization Ustashe made a genocide or genocidal massacre against Serbs. By USA Holocaust Memorial Museum, between 1941-45, approximately 320.000 - 340.000 Serbs who lived in Croatia and Bosnia were killed by the Nazi collaborator Ustache regime. According to the Shoah Research Center, in this period, approximately 500.000 Serbs were killed, 250.000 were deported and 200.000 were forced to convert to Catholicism. Children concentration camp of Sisak, concentration camps of Sisak and Jasenovac were in the most active concentration camps in Axis collaborator Croatia, Three camps were very close to Petrinja. In Only concentration camp of Jasenovac, 45-52.000 people were killed by Nazi collaborator Croatian regime. (***Shoah Resource Center, pp.1-2). By the Federal Institute for Statistics in Belgrade, all WW2 period, because of war, in all Yugoslavia, 597,323 people dead: 346,740 were Serbs and 83,257 were Croats (McAdams, 1992, p.17).

\section{Demographic crisis and vacant real estate problem after 1995}

The majority of the population in Petrinja was historically the Serbs. After WW2 (***Shoah Resource Center, pp.1-2) genocidal massacres, they lost their demographic advantages (Čacic, Nejasmc, 1999, p.260) but in 1991 they regained it, but they are erased mass to Petrija by NATO operation (Operation Storm) in 1995. Approximately 250.000 Serbs were forced to leave from all over the Republic of Serbian Krajina territory. (Amnesty International, 2005) Petrinja was a part of it. They were deported and the Krajina Serbian Republic was erased. Currently, the total population of Petrinja is approximately 25.000: 15.000 live in urban part and 10.000 live in rural part of Petrinja. Before the Yugoslavian Civil War of 1991, the population of Petrinja was approximately 70.0004. After 1995, Petrinja went through a demographic crisis: the city lost approximately $70 \%$ of its total population. To solve the problem, Croatian government accepted the Catholic Croats from Bosnia and Herzegovina and relocated them in Petrinja and giving the Serbians' properties. In Bosnia and Herzegovina, historically the Muslims (Bosnians) are the majority in Bosnia and the 
Catholics are the majority in Herzegovina. The government gave away properties for free of those Serbs who were already deported or killed but it couldn't solve the legal status problem. The owners of the properties are still officially the Serbs. The government "captures"/gives a public property status to vacant real estates. 25 years after the civil war, in Petrinja, 50\% of the real estates are stated vacancies. The situation is very similar to the Turkish cities after 1915 Tragedy/deportation/genocide/genocidal massacre, how to call. The best part of the Serbs' properties is captured by "veterans". There is academic research on the claims of the war crimes and especially sexual violence against women by the "veterans" in civil war period in Petrinja (Stevanović, 1998, pp.63-76).

Table 1. Demography of Petrinja in History (Census:2011)

Historical Population of Petrinja

\begin{tabular}{|c|c|c|}
\hline Year & Population & +/_\% \\
\hline 1857 & 18,448 & ---- \\
\hline 1869 & 20,403 & $+10,6 \%$ \\
\hline 1880 & 21,091 & $+3.4 \%$ \\
\hline 1890 & 24,958 & $+18.3 \%$ \\
\hline 1900 & 27,873 & $+11.7 \%$ \\
\hline 1910 & 29,633 & $+6.3 \%$ \\
\hline 1921 & 28,383 & $-4.2 \%$ \\
\hline 1931 & 29,808 & $+5.0 \%$ \\
\hline 1948 & 24,293 & $-18.5 \%$ \\
\hline 1953 & 25,070 & $+3.2 \%$ \\
\hline 1961 & 38,465 & $+53.4 \%$ \\
\hline 1971 & 49,545 & $+28.8 \%$ \\
\hline 1981 & 61,124 & $+23.4 \%$ \\
\hline 1991 & 69,151 & $+13.1 \%$ \\
\hline 2001 & 23,414 & $-66.1 \%$ \\
\hline 2011 & 24,671 & $+5.3 \%$ \\
\hline
\end{tabular}

Table 2. Population by ethnicity in Petrinja in History (Census,2011)

Population by ethnicity

\begin{tabular}{|c|c|c|c|c|}
\hline Year of census & Total & Croats & Serbs & Others \\
\hline 1961 & 27,517 & $14,942(54.30 \%)$ & $11,955(43.45 \%)$ & $620(2.25 \%)$ \\
\hline 1981 & 33,570 & $14,621(43.55 \%)$ & $12,617(37.58 \%)$ & $6,332(18.86 \%)$ \\
\hline 1991 & 33,565 & $15,791(44.40 \%)$ & $15,969(44.90 \%)$ & $3,805(10.70 \%)$ \\
\hline 2001 & 23,413 & $19,280(82.35 \%)$ & $2,809(12.00 \%)$ & $1,324(5.65 \%)$ \\
\hline 2011 & 24,671 & $20,925(84.82 \%)$ & $2,710(10.98 \%)$ & $1,036(4.20 \%)$ \\
\hline
\end{tabular}

\section{Contemporary Petrinja}

After the war in 1991, Petrinja lost approximately $70 \%$ of its total population. The total population now is approximately 25.000: 15.000 live in urban and 10.000 live in rural areas. The industrial infrastructure is broken. (Stipersky and Braičić, 2009, pp.103-112) With the exception of the historical and symbol factory of Croatian industry: Gavriloviç sausage factory (Vuksic, 2011, 
p.8), which stayed in Petrinja but lost the railway facility of the factory because of the war. 25 years after the war, even today the railway hasn't yet been repaired (Braičić and Lončar, 2011, p.99). After 1995, a lot of NGOs from all over Europe, especially from Germany arrived in Petrinja to improve post-war rehabilitation process: repair the houses, reconstruct the schools, offering social aid for the disadvantaged population. The first basis of NGO sectors of Petrinja were created in this period. The first local contacts (translators for foreign NGO workers and communication facilitators) became the future NGO leaders of Petrinja. As it was a deindustrialized area, NGO sector looked like a new fruitful one. After Croatia got the EU membership in 2013, NGO sector developed with EU funds and programs like Erasmus+. This sector gave a chance even ex-Yugoslav returned immigrants: Yugoslavia had immigration facility agreement for some developed countries like Germany and Australia. Some Croatian retired ex-immigrants could get a chance to find a job in NGO sector thanks to their foreign language skills. Contemporary Petrinja has very few jobs offers: in NGO sector, in public services or temporary jobs like waitressing. There is only one branch of faculty: Zagreb University's Faculty of Pedagogy. Contemporary population of Petrinja is eroded by two immigration tendencies: Internal and external. Internal emigration tendency could be divided into seasonal and permanent tendencies. Seasonal: Each summer, a great amount of Petrinja's population moves to Seaside of Croatia (especially Split, Zadar and Dubrovnik) to work temporary jobs in the tourism sector, especially in restauration sector. The permanent tendency of internal emigration could be evaluated about education and to find a fixed job: most of young people would like to look for a steady job or pursuing a university degree, principally in Zagreb. Zagreb as a capital attracts them. External migration tendency would be evaluated as permanent. Germany, Australia, and Austria are traditional preferred countries. For youth, new interesting countries for immigration are Ireland and UK. The USA could be a "dream country" for youth, Croatian citizens couldn't yet benefice visa-free regime for the USA. That's why there is no immigration facility for the USA. The emigrants work mainly in the restauration sector, as homecare assistants or security guards. Some of the external immigrants prefer to spend their holiday in Petrinja. Because of exchange rate difference between Euro and Croatian national money Kuna, they could get a purchasing power advantage. On another hand, the external money flow could be a cause of relatively high life cost of Croatia. FMCG prices could be evaluated approximately 2 times expensive in Croatia than Serbia, Bosnia, and Macedonia. Unemployment, an ominous depression, alcoholism and a high support for right-wing movement could be evaluated as the principal contemporary problems of Petrinja.

\section{Theoretical conceptions/literature review on Activist identity in the West Balkan}

West Balkans social context is examined as an academic topic on war crimes and post-war traumas. Petrinja can be studied as a specific area in this research, but in the academic literature, a unique specific approach about the NGO's role in postwar West Balkan cities, especially in Petrinja sets an example, for understanding the activism/activist identity like the research of Sampson (Sampson, 2002). The title of Sampson's study could be regarded as a sample of his point of view: "Weak States, Uncivil societies and thousands of NGOs: Benevolent colonialism in the Balkans" Sampson's paper could be evaluated as a consistent debriefing of the situation but the article could also be criticized from two different aspects: First, from 2002 to 2017, the new facts need new reviews: In 2002, according to Sampson, the NGOs and activist movements could create the "new elite". After Ukrainian and Georgian "color revolution" experiences, now, the "new elite" could be evaluated more specifically as pro-Western lumpen de-classed elements' within an unshaped mass. By its literature review, the article about the recreation of individual activist image enriches the 
information on a subject still fresh. It's significant and original, because it shows new specific information on the subject, with clear results and a reevaluation of available information. Also, the literature review shows us the same subject was treated via different examples from Kosovo or Bosnia but using as an example Petrinja/Krajina is the first time done by any study. The literature review of Sampson's study could be evaluated as a sample of the situation but his explaining for the main causes of the situation can be reevaluated and updated with the new information. Sampson used the term "NGO-mafia" to describe predominantly the NGOs of West Balkans touched by corruption. This term could be explicative also for the new post-war geographies corruptive NGOs like Syria, especially Idlib zone and future possible post-war geographies like Iran or/and Bosnia. When Sampson's study was published in 2002, Croatia was not an EU member state and Germany's dominant role was not as clear as nowadays. Also, Russia in 2002 did not have such an active role in international affairs like nowadays. Sampson named the NGO workers and activists a new elite, but after Ukraine's and Georgia's color revolution, the same groups were evaluated as lumpen, adventurous and declassed and as 'fifth column' of different international powers. In this table, Sampson searched the causes of the corruption and benevolent colonialism's root in Balkan traditions and family/clan relationships. Nowadays, this study proves also that the real source of the corruption is not the traditions or family/clan relationships, they are much probably that the deindustrialization and also by the research, the local communities don't believe that the EU could be a solution to the corruption problem. Croatia is an EU member from 2013 and today the facts that were noticed by Sampson's study in 2002 still stayed in a central position of the public mind. EU's deindustrialization and the mass immigration policy are created and executed by Germanydominated EU are decreasing the rehabilitation potential of the post-war areas.

\section{Objectives}

The objective of the article is to look for a sustainable model as theoretical cadre for explaining of NGO activities and activist image in post-war geographies on the West Balkans and especially in Petrinja. In post-war geographies, could NGO activities be used as a tool for neocolonialist politics? Could West Balkans experiences before the 1991-95 war be an example to prove it? Could Pro-Western activist movements be counted as the 'fifth column' in Ex-Yugoslavia and/or Ex-Soviet geographies? How to describe the position and role of the Pro-Russian NGO's and right-wing movements in this table? The aim of this study was to determine the source of the social difficulties by carrying out an analysis on the evolution of individual activist identity in Petrinja as an example. Which difficulties block the relevant communication/relation between the local communities and activist movements? Why pro-western NGOs could be evaluated as corruptive and why the activist movements are evaluated as degenerate by local communities? How the local communities' mindset creates these perceptions? The aim of the study is to understand the source of the image in the middle of the local communities' mind, via the example of Petrinja. The study could be a theoretical base to understand the NGO activities' character, target and goal in current and previous post-war areas like Idlib/Syria for now and possibly for Iran and Bosnia in future. The authenticity of the study is that it enriches the information about the specific area: NGOs' position and activists' image in post-war zones' communities and the specific communication/relation difficulties for both sides via the example of Petrinja/West Balkans. For example, the study discusses the roles and positions of NGOs (either Pro-EU or Pro-Russian or local left-wing) in postwar areas' communities' mindsets. The importance of the study is that it could offer a consistent and relevant explanation of these specific areas becoming a theoretical base for new researchers. Thanks to this, a new academic perspective on activism and NGO works, neither pro-western nor pro- 
Russian or pro-local right-wing, more relevant, trustworthy and effective could be gained - an independent perspective acting as facilitator for improving the activist - local communities communications for post-war areas' rehabilitation projects. The arguments defended by the study are historically consistent and relevant, as available literature shows us the problems and situation have been already researched (Sampson, 2002). The study condenses, reevaluates and enriches the available information on the subject from 1991-95 to 2017 and offers an academic perspective for a future similar situation and also an analysis tool.

\section{Materials and methods}

The in-depth interviews were realized from September 2016 to March 2017. The description of stakeholders was constructed on a solid historical and socioeconomic analysis of Petrinja: Pro-EU and Pro-government NGO participants; volunteers and social workers and their relatives; EU institutions public servants in Petrinja. In a larger scale, the non-structured in-depth interviews were realized by small shop-owners and high school students in Petrinja. The plan of indepth interviews was constructed on two parts: build up the more effective and concrete questions about daily life practices and mindsets as activists in Petrinja - details about the present status as activists and the main subjects of their daily life, their auto-perception and the perception of Petrinja inhabitants. Non-structured in-depth interviews could give an occasion for describing the main subjects of the activist and local community members' mindset about daily life practices. After a description of main subjects, there is a solid base to propose the semi-structured in-depth interview to get more specific information and to collect data. The individuals in Petrinja with whom the indepth interviews were realized represent: one pro-EU, two Pro-government, one neutral NGO's social workers and volunteers, one local EU rural development office and one local administration office's public servants. The number of participants is forty. Content / speech analysis is also used for the research.

Depth interview plan is prepared following 6 steps (Boyce, Neale, 2009): Planning, Develop Instruments, Train data collectors, Collect Data, Analyze Data, Disseminate finding. In the planning process, the NGO workers and activist are defined as the principal source for NGO sector and activist movement. The local community members are the main information source for the general situation and all interview questions are supported by bibliography. The socioeconomic general table is created upon data collections, which is based on bibliography. The theoretical background needed for the study is put together using two sources: bibliography and participative observation. Basic questions like "Why $50 \%$ of the city is empty?"; "Where are the owners of the properties?" came from observations and historical background following ideas and theories found in bibliography and using them as framework for the results. The instruments developing stage consisted in recorded interviews on video camera. The questions focused directly on specific subjects. Participants felt comfortable and relaxed. They were well informed about the aim and structure of the interview. In the third stage (Training Data Collectors) the interviews were constructed in a professional intercultural and interpersonal communication manner, addressing: duration, the number of questions, effective using of time and insuring the interviews were ethically conducted. In the fourth stage (Collect Data) the interviews were realized over a long period. This allowed the check and recheck the results and insured the sustainable, reliable and consistent data collection on the subject. As the fifth stage (Data Analysis) the results were interpreted in a qualitative research approach by speech analysis and plus, they were also included in statistics. Each response is matched with a specific topic and the source of the information and classified by the 
specific position. In this case, the content is evaluated via double check by two parameters (by source and by subject). As the six and last stage, the final overview study is executed.

\section{Classification of the participants}

The present government in Croatia can be evaluated as far-right and Eurosceptic. NGO sector of Petrinja is divided in two principal orientations: Pro-EU and pro-government. There was only one NGO which was allowed to join Erasmus+ projects until 2017. Nevertheless, same association could beneficiate one time of EU funding and another time of local government fund or, in some cases, it could beneficiate of both types of funding at the same time.

Table 3. Classification of the participants

\begin{tabular}{|c|c|c|c|c|c|c|c|c|c|}
\hline \multicolumn{7}{|c|}{ CLASSIFICATION OF THE PARTICIPANTS } \\
\hline \multicolumn{2}{|c|}{$\begin{array}{c}\text { Pro-EU } \\
\text { Association }\end{array}$} & $\begin{array}{c}\text { Pro-Government } \\
\text { Association }\end{array}$ & \multicolumn{2}{c|}{$\begin{array}{c}\text { Neutral } \\
\text { Association }\end{array}$} & $\begin{array}{c}\text { Local } \\
\text { Administration }\end{array}$ & \multicolumn{2}{c|}{$\begin{array}{c}\text { EU } \\
\text { Office }\end{array}$} \\
\hline $\begin{array}{c}\text { Social } \\
\text { Worker }\end{array}$ & $\begin{array}{c}\text { Local } \\
\text { Community }\end{array}$ & $\begin{array}{c}\text { Social } \\
\text { Worker }\end{array}$ & $\begin{array}{c}\text { Local } \\
\text { Community }\end{array}$ & $\begin{array}{c}\text { Social } \\
\text { Worker }\end{array}$ & $\begin{array}{c}\text { Local } \\
\text { Community }\end{array}$ & Officers & Officer & $\begin{array}{c}\text { Local } \\
\text { Community }\end{array}$ \\
\hline Total & 7 & 8 & 3 & 6 & 1 & 6 & 2 & 3 & 6 \\
\hline Men & 2 & 2 & 1 & 5 & 0 & 1 & 1 & 3 & 2 \\
\hline Women & 5 & 6 & 2 & 1 & 1 & 5 & 1 & 0 & 4 \\
\hline
\end{tabular}

2.a. The questionnaire: 20 questions were prepared for each participant at different times in groups of 10. In each session, a maximum of 15 questions were asked of the participants.

The 21st question was: “A gdje si ti bio 91.?” or “A di si ti bijo 91.?” (Where were you at 1991)? All in-depth interviews show that the answer to the question "where you in 1991?" describes the participants social status. The war participants, nowadays they are veterans, get the highest social status in the local community. Their confirmation is the main source of legitimacy there. The Catholic Croatian "refugees" from Bosnia have also social acceptance. The Serbian or CroatianSerbian mix family members were forced to leave Petrinja in this period. After the war, the families which came back to Petrinja couldn't beneficiate of the social acceptance. For example, one of the vice presidents of Pro-EU association is an ethnic Serbian; among 40 Catholic Croat participants to interviews, nobody expressed positive opinions or feelings about her. The Yugoslavian immigrants who worked abroad in this period also couldn't benefice the social acceptance. Another vice president of the association was an immigrant who worked 15 years abroad. The positive opinion and feeling expression rate were the same: zero. On the other hand, these minorities are accused of an exploitation of EU funds, corruption and "degenerating the local culture in hiding behind the EU values". For example: even an association's own social workers believed that the corruption claims 
about the association were true. Nowadays two vice-presidents of the association are tried in court with corruption. According to one ethnic Serb social worker participant from a neutral Association: "She (a vice-president) exploits her "victim status, she was perhaps victim 25 years ago, now she is just an exploiter." These negative images established also the difficulties for activists to communicate with the local community.

Table 4. The subjects and positions: Discourse Analysis

\begin{tabular}{|c|c|c|}
\hline Subject & Pro-EU Activist Positions & Pro-Government Positions \\
\hline $\begin{array}{l}\text { Pro-EU Activist Position } \\
\text { Pro-Government Position } \\
\text { Emigration: } \\
\text { Interior: Seaside: Split } \\
\text { Dubrovnik } \\
\text { Zadar } \\
\text { Zagreb } \\
\text { Abroad: Germany } \\
\text { Austria } \\
\text { Ireland } \\
\text { UK } \\
\text { Australia }\end{array}$ & $\begin{array}{l}\text { Local and sustainable } \\
\text { development for Petrinja (by } \\
\text { discourse) } \\
\text { Project writing and trying to } \\
\text { benefice EU funds for useless } \\
\text { activities (by practice) }\end{array}$ & $\begin{array}{l}\text { Absolut pessimism: EU couldn't } \\
\text { help us. Russia is an enemy. } \\
\text { Croatia should be saved by } \\
\text { Croatian State and Croatians }\end{array}$ \\
\hline Unemployment & $\begin{array}{l}\text { Deindustrialization couldn't be } \\
\text { changed. Ecotourism, micro- } \\
\text { credit and start up projects could } \\
\text { be the new future (by discourse) }\end{array}$ & $\begin{array}{l}\text { The local development comes } \\
\text { from local administration and its } \\
\text { budget. EU funds could be } \\
\text { profitable for solid Agriculture } \\
\text { projects. Petrinja could be a new } \\
\text { agriculture area. }\end{array}$ \\
\hline Veterans & Veterans are fascists & Veterans are heroes. \\
\hline Vacant Estate & $\begin{array}{l}\text { Greta buildings could be } \\
\text { dedicated for Pro-EU NGOs. For } \\
\text { simple building: Silence. }\end{array}$ & $\begin{array}{l}\text { Absolut silence. } \\
\text { (NB: They have already } \\
\text { benefited the buildings.) }\end{array}$ \\
\hline Demographic crisis & $\begin{array}{l}\text { Immigration will finish the } \\
\text { Croatian nation. In long term, } \\
\text { there is no hope for Croatians. }\end{array}$ & $\begin{array}{l}\text { Abortion should be illegal. Only } \\
\text { Catholic values could save our } \\
\text { nation. }\end{array}$ \\
\hline Deindustrialization & Destiny & $\begin{array}{l}\text { Create a new light industry on } \\
\text { agriculture base is possible. }\end{array}$ \\
\hline Economic depression & Immigration is unique solution & $\begin{array}{l}\text { Agriculture projects could } \\
\text { decrease the immigration flux } \\
\text { from Croatia to abroad. }\end{array}$ \\
\hline Corruption & $\begin{array}{l}\text { All political parties are cheaters. } \\
\text { Croats are politics or fascists. } \\
\text { They are all corruptive. }\end{array}$ & $\begin{array}{l}\text { If you work with the public, you } \\
\text { can benefice a limited occasion. } \\
\text { If you do nothing for public and } \\
\text { benefice an occasion, that's the } \\
\text { corruption. Pro-Eu activists are } \\
\text { corruptive. }\end{array}$ \\
\hline Political absenteeism & All are same. & High political participation \\
\hline Wahhabism-Sala & A new Balkan & A new Balkan war is coming \\
\hline
\end{tabular}




\begin{tabular}{|c|c|}
\hline $\begin{array}{l}\text { Economic genc } \\
\text { Slavonia }\end{array}$ & $\begin{array}{l}\text { EU destroys Croatia and it } \mid \text { EU destroys Croatia and it } \\
\text { makes an economic genocide } \text { makes an economic genocide } \\
\begin{array}{l}\text { against Croats. Germans see the against Croats. Germans see the } \\
\text { Croats as their slaves. }\end{array} \\
\text { Croats as their slaves. }\end{array}$ \\
\hline EU/Future of EU & $\begin{array}{l}\text { Germany wants to assimilate the Germany wants to assimilate the } \\
\text { Croats. They have already Croats. They have already } \\
\text { assimilated the Slovenes. They assimilated the Slovenes. They } \\
\text { see the Croats as their slaves. EU see the Croats as their slaves.EU } \\
\text { destroys Croatia, but at the same destroys Croatia. Croatia should } \\
\text { time EU is unique hope for draw its own way to economic } \\
\text { Croatians for looking for a job development. Croatia has a } \\
\text { and if there is no EU, Serbs will geopolitical importance. The } \\
\text { come back thanks to Russians. Western and Catholic world will } \\
\text { EU will be dissolved in near- protect us. } \\
\text { future. }\end{array}$ \\
\hline Alcoholism & \begin{tabular}{l|l} 
& National/Slavic culture \\
\end{tabular} \\
\hline Conservatism & $\begin{array}{l}\begin{array}{l}\text { Croats are highly Catholic and } \\
\text { patriotic. }\end{array} \\
\begin{array}{l}\text { Croats are highly Catholic and } \\
\text { patriotic but at the same time, } \\
\text { they try to be adapted for new } \\
\text { things in protecting their values. }\end{array}\end{array}$ \\
\hline LGBTI rights & $\begin{array}{l}\text { We should support the LGBTI } \\
\text { rights but the community is so economically help for LGBTI } \\
\text { conservative, that's why we persons if they don't show } \\
\begin{array}{l}\text { can't. Plus, LGBTs are openly their identity. Because } \\
\text { disgusting. }\end{array} \\
\begin{array}{l}\text { LGBTI could be contagious for } \\
\text { Youngs. We need to increase the } \\
\text { population. Gay marriage is } \\
\text { against Catholic values. They are } \\
\text { not disgusting. }\end{array}\end{array}$ \\
\hline Drug addiction & \begin{tabular}{l|l|} 
We couldn't see but one-day & We should erase all drugs in \\
cannabis will be legal in Croatia. & Croatia to save the health of new \\
Synthetic drugs are ruined & generation and increase the \\
Croatian youth. Unemployment population of Croats. Trying \\
increases the consumption. State \\
should fight against it & drugs is exactly acceptable.
\end{tabular} \\
\hline Future & Immigration \\
\hline
\end{tabular}

After 20 questions (with sub questions), the answer focalizes on 10 principal topics.

\section{Results}

These face-to-face in-depth interviews were conducted on the question of property, veteran status, and unemployed (socio-economic) problems. During these interviews, three sequences that addressed time were used: War period, the property and veteran status, the problem of inheritance. At the time the interviews were carried out 25 years after the war when nearly $50 \%$ of the real estates in the city were abandoned (vacant estate). Anti-EU and xenophobic-homophobic sentiments are strong amongst the participants, especially amongst those who come from veteran families; a feeling of powerlessness is shared by the youth in general, voting participation rates are therefore 
nearly $15 \%$. Local development perspective is found less popular than immigration option by the youth. Young people are looking for new immigration routes like Canada, New Zealand, and Vietnam. Activists represent a very limited minority of the population and in general, they have either a multicultural background (mixt marriages), or are refugees, or come from immigrant workers families. The "strange"/ "foreign" image limits their social integration capacity in the local community.

Pro-Eu and Eurosceptic/Pro-government side, accuse each other of corruption. Pro-Eu NGOs are accused of corruption with to EU funds by Pro-government agents and Pro-government local and central structures are accused by Pro-EU activists of corruption with public budget. Pro-EU activists' arguments look like coming from one source, uniformized and not related to any specific situation. In this case, their accusation could be evaluated as a classic "color revolution propaganda". It could be evaluated also as a psychologic reflection for both of two sides. The main daily conversation subjects are totally same for both sides. For example: they want to join the demonstrations against the criminalization of abortion right in Croatia but on the other side, they are afraid of the decrease of Croatian population due to demographic crisis - that's why they couldn't have a sharp position on this topic. They beneficiate of the EU funds but they accused at the same time EU of making an "economic genocide in Slavonia". They want to go to Germany to work, they send their children to German high school in Petrinja, they speak German in open bazaar of town but at the same time, they are afraid to "assimilate to a German" for their children. The majority of activists' dream is escaping not only Petrinja but also Croatia, to immigrate USA, Australia, Germany, UK, Ireland or Austria.

\section{Discussions}

The veterans, who are sometimes evaluated as the war criminals, represent a moral and economic force in Petrinja. Their confirmation for an event or an association could be the main source of legitimacy there. The veterans' attitude and abandoned estates represents vivid topics that fuel far-right movements. On the other side, Pro-EU activists are trapped in ethnic-religion minorities' issues. Pro-EU associations couldn't find easily participants from Croatian Catholic majority. Especially because the majority of activists/social workers are of Muslim origin, Orthodox Christian Serbs, Muslim Roma and LGBT individuals. After 1991 war changed dramatically the demographic situation in Petrinja. After 2013 EU-accession, the immigration flux to Germany, UK, Ireland, and Austria increased. Both sides of the local community (pro-EU and Eurosceptic) shared same feelings against EU: helplessness and a sort of "Stockholm Syndrome": Their feelings about EU are evaluated at least as skeptic. But their geopolitical and demographic situation put them in a unique position: Petrinja was historically a Serbian city. Until 1993-95 it kept the Serbian identity. Because of this fact, as emerged from the interviews, Croatian Catholic majority has some antiSerbian/ anti-Orthodox feelings and they think that Russia supports Serbians, therefore they have anti-Russian feelings. In this case, classic "Pro-EU-Pro-Russian" contradiction doesn't work in Petrinja. The Pro-EU side has Eurosceptic feelings, they accuse EU of "economic genocide" in Slavonia, consisting of population decrease, deindustrialization and country's destruction. Their point of view is totally same with the Pro-government NGOs, but at the same time, they think that EU is unique hope of salvation for Croatians, but not Croatia. The pro-government side at the same time has negative ideas and feeling against EU and Russia. They represent the majority in Petrinja. This situation creates a unique socio-psychologic ambiance: Pro-EU activist could be evaluated as "western spy/EU spy" in an EU member country (Croatia) by another EU citizens: Croatians. The deindustrialization process after 1991 could show some part of the majority the EU funds as a new 
economic sector to earn their living. The local people with different backgrounds and different purposes try to beneficiate of these funds. In some cases, the corruption claims couldn't stay as a public rumor. In the 2016-2017 period, largest pro-EU Association of Petrinja was arraigned with corruption. After the war, one German NGO helped the reconstruction of Petrinja. This association's local contacts remained as a human resource base for all contemporary NGO sector in Petrinja. Progovernment NGO participants have no problem with integration in the local community. They have no contradiction about traditional values. Pro-EU association social workers and participants have strong integration problem with local communities. They are seen as "western spies" and their activity could be evaluated by the local community as detrimental to their local, patriotic and religious values. In some case, even their own families reject them because of their opposition to the central and local government. In some case, families think that they could lose their good relations with local administrations and some social benefits because of a family member who is activist, therefore they break contact with this one. Activists cannot create a coherent ideologic line and social identity for themselves, settling only to the use the EU funding benefits.

\section{Conclusions}

Petrinja, from "battleground" to concentration camps of WW2 and Operation Storm of 90's, has a unique and tragic history. Contemporary Petrinja is ruined by the demographic crisis, deindustrialization, and alcoholism. In this context, to find a reliable solution could be possible. Benefits for Serbian veterans, killed/deported relatives could use the same measurement as for the mass majority. By discourse, Pro-EU activist represents the universal humanitarian values but by practice, they are not untouched by corruption. Deindustrialization and very high unemployment rate poison the activism. Around the EU funds, corruption claims are shared by the mass majority and they are approved by courts. Some declassed and lumpen individuals could search an economic benefit on EU funds in NGO sector with a fake activist identity. Or some other part of "activists" could find the EU supported activities as a source of socialization or just sexual exploitation. In 2017, a sexual exploitation scandal aimed the interviews for recruitment in Pro-EU NGOs. Catholic Croat immigrants who were invited by Croatian government to solve the demographic crisis in Petrinja could be a solution for the crisis. Although this population also could become as a part of the problem, not the solution, like war-criminal veterans.

As the war's main "heritage", property issues and veteran status problems limit the positive changing capacity of the local communities. Activist identity and activist values stay isolated and "strange". The powerlessness increases the immigration tendency amongst the local youth. A new activist policy is needed regarding veterans and local communities, which must facilitate positive change and development in the local communities.

To get the contribution of not war criminal veterans as a community for activism could be a reliable step to advance the universal democracy base NGO activities. The activist may break the delusion: "Mass majority in Petrinja is far-right". This delusion comes from their isolation and increases it. The mass majority is not far-right there, also the activists are not the champions of democracy. Petrinja is a post-war, post-ethnic clarification city. The "mass far right" delusion could give euphoria and self-proclaimed status as "unique defender of democracy and humanitarian" value but also, it's a delusion. Their image is ruined by corruption/exploit of EU funds/tax and "Western spy" claims.

A genuine solution could be inviting the Serbian population of Petrinja to take back their property and setting up a "truth and reconciliation commission" like South Africa after Apartheid regime for war criminal veterans, reindustrialization the territory, support the local economy, 
ecotourism, create the local and sustainable ecologic development there and terminate the pseudo role of EU funds as an economic support for unemployed purposeless people. These steps could be a solid base to create a peaceful multicultural local community in Petrinja.

\section{References}

1. Boyce, C., Neale, P., 2009. Conducting In-Depth Interviews for Evaluation Input. Pathfinder International, Available at: <www.thesisscientist.com/Docs/Documents/c138f03c-1b79-4efa9631-fe07b00ce48e > [Accessed 29 August 2017]

2. Braičić, Z. and Lončar, J., 2011. Intra-regional disparities in Sisak-Moslavina County. Geoadria 16(1), pp.93-118. https://doi.org/10.15291/geoadria.281 Available at: https://hrcak.srce.hr/file/106881

3. Braičić, Z. and Stipersky, Z., 2009. The influence of war on the dynamics of unemployment in Banovina (Croatia). Revija za geografijo (Journal for Geography), 4-2, pp.103-112. Available at: <www.ff.um.si/zalozba-in-knjigarna/ponudba/zbirke-in-revije/revija-zageografijo/clanki/stevilka-4-2-2009/042-09_stiperski_bracic.pdf > [Accessed 22 June 2017]

4. Čačić-Kumpes, J. and Nejašmić, J., 1999. Društvene promjene, migracije i etnička struktura: primjer Petrinje (Hrvatska) (Social change, migration and ethnic structure: the example of Petrinja -Croatia), pp. 253-275, Available at: <www.researchgate.net/publication/27204424_Drustvene_promjene_migracije_i_etnicka_strukt ura_primjer_Petrinje_Hrvatska > [Accessed 22 June 2017]

5. McAdams, C.M., 1992. Croatia: Myth and Reality. First edition, C I S Pub.

6. Stevanović, I., 1998. Violence Against Women in the Yugoslav war as told by WomenRefugees. International Review of Victimology, 6(1), Available at: <www.journals.sagepub.com/doi/abs/10.1177/026975809800600105 > [Accessed 22 June 2017]

7. Sampson, S., 2002. Weak States, Uncivil societies and thousands of NGOs: Benevolent colonialism in the Balkans. In: S. Resic, and B. Törnquist-Plewa, eds. The Balkans in Focus: Cultural Boundaries in Europe, Lund Univ. Press. pp.27-44. Available at: <www.anthrobase.com/Txt/S/Sampson_S_01.htm > [Accessed 29 August 2017]

8. Stiperski, Z. and Braičić, Z., 2009. The influence of war on the dynamics of unemployment in Banovina (Croatia). Revija za geografijo (Journal for Geography), 4-2, pp.103-112. Available at: $\quad$ www.ff.um.si/zalozba-in-knjigarna/ponudba/zbirke-in-revije/revija-zageografijo/clanki/stevilka-4-2-2009/042-09_stiperski_bracic.pdf [Accessed 22 June 2017]

9. Vuksic, A.A., 2011. The Gavrilović Meat Company: Surviving and Thriving Through Years of Chaos in Croatia, Lynn University, ProQuest Dissertations Publishing, p.1-24 Available at: <http://search.proquest.com/openview/56e96d8e73f4c3700e0dabcfbb0927c4/1?pqorigsite $=$ gscholar $\& \mathrm{cbl}=18750 \&$ diss $=\mathrm{y}>$ [Accessed 22 June 2017]

10. ${ }^{* * *}$ Amnesty International UK, 2005. Croatia: Operation Storm - still no justice ten years on. Press Release. 03 Aug 2005. Available at: https://www.amnesty.org.uk/press-releases/croatiaoperation-storm-still-no-justice-ten-years [Accessed 22 June 2017]

11. ***DZS (Croatian Bureau of Statistic), 2011. Census 2011: Census of Population, Households and Dwellings 2011, Available at: www.dzs.hr/Eng/censuses/census2011/results/censustabshtm.htm [Accessed 22 June 2017]

12. *** Shoah Resource Center, The International School for Holocaust Studies. Croatia. Available at: http://www.yadvashem.org/odot_pdf/Microsoft\%20Word\%20-\%205930.pdf [Accessed 22 June 2017] 


\title{
Health of Public Life in the philosophy of Hannah Arendt: the relation of the public and private realms in the centuries of modernity
}

\section{DOI: $\underline{\text { http://doi.org/10.26758/8.1.21 }}$}

\section{Gábor Kovács}

Senior Research Fellow, Institute of Philosophy, Research Centre for the Humanities, Hungarian Academy of Sciences, Budapest, Hungary

Address correspondence to: Gábor Kovács, E-mail: kovacs.gabor@btk.mta.hu

\begin{abstract}
In The Human Condition (1959), which is mentioned as her opus magnum, Arendt gives a political ontology applying a phenomenological method; she blends the chronological explanation with a conceptual analysis. The axis of thought train is the private-public distinction put in a historical framework. The feminist authors warn us, that this distinction is not a neutral analytical instrument but an abstraction deduced from the reality of the antique patriarchal society. At the same time, Arendt, in other feminist interpretations is a forerunner of feminism who, in her biography written on Rahel Varnhagen, a Jewish woman of Berlin in the first half of the $19^{\text {th }}$ century, created a role model of modern woman who dared to risk of entering the light of the public realm that had previously been dominated by males and, in her Berlin saloon, offered an alternative space where the women were peers of men. The pro-Arendt feminist interpreters assert, the Arendtian philosophy outlines the possibility for a no male-dominated, really democratic public realm.

The political philosophy of Hannah Arendt has been flavored by a history of decline. The beginning of the modernity, in this interpretation, is the moment of derailment. During the centuries of modernity, step by step, the division lines between private and public spheres disappear. Lasting institutions, warranting the public sphere, dissolve in the never-ending procession of material production: everything becomes fluid: culture and politics change into the objects of the everwidening cycles of consumption devouring whole reality and the intimacy, conquering and distorting the emptied public realm, creates proper constellation for totalitarian political practices.
\end{abstract}

Keywords: public space, private space, equality, male, female, feminism, privacy.

\section{Introduction}

The distinction between private and public spaces has been a basic tenet of political thought since the beginning of modernity. In public space, individuals strive for gaining the respect of others. Private space is a field of particular human needs that must be excluded from public space. Is this distinction tenable in our age? Our era, this is frequently said, is un-interpretable with the classical binary notions of modernity (Hardt and Negri, 2000, p.151). The requirement of a well trenched public space with its lasting institutions, from the perspective of late or post-modernity, seems to be irrelevant. Many thinkers assert that the elimination of borders and the hybridization of life spheres are the main characteristics of our age. Zygmunt Baumann has coined the term of liquid modernity by which he refers to the overall dissolution of borders, institutions and solid, lasting identities (Baumann, 2000, pp.7-8). 
At the same time, this duality is the precondition of a healthy and well-balanced economy of human existence. Public and private spaces as autonomous, distinct, well-fenced ontological terrains are, in the interpretation of Hannah Arendt, in a complementary relation: they exclude and postulate each other at the same time. Without protected private space, the depth of human existence flattens and becomes shallow. Human beings need a home, a shelter for keeping their physical and psychical health and integrity (Arendt, 1958, p.71.) At the same time, it is true as well that, without protected public space, human existence remains one-sided and truncated.

\section{Spatial essentialism and cultural criticism: the theatre as a model for public space}

The health of public life depends on the strict separation of private and public realms - it is the core of the Arendtian approach. Both terrains of human existence have to be strictly separated from each other and entrenched within the borders of their territories - this spatial essentialism gives the basic framework of the Arendtian political philosophy. Without this separation a wellfunctioning political democracy is impossible, Arendt warns us, and many thinkers, following her argumentation, trace back the crisis symptoms of contemporary democracy to the elimination of a distinct public space. This is the basic tenet of the Arendt disciple Richard Sennett who develops his own theory within an Arendtian theoretical framework.

German Existenz-philosophy, through Jaspers and Heidegger, and the experience of Nazi totalitarianism had undoubtedly deeply influenced the thought of Arendt (Canovan, 1992; YoungBruehl, 1982). Politics conceived in the Arendtian philosophy in a definitely non-Weberian meaning; it is not a striving for power but a res publica, a common business of every citizen rooted in the human plurality; human beings live in a common world constituted and maintained by human action, which cannot be accomplished without human togetherness. The phenomenological approach is one of the most important elements of her intellectual tool-box inherited from her masters. The phenomenological description of the shared human world is the main aim of the Arendtian political phenomenology. Human existence is communal existence. The human being, according to Existenz-philosophy, has been thrown into the world but he/she exists together with others in this world. Arendt describes the ontological situation of human beings from two different perspectives; a pessimistic cultural criticism and an optimistic political philosophy. Cultural criticism is part and parcel of her German heritage of the inter-war period; it is gloomy theory describing modernity as an era of decay: human history is a history of decline (Verfallsgeschichte).

Arendt borrowed motifs mainly from her master Martin Heidegger whose existential ontology seriously influenced her approach (see Zimmerman, 1990, for the Heideggerian cultural criticism). In The Human Condition, she gives a political ontology outlined by the help of phenomenological method; she blends chronological explanation with conceptual analysis. The axis of thought train is the private-public distinction embedded in a historical framework. The beginning of the modernity is a moment of derailment; the division line between private and public spheres disappears and a new hybrid realm emerges: it is the sphere of social (see Pitkin, 1998, for the detailed analysis of social). The lasting institutions, warranties of a well-functioning public sphere, dissolve in a never-ending procession of material production: everything becomes fluid and an object of the ever-widening cycles of consumption devouring whole reality. The elimination of public realm, because of the fatal constellations of the interwar period, creates proper constellation for the totalitarian political practices of the $20^{\text {th }}$ century (Arendt, 1976).

This interpretation of the history of modernity is very similar to the theory of cultural industry explained in the common book of Adorno and Horkheimer, The dialectics of modernity. 
Modernity, in the peculiar Arendtian interpretation, is an age of re-naturalization taking place at the expense of the field of human artefacts from culture to politics (Kovács, 2012).

Her opus magnum, The Human Condition (1958) is dominated by a decline-narrative while in next book The revolution (1964) she changes her perspective; here modernity is not an age of total sinfulness anymore because modern revolutions give hope for gaining authentic political experience and recovering authentic public space (Arendt, 1990). Arendt uses the Greek polis model in which public and private space are rigorously divided from each other; the former is constituted by the polis-citizens on the agora. Liberty and equality - which are artefacts and not natural innate qualities of human beings in the Arendtian interpretation - appear in the light of public space: they are embodied in human actions and human speeches. But these are male actions and male speeches - women, similarly to the servants, are prohibited from the agora. Private realm, on the contrary, is a female terrain; it is the sphere of inequality and hierarchical relations.

\section{Arendt and the feminist perspective: Rahel Varnhagen and a $19^{\text {th }}$-century attempt for the foundation of a feminine public space.}

The Arendtian private-public distinction, the feminist authors warn us, is not a neutral analytical instrument but an abstraction deduced from the reality of the antique patriarchal society based on male domination (Pitkin, 1994). The Greek polis had been established on the institutions of slavery and the household. The latter was a scene of unequal social relations between men and women. The household gave protection to the patriarchal family in which women and children were subdued to the despotic male rule. The price of political liberty enjoyed by the men on the agora, on the stage of politics, was paid by women. However, without some kind of subjugation, it is one of the basic tenets of Arendtian political philosophy, liberty cannot exist at all: you must deliberate yourself from the burden of biological necessity including of producing foodstuff, ensuring shelter and bearing children - in the antiquity these activities were the tasks of slaves and women; the price of liberty, in premodern world, was paid by other human beings. The burden of biological necessity, in modern times, can be shifted upon machines. At the same time, this burden always remains a necessary part of human life. It can be fenced within a closed territory; household, family, factory etc. but it can't be eliminated at all. Arendt's deepest conviction is that liberty needs a closed territory exempted from necessity. Human equality is not natural; it is a fragile human artefact maintained by the political community.

Feminist interpretations of Arendt are ambivalent; it is the reflection of the ambivalence of her oeuvre. Arendtian political philosophy, as a consequence of her 'Grecophily', can really be interpreted as a macho theory: the privilege of free action in the public realm, in the space of appearance, is reserved for male agents. Arendt, her feminist critics assert, perpetuates the Greek polis model and her idealized public-political actors are typical male characters: their try to prove their own excellences, similarly to the Greek heroes of the Iliad, by ostentatious acts and speeches. They try avidly to get the admiration of the outer world concealing and overcompensating their inner uncertainty and vulnerability by glittering rhetoric and spectacular deeds (Pitkin, 1994).

This interpretation of the Arendtian political ontology is one sided but it is not without cause. The Arendtian theory for action is undeniably burdened with ambivalences (d'Entreves, 1994, pp.64-100). Arendt refers to two kinds of action without making a definite distinction between them. What is the target of the feminist critique is the agonistic-expressive action; it has been associated by Arendt with Greek polis. The male actor, acting this way, presents his excellence in an egoistic manner to the detriment of his fellow humans. At the same time, communicative action, 
contrary to the expressive type, takes place in the situations of plurality when the peers are really equal and the field of action hasn't been distorted by the conditions of subordination.

But there is another side of the coin. Seyla Benhabib, one of the pro-Arendt feminist authors, interprets Arendt as a forerunner of feminism who, in her biography written on Rahel Varnhagen, the Jewish woman of Berlin in the first half of the $19^{\text {th }}$ century, created a role model of modern woman daring to risk of entering the light of the public realm that had previously been dominated by males and, in her Berlin saloon, offered an alternative space where the women were peers of men (Benhabib, 1996, pp.20-21).

Arendt, in this early book, examining the life-situation of her heroine, connects the problem of Jewish and female identities. The historical context is Prussia, more precisely Berlin at the turn of $18-19^{\text {th }}$ centuries, during the period of the French occupation and in the consequent decades. Arendt gives a parallel analysis of different Jewish life strategies among the conditions of the Prussian nation-building in a transitional period between the mixed society of the late $18^{\text {th }}$ century and the homogenized society of the $19^{\text {th }}$-century nation-state. The referential framework is a toolbox inherited from German Existenz-philosophy. The book is a Bildung-Roman, an educational novel describing the attempt of constructing an alternative public space in a Berlin saloon where a Jewish woman, playing the role of a mediator between the Prussian bourgeoisie and the Prussian aristocracy, tries to construct for herself an identity by the way of assimilation into the Christian society of the emerging modern Prussian nation-state. Rahel Varnhagen goes over the accustomed way of assimilation of the early $19^{\text {th }}$ century: she converts from Jewish religion to Christianity and gets married to a Christian man, trying, Arendt concludes, to become a paradigmatic parvenu, but, at the end of her life, she has to realize that this life-strategy requires a total and perpetual selfsurrender from her (Arendt, 1997, p.256).

The attempts of Rahel Varnhagen fail as well on the level of public realm: her saloon of Berlin proves to be a temporary phenomenon. The cause of it is an inherent paradox built in the dynamic of modernity. At the time of the emerging of $19^{\text {th }}$ century Prussian nation state Jewish political emancipation invests Jews with political rights but, at the same time, gives rise to modern political Anti-Semitism. With the decline of the idea of a mixed society inherited from the Enlightenment the Jew ceases to be the representative of an interesting, exciting specimen of the foreigner and becomes a suspicious figure in the homogenizing atmosphere of the nation-state; the inclusivist type of alien-construction rooted in the ideas of Enlightenment is replaced by a new $19^{\text {th }}$ century exclusivist-type conception and the temporary broker-role of Rahel Varnhagen as a Jewish woman loses its ground (Arendt, 1997, p.127). At the same time, the figure of Rahel Warnhagen is important, the pro-Arendt feminist interpreters assert, because this proves that the Arendtian political philosophy anticipates the possibility for a no male-dominated, really democratic public realm, so the Arendtian theory is able to give referential points for feminism as well.

\section{The age of intimacy and the end of public realm}

The end-result of the process of dissolution taking place in an accelerating way during the centuries of modernity, in the Arendtian interpretation, is the age of intimacy and the end of public realm. Arendt (1990, p.104) distinguishes three stages of this process: the 18th century is the era of high society, in the 19th century emerges the genteel society and in the 20th century takes place the mass society, a precondition of modern totalitarianisms. The motor of these transformations is the swelling of the terrain of intimacy. The members of high society constitute a thin stratum, the aristocrats, genteel society embraces a much wider segment of the population, the bourgeoisie, mass society comprehends every member of the collectivity. The irresistible expansion of the intimacy 
contributes in a great amount to the dissolution of lasting institutions. The totalitarian regimes of the 20th centuries with their amorphous structures eliminating both public and private realms emerge from this constellation.

Naked private personality without a protecting shield, Arendt warns, corrodes and, in the long run, destroys public sphere, a terrain of human interaction based on the plurality of human beings. That is why, Arendt argues, in Greek tragedy actors hid their faces beyond masks to insulate the natural man from the artificially constructed public man:

"The profound meaningfulness inherent in the many political metaphors derived from the theatre is perhaps best illustrated by the history of the Latin word persona. In its original meaning, it signified the mask ancient actors used to wear in a play. (...) The mask as such obviously had two functions: it had to hide, or rather to replace, the actor's own face and countenance, but in a way that would make it possible for the voice to sound through. (...) the word persona became a metaphor and was carried from the language of the theatre into legal terminology. The distinction between a private individual in Rome and a Roman citizen was that the latter had a persona, a legal personality, as we would say (...) Without his persona, there would be an individual without rights and duties, perhaps a 'natural man' - that is, a human being or homo in the original meaning of the word, indicating someone outside the range of the law and the body politic of the citizens, as for instance a slave but certainly a politically irrelevant being" (Arendt, 1990, pp.106-107).

This theatre-metaphoric, in the theory of Arendt-disciple Richard Sennett, plays a central role. Sennett gives an interpretation of modernity between $18^{\text {th }}$ and $20^{\text {th }}$ centuries in which he uses the referential frame of the Arendtian thought. He focuses upon the transformations of the structure of public and private realms during these centuries. The apex, according to Sennett, was the $18^{\text {th }}$ century with a flourishing public life. It was an age when the autonomy of public space and its intactness from the intrusion of private sphere were maintained by some kind of impersonality. It had been ensured by distinctive marks; dresses, gestures, behavioral patterns promoting social interactions among foreigners who came from the different segments of society. Men were considered to be actors both on the stage of theaters and on the streets of the emerging modern metropolises as Paris and London. Shared human acts in this model are distanced from the private contents of human personality; the actors of the theatre and the persons on the streets of the city wore fictive mask-like characters concealing their personal feeling and emotions; this artificial distance-making impersonality was the most important presupposition to present a common theatrical play and to conduct shared social and political action (Sennett, 1977, pp.107-122).

The $19^{\text {th }}$ century proved a turning point in the history of modernity; naked human personality intruded into the public realm. It was a prelude to the intimate society of our age and introduced a new kind of political domination in which the politician brings the people under his/her sway by the presentation of his/her private feelings and emotions; what counts it is not his/her program or the schedule of the political acts he/she wants to realize but what he/she is like. His/her electoral success hinges on whether he/she is able to present himself/herself as an authentic personality. That kind of political manipulation involves the emergence of a collective personality, using the phrase of Sennett, a destructive gemeinschaft in a dead public space. In the ages of a vigorous, flourishing public realm collective identity has been shaped by collective action while in the ages of inflated private space without public realm collective identity has been shaped by fantasies and projection. The doer has been replaced by the passive voyeur, a collective personality motivated by fear and hate: 
"Just as personality itself has become an antisocial idea, collective personality becomes group identity in society hostile to, difficult to translate into, group activity. Community has become a phenomenon of collective being rather than collective action, save in one way. The only transaction for the group to engage in is that of purification, of rejection and chastisement of those who are not "like" the others. (...) The logic of collective personality is the purge (...) Broadly stated, when people today seek to have full and open emotional relations with each other, they succeed only in wounding each other. This is the logical consequence of the destructive gemeinschaft which arose when personality made its appearance in society" (Sennett, 1977, p.223).

\section{Conclusion}

The 'destructive gemeinschaft' arises in the late $19^{\text {th }}$ century. The Dreyfus affair analyzed in a detailed way by both Arendt and Sennett is a historical prefiguration of the $20^{\text {th }}$-century constellation leading to totalitarian regimes. Albeit totalitarianism suffered defeat, Arendt warns, without the healthy balance of mutually protected private and public realms, among the conditions distorted by the dominance of privacy, destructive gemeinschaft with its xenophobe exclusivist logic appears again and again. The post-democracy of late modernity (Crouch, 2004) can easily be a hotbed of new kinds of totalitarianism.

\section{Acknowledgment}

The paper was supported by a research project of the Hungarian Scientific Research Fund, entitled Arts and Scholarship in the Service of the Nation-building in the Nineteenth-Century Hungary (OTKA K 108670).

\section{References}

1. Arendt, H., 1976. The Origins of Totalitarianism. San Diego, New York, London, Harcourt Brace \& Company.

2. Arendt, H.,1990. On Revolution: London, Penguin Books.

3. Arendt, H., 1997. Rahel Varnhagen. The Life of a Jewess. Edited by Liliane Weissberg, translated by Richard and Clara Winston. Baltimore and London: The Johns Hopkins University Press.

4. Canovan, M., 1992. Hannah Arendt. A Reinterpretation of Her Political Thought. Cambridge: Cambridge University Press.

5. Crouch, C., 2004. Post-Democracy. Cambridge, UK-Malden, USA, Polity Press.

6. d'Entreves, M.P., 1994. The Political Philosophy of Hannah Arendt. New York: Routledge.

7. Hardt, M. and Negri, A., 2000. Empire. Cambridge, Massachusetts \& London, England: Harvard University Press, 2000.

8. Kovács, G., 2012. Hannah Arendt's Interpretation of Natural and Artificial in the Political Phenomenology of the Human Condition. Limes: Regionalistics (Vilnius), 5(2), pp.93-102.

9. Pitkin, H. F. 1994 Justice: On relating Private and Public. In: L.P. Hinchman and S.K. Hinchman, eds. Hannah Arendt. Critical Essays. New York: State University of New York Press, pp.261-88.

10. Pitkin, H.F., 1998. The Attack of the Blob.Hannah Arendt's Concept of the Social. Chicago \& London: The University of Chicago Press. 
11. Zimmerman, M., 1990. Heidegger's Confrontation with Modernity. Technology, Politics, Art. Bloomington and Indianapolis: Indiana University Press.

12. Zygmunt, B., 2000. Liquid modernity. Cambridge: Polity Press.

13. Young-Bruehl, E., 1982. Hannah Arendt. For Love of the World. New Haven and London: Yale University Press. 


\title{
Representation of 'family' in indian television serials
}

\section{DOI: http://doi.org/10.26758/8.1.22}

Gudipaty Nagamallika

The English and Foreign Languages University, Hyderabad, India

Address correspondence to: Gudipaty Nagamallika; email: nagamallika.gudipaty@gmail.com

\begin{abstract}
Objectives. Effects of globalization have been limited in relation to Indian family structure and culture. Television, an important source of infotainment for most Indian households, reflects social reality with real-time, tempered with elements of drama and stereotypical depictions of characters within families. This paper analyses family as a unit, a universal theme in most television serials, its inter and intra family relationships and extent of dramatic liberty to overcome the limitations of a serial's life.

Material and methods. Ethnographic content analysis of the top ten Hindi serials (national language of India) of 2016 (based on Broadcast Audience Research Council, India) was conducted with main characters within family as the unit of analysis. Descriptions of protagonists and the power equations determine the relationships and hierarchies within television families. Categories that emerged from the narratives using grounded theory were: structure of the family, the power centers within the family, the portrayal of 'good' and 'evil' and its relation to power equations within the family members.

Results and Conclusions. As a descriptive study, the results obtained reflect the conclusions. Rich, upper-middle-class joint families are still the most popular institutions in television serials and women continue to be dominant forces in soap operas. A shift in the importance of characters within the family fold incorporates the changing dynamics in the current Indian society. The naturalization of 'supernatural beings' in the family serials helped overcome the temporal and spatial limitations of an ordinary serial, a trend reflecting global agenda.
\end{abstract}

Keywords: joint family; matriarch; supernatural beings; serials.

\section{Introduction}

Television entered India in 1959, but it was only after the telecast of Asian Games in 1982 in color, that television became popular commercially. Initially, Doordarshan, the public broadcaster under the government of India had a virtual monopoly over the television market. Economic liberalization from the ' 90 s increased the number of private channels, now over 883 , widening the scope and growth of technological as well as programming content. Today, there are over 600 million viewers in 146 million homes with television channels and a market estimated to be worth 588 billion INR. (913 million USD) (KPMG-India, 2016). There are specialized channels ranging from entertainment to sports, children, and news but the general-interest entertainment channels (GEC) in Hindi and regional languages dominate the television market with around 55\% 
viewership (KPMG-India, 2016). The general entertainment channels (GEC) space accounted for 8 out of 10 top prime-time shows in 2016 (KPMG-India, 2017) of which family-based soap-operas or serials form a major part. Soap-operas that began as weekly serials telecast on Doordarshan in the ' 80 s, turned into daily serials with the entry of $24 \times 7$ private television channels in the ' 90 s. Since then, the competition has been fierce in a fragmented market, rapid growth in the number of channels and regionalization; conversely, this leads to an increase in the number of soap-operas (Lecuyer, 2013). The serials one find on television in India today fit the Webster's dictionary definition of a soap opera: 'serial drama performed originally on a daytime radio or television program and chiefly characterized by tangled interpersonal situations and melodramatic or sentimental treatment'. The longest series in the history of Indian television, Kyunki Saas Bhi Kabhi Bahu Thi, (Because the mother-in-law was a daughter-in-law once) was aired for 8 years and 8 months, amounting to 1,830 episodes. It has been the most-watched series in Asia, maintaining twofigure audience ratings for over 5 successive years with over the 110 million viewer mark for one of its flagship episodes (Lecuyer, 2013).

The present study analyses television serials from the top ten of the last quarter of 2016 to examine if they reflect the existing socio-cultural conditions and transformations that a country like India with its multicultural milieu exhibits. Do the Indian soap-operas portray the real and/or hidden structures that exist in archetypes or do the mythical narratives of the serials make it possible to exhibit the underlying substructure of various cultural phenomena such as customs, rites, and habits within a social institution represented by a family? In this paper, the terms soap-operas and serials are used interchangeably as there are no distinct differences between them in today's television programs. By serials/soap-operas I mean the daily programs which are aired from half hour to one hour with a storyline that revolves around a family or two for generations, sometimes with a closure and at other times continue for years or pulled off air suddenly keeping in mind the popularity of the program. The scope of this paper is limited to examining only the national language (Hindi) serials.

\section{Changing Structure of Indian families}

Families always form a strong social base in India whether they are joint or nuclear. The dynamic changes in Indian society resulted in the transformation of joint families to nuclear. Traditionally, India had a patriarchal family system with a few exceptions, which follow the matriarchal system (Rao, 2011). Every member of the family had a defined role that was acculturated and socialized into the community. Urbanization and industrialization brought in structural changes within families and villages (Khan and Rizvi, 2015). A consequence of such changes was a large-scale migration to urban areas and conversion of joint families to nuclear (Khan and Rizvi, 2015). The children migrated to the towns and cities in search of jobs with their families, leaving behind the parents; returning annually to visit them. Westernization also led to modernization resulting in education and an increase in women workforce.

The technological leap that India took in the last two decades due to Information Technology resulted in double incomes, the high economic growth of families, and economic independence for women, absent earlier. An interesting outcome of this is a reversal in the structure of nuclear families. According to the Indian census data, the percentage of nuclear families decreased slightly between 2001 and 2011 from $70.34 \%$ to $70.11 \%$. Although the overall number of nuclear families increased (from 135 million in 2001 to 172 million in 2011), it was at a slower pace than the overall population growth (Raja, 2014). The government of India stated that families are increasingly fragmenting in rural areas, but more people in cities are choosing to live in extended 
families. Between 2001 and 2011, joint families in urban India grew 29\%, whereas in rural areas they rose only $2 \%$ (indiatimes.com, 2017).

Concurrently, the family that was the nucleus, around which the Indian society functioned, is undergoing changes with an increasing number of cases of divorce and separation, single parents, and people marrying late or opting to stay single; (Raja, 2014) mostly experienced in the urban metros. They may opt to stay with parents or siblings or children leading to 'sub-nuclear units' (indiatimes.com, 2017). Such developments have not completely disintegrated the notion of a defined family but led to a new kind of hybrid family structure as most nuclear households continue to exist as constituents of joint families (Mondal, 2016). With parents working, the grandparents stay home to take care of the children. Not many parents opt for commercial arrangements as the traditional notion of familial roles have not been discarded. Another reason is the financial burden such arrangements involve. According to TV Sekher, a professor at the International Institute of Population Studies (IIPS) in Mumbai, "In urban areas, with the scarcity of housing, there is a tendency of families to stay together" (Raja, 2014). It is economical to revert to a joint family setting than stay nuclear. However, the traditional structure and roles of members within a joint family system changed as the children do not live with the parents but vice versa, where the parents stay as 'guests' and not as 'heads' of joint family. It is more of a democratic collective than autocratic; as individual freedom and independence is guaranteed with economic limitations and emotional needs binding them (Ruchismita, 2012). In the case of rich and/or business families' preference for joint families, involving the family members in their business, has increased. The support system and the economic compulsions of keeping the family business intact are the prime reasons. However, the extent of autonomy and democracy may vary from region to region, community to community and caste to caste, depending upon the degree of its adaptation of the modern values and the urban way of life (Mondal, 2016).

\section{Indian family in television serials}

The family is one of the most popular social institutions represented in television serials to depict the social 'reality'. But do television serials construct the notion of 'reality' while fulfilling the features of a dramatic 'theatrical' through their narratives is the question that needs to be answered.

From being a mediator of reality, television has come to construct reality. Television soaps may have created a reality and culture that transformed the idea of an Indian family. The families on the shows may not be realistic, but they do remain relatable to a certain extent although the depiction might take certain liberties with sensational content and larger than life characters and the high drama. The melodramatic component of a television serial within the format of realistic portrayal of families become specific features of serials that condition the treatment of certain issues in contemporary social problems (Geraghty, 1991).

A pan Indian notion of a joint family, upper class, rich and heading huge business empires has become the stereotypical image of Indian families on television, subsuming the diverse cultures represented by different classes, regions, and castes which is the reality. The social representation of a family and the power, authority and status that some members hold, as depicted in soaps, may not necessarily reflect the existing family structures or cultures. However, the soaps continue to hold sway over a majority of viewers who watch the family dramas as they might have accepted the new normal in a dynamic socio-cultural setting.

The television family's depiction of Indian societal values has undergone changes in the last two decades - with a dilemma between modernity and tradition - much like the family systems 
in India. In the ' $80 \mathrm{~s}$, when the early television serials were produced, they were quite different from the regular soaps of the west. The initial serials aired by the public broadcaster Doordarshan were modeled on the Latin American soap-operas which dealt with identity and treatment of social issues. Serials like Hum Log (1984) (We the people) discussed issues of health, schooling, family planning, education and others to which the middle class related. The pro-development television soap-operas were melodramatic serials broadcast in order to entertain and to convey subtly an educational theme to promote development (Singhal and Rogers, 1988). The emergence of Hindutva politics in the ' 80 s later influenced the kind of serials made. Serials made on Ramayan (1986) and Mahabharat, (1988) the two Indian epics became very popular, brought in a new notion of Hindu national identity as distinct from the secular. This was followed by the economic liberalization of the '90s, coupled with the rise of Hindutva, became the predominant factor to hegemonically characterize these notions (Lata, 2016). The socio-economic-political scenario reflected in the changing patterns of storylines, in turn influencing the notions of family, gender, and nation (Lata, 2016). The interplay between tradition and modernity is usually evident in the storylines that deal with child marriages and the stereotypical representation of the Indian women in their familial roles, to which a recent addition has been supernatural mythical tales, however, set in modern urban backdrops like marble mansions and opulent sets and relationship patterns that are modern in their approach.

\section{The mythical and the social institutions in Indian serials}

With TRPs driving the storylines, the latest development in Indian televisions serials is the entry of supernatural elements into family plots. As Lévi-Strauss says, myths have the dual nature of submitting to time and transcending time, which makes it both temporal and atemporal (Casalis, 1974). This serves the purpose of the serials that regularly transcend time by jumping decades and now took a bigger leap of bringing in characters from the world beyond like devils, ghosts, and witches. The myth is a logical tool to overcome contradictions (Casalis, 1974) and the serials have used this 'tool' to overcome the many contradictions that an open-ended program encounters. The introduction of paranormal elements into family settings in the serials has served the purpose of overcoming the limits set by the 'ordinary'. Today, the Naagins, (Snakes) Daayans, (Witches) and Shaitans (devils) are more popular than shows that deal with human beings alone as the paranormal elements symbolize the existence, logic, and justification of some of the beliefs and values within the Indian cultural milieu apart from being interesting. Black magic and witchcraft form part of the 'mythical normality', as such issues, relatable especially in rural areas are part of social reality. People lynched or killed on suspicion of practicing witchcraft and black magic has been reported and form part of the larger symbolic cultural practices even today. So combining a myth (traditional eastern thought of anamnesis of mythical events) within a tale (a western notion of historical time) (Eliade, 1963, p.138) overcomes the limitations of both and acquires their collective strengths. This leads the serials to overcome logic and acquire more freedom and arbitrariness in molding their storyline and characters. As Lévi-Strauss (1976, p.128) says, 'anything becomes possible with myth' making it therapeutic by projecting the hidden social repressions not otherwise visible in the everyday reality.

Just as the werewolves and vampires work in the West, Naag, (snakes) Naagin, (snake woman) tantra, and kala jaadu (black magic), work in India, as both of them demonstrate the cultural variants as per their social understanding of the world. "The fantasy-fiction genre attracts a lot of young viewers, and it takes you away from the mundane. That's why historical and mythological dramas work too. These supernatural elements are part of our culture" according to a television actress (Awaasthi, 2016). As Ekta Kapoor, a famous television producer said, "The target 
audience for all these (supernatural) serials are the rural consumers as the urban youth do not watch Indian television as they are hooked to American fantasy genres like the Twilight series and Game Of Thrones (GOT)" (Awaasthi, 2016). Women and kids in rural households regularly watch the TV shows and the producers and broadcasters cater to this demand. The Broadcasting Content Complaints Council issued an advisory to channels to exercise caution and restraint while airing such shows, as the horror and occult tracks propagate superstition. But channels defend themselves with disclaimers on their shows (Awaasthi, 2016).

\section{Methodology}

Research method of Ethnographic Content Analysis (Altheide, 1987) has been adopted to analyze the top ten Hindi (national language of India) shows based on the viewership ratings as per Broadcast Audience Research Council, India (BARC). Of these, one comedy show was not considered for analysis, as it did not fit into the main theme of family. The other nine are serials running between 2010 and 2016. Ethnography refers to the description of people and their culture (Schwartz and Jacobs, 1979) with in-depth observations of the researcher who forms part of the research tool. Content analysis deals with the objective content of written and electronic documents to verify hypothetical relationships with a positivistic approach. Although television serials reflect exaggerated aspects of culture, they form an integral part of the cultural conundrum of modern societies. As a regular viewer one is drawn into the dilemmas and conflicts of the television family comparable to the 'fly on the wall' as one identifies with the issues. So an Ethnographic Content Analysis is holistic as a methodology as it documents and communicates meanings to verify theoretical relationships where the meaning of a message is assumed to be reflected in various modes of information exchange, format, and style as well as in the context of the text (Altheide, 1987); in this case, television serials. As family forms a cultural unit, it is meaningful for a reflexive study of one particular aspect of culture, which is the family, in the context of Indian television culture. From the detailed viewing of the serials selected, the following themes that recurred were selected for a descriptive analysis: family structures, the power centers within the family and the portrayal of 'good' and 'evil' and the power equations within each serial. The meaning that was communicated of the people involved in the families through their exchange, the format and the context in which the serials were set were described through the analysis. Only the family units and the predominant relations that are visible under each theme were considered but not individual episodes. The top ten serials considered were: Naagin, 2 (Snake Woman Season 2) Kumkum Bhagya, (Vermillon in my destiny) Saath Nibhana Saathiya, (Be with me friend/partner) Naagin, (Snake woman- repeat of previous season), Shakti, Astitva ke Ehsaas ki, (Strength Of Feeling Of Existence) Kapil Sharma show (Kapil Sharma's show), Sasural Simar ka, (Simar's Inlaw's house) Yeh hai mohabbatein, (This is love) Ishqbaaaz (Lovers) and Brahmarakshas (Demon).

\section{Brief storylines of the serials}

1. Naagin 2 (Snake woman): is the story of two sisters who are shape -shifting serpents. The story continues from Season 1. (storyline is described below under Naagin Season 1). The popularity of the supernatural genres is established by the fact that the repeat telecast of Naagin (Season 1) has also found place in the top ten most popular programs with high TRP ratings. This is the first time that a serial is being shown in seasons and not continuously. 
2. Kumkum Bhagya (Vermillion in my Destiny): The show is loosely based on the novel Sense and Sensibility by Jane Austen. Kumkum Bhagya is its Indian interpretation, which follows the life of a Hindu-Punjabi matriarch, Sarla Arora, who runs a marriage hall. Sarla lives with the hope of seeing her two daughters Pragya and Bulbul, happily married some day. The pivotal characters of this show are strong, feisty women, living together in an all-female matriarchal family. The show follows the lives of the two sisters and their hopes, dreams, and aspirations. It takes several twists and turns as one of the sisters Bulbul dies. Pragya a simple serious working girl gets married to Abhi, a rock star. Later on, he loses his memory in an accident and forgets her. His sister and her friend who wants to marry Abhi try in several ways to separate them.

3. Saath Nibhaana Saathiya (Be with me friend/partner): Began telecast in 2010 and is still popular. The series revolves around the fictitious Modi family, who live in a mansion in Rajkot. The show explores morals and family values of a typical Gujarati joint family. Initially, the show focused on the life and arranged marriage of two female cousins (Gopi and Rashi) and their contrasting personalities. Urmila and Jitu adopt Gopi (the latter's niece) after Gopi's parents pass away; she is left illiterate, naive, kind and shy while Rashi, their own daughter, is educated, outgoing, vivacious and cunning. It is the story of how Kokila Modi - the strict, strong-minded mother-in-law of Gopi, transforms the latter into a confident and smarter woman so that she gets accepted by her husband. Rashi tries numerous unsuccessful attempts to create difficulties for Gopi, but, in the end, both cousins get accepted into their families and by their spouses. The storyline took a leap of eight years in February 2014, a further leap of ten years in March 2015, and a final leap of four years in May 2016, which brought in many changes. Saath Nibhaana Saathiya has been made in several different Indian languages. Internationally it airs in Sri Lanka dubbed into Sinhala.

4. Naagin (Snake Woman): The first season of the serial became popular and is having repeat telecast in Season 2 and is in the top ten. This is the story of two shape-shifting serpents, or Ichchhadhari Naagins - Shivanya and her cousin Shesha. They want to avenge Shivanya's parents' death. There were five murderers, but Shivanya sees only three of them: Ankush, Viren and Shailesh. They kill Shivanya's parents in a failed attempt to attain a precious gem called the Naagmani. As part of her revenge, Shivanya enters Ankush's house as a maiden. Ankush's son Ritik, a kind-hearted young man, subsequently falls in love with her. Upon finding out about Ritik's feelings for her, Shivanya marries him for revenge. Later, she kills Viren (the first murderer) and Shailesh (the third murderer); Shivanya and Shesha also kill Ankush's friend, Suri, who is the fourth murderer. Shivanya realises that Ritik is a good person, and eventually falls in love with him, much to the disappointment of Shesha, who thinks that Shivanya won't be able to kill Ankush (second murderer) because of her love for his son, Ritik.

5. Shakti, Astitva ke Ehsaas ki (Strength in the Feeling of Existence): The story is about two sisters, Soumya and Surbhi. Soumya is not liked by her father and grandmother but is adored by her mother. Surbhi gets all the attention from her father. Soumya is a calm and quiet girl, but Surbhi is a fun-loving and loquacious girl. Soumya is shocked to learn that she is transgender and attempts suicide but is rescued by Harman who wants to marry her. But later she learns that she is not a transgender.

6. Kapil Sharma show: This is the only non serial that made it to the top ten. It is a comedy show hosted by Kapil Sharma a standup comedian who invites guests to his show and interviews them. 
7. Sasural Simar Ka (Simar's in-law's house): It tells the story of two sisters, Roli and Simar, who fall in love with two brothers, Siddhant and Prem, and live together as daughters-in-law in the Bharadwaj household. The story takes three leaps. After the first leap, the story revolves around supernatural creatures and evil spirits who come to destroy the Bharadwaj family. The first one is Maya, an Icchadari Naagin (Snake Woman). Then, a Daayan (witch) named Mohini comes to destroy the Bharadwajs. Simar (the heroine) kills the witch. Next, the witch's spirit, Indrawati (who was Simar's sister in her previous life) comes to Simar's house and wants to marry Prem, Simar's husband, but is killed by Simar. Next enters an evil goddess named Patali Devi who comes to take revenge on behalf of Indrawati and Mohini (both witches) from Simar but her spirit is captured in a statue. Devika, a fairy godmother, gives Simar a Chandramani (a precious stone) for her safety from all the evil spirits.

8. Yeh hai mohabbatein (This is love): The show follows the love story of Dr. Ishita Iyer, who is a Tamilian and Ramankumar Bhalla, who is a Punjabi. Ishita is unable to bear a child and so gets emotionally attached to Raman's daughter, Ruhi, who lives with her divorced father. Raman's exwife, Shagun, lives with her boyfriend and Raman's ex-boss Ashok Khanna, along with her son with Raman, Aditya. Bhallas and Iyers are neighbors. Due to circumstances, Raman and Ishita marry each other for Ruhi's custody and gradually fall in love with each other and lead a happy life. The story also takes a leap of 7 years where Ishita conceives but later on misunderstandings between Raman and Ishita leads to their separation.

9. Ishqbaaaz (Lovers): The story is about the lives of a rich business family, the Oberoi family who face difficult and challenging situations from time to time. The family consists of two brothers and their wives. The elder brother Tej has a wife, Jhanvi who is an alcoholic addict, because of Tej's illicit affair with his secretary, Svetlana. Tej and Jhanvi have three children. Their eldest son Omkara is a sculptor and a self-made billionaire but a drug addict. Tej and Jhanvi's second child, Rudra, is a playboy and loves partying but does not believe in marriage. They also have a daughter, Priyanka who is a quiet, sweet and simple girl who has social anxiety disorder. Tej's younger brother, Shakti has a wife Pinky and a son, Shivaay, who is the eldest son and the face of the Oberoi's industry. He is a business tycoon with a strict personality that matches his uncle, Tej. He is arrogant, snobbish and judges people on the basis of their lineage and social status, rather than their personality or work.

10. Brahmarakshas: Jaag Utha Shaitaan (Demon: the devil rises): The story of Brahmarakshas revolves around a young girl Raina who comes to a small village Kamalapura for a wedding, completely unaware of the existence of Brahmarakshas (demon). The demon kills newly married brides who wear the sindoor (vermillon worn in the hair parting) chooda (bangles) and mangalsutra (a chain worn by married women) (all symbols of being married). Raina gets into a contract marriage with Rishabh to fight the demon; later they have differences and separate but Raina continues to fight the evil demon.

\section{Analysis}

The analyses of the serials' formats, the style, and context in which the family is presented elicited certain common features. For instance, all the serials selected except Naagin $1 \& 2$ were aired continuously for the past six years. Unlike the west, the serials do not follow the seasons, but are featured all round the year; so Naagin set a new trend. All the serials followed the long form 
narratives where the stories unfold over the years and generations with leisurely storytelling. The serials are heavily influenced by the Indian film formats of elaborate sets, photographic angles, costumes, heavy dialogues and song $\&$ dance sequences. They all telecast using real-time; festivals coincide with real festivals and other rituals like birth, death, weddings, and poojas performed at home and in temples showcase the traditional Indian family making the viewer an observer as well as a participant. The characters dress in traditional clothes of a particular region the serial represents. For example, in Brahmrakshas (Demon) entire episodes are devoted to the wedding of the protagonist, who is adorned with vermillion, bangles, and chain dressed in red that symbolizes North Indian tradition. The demon kills any newlywed woman attired in red. The spoken language although Hindi, (the national language of India), retains the flavor of the region. For example, if the serial depicts a family from Uttar Pradesh or Gujarat, Hindi with an intonation of that particular province is used. This ensures that while the language is understood widely, the region is also represented. In states (provinces) that do not understand Hindi, the serials are dubbed in the local language. In this sense, television homogenized Indian culture, which in reality exhibits a variety of subcultures. The settings and the visuals represent the lifestyle of the upper middle class/ rich which most families aspire to reach while the plots cater to the rural audiences with storylines based on supernatural beings, to kill or send someone away from the family fold with clearly marked differences between the protagonist and antagonist through dressing, expressions, and dialogues. These serials draw clear distinctions between the urban and rural audiences. The distinction between the wealthy and the rest is also clearly established through the opulent settings, female characters attired in silks, bedecked with jewelry and the males in suits. In all, the settings resembling houses of the rich and famous in India, with the layered plots and the devilish scheming characters that add to the element of melodrama, make up the schema/context of Indian televisions serials. Currently, the majority of the selected serials (7/10) has adopted fantasy elements with supernatural beings becoming part of a modern family. Such elements are introduced from past lives and/or possession by spirits which Indian philosophy steeped in theism and animism find acceptable. Folklores also form an important part of Indian culture, which is now being incorporated in the storylines. A fine balance between tradition and modernity is achieved as the themes deal with social issues, but the settings, characters, and solutions are most often mainstream. For example, in a serial called Shakti, Astitva ke Ehsaas ki (Strength in the Feeling of Existence), a social issue like transgenders and their acceptance in society is taken up, with the heroine being a transgender, but falls back on the majoritarian view, declaring that she is in fact 'normal'. Similarly, Yeh hai mohabbatein (This is love) deals with divorcees and Saath Nibhaana Saathiya (Be with me friend/partner) deals with the importance of adult education although they revert to formulaic narratives in the latter episodes.

The following themes emerged after viewing the data in which the interpretation was more reflexive than objective. This helps to arrive at a theoretical understanding of the meaning in the depiction of family relations in television serials.

\section{Structure of the family}

All the serials selected for the study depict a family unit with stories revolving around family members. From the various characters introduced over the years, and their relationship with the central characters it becomes clear that all families are extended families with two or three generations living together under one roof. For instance, in all serials, there are grandparents, parents, uncles, aunts, and their children- the nephews and nieces- living together. Most television serials portray the rich and the powerful in a joint family. This kind of structure within such genres is important more so to carry the open-ended narratives forward, aired for long intervals of time. 
Interestingly, in recent times, it is found that many of the rich business families in India prefer the modern kind of joint family system where the extended family stays together but there is more involvement of youngsters in decision-making (Prasad et al., 2010), unlike the traditional patriarchal joint family system. In a nation where almost $90 \%$ of the population falls below the poverty line at the global level and only $1 \%$ form the so-called rich or upper-class Indian families (The Hindu, 2017), the television families do not represent an average Indian family. However, the serials form a good basis for the growing aspirations of the middle-income families in India to be part of the privileged society. Keeping with the tradition of women dominating the serials or soaps, it is the matriarch that usually heads the family. The story takes off from the childhood or adolescence of the main protagonist and with all serials taking leaps across years, follow them to their middle age.

\section{The power centers within the family}

A common phenomenon worldwide is the dominance of female characters in television soap-operas. It is the same with the Indian television serials with the dominance of female members unlike the real-life Indian families, which are, in general, patriarchal. One finds that, if the television family is headed by the grandmother, she will be a matriarch, but if it is a man, he is dominated by his wife or daughter-in-law. The plots of the early serials in the '90s and early 2000s, famous for the mother-in-law daughter-in-law skirmishes now shifted to the daughters of the house, with two sisters as their protagonists and/or antagonists typically plotting against her/his sister/brother. This also symbolizes the shifting family structures in India where the domination of the older generation in joint families has decreased. Those in power are the ones who control the rest of the family, be it good or evil. Even the male member falls in line with the dictates of the one in power however unreasonable the behavior might be. For instance, in Kumkum Bhagya, (Vermillion in my Destiny) even though Abhi, husband of the protagonist Pragya is about to get married to another girl due to the machinations of Abhi's sister, (as he loses his memory) no one will stop it or reveal the truth to him, including his wife. Similarly, in Saath Nibhaana Saathiya (Be with me friend/partner), Gopi is the protagonist who is punished with life imprisonment on wrong charges of murder again due to her sister. It is the female who is the power centre in most of the serials like Kumkum Bhagya (Vermillion in my Destiny) where Sarla, mother of Pragya runs a marriage hall; there is Gopi's mother-in-law Kokila who is the matriarch in Saath Nibhana Sathiya (Be with me friend/partner); with Gopi in the next generation. We also have the female serpent-woman who is the center of power in Naagin (Snake woman) while in Brahmarakshas (Demon) it is the heroine Raina who continues to fight the evil. Though there are stories of brothers like Ishqbaaaz, (Lovers) they are in the minority. One can also argue that the supernatural elements in the serials imply the manifestations of the hitherto hidden presence of power and control.

\section{Portrayal of 'good' and 'evil'}

A decade ago, in the 2000s, the 'mother-in-law and daughter-in-law' sagas were popular with the mother-in-law or the sister-in-law personifying 'evil' with all efforts to control and wrest power, while the 'good' obedient suffering daughter-in-law was targeted and tortured. Every serial's plot moves forward only through the struggle between good and evil, more so in Indian television serials where melodrama reigns supreme. There has been a difference in the portrayal of 'good' and 'evil' in the last couple of years in Indian television. The manifestation of evil in humans, apparent in their behavior patterns and exchanges between characters and acts now exhibit a more overt form as supernatural beings. The demons and spirits defy the limitations of the human being. The 
retribution of the evil is no longer easy as the protagonist now has to take on extra-terrestrial beings with supernatural powers. Exorcising the demons made powerful with black magic has become a part of many serials that can find an identity in the rural masses. But the tradition of good winning over evil continues.

Technology has been the key element that made such exposition simple and cost-effective. Even the serials with modern themes initially, veer towards the supernatural after some episodes due to the compulsions of competition and advertisers. For instance, the serial 'Yeh hai Mohabattein (This is love) which began with two divorcees (a progressive theme in India) took off on a tangent with the heroine Ishita becoming possessed with Raman's (her husband) ex-wife, Shagun's spirit after the latter commits suicide. Similarly, in another serial Sasuraal Simar Ka (Simar's In laws' house) various supernatural beings like a snake woman, a witch, and devil were introduced into a normal modern household. Since then, the ratings of the show improved. The latest twist upped the quotient by turning the protagonist, Simar, into a housefly and she gets pregnant with a devil's child. Similarly, in Naagin land 2 (Snake Woman), the heroine who is a shape-shifting snake, takes revenge on her parents' killers. This is the first of the supernatural themes whose popularity spawned serials with similar storylines. With the trend in Hollywood and Bollywood (Hindi films) moving towards aliens and paranormal themes, it is a natural consequence to see more plots and storylines based on such themes. Simultaneously, there has been an increase in the number of mythologicals, with deities and Gods depicting both good and evil, which also embody the magic and supernatural power of superhuman beings, an accepted genre in Indian culture. Further, the present Government in power espouses its ideology with a clear emphasis on the 'rich, ancient Indian culture and tradition', which includes mythologies and the vast pantheon of Gods. This reflects Strauss's argument that the myths and the social structures of kinship are contextual. The text in this instance should be understood within the context of the socio-political trends in society today as well as the cultural milieu of India that dictates the mythical explorations of the serials being aired currently.

\section{Conclusions}

The analysis shows that television families do not necessarily reflect the true Indian family structures as there is a homogenization of the family as a cultural entity. The matriarchal domination, the joint nature of families or their economic class only serve to meet the needs of an aspirational class. However, globalization has had an effect as power centers shifted to those having financial control. With the younger generation becoming the earning members, there has been a change in the real world with the 'nextgen' having a say in family matters. This reflected within the television families with a shift in the focus on the younger generation with access to more power and consequently centers of conflict. The shift towards fantasy and mythology can be attributed to globalization too with ease of access to technology and Hollywood content. Technology is being used in the creativity front while the fantasy elements in the content are Indianised to suit the sensibilities of the Indian audience.

To sum up, the plots and characters within the serials have been defined by the changing profiles of the audience in a changing socio-political atmosphere, from the first serial aired nearly forty years ago until now. Theoretically speaking, the storylines of the television serials can be divided into four phases, which reflect how a common man can identify with a character or a serial identification, aspiration, distinction (Sahu, 2014) and fantasy contextually.

In the first phase, Doordarshan as the public broadcaster was the only source of teleserials, with emphasis on development, featuring middle-class families to discuss issues familiar to 
them. The Indian audience, which believed in the socialist development model, could identify with these serials. Economic liberalization in the '90s brought in the entry of private television channels signaling the beginning of competition to a hitherto monopolistic Doordarshan.

The immensely popular family drama Kyunki saas bhi kabhi bahu thi (Because mother-inlaw was a daughter-in-law once) aired in 2000 heralded the second phase in the history of television serials post liberalization. The characters satisfied the urban middle-class Indian audiences' aspirations to be like the onscreen characters that were modern in a capitalistic society without losing sight of the traditional morality and Indian values. The formula lasted for decades because it put identifiable characters into aspirational settings (Stanley, 2012).

During the third phase, in the latter half of the 2000s, the audience base widened with the penetration of private television market into rural areas and subsequently a rise in regional language channels. The plots of serials being aired changed slightly to suit the changing demographics. The rich business families continued to dominate but the plots began to incorporate the rural rich, set in rural areas. The focus shifted from the bahus (daughters-in-law) to betis (daughters). They dealt with issues like child marriage, female foeticide, widow remarriage, girl education, dowry harassment etc. While the rural audiences could identify with the stories, the urban audiences were curious to see issues distinct from their experiences, which held their interest. By this time, the entry of online media and web access to the urban audiences made television a secondary source of entertainment. The intense competition and the changing audience profiles made the television serials structure their stories to suit them.

The fourth phase has been the introduction of fantasy into the narratives through supernatural beings in modern family dramas, which is reflected in the serials selected for the study. The effects of globalization have not escaped the trends in televisions serials too. As the West is veering towards the supernatural and the paranormal, the Indian films and television serials have not been far in incorporating such themes into family dramas. The plots have introduced elements of the supernatural like witchcraft, black magic, devils, snake women, etc., which are contextualized to suit the Indian audience and the social mores. The rural audiences relate to such paranormal themes as the serials continue to hold their interest showing social fears, stigmas, and beliefs. At the same time, their aspirations are met through the modern settings and rituals based on religious beliefs like festivals and weddings.

Despite the changing plots that accommodate the mythical and the real, the traditional and the modern, the central themes of family-based serials in Indian television remain centered around the family where women dominate the narratives, as they continue to entertain and capture the imagination of a large section of the Indian audience.

\section{References}

1. Altheide, D.L., 1987. Reflections. Ethnographic Content Analysis. Qualitative Sociology, 101(1), pp.65-77.

2. Awaasthi, K., 2016. Supernatural creatures to shape shifting animals: How low will Indian TV go? Hindustan Times, June 30. Available at: $<$ http://www.hindustantimes.com/tv/supernatural-creatures-to-shape-shifting-animals-how-lowwill-indian-tv-go/story-ChpUj1ViP4HwYuTTIgjG4N.html> [Accessed 6 June 2017].

3. Casalis, M., 1974. Levis-Strauss Structural Analysis Of Myths: A Study In Methodology. Southwest Philosophical Studies by New Mexico-West Texas Philosophical Society. Available at: 〈http://nmwt.org/nmwt/?r=article/view\&id=421> [Accessed 18 July 2017].

4. Eliade, M., 1963. Myth and Reality, New York: Harper and Row. 
5. Geraghty, C., 1991. Women and Soap Opera: A Study of Prime Time Soaps. Cambridge, UK: Polity Press.

6. Khan, N. and Nuzhat R., 2015. Urbanization and Its Effect on Joint Family System In India. International Journal on Recent and Innovation Trends in Computing and Communication [online] February. 3(2), pp. 154-6. Available at: < http://www.ijritcc.org> [Accessed 16 July 2017].

7. Lata, K., 2016. Family, Gender And Nation in Indian Television serials. A sociological study of Hindi soap operas. UK: Lambert Academic Publishing.

8. Lecuyer, H., 2013. Soap operas dominate prime-time television in India. Ina Global, 16 May. Available at: <http://www.inaglobal.fr/en/television/article/soap-operas-dominate-prime-timetelevision-india $>$ [Accessed 16 July 2017].

9. Lévi-Strauss, Cl., 1976. Structural Anthropology, Vol II, New York: Basic Books.

10. Mondal, P., 2016. Recent Changes in the Family System in India. Yourarticlelibrary.com. Available at: <http://www.yourarticlelibrary.com/essay/recent-changes-in-the-family-system-in India/30751/> [Accessed 16 July 2017].

11. Prasad, S., Nath, S. and Ramnath, N.S., 2010. Indian Family Businesses. Forbes. 22 October. Available at: < https://www.forbes.com/2010/10/22/forbes-india-indian-family-businesses-turnto-professionals.html $>$ [Accessed 16 July 2017].

12. Rao, S.C.N., 2011. Sociology: Principles of sociology with an introduction to social thought. 6th Edition. New Delhi: S. Chand \& Company Ltd. pp. 353-359

13. Raja, D.J.S., 2014. Actually, the nuclear family is on the decline in India, Quartz India, 1 July. Available at: <https://qz.com/228405/india-is-urbanizing-rapidly-but-the-nuclear-family-isactually-shrinking/ [Accessed 16 July 2017].

14. Ruchismita, 2012. Is the Joint family system in India disintegrating? Preserved articles.com. Available at: <http://www.preservearticles.com/2011111517230/is-the-joint-family-system-inindia-disintegrating-essay.html > [Accessed 17 July 2017].

15. Sahu, S., 2014. Making sense of TV soap operas: a study of audience response. Ph D thesis. Unpublished 26-September. Sodhganga. Available at: http://shodhganga.inflibnet.ac.in/handle/10603/26088 > [Accessed 17 July, 2017)

16. Singhal, A. and Rogers, E.M. 1988. Television soap operas for development in India. Gazette, 41, pp.109-126. Dordrecht: Kluwer Academic Publishers. Available at: < http://utminers.utep.edu/asinghal/Articles\%20and\%20Chapters/JA\%20Singhal\%20\&\%20Rogers \%201988\%20Gazette_R.pdf> [Accessed 6 June, 2017]

17. Stanley, A., 2012. As India's Soap Opera World Turns, Mother-in-Law Always Reigns. The New York Times, 25 December. Available at: 〈http://www.cnbc.com/id/100339141> [Accessed 6 June, 2017].

18. Schwartz, H. and Jacobs, J., 1979. Qualitative Sociology. New York: The Free Press.

19. ***indiatimes.com 2017. Why joint families are back in urban India? Times of India, 16 July. Available at: <http://timesofindia.indiatimes.com/home/sunday-times/why-joint-families-areback-in-urban-india/articleshow/59614752.cms > [Accessed 7 June 2017].

20. ***The Hindu, 2017. Richest $1 \%$ own $58 \%$ of total wealth in India: Oxfam. PTI. Davos, 16 January. Available at: 〈http://www.thehindu.com/business/Economy/Richest-1-own-58-of-totalwealth-in-India-Oxfam/article17044486.ece> [Accessed 8 December, 2017].

21. ***KPMG India - FICCI, 2016. The Future: Now Streaming. Media and Entertainment Industry Report. Available at: <https://home.kpmg.com/content/dam/kpmg/pdf/2016/04/The-Future-nowstreaming.pdf $>$ [Accessed 7 June 2017]. 
22. ***KPMG India - FICCI, 2017. Media for the masses: The promise unfolds. Media and Entertainment Report. Available at: 〈https://assets.kpmg.com/content/dam/kpmg/in/pdf/2017/04/FICCI-Frames-2017.pdf> [Accessed 8 June 2017]. 


\title{
The Family and National Development: How can the Family Forestall Future Insurgency Activities in the Nigerian Society?
}

DOI: http://doi.org/10.26758/8.1.23

Yinusa Mohammed (1), Oluyemi Joseph (1), Bashiru Salawu (1), Abdulateef Raji (1), Emmanuel Atolagbe (1), Adejoke Joseph (2)

(1) Department of Sociology, University of Ilorin, Ilorin, Nigeria

(2) Department of Medical Microbiology and Parasitology, Bowen University, Iwo, Nigeria.

Address correspondence to: Joseph Oluyemi, Department of Sociology, Faculty of Social Sciences, University of Ilorin, Kwara State Nigeria. Phone number: +234/018034205013. Email: josepholuyemi1@gmail.com

\begin{abstract}
Objectives. This study investigated the factors responsible for the Boko-Haram insurgency activities in North Central Nigeria, and how the family could help to forestall future occurrence of insurgent activities as an institution of change in the society.

Materials and Methodology. The study was conducted in Ilorin, headquarters of Kwara State North-Central region of Nigeria. 20 participants selected through purposive sampling method were included in the study. Information was retrieved through in-depth interviews with key informants while the study was explained by attachment and Social Control theories.

Findings. Results showed that poor parental training, poor parental values, poor parental care and poor parental monitoring and guidance are responsible for the involvement of children in insurgency activities in the region. However, child education, proper child upbringing, parent-child closeness, proper parental monitoring and parents being good examples to their children were suggested in the study as measures that could be put in place to forestall future occurrence of insurgency activities in Nigeria.

Conclusion and Recommendation. The study concluded that the role of the family in maintaining order in the society cannot be overemphasized and as such, parental attachment and control is imperative in the family. It, therefore, recommends that, in order to forestall future occurrence of insurgency activities in Nigeria, it is necessary for families to ensure that child-parent attachment and emotional support in the family is not lacking so that individuals do not become miscreants in the society and tools used by deviants to disrupt national development in the Nigerian society.
\end{abstract}

Keywords: parental closeness; parental monitoring; parental values; poor parental care; child education.

\section{Introduction}

National development, which is defined as the gradual manifestation of positive changes in the economic, industrial, political social, cultural and administrative life of a country (Ogai, 2007), is imperative to the continued existence of any society. However, the family, which is the cornerstone and the basic unit of social organization of the society, which carries out a vital task like socialization of the children, has a major role to play in ensuring that this role is played. Although 
no single definition of "the family" captures the many forms of family units around the world, The U.S. Census Bureau (2001) has defined the family as that which includes a householder and one or more people living in the same household who are related to the householder by birth, marriage, or adoption while the Population Reference Bureau (2000) described the family as a group of people held together by birth, marriage, or adoption or by common residence or close emotional attachment (Patterson, 2002).

However, in Africa, the family is seen in another dimension, more as an extended family comprising of a married couple, their offspring and immediate kith and kin-brothers and sisters of the bride, groom and the parents, relatives, in-laws and any other dependants (Nwobi, 1997). The family has been said to provide several important functions for society, some of which include: family formation, economic support, nurturance, and socialization, as well as protection of vulnerable members (Shaffer, 2000). Yet, despite this, it is sad to note that, many of the miscreants in the Nigerian society were born into one family or another. The Nigerian society recently is witnessing a high level of moral decay and there is an implosion in the number of youths and adolescents exhibiting anti-social and immoral behaviors (Nwosuji, 2008) causing a drastic change in the quality and quantity of relationships in the family (Ziehl, 2003).

Nigeria is faced with many inherent social problems, but in recent years the Boko Haram insurgency seems to be one of the most problematic issues that threaten the economic, political and social development of the country. The insurgent group whose official name is Jamā'atu Ahli'sSunna li'd-Da'wati wa'l-Jihād (an Arabic name that means Society of Adherents to the Prophet's Teachings Committed to the Propagation of the Faith and Jihad) was established in Maiduguri, the capital of Borno State Northeast Nigeria (Chothia, 2014) and has brought widespread insecurity to many parts of the region thereby threatening national development in the country. The lingering poverty in the country has caused many of Nigerian citizens to engage in social violence. Those Almajiri (child pupil) who are scattered all over the streets in northern Nigeria begging for alms (Shettima, 2009), are recruited to join Boko Haram and engage in violent aggression and other social and criminal activities of Boko Haram of suicide bombing. Many of these attacks have brought a serious paralysis to business activities in the region (Okereocha, 2012), leading to economic backwardness and consequently an increase of poverty, unemployment, insecurity, and failure of the sustainable human development (Shehu, 2015).

For almost a decade now, over 13,000 people have been killed while thousands of others have been displaced from their families especially in the northeastern region of the country the home of the sect (Shuaibu and Saleh, 2015), in a bid to flee for their dear lives. The question is, therefore: are not these individuals born into families with parents and significant others? The underlying assumption of the research is that a vacuum has been created by the family as a primary agent of socialization with the task of imbibing in children norms and values imperative to the development of their personality in order to help them contribute their quota to the peaceful coexistence of the society. It is against this backdrop that this study is been conducted.

\section{Theoretical Orientation}

\section{Attachment Theory}

Attachment theory was propounded by John Bowlby in 1969. The central focus of the theory is on the dynamics of long-term interpersonal relationship between people. According to Bowlby (1969), attachment begins in infancy and continues throughout the lifetime of a person. The theory proposed that an infant needs to develop a relationship with parents that will enhance the child's successful social and emotional development and in particular for learning how to effectively 
regulate their feelings. This attachment will create a bond between the child and parents, which will eventually pattern their relationship as the child grows in life.

Resting on the propositions of this theory, this study can be explained on the premise that, when a bond is formed between either the father or the mother and the child at infancy, such bond will develop into a form of intimacy, resulting into trust and cordial communication between parents and the child. This closeness is therefore expected to help children avert immoral behaviors and normlessness because parental closeness with the child may allow for proper socialization of the child by the parents in whom good moral values are inculcated into the children by the parents.

Attachment theory was however criticized for over blaming parents for what becomes of a child, bearing in mind that peer groups and environment have an equal influence on his evolution.

\section{Social Control Theory}

The social control theory of Iva Nye (1958) proposes that the process of socialization and social learning builds self-control and reduces the inclination to indulge in behavior recognized as antisocial. The theory postulates that-social control may come in the form of direct enforcement in which punishment is threatened or applied for wrongful behavior, while compliance to lay down rules is rewarded by parents, family and authority figures.

Building on this theory in explaining normlessness among children recruited into the Boko Haram insurgency group, it is assumed that if proper parental control is exerted on children, they would not be involved in such social vices, or this possibility would be considerably diminished.

Normlessness can be controlled directly by giving children standing rules, monitoring the kind of friends they associate with and staying out late or for a long time, and applying punishments when children deviate from them. This will serve as a deterrent to them and would avert future occurrence. It is also expected that if a child is aware that he/she will be punished for deviating from parental rules, there is an increased possibility that he/she would be willing to conform to such rules.

\section{Materials and Methodology}

This study was conducted in Irewolede area of Ilorin, headquarters of Kwara State, located in north-central Nigeria. The slogan for the State is "State of Harmony" because of the relative peace that is particular to the state and is being enjoyed by its inhabitants, thus serving as a refuge for many Nigerians seeking to reside in a peaceful environment. The city has was purposely selected for the study because of the relative peace that is being experienced in the State, which is the exact opposite of what entails in Maiduguri, the seat of the Boko Haram insurgence, so as to explore the factors responsible for the peace as it relates to the family when comparison is done and to determine how future insurgency activities in the region can be forestalled.

20 male family-heads, sixty years and above from diverse socio-economic backgrounds were purposively selected for the study. Although socialization of children in the family lies with both parents, male heads were selected for the study because, Nigeria is mainly a patriarchal society (Duze and Mohammed, 2006) in which family headship lies with the male. The families that were involved in the study have been able to raise their children successfully, reporting no cases of miscreants among them or anyone of the children as issues to the society. The qualitative method of inquiry that was used included an exploratory and explanatory case study approach to reveal the vacuum that has been created by the families in which members of the insurgent groups were born into. 
The particular choice of a qualitative approach was dictated by the intention to gain insight into how the family could help in curbing insurgency activities in Nigeria. Information was retrieved from participants through unstructured in-depth interviews. Informants' consent was sought before the interview was conducted and informants' identities were treated with anonymity to gain the informants' confidence. In order to protect the confidentiality of the informants, the identities of the informants were indicated solely by their age and occupation in the society.

\section{Results}

\section{How has the family been able to contribute to Boko Haram Insurgency in Nigeria?}

Participants in the study had varying views about how the family has contributed to the insurgency activities of the Boko Haram Sect in Nigeria. The following were some of the factors enumerated by the participants.

\subsection{Poor Home Training}

Many of the participants emphasized on lack of home training as a determining factor enhancing the participation of individuals from many families in the Boko Haram activities in the country. Some participants have this to say:

"As a Christian, the bible says we should train up a child in the way he should go and when he grows old he will not depart from it. When you don't train a child with the right morals, and instill the right values in him, especially at the formative stage, you can rest assured that the child will be a serious concern to the society. I believe children in the region where insurgency activities are happening are not adequately trained and as such it is easy for them to be recruited into insurgency groups" (medical doctor, 65 years).

Somebody else has something similar to say, listen to this:

"Normally, a child that is well trained from home and has the right value instilled into him/her will not likely be involved in unruly activities in the society. This entails the fear of God, the fear of elderly ones and the fear of the people around you. I believe whoever loves his fellow neighbor will not be involved in the killing of his neighbor" (petty trader, 62 years).

\subsection{Poor Parental Values}

Another issue mentioned by the participants in the study is that of the poor parental values among many parents in the families in the region where insurgency occurs. Some of the participants have this to say:

"I believe some parents themselves in this region where Boko Haram activities are predominant lack the right values and so they cannot pass the right values to their children. Many of them are not educated so do not know their right from their wrong. For example, many uneducated men in the region marry many wives and also give birth to so many children that they cannot fend for then what you expect from such a place" (retired civil servant, 66 years). 
In the same vein, another participant has this to say:

"Children who engage in insurgent activities don't know what they are doing, it is what they are asked to do that they do. The trouble starts with the parents; they are not performing their duties as parents. The question is that, do these parents know what is right from what is wrong? You can only give what you have; a parent that does not possess the right values cannot pass the right values to the child" (farmer, 62 years).

Another participant has something to say in line with this view, take a look at this:

"Of course.... It is mandatory that parents with wrong values will pass such values to their children. There is an adage that says, it is the thread that a mother pulls that the child will use. The bible also says that everything produces after itself. So if a father is a drunkard or promiscuous, there is every probability that children from such parent will produce such traits" (clergy, 68 years).

\subsection{Poor Parental Care}

Another family-related factor identified by the participants in the study as contributing to the insurgency activities in this region is poor parental care. The following are some of their submissions:

"Many of the parents from the families in which these children belong did not perform their duties as parents. I believe it is because parents from this region did not give their children adequate care, that is why these children give themselves up to Boko Haram" (artisan, 61 years).

Another participant has something similar to say, hear this:

"Well...it is because parents in this region do not cater for their children that is why many of them engage in unruly activities and join bad groups. There is an adage that says that to lose your child to death is better than the child being lost. In many families in this region, parents do not care about their children; whatever becomes of the child is the child's problem, and parents are not bothered about this. Early in the life of a child, he is given out by parents to their religious mallams who engage them in begging for alms and other derogatory activities which makes it easy for insurgent groups such as Boko Haram to recruit them" (businessman, 71 years).

\subsection{Poor Parental Monitoring and Guidance}

On parental monitoring, a participant has this to say:

"I believe the parents of these children have a fault in monitoring their children. The children are not adequately monitored by their parents, especially in the formative years of their lives. In a case where a man has many wives and many children whom they cannot cater for or even believe they are responsible for. Many of those children will lack parental guidance, and would not have someone they fear who can serve as a guide for them" (educationist, 69 years).

Similarly, another participant has this to say:

"Most of these children are not adequately guided especially in their childhood. I once lived among them and sometimes I ask myself, where are their parents. When they get to the age of 7 or 8 they 
are given out to the streets to go and beg for alms so as to sustain themselves. Many of these children do not have any form of address. In fact, whenever there is uproar anywhere they are the ones who are always used in such occasion. So they have no parental guidance a large number of them are people of no fixed address, so they don't really bother what is the consequences of their actions" (retired teacher, 64 years).

\section{How can the Family help to forestall future insurgency activities in Nigeria?}

Diverse opinions were given by the participants on what can be done by the family to forestall future occurrence of insurgency activities in Nigeria. These are some of their opinions.

\subsection{Child Education}

The need for proper and adequate education of the children was seriously emphasized as a measure to curbing the menace of insurgency activities in Nigeria and therefore ensuring national development in the country. For example, this participant has this to say:

"... Lack of education among the people in this region where insurgency activities occur is what causes this problem. It is therefore important that parents should give their children an adequate education. Once their parents give them the right education, the issue of insurgency will be a thing of the past" (lawyer, 66 years).

Similarly, another participant equally stressed the need for a proper and adequate education of children in the family as a way the family can help curb insurgency activities in the country. Listen to this:

"In order for Nigeria not to continue to witness insurgency activities in the country and to avoid trouble in the country every day, it is important for parents to take the issue of child education seriously. They should give their children a proper education. If this is done, the children will not grow up to become miscreants and menace to the society because they will be able to know what is good for them and how to plan their future" (lecturer, 64 years).

In the same vein, another participant has this view about education. Take a look at this:

"... Well, my advice to parents and families in this region is that they should allow these children to be sufficiently educated. Education is a liberator, if these children are given the needed amount of education, they would be able to see the weaknesses in their culture, the one they know would be too retrogressive for them to fulfill their destiny, and they will discard and encourage the one that will take them to where they desire to be in life. So education could be very costly, but the end result cannot be underestimated. If those children have decent and good education, there is every likelihood that their eyes will be open; nobody will just gather them in one corner and give them the wrong ideology that will be detrimental to their lives, destiny and the society at large. Therefore, no matter what the cost is, parents should invest in the education of their children" (retired teacher, 67 years) 


\subsection{Proper Child Upbringing}

Another way the family can help forestall future insurgency activities as enumerated by the participants in the study is to give children a proper upbringing as they grow up in life especially at the formative stage of their lives. Hear what this participant has to say:

"The role of the family in raising the child cannot be overemphasized. The family is a key to ensuring that children behave properly in the society by giving them the right orientation from childhood. I believe if children in the families in this region are given the right orientation especially during their formative years, they may not likely derail from them when they grow up in life" (businessman, 69 years).

Similarly, another participant has this to say:

"The way we behave in the society is a function of our upbringing in the family we are born into or raised. Even when the children come under peer pressure, and they have had a good upbringing in their formative stages in life, at that point that child will remember that, given whom I am, I cannot be involved in the wrong unruly behaviors. So if they have the right orientation from childhood, they are not likely to depart from it when they grow up" (trader, 66 years).

In the same vein, another participant has this to say:

"There is no doubt about it; many of the children who engage in insurgency activities in this region are not well brought up by their parents. I believe if the family over there can cooperate together and raise these children, they will be better children in society. Families should also give birth to children that they can afford to raise and bring up properly. The belief that God gives children and takes care of them should be seriously discouraged. People should only give birth to children that they can afford to raise rather than having children like chicken and leaving them for the society to cater for them and in the process exposing them to joining bad groups such as Boko Haram" (businessman, 71years).

\subsection{Parent-child Closeness}

Further findings from the study suggested that parental closeness with children could help forestall future insurgency activities in Nigeria. The following participants have these to say:

"From childhood, parents should create a bond with their children by ensuring that they are close to them. When parents are close to their children, children are likely not to be wayward. For instance, since my children were small, my wife and I were close to them, we read the Bible together, we prayed together and did many things together which they were able to pick from us and became part of them, which is instrumental to their success today. Children must be close to their parents; they must eat together, talk together, play together and laugh together. This will, therefore give them the opportunity to know the type of company they keep and once they want to start going wayward, it will be easy for their parents to detect and quickly address the situation. But when parents are not close to their children, they may be following the wrong company which the parents may not have the knowledge of" (retired civil servant, 66 years). 
Another participant has something similar to say, take a look at this:

"I will advise parents to be close to their children. Parental closeness to children will go a long way in curbing insurgency activities in Nigeria if this can be adopted by families in the country. For instance, I am very close to my children, I know all their friends and I scrutinize them even at their formative stages, this helped them as they grow up in life to become responsible children who are worthy of emulation" (businessman, 69 years).

\subsection{Proper Parental Monitoring}

A number of participants in the study stressed the need for parents to monitor their children as a measure that could be adopted in curbing insurgent activities in Nigeria. One of them has this to say:

"I believe when parents monitor their children properly, they will be able to check them early from unruly behaviors before it gets out of hand. My children, for instance, know I am a no-nonsense type, although I never beat anyone of them, but they distinguish what I want from what I don't want. I give them red lines that they must never cross, I don't joke with their academics, moral behaviors and their social behaviors and, of course, they know that they have to protect the name of the family by behaving well in the society. I am a close monitor father, when I see things with my children that are beyond what the family can afford, I query them so they know me from the world go that I will not take nonsense" (artisan, 61 years).

\subsection{Parents Being a Good Example to their Children}

Some of the participants emphasized the need for parents to lead by example. According to them, this would help the children to emulate the right values, which their parents try to imbibe on them. The following are some of the views of the participants as regards this:

"It is one thing to say a thing; it is another thing to do it. Many parents only tell their children what to do without them doing those things. The values most parents instill in their children are quite different from their own behavior. For instance, my wife and I are serious about our faith, we lived out our faith before our children and we taught them the Christian way and by the Grace of God, our children have tolled that path. So, whatever we do at home and in the larger society was geared towards our Christian faith and that was what our children also emulated, which by God's grace has helped them till today. So what parents do most times speak louder than what we say. By the Grace of God we didn't tell our children to do the right thing and then we do the wrong thing. Doing the right thing may be costly, but I think if parents learn to do what they preach to their children, our society will be a better place for us to live in" (medical doctor, 65 years).

This view is also in line with the view of this participant; hear what he has to say:

"I can say that, by the kind of life that I and my wife lived before our children, they have been able to emulate the right values from us, which has made them good children today. During their high school days, I specifically told them, never you ask for any help from anybody in any examination and never give such help because it will only help such people to deceive their world. And as a result of that, they never cheat on anyone or but only depend on what they could write in the examination hall and I, as their father, have never also had any reason to cheat in any examination from my elementary school to the time I graduated from the university. So it is not only enough for 
parents to instill the right values on their children but also to live by such examples" (retired teacher, 67 years).

\section{Discussions}

The study has been able to explore the contribution of the family to insurgency activities in Nigeria and how the family can help forestall future insurgency activities in Nigeria. One of the ways the family has contributed to these activities that were mentioned in the study is poor home training for the child. This result corroborates to the findings of Adnan, Arifin and Borhan (2014), in their research conducted on barriers to the moral development of children and parental responsibility. The finding also aligns with the view of Ismail (2014), who blames, for the insurgency activities, the prevailing almajiri system in the region and the inability of some parents to give their children adequate care and morals necessary to counter deviant behaviors.

Another way the family has been able to contribute to the insurgency activities in northeastern Nigeria is through poor parental values. This finding is in tandem with the research conducted by Jaccard et al. (1996) and Miller et al. (1999) on the significant effects of parental values on children behavior. Furthermore, insurgency activities in the region were also attributed to poor parental care prevalent in the region. This is also supported by the study carried out by Neema et al. (2006), which showed a relationship between children behavior and the emotional support provided by parents in the formative years of the child. This also validates the outcome of research conducted by Ngom, Magadi and Owuor (2003), which found that children living apart from parents and guardian represent a significant risk factor for the deviant behaviors.

At the same time, the problem of poor parental monitoring and guidance was also highlighted by the participants. This rests on similar result found in a cross-sectional and longitudinal study conducted by Romev et al. (1999), which found a significant relationship between parental monitoring and children negative behaviors. This also agrees with the study conducted by Diclemente, Crosby and Wingood (2002), which found a positive relationship between a lower level of perceived parental monitoring and several risky behaviors among children.

Nevertheless, one of the most important and efficient measures mentioned in the study on how the family can help forestall future insurgency in Nigeria is child education. This corroborates to the view of Rogers (2012), who opined that lack of adequate education is instrumental to the prevailing terrorism in the region. This finding is also in line with the view of Durotoye (2015) who asserted that lack of access to adequate education is one of the major causes of Boko Haram insurgency in the country. The focus of the participants on the role of proper upbringing in curbing the future occurrence of insurgency activity is similar to that of Hardon (1998) on the importance of family upbringing upon child development, resilience, and behaviors.

Furthermore, parental closeness was emphasized as imperative to curbing future insurgency in Nigeria. This confirms the conclusions of Neema et al. (2006), which showed a link between the emotional support that parents provide for children and delinquent behaviors. In addition, another measure that the family can put in place in curbing insurgency in Nigeria that was mentioned in the study by participants is proper monitoring and guidance by the parents. This rests on the views of Adewunmi, Olojo and Falemu (2012), who opined that the role of a parent to a child at any given time couldn't be overemphasized. This finding is also similar to the views of Wamoyi et al. (2011), on their study on parental control and monitoring of young people's behavior.

Finally, parents were advised to be good examples to their children, as this will go a long way in curbing insurgent activities in the country. This recommendation corresponds with the views 
of Geramian et al. (2012), who suggested that the influence of parental values on children behaviors couldn't be overemphasized.

\section{Conclusion}

This study investigated the family-related factors responsible for the Boko-Haram insurgency activities in the Nigerian society and how the family could help to forestall future occurrence of such activities as an institution of change in the society. The study was conducted in Ilorin, headquarters of Kwara State, North Central Nigeria. 20 participants that were selected through purposive sampling method were included in the study while information was retrieved through in-depth interviews with key informants.

Findings showed that poor parental training, poor parental values, poor parental care and poor parental monitoring and guidance are responsible for the involvement of children in insurgency activities in the region. However, child education, proper child upbringing, parent-child closeness, proper parental monitoring and parents being good examples to their children were suggested in the study as measures that could be put in place to forestall future occurrence of such activities.

The study concluded that insurgency activities of the Boko Haram sect in the country are also facilitated by the lack of parental attachment in the family and that children from such families are prone to become juvenile delinquents and deviants to the society. The study recommends improved child-parental attachment and emotional support for the child in the family to prevent them from becoming deviants in the society and being used as tools to disrupt National development.

\section{References}

1. Adewunmi, M.G., Olojo, O.J., and Falemu, F.A, 2012. Roles of parent on the academic performance of pupils in elementary schools. International Journal of Academic Research in Business and Social Sciences, 2(1). Available at: http://www.hrmars.com/admin/pics/487.pdf. [Accessed 31August 2017].

2. Adnan, A.R., Arifin, M., and Borhan, I., 2014. Barriers to Moral Development of Adolescents and Parental Responsibility: The Case of Malay Working Parents. International Journal of Humanities Social Sciences and Education, 1(6), pp.40-48. Available at: https://www.arcjournals.org/pdfs/ijhsse/v1-i6/6.pdf. [Accessed 30 August 2017].

3. Aguilar, T., 1999. Families of the New Millennium. Available at: http://www.prb.org/pdf/definingfamily.pdf. [Accessed 18 July 2017].

4. Aina, I.O., 1998. Women, culture and Society in A. Sesay and A.Odebiyi, eds. Nigerian Women in Society and Development. Ibadan: Dokun Publishing House/INTEC, pp.3-33

5. Anyadike, I. and Nkechi, O 2013. Boko Haram and National Security Challenges in Nigeria; Causes and Solutions. Journal of Economics and Sustainable Development, 4(5), pp 2222-2855.

6. Awogbenle, A.C. and Iwuamadi, K.C., 2010. Youth Unemployment: Entrepreneurship Development Programme as an Intervention Mechanism. African Journal of Business management, 4(6), pp.831-835.

7. Baumrind, D., 1991. The influence of parenting style on adolescent competence and substance use. Journal of Early Adolescence, 11(1), pp.56-95.

8. Bowlby, J., 1969. Attachment and Loss, Vol.1: Attachment. New York: Basic Books. 
9. Christian, L.G., 2006. Understanding families: Applying family systems theory to early childhood practice. Young Children, 61(1), pp.12-20.

10. Chothia, F., 2014. Who Are Nigeria's Boko Haram Islamists? BBC NEWS AFRICA, 20 May, Available at: http://www. bbc.com/news/world-africa-13809501.

11. Diclemente, R.J, Crosby, R.A, and Wingood, G.M., 2002. Enhancing STD/HIV prevention among adolescents: the importance of parental monitoring. Minerva pediatrica, 54(3), pp.171-7.

12. Durotoye, A., 2015. Economic consequences and management of Boko Haram insurgency in Nigeria, International Journal of Economics, Commerce and Management, 3(6). Available at: http://ijecm.co.uk/wp-content/uploads/2015/06/3675.pdf [Accessed 31 August 2017].

13. Duze, M.C. and Mohammed, I.Z., 2006. Male Knowledge, Attitude, and Family Planning Practices in Northern Nigeria. African Journal of Reproductive Health, 10(3) [online] Available at: https://www.ajol.info/index.php/ajrh/article/view/7899. [Accessed 30 August 2017].

14. Enrique, J., Howk, H., and Huitt, W., 2007. An overview of family development. Educational Psychology Interactive. Valdosta, GA: Valdosta State University. Available at: http://www.edpsycinteractive.org/papers/family.pdf. [Accessed 18 July 2017].

15. Geramian, N., Akhavan, S., Gharaat, L., Tehrani, A.M., Farajzadegan, Z., 2012. Determinants of drug abuse in high school students and their related knowledge and attitude. Journal of the Pakistan Medical Association, 62(3 Suppl 2), S.62-6. Available at: http://eprints.skums.ac.ir/id/eprint/5942 [Accessed 21 August 2017].

16. Hunter, J.E. and Schuman, N., 1980. Chronic reconstitution as a family style. Social Work, 25(6), pp.446-451.

17. Ismail, A., 2014. Panacea to Boko Haram Insurgency in Nigeria. The Nigerian Voice, 27 June, Available at: https://www.thenigerianvoice.com/news/150954/1/panacea-to-boko-haraminsurgency.html. [Accessed 30 August 2017].

18. Jaccard, J., Dihus D.J., \& Liturdo H.A, 1996. Parent adolescent communication about sex and birth control: Implication from parents based interventions to reduce unintended adolescent pregnancy. In: L.J Severy, W.B., Miller and L., Severy, eds. Advances in population. Psychological perspective, Vol. 3. London: Jessica Kingsley Publishers.

19. Kester, K.O., 2012. National Economic Transformation: Issues, Perspective and Challenges. A paper presented at the $10^{\text {th }}$ National Conference of the School of Arts and Social Sciences, Federal College of Education, Osiele, Abeokuta, Ogun State, Nigeria, $21^{\text {st }}-25^{\text {th }}$ May, 2012.

20. Miller, W.B., Pasta, D.J., Mac-Murry, J., Chiu, C., WU, H. and Coming, D.E, 1999. Dopamine receptor genes associated with age at first sexual intercourse. Journal of Biosocial Science, 31(1), pp.43-54.

21. Muhammad, A.P., and Joel, S 2012. Africa's Growing Giant - Population Dynamics in Nigeria. Population Dynamics in Muslim Countries pp 211-224. Available at: https://link.springer.com/chapter/10.1007/978-3-642-27881-5_13. [Accessed 30 August 2017].

22. Neema, S., Ahmed. F.H., Kibombo. R., Bankole, A., 2006. Adolescent sexual and reproductive health in Uganda: Results from the 2004 Uganda national survey of adolescents (Occasional Report No 26). New York: Guttmacher Institute.

23. Ngom, P., Magadi, M.A., Owuor, T., 2003. Parental presence and adolescent reproductive health among the Nairobi urban poor. Journal of Adolescent Health, 2003, 33(5), pp.369-377.

24. Nwobi,P.C., 1997. Marriage and Family Counselling. Enugu: Pan Africa Publishers.

25. Nwosuji, E., 2008. The role of husband \& wife in contemporary Nigeria society. Available at: http://nigsocioculture.blogspot.ro/2008/08/role-of-husband-wife-in-contemporary.html [Accessed 19 July 2017]. 
26. Nye, F.I., 1958. Family relationships and delinquent behavior. New York: Wiley; London: Chapman \& Hall.

27. Ogai, J.O., 2007. An Analysis of the concept of Development and Underdevelopment in Communication National Development. Available at: http://martinslibrary.blogspot.com/2014/05/the-meaning-and-concept-of-national.html. [Accessed 24 July 2017].

28. Ogunlesi, T., 2014. Nigeria overtakes South Africa to become Africa's largest economy. The Guardian, 7 April. Available at: https://www.theguardian.com/world/2014/apr/07/nigeria-southafrica-largest-economy [Accessed 30 August 2017].

29. Okereocha, C., 2012. Heartache for the Economy. TELL, May 14, pp. $46-47$.

30. Patterson, J.M., 2002. Understanding family resilience. Journal of clinical Psychology, 58(3), pp.233-246.

31. Rogers, P., April 3, 2012. Nigeria: the generic context of the Boko Haram Violence. Monthly Global Security Briefing, 30 April. Available at: http://www.oxfordresearchgroup.org.uk/sites/default/files/AprEn12.pdf. [Accessed 31 August 2017].

32. Romer, D., Stanton, B., Galbraith, J., Feigelman, S., Black, M.M., Li, X., 1999. Parental influence on adolescent sexual behavior in high poverty setting. Archives of pediatrics \& adolescent medicine, 153(10), pp.1055-62.

33. Shaffer, D.R., 2000. Social and personality development (4th ed.). Belmont, CA: Wadsworth.

34. Shehu, S. 2015. The impact of Boko Haram on Nigerian national development. In: Universiti Sultan Zainal Abidin, Malaysia, International Conference on Empowering Islamic Civilization in the $21^{\text {st }}$ Century. Kuala Lumpur, Malaysia, 6-7 September 2015. Available at: https://www.unisza.edu.my/icic/images/Fullpaper/06___Sani_Shehu.pdf. [Accessed 24 July 2017].

35. Shettima, A.G., 2009. The Almajiri syndrome: A response to General Babangida. Available at: http://www.amanaonline.com/Arti cles/Shettima/Shettima_30.htm [Accessed 24 July 2017].

36. Shuaibu, S.S. and Saleh, M.A., 2015. Historical evolution of Boko Haram in Nigeria: causes and solutions. In: Universiti Sultan Zainal Abidin, Malaysia, International Conference on Empowering Islamic Civilization in the $21^{\text {st }}$ Century. Kuala Lumpur, Malaysia, 6-7 September 2015. Available at: https://www.unisza.edu.my/.../Fullpaper/20_-_Salisu_Salisu_Shuaibu.pdf [Accessed 30 August 2017].

37. von Bertalanffy, L., 1968. General System Theory: Foundations, Development, Applications. New York: George Braziller.

38. Wamoyi, J., Fenwick, A., Urassa, M., Zaba, B. and Stones, W., 2011. Parental control and monitoring of young people's sexual behavior in rural North-Western Tanzania: Implications for sexual and reproductive health interventions. BMC Public Health (online), 11:106. Available at: https://bmcpublichealth.biomedcentral.com/articles/10.1186/1471-2458-11-106 [Accessed 31 August 2017].

39. Ziehl, S.C., 2003. Forging the links: Globalization and family patterns. Society in Transition, 34(2), pp.320-337.

40. ***International Crisis Group. Curbing Violence in Nigeria (II): The Boko Haram Insurgency. Report No.216 / AFRICA. Available at: https://www.crisisgroup.org/file/1094/download?token=Ybn0wuzJ [Accessed 30 August 2017].

41. ***IRIN (Integrated Regional Information Networks), 2013. Updated timeline of Boko Haram attacks and related violence, 12 Dec. Available at: 
http://www.irinnews.org/report/99319/updated-timeline-of-boko-haram-attacks-and-relatedviolence [Accessed 23 July 2017].

42. ***National Consortium for the Study of Terrorism and Responses to Terrorism, a Department of Homeland Security Center of Excellence led by the University of Maryland, 2014. Boko Haram recent attacks (START Background report). Available at: http://www.start.umd.edu/sites/default/files/files/STARTBackgroundReport_BokoHaramRecent Attacks_May2014_0.pdf [Accessed 29 August 2017].

43. *** Population Reference Bureau, 2000. Conveying concerns: Women report on families in transition. Available at: https://www.popline.org/node/242558 [Accessed 31 August 2017].

44. ***U.S. Department of State, 2014. Country reports on terrorism 2013. Available at: https://www.state.gov/documents/organization/225886.pdf [Accessed 30 August 2017].

45. ***U.S. Census Bureau, 2001. Census 2000 Profiles of General Demographic Characteristics. Available at: http://www.census.gov/prod/cen2000/doc/ProfilesTD.pdf. [Accessed 18 July 2017].

46. ***Voice of America, 2014, Boko Haram Claims Lagos, Abuja Attacks. VOA News, 14 July. Available at: http://www.voanews.com/content/boko-haram-claims-lagos-abujaattacks/1956928.html. [Accessed 23 July 2017]. 


\title{
Literati's Health and Illness as Metaphors of the Reflections to the Modernity in the $19^{\text {th }}$ - century Hungarian Intellectual History
}

DOI: http://doi.org/10.26758/8.1.24

Béla Mester

Senior Research Fellow, Institute of Philosophy, Research Center for the Humanities, Hungarian Academy of Sciences, Budapest, Hungary

Address correspondence to: Béla Mester, E-mail: mester.bela@btk.mta.hu

\begin{abstract}
The present paper offers a description of several trends of the mental history of the $19^{\text {th }}$-century Hungarian intelligentsia as special answers to the questions of modernity and modernization. The often usage of the metaphors of health and illness in the public discourse of the researched epoch both in politics and in the cultural life is a form of the description of the problems of modernity and modernization. This paper offers an analysis of the differences between the approaches of modernity and modernization in the period of the Hungarian Controversy on Kant (1792-1822), in the Hungarian Reform Era (1825-1848), in the time of neo-absolutism (1849-1867), and in the period of the Austro-Hungarian Monarchy (1867-1918), including the first post-war reflections to this period. It will be continuously focused on the usage of the metaphors of health and illness, connected with the description of the types, and possible roles of the intelligentsia, embedded in the discourse about the characteristics, types, roles, virtues and weaknesses of the Hungarian cities. By the hypothesis of the author, the complex of the abovementioned problems can be interpreted within a framework of the structural turn of the scholar public sphere used by the intelligentsia, from the point of view of the history of philosophy, including the interpretation of the theoretical reflections to the communicational turn in the past.
\end{abstract}

Keywords: history of intelligentsia; history of mentality; Hungarian Controversy on Kant; Hungarian philosophy; turn of scholar public sphere.

\section{Introduction}

The topics analyzed in this article are parts of a common research project of the Polish and Hungarian Academies, concerning the role of the intelligentsia in the formation of the Polish and Hungarian nations as modern political communities. This ongoing research is a follow-up project of a previous research organized in the same frame, entitled The Impact of Noble Legacy in Shaping Citizenship in Central Europe (2014-2016). However, these projects are bilateral ones; consequently, the contributors' main task is to make a comparison between the Polish and Hungarian research results in the same field; research plans of these projects contain an endeavor for extending this comparison for third countries, and finally, in an ideal-typical case, for the whole of the East-Central European region. Consequently; however, this present case study is an analysis of the development of the usage of the metaphors of health and illness in the Hungarian intellectual history of the "long $19^{\text {th }}$ century", focused on the topic of the reflections to the process of the modernization; the final aim of the investigations in this field is to offer a contribution for the 
historiography of the typical problems of the modernization in the whole East-Central European region.

It is not possible to discuss in detail all the typical cases of the usage of the metaphors of health and illness in the analyzed period, in this relatively short paper. Data related to the Hungarian history of philosophy will be used, especially the texts of the significant controversies as sensitive indicators of the emergence of metaphors of health and illness as special types of body metaphors, in the philosophical discourse as answers for the challenges of the process of modernization in the sphere of the Hungarian intelligentsia. In the first section, the cultural shock caused by the transformation of the scholars' public sphere in the times of the Hungarian Controversy on Kant (1792-1822) will be discussed. A series of the typical cultural reflections of the intelligentsia for the emergence of the machinery of modern cultural industry, incarnated in capitalist editing houses, in the time of the Hungarian Reform Era (1825-1848) is the topic of the second section. Historical reflections to the romanticism of the Hungarian Reform Era and the revolution of 1848-1849, formulated in the period of the neo-absolutism (1849-1868) are the topics of the third section. In the fourth and the last section, a metamorphosis of the usage of the cultural heritage of the well-known body-metaphors, adapted for the circumstances and needs of the modern politics will be discussed.

\section{"Dying Kant" and "Kant's soul" as new metaphors of illness and health in the Hungarian philosophical discourse}

In the very last period of the Hungarian debate on Kant (1792-1822), a highly ironic pasquinade was published in Hungarian language, entitled The Priest and the Doctor around the Dying Kant (Rozgonyi, 1819), written by the same author, who was the initiator of this great controversy of the Hungarian philosophical life in the beginning of the "long $19^{\text {th }}$ century" as the author of the first critique of Kant, published in Hungary, shorty referred in the literature of philosophical historiography as Dubia (Rozgonyi, 1792). Dubia is a discussion paper in a separate volume, written in Latin, and formulated by the academic standards; The Priest and the Doctor is a popular pasquinade, published as a cheap brochure, written in Hungarian, far from any academic standards (without references, quotations, etc.). The links between these works are their common author and their common philosophical essence. Their author, József Rozgonyi (1756-1823) was a part of the intellectual establishment as a professor of philosophy of Calvinist colleges (in the town of Losonc, later in Sárospatak) both in the times of the publication of his former and later work. The core of the philosophical opinions outlined in these texts is the same; a derivation of the Kantian philosophy from the theory of causality of Hume, and a refutation of this supposed Humeian foundation of the Kantian philosophy, based on the critique of Hume formulated by the Scottish common sense tradition, especially by Thomas Reid (1710-1796). Opponents of Rozgonyi are the German and Hungarian followers of Kant in his generation, and not Kant himself, directly. One of the most significant differences between the styles of these works, identical ones in their philosophical content is the usage of a strong metaphor of illness in the argumentation of the Hungarian brochure. The contemporary philosophical life of Europe, in Rozgonyi's opinion, has an invalid participant in a highly bad condition, i.e. Kantianism, personified by Kant himself. (Kant was not alive at the time when the brochure was published. His figure is symbolic; Rozgonyi does not speak about Kant's personal death.) As usual, people (the philosophical public of Europe) call a priest and a doctor for the dying Kant. (One of his opponents in the controversy on Kant was a Roman Catholic priest, and the other one, however, was not a medical doctor, but a Ph.D. of Göttingen.) The meaning of this metaphor of illness is clear; the Kantian philosophy is not a false, 
refuted theory, only, but an illness, a source of an epidemic, and a living dead in, and for the European philosophical life.

In the last period of the same controversy, similar phenomena can be observed on the other, Kantian side, as well. One of the alumni of Rozgonyi’s college of Sárospatak, László Ungvárnémeti Tóth (1788-1820), a significant poet of his age has used a little bit morbid scenery in his popular article in Hungarian, written for the Kantian philosophy (Ungvárnémeti Tóth, 1819). The frame of his story is a fictive conversation between Kant, Aristippus (the head of the Hedonist school of ethics), and Mercurius (as the guide of the dead's souls), in the Elysian Fields. The main question of their conversation is that whether the Hedonist or, the Kantian souls represent the majority of the Hungarian newcomers in the other world. Ungvárnémeti Tóth's writing is another type of the usage of the metaphor of health and illness; it refers to the mental condition of the Hungarian nation as a body, or as an organism. The philosophical meaning of this writing is indirect, and depends on the ethical content; the moral quality of the dead Hungarian souls is a consequence of the popularity of the Kantian movement amongst the living Hungarians, by Ungvárnémeti Tóth's argumentation. It is symptomatic that Rozgonyi has not tolerated the usage of this metaphor in the writing of his alumnus-opponent; and he has identified it as an anomaly in a philosophical discourse. His answer for the defense of Aristippus (Rozgonyi, 1822) is actually his last lesson of the history of philosophy, on the historical values of the Cyrene School of Hedonism, for his talent, but perfidious alumnus. (Actually, it was his last writing before his death, and the last work of the Hungarian controversy on Kant, as well.)

The above-detailed characteristics of the Hungarian controversy on Kant show well the consequences of the change of the structure of the scholar public sphere in the mirror of the methods of the usage of the metaphors of health and illness, in East-Central Europe, in the turn of the $18^{\text {th }}$ and $19^{\text {th }}$ centuries. At first, it can be observed a dual usage of the Hungarian and Latin languages within the philosophical discourse of the same (Hungarian) scholar community. Works published in Latin follow the international academic standards, and their style avoids the usage of metaphors. Works, written in Hungarian, sometimes by the same author, are full of metaphors, and they are out of the availability of the academic standard. It is clear that the target audiences of these publications are different; Latin works are written for the scholars, Hungarian ones for the uneducated, laic audience. The authors, who have published their works both in Latin and in Hungarian, at the same time, were under conditions of the so-called functional bilingualism.

This turn of the structure of the open sphere of the scholars has not restricted to the linguistic aspects, and it was not a specialty of the East-Central European region, only. The core of this change was the emergence of the public philosophy, out of the walls of the universities, and other institutions of the traditional intellectual establishment, e.g. the churches. (The Hungarian case is symptomatic from this point of view; the controversy on Kant was the first intellectual debate in the history of the Hungarian philosophy with participation both of Protestants and Catholics, in a common, laic communicational sphere.) The gap between the new public philosophy and the traditional philosophical systems of the intellectual establishment has its classic analysis in the wellknown Kantian terms of philosophia in sensu scholastico, and philosophia in sensu cosmopolitico. However, Kant himself has formulated the distinction between these two methods of the philosophical thinking neutrally concerning their languages, a tension between the aristocratic but international vernacular of Latin, and the democratic but local discourse of the public philosophy, formulated in national languages, has emerged. The most important dilemma of the new situation was the inherent controversy of the philosophia in sensu cosmopolitico in a national language, determined to be local, and particular. This dilemma of the segmented public sphere and functional bilingualism of the philosophical life was not restricted to the smaller languages, or to the East- 
Central European region, it was a problem for as large and developed scholar community and its audience, as the German philosophical life is. This general European problem has been mirrored within the German philosophy in the endeavors of the first generation of the Kantian philosophers for the distribution of the Kantian philosophy out of the familiar, domestic, but local and particular atmosphere of the German language, throughout in the European culture - in the language of the international audience of the Western philosophy, in Latin, as Friedrich Gottlob Born, professor of the Leipzig University has formulated in his correspondence with Immanuel Kant about the topic of his plan of the Latin translation of the main works of the Kantian critical philosophy, what was fulfilled successfully several years later, in Kant's lifetime, yet (Kant, 1796-1798).

However, the emergence of the public philosophy, formulated in national languages was linked with similar problems everywhere within the European philosophy; the smaller languages of the East-Central European region were highly sensitive for its consequences, for two reasons. At first, these language communities have never had the illusion that their language will be the new, common vernacular of the international philosophical life, after the rule of Latin, consequently, they have reflected consciously to the tension of the locality of the language of the public philosophy, and its cosmopolitan endeavors. Secondly, the turn of the structure of the scholar public sphere has happened relatively quickly, within the active life of the same generation, at least, in the Hungarian case. Within these circumstances, the malleability of the norms of the newcomer public philosophy it is not a surprising phenomenon. The frequent usage of the metaphors of illness in the works written in Hungarian, in the period of the communicational turn is a kind of the answer for the needs of a new type philosophy for a new type audience, with a non-traditional institutional background, and a new function.

In the next period of the Hungarian philosophy, after the establishment of the Hungarian Scholarly Society (1825, now: Hungarian Academy of Sciences), and before the revolution of 1848, in the so-called Reform Era, the changed conditions of the personal Lebenswelt (lifeworld) of the philosophical authors have supported the usage of the metaphors of health and illness within the controversies and debates of the Hungarian philosophical life. The milieu of the suddenly established scientific periodicals, with their formal requirements, deadlines, and size-limits was completely different from a university or college chair or a study room of a country gentleman. The Hungarian Academy of Sciences was a fundamental factor in the management of this modernization process, not only by the support of the scientific press. This management of the modernization of Hungarian science had a significant influence on the everyday life of the academic people, especially those members of the Academy who have lived regularly in Pest. (The rules of the Academy have distinguished the residents of Pest, and of the countryside.) The annual awards of the Academy have required the fulfillment of the task of reviews on the submitted manuscripts for a fixed deadline, by formal standards. The most of them were written by the members of the Academy living in Pest. The audience of the regular lectures and meetings was recruited from the same circles, etc. It is a symbolic phenomenon of the modernization that the Academy has required the submission of professional CVs of its new members, including the self-evaluation of their previous scientific careers, with short and longtime personal research programs and plans. (For Szontagh's $\mathrm{CV}$, written "for the order of the secretary of the Academy", submitted on $10^{\text {th }}$ May 1839, amongst the dozens of similar documents see: Szontagh, 1839a.) However, while the Hungarian philosophical authors of this age have evaluated their epoch as a blossom of their national culture, and the philosophy within it, in their personal life they were seriously shocked by the machinery of the modern cultural industry. In the next section, the answers to this change of the Lebenswelt (lifeworld) of the intelligentsia will be analyzed, exemplified by the writings of a typical 
representative of the new type of the public intellectual in the field of philosophy, Gusztáv Szontagh.

\section{Alienation from the objective world and from the female world as symptoms of the literati's illness, caused by the milieu of the modernity}

Gusztáv Szontagh (1793-1858), as one of the main professional critics of the Hungarian philosophical literature and belles-lettres, as the author of the programme of the development of the Hungarian philosophy (Szontagh, 1839) and the political philosophy (Szontagh, 1843), was a prototype of the independent, modern public intellectual. Through his philosophical programmes and criticisms, he heavily influenced the public opinion of his age, especially in the field of philosophy. A standard element of Szontagh's criticisms was an analysis of the author's relationship to the empirical experiences both in the physical and social world. One of the most important indicators of the sound, reliable description of the world both in the belles-lettres and in the philosophy is the author's relationship with the female world, mirrored in their works (Szontagh's criticisms has referred male authors); the reliability of the female characters is the criterion of the sound literary world in the belles-lettres, and the successful argumentation for a philosophical opinion in a saloon maintained by educated women is the criterion for a sound philosophical worldview, by Szontagh's argumentation.

This female glance of the culture has emerged in his writings as early as 1826 , when he has participated in a literary controversy about the women's role in culture. The cause of this debate was a negative criticism on a collection of average comedies, written by one of the first Hungarian female public intellectuals, Éva Takáts (1780-1845) (Takáts, 1822). Takáts has focussed on the unreality of the characters of the plays, especially the female ones. The (male) author of the comedies, Gábor Sebestyén (1784-1864), a lawyer and politician with extended influence, in his answer has formulated an ultra-conservative opinion about the prohibition of the female presence in any segment of the public sphere, including the pages of periodicals, based on Scriptural fundaments (Sebestyén, 1826). Szontagh in his contribution (Szontagh, 1826) did not restrict his ideas to the simple right of the women in the public sphere; in his argumentation were formulated the advantages of the presence of a female glance, or, female world-view in the public sphere, for the correction of the male point of view, what is inclined to the alienation from the real world.

In Szontagh's ideas, these (usually sound) female and (often unrealistic) male world-views have no biological determination, they are dependent on the social status of the males and females in the $19^{\text {th }}$-century Europe. The gender aspects of the possible world-views meet here a reflection of modernity. The dependence of the male intellectuals on the institutional network of the modern culture and their assimilation to its standards press them to be a resident of the pseudo-world of these cultural institutions, instead of the empirical world, ruled by common sense. This unrealism of the male world-view of the epoch of his lifetime was always incarnated in alienation in the words, or (by an anachronistically modern term) in a false logo-centrism, in Szontagh's criticisms and discussion papers. This symptom of alienation is detectable throughout the societal and intellectual life, in his analysis. In the political life, it appears as the hegemony of the mere rhetoric, instead of the analysis of the statistics, economy, and the functionality of the institutions. In the field of the national historiography, especially, in the section of the ethno-genesis, the same alienation means the rule of the speculative narratives, based on rare and laconic data of the written sources, over the objective, empirical data of the archaeology, and the ethnographical parallels of the economics, tools, clothes, and houses of the peoples who live far from the influence of the modern civilization. This critical view of the modern alienation in the words, in the language, is the root of Szontagh's 
role in the so-called "trial on Hegel", one of the most discussed controversies of the Hungarian philosophical life in the 1830s, as the protagonist of the anti-Hegelian side. Szontagh's critique of the Hegelianism, at least, the Hungarian branch of the Hegelian movement of the European philosophical life, has focused on the Hegelian concept of speculative philosophy, and the Hegelian terminology, what has become an autonomic, auto-poetic (self-creating) system, or, by other worlds, an alternative reality, instead of the real, empirical world, by the analysis of Szontagh. Within these circumstances, Hegelian philosophy cannot offer a sound description of the empirical world, just an escape from it, and can be an ideal-typical philosophical basis of the abovementioned illusions in the belles-lettres, historiography, and politics, as well.

This image of the alienation of the (male) authors from the real world in the imagined empire of the language, connected to a kind of the German idealism, especially to the Hegelian one, and linked to the alienation from the female glance, offers another opportunity for the usage of the metaphors of health and illness, concerning the lifestyles, and personalities of the criticized authors. However, the modern $\left(19^{\text {th }}\right.$-century) culture is almost purely masculine, this fact is not a symbol of the power and health; on the contrary, the pure masculinity is the root of the weakness, in this line of ideas. The absence of the objectivity of the world-view, and its symbol, the female glance make ill the lonely male souls in the machine of the modern institutional network of the cultural production. The description of the literati's illnesses is between the real, physiological diagnosis, and the metaphor of illness, when it has appeared at first in the Hungarian culture as the reason why of the alienation from the real world, detailed above. It will be exemplified by the author's next period, by the description of the physiological symptoms of the intellectuals of his generation, and by his own ones, as well as in his memoirs (Szontagh, 1849-1851). It will be the topic of the next section of the present article.

\section{Physiological symptoms of the literati of the Hungarian Reform Era (1825-1848) as the reason why of the world-view mirrored in their works, from a retrospective point of view}

Szontagh's endeavor in his memoirs was to offer a formulation of the synthesis of his philosophical opinions in an epitome, published sporadically, within the frame of criticisms, discussion papers, and philosophical programmes. A part of this aim was the synthesis of his opinions about the connection of the literati's personal health and illness, and their sound, or false world-view. The first step was the formulation of his own, mental and physical condition, connected to his role in the machinery of the modern cultural industry, represented by the urban Lebenswelt (lifeworld) of Pest in his epoch. Szontagh, after the sporadic publication of several smaller but sometimes-important articles on the pages of the top-level Hungarian periodicals, has suddenly become a part of the sphere of the professional intellectuals of the Hungarian capital, in the 1830s. He offered a sensitive description of his arriving. It was winter, he had several dental problems and rented a flat on the fourth floor of a new building, which was still wet. Its windows only offered the panorama of the roofs of the neighboring houses. In spite of these circumstances of disillusion, he was inspired by the new intellectual environment, he had written the criticisms and discussion papers in industrial amount, and he had outlined the concept of his first serious philosophical monograph (Szontagh, 1839), in the same time, which was written within several moons, later honored by the correspondent membership of the Hungarian Academy of Sciences. The hard and exclusively intellectual work had an effect on his health. The first, easy realizable symptoms, concerning his physical conditions, were the piles, because of the continuous sitting in the libraries, and in his study room. The second symptom, concerning his mental conditions, probably was a light form of the nervous breakdown, based on his laconic description. Under these circumstances, after 
the submission of the manuscript of his abovementioned monograph, he has left Pest for a medical cure in Starý Smokovec in the North Carpathians, near his parents' home, and has become an active, but "correspondent" participant of the intellectual life of Pest, for a few years (1839-1844). When he moved to Pest again in 1844, after an auto-therapy, he developed a healthy way of the urban life for himself. Based on these personal experiences, he had offered a general physiological cause of the alienation from the real world in his memoirs written between 1849 and 1851.

In the chapter of his memoirs entitled Hungarian literature, all his previous discussion papers, criticisms, and programmes have been connected to a physiological description of the lifestyle and the typical illnesses of the modern intelligentsia, in opposite of the ancient Greek culture, and the negative consequences of these illnesses for the modern world-view, with physiological and philosophical advices for the escape from the labyrinth of the ill, alienated pseudo-worlds, created by these modern intellectuals. His sporadic notes about the unhealthy lifestyle and illnesses of concrete individuals have been generalized in an overall visage of the ill intelligentsia, and its therapy. His diagnosis is relatively concrete; diseases of the modern intellectuals are the piles, because of the continuous sitting on the workdays, and the lack of body exercise, hypochondria, because of an over-reflection to the physical conditions of their own body as a consequence of the restricted perception of the outside world, and different nervous problems as consequences of the abovementioned psychophysiological symptoms. It is easy to see that this diagnosis is identical with the description of his personal diseases, in the same memoirs. The only difference between him and other intellectuals of his generation is the consciousness of the problem and the endeavor for its solution. However, this usage of the topic of the illness in and of the culture was rooted in a reflection of the consequences of the modernity and was connected to the unnatural urban lifestyle, and the unhealthy artificial environment of the cities, Szontagh has never become an opponent of the urbanity, he has searched the solution of his problems in an urbane way, within the frames of the modernity.

\section{Instead of a conclusion: survival of Szontagh's topic in other function}

Two decades after Szontagh's memoirs had been published, a brochure of a young intellectual and politician, János Asbóth (1845-1911) was released, as the first document of his conversion from the liberalism to the conservatism (Asbóth, 1873). It is interesting to see that the topics of this brochure are mainly similar to Szontagh's loci. The analyzed and criticized personalities of the Reform Era are almost the same, the parallelisms between the literary and political life appear in the same form in both of the texts. (The direct influence should be excluded; Szontagh was dead at the beginning of Asbóth's career, and his memoirs were not available.) The usage of the metaphor of illness is highly similar, as well; Asbóth's specialty is the description of the theatrical swoons of the politicians in a public realm, character and (bodily and mental) health of the described persons are in close connection in his chain of ideas. The gender aspect appears in another form in Asbóth's writings, he speaks about the feminine character of his (male) opponents. Despite these similarities, Asbóth's point of view is totally different from that of Szontagh; it is free from the personal experiences. By Asbóth's ideology, appeared in more radical form two years later in his conservative manifesto (Asbóth, 1875), the illness in and of the modern culture is not the problem of the whole of the nation, at least, its intelligentsia, but a characteristic of the representatives of his political opponents, only. The solution of the problem is different, as well, in Asbóth's writings; he has searched the methods of the escape from the modern world, but he has not linked the modernity and the urbanity, yet. In the Hungarian conservative thought, the connection between the criticism of the modernity and urbanity has appeared in a vivid form after the WWI, in 
the book of great impact written by Gyula Szekfü (1883-1955) (Szekfü, 1920), linked to the term of sinful city.

Szekfü's essay has been directly rooted in Asbóth's one, their titles are the same, as well; and Asbóth's analysis has used the same topics that the contemporaries of the Reform Era, e.g. Szontagh, has described. The personal experience of the shock of the modernization in the Lebenswelt (lifeworld) has evaporated during seventy years, what remained is an ideological usage of the topics of illness, and sinful city, with programmes of the solution out of the sphere of the urbanity, and modernity. It has become a mere rhetoric; open for the biological metaphors of the $20^{\text {th }}$-century languages of politics, far from the atmosphere of the Reform Era.

\section{Acknowledgments}

The research reported in this publication was supported by the bilateral program financed by the Polish Academy of Sciences and the Hungarian Academy of Sciences, entitled The role of intelligentsia in shaping collective identities of Poles and Hungarians in $19^{\text {th }}$ and $20^{\text {th }}$ centuries. The preparation of the final version of this article was supported by a research project of the Hungarian Scientific Research Fund, entitled Arts and Scholarship in the Service of the Nation-building in Nineteenth-Century Hungary (OTKA K 108670).

\section{References}

1. Asbóth, J., 1873. Három nemzedék. Széchenyi és Vörösmarty. Kossuth és Petöfi. Deák és Arany [Three Generation. Széchenyi and Vörösmarty. Kossuth and Petöfi. Deák and Arany]. Budapest: Franklin-társulat. [For a modern edition with notes see: Kiczenko, J., ed. 2002. Asbóth János válogatott müvei. Piliscsaba: Pázmány Péter Katolikus Egyetem Bölcsészettudományi Kar. pp.29-49.]

2. Asbóth, J., 1875. Magyar Conservative Politika [Hungarian Conservative Politics]. Budapest: Légrády Testvérek.

3. Kant, I., 1796-1798. Opera ad philosophiam criticam. Latine vertit Fredericus Gottlob Born. Lipsiae: Engelhard Beniamin Schwickert.

4. Rozgonyi, J., 1792. Dubia de initiis transcendentalis idealism Kantiani. Pestini: Trattner. [For its modern edition with Hungarian translation and notes see: Mester, B. (ed. and notes); Guba, Á. (transl.) 2017. Rozgonyi József: Dubia de initiis transcendentalis idealism Kantiani. Budapest: Gondolat Kiadó - MTA Bölcsészettudományi Kutatóközpont, Filozófiai Intézet.]

5. Rozgonyi, J., 1819. A’ Pap és a’ Doctor a' sínlödö Kánt körül [The Priest and the Doctor around the Dying Kant]. S. Patak: Nádaskay. [For its modern edition see: Várszegi, M.; Köszegi, L. (eds.) 1994. Elmész. Comitatus: Veszprém, pp.69-86.]

6. Rozgonyi, J., 1822. Aristippus védelme [In Defence of Aristippus]. Tudományos Gyüjtemény, 6(7), pp.52-61.

7. Sebestyén, G., 1826. Menyből jött kirekesztő Privilegium [Excusive Privilege from the Heavens]. Tudományos Gyüjtemény, 10(2), pp.124-126.

8. Szekfü, Gy., 1920. Három nemzedék. Egy hanyatló kor története [Three generations. The History of a Declining Epoch]. Budapest: Élet.

9. Szontagh, G., 1826. Bajnoki Hartz, Takáts Éva Aszszony ügyében az Aszszonyi Nem érdemei 's Jussaiért [Duel in the Case of Lady Éva Takáts, for the Women's Merits and Rights]. Tudományos Gyüjtemény, 10(8), pp.72-104. 
10. Szontagh, G., 1839. Propylaeumok a magyar philosophiához [Propylaea for the Hungarian Philosophy]. Buda: Magyar Kir. Egyetem.

11. Szontagh, G., 1839a. Életírási adatok [Biographical data]. Manuscript from the Department of Manuscripts of the Library of Hungarian Academy, Történl. 2r 11b.

12. Szontagh, G., 1843. Propylaeumok a társasági philosophiához [Propylaea for the Social Philosophy]. Pest: Emich.

13. Szontagh, G., 1849-1851. Emlékezések életemböl [Memoirs]. Manuscript from the Department of Manuscripts of the Library of Hungarian Academy, Történl. 2r 11c. [For its modern edition with notes see: Mester, B. (ed. and notes) 2017. Szontagh Gusztáv: Emlékezések életemböl. Budapest: Gondolat Kiadó - MTA Bölcsészettudományi Kutatóközpont, Filozófiai Intézet.]

14. Takáts, É., 1822. Sebestyén Gábor eredeti víg- és érzékeny játékai [Gábor Sebestyén’s Comedies and Sentimental Plays]. Tudományos Gyüjtemény, 6(10), pp.110-113.

15. Ungvárnémeti Tóth, L., 1819. Beszélgetés. Arisztipp, Kant, Merkúr [A Dialog. Aristippus, Kant, Mercurius]. Hasznos Mulatságok, 3(36), pp.281-284. [For its modern edition see: Merényi, A.; Tóth, S. A, eds. 2008. Ungvárnémeti Tóth László müvei. Budapest: Universitas, pp.541-542.] 


\title{
Social Movement and Civil Society in Post-communist Romania: Local Evolution, Global Comparison
}

\section{DOI: http://doi.org/10.26758/8.1.25}

Antoine Heemeryck

Centre d'études en sciences sociales sur les mondes africaines, américaines et asiatique (CESSMA), Université Paris Diderot, France

Address correspondence to: Antoine Heemeryck; E-mail: heemeryckantoine@yahoo.com

\begin{abstract}
This article highlights the disjunction between, on the one hand, the Romanian civic and environmental local movements and the transnational NGOs actively working to implement "democracy" and "civil society" programs in Romania. The 2012-2013 environmental and social mobilizations against the whole Romanian political class brought to the surface this compartmentalization, hitherto latent. These social realities cannot be understood without a discussion of the history of NGOs in post-communist Romania. I argue that the big NGO democratization programs have been oriented towards an imagined normalization of Romania, based on an anti-communist and neoliberal ideology. This explains why they cannot be representative of a larger social spectrum. Next, I discuss the new social movements that emerged in 2012, built around gold-mining issues in the Roșia Montană region. An analysis of the mobilizations and debate around the gold-mines reveals a gap between two civil societies with divergent interests: one favoring the reproduction of capitalism, the other representing local aspirations. In conclusion, this article proposes a more general view on this topic comparing this situation with those of Georgia and Cambodia.
\end{abstract}

Keywords: civil society, social movement, neoliberalism, democratization, environment.

Early in 2012, a social movement both unexpected and unusual took center stage of Romanian public life. The Undersecretary of State with the Ministry of Health Raed Arafat, a former doctor with no actual political affiliation, was officially relieved of his duties after being admonished by the Romanian President during a TV show. The bone of contention was the privatization of the emergency medical services, which had been the creation and pet project of R. Arafat. This was part of a long chain of "shock therapy" policies aimed at dismantling the "welfare state". In response to this new episode of mass-media politics, a small group of actors consisting mainly of culture professionals got mobilized in Bucharest. One prominent figure in the group was Sandra Pralong, former Ph.D. candidate under Raymond Aron's supervision in Paris, former communication director for Newsweek in New York, and, more recently, former head of the Romanian Open Society Foundation (the creation of George Soros; for more on the Open Society Foundation - Soros, with its headquarters in Budapest, see Guilhot, 2007).

As the protests quickly spread to more than fifty cities, they underwent a constant change; most significantly the social categories became very heterogeneous. The demands now went beyond the original scope of the protest as the protesters asked for the resignation of the Romanian President, the Government, and the whole political class. In Bucharest's University Square - the place of social mobilization par excellence after the fall of communism -, the main NGOs made a tentative appearance, but they failed to become a part of the social movement. To make things 
worse, the division between the protesters and the so-called civil society representatives - also a spatial division within University Square - was so obvious that it was picked up even by the mass media. The phrase "the two University Squares" - one belonging to the protesters, the other to the NGOs - sums up this very split which until then had lain dormant (Heemeryck, 2010, Cîrstocea and Heemeryck, 2004).

It is in this context that a journalist, during a TV interview (broadcasted by B1TV) with the head of one of the main NGOs (The Resource Center for Public Participation which is in fact the former Romanian branch of the National Democratic Institute-US), questioned the representativeness of the aforesaid organizations. "What matters is not to be representative," the head of the NGO replied, "but to be relevant." The purpose of this statement is to cancel out the question of the main NGO legitimacy and to hide the deep and long-lasting split within the civil society between, on the one hand, its dominant branch and, on the other, the protests of the politically organized society. This division resurfaced sometime later during the protests against gold mining in the Apuseni Mountains and against hydraulic fracturing for shale gas ("fracking") in Pungești.

Looking at the gap between large NGOs and a social movement over which they could have little or no control at all allows the inquiry into the sensitive issue of the conceptions, uses and forms of civil society as well as the causes of such disjunctions which seem to shape the functioning of civil society in Romania and elsewhere. I argue that the big NGOs behave nolens volens as drive belts for neoliberalism. To a large extent, they are, in the words of Antonio Gramsci, similar to an ideological "hegemonic apparatus". Further, I claim, a counter civil society emerges to curb the former's domination and promote a project closer to the nation, to culture and nature.

This article is based on several years' worth of fieldwork in Romania. I have conducted an investigation in the big Romanian NGOs for more than one and a half years, to which I added observation of everyday relations in several NGOs and over seventy interviews. As concerns the 2012 and 2013 protests, apart from my on-site observation, I had the opportunity to discuss them several times, during my Comparative Sociology seminars, with some of my students who were actually involved in the protests. My fieldwork inquiries were supported by extensive research analyses of press materials, NGO documentations, activist websites, funder.

In order to follow up on this claim, I will first focus on the leading NGOs which are supposed to represent civil society as a whole. Next, I will discuss the biggest social movement in post-communist Romania, i.e. the protests against gold mining at Roșia Montană (RM). This emergence of the RM mobilization fits into a chain of social movements which is currently gathering momentum.

\section{A Civil Society Caught Between Anti-communism, Normalization, and Neoliberalism}

\section{About anti-communism as a mode of action}

The dominant branch of Romanian NGOs is made up of a dozen NGOs at the most, all of them created in 1990. Their ideology can be described by a strong anti-communist stance, which was shaped during the first months after the fall of communism, modes of action that aim at an abstract normalization, and the promotion of a latent neoliberalism. It is against this backdrop that the structuring effects need to be reconsidered (on the debate surrounding the uses of the memory of communism see Heemeryck, 2014).

The 1980s saw an extreme development of the communist regime's means of surveillance and the undertaking of gigantic construction projects, epitomized by the People's Palace in Bucharest. Coupled with a policy of repayment of the foreign debt, these titanic construction 
projects brought about a sharp decrease in the population's standards of living. The political structures were largely monopolized by the Ceaușescu and their reference group as illustrated by the policy of rotating cadres (both geographically and administratively) and the appointment of people to the top positions in the state exclusively based on nepotism. These are the two levels that allow one to understand the overthrow of the regime in 1989, which can be described as a coup taking place against the background of a popular uprising.

It is in this context that the 1989 mass protests took place. Despite their authoritarian nature, the first policies adopted by the first post-1989 Gorbachev-inspired government were experienced as a breath of fresh air by a harassed and starving population. This explains the considerable electoral success of the new political coalition despite their repeatedly rigging the elections in 1990 and 1992. However, the takeover does not go uncontested and a student social movement, backed by the right-wing political parties freshly (re)created and fully supported by Western countries, occupies Bucharest's University Square in April 1990. The protesters naively demand the lustration of institutions, i.e. forbidding former members of Securitate (the political police) and members of the Communist Party to run in the elections during several terms. Acting out old authoritarian habits, on June 14 and 15, 1990, the government organized a violent repression of the protests with the help of Jiu Valley miners, resulting in 277 people wounded and 7 dead. It would not take long for this event to become a genuine origin myth, central to the collective imaginary of both the NGOs and the right-wing opposition parties.

Anti-communism, which deems any progressive ideology as conducive to totalitarianism becomes the credo and the glue of the very heterogeneous University Square social movement. The pattern of the political and associative opposition to the government was embodied by the Civic Alliance. The motto of this macro NGO, unchanged since December 1990, is representative of this movement: "As long as the Romanian society does not enter a state of normality, as long as the Securitate members, the crooks and those who steal from the Romanian people do not disappear from Romania's political life, the Civic Alliance will be on the barricades, holding the banner up". A large proportion of the movement joined forces with the right-wing political parties (Huiu, Pavel, 2003) and obtained, in 1996, a great yet short-lived success. The first post-communist neoliberal political era, between 1996 and 2000, will prove to be a disaster.

To this day, all the big NGOs share this multi-purpose abstract anti-communism. From an insider's perspective, it grants the movement an appearance of solidarity and coherence. From the outside, it appears to justify their discrediting of the so-called left-wing parties and, as a corollary, their constant alliances with right-wing parties, which are known to show their gratitude to these social groups when they accede to power. There is an actual circulation of elites between the NGOs and the political parties. It also makes it possible to discredit the population, deemed spineless because it refuses to vote the way these NGO members want it to vote. In both cases, they decry a mentality seen as incompatible with democracy. Finally, from the perspective of class relations, this particular brand of anti-communism allows this lower tier of the elite to conceive of itself as a new political avant-garde and, consequently, to grant itself a special positive status at the expense of undermining the political class and the population.

In passing, let us note the change in the way the local actor is represented: formerly, back at the dawn of the development era, imagined as a political force, the local actor becomes, starting with the 1980s and the emergence of the humanitarian sector, a victim or a body whose biological survival needs to be ensured. In post-communist countries, the local actor is deemed, when they do not pledge allegiance to the neoliberal parties, alienated by life under dictatorship, in line with the representations that funders and development agencies have of the local actor. 
The 2004 program "for a clean parliament", supported by eight NGOs (Freedom House Romania, Open Society-Romania, Transparency International Romania, etc.) during the 2004 legislative elections, is an illustration of how persistent this view of society really is. The NGO coalition envisaged putting pressure on the political parties to get rid of candidates that were falling into the following categories:

The candidate or a member of his/her family pursues business relations with the state while holding a position of power in a state institution; the candidate has a history of migrating from one party to another during the same term; there is a gap between the candidate's stated income and his/her actual income; the candidate collaborated with the former Securitate and/ or was a PCR (Romanian Communist Party) cadre during communism.

\section{Global Standards, Virtual Democracy}

The neo-liberalization of the United States coincides with the reviving of an anticommunist stance as illustrated by Ronald Reagan's Evil Empire Speech (1983). The international political institutions created during his reform of the state, such as the National Democratic Institute (1983), the International Republican Institute (1983), will be the ones to invest and to set up the main NGOs in post-communist countries. By recalling this historical moment, I aim to reveal the convergence of anti-communism, democratization, and neoliberalism as manifested in the early 1980s. This ideological triad reflects the collective identity and the modes of action of the big Romanian NGOs.

As a matter of fact, the strongest Romanian NGOs operate in the fields of democratization and civil society building. Most of them were created following the massive intervention of US and European institutions. This applies to the entire post-Soviet area and there are no frictions between these different organizations but rather a mutually agreed division of labor. However, these relations can prove very difficult to account for in their home societies.

Financially, the NGOs are fully dependent on their funders. This is a subcontracting type of relationship which does not allow for the development of critical thinking. The symbolic economy of these social fields illustrates to what extent the submission was internalized: the awards granted by Western institutions are displayed in the organizations' headquarters as the only markers of legitimate acknowledgment of the work done by an NGO. All consecration exists solely under the control of the external authority - be it imagined or not.

As a result, the programs of these NGOs, a reflection of their funders' agendas, are focused on the election process, the respect for the Constitution, the behavior of the members of Parliament, of politicians, on the sustainability of the civil society, transparency, and the fight against corruption. From Romania to Kyrgyzstan, these endoxic standards are the same. From this perspective, democratization is designed as both mode of transformation and monitoring of political and administrative structures and proliferation of associations. It targets the top of society and not the bottom. There is no better proof than the almost total lack of programs that explicitly use the word grassroots. The concept of empowerment is also absent from this world.

Therefore, these organizations work as proxies of minimal global political standards (transparency, rule of law, human rights, a competitive market-economy, a strong civil society, etc.). These are no longer Durkheimian norms, i.e. social norms that ensure the reproduction of a society, but virtual norms modeled by hypostasized Western societies. This is one of the prerequisites of their global applicability, of their postulated universality. 
The internalization of this power relationship in these NGOs is explained by the reinvention, after 1989, of an "allocentrism" directed at the West, otherwise traditional in Romanian culture. The entire Romanian national history, unfolding at a crossroads of empires (AustrianHungarian, Ottoman, Russian, USSR), was marked by identity stretching between an often ethnically-flavored autochthonism, on the one hand, and a synchronism centered on the belief that the West is a social, political and economic space that Romania should emulate in order to become civilized. The civilizing role is attributed to intellectuals and NGOs. This explains why there are few or no voices critical of the European Union, the USA or NATO in these NGOs.

While, as a rule, throughout the post-communist landscape, this particular type of NGOs did not oppose their funders and foreign partners - with the notable exception of Cambodia as we will discuss later in this article -, in the Romanian case, this reinvention of tradition rather proved to be a breeding ground for them. Indeed, the "partners" know how to be authoritarian and can terminate an entire NGO network if they do not approve of the political choices of the members as illustrated by the case of the NDI in Kyrgyzstan (Pétric, 2008). Subservience is, therefore, a must. But recent history also favors this attitude of consenting to authority: in the first hours following the fall of communism, democratization agencies and their funders were the only ones to provide support to the pioneering seeds of civil society. As a result, this is also a debt to their foreign partners, a debt that senior activists who now hold managing positions have "inherited".

Democracy and civil society thus become fetishes of globalization. Globalization prevails as the last stage of human evolution, hence its apodictic nature. It regulates legitimate hierarchies between nation states, between those whose past is stained by dictatorship and those who can claim historical primacy.

Therefore, we can speak of an instrumentalization of global power relations: since Romania is a post-communist country, because of this stigma, it is perceived internationally as a backward country. NGO activists appropriate these power relations via an instrumental allocentrism and reflect back to the population and the political class a degrading image of communism in order to better distance themselves from it.

It stands to reason that these organizations have little interest, to this present-day, in local issues that challenge the alleged Western sociopolitical model. This evidently pairs well with the conception of a government controlled by an enlightened elite, an avant-garde, an ideal also dear to neoliberal followers.

\section{A Neoliberal Democracy?}

During the winter 2012 protests, in a letter addressed to the government and to the President of Romania, signed by twenty-four organizations, the NGOs protested against "corruption", "savage deforestation", "the destruction of national heritage architecture", "the arrogance of government officials", "the violation of the rights and liberties of disadvantaged groups", "the maintaining of the huge gap between rich and poor by the entire political class". Born out of an exceptional context - a sudden social movement that does without the NGOs - this letter voices an almost unprecedented level of social, ecological and political criticism.

The main cause of this exceptionally broad claim-making is the participation of a larger number of non-governmental organizations. More critical organizations, such as the Internet-based criticatac.ro journal, were called on to make their contribution to the claim-making. Nonetheless, with the exception of environmental NGOs, this message was unusual for the big Romanian NGOs. The latter's criticism is - as ever - rather general; it did not result in action; and it was aimed at capitalizing on then-ongoing social movement. They were actually incapable of putting forward a fiscal and redistributive policy meant to diminish inequalities. Although they expressed regret about 
the harassment and random arrests made by the police, which were - I can bear witness - a source of constant fear for the protesters, they were incapable of supplying the needed legal assistance.

As far as the organizations meant to represent the civil society are concerned, criticizing capitalism is simply unthinkable for them. These NGOs see themselves as mediators between "the Western wisdom", the very source of democracy and capitalism, and Romania's perceived lack of civilization. Being critical about capitalism can mean betraying many years of personal investment and would constrain activist to a reconstruction of a specific subjectivity. This also partly explains why these organizations cannot foster change and alternatives.

Defying all expectations, the 2007 economic crisis has had no impact on their public position. Like multinational corporations, these NGOs seem to be remarkably resilient. Their moral economy calls for the prosecution of local elites. In their view, the dysfunctional Romanian economic system and institutions are the result of Romanian capitalism being a fake capitalism, spoiled by the former communist elites and by corruption. Therefore, they make a distinction between genuine capitalism, which remains fair and desirable, and fake capitalism, which is local, savage, the kind that you can find in Romania.

On yet another level, the normalization operated by previously mentioned NGOs limits the exercising of sovereignty and democratic representativeness to the electoral process, the transparency and the monitoring of public institutions, without criticizing the current capitalist system. They share this conception of politics with neoliberal doctrines. From the very beginning, neoliberal ideologists were faced with a contradiction between the market system and popular sovereignty.

In short, one could say neoliberalism consists of the will to impose the pattern of the market all the way to the cellular level of society (for more on the genesis and evolution of neoliberalism see Dardot and Laval, 2009). This presupposes the transformation of all social forms into companies subjected to efficiency calculus. The notion of the market undergoes a subtle change: the emphasis is no longer on the exchange, the commodification (etc.) but rather on the competitive nature of relationships among agents.

Unlike the greatest liberal thinkers of the XIXth century (J. Spencer, J. S. Mill), the neoliberals do not believe that the market system is a natural one. Contrary to the widespread confusion within the social sciences, neoliberal conceptions are radically alien to the laissez-faire doctrine. If the market system is not natural, it then must be instituted and maintained through the intervention of the state. The state is, therefore, the main agent that ensures the implementation and maintaining of the market as a social order (Dardot and Laval, 2009). Now, this endeavor is hindered by one huge obstacle, i.e. democratic sovereignty and the "irrational masses". This explains why, according to Walter Lippman, democracy needs to be strictly limited to the electoral processes (Lippman, 1943). Ordoliberals go even further pleading in favor of constitutionalizing neoliberal economic policies so as to place them outside the deliberative system. According to this view, the European Union is the perfect expression of this policy (Dardot and Laval, 2009, pp.328346; Denord and Schwartz, 2009). The anti-democratic nature of this conception is revealed in the work of F. Hayek and his open preference for a liberal dictatorship rather than a social democracy. However, I must point out that the ordoliberal functioning of the EU has been repeatedly shown to be incompatible with the sovereign expression of the people (see for instance the 2005 referendums on the ratification of the European Constitutional Treaty - to which several people said 'no' only to be forcefully adopted by their elites).

The NGOs I discuss clearly chair this worldview. They have reduced democracy to a formal standard built around electoral procedures. They rule out de facto any claim-making beyond the scope of electoral claims, except for challenges to the authoritarian tendencies of the state, thus 
allowing for the maintenance of an environment favorable to market development and securing foreign investments. They work as an alibi for neoliberalism; in the absence of elections - despite most thinkers', from Aristotle to Montesquieu (Manin, 1997), having conceived elections as the tool of an aristocratic government - any society would become a morally bankrupt project. Finally, one could also wonder what is the use of fully legal elections and total freedom of expression for every citizen if the choices in terms of economic policies and social projects have been set in stone by the European treaties.

NGOs are often perceived as the vectors of global claim-making, according to an idyllic view recurrent in the social sciences. Quite on the contrary, these organizations turn out to be keys to global domination. This aspect becomes obvious in the case of so-called democratization NGOs, whose task is to impose a hegemonic ideological framework in the name of an alleged popular representativeness. Nevertheless, exposure to globalized capitalism and neoliberalism characterized by oppressive tendencies forces societies to find alternative solutions to ensure their political, economic, social or even biological survival. As a result, heterodox social movements emerge and contribute to the creation of a counter civil society. And this becomes the locus of nascent subversion. Next, we are going to see how this happens based on the case study of a social movement that opposes gold-mining at Roșia Montană.

\section{The Polymorphism of the Counter Civil Society}

The Roșia Montană gold-mining project has generated the largest, most important social movement in post-communist Romania. (As concerns the Save Roșia Montană Campaign (CSRM), the journalist Mihai Goțiu provides the best synthesis of information in his book - see Goțiu, 2013.) Roșia Montană is a small commune comprising a few thousand inhabitants, located in the heart of the Apuseni Mountains, a mountain region known for its magnificent views but also for its mineral resources. It is this particular richness that stirred the interest of big Wall-Street investors (Thomas Kaplan, John Paulson, Beny Steinmetz) and the Canadian mining industry about fifteen years ago. An estimated 300 tons of gold and 1,600 tons of silver could be extracted over a period of fifteen years. This would make it the biggest cyanide gold mining project in Europe. In addition to the environmental damage, the mining method would entail the construction of a dam, displacing almost all the inhabitants of one village and destroying an archeological heritage site over 2000 year old.

This particular mining project reveals a general phenomenon of "condensation" (Poulantzas, 2013) involving the main global capitalist actors and the local political and administrative structures. On the one side, there are the Romanian investors - known for their past connections with drug dealing in Australia and later as members of the international financial elite and the foreign investors involved in the "blood diamonds" mining industry in Sierra Leone. On the other side, starting from Romanian President Traian Băsescu (2006-2010, 2010-2014) going through the various ministries (culture and religions, environment, economy) and down to the level of the regional and local administrations, there are the elites who used their power to make the project possible (Goţiu, 2013, 25-141). The first contract-awarding procedures started in 1999 and followed the usual pattern for the privatization of profitable state-owned companies. With the involvement of the World Bank, the Canadian and US diplomacies, the operation built on a sequence of corruption acts is indeed reminiscent of postcolonial scenarios.

Before going any further, I need to provide some background information on the Romanian case. In 2008, Romania started to feel the consequences of the global financial crisis. As in many countries, its upper middle class, the holders of considerable cultural and technical capital, was deeply impacted. As in many Western countries, the crisis was a good opportunity for speeding up 
neoliberal reforms. Moreover, the ideological homogeneity of the political field, attributable to the weakness of the state, became increasingly visible: the three main political parties, the SocialDemocrat Party (PSD) - perceived as a left-wing party -, the National Liberal Party (PNL) and the Liberal Democrat Party (PDL) - both right-wing parties - took turns in forming alliances to govern the country: the PNL-PDL alliance between 2004 and 2007, PDL-PSD between 2008 and 2009, PSD-PNL from 2011 to 2014. Finally, in 2012, the Parliament introduced a referendum procedure for the impeachment of President Traian Băsescu. It was the biggest voter turnout since 1989, i.e. around eight and a half million voters - or $46.24 \%$ participation -, out of which $87.52 \%$ were in favor of the removal from office. Owing to a legal loophole, Traian Băsescu was able to remain in office. That much can be said for the democratic political scene and democratic legal means. This enticed large shares of the population to become involved in a larger social movement. The multiplying crises, typical of neoliberal governmentality, led to a clear division between capitalism and democracy, on the one hand, and original social movements, on the other.

The opposition to the Roșia Montană mining project started to take shape in 2002 . The national power dynamics were such that the villagers had virtually no chance to oppose the project on their own. Moreover, they were subjected to a skillfully maintained doxa according to which the foreign investor is a messianic figure, reminiscent of some Melanesian cargo cults. The local opponents of the project were quick to create an association, Alburnus Maior, and to invite NGOs and activists to their first meeting. Most of these actors came from Cluj-Napoca, a Romanian city which, as opposed to Bucharest, had a genuine progressive and protest-oriented intellectual tradition. The success of the movement, as it would turn out, lay with its capacity to form alliances with very diverse social groups. This allowed the movement to reach transnational status instantly. The Roșia Montană issue gained international recognition with the publication, in the 2000s, of articles in the international press such as: Le monde, The Guardian, The New York Times, Der Spiegel, The Ecologist, etc. A prerequisite of the movement's expansion beyond the level of the state and of its national success, these alliances with urban organizations and actors, not at all common in Romania, would only become stronger in time.

The nature of the mobilization is polymorphic: the village inhabitants whose ownership rights were violated are definitely the most concerned, but alongside them we find environmental NGOs dedicated to the environment preservation, cultural heritage aficionados or professionals, miners who are against mindless extraction, etc. The actors come from very diverse social strata: journalists, architects, legal experts, graphic designers, peasants, former miners, NGO workers, writers, students, unemployed people, etc. The chair of Alburnus Maior himself embodies this social kaleidoscope. The toothless 46-year old man, a former employee of the state-owned mining company of Roșia Montană, can be seen performing tasks ranging from manual haymaking to lecturing at conferences on the entanglement of transnational and national economic interests in this particular mining project.

This plurality of voices within the movement implies a minimal or overlapping consensus. In Romania, the rejection of the elites defined as consummately cynical and greedy is a representation rooted and visible in the granite-like stability of the indicators of trust in the institutions. ( $C f$. on this point to the opinion barometers published by the Open Society FoundationRomania together with Gallup.) Consequently, the ideal framework, inclusive of all the different shareholders, claims to be apolitical. Centered on the protection of nature, culture and moral values, its definition can be backward-looking or neutral at best. Here it is in the words of one activist: "Roșia Montană is this threshold between absolute corruption and the hope that the Romanian people will one day find its way towards healthy moral values." 
The movement's lack of ideological consistency, which could be seen as a weakness at first sight, quite on the contrary, allows it to integrate large sections of the population and to support alliances of social groups geographically and socially far apart from each other. As a result, the movement cannot be controlled by its enemies, since the Save Roșia Montană campaign (CSRM) is not a legal entity and it has a hydra-like organizational structure.

The same observation applies to the winter 2012 protests, although they were much more loosely structured. During the day, groups of elderly people would protest in University Square, while in the evenings, groups of young people, some of them coming straight from work, would take their place. During the October 2013 protests against "fracking" and, by extension, against the Romanian government and Chevron Company, groups of poor and uneducated peasants attempted to resist the installation of a gas drill in the village of Pungeşti, while groups of younger people, holders of cultural capital, protested in Bucharest alongside environmental NGOs. These alliances are clear proof of the repoliticization of large categories of the population formerly excluded from the official mono-ideological environment of the political structures. This social plurality, particularly in the CSRM case, allows for an extraordinary accumulation of technical and tactical skills: design, legal, archeological, etc. This last point is crucial since the battle will be fought over very complex technical issues and will take the form of a fierce propaganda war.

A group of street-art anti-establishment activists - Mindbomb - will become one of the driving forces of this tactical war. On the one hand, the alumni of the art and design school, whose works are being exhibited all over the world, will provide the movement's key symbols (logo, flag, etc.) whose transposability will reinforce the identity of the movement both nationally and internationally. Moreover, the use of the symbols being free, anyone will be able to claim an action on behalf of CSRM. For instance, a group of Romanian mountain climbers will carry the CSRM flag to the top of the Mont Blanc. On the other hand, inspired by the San Francisco Print Collective, whom they had an opportunity to see at work, the Mindbomb activists will start a subversive poster campaign meant to question the interests of Romanian elected representatives connected to the gold mining project. Their network structure will allow them, for instance, to paste 10,000 posters in one night, in sixteen Romanian cities (Goţiu, 213: 378-379). This goes to show the extent to which this particular group is able to conquer public space.

The involvement of legal experts is just as decisive. Repeated demonstrations will take place in Cluj-Napoca and Bucharest and the participants will be subjects to a soft but nonetheless constant repression by the law enforcement forces. In Cluj-Napoca, lawyers will defend pro bono activists illegally arrested by the police and the riot police. This is precisely what the big Bucharest NGOs failed to do in these last years' sporadic protests. Furthermore, flyers containing legal advice will be put together fast and shared among participants so that each one of them could face the state's repressive forces. In brief, this is a genuine modus operandi aimed at bypassing the objective balance of power unfavorable to this fragmented movement. The same legal skills will be put to good use in getting annulled in court all of the permits that Roșia Montană Gold Corporation (RMCG) had obtained fraudulently from the public authorities: Certificate of exemption from listing as cultural heritage, the General Urban Plan, the Planning Certificate, the various reports issued by central authorities used by various ministries as support for their decisions, etc.

Faced with this kind of mobilization, the Canadian-Romanian company will launch their counter-offensive. An invalid local referendum is conducted under the direction of the multinational corporation, with a less than $28 \%$ turnout. Further, a mock civil society is created with the help of NGOs incentivized by people with vested interests in the mining project. Nothing was easier than to co-opt these NGOs, following the example of the big environment preservation foundations (WWF, Conservation International) which are today funded by the world's most polluting industries. 
In an attempt to counter the involvement of a part of the transnational science community, the company calls on a few members of the Romanian Science Academy. This is a common strategy of securing the services of a few actors and allowing them, due to resources from outside their field of reference, to change their position in the field's hierarchy. Once one or several actors are coopted, it becomes easier to claim and use fallaciously the agreement of the institution as a whole. However, this strategy will backfire as the Romanian Academy, clinging to its precarious independence gained after the fall of communism, will unequivocally and repeatedly make public its opposition to the Roșia Montană mining project.

Next, RMGC will put more pressure on the media. They will first muzzle the media through their main shareholders as the latter are connected to political parties which, in their turn, are connected to the gold mining project. The mass purchase of advertising space will also make it easier to buy off a parti-pris purged of divergent opinions. The censorship of the media will be further enabled by co-opting actors in authority positions (editors in chief, TV presenters, moderators, etc.). They will be convinced by the multinational corporation with the help of luxury "research" trips to New Zealand.

The relentlessness of the multinational company - which otherwise has not produced any wealth so far - can only be explained by the speculative nature of today's capitalism. The actual purpose of this company is to maintain the stock market price of a virtual swappable product in order to ensure its circulation and the drain of money. This also applies to the local elite for whom this company is a source of extraordinary wealth. However, the success of this strategy relies on the heteronomy of the social fields targeted by the mentioned company and, consequently, on their versatility.

As a corollary, this strategy of creating a fictional democracy reveals both the internalization of constraint typical of globalized moral standards manifested as fair and free elections, civil society and the freedom of expression, and the transformation of the relations between power and counter-power. From here on, this pantomime of democracy will have to be reenacted every time one wants to raise public awareness. This is the main quality but also the main drawback of globalized moral standards.

The participants in CSRM will also take it upon themselves to educate these populations who are not used to voicing their opinion. This is another fundamental feature that sets them apart from the main democratization NGOs in Romania who provide at best a few reports and brochures on the leanings of political parties and the biographies of their members. The work of organizing a march from Cluj-Napoca to Roșia Montană illustrates this educational endeavor. The organizers stopped in each village and talked at length, sometimes meeting with a lot of bitterness from the villagers, about the underlying stakes of the mining project (Goţiu, 2013: 364-367). It is important to emphasize that this region in Romania is marked by high unemployment rates, an argument that was used ad nauseam by the Romanian-Canadian mining company.

As an extension of their actions, the movement will focus on the village of Roșia Montană and set up several projects there: an architecture summer school on heritage building restoration, an annual music festival to help develop tourism in the local guesthouses. Given the spatial dimension of the political struggle, the activists had to appropriate a space previously under the control of the company - which had bought property in the village - in order to effectively operate the shift in the balance of power. The restoration of the Greek-Catholic parish house gave the activists the opportunity to appropriate a place and to convert it into a museum that would host their lectures and public debates. This happened on several occasions and led to the Alburnus Maior association's claiming for the parish house as its headquarters. 
For the activists, the alternative to the gold mining project is to turn this place into a tourist attraction, with cultural heritage and agritourism at its center. There are surely many arguments in favor of this. But there is no real break with the dominant global ideologies as these propositions are clearly part of yet another register of the political hegemony of globalization. First, these propositions push the debate in the cultural sphere at the expense of the political, overlooking, for instance, political ecology. Second, they encourage the commodification of culture, identity and heritage, all of them being reinvested in the intangible economy of tourism (Bazin, 2001; Heemeryck, 2008). It stands for the very demise of the industry, in this case, mining, on which the legitimacy of the state relied in the past and which now allows for its commodification as tourism. The same might apply to the environmental-friendly tourism that the CSRM key members praise so much. Finally, one can only wonder if this urban petite bourgeoisie a.k.a. creative class (gentry) is not actually imposing its own worldview on the others. Being a tourist requires having surplus earnings and only a few social categories will be able to afford that. By way of illustration, during the 2014 FânFest music festival, the prices of accommodation ranged from $€ 20 /$ night for setting up your tent in a villager's yard to $€ 42 /$ night for a room in a villager's house, in a country where the minimum net monthly salary is $€ 115$ and the average net monthly salary is $€ 366$. This is where the narrowness of these activists' vision becomes apparent.

\section{Conclusion}

In his prison writings, Antonio Gramsci distinguished between a political society (the night-watchman state), an equivalent of the legitimate functions of the state (the army, the police, the legal system, etc.), and a civil society whose role is to maintain a cultural hegemony favorable to the dominant classes. There are two criticisms of this view. Gramsci's political society is undoubtedly the least open to political stakes. Moreover, his definition of civil society stands only for part of the civil society, which, because of its hegemonic nature, puts a strain on all forms of claim-making within a society. Now, my case study reveals the cracks in the myth of the hegemonic civil society as illustrated by the problematic nature of the relations between the main democratization NGOs, Pro Democraţia Association, the Center of Support for Non-Governmental Organizations, on the one hand, and the local Alburnus Maior, on the other. This particular civil society appears to have an amphibological nature. The former loses the monopoly on the claim to represent the society and the latter creates its own place independently of the former.

In this respect, the Romanian case is close to the Georgian one (Jones, 2012). After the "Revolution of Roses", a great number of NGO activists joined the government structures. This coincided with the two terms of Mikheil Saakashivili as President of Georgia (2004-2007, 20082013), a period of authoritarian neoliberal policies (Serrano, 2008), and ultimately led to the emergence of a counter civil society, opposed to the government. (Muskhelishvili and Jorjoliani, 2009).

The disjunctions of civil society create a parallax effect in the very concept of civil society. This historical configuration emphasizes the emergence of a counter civil society resulting from the colonization of civil society by neoliberalism. The comparison with another faraway postcommunist country will help us understand better why the big Romanian NGOs gradually confine themselves to an ideological straightjacket.

Like Romania, Cambodia is one of the first post-communist countries to have its territory swept by a wave of NGOs in the early 1990s. Following the massacres committed by the Khmers rouges and their defeat by the Vietnamese army (1975-1979), an international embargo was imposed on Cambodia until 1991. In 1992, after the Paris agreements (1991), the United Nations Transitional 
Authority in Cambodia (UNTAC) is appointed to ensure Cambodia's transition to peace, democracy, and a market economy. From then on, a vast number of NGOs set up camp in Cambodia, most of them funded by multilateral or Western institutions. However, there also emerged a minority wave of fully independent NGOs; among these, the child sponsorship and education NGOs (Trannin, 2005).

Under these circumstances, corruption and all types of trafficking spread like wildfire allowing the authoritarian State to make full use of its means of repression. Phrases like "aid market" (Hughes, 2003) and "NGO economy" (Trannin, 2005) could be heard everywhere. The aid is not coordinated, some sectors are overfunded (health-AIDS), others are overlooked (mental illnesses and psychological counseling for the survivors of the Khmers rouges era). To better control this chaos, the funders create structures for conveying and increasingly strict monitoring of aid: the "umbrella" multilevel structures, with a big NGO placed at the top and several smaller ones under its direction. Each "umbrella" specializes in one aid sector - health, microfinance, education, etc. In this context, one could say that "foreign assistance undermines democracy" and civil society development (Ear, 2012).

This is to say that the Cambodian NGOs are in no way more prone than their Romanian counterparts to increased autonomy. Nonetheless, human rights NGOs such as the Cambodian Human Rights and Development Association (French acronym ADHOC) or the Cambodian League for the Promotion and Defense of Human Rights (French acronym LICADHO), ever since their creation, have shown an ability to make a common front with the anti-establishment movements in the post-UN history of Cambodia. These social movements will peak again in 2013-2014, with the garment workers' strike. How can one explain the fundamental difference between the Cambodian NGOs and the big Romanian NGOs?

First, the Cambodian NGOs refused the paternalist attitude of the UNTAC from the very beginning and were even having open contentious relations with the latter. This was the first step towards building a form of independence. But this was not enough. These activists, just like some local Buddhist figures, would invent a Cambodian tradition of the rule of law based on the notion of justice (Pouligny, 2007). This fictional appropriation allows them to make independent claims about human rights, rule of law, etc. Finally, these NGOs' actions are aimed at helping the population in their exchanges with the state and the elites. In addition to denouncing corruption, they focus on the victims of state violence whom they provide with legal, medical and financial support. When it comes to the victims of expropriation from their lands and properties, they go as far as to bring them a roof and food provisions. This is a big issue as a surface area of more than 2 million hectares was subject to dispossession by the state since 1993, giving rise to violent conflicts (see this history on interactive maps Great Cambodian Giveaway, Visualizing Land Concessions over Time on the LICADHO website). Several neighborhoods in Phnom Penh are chronically enraged by the elite-led dispossession, while the imprisoned activists receive help from these maverick NGOs.

While, in general, the normalization operated by the NGOs is a type of global and abstract standardization, the Cambodian NGOs are still making local claims. Their agenda is built on local issues. Hence, their integration in the social movements which regularly shake this country. It is in the name of impartiality that the big Romanian NGOs refuse to get involved in social movements. The 'each person has the right to speak' equidistant attitude pairs well with the new advocacy methods. But in a world where power relations are both complex and increasingly inflexible, this position is utopian. Moreover, this position makes difficult even impossible any solidarity with the population.

This detour through the Cambodian case provides many lessons. As opposed to Cambodian NGOs, Romanian organizations claiming to represent the civil society were not able to appropriate 
democratization and the rule of law. As for their connections to the social movements, they are only formal if not altogether contentious. Notwithstanding, Romanian history provides its own example of a revolution that succeeded in bringing together the people and part of the bourgeoisie. This was the 1848 revolution, responsible for the birth of Romania as a nation-state. And some of its main figures came from the small village of Roșia Montană.

\section{References}

1. Bazin, L., 2001. Patrimoine, mémoire, généalogie. Quelques considérations critiques. Revue Espace Marx Lille, $\mathrm{n}^{\circ}$ 16-17, pp.44-53.

2. Castoriadis, C., 1972. L’institution imaginaire de la société. Paris: Seuil.

3. Cîrstocea, I., Heemeryck, A, 2004. Occurrences paradoxales du politique en Roumanie. Journal des anthropologues, $\mathrm{n}^{\circ}$ 102-103, Paris, pp.371-409.

4. Dardot, C. and Laval, C., 2009. La nouvelle raison du monde. Essai sur la société néolibérale. Paris: La découverte.

5. Denord, F. and Schwartz, A., 2009. L'Europe sociale n'aura pas lieu. Paris : Raisons d'agir.

6. Ear, S., 2012. Aid Dependence in Cambodia, How Foreign Assistance Undermines Democracy, New-York: Columbia University Press.

7. Gramsci, A., 1996. Les cahiers de prison. Gallimard: Paris.

8. Guilhot, N., 2007. Reforming the World. George Soros, Global Capitalism, and the Philanthropic Management of the Social Sciences. Critical Sociology, 33, pp. 447-479.

9. Goțiu, M., 2013. Afacerea Roşia Montană, Cluj-Napoca: Tact.

10. Heemeryck, A., 2010. L'importation démocratique en Roumanie. Une perspective anthropologique sur la construction d'une société post-dicatoriale. Paris: L'Harmattan.

11. Heemeryck, A., 2008. Le patrimoine culturel immatériel entre marché, État et culture nationale : une esquisse de problématisation autour de l'exemple de la Roumanie. Martor. The Museum of the Romanian Peasant Anthropology Review, Bucuresti, 13, pp.67-85.

12. Heemeryck, A., 2014. The Imaginary Debt of Comunism: Political Conflicts and Historical Legitimization in Romania in Ould-Ahmed. P., Hours, B.. Dette de qui, dette de quoi ? Une économie anthropologique de la dette. Paris: L'Harmattan.

13. Hours, B., 1998. L'idéologie humanitaire ou le spectacle de l'altérité perdu. Paris: L'Harmattan. 14. Hours, B. and Selim, M., 2012. Anthropologie politique de la globalisation. Paris: L'Harmattan.

15. Hours, B., 2008. Les marchandises morales globales ou le blanchiment du capitalisme in Baumann E. Anthropologues et économistes face à la globalisation. Paris: L'Harmattan, pp.7786.

16. Hughes. C., 2003. The political Economy of Cambodia's Transition 1991-2001. London \& NewYork: Routledge.

17. Huiu, I., Pavel, D., 2003. Nu putem reuşi decît impreună . O istorie analitică a Convenţiei Democratice, 1989 - 2000. Iaşi: Polirom.

18. Jones, S. F., 2012. Georgia: A Political History Since Independence. London and New-York: I. B. Tauris.

19. Lippmann. W., 1943. The Good Society. George Allen and Unwin Ltd.

20. Manin, B., 1997. The Principles of Representative Government. Cambridge: Cambridge University Press.

21. Muskhelishvili, M., Jorjoliani, G., 2009. Georgia's ongoing struggle for a better future continued: democracy promotion through civil society development. Democratization, 16(4), pp.682-708. 
22. Pétric, M., 2008. Observation électorale et réseaux d'ONG transnationaux : le cas du Kirghizstan, Revue Tiers-Monde, 1 - n 193, pp.91-109.

23. Poulantzas, N., 2013. L'Etat, le pouvoir et le socialisme. Paris: Les Prairies ordinaires.

24. Pouligny, B., 2007. UN peace operations, INGOs, NGOs, and promoting the rule of law: exploring the intersection of international and local norms in different postwar contexts. Journal of Human Rights, 2(3), pp.359- 377

25. Rist, G., 2007. Le développement histoire d'une croyance occidentale. Paris: Presse de sciences Po.

26. Serrano, S., 2008. La Géorgie post-soviétique : Lost in transition ?. Revue Tiers-Monde, 1 $\mathrm{n}^{\circ} 193, \mathrm{pp} .67-90$.

27. Trannin, S., 2005. Les ONG occidentales au Cambodge: La réalité derrière le mythe. Paris: L'Harmattan.

28. LICADHO website: http://www.licadho-cambodia.org/concession_timelapse/ [Accesed on April $1^{\text {st } 2017]}$ 


\title{
From spontaneous cyber-solidarities to radicalization of protest speech
}

DOI: http://doi.org/10.26758/8.1.26

Gabriel Stoiciu

'Francisc I. Rainer' Anthropology Institute of the Romanian Academy, Bucharest, Romania,

Address correspondence to: Gabriel Stoiciu, Socio-Cultural Department, 'Francisc I. Rainer' Anthropology Institute of the Romanian Academy, Academy House, 13 September Avenue, No.13, 5th District, Bucharest, Romania, Zip Code 050711, tel. +40728824852; fax +4021.3175072; Email: gabriel.stoiciu@gmail.com

"Once upon a time there were mass media, and they were wicked" Umberto Eco, Travels in Hyperreality

\begin{abstract}
Objectives. Our main goal is to show how important is the role of social media in spontaneous solidarities and the way in which an extreme speech regarding the role and place of religion and state as allegedly responsible institutions for such tragedies can emerge in this environment.

Material and methods. An assessment has been carried out on different social network platforms, among which we chose to present Facebook examples, regarding the attitudes of concerned citizens towards three tragic events that occurred in 2015 in France and Romania. It is also shown the responses of the authorities' to the social media echo of these events.

Results. Even if not widespread, radical attitudes emerge in times of crisis and can leave a trace on future dominant social behavior.

Conclusions. Unfortunately, the most powerful impact in social media, as in the mainstream one, is caused by the "terrible news". The emotional complex surrounding this kind of events varies from despair to anger and sometimes develops into extreme speech.
\end{abstract}

Keywords: Social Media, Tragic Events, Radicalization, Virtual Communities

\section{New media - "Mirror, mirror" or "Jeannie in the lamp"}

Social media - computer platforms for communication and socialization - are becoming more and more "the weapon of choice" used by public opinion to convey their messages, while the mainstream press is often perceived as manipulative and submitted to the interests of the establishment. Platforms like Facebook and Twitter are considered to be more reliable sources of information (a proof is also the number of users over 2.5 billion - higher than any print or TV audience) because censorship seems to be, in this case, less efficient. Newspapers, radio stations, and private televisions are integrated into large business conglomerates and, consequently, they seem only to create an impression of sympathetic interfaces of large unscrupulous companies.

Mainstream media has an institutional form: an organization whose object of activity is to generate cultural products (articles, reports, radio-TV programs) addressed to an audience of individuals who are in a passive posture - that of recipients who are unable to provide an instant reply to the information and opinions that are communicated to them. 
"Media are forces that provide the public with ways to perceive and interpret the world, ways that ultimately structure its very existence and participation in a given society" (Spitulnik, 1993, p.294).

The web 2.0, whether we are talking about forums, blogs or social networking platforms, make it possible for the perception of an event to be changed directly and spontaneously by those who are addressing it. This is happening independently of the filter of professional public opinion analysts/commentators. At the same time, new information and communication technologies leave the impression that they can offer "instant gratification" to the user and provide the opportunity for someone to become famous overnight. This is the essence of what we call web 2.0 - the era in which the Internet is no longer composed, like the press, of pre-fabricated content (as it was in the beginning) but is constantly under the influence of the ideas and opinions that are associated with the initial message - its essence being the creation and animation of „virtual communities”. Using the computer as the primary means of communication has led to the formation of a "public sphere" within the virtual space - a virtual or "imagined community - that does not necessarily exist in an identifiable space." (Habermas, 1962) Such groups are often formed around the need to communicate and socialize, but also as a "community of interest" - in which members "exchange information in order to get answers to questions or personal problems, in order to and improve understanding of a subject, to share common passions or simply to play" (Henri and Pudelko, 2003, p.485). However, there are situations where such communities develop spontaneously - in response to an event of great interest.

Public events with a tragic connotation, reflected by the mass media, can induce two behavioral rearing at the receptor level: indifference or empathy. The latter can be expressed both publicly and privately through an affective complex ranging from despair to anger. Anger involves an intention, a willingness to act, and an orientation (a target). Most often, the target of anger reactions are the authors of the tragedy, but also the authorities, a fragment of society or a system of values considered wrong (religion, democracy, etc.).

On the channels of the new media, the tragic news come instantly - accompanied almost simultaneously by the public's reactions. This kind of events creates spontaneous cyber-solidarities generating - what Robert Putnam called - ,social capital”.

The main objective of this material is to highlight, through the comparative method, the role that socialization platforms play in the formation of spontaneous solidarities and the way in which radical opinions and attitudes directed against secular or religious authorities arise in such situations. At the same time, we will also analyze the authorities' response to these attitudes.

\section{Collective emotions in the face of social tragedies}

Unfortunately, for both conventional media and social networking platforms, the so-called "terrible news" gets the strongest impact. The emotional complexity that accompanies this type of events varies from despair to anger and sometimes develops even in radical attitudes.

The year 2015 brought a maximum exposure to terrorist attacks claimed in the name of Islamic fundamentalism committed in France ("Charlie Hebdo" and "Bataclan"). These events offered the possibility for extreme right activists to challenge the legitimacy and authority of political leaders in office. 


\section{Attack against Charlie Hebdo}

Charlie Hebdo is a weekly French magazine of political and social satire, which has often created controversy because of its provocative style, often caricaturing the founding characters of religions (Jesus, Mahomed, Moses). Due to the caricatures of the Prophet Muhammad, journalists received many threats, and the first headquarters of the magazine had been fire-bombed in 2011.

Parisian prosecutors confirmed that on the morning of January 7, 2015, two masked and armed attackers stormed editorial offices located in Paris and began firing automatic weapons. 12 people were killed (10 journalists and 2 policemen) and 11 were injured in the attack on the satirical weekly. The authors of the attack were identified as Saïd Kouachi and Chérif Kouachi, aged 34 and 32 respectively. They were shot, during an ambush, two days after the attack.

The popular reaction was immediate, although the publication did not have a very large audience. Information disseminated on social media platforms, especially on Facebook and Twitter, has generated solidarity under the slogan "Je suis Charlie" (Image 1, promoted also as a hashtag) around the principles underlying the independence of the press and freedom of expression.

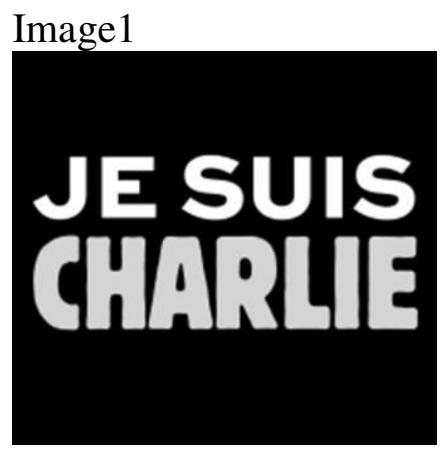

This solidarity also emerged in the streets, through massive protest movements that took place in the evening of the bombing and in the coming days in many cities in France and around the world. The slogan "Je suis Charlie" would be adapted later on by replacing the name of the publication with that of the cities where attacks were claimed in the name of Islamic fundamentalism (Je suis Orlando, Je suis Brussels, Je suis Istanbul, etc.). Besides the reactions of peaceful solidarity around democratic values, there have been also violent reactions both in language (injuries, threats, and instigations spread on social networking platforms) and in action (burning and vandalizing mosques, shuffling people, including children of Muslim religion). The President of France and the majority of the political class have taken the initiative to organize a protest march involving 1 million people. French heads of state were joined by other EU heads of state and leaders.

\section{The terrorist attacks in Paris on 13 November 2015}

They were series of armed attacks, bombings, and hostage-taking, which took place in the capital city of France on the evening of 13 November 2015 and in the early hours of the following day in the 10th and 11th arrondissements and near Stade de France, located in Saint-Denis. The attacks, which were claimed by the Islamic State (ISIL) group, consisted of three explosions and six armed attacks. The day was chosen because there was a football match between France and Germany, which attracted the participation of many French on the stadium, but also in gatherings in Paris cafes. Explosions by self-detonation took place near Stade de France, and the shootings (more 
randomly drawn) targeted the cafes. But the bloodiest attack happened in the Bataclan Theater, where a rock concert took place. More than 100 persons were arrested and killed in Bataclan, and the terrorists eventually committed suicide. In total, the November 2015 attacks resulted in 130 people killed and 368 injured.

The Parisians responded to these abominable acts through immense solidarity. The hashtag \#portesouvertes was launched on the social networking platforms for those who were in the city and were afraid to travel to their hometown. There were also, Facebook users have adopted logos with French tricolor and the mention "Je suis Paris". Online pages were opened in which those known to be in the areas concerned by the attacks would leave a "proof of life" to calm their friends and relatives. Also, spontaneous displays of feelings of resentment in the face of terrorism and compassion towards those close to the victims animated the big cities in France. President François Hollande declared a state of emergency for a period of three months and again called for solidarity. This time, however, public opinion, especially on online networks, has adopted a critical orientation towards political leaders and especially the head of state.

\section{Fire at Collective Club}

Also, in 2015, Romania had its part of "terrible news" with the fire that burned down the "Collective" night-club in Bucharest, killing 64 people and injuring 147. The official reports, mentioned by daily newspaper Romania Liberă, certified as a cause of fires: a tragic association between the fact that "the fireworks that were mounted in the Collective club (especially for the concert $n n$ ) were not correctly positioned", and "the fact that there were no extinguishers in the club." To them, it was added "the non-fireproofing of the polyurethane foam (mounted on the walls of the silent $n n$ ) which rapidly ignited". There have been and still are opinions that invoke the possibility of other causes, reaching up to different conspiration theories.

The fact that this metal-core concert took place on Halloween night fueled radical positions of Christian-Orthodox self-declared observers, expressed on social networking platforms. These have attracted equally vehemently secular replies, not directed to the contributors, but to clergy and Orthodox religion. The message "We want hospitals, not cathedrals" (Image 2) has become a slogan strongly promoted by online social media platforms. Through the same channels, the call for a march, two days after the tragedy was launched on November 1. The march took the form of a protest against the incompetence and perfidy of central and local government officials (specifically, the Mayor of $4^{\text {th }}$ District of Bucharest - where Collective club was situated). The participants' resentment expressions found an essentialization in the slogan "Corruption kills", which later became the name of a Facebook page followed by many of those who blamed the authorities for the Collective tragedy and which served as the main channel for mobilizing resistance to abuse committed by the State. The authorities let the impression that they are insensitive to people's inquiring and launched the information that the number of victims diminished in order to control the public's reaction. This fact has quickly come to the surface, a new march was organized on November 3rd, an occasion where explicitly was requested the resignation of Prime Minister Victor Ponta (and thus the Government) and of the Mayor of $4^{\text {th }}$ district, Cristian Popescu-Piedone. These gestures of the two politicians came the next day. 
Image 2

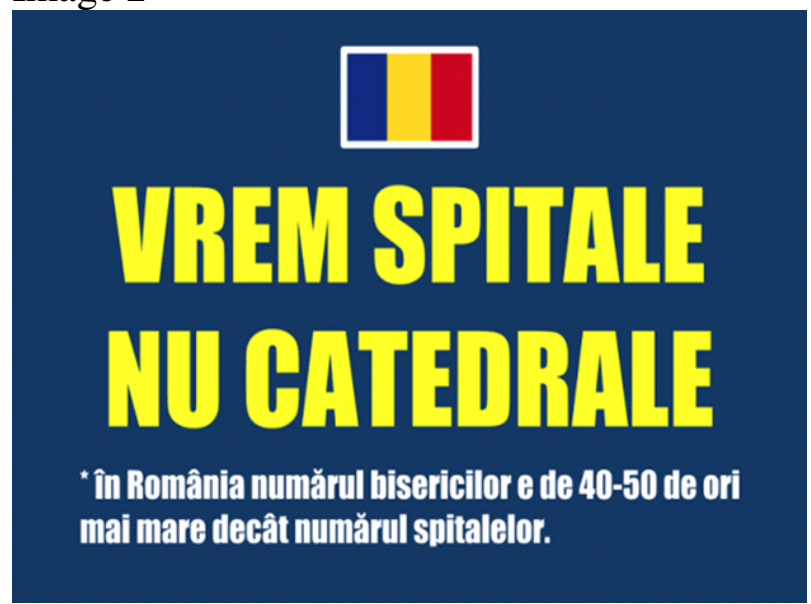

\section{Hacktivism and E-democracy in the context of tragic social events}

Virtual communities often demonstrate civic engagement through initiatives that address issues of public interest. Xenos and Moy (2007, p.708) show that the Internet does help civic engagement but also give "unjustifiable euphoria, abrupt and equally unjustifiable skepticism, and gradual realization that web-based human interaction really does have unique and politically significant properties." Activism that uses Internet resources can take on multiple forms of expression: online petitions, hacking (eg "leakage" of confidential information - Wikileaks or Anonymus), calls to mobilize to public protests or riots, etc. All of these actions fit into the conceptual universe of E-democracy, which implies the use of virtual space to create economic, social and cultural conditions to support the promotion of individual freedoms. These premises underpinned the emergence of major international social movements (Occupy, Indignados, Arab Spring) and mobilization at country level like: Salvaţi Roşia Montana (Save Roşia Montana), Corupţia Ucide (Corruption Kills) in Romania.

The most widespread form of E-democracy manifestation is to address online platforms. Both in the case of the terrorist attacks in France and the fire at the Collective Club, the official pages of some institutions, but also the Facebook and Twitter platforms hosted the views expressed by several thousand people. The present paper aims to point out in a comparative perspective some radical attitudes of different individuals confronted with the above-mentioned events expressed on Facebook. Here are some examples of resentment attitudes (more varied in form and content than the compassionate ones):

a) François Hollande's official Facebook page of the President of the French Republic (https://www.facebook.com/francoishollande.fr/?fref=nf):

Maël Guinot: „Arrête de dire qu'on vainc les terroristes ... on ne fait qu'encaisser les coups sans rien faire ! ... Ce n'est pas en marchant dans la rue que tout cela va s'arranger" (Stop saying we will overcome the terrorists ... we only take blows without doing anything! ... Not by marching in the streets all this will be solved)

Like • 5,098 • November 14, 2015 at 01:25

Alexander Gharib: "François Hollande demande la fermeture des Frontières afin d'éviter aux terroristes de venir sur le territoire français. Tout le monde critiquait Marine Le Pen qui l'a toujours 
demandé. Bravo Hollande d'avoir attendu 120 morts pour cela !!!!!!!!!!” (F. Hollande calls for the closure of the frontiers today to avoid the intrusion of terrorists into French territory. Everyone criticizes M. le Pen who has always demanded that. Bravo Hollande, it took 120 dead for you to do this !!!)

Like $\bullet 460 \bullet$ November 14, 2015 at 04:18

b) Facebook page for the Bataclan Paris attack (https://www.facebook.com/Je-suis-paris$\underline{1663517807228311 /)}$

David Lucas: "Au vue de votre incompétence évidente, vous devez démissionner dans l'urgence ainsi que tout le gouvernement de corrompus qui vous accompagne!!! Vous êtes un traître envers la France et les français !!!!!" (Due to your obvious incompetence, you should resign urgently along with the corrupt government that accompanies you!!! You are a traitor of France and the French!!!!)

Like $\cdot 77 \cdot$ November 14, 2015 at 20:25

Clo Lacour: “ C'est bizarre mais nous n'avons en France aucun problème avec d'autres religions, la seule avec qui les problèmes s'accumulent, devinez, "l'Islam". J'ai 70 ans je ne le verrai pas mais je plains mes enfants, la troisième guerre mondiale viendra de ces barbares qui tuent, qui violent..." (It's strange, but we do not have any problem with other religions in France, the only one where problems pile up, guess which: the Islam. I'm 70 years old, I will not grab, but I'm crying my children, the third world war will come from these barbarians, who kill, who violates...) Like $37 \cdot$ November 15,2015 at 12:27

c) Bucharest: October 30, $2015-$ Colectiv Club - Facebook page (https://www.facebook.com/pg/ajutorcolectiv/posts/?ref=page_internal)

Corina Maria Unga: "Daca ar fura mai puţin (cei din guvern) şi s-ar gândii [sic!] şi la noi oamenii de rând, am putea fii [sic!] o ţară exemplară, cu locuri de muncă bine plătite.. cu spitale amenajate corespunzător.. cu străzi fără gropi.. etc.. şi noi am putea trăi acasă lângă copii [sic!] nostri.. nu la mii de km depărtare" (If they would steal less (the government) and would think of us ordinary people, we could be an exemplary country with well-paid jobs ... with proper hospitals .. with streets without pits. etc. ... and we could live at home beside our children ... not thousands of miles away) Like $13 \cdot$ November 1,2015 at 6:40 pm

Mihai Cristea: "Din cauza voastră s-a întâmplat tot carnagiul asta, voi sunteţi de vină vă este frică de generaţia noastră credeţi că noi dormim dar o să vină şi ziua în care o să plătiţi voi cu vârf şi îndesat pentru tot ceea ce a-ti [sic!] făcut în Ţara asta jeguri nesimţite." (Because of you all this carnage happened, you are to blame, you are afraid of our generation you think we are sleeping but it will come the day you will pay in full for everything you did in this country, you insensitive scam.) Like 72 - November 2, 2015 at 20:56

Frenk Soja: "Acum chiar ne-au ajutat cele 18.000 de biserici care [sic!] le avem în ţară". (On this occasion, the 18,000 churches that we have in the country "really" helped.)

Like $45 \cdot$ October 31, 2015 at 15:15 
Gabriela Serban: "acum 25 de ani nu se știa de sărbatoarea halloween! ...este o sarbătoare ...satanistă "(25 years ago, nobody knew about Halloween! ... it is a satanic celebration ...) Like $85 \cdot$ November 1, 2015 at 01:23

Mereuta Gicu Jimmy: " Politicienii bagă bani în biserici, nu în spitale. Şi în cazuri din astea, se cere ajutorul populaţiei pt donaţii... să dea D-zeu un incendiu de 10 ori mai mare, în camera Parlamentului...să ardeti toţi de vii, politicieni corupţi ce sunteţi!!!” (Politicians are spending money for churches, not hospitals. And in these cases, donations are needed from the population ... let God bring a 10 times bigger fire in the Chamber of Parliament ... let all you corrupt politicians burn alive!!!)

Like $41 \cdot$ November 2, 2015 at 08:32

The common trait of all these attitudes is the fact that they address real problems in an uninhibited manner, to say the least. And even they were not the dominant trend and did not generate large-scale public unrest, this kind of radical speech had its echo on collective conscience. President F. Hollande became the most unpopular president ever and gave up the pursuit of a second term. Marine Le Pen the candidate of far-right party, Front National, reached the second tour of presidential elections. Victor Ponta, Romania's prime minister in 2015 resigned and became an unimportant actor in the political landscape.

\section{Conclusions}

Regardless of what geographic and cultural space would come from, people's reactions to such deep tragedies reach an equivalent level of intensity. Beyond the opportunity to express ideas, criticisms, or even bad language to the shelter of anonymity, the online environment also creates the possibility of crystallizing collective attitudes in support of causes or principles that cross geographical or political delimitations. Cyber-activism is not protected from attempts to manipulate or hijacking (trolling), but unlike the mainstream media, the lack of opinion leaders or spokespersons makes these actions less effective. Also, the lack of censorship or a 'code of ethics' allows the information to reach the individual in its raw state, which is why the quantity and intensity of the first emotions are considerably higher than when receiving information from the press.

Virtual communities are "goal-oriented, created to carry-out a specific mandate" which rely on ,sharing of diverse perspectives and objects commissioned by the mandate" and on "knowledge construction from diverse knowledge systems towards collective use" (Henri and Pudelko, 2003). National and international authorities cannot ignore these new forms of expression of solidarity, either spontaneous or built over time. Beside sporadic extremist accents, collective attitude is essentially manifested through actions meant to defend universal principles and values on which modern civilization is founded.

\section{References}

1. Anderson, B., 1991. Imagined communities: reflections on the origin and spread of nationalism. London: Verso. 
2. Habermas, J., 1989. (1962) The Structural Transformation of the Public Sphere. Cambridge: Polity.

3. Henri, F., Pudelko, B., 2003. Understanding and analysing activity and learning in virtual communities. Journal of Computer Assisted Learning, 19, pp.474-487.

4. Melucci, A., 1995. The Process of Collective Identity. In: H. Johnston and B. Klandermans, eds. Social Movements and Culture. Minneapolis: University of Minnesota Press. pp.41-63.

5. Mitrovici, E., 2016. Raport final în tragedia din Colectiv: Flăcările s-au propagat mai repede decât se crede. România Liberă (daily newspaper) (online version) Available at: http://romanialibera.ro/actualitate/eveniment/flacarile-s-au-propagat-mai-repede-decat-secredea--se-spune-in-raportul-final-in-ancheta-colectiv-412137 [Accessed 22 January 2018]

6. Putnam, R., 2000. Bowling Alone: Collapse and Revival of American Community. New York: Simon \& Schuster.

7. Rheingold, H., 1993. The Virtual Communities: Homsteading on the Electronic Frontier. Reding, Massachusets: Addison-Wesley.

8. Spitulnik, D., 1993. Anthropology and Mass Media. Annual Review of Anthropology, 22, pp.293-315.

9. Xenos, M., and Moy, P., 2007. Direct and differential effects of the Internet on political and civic engagement. Journal of Communication, 57(4), pp.704-718. 


\title{
Civilized and wild heterotopia - the case of the Polish cemeteries
}

\section{DOI: $\underline{\text { http://doi.org/10.26758/8.1.27 }}$}

\author{
Anna E. Kubiak
}

Institute of Philosophy and Sociology, Polish Academy of Sciences

Address correspondence to: Anna E. Kubiak, Institute of Philosophy and Sociology, Polish Academy of Sciences, Nowy Świat 72, Pałac Staszica, 00-330 Warszawa. Ph.: (48 22) 8267181; Fax: (48 22) 8269948; E-mail: akubiak@ifispan.waw.pl

\begin{abstract}
Objectives. The main goal of this paper is to present the characteristic features of Polish cemeteries as a unique expression of Polish traditions. The Poles have strong and ritually supported bonds with their ancestors.

Material and methods. In 2010-2012, I interviewed funeral directors, some of whom were also cemetery managers. Qualitative methods were employed in the form of semi-structured interviews. I also analyzed the journals Memento and Kultura Pogrzebu (Funeral Culture) produced by funeral institutions. Content analysis of the ethnographic and popular literature on Polish cemeteries was followed by the identification of the characteristic features of Polish necropolises, those that are unique to Polish culture.

Results and Conclusions. The Poles are devoted to preserving the past which they find in cemeteries. They cultivate social bonds with their families and Polish heroes while visiting necropolises and talking with the dead. I propose the model of opposition between civilized and wild heterotopy. We can talk about two types of necropolis in Poland: civilized heterotopy (which is Polish classic cemetery) and wild heterotopy. Wild heterotopy can be found in forests or groves. There are places with unwanted (e.g., Germans, Jews) and forgotten dead (e.g., Old Believers).
\end{abstract}

Keywords: cemetery; archive; memory; social bonds; heterotopy.

\section{Introduction}

The main goal of this article is to present the characteristic features of Polish cemeteries as a unique expression of Polish traditions and national identity. Robert P. Harrison, in the introduction to his The Dominion of the Dead (2003, p. xi), suggests that "humanity is not a species (Homo sapiens is a species); it is a way of being mortal and relating to the dead. To be human means above all to bury." He goes on to argue, quoting Giambattista Vico, that the word humanitas is derived from humando, "burying." To be human means above all to bury. Burial means not only laying the body in the grave but, in a broader sense, relates to preserving, protecting, and cultivating the past. In The Work of the Dead (2015) Thomas Laqueur analyses how a complex mix of factors including concern with public health, the waning power of the Catholic Church, and the emergence of a belief that the place where one is buried should be a matter of personal choice - produced a shift whereby necropolises supplanted the church graveyard as the chief place of interment. He describes how sites were created in which the dead were separated from the living as they had not been when they were interred in or near places of worship. With the rise of cemeteries, the dead 
could be remembered as individuals and buried with their families in a way that was impractical in overcrowded churchyards. He writes that no culture has been indifferent to mortal remains. Even in our late modern time, the dead body still matters - for individuals, communities, and nations. These words aptly describe Polish commemorative culture.

After presenting methods, the importance of necropolis in the Polish commemorative culture is shown. Then follows an analysis of cemeteries in the context of Foucault's notion of heterotopia, which is further followed by examples of historic necropolises. The problem of postwar graveyards is discussed in esthetic terms. Then the case of some of necropolises of faiths other than Roman Catholicism in the proposed category of wild heterotopia in opposition to civilized heterotopia is analyzed.

\section{Material and methods}

During 2010-2012, undertakers and cemetery managers were interviewed about the crucial problems of the funeral industry and necropolises. Qualitative methods were employed in the form of semi-structured interviews. In 2010-2012 the content of the journals Memento and Kultura Pogrzebu (Funeral Culture) produced by funeral institutions were also analyzed. Memento was founded in 1995 by Wojciech Krawczyk, a journalist and an enthusiast of death-related issues and is published every 2 months by the Polish Funeral Association. The Funeral Culture magazine was founded in 2004 by an undertaker and is associated with the Polish Funeral Chamber. Recipients of magazines are undertakers, producers of burial facilities and graveyard managers. Both magazines have a rich layout and upload numerous photographs of funeral homes, manufacturing companies, artifacts, hearses, graveyards and undertakers on the occasion of the training and the fair. Both journals present cemeteries in Poland and necropolises from abroad. Also, legal procedures of cemeteries and burials are discussed. Content analysis of the ethnographic and popular literature on Polish cemeteries was also conducted in order to identify the characteristic features of Polish necropolises, those unique to Polish culture.

\section{Results}

Elsewhere (Kubiak, 2014) the most characteristic features of this culture were identified: mourning, strong bonds with ancestors, myths of tribal catastrophes and the achievements of heroes. The main rituals take place in the sacral spaces of ancestor cults. The topoi of the mythic narrations are death, suffering, communication with heroes and ancestors, and bloody sacrifices. The Poles have strong and ritually supported bonds with their ancestors. Cemeteries are often visited, obligatorily on All Saints' Day, Christmas and Easter. The graves are carefully cleaned and decorated with garlands, flowers, and candles. All Saints' Day together with All Souls' Day is the most collective holiday in the public space. For a long time before the holiday, markets are full of ever-burning fires. One cannot forget about the approach of All Saints' Day because mourning flowers - chrysanthemums - and flames can be seen everywhere: when buying newspapers from newsstands, on the streets, in squares, and in supermarkets. The Poles collectively go to the cemeteries. Bringing candles and flowers to graves and meeting with families and friends is part of the process of affirming social bonds among the living and between the living and the dead. During these days, bus and train lines change routes to the necropolises. The police, under the banner of "the ever-burning fire," try to prevent traffic jams and accidents. Poles independently of their structural characteristics, such as the age or socio-economic position follow this tradition. The spirit of this holiday is very well expressed by Paul Allen (2008, p.15): "This ceremony performed in the 
smallest village and in the biggest city defines what it means to be the Pole. This is the pilgrimage, which cannot be avoided. The consciousness who they are, the Poles owe to the strong belief that on All Saints Day the ancestors speak beyond the grave".

As Michel Foucault has taught us, the category of space is one of the basic notions. Space is - unlike time - still heterogenic and cannot be reduced to something else. Heterotopia is, in a way, an unreal, peculiar, odd place. It differs "in an absolute way from all other places" and is "sort of contre-emplacements" (Foucault, 2005, p.120), contesting and dislocating the order of other places. A cemetery is a classic heterotopia. As a sacral space, this heterotopia is isolated, surrounded by a fence and with a special entrance: the gate. The Polish anthropologist Stefan Czarnowski (1956) stated that every religious unit is a space isolated from the rest. It consists of the middle, the border and the space between them. In the middle and on the border are the greatest levels of intensity of holiness. In the middle of the cemetery, as a sacred space, there is a cross or a chapel which is, according to Czarnowski, opened toward the vertical - heaven. It has been the most desired place for burial (Sikora, 1986, p.60). On the borders, in one particular corner, dangerous people were buried: unbaptized children, suicides, Jehovah's Witnesses, and unbelievers (Sikora, 1986, p.60), which is not the case anymore. The cross of borders has the greatest intensity of power. What kind of power? The word sacer means holy and damned at the same time (Sikora, 1986, p.60). This ambivalent character of the religious space has been underlined by phenomenological anthropologists like Mircea Eliade (1970) or Gerardus van der Leeuw (1978). In this unhallowed corner were the dead who will go to hell or become extraterritorial and wander around as demons (Sikora, 1986, p.60).

Cemeteries were absorbed by the city as it expanded and the risk of epidemics disappeared. So now it is the Other City - the City of the Dead (as it is used to say in Poland) - in the city. In Polish tradition, tombs are treated like houses and the coffin is named "overcoat." While visiting the cemetery, people talk with their ancestors. The director of Powązki, the Warsaw cemetery, says, "There comes the moment in a human's life when he starts to care and plan for his tomb, as for the house before. Today nobody wants to have an earth tomb, everybody wants to have brick, with a monument. The best is from granite to preserve it for a long time. Important are the place, the quarter and the neighbors" (Sikora, 1986, p.57).

One of the roles of a heterotopia mentioned by Foucault (2005) is its historic importance as an archive. The cemetery is an archive of symbolically important times of war, catastrophe, and so on. In Poland, the dead are very mobile. There is a special category of "exhumans" (exhumed persons) who change their location. There are "exhumans" coming back from abroad and being welcomed with enthusiasm. Corpses are very useful for the "politics of dead bodies" described by Katherine Verdery (1999), a question of private and collective memory which an object of political manipulation is also. In Polish the word: tomb - pomnik - is connected to the word memory pamięć. The role of memory is repeated often in the discourse of cemeteries and the Day of the Dead (All Saints' Day and All Souls' Day) - the most public holiday in Poland. The word pamiatka (remembrance) appears often in epitaphs on tombs. There is the tradition, now undergoing a revival, of memorial tomb photography. It is a sign of the importance of family memory. Most of the photographs have an ellipse shape which corresponds to the form of imago clipeata (an ellipse shape), characteristic of coffin portraits (Kubiak, 1986).

The funeral journals present the best examples of Polish historical cemeteries as places of Polish heritage, collective memory, and national identity. The authors of the articles underline the devotion of Poles to preserve and renovate them. The most famous necropolis is the Central Cemetery in Szczecin. It is the cemetery with the biggest variety of graves, from well-preserved old tombs to new designs. It is the biggest necropolis in Poland and the third largest in Europe. It has 
won the award in a competition organized by the National Geographic Traveler for seven "miracles" in Poland. Officially opened in 1901, it took its design from the necropolises in Hamburg and Vienna. It occupies 172 hectares and includes 400 types of trees and shrubs (Wolicki, 2011, p. 10). The project was prepared by the architect Wilhelm Meyer-Schwartau, who included the natural landscape: hills, stones and water flows. There is a botanical pathway through the most interesting natural features. The tourist guide features a description of flora with references to their symbolism: yew in Celtic tradition symbolizes the gate to the other world, the box means hope of resurrection and eternity, hornbeam is identified with care, ilex is the symbol of the Christmas holiday, ivy relates to the memory of the dead. There are representations of wild animals: birds, foxes, raccoons, badgers, hares, hedgehogs, red squirrels, wild boar, frogs, snakes and wild ducks. Owing to the manager of the cemetery, Maria Michalak, who is devoted to her work, lapidarium has been laid. It is a place where German tomb relics are gathered and renovated. In the interview she said:

"There are quite a few remains of the German, that I rescue and still think, that it is what I saved from oblivion and I admire what was before us, that is, prior to this period, when the cemetery was taken over (by the Polish communist regime - AEK). And, you know, I assert with all the responsibility that the designers of this cemetery were phenomenal. Today no cemetery, none, I emphasize, with full responsibility, there is no such message, such a vision of the perspective of such thinking forward. Here everything is thought out in detail" (The interview no. 16).

Powązki, the oldest cemetery in Warsaw, was founded in 1790. It was enlarged 19 times and now includes 43 hectares. More than 2.5 million people have been buried there (Danecka, 2010, p. 34). It was devastated during the Second World War and for a long time only paths, greenery, water and electric structures were renovated. In 1974, a social committee was founded by the writer Jerzy Waldorf and some famous actors, among others. Every year, during All Saints' Day, they organize collections: actors stand by the gates with cans and people donate with enthusiasm. For Warsaw inhabitants, visiting Powązki is a popular ritual, even if relatives are buried elsewhere.

The Old Cemetery in Rzeszów was founded in 1792 and has been abandoned twice: during the Second World War and when the Communist authorities decided to close it and a fighting squad destroyed many tombs, which were used as building material for roads. A passionate group of volunteers committed to preserving cultural heritage, with Włodzimierz Kozło as their leader, sought to save the cemetery. Owing to their work, the necropolis was registered as a relic in 1968. But only political changes helped to speed the conservation process and, in 2001, the Society of Care over the Old Cemetery was founded. They took care of the old stands of trees and sepulchral sculpture. The Old Cemetery occupies 365 hectares and includes 622 tombs. Many of its sculptures come from the famous Schimser Lwow atelier. There are examples of historical styles such as classicist and Neo-Gothic, and some sculptures feature heraldic arms and stone figures (Kałuszko, 2011a, pp.34-36).

One of the oldest necropolises in Poland is the Roman Catholic cemetery in Radom. It was founded in 1812 and more than 200 people were buried there. Once again, through the efforts of cultural workers and pupils, who were educated in restoration techniques and conducted descriptive and photographic inventories, the cemetery has been renovated. The main source of financing comes from social donations, which are a Polish custom during the Day of the Dead. The cemetery at Radom preserves 335 objects registered as historical relics (Kałuszko, 2011b, pp. 24-26). The renovation of cemeteries is understood as necessary to the preservation of the nation's heritage. Historical necropolises are reminiscent of art galleries in which sepulchral sculptures and green relics compose the art space. 
Benjamin Franklin is supposed to have said, "Show me your cemeteries, and I will tell you what kind of people you are" (West Virginia Arnold Hill Cemetery Association, 2013). Polish undertakers notice positive changes in the Polish cemeteries since the 90s. Here are some illustrative fragments from the interviews:

"The change is also that almost everyone has the tombstone. At the moment people like monuments and take care of them because it is publicly exposed. It is the difference between a cemetery before fifty years and today" (The interview with the undertaker no. 12).

"But I have to tell you, that how I look in retrospect, these cemeteries are increasingly cared for, even these smaller cemeteries. Some have cheaper monuments but they are gravestones and they will survive years. These cemeteries are getting nicer. People bring lots of flowers and other decorations. Once on the villages, who walked to the cemetery after the funeral? Before All Saints, possibly some during kind of anniversary and that is all. But nowadays in the countryside cemeteries are not different from the city. That is changing" (The interview with the undertaker no. $35)$.

The look of the necropolis depends on the culture and its system of values. These have their consequences in cemetery law. Since 1846, when the regulation governing cemeteries was founded by the administration of the Polish Kingdom during the rule of Tsar Nicolay I (Długozima, 2011b, p. 15), cemetery managers have had to take care of the aesthetic dimensions of the necropolis. The present Polish law on cemeteries and the legal mandate for the deceased dates from 1959 and duplicates provisions enacted even earlier, in 1932. There are around 20 new legislative acts, so the rules are dispersed. There is a regulation mandating that cemeteries should be treated like parks. But this is only the intention of the legislator. While the Nature Protection Act keeps historic cemeteries safe, those not covered by conservation rules are at the mercy of officials at the lowest level. Upkeep decisions are often left to a parish priest, supported by inhabitants who are more interested in the practical aspects of cleaning (no leaves and bird excrement) than in caring for greenery and making sure trees are pruned. In new cemeteries, this greenery is often neglected, and there is a fatal practice of Polish managers leveling the ground instead of preserving the natural layout of the area (Długozima, 2011a, p.17). Although research into the natural environment is legally mandated when planning a new cemetery, it is not legally required that the results be implemented when developing necropolis projects (Długozima, 2011b, p. 40). Until the Second World War, there were many specialists in cemetery projects. Now new necropolises are kitschy and identical, because of limited choice and of the prize of tombstones. So many people choose lastric tombs in 80-ties and now ready-made tombs from China (Długozima, 2011c, pp.17-19). Owing to the initiative of Anna Długozima and the foundation of the Sepulchral Art Section at the Department of Landscape Art at the Main School of the Village Farm in Warsaw, there are efforts underway to change this and propose alternatives to serial, standard patterns both in greenery and monuments.

Funeral press criticizes cheap tombstones and decorations from popular culture: "In the historic cemeteries in Warsaw and other cities, between old tombs, which often were designed by great artists, the tombstones from the Chinese marble or other stone, in the shape of a simple disc equipped at the top of the vertical surface in the shape of a wave began to appear in the recent years. There are many of them. It is hardly surprising because they are relatively cheap. People gifted with aesthetic sensibility are not able to come to terms with the fact that these monsters with impunity are penetrating the mood of the necropolis, to stand right next to the beautiful sculptures of the 19th century" (Memento 2010, no.3, p.12). 
"Unfortunately, the free market also leads to unhealthy competition that results in progressive kitsch cemetery ornaments. Popular are also candles with LED. You do not have to light up matches any longer. Steel flower, colorful granite and marble, liquid crystal display screen and plaster figurines, music boxes and letters only golden. This is the shortest list of pervasive, cemetery kitsch" (Funeral Culture 2012, no 8, p 12).

The editors of both journals: Memento and Funeral Culture try to promote positive patterns through presenting old Polish necropolis, as well as presentations of Polish artists of the sepulchral, commemorative, vanitative and floristic art. Memento also posted the text of the outcome of the contest of modern tomb, organized by the Office of Capital Historic Preservation and Polish Architects Association. The problem of the esthetic of postwar cemeteries has been also the permanent topic of complaints among funeral directors and cemetery managers. One of them said:

„Here, for example, this cemetery (the Central Cemetery in Szczecin) was founded in the unspoilt former gravel workings. This inequality was used perfectly on-the-spot, to the cemetery to spice things up, to not close out various lakes, various terraces, bleeds, descend, paths. This is fantastic. And what we today we do when we design a larger cemetery? First of all, we focus on leveling the terrain. This is a huge mistake" (The interview no. 16).

In Poland, there are also necropolises of faiths other than Roman Catholicism: Evangelical-Augsburg (Lutheran), Orthodox, Jewish, Old Believers, Protestant, Mnemonic, Greek Orthodox and Tatars. The Jewish cemetery in Łódź is the largest Jewish cemetery in Europe. There are approximately 180,000 tombstones. The cemetery was founded in 1892. In the southern part of the cemetery can be found the field of the ghetto - the burial place of about 45,000 victims of the Litzmannstadt Ghetto.

More than four hundred Jewish cemeteries have not survived. They have been developed for housing, playgrounds, landfill or mine sand. "Sand, used in the construction of apartment blocks is mixed with human remains," according to Mikołaj Gliński (2013). Only 150 Jewish cemeteries contain more than one hundred tombstones. Jewish tombstones decorated with symbols and inscriptions carry with them information about the lives of actual people and families. It is difficult to estimate how many matzevot (Jewish tombstones) existed before the Second World War in the 1,200 Jewish cemeteries in Poland. Maybe a few hundred thousand, maybe a few million. During the war, the German occupiers used them to pave roads and the yards occupied by buildings. The Poles continued these practices after the war. They used them to pave a railway embankment or the shore of a river. They used them to build ovens, floors, curbs. In the Polish villages you can find hundreds of grinding wheels made of Jewish tombstones. Still, you can see in them the Hebrew inscriptions. An album by Łukasz Baksik (2013) includes photographs of such multipurpose matzevot in Polish villages and in the cities. These are the gravestones as paving slabs and curbs, as querns (used for grinding grain to make bread), as a wall, as stairs, as hardened roads - in the end, they were repurposed as Christian tombstones. These missing gravestones Baksik found located in the backyards of farms, in town squares, within the walls of Christian cemeteries, in buildings, barns, as building blocks of bridges, towers, monuments. To photograph these often heavily camouflaged matzevot he had to break the taboo of the community - "a community of shame," as Joanna Tokarska-Bakir says (Glinski, 2013). "I am surprised by this stealing from the cemeteries. Not only because the sandstone, from which generally gravestones are made, is a weak building material. After all, it is also, for Poles, for Catholics, a sacred thing. We are enraged about when someone will devastate the Eaglets' Lwow Cemetery, tip over a headstone or a cross. And in the matter of the Jewish necropolis we are completely insensible," says Baksik (Glinski, 2013). His 
photographs document how far advanced is the obliteration of all traces of Jewish culture, not only by the Germans, but also Poles. "Trying to understand this lack of indignation at the sight of all these different places and new uses of matzevot he wonders whether these scattered gravestones Poland do not travel in the search for the dead and there are, where Baksik photographed them, as it were, in the right place? [...] So I guess it must be that the dead, who have not been decently buried, wander among the living, not giving them peace," says Jan Tomasz Gross and continues, "Until finally, the time comes when we tell ourselves this human disaster as part of our own history. And in place of complacency and its benefits will come the understanding of loss and a mourning sadness in the collective consciousness of the Poles. And then the war nightmares' torment will stop, and the gravestones photographed by Baksik return to the cemeteries" (Glinski, 2013).

Old Believers, called also Filippians, left Russia in the $17^{\text {th }}$ century because they were in conflict with the Orthodox Church and so were exiled to Sybir. Many of them settled down in Mazury in the first half of the $19^{\text {th }}$ century, about five thousand of them near Suwałki and some near Ruciane-Nida. Their main religious center was in Wojnowo, where there is still a molenna - the house of prayer. In 1945 the Red Army exiled them to Sybir and some migrated to Germany. As I spend my vacations near Wojnowo, in Zgon (which means death in Polish), I became acquainted with several Old Believers' graveyards and one German cemetery in Zgon which are neglected and hard to find in the forest. As Old Believers had never been the part of the local community, so they are still considered non-people. They can be forgotten and their cemeteries are omitted. Germans are remembered as aggressors and inhabitants don't want to take care of Evangelic graveyard.

\section{Conclusions}

The cemetery described by many ethnographers and historians as the space of sacrum, cultural heritage, memory, and identity is particularly relevant in the case of Polish cemeteries. They have a special status and canon of behavior. The Poles are devoted to preserving the past which they find in cemeteries. They cultivate social bonds with their families and Polish heroes while visiting necropolises and talking with the dead. But the examples of graveyards on post-migrant territories of Poland are contre-emplacements which display the importance who are the dead. Thus, this study proposes the model of opposition between cultivated and abandoned cemeteries. We can talk about two types of necropolises in Poland (there can be more typologies): civilized heterotopias and wild heterotopias.

Wild heterotopias are atopic places. They are absorbed by Nature. Here the border between culture and nature is blurred. Also the border between life and death - so well kept in civilized heterotopias - is blurred. Here we can expect a second life of the dead, or at least a second life of corpses. Looking for other metaphors of wild heterotopias, we can think about "places of nomemory," as described by Pierre Nora (2009). They are "no-places in the dialectics of memory and forgetting" (Czaja, 2013, p.302). We can also take into account Claude Lanzmann's description of such lost graveyards as non-places of memory. Even funeral journals and undertakers don't mention the problem of neglected necropolis. Georges Didi-Huberman (2012) writes about "places despite everything." There are rituals which are no-rituals performed by accidental tourists, men looking for a place to drink and conscious visitors like new people having summer houses and bringing and lighting the ever-burning fires. Their imagination surrounds these non-cemeteries with a special, symbolic aura. By local people these places are made active in the way that they are passed by, omitted - made the taboo places. Locals want to forget them - or, rather, not to remember them. These non-places recall also the Derridean notion of "chora" (1999). Giorgio Agamben refers to the notion of "hypostasis" as "something of the shape of the substrate, primers or sludge, what historical 
processes of subjectivation and de-subjectivation, humanization and dehumanization leave one after the other like the foundation of its development" (Agamben, 2008, p.159). It can be also called "post place," a place which after traumatic history has been lost and left and is taken in by the power of Nature. At the same time, it is the place which owing to "post memory" is enlivened, but "using Hirsch's (2008) words, in a 'substitutive and usurping way"' (Sznajderman, 2013, p.56). There is also the notion of "xenotropy" proposed by Robert Macfarlane (2013) for the strange places he met during his journeys. He had the feeling of entering into a completely different, separate world. Wild heterotopias can be found in forests or groves. There are places with unwanted (e.g. Germans, Jews) and forgotten dead (e.g., Old Believers).

China Miéville in the science fiction novel The City and the City (2009) describes two cities existing in one place. To live and move around, inhabitants have to learn how not to see, how to omit the space of the other city. Poles analogically cultivate commemorative memory of their dead but are educated not to see aliens' dead. As the cultural anthropologist Joanna Tokarska-Bakir (2013, p. 10) writes, they are trained to "actively avoid" the historical meanings of artifacts (images of a Jew with a coin) and places. Although collective memory simply renounces inconvenient stories that show the community in a "bad light" (such as using matzevot in a profane way), it does not eliminate them. Collective memory preserves traumas on deeper levels. These underground layers of memory are the equivalent of the "forgotten," lost in the landscape, "wild heterotopias." Fortunately, new, informal, local communities arise and start the process of revitalization of destructed cemeteries (Zawiła, 2017).

\section{Acknowledgments}

This research was supported by founding from the National Science Centre, grant no. 116081739.

\section{References}

1. Agamben, G., 2008. Co zostaje z Auschwitz (Remnants of Auschwitz). Warszawa: Sic!.

2. Allen, P., 2008. Amerykanin jedzie na Powązki (An American goes to Powazki). Gazeta Wyborcza, 31 Oct. - 2 Nov. (Feuilleton), p. 15.

3. Baksik, Ł., 2013. Macewy codziennego użytku (Matzevot of everyday use). Czarne: Wołowiec.

4. Czaja, D., 2013. Nie-miejsca. Przybliżenia, rewizje (Non-places). In: D. Czaja, ed. 2013. Inne przestrzenie, inne miejsca: Mapy i terytoria (Other Spaces, Other Places. Maps and Territories). Czarne: Wołowiec, pp.48-62.

5. Czaja, D. ed., 2013. Inne przestrzenie, inne miejsca: Mapy i terytoria (Other Spaces, Other Places: Maps and Territories). Czarne: Wołowiec.

6. Czarnowski, S., 1956. Kultura religijna wiejskiego ludu polskiego (Religious culture of the Polish folk). Warsaw: PWN.

7. Danecka, A., 2010. Coroczne kwesty ratunkiem dla zabytkowych Powązek (Every year donations save Powązki). Memento, 1, pp.34-35.

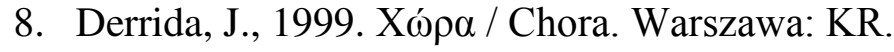

9. Didi-Huberman, G., 2012. Obrazy mimo wszystko (Images despite everything). Warszawa: Universitas.

10. Długozima, A., 2011a. Polska kontra reszta świata (Poland versus the rest of the world). Kultura Pogrzebu, 8, pp.14-17.

11. Długozima, A., 2011b. Prawodawstwo cmentarne na Zachodzie (Cemetery legislation of the West). Kultura Pogrzebu, 8, pp.40-41. 
12. Długozima, A., 2011c. Oryginalność made in China (Originality made in China). Kultura Pogrzebu, 7, pp 17-19.

13. Eliade, M., 1970. Sacrum mit historia (Sacrum myth history). Warszawa: PIW.

14. Foucault, M., 2005. Inne Przestrzenie (Different Spaces). Teksty Drugie, 6, pp.117-125.

15. Gliński, M., 2013. Łukasz Baksik, Macewy Codziennego Użytku (Matzevot of Everyday Use). Culture.PL [online]. Available at: http://culture.pl/pl/artykul/lukasz-baksik-macewycodziennego-uzytku [Accessed June 22, 2017].

16. Harrison, R.P., 2003. The Dominion of the Dead. Chicago: University of Chicago Press.

17. Hirsch, M., 2008. The Generation of Postmemory. Poetics Today, 1(29), pp.103-128.

18. Kałuszko, J., 2011a. Stary Cmentarz w Rzeszowie i jego obrońcy (Old Cemetery in Rzeszow and its defenders). Kultura Pogrzebu, 10, pp.33-36.

19. Kałuszko, J., 2011b. Stary Cmentarz ma opiekunów (Old cemetery has guardians). Kultura Pogrzebu, 11, pp.24-27.

20. Kubiak, A.E., 2014. Inne śmierci: Antropologia umierania i żałoby $w$ późnej nowoczesności (Other deaths: Anthropology of dying and mourning in late modernity). Warszawa: Universitas.

21. Kubiak, K., 1986. Wokół fotografii nagrobnej (Around tombstone photography). Polska Sztuka Ludowa, 1-2, pp.69-82.

22. Laqueur, T.W., 2015. The Work of the Dead: A Cultural History of Mortal Remains. Princeton: Princeton University Press.

23. Macfarlane, R., 2013. The Old Ways. A Journey on Foot. London: Penguin.

24. Miéville, C., 2009. The City and the City. London: Macmillan.

25. Nora, P., 2009. Między pamięcią i historią (Between memory and history). Archiwum, 2, pp.412.

26. Sikora, S., 1986. Cmentarz: Antropologia pamięci (Cemetery: The anthropology of memory). Polska Sztuka Ludowa, 1-2, pp.57-68.

27. Sznajderman, M., 2013. Przerwy w pamięci: Historia rodzinna (Interactions in memory: Family history). In: D. Czaja, ed. 2013. Inne przestrzenie, inne miejsca: Mapy i terytoria (Other Spaces, Other Places: Maps and Territories). Czarne: Wołowiec. P. 56

28. Tokarska-Bakir, J. Żyd z pieniążkiem (Jew with coin). In: J. Tokarska Bakir, ed. 2013. Tożsamość wyobrażona (Imagined identity). Warszawa: Czarna Owca. p.10

29. Van der Leeuw, G., 1978. Fenomenologia religii (Phenomenology of religion). Warszawa: Książka i Wiedza.

30. Verdery, K., 1999. The Political Lives of Dead Bodies: Reburial and Postsocialist Change. New York: Columbia University Press.

31. Wolicki, K., 2011. Cudowny Cmentarz (Miraculous Cemetery). Kultura Pogrzebu, 10, pp.1011.

32. Zawiła, M., 2017. Cemeteries revitalized by local communities - local communities revitalized by cemeteries in the post migrant territories of Poland. A mutual relation of heritage and society Paper presented 5th workshop conference of Architecture, Archaeology and Contemporary City Planning (AACCP), Turku, 15-18 May

33. ***West Virginia Arnold Hill Cemetery Association, 2013. History of Arnold Hill Cemetery [online]. Available at: http://www.rootsweb.ancestry.com/ wvahca/history.htm [Accessed January 22, 2017]. 


\title{
An investigation of television programs that illustrates superstition and its effect on viewers
}

\section{DOI: http://doi.org/10.26758/8.1.28}

\author{
Arulchelvan Sriram
}

Department of Media Sciences, Anna University, Chennai, India

Address correspondence to: Arulchelvan Sriram; E-mail: arulchelvansriram@gmail.com

\begin{abstract}
Objectives. Superstitious beliefs continue to plague the Indian society despite efforts from revolutionists and various organizations, who have used science to eradicate some beliefs. People with deep rooted superstitions face the risk of losing their families and livelihoods due to their over dependence on such beliefs. To overcome this problem, media are used to create awareness among people. This study aims to check whether non-fiction television programs on superstitions play a role in changing people's mind-sets.

Materials and Methods. Content analysis was done on non-fiction programs like Moondravathu Kan, Nambinal Nambungal and Marmam that aired during February and March 2016. Totally 40 episodes of the programs were analysed. The survey method was adopted to understand how superstitious content in Tamil television affected the audience. A purposive sampling technique was used to identify 132 respondents.

Results. Majority of the content is related to religious beliefs and blind beliefs like magic healing, future prediction and black magic. These programs are produced based on information gathered from superstitious practitioners or the public and is telecast in a dramatized form. Almost $65 \%$ of the episodes use a neutral narrative tone passing no judgments on such beliefs. The survey revealed that around half of the respondents believe in superstitions. People believe that the majority of the stories are only partially true.

Conclusion. Watching of these programs has resulted in superstitious beliefs being reinforced in few people and has stimulated interests in some people to know more about such superstitions rather than creating awareness on the negative effects. This study therefore recommends that programs focus on providing scientific explanations and having expert discussions that provide an in depth understanding of a superstition rather on simply showcasing a superstition.
\end{abstract}

Keywords: superstitions; TV programs; awareness; audiences; eradication

\section{Introduction}

Superstitions are beliefs or practices that presuppose a faulty understanding about cause and effect, usually by assuming concepts of causality that have been rejected by modern science but may represent long-standing popular beliefs or practices. Superstition simply means a belief with no scientific reason but followed by many as blind beliefs with the thought that there may be any reason behind such beliefs. Many such superstitious beliefs may be harmless but few others are physically, psychologically and economically harmful. This study is about some of the harmful beliefs like black magic, witchcraft, supernatural shown in non-fiction television shows and the audience's perception about these shows and their content. 


\subsection{Superstition}

Superstition has many definitions which differ from each other in few aspects and show similarity in few other aspects. According to Corsini (2002, p. 419), superstition is a belief or a practice based on the operation of supernatural or magical forces, such as charms, omens, and exorcism, or any unscientific belief accepted without question, groundless or unfounded notion. Alternatively, superstition is defined as an irrational belief or practice resulting from ignorance or fear of the unknown. The validity of superstitions is based on belief in the power of magic and witchcraft and in such invisible forces as spirits and demons.

Superstitions and selfish desires weave a pattern of mind which interprets objective and subjective happenings in life as forebodings of personal weal and woe. Superstitions have been in existence from stone age because people in the olden days were not aware of the science behind the uncontrollable events (Khantipalo, 2013). "The origin of certain superstitions is often connected to the intention of attributing adverse events to specific causes" (Cercignani quoted in Morris, 2013, p.39).

This idea about understanding of superstition is that inclinations towards illusion make weak men superstitious and superstitious men weak. The illusion that leads them to mistake the subjective for the objective, to take the voice of inner sense for knowledge of things themselves, also makes the tendency to superstition comprehensible.

Superstitions exist in all cultures throughout the globe and are as old as mankind. Many customs that are being followed now as a part of our culture have evolved from superstitious beliefs of the past. It is also said that superstitions of today are the scientific facts of tomorrow (Balderston, 1927).

\subsection{Superstition and Psychology}

Richard Wiseman et al. (2004) says a large body of research has attempted to develop theories about the function and origin of superstitious beliefs on the basis of the psychological correlates of such beliefs. Most of this work has measured superstitious belief using the paranormal belief scale (PBS), and tended to find that superstitious belief is associated with poor psychological adjustment such as low self-efficacy and high trait anxiety. However, the PBS refers solely to negative superstitions (e.g., breaking a mirror will cause bad luck) and omits items referring to positive superstitions (e.g., carrying a lucky charm will bring good luck). Positive superstitions may serve different psychological functions in comparison with negative superstitions.

According to Ofori et al. (2016), superstitions are behaviors that people perform in an attempt to affect or control their future. Superstitious behaviours are a way people think they can control their fate by performing certain tasks in a certain way to either help alleviate anxiety or to simply better their chances in a certain situation.

Most human behavior can be classified as a superstitious ritual. Many of very same belief are the ones change how the person feels. People try to remove needless and trivial superstitions by casting them on the basis of enlightenment and progress, but invariably they would find it harder to exclude them from altogether. Even though it acts like superficially irrational and also might seem reasonable in many cases. For them, superstitious beliefs and ritual work on the basis of psychology rather than magic (Risen and Nussbaum, 2013).

The earlier studies on supernatural and paranormal belief tend to be more dismissive towards the believers and further question their intellectual ability, educational qualification and 
even their personal belief (Emme, 1940; Lundeen and Caldwell, 1930). However, those studies heavily lean on simple superstitions, but in recent research focus on more nuanced and complex phenomena in likes of ESP, psychokinesis, and precognition (Boshier, 1973; Irwin, 1993). Many other researches have found that people who believe in paranormal phenomena especially among college and university students do not generally reject the notion of mainstream science or technology (Schouten, 1983). Also, some research concludes that in some cases people who have higher education and intellectual abilities tend to believe in paranormal phenomena (McGarry and Newberry, 1981).

The further studies shown there are significant gender gaps among the paranormal believers. Here the women believe in paranormal phenomena more their male counterparts. (Irwin, 1993; Rice, 2003). As men have prone to believe in extra-terrestrials, UFOs, alien technologies and other scientific myths (e.g. Rice, 2003). According to Blackmore (1994), males are socialized and exposed to contents associated with science-based contents. And women tend to lean towards in religious and fantasy based myths. Additionally, a study by Lester, Thinschmidt and Trautman (1987) state that precognition experience and paranormal belief were linked to feeling and intuition, and support the view that believers could be less logical.

\subsection{Superstition and Religion}

Many of the superstitions prevailing today are associated with religion. Different religions have different superstitions, which are mostly correlated with their religious culture. Burhmann and Zausg (1983) found that superstitious behaviors and practice were directly correlated with religious beliefs. Earlier studies also found that traditional religious belief correlated positively with belief such as witchcraft and precognition, but negatively with belief such as spiritualism and nonsignificantly with belief in psi, superstition, and extraordinary life forms (Tobayck and Milford, 1983). Another study found that the results differ slightly different with religiosity correlating positively with belief in psychic healing and negatively with UFO belief (Clarke, 1991).

Wuthnow (1976) also reported that belief in astrology is stronger in people who are unable to work or who are looking for a job, but, in the study by Emmons and Sobal (1981), the correlation between astrological belief and unemployment was not significant. The significant data for religion, superstitions, and astrology nevertheless are consistent with the social marginality hypothesis.

Tobacyk et al. (1988) consider that traditional religious belief may be a major exception to the general trend of a decline in number of paranormal beliefs across groups of increasing age. But Emmons and Sobal (1981) found that there are no significant age-related differences in religious belief, and other studies have actually noted an increase in religiosity among elderly.

According to Sparks and Miller (2001), there are sound conceptual reasons, by which the less relationship between superstition and religious belief domains are explained. As Sparks suggests, there are complex reasons surrounding the lack of endorsement in most paranormal phenomena when it deals with religious fundamentals This is due, in a way, to religious believers who shun the possibility of occurrence of such phenomena and secondly, to the direct religious teachings which insists that the followers have complete and unflinching faiths. These factors are untreatable using the scientific method.

\subsection{Superstitions in India}

Though we are living in the era of advanced science and technology, few old beliefs, customs, and superstitions have yet changed. There are many superstitions and blind beliefs 
predominant in India. The only remedy of these blind beliefs is considered to be education and social awareness. Most of the people are superstitious in some way without their knowledge. It is said that science alone can solve the problems of hunger and poverty, of insanitation and illiteracy, of superstition and deadening custom and tradition, of vast resources running to waste, of a rich country inhabited by starving people.

There are endless beliefs and superstitions in India which are associated with every aspect of daily life right from birth to death of a person. Few beliefs find their way into the religious texts and scriptures of India. In India, till mid-nineteenth century, many women were burnt alive in their husbands' funeral pyre because of the superstition that they would live together in heaven. Similarly, human sacrifices were carried out all over India, either to appease God or to get blessings of god. Likewise, many superstitions existed in India. These beliefs act as destruction to our knowledge and depress the basic impulse to think and act. All superstitions are unsafe since they inactivate the thinking capacity of people. Besides, they capture human attempt and activity. And also they make individuals misuse their vitality, time and cash in useless customs and rituals. These things lead to delay in the advancement of society. Thus, it is necessary for a society to be cautious about superstitions. These things collectively reduce the reasoning brain of our people and reinforce the roots of superstitions among the society.

\subsection{Superstition and Media}

Media interpretation of the superstitious beliefs and practices influence the way people think about the subject particularly the emotional effects of frightening in movies and television programs. Such films and Television serials can dramatically raise the levels of physiological arousal and induce a variety of post-viewing effects, such as haunting images, bad dreams, fear of being alone, and the fear of going into a certain room in the house (Cantor 1994; Sparks, Spirek and Hodgson 1993).

According to Gerbner et al. (2002), television cultivates a common outlook or world view among its viewers. The more television a person watches, the more likely he or she is to accept the premises and facts of television reality as if they were facts of the world of everyday reality.

Media has a role to play in removing the blind beliefs from a society especially television channels owing to their impact on audience. But there are certain television channels that force us to believe certain blind faiths. The pictures in people heads are mainly constructed from the pictures they get from mass media (Lippmann, 1922).

Among scholars and skeptics, there is a common assumption that the mass media should take a major responsibility for the fact that so many people seem to accept paranormal claims uncritically. The reason for the prevalence of "absurd beliefs" among the populaces of very culture is to be found in the uncritical acceptance and promotion of these notions by the media. Kurtz (1985) called attention to the, "dominant influence of the media in forming [paranormal] attitudes and beliefs," and charged that the media often "behave totally irresponsibly in treating 'paranormal' occurrences". Feder (1984) blamed the media for the problems faced by archaeologists in their attempts to overcome the many reports of "unverified claims". Maione (1998) wrote that the programs on major TV networks often present a misleading account of the scientific status of paranormal claims by failing to fairly present the skeptical side of the story. A program that misrepresents the evidence for a particular claim is bad, but one that misrepresents the scientific method in doing so is many times worse. These blind beliefs shown on television have greater impact on audience behavior. 
Television has great impact on psychology of the audience; the audience tends to believe most of the things which they see on television. The more television a person watches, there is more chance that the person may accept the premises and particulars of television as if they were real facts of the world. So, the superstitions shown in Non-Fiction programs can reinforce superstitious beliefs in audience, which may result in adverse reaction in audience psychological behavior and it may act as a barrier to the development of scientific knowledge in individuals. Superstition also has close relation with age, gender, geography and educational qualifications of individuals because it is found that educated youths possess less superstitious beliefs than elders. It is also found that media programs are one of the reasons for the existence of superstitions in the society.

\subsection{Superstition activities in media and Laws in India}

The News Broadcasters Association (NBA), Press Council of India and the Union Ministry of Information and Broadcasting have issued guidelines for telecasting programs and advertisements in this regard. But the television channels neglect them and continue to air such programs encouraged by the stance of the government as well as the parties. Many anti-superstition activists such as Narendra Dabholkar have criticized that television programs are promoting superstition.

Indian Ministry of Information and Broadcasting has issued an advisory to various entertainment and news channels not to engage in contents that heavily encourages in superstition and blind belief. This advisory was sent on 7th June 2013 to the media organizations such as News Broadcasters Association (NBA), the Indian Broadcasting Foundation (IBF) and the Advertising Standards Council of India. Later a copy of the note was also sent to other media organizations like Electronic Media Monitoring Centre, or EMMC, a unit of the government that monitors television and radio content. The note which was circulated among various broadcasting companies said some channels have been showing programs that encourage superstitious beliefs. The advisory also insists on miraculous solutions or cure to problems by unauthorized babas or self-proclaimed gurus or godmen should be avoided.

The Maharashtra Prevention and Eradication of Human Sacrifice and other Inhuman, Evil and Aghori Practices and Black Magic Act, 2013 is a criminal law act for the state of Maharashtra. The act criminalizes practices related to black magic, human sacrifices, use of magic remedies to cure disorder and other such acts which exploit people's superstitions. The bill has 12 clauses which criminalize the acts such as defrauding or terrorizing people in the name of miracle, Carrying out or encouraging acts which endanger life or cause grievous injury in order to gain supernatural powers, Carrying out or encouraging inhuman acts or human sacrifice in quest of some bounty or reward, Creating the impression that a person has supernatural powers and compelling people to follow his/her orders, Claiming the ability to invoke ghosts, causing panic or intimidating others by threatening to invoke ghosts, or creating the impression of possession, preventing the person from seeking medical treatment, and compelling him/her to inhuman acts, Preventing a person from seeking medical advice and compelling him/her to take magic remedies, Claiming to perform surgery by fingers (psychic surgery) and claiming to change the sex of an unborn foetus.

Although the human sacrifice is already considered murder in India, encouraging human sacrifice has been criminalized in this law. Each infraction carries a minimum sentence of six months and a maximum sentence of seven years, including a fine ranging from 5,000 to 50,000 rupees. The offenses are non-bailable and cognizable. There are only around 5 states in India that have a law against such practices. 
Programme and Advertising Codes Prescribed under the Cable Television Network Rules, 1994 Rule- 6. No program which encourages superstition or blind belief should be carried in the cable service; Superstition gives rise to various fears and anxieties that are unfounded. It holds back the achievements of many healthy and good programs. Superstitions retard the scientific knowledge of civilization. Previous studies indicate that nowadays, the Indians in particular, rather than all the Asians, are exceptionally superstitious like Europeans used to be about one thousand years ago. Even educated persons fall prey to superstitions.

\subsection{Non-Fiction Television Programs}

Non-fiction is the form of any narrative or other communicative work whose assertions are understood to be fact. Narrative non-fiction relates stories that really happened but in a way that draws the attention of audience just like fictional stories, it tells a true story but with lots of drama in it. This presentation may be accurate or not which means it can give either a true or a false account of the subject in question. However, it is generally assumed that authors of such accounts mostly believe them to be true at the time of their composition or, at least, pose them to their audience as true events. According to the authors reporting the beliefs of others in a non-fiction format is not necessarily an endorsement of the ultimate authenticity of those beliefs, it is simply like saying it is true that people believe in them. These kinds of Non-Fiction programs make use of curiosity of audience to gain popularity among people. In that way, they popularize the superstitions of one place to many others.

Similarly, every Tamil channel would have at least one Non-Fiction programs scheduled in prime hours or at weekends which would be the popular program of that channel, for example, programs like Nandanthathu Enna, Nijam, Nambinal Nambungal, and Munjenmam were all popular Non-Fiction programs of that period. Some of the superstitious beliefs which are mostly portrayed in Tamil Non-Fiction programs are supernatural beings, ghosts, religious sentiments, predictions, precognitions, and miraculous healing methods. These programs may influence the viewers and make them believe in certain practices related to superstitions, which may have a psychological and financial impact on them.

Hence, the television plays an important role in entertaining and educating people and creates an impact on audiences in terms of communication, education, behavior, etc. The Constitution of India stresses cultivating awareness about science as the responsibility of the people. This incorporates media also. A lot of previous insights from literature has also suggested that rather than telecasting such programs, it can attempt to make awareness about such people who trick the general population for their own benefit and fame. So, this study attempted in order to explain the impact of non-fiction programs in Tamil channels, which are reinforcing superstition among the general audience.

To study the above-said research problem, this research has analyzed the content of superstitious programs in Tamil Television channels as well as its impact on the audience. The three major objectives to meet in this study are:

- To identify the superstitious programs that have been broadcasted on Tamil Television channels.

- To analyze the structure and presentation of the superstition related programs on Tamil Television channels.

- To find out the impact of the superstitious content broadcasted on Television upon the audience. 


\section{Material and methods}

In this research, content analysis and survey methods were followed for data collection. The content analysis was done on selected Non-Fiction programs such as Moondravathu Kan (Vendhar TV), Nambinal Nambungal (Zee Tamil TV), Marmam (Vasanth TV), for a period of one month i.e. from $1^{\text {st }}$ February 2016 to $1^{\text {st }}$ March 2016. Totally 40 episodes of above programs were analysed during the study. The content related to superstition, documentary style, the tone of narration, and presentation style were analyzed. The defined set of parameters was drawn and the content analysis was done.

The survey method was adopted for the study to find out the influence of superstitious content of Tamil television Non-fiction shows. The survey was conducted among the audience aged between 18 to 70 years through a questionnaire. The sampling technique adopted for this study is non-probability purposive sampling. The samples who watch Non-Fiction television programs were identified and the number of samples for this study is about 132 respondents.

\section{Results}

\subsection{Results of content analysis}

The content analysis was done on selected non-fiction programs such as Moondravathu Kan (Vendhar TV), Nambinal Nambungal (Zee Tamil TV), Marmam (Vasanth TV), for a period of one month.

Table1 . Synopsis of Superstition Non-Fiction Programs

\begin{tabular}{|c|c|c|c|}
\hline $\begin{array}{l}\text { Parameters/ } \\
\text { Channels }\end{array}$ & Vendhar TV & Zee Tamil TV & Vasanth TV \\
\hline $\begin{array}{l}\text { Title of the } \\
\text { program }\end{array}$ & Moondravathu Kan & Nambinal Nambungal & Marmam \\
\hline $\begin{array}{l}\text { Duration of the } \\
\text { program }\end{array}$ & 30 minutes & 60 minutes & 30 minutes \\
\hline Time slot & $9.30 \mathrm{pm}$ to $10 \mathrm{pm}$ & $9.00 \mathrm{pm}$ to $10 \mathrm{pm}$ & $9.00 \mathrm{pm}$ to $9.30 \mathrm{pm}$ \\
\hline Day of Telecast & Monday to Friday & Sunday & Sunday \\
\hline $\begin{array}{l}\text { Genre of the } \\
\text { program }\end{array}$ & Non-fiction & Non-fiction & Non-fiction \\
\hline $\begin{array}{l}\text { Theme of } \\
\text { program }\end{array}$ & Mystery, & Thriller, Mystery, Horror & $\begin{array}{l}\text { Thriller, Mystery, } \\
\text { Horror }\end{array}$ \\
\hline $\begin{array}{l}\text { Format of } \\
\text { program }\end{array}$ & Documentary & $\begin{array}{l}\text { Documentary, } \\
\text { Docudrama }\end{array}$ & $\begin{array}{l}\text { Documentary, } \\
\text { Docudrama }\end{array}$ \\
\hline $\begin{array}{l}\text { Content of the } \\
\text { program }\end{array}$ & $\begin{array}{l}\text { Religious } \\
\text { Supernatural beliefs, } \\
\text { Blind } \\
\text { Precognition, } \\
\text { Paranormal beliefs. }\end{array}$ & $\begin{array}{lr}\text { Religious } & \text { beliefs, } \\
\text { Supernatural } & \text { beliefs, } \\
\text { Blind } & \text { beliefs, } \\
\text { Precognition, Paranormal } \\
\text { beliefs. }\end{array}$ & $\begin{array}{l}\text { Religious beliefs, } \\
\text { Supernatural } \\
\text { beliefs, } \\
\text { beliefs, } \\
\text { Precognition, } \\
\text { Paranormal beliefs. }\end{array}$ \\
\hline
\end{tabular}




\begin{tabular}{|l|l|l|l|}
\hline $\begin{array}{l}\text { Method of } \\
\text { collecting } \\
\text { information for } \\
\text { program }\end{array}$ & $\begin{array}{l}\text { The crew of the } \\
\text { program collects the } \\
\text { information through } \\
\text { their Facebook page } \\
\text { from the public. }\end{array}$ & $\begin{array}{l}\text { The research team of the } \\
\text { program collects } \\
\text { information and they } \\
\text { provide contact number } \\
\text { in the end of the program } \\
\text { and ask public for } \\
\text { information. }\end{array}$ & $\begin{array}{l}\text { This channel } \\
\text { gathers information } \\
\text { from news sources } \\
\text { and the details of } \\
\text { the information's } \\
\text { obtained are } \\
\text { investigated }\end{array}$ \\
\hline $\begin{array}{l}\text { Audience rate of } \\
\text { interest }\end{array}$ & $45 \%$ & $35 \%$ & $20 \%$ \\
\hline $\begin{array}{l}\text { Disclaimer } \\
\text { warning }\end{array}$ & Yes & Yes & No \\
\hline Segments & 2 & 4 & 2 \\
\hline
\end{tabular}

\subsubsection{Theme of Program}

The theme followed by the programs is a combination of mystery, suspense and horror. The program explores various elements related to myths and mysteries all over the world which makes these programs popular by grabbing the attention of people who are clueless about the mysteries of the world and the reason behind it. The programs Moondravathu Kan and Nambinal Nambungal explore myths and mysteries that are within the country, whereas Marmam explores various myths and mysteries from different parts of the world.

\subsubsection{Format of the Program}

The Non-Fiction programs Nambinal Nambungal and Marmam follow both documentary and docudrama formats of storytelling, where the story follows either observational documentary style or Participatory documentary style in which the anchor participates in lively action along with the people and investigates the details. In docudrama format, the real incident is enacted as a drama to convey the story to the audience.

\section{Figure 1. Format of the programs}

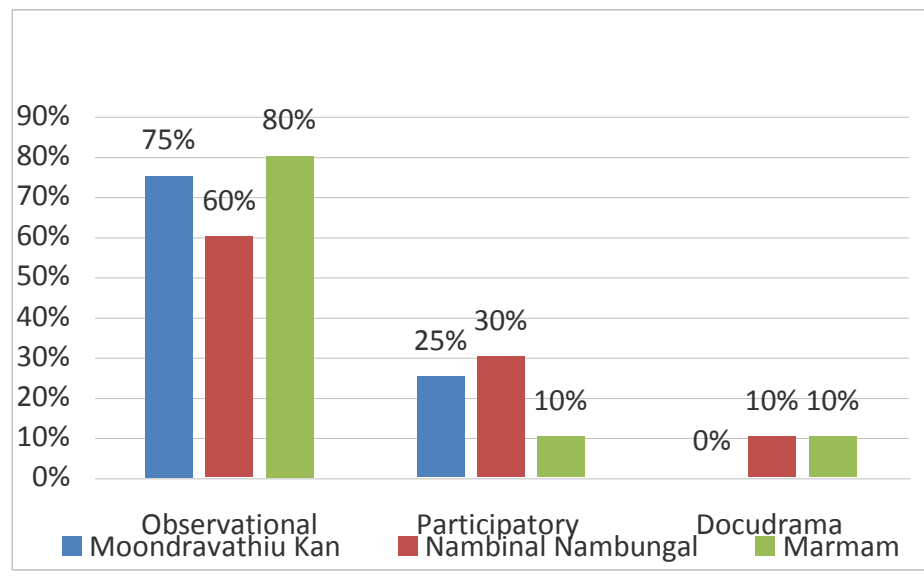

The 40 episodes of overall Non-Fiction programs were analyzed in one-month period. All the three programs had mostly used observational documentary format which is the highest 
percentage with $72 \%$ in average. The docudrama is the least followed format which is $10 \%$, while the participatory documentary style is followed in an average of $22 \%$.

\subsubsection{Content Types of the Programs}

The content of the analyzed programs was mostly related to traditional religious beliefs, precognition, blind beliefs (such as self-hurting, magic healing) and paranormal beliefs. It is clear that the content of the program is mostly related to religious beliefs with a highest average percentage of $38.3 \%$, followed by blind beliefs, paranormal beliefs, and precognition with the average of $35 \%, 15 \%$, and $11.6 \%$ respectively.

Figure 2. Content Types of superstitions shown in programs

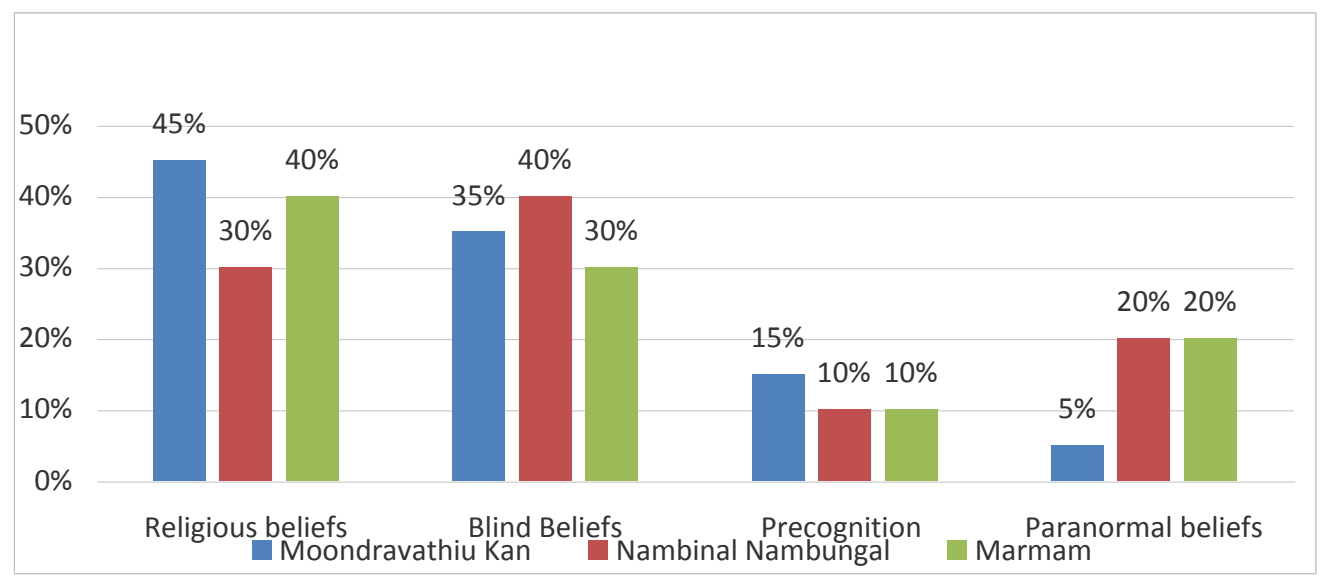

\subsubsection{Narration Style}

Narration plays an important role in Non-Fiction programs; it gives the people the sense of what is discussed in the visuals. The narration style followed is either anchor based (the anchor narrates the incident in a lively action) or voice-over based (recorded voice narrates the visuals to the audience) or a combination of both. Moondravathu Kan mostly made use of anchor based narration whereas Marmam mostly used voice-overs for narration. Nambinal Nambungal made equal use of both the styles.

\subsubsection{Tone of Narration}

The tone of narration reflects the seriousness of the story and narrators perception about the lively actions. Thus the tone of narration has great influence on the listeners, which means it indirectly draws conclusions in the mind of listeners in favor of the action shown or against it making them to believe or to criticize. So, to be on safer side, these programs mostly follow the neutral tone of narration, leaving the conclusions in the hands of the audience. The data reveals that the tone of the narration is $15 \%$ supportive, $20 \%$ criticizing and $65 \%$ neutral. 
Table 2. Narration Followed in the Non-Fiction programs

\begin{tabular}{|l|c|c|c|}
\hline $\begin{array}{l}\text { Tone of the narration and } \\
\text { conclusions drawn }\end{array}$ & Moondravathu Kan & $\begin{array}{c}\text { Nambinal } \\
\text { Nambungal }\end{array}$ & Marmam \\
\hline Supportive & $25 \%$ & $10 \%$ & $10 \%$ \\
\hline Criticism & $10 \%$ & $20 \%$ & $30 \%$ \\
\hline Neutral & $65 \%$ & $70 \%$ & $60 \%$ \\
\hline
\end{tabular}

\subsubsection{Interview Component with Stakeholders in the Programs}

The interview of persons who are associated with the story adds advantage to the program. By this way, the programs try to add credibility to the content. The interview of experts gives a better idea about the content supporting or clashing against it. Interview of experts reveals the scientific reason behind the superstitions and help in better understanding and eradicating blind beliefs among the audience, but the programs like Moondravathu Kan and Nambinal Nambungal have very less number of expert interviews which means it covers only the believers of the issue. Out of three categories, the interview of victims/witness is the highest with $68.3 \%$ in average of overall three programs and it is followed by other two categories with $18.3 \%$ and $13.3 \%$ in average.

Table 3. Interview Component with Stakeholders in the Programs

\begin{tabular}{|l|c|c|c|}
\hline \multicolumn{1}{|c|}{ Elements } & Moondravathu Kan & Nambinal Nambungal & Marmam \\
\hline $\begin{array}{l}\text { Interview with } \\
\text { victims/witness }\end{array}$ & $65 \%$ & $90 \%$ & $50 \%$ \\
\hline Interview with experts & $5 \%$ & $0 \%$ & $50 \%$ \\
\hline No interviews & $30 \%$ & $10 \%$ & $0 \%$ \\
\hline
\end{tabular}

\subsubsection{Appeal of the Programs}

The appeal is the emotional response that program creates in the audience. The emotional response varies based on the content of the program. The program propagates in a way that it occupies the audience with a thrilling feel and sometimes it also gives horror feel, especially when the content is based on paranormal activities. The program Moondravathu Kan creates a thrilling feel.

\subsubsection{Visual Effects/ Animation}

The programs make use of different kinds of visual elements to make the content more interesting and sensible. Few programs (Moondravathu Kan, Marmam) have used pictures to represent the history of the issue and $60 \%$ of the total episodes use visual elements like pictures, animations and video effects. Nambinal Nambungal has used only minimal (10\%) pictures and animation in total episodes analyzed during the research period.

\subsection{Results of the survey}

The researcher identified 132 audiences who watch Non-Fiction programs and survey was conducted among them. The responses are presented below: 


\subsubsection{Demographic Profile of Survey Participants}

The age span of respondents who watched the Non-Fiction programs was between 18 and 60. Most of the respondents belong to age span between 18 and 25 because like to watch NonFiction programs more. $26 \%$ of the respondents belong to age category $26-35$, and $21 \%$ of the respondents belong to age category 36-45. 19\% of the respondents were aged between 46 and 60 . Regarding the gender $52 \%$ of the respondents were males and $48 \%$ were females.

Figure 3. Age group of the respondents

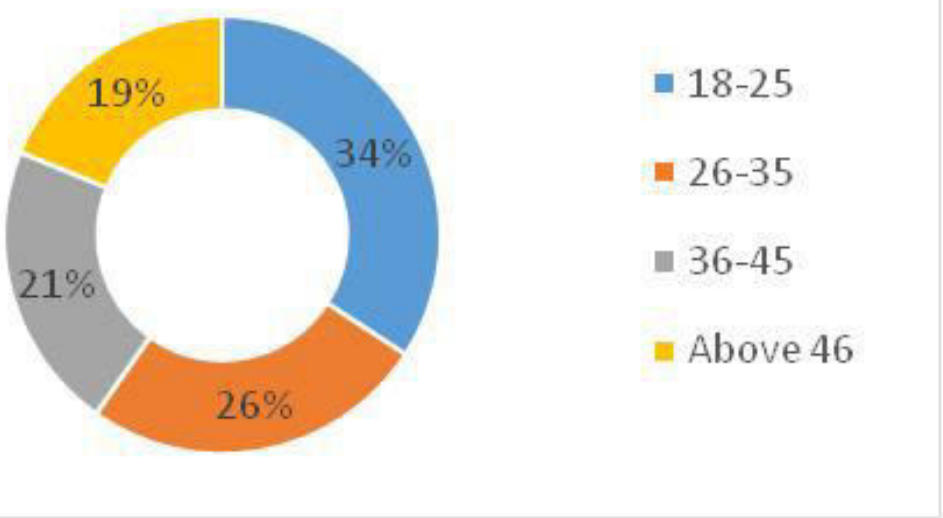

\subsubsection{Respondents' Favorite Program Category}

On television channels, many programs are telecasted. But, the audience is watching few programs, which are of interest. About $42 \%$ of the respondents liked to watch Non-Fiction programs because they find these programs very interesting. About $23 \%$ of the respondents liked to watch serials, and other $23 \%$ of the respondents liked to watch talk shows because these shows involve celebrities and/or discuss interesting topics.

Figure 4. Respondent's favorite program category

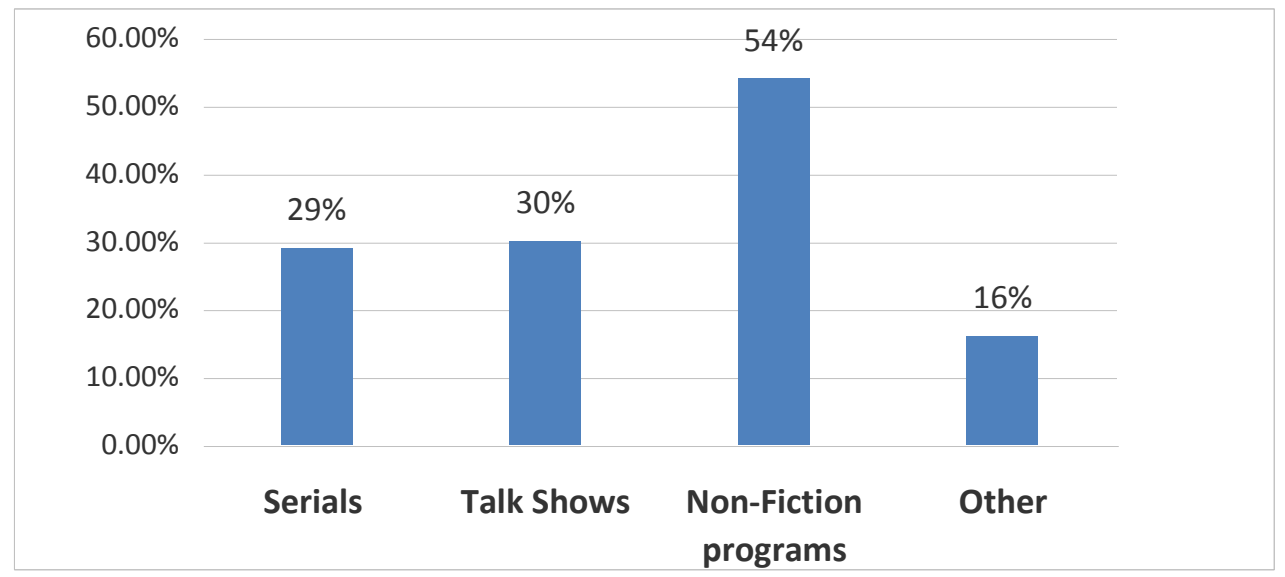




\subsubsection{Respondents' Preferences on Non-Fiction Programs involving Superstitions}

Next to their favorite programs, the research asked another question on their preference on non-fiction programs involving superstitions. About $29 \%$ of the respondents watched Moondravathu Kan program because it explores a different story in each episode and it creates suspense among viewers thereby stimulating their curiosity. Fear Files stood next with $28 \%$ of the viewer's interest because this program depicts real-life stories with added fiction. Apart from this, $20 \%$ of the respondents watched Nambinal Nambungal, and $13 \%$ of respondents watched Marmam, because this program has less exposure than other programs.

Figure 5. Respondents' preferences for Non-Fiction programs

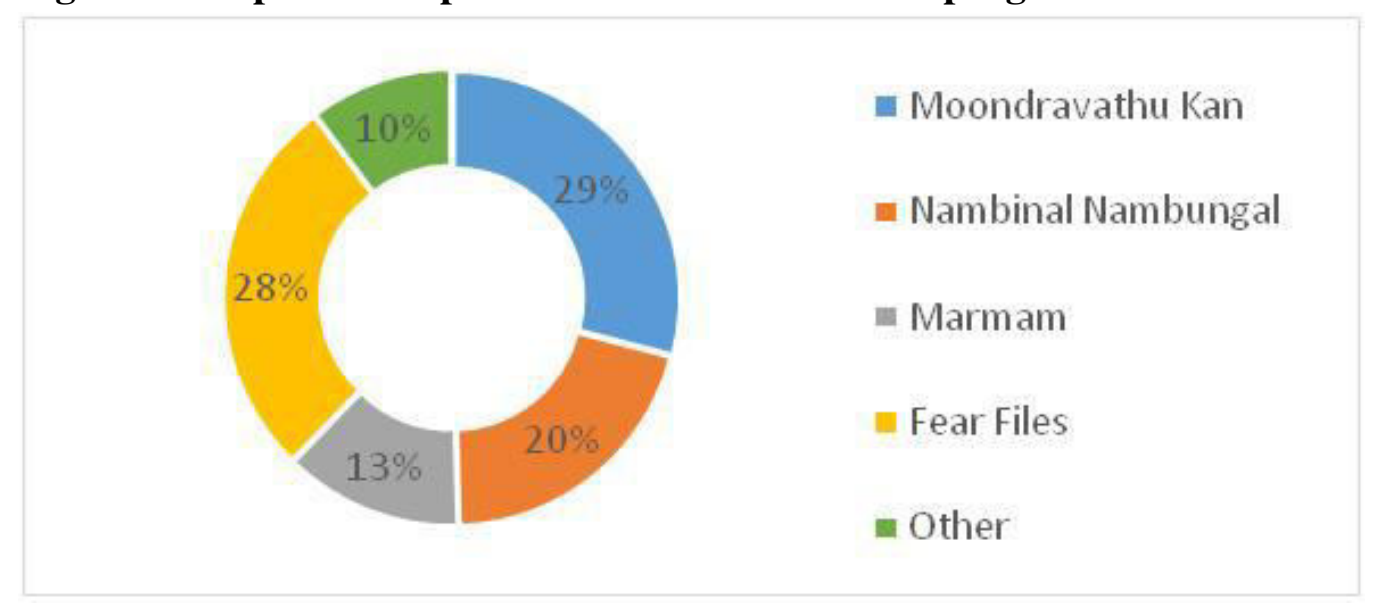

\subsubsection{Respondents' Frequency in Watching Non-Fiction programs}

Among the audience, $34 \%$ of the respondents watched these Non-Fiction programs regularly because they feel it is very interesting and they don't want miss an interesting episode and $43 \%$ of respondents watch these programs rarely because they only watched episodes that discussed their topic of interest and few others watched these programs only when they have got time to watch them because these programs were aired during prime time and on weekends, so there was a competition with other popular prime time programs.

Figure 6. Respondents' frequency in watching non-fiction programs

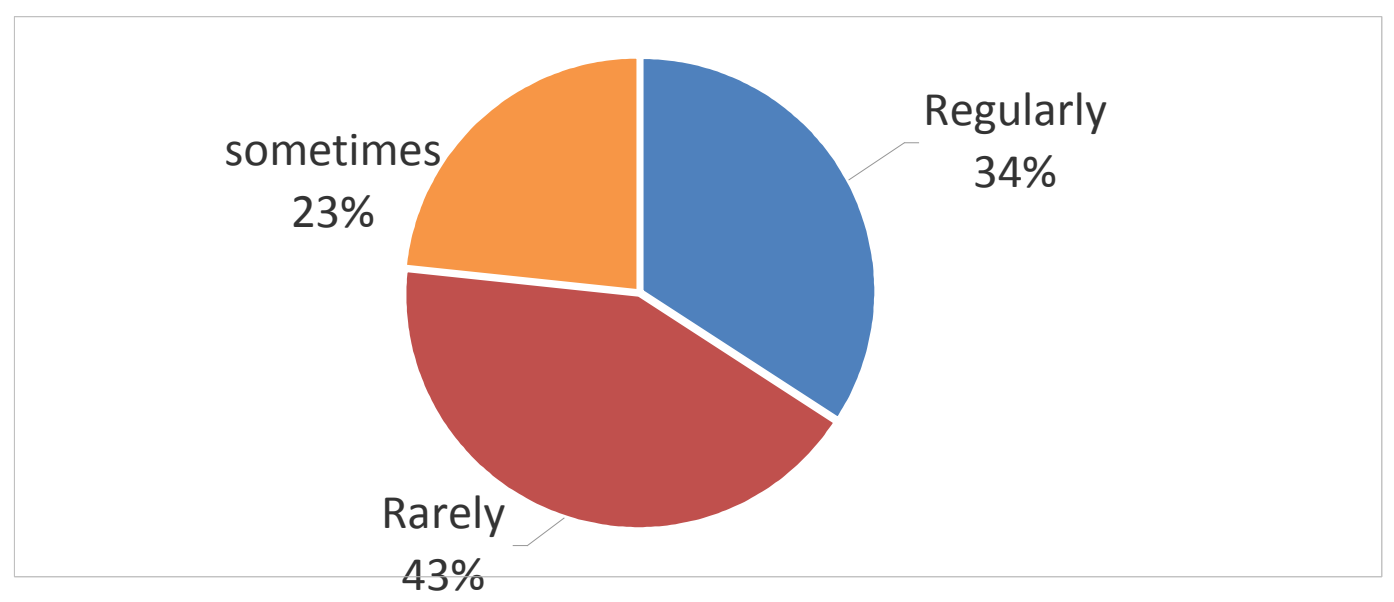




\subsubsection{Time Spent by the Respondents}

More than half $(51 \%)$ of the respondents spent more than 2 hours watching Non-Fiction television programs, while $34 \%$ of the respondents spend only an hour watching Non-Fiction programs. Apart from this, $15 \%$ of respondents watch Non-Fiction programs less an hour because they watch them just for entertainment.

\subsubsection{Respondents' Beliefs in Superstitions}

The respondents who believe the superstitions and those who don't are in equal percentage. The reason why respondents believe in superstitions is because of their parents influence and in few cases they believe because of their personal experience related to superstitions. The reason why $50 \%$ of respondents didn't believe in superstitions is because they were well educated and they felt that few superstitions are rumours that were spread by few people for their own benefits.

\subsubsection{Respondents' Belief in different types of Superstitions}

Respondents were holding beliefs in various superstitions. Among the respondents $47 \%$ believed in astrology and 30\% of the respondents believde in paranormal beliefs due to personal experiences regarding such beliefs. $22 \%$ of respondents believed that black magic is real, and $14 \%$ believed in magic healing.

Figure 7. Respondents' belief in different type of superstitions

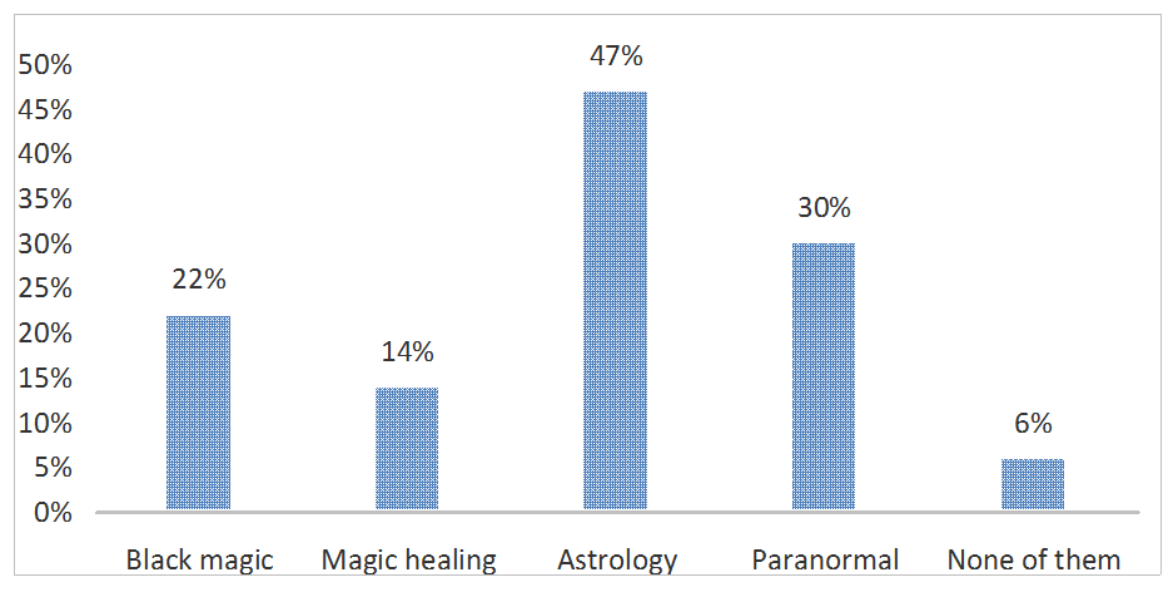

\subsubsection{Respondents' sources of Knowledge about Superstitions}

The respondents have knowledge about superstitions from various sources. Most of the respondents $(50 \%)$ learn superstitions from the Television, $28 \%$ of the respondents learn superstitions from society/friends, while $16 \%$ of the respondents learn superstitions from their parents and only $6 \%$ of the people learned superstitions from their personal experiences. 
Figure 8. Respondent's source of knowledge about superstitions

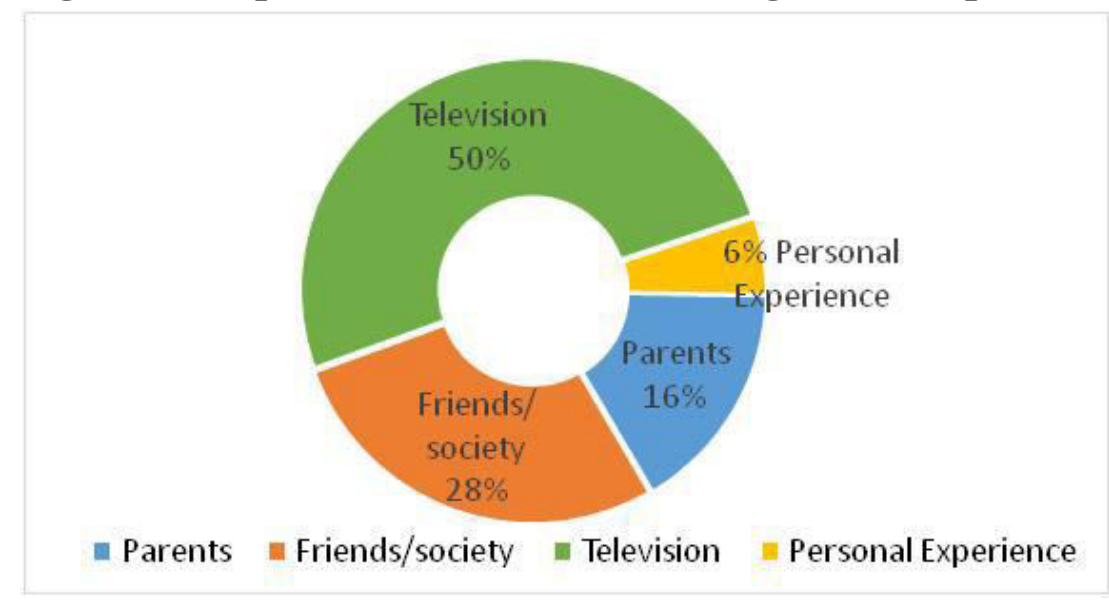

\subsubsection{Respondents' personal experiences about superstitions in real life}

The majority of the respondents (78\%) didn't encounter personally any superstitions that they saw in Non-Fiction television programs, whereas $22 \%$ of the respondents have encountered in real life, superstitions which they watched on television.

\subsubsection{Respondents' opinions about non-fiction programs involving superstitions}

The majority of the respondents (47\%) only partially believed that the stories shown in NonFiction programs were true. Only about $26 \%$ of respondents believed that the stories shown in NonFiction Television programs were absolutely true, while $27 \%$ of the respondents did believe that the stories were absolutely not true.

\subsubsection{Superstition practices suggested to friends by the respondents}

$72 \%$ of the respondents neither supported nor suggested the superstitions to others which they learned from television program, $15 \%$ of the respondents have not practiced but suggested few superstitions-related practices to others, whereas $7 \%$ of the respondents have practiced but not suggested superstitions-related practices to others. Only 6\% of the respondents had practiced and also suggested others to practice superstition which they saw in Non-Fiction Television programs..

\section{Figure 9. Respondents who have practiced or suggested superstitions}

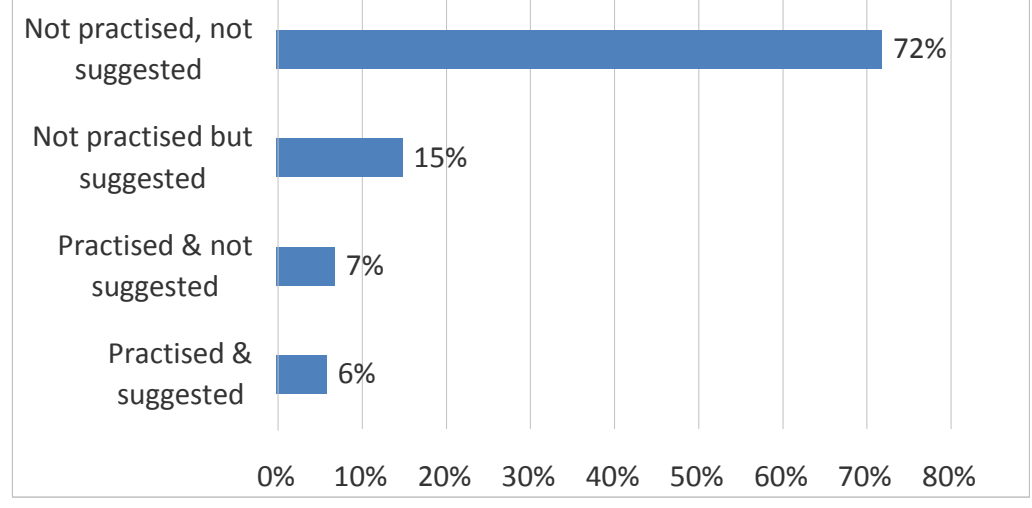




\subsubsection{Respondents' emotions while watching Non-Fiction Programs}

One-fourth of the respondents $(25 \%)$ felt amused while watching Non-Fiction television program, $21 \%$ of the respondents felt indifferent while watching programs that showed content related to superstition, $18 \%$ of the respondents felt excited while watching these programs and $14 \%$ of the respondents felt angry while they watched Non-Fiction Television programs.

\section{Figure 10. Respondents' emotions while watching Non-Fiction Programs}

\subsubsection{Influence of Non-Fiction program on the Level of Belief among the Respondents}

About half (48\%) of the respondents said watching Non-Fiction programs did not have any effect on their existing beliefs while $30 \%$ of the respondents feel that watching these programs have stimulated their interest in superstitions. Apart from this, $18 \%$ of the respondents felt that watching Non-fiction shows had strengthened their belief in superstitions.

Figure 11. Influence of non-fiction program on the Level of Belief among the Respondents

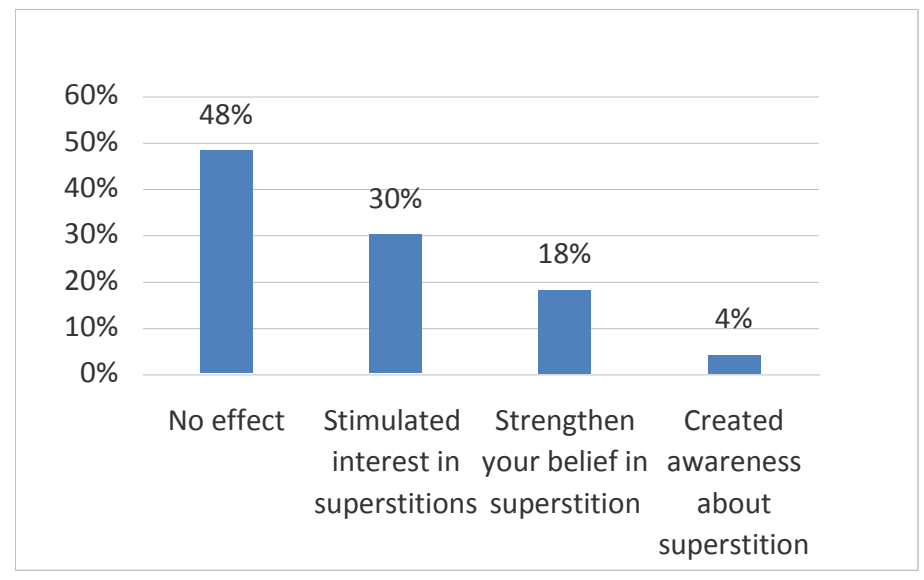

\subsubsection{Respondents' Opinions on Telecasting Content Related to Superstition}

The respondents were asked whether it is right to broadcast content related to superstition in television programs. Their answers were: $60 \%$ of the respondents felt it was right to telecast content related to superstition in television programs because there are people who just watch these programs for entertainment and others who believe in superstition and like to know more about 
them, whereas $40 \%$ of the respondents say that it is not right to telecast content related to superstitions because they don't believe in superstitions and telecasting such content can be harmful to people.

\section{Discussions}

Most of the superstition programs were being telecasted in the prime time especially on weekends. The majority of the content was related to religious beliefs and blind beliefs like magic healing, future prediction, and black magic. These programs gather information from practitioners or public and analyze the details and telecast them in a dramatized format. Almost $65 \%$ of the episodes used a neutral tone of narration and drew no judgment about the fact. About $50 \%$ of the respondents believed in superstitions and 50\% didn't. About 34\% of respondents watched Non-Fiction programs regularly. The majority $(50 \%)$ of the respondent said that they came to know about superstitions from the television. About $27 \%$ of respondents had followed practices related to superstitions after watching them on television programs. A majority of $47 \%$ of the respondents believes that the stories shown in Non-Fiction programs were partially true. Among the respondents, $48 \%$ of them said that they felt no effect from watching Non-Fiction programs, while $30 \%$ of respondents felt that it stimulated their interest towards superstitions. $60 \%$ of the respondents said it is right to broadcast programs about superstition on television channels for entertainment purposes, while $40 \%$ of respondents opposed this view and said these created bad social influence. Most respondents believed in astrology, whereas least number of respondents believed in magic healing.

\section{Conclusion}

From this study, it is evident that $50 \%$ of the people still believe in superstitions. Since, people believe that the majority of the stories in Non-Fiction programs are only partially true, these don't have much effect of program on them. But watching these programs have reinforced superstitious beliefs in few people and also stimulated interest towards superstitions in few others. The non-believers don't care about watching content related to superstition because it is just an entertainment to them, while the believers want these programs to broadcast such content because they are interested in it and they embrace it. Another important fact to be noted is that this study revealed that television, despite raising awareness, has enhanced superstition in the majority of people. Television channels and program producers should avoid telecasting content that would reinforce superstitious beliefs in the audience. Television programs should include, as much as possible, expert opinions about the topics - which may provide deeper understanding of the events along with scientific explanations on matter. Television programs should make some effort to clarify the tricks behind the superstitions rather than just simply stating the facts. This way, awareness can be raised in society.

\section{References}

1. Balderston, John L. in the play Dracula (1927), spoken by the character Von Helsing. In the script Dracula: the Vampire Play in Three Acts (Samuel French Inc., 1960), 25. Available at: http://quotes.yourdictionary.com/author/quote/547782\#oWyYiPL3gD7DJb0E.99. [Accessed 27 June 2017]

2. Boshier, R., 1973. An Empirical Investigation of the Relationship between Conservatism and Superstition. British Journal of Social and Clinical Psychology, 12, pp.262-267. 
3. Blackmore, S.J., 1994. Are women more sheepish? Gender differences in belief in the paranormal. In: Women and parapsychology (International conference), Dublin, 1991. New York: Parapsychology Foundation.

4. Cantor, J., Zillmann, D., and Bryant, J., 1994. Confronting children's fright responses to mass media. In: D. Zillmann, J. Bryant and A.C. Huston, eds. Media, children, and the family: Social scientific, psychodynamic, and clinical perspectives. Hillsdale, N.J: Erlbaum. pp.139-50.

5. Clarke, D., 1991. Belief in the paranormal: A New Zealand survey. Journal of the Society for Psychical Research, 57(823), pp.412-425.

6. Corsini, R.J., 2002. Dictionary of psychology. Philidelphia, PA: Brunner/Mazel.

7. Emme, E.E., 1940. Modification and origin of certain beliefs in superstition among 96 college students. Journal of Psychology, 10(2), pp.279-291.

8. Emmons, C.F. and Sobal, J., 1981. Paranormal beliefs: Testing the marginality hypothesis. Sociological Focus, 14(1), pp.49-56.

9. Feder, K.L., 1984. Irrationality and popular archaeology. American Antiquity, 49(3), pp.525-541.

10. Gerbner, G., Gross, L., Morgan, M., Signorielli, N., and Shanahan, J., 2002. Growing up with television: Cultivation processes. In: J. Bryant and D. Zillmann, eds., LEA's communication series. Media effects: Advances in theory and research. Mahwah, NJ, US: Lawrence Erlbaum Associates Publishers. pp.43-67.

11. Irwin, H.J., 1993. Belief in the Paranormal: A Review of the Empirical Literature. Journal of the American Society for Psychical Research, 87(1), pp.1-39.

12. Khantipalo, Bhikkhu, ed., 2013. Life's Highest Blessings: The Maha Mangala Sutta. Translation and commentary by R.L. Soni. Sri Lanka: Buddhist Publication Society.

13. Kurtz, P., 1985. The responsibilities of the media and paranormal claims. Skeptical Inquirer, 9(4), pp.357-62.

14. Lester, D., Thinschmidt, J.S., and Trautman, L.A., 1987. Paranormal belief and Jungian dimensions of personality. Psychological Reports, 61(1), p.182. Available at: http://journals.sagepub.com/doi/pdf/10.2466/pr0.1987.61.1.182 [Accessed 26 June 2017]

15. Lippmann, W., 1922. Public Opinion. Ch.1.: The world outside and the pictures in our heads. New York: MacMillan Co.

16. Lundeen, G.E. and Caldwell, O.W., 1930. A study of unfounded beliefs among school seniors and college students. Journal of Educational Research, 22, pp.257-273.

17. Maione, I., 1998. Testing Put to the Test. Skeptical Inquirer, 22(3), pp.21-22.

18. McGarry, J.J., and Newberry, B.H., 1981. Beliefs in paranormal phenomena and locus of control: A field study. Journal of Personality and Social Psychology, 41(4), 725-736.

19. Morris, B., 2013. Quotes we cherish. Quotations from Fausto Cercignani, eBook. p. 39. Available at: http://www.lulu.com/shop/brian-morris/quotes-we-cherish-quotations-from-faustocercignani/ebook/product-22207290.html [Accessed 28 June 2017]

20. Ofori, P.K., Tod, D., and Lavallee, D., 2016. An exploratory investigation of superstitious behaviours, coping, control strategies, and personal control in Ghanaian and British studentathletes. International Journal of Sport and Exercise Psychology, pp.3-19.

21. Risen, J.L. and Nussbaum, D., 2013. Sense and Superstition. New York Times. SR 12, 4 October. Available at: https://www.nytimes.com/2013/10/06/opinion/sunday/sense-and-superstition.html [Accessed 26 June 2017]

22. Sparks, G.G., Spirek, M.M., and Hodgson, K., 1993. Individual differences in arousability: Implications for understanding immediate and lingering emotional reactions to frightening mass media. Communication Quarterly, 41(4), pp.465-476. 
23. Tobacyk, J.J., Nagot, E., and Miller, M., 1988. Paranormal beliefs and locus of control: A multidimensional examination. Journal of personality assessment, 52(2), pp.241-246.

24. Wiseman, R. and Watt, C., 2004. Measuring superstitious belief: Why lucky charms matter. Personality and Individual Differences, 37(8), pp.1533-1541.

25. Wuthnow, R., 1976. Astrology and marginality. Journal for the Scientific Study of Religion, 15(2), pp.157-168.

26. *** Maharashtra Prevention and Eradication of Human Sacrifice and other Inhuman, Evil and Aghori Practices and Black Magic Act, 2013. Nagpur: Maharashtra Legislative Assembly. 


\title{
The Bulgarian family in the early $21^{\text {st }}$ century
}

\section{DOI: http://doi.org/10.26758/8.1.29}

Petya Pachkova

South-West University “Neofit Rilski”, Faculty of Philosophy, Blagoevgrad, Bulgaria

Address correspondence to: Petya Pachkova; E-mail: pepun@abv.bg

\begin{abstract}
Objectives. The research examines some major trends in the development of the Bulgarian family in the early $21^{\text {st }}$ century. One of these trends is characteristic for all the industrial societies - the increase of the number of people who do not want to start a family. On the other hand, there is a switch from the typical model of a family with two children to the family model with one child or without children. These general trends in Bulgaria are reinforced by a number of factors specific for the period of transition. The study is focused on the development of alternative forms of family life - their distribution, the development of the legal framework for their regulation and the public opinion towards them. From the beginning of the Bulgarian transition period, the influence of the characteristics of the family on the education system, the demographic crisis and the moral values of society has qualitatively changed. The analysis shows that the political elites are mainly improvising in shaping their social policy regarding family, and sexual education.

Material and methods. The methods of testing are as follows: analysis of data from sociological and other empirical researches; bibliographic analysis; deep monitoring of real social processes during the transition.

Results. Bulgarian family undergoes a noticeable degradation. The dissolution of traditional family is consistent with the increased number of unhappy individuals who cannot find fulfillment in starting a family and raising children.

Conclusions. On one hand, in Bulgarian social policy, there are measures that are up to date. On the other hand, there are many legislative gaps and inconsistencies. Moreover, Bulgarian citizens seem to realize lately that the rush to embrace alternative forms of family life and the postponement of the right decisions regarding family planning are harmful to them and rethink their behavior.
\end{abstract}

Keywords: family; demographic crisis; education system; family social policy.

\section{Introduction}

The study of the Bulgarian family is of great importance for the development of the whole society because its condition affects all other social trends - economic development, demographic problems, educational system, morality, etc. The article examines the main trends in the development of the Bulgarian family since the beginning of the transitional period in 1989 to the present day. 


\section{Material and methods}

Methods of research include: analysis of data from sociological and other research, bibliographic analysis and social observation.

\section{Findings and discussions}

The most basic trend is the degradation of the Bulgarian family and the sharp decline in birth rates. The reasons are of a various nature. Some of them are characteristic of industrial societies in general. The common, trait of this type of society is a deepening globalization process. And in the former so-called 'socialist' countries there are additional factors that contribute to the degradation of the family. As a result, the negative impacts on families in this type of countries are multiplied, and the degradation of this major social unit is faster and worse in comparison to more developed countries.

At the end of state capitalism, in 1989, the population of Bulgaria was nearly 9 million people. Now it is under 7 million people, including about two million of living abroad. In the public sphere, many voices deplore this phenomenon by calling it a "genocide of Bulgarian nation, carried out and stimulated by external and internal factors exceeding the number of oppressed people by the communist regime until 1989”. (Ханджиев/Handjyev, 2016)

The result of the impact of these factors is, on the one hand, an increase in the number of people who do not intend to start and do not start a family. "Two-thirds of the adult population in Bulgaria are fond of the institution of marriage", according to a survey by Gallup International from 2011 (quoted by website www.klassa.bg). Only 19\% of them believe it is outdated. However, this percentage among young people is much higher (about 50\%). Even fewer are those who actually marry or consider living together.

On the other hand, there is a transition from a mass model of a family with two children to a family model with one child or without any children and, consequently, there is a sharp decrease in the birth rate, especially among the ethnic majority (Bulgarian). In 1988, the living births numbered 117,000, and 10 years later they were about 65,000. The number of underaged to give birth has increased as well. This is also the reason for the increase of the abandonment of children, not only by mothers of Roma origin but also by mothers from the Bulgarian ethnic group.

Thirdly, the number of unmarried cohabitants, lonely parenthood, and homosexual cohabitation has dramatically increased, although formal marriage is preserved as the dominant pattern. The quantity of marriages in the year 2000 is the lowest in the history of Bulgarian statistics. The decline in marriages leads to a decline in marital birth rates. The birth rate decreased, the number of extramarital births increased. The children born within marriage are outnumbered by the children born out of wedlock (Ячкова/Iashkova, 2002). In 1999, two-thirds of the children were born of parents not legally married to each other.

The number of divorces has grown, as well as the number of spouses that live separated (due to internal and external migration or other reasons).

There has been a sharp increase in family violence. It is part of the general trend of the increase in crime in the country. Before 1989, Bulgaria was among the countries with the lowest crime rate in the world but, during the transition, it had come to rank among those with the highest increase in crime rate (Айдаров/Aidarov, 1998, p.165). This can be seen in the area of family violence and that of crimes among family members.

On the one hand, there is an obvious return and widespread of physical and psychological violence of the parents towards the children - expanding of physical punishment of the children 
when it comes to upbringing, forcing prostitution, begging, increase of sexual offenses within the family. The sexual exploitation of children has grown, as well as their sale - due to low parental control, poverty, the technology development, the development of the mafia, and so on (Бояджиева/Boiadjyeva, 2004). Bulgaria occupies a leading place in the EU in terms of the number of suicides among children and young adults (Ячкова/Iashkova, 2002), which is a direct result of the increased violence. Violence and poor upbringing in the family have also affected relations in schools. Due to other factors, aggressiveness and deviant behavior in school and among young people in general have exploded (Михова/Mihova, 2017).

On the other hand, there is the opposite tendency of children's violence against their parents and grandparents. This reverse trend is a new phenomenon. It is related to the increased problems of the children combined with the uniquely decreasing authority of the adults, of the parents. Although difficult to prove with rigorous scientific data, this kind of aggression seems unprecedented in the history of Bulgaria. No other recollection of children displaying such disrespect and acting so violently and cruelly in relation to their parents and grandparents exists.

Violence among partners is also growing. In some cases, there is an increase in family violence ending in the murder of the partner and even of the children. Such cases were unknown during the communist regime. Nowadays, this type of news is regularly published in the media. It seems we witness a record number of crimes (including killings) in the family (for example, by jealousy), with a record number of murders and suicides of parents and their children.

Another reason for the increase of family violence, along with other more well-known and traditional reasons, is the growing role of alternative forms of marriage. All of them create a lower level of security and equilibrium for the partners, especially for the woman (Ячкова/Iashkova, 2002, p.38), compared to the members of the married family (without trying to idealize the marital status). Greater irresponsibility of partners, especially of men, stimulates violence between spouses as well as between parents and children, for example, in case of cohabitation. This form of family stimulates a more frequent change of partners, weakens the role of the biological tie between parents and children, and increases the conditions for violence - for example, sexual abuse by the mother's partner in relation to her children.

The increase of psychological and physical violence in the family as well as in the environment also affected the psychic status of the population. The number of people with mental health problems has sharply risen. This situation, coupled with the lack of adequate, institutionalized, permanent care for these people, generates another source of risks since patients are walking freely in the streets, allowed to commit acts of violence (sometimes even murders) against unknown citizens and their relatives as well.

During the early exercise of democracy, the political partisanship or simply the strong political opinions and beliefs have often divided the family members into adverse camps. Gradually, the political emotions ceased to be such an incentive for scandals, conflicts, and divisions. Most people understood that there was no significant difference in the policy of the main parliamentary parties during the transition and this negative pressure for the family unity has diminished considerably. But the influence of other negative factors has increased.

The most serious factor for degradation of family relations was the change in the professional, economic and health status of population. Throughout the whole period, the level of social security has been decreasing for a large part of their families as a result of the restructuring and degradation of the economy, of the legitimate and illegitimate redistributive relations and processes within it. Due to the strong deterioration of their economic status, some of them further abstained from the family formation and childbirth or separated. 
After November $10^{\text {th }}$, economic insecurity and lack of work or income, especially in the case male family head, played a very detrimental family role. The Bulgarian middle class did not offer jobs, so the minority groups and women dropped out of the labor market. The concept of 'the two worlds' - the male and the female - has been revived in order to explain to women who dropped out of the labor market that the model "working man - housewife" is the most wonderful one, so as not to try to compete with the already diminished number of jobs for men. Some men tend to return to the patriarchal type of thinking - especially among young ones. Some of them are waiting to get rich because they feel obliged to provide everything before they get married. And since they do not get rich, they do not marry. In movies, this is expressed by the imposed model the woman eagerly waits for the man to give her a ring with a marriage proposal.

Some factors usually spoil family relationships. In other situation, the same factors, combined with other, can stimulate them - for example, the crisis, poverty, and so on. These factors usually create tensions in the family, shatter it, but sometimes can also strengthen it - as a means of salvation, finding peace and comfort, support.

The decrease in significance of traditional family enhances the number of people who do not see themselves fulfilled in starting a family and raising children. However, more unmarried people are feeling a huge dissatisfaction with life, though they often try to conceal it. Some of them find an alternative in overworking and burn themselves out. They help greedy employers benefiting from their dedication to work. Another part of them comes to hate people, their work, and their lives. In some cases, they lead to deviant behavior, and to crimes.

Changes in the social environment have led to the emergence of tolerance for alternative forms of family life - their dissemination, the development of the legal framework for their regulation, the development of excessive, unnecessary 'democratic' attitudes towards them from the side of public opinion. But despite the liberalization of the attitude of public opinion towards marriage, it remains a preferred form of family life (Ячкова/Iashkova, 2002, p.39).

Family conflicts and the difficulty in finding an intimate, spouse to be partner were reinforced by the mobility of many people, caused by the social development - both internally and externally. Thousands of people moved. Most of the population was concentrated in Sofia and several other big cities. They were looking for livelihood, housing, security. While looking to meet these needs, they did not have time to think about family and children.

At the time of state capitalism from 1944 to 1989, the nomenclature pursued a policy of more even distribution of different types of infrastructure - industrial, human, social, of their balancing. There was a policy of more even development of the various regions in the country to make better use of their resources for the modernization of the country. Productions, education, health and culture were developed in smaller settlements, and there was welfare, more children were born, and people did not need migration as they do now.

During the transition, part of the population was superfluous for the new Bulgarian bourgeoisie and the economic elite. And, of course, politics was to allow the migration of many people from smaller settlements to the larger ones, and especially to the major cities. Any such migration has a detrimental effect on birth rates and families. It is a factor in family breakdown and birth rate degradation.

Even more negative was the external migration, especially when the one parent migrates. And the worst option is the more and more widespread variant of migration - of the mother looking for work and income outside the country. Splitting naturally hampers the lives of families and the birth of children. It hinders the normal upbringing and socialization of the children already born as well. The Bulgarian reality has confirmed the truth that the education of children from such family and unmarried cohabitation is very problematic. They are educated by grandparents who 
have a diminishing ability to meet all the children's needs due to physical, health and generational features.

The idea of a good family for such children is questioned. They witness rather bad family relationships, problematic relationships that distort the image of a family. And this, in turn, worsens the perception and desire of starting their own families in future. Among such families, the number of children who have been disqualified to study and work has increased. Their parents send them funds that make them feel better than many other children, which spoils them, those around them spare them because of their social status, and they are unmotivated to serious activity and selfimprovement. Some of them are recruited by drug dealers/become victims of drug addiction, alcohol, and indiscriminate sex.

Throughout the whole transition period, the importance of consumerist thinking has rapidly increased (Пачкова/Pachkova, 2009). Consumerism was entirely deliberately and purposefully formed in the younger generation. The rights were emphasized, the obligations were underestimated. This is in complete harmony with the main trend in the development of our civilization (Фукуяма/ Fukuyama, 2002), the Western type of capitalism.

In this line, there was a criticism to the time before 1989, with its lesser tendency towards consumerism, the cultivation of collectivist feelings and behavior, the cultivation of responsibility for the whole of society, and the lesser consideration of material values. During the transition, aggressively and consistently young people were educated to consume more and more material values, to resist everything that leads to limiting pleasures and material fulfillment, to lower the degree of their tolerance to the flaws of the partners (Мирчев/Mirchev, 2009, pp.79-80). And the creation and maintenance of a good family, the birth and the raising of children is related to a certain self-restraint, to the devotion to others, to greater tension and pain, with the desire to make compromises.

The number of young women who think they can live well without children is growing. And the growth of this view of life among young men is even greater (***HПИ/National Representative Survey, 2006). An increasing number of women adopt a compromise behavior - they do not get married to avoid having to attend a husband's needs but have at least one child in order to satisfy their maternal instinct (Рашевич/Rashevich, 2007, pp.69-75).

It went so far as to women learn to be afraid of giving birth due to the fact that it is accompanied by pain. And they are being pushed into the hands of physicians who have turned the Cesarean birth into an inhumane and lucrative business.

Unlike nowadays, the time of state capitalism, young people have been educated to think that it is normal for them to get married, to give birth to at least two children, to endure the pain of childbirth. Labor-pains, difficulties of childcare and attending for the partner needs were not an issue of debate. They were portrayed as the most natural thing in the world.

Nowadays, family formation, childbirth and their raising are presented not as a commitment to society, to the nation and country, but as a matter of completely free and democratic personal choice. The lack of patriotic upbringing, the promotion of cosmopolitan feelings contributes to the massification of such perception and behavior.

Worsen health, widespread smoking (including among women), alcoholism, drug abuse, unhealthy eating, indiscriminate sex, unreasonable abortion, increased levels of stress in the nation have affected the reproductive capacity of families. The number of families with reproductive problems has sharply risen (***Национална стратегия.../ National strategy, 2007).

In times of crisis, transition, a major social transformation, such as the Bulgarian one, the circumstances that lead to 'generation conflict', qualitatively different ways of life, the 
transformation of values, of assessments of the past and the future, are increasing (Мирчев/Mirchev, 2009 , p.52). And these further lead youngsters away from the patterns of behavior of the elderly.

Laissez-faire democracy in this situation is detrimental to the future of society. Lack of natality worsens economic performance, reduces the well-being of people - working ones, unemployed and retired. In short, societies are degrading. Some salvation would be to change politics, promote accountability and patriotic thinking. However, this is not in the interest of the economic actors who profit from alternative forms of family life. Lonely, unmarried people go on excursions more frequently - the change in their family model will damage the tourist business. Unmarried people more often make use of services of a prostitute, as well as more frequently enjoy the services of the porn industry, and so on. If they become exemplary spouses, the profits of a huge number of people who benefit from these economic sectors will be reduced. Alcoholised and stoned people are convenient customers of major sectors of the informal economy, the tourism industry. If emigration from the poorer to the richer societies is not allowed and even stimulated, the economies and prosperity of rich societies will worsen, etc. Too much harm to too many well-settled strata of people.

Another policy to be considered by decision-makers in Bulgaria would allow immigrants from even poorer or failed countries to rejuvenate the society. This means, on one hand, to look for workers from other countries, and, on the other hand, to allow mixed couples.

But this is also an outcome with many unknown risks due to the collision of global interests and policies of influential geopolitical players, due to the clash of religions, cultures, and so on.

The most likely outcome is societies such as ours will continue to support the development of other richer societies and will maintain the development of their negative trends at the expense of allowing these tendencies to deepen in Bulgaria.

Since the beginning of the Bulgarian transition period, the influence of family characteristics on the educational system, the demographic crisis and the moral values of society has qualitatively changed. The effect is largely negative. Family degradation and insufficient birth rates are among the main factors for the degradation of the education system and negative changes in the moral values taught at school and in society as a whole.

The analysis shows that the political elite is inconsistent in its efforts of shaping the social policy regarding the Bulgarian family, its reproductive behavior and its educational functions. On the one hand, it is guided by the interests of the economic elites, on the other hand, it is vulnerable to the external factors which are interested in the degradation of the Bulgarian nation and family. On the third hand, in order to have someone to rule, it is necessary to care for the population.

The ruling elite, on the one hand, supports a number of mechanisms to sustain the family, developed and practiced during the period of state capitalism until 1989. On the other hand, it introduced some new mechanisms. But most of them do not have the same level of quality and do not achieve the desired effect. There are world-class measures (such as the length of maternity leave), along with mistrust and frank de-stimulation of normal marital cohabitation and fertility.

But the worst thing is that the elite does not create the conditions to strengthen the positive influence of the main determinant factor in family planning - the good economic situation of the population, especially young people. Thus, the complex of incentives for family development is too contradictory and therefore ineffective. Most factors facilitate the degradation rather than the strengthening of the Bulgarian family. 


\section{Conclusion}

The influence of the tendencies in the development of the Bulgarian family described above continues to exist. But lately, some Bulgarians realize that rushing into alternative forms of family life or postponing the decisions to start a family is detrimental to them and are beginning to rethink their behavior. The instinct for self-preservation of individuals seems to reclaim its rights - albeit with little rates, but fertility increases, the desire for marital co-existence begins to recover, the explosive increase in cohabitation seems to have slowed down. The euphoria of the possibility of practicing alternative forms of family life has diminished. Many people have been scared by the specter of a childless, married life, of single parenthood, of unmarried life, and so on.

But the hope for a solid family strengthening and a substantial increase in birth rates in the near future is unlikely to be fostered. Very objective trends in public life, which can hardly be overcome even with good political decisions, continue to undermine family and birth rates. According to some studies, by 2030 the population in Bulgaria will decrease, as well as in Hungary, the Czech Republic, Romania and other countries (Атанасов/Atanasov, 2007, p.33).

\section{Bibliography}

1. Айдаров, Й. 1998. Криминология, София: Сиела, стр. 165 (Aidarov, I. 1998. Crimnology, Sofia: Siela p.165).

2. Атанасов, Ат., 2007. Населението на България - към по-голям брой или с по-добро качество. Списание на БАН, София, кн. 1, стр. 33 (Atanasov, A., 2007. The population of Bulgaria - to a higher number or better quality. Bulgarian Academy Magazine, Sofia, p.33).

3. Бояджиева, Ю., 2004. Компютърна престъпност, София, (Boiadjyeva, I., 2004. Coтputer Crime, Sofia).

4. Мирчев, М., 2009. Социална динамика и цчивилизационно разслояване, София: М-8-М, стр. 52 (Mirchev, M., 2009. Social dynamics and civilization stratification, Sofia: M-8M, p.52).

5. Михова, А., 2017. Осъждат по 4 деца на ден за кражби, грабежи или побой. „,24 часа“, 8 май 2017 г. (Mihova, А. 2017. Four children a day are sentenced for theft, robbery or beating, 24 Hors Journal, 8 May).

6. Пачкова, П., 2009. Медии, солидарност, гражданска активност на младежта. Моралът $в$ българските медии, София. (Pachkova, P., 2009. Media, solidarity, civic activity of youth. Moral in the Bulgarian media, Sofia).

7. Рашевич, М., 2007. Популяционные сценарии будущего Обьединенной Европы. Социологические исследования, бр. 4, Москва, стр.69-75 (Rashevich, M., 2007. Population scenarios for a future united Europe, Sociological Research, Moscow, pp.69-75).

8. Фукуяма, Фр., 2002. Нашето постчовешко бъдеще. Последицте от биотехнологичната револючия, София: Обсидиан (Fukuyama, F. 2002. Our post-human future. The consequences of the biotechnological revolution, Sofia: Obsidian).

9. Ханджиев, Р., 2016. Шо е тероризъм като проявление на фашизма и има ли той почва у нас? Фашизмът, София: Земя (Handjyev, R. Is terrorism a manifestation of fascism, and could it happen in our country? Fascism. Sofia: Zemya).

10. Ячкова, М., 2002. Семейството в България между XX и XXI век, София: АССА-М, стр. 38 (Iashkova, M. 2002. The family in Bulgaria between XX and XXI centuries, Sofia: ACCA-M, p.38) 
11. ***Всеки втори от младите между 18 и 25 у нас смятат, че бракът е отживелица. (Half of youngsters between 18 and 25 in our country believe that marriage is outdated) klassa.bg,21.3.2011 http://klassa.bg/news/Read/article/162743 [Accessed 21 March 2011]

12. *** Национално представително изследване (НПИ), Агенция за социални проучвания и анализи (ACCA-M), Май 1994 г. Май 2006 г. (National Representative Survey, Agency for Social Surveys and Analyses, May 1994 and May 2006)

13. ***Национална стратегия за демографско развитие на Република България 2006-2020, Министерство на труда и социалната политика (МТСП), Фонд на ООН за населението, Националния съвет за сьтрудничество по етническите и демографските въпроси (НССЕДВ) при МС, БАН, НСИ, С., 2007 (National Strategy for Demographic Development of the Republic of Bulgaria 2006-2020, study funded by Ministry of Labor and Social Policy, UN Fund for Population, National Council for Cooperation on Ethnic and Demographic Issues) 


\title{
Students' research activity as a contribution to modern university
}

\section{DOI: http://doi.org/10.26758/8.1.30}

Boris Manov (1), Valentina Milenkova (2)

(1) Political Sciences Department, South-West University "Neofit Rilski", Blagoevgrad, Bulgaria

(2) Sociology Department, South-West University "Neofit Rilski", Blagoevgrad, Bulgaria;

Address correspondence to: Boris Manov, Political Sciences Department, South-West University "Neofit Rilski", Bulgaria, 66 Ivan Mihajlov Str., Blagoevgrad, Ph.: 00359887546 766; E-mail: bmanov@swu.bg

Address correspondence to: Valentina Milenkova, Sociology Department, South-West University "Neofit Rilski", Bulgaria, 66 Ivan Mihajlov Str., Blagoevgrad, Ph.: 00359877917 044; E-mail: vmilenkova@gmail.com

\begin{abstract}
Objectives. The present article aims to analyze some aspects of student's training and the quality of lecturing as a specific basis for modern university support students' integration to research activities. The article focuses on how students assess the educational process, what is the quality of teaching, what part of the training is associated with the development of research activities among students; in what specific research activities students are participating. Special attention is paid to Ph.D. students as actors who have already made their choice for linking with research. Another important aspect of the analysis is the role of the family as an environment that stimulates and supports young people in their choices, preferences, and interests.

Material and methods. The paper is based on results obtained through quantitative as well as qualitative methods in the course of research projects carried out in 2013, 2015, and 2017 at SouthWest University (SWU). The main methods of obtaining information are focus groups and survey conducted with students from bachelor and master programs as well as with Ph.D. students in the Faculty of Philosophy, SWU.

Results and conclusions. The basic conclusion of the study is that the quality of education and the formation of creativity skills and student's research activity are related to the development of the modern university and the high level of education and training. Research activity forms many qualities that have both professional and social character and are important for the future realization of young people. The development of doctoral education is a prerequisite for the reproduction of the research potential of the university, so investments aimed at doctoral training are of great importance for the future of the university system and the stimulation of young people to develop their research workload.
\end{abstract}

Keywords: Ph.D. research activity; university; quality of education; departmental environment. 


\section{Introduction}

Development of Bulgarian higher education is connected with improving various training aspects, research activities, and teaching methods. One of the aims of higher education is to stimulate individuals to form a positive attitude towards the study process and to improve one's qualification and flexibility. The expansion of higher education brought about a worldwide increase in the number of universities. This growth has led to the establishment of new models and methods of education, which, in turn, have created a few challenges related to the efficiency and quality of the offered education (Royal, 2011). The quality of higher education reflects the relationship between society and tertiary education institutions; it is also a combination of various scientific, social, cultural and economic factors, revealing the significance of market economy as a tool for controlling higher education (Furst-Bowe, 2011, p.5). In a constantly changing world, quality of education is a continuous course of action, which depends on the positive outcome from the relationship between various actors, i.e. lecturers, students, parents, state institutions, and private partners.

The university is the institution that provides unity of training and research and in this sense focuses its efforts on the formation of Ph.D. students such as social actors who ensure the continuity of scientific work and research activities. The issues related to doctoral training are particularly important and current today. They include the quality of doctoral studies, the qualifications of the supervisors, the skills of Ph.D. students, the development of teamwork and various forms of collaboration, the enhancement of publishing activities and the creation of research networks of Ph.D. students from different national and European universities. Ph.D. is based on high-quality bachelor's and master's degree education because only good theoretical and methodological preparation implies a high level of performance of the doctoral program. Moreover, it is the lecturers in the bachelor and master's programs who prepare the Ph.D. students. In this connection, it is the correlation between variables referring to teaching process and the learning experiences of students in the context of higher education. The study leans on the thesis that university system encompasses interrelated organizational practices and the very understanding of these relations is critical for achieving the desired results.

The present article aims at analyzing several important aspects of rationalizing university education as an environment of intellectual and research transmission as well as supporting the high quality of students and Ph.D. students training, formation skills for research work and stimulating a communicative environment in the department.

This article is an analysis of the students and their point of view on the current inclusion in different research activities.

\section{Material and Methods}

The analysis is based in the empirical plan on several sociological surveys, used quantitative and qualitative methods, and covers the period 2013 - 2017.

- The survey "Integration of social- psychological sciences in a globalized world" conducted in 2013 in South-West University (SWU) with team leader Prof. Valentina Milenkova. Two methods were used: structured interviews and focus groups. The sample was unrepresentative and included 290 students from various faculties of the university; the sample was made under an experimental design scheme. The other method used was a focus group. There were three focus groups carried out with students and Ph.D. students from Sociology, Psychology and Political Science specialties of SWU. 
- A survey „Cultural universals in the academic environment” was carried out in 2015 at SWU with students and Ph.D. students from Social study specialties: Sociology, Political Sciences, and Psychology; there were conducted 5 focus groups. Team leader of the project was Prof. Valentina Milenkova.

- A survey in 2017 carried out under the project "The Role of Ph.D. students in the modern research process: towards creating highly qualified and proactive staff" in the Faculty of Philosophy at the South-West University with team leader Prof. Boris Manov. The study aimed at showing the place of Ph.D. students in the contemporary research process, as well as the improvement and support of their academic work by their thesis supervisor, department, and the family. In the process of the survey, 51 Ph.D. students from all majors of the Faculty of Philosophy (Psychology, Sociology, Political Science, and Philosophy) were questioned anonymously. The age range was from 24 to 66 years of age. The number of women was 36, and men were 15, which raises the problem of feminization of Ph.D. studies as a degree in the educational and academic training of researchers.

Apart from Ph.D. students, 130 B.A. and M.A. students from all majors of the Faculty of Philosophy were also questioned. B.A. students were 53, and M.A. students were 77. The research team added the opinions shared by B.A. and M.A. students to the information obtained about Ph.D. students because it was important to study the readiness of B.A. and M.A. students form the teaching programs of the faculty to engage in research activities; whether they had been involved in such activities; do they wish to continue their education in a Ph.D. program; do they receive support from their milieu - colleagues, friends, and family.

The main methods of information gathering were focus groups and survey conducted with graduate students, bachelor and master students in the Faculty of Philosophy, SWU.

\section{Results}

We have assumed that the high quality of doctoral training depends on the high quality of bachelor's and master's degree education. In this respect, in the quantitative study of 2013, we put the following question to the students: - How do you evaluate the study process and the quality of teaching?

The assessment in education is a two-way process between two sets of actors: 1) lecturers and students and 2) students and lecturers. Assessment of students' achievements should be impartial, without involving sympathy or antipathy; it brings into focus the real students' abilities and personalities (Brown, 1994). The final mark is a result of accumulation and interpretation of gathered information, results or skills; as a consequence, the assessment reveals the degree of correspondence between achievements and established standards. The assessment in education gives a clear notion of teaching and learning practices and their effectiveness. From this point of view, it is vital for the evaluation system to be reformed and renewed, to improve the old methods and to implement new ones.

The evaluation is a complex method which gives information about: 1) level of knowledge of the learning groups; 2) the progress of educational milieu - the professionalism of lecturers, the organization of classes; and 3) the set goals which need to be achieved. The object of evaluation is the whole system in the different aspects of its functioning - practices, experience, innovations, policies, and reforms. Evaluation does not have only controlling functions; it also has an encouraging and prognostic role, since its meaning is to reveal student's potential. Generally, students' achievements are a function of: 1) personal and social characteristics (gender, age, social origin) and 2) the educational environment (organization of the study process, lecturers' qualification and skills). Measuring resources (human, financial, social) and results give information 
on the effectiveness of the system. A frequent analysis of the educational environment and student's attainments outlines good possibilities for optimization of results.

An important part of the evaluation is the feedback. The lecturers assess student's knowledge, the way of thinking, ideas and skills according to certain standards. However, any grade has not only an informative facet but it must also involve a two-way communication.

Students' evaluation of teacher performance is one of the most controversial techniques used to identify the effectiveness of teachers (Nightingale, 1996). Aleamoni (1981) offers the following arguments to support the use of students' ratings on teachers' performance:

- Students are the main source of information about the learning environment, including teachers' ability to motivate students for continuing learning, empathy or the degree of the two-sided communication between instructors and students.

- Students are the logical evaluators of quality, effectiveness and satisfaction from course content, methods of teaching, textbooks, homework, and the degree of trainees' interest.

- Student ratings encourage communication between trainees and instructors.

The main idea of evaluation is rewarding and enhancing the development of the evaluated professionals: to know how students react to their grades; whether students take the grades into account; to what extent students strive to widen their knowledge, qualification, etc.

The criteria for education are based on a set of core values and concepts, which are interrelated, and those include visionary leadership, learning-centered education, and systems perspective (Furst-Bowe, 2011, p.3). In the conducted survey in 2013, the students were asked to evaluate diverse characteristics of "teachers' professionalism and qualification", such as: level of systematic organization of the study content; teachers' erudition and creativeness; quality of handouts, teaching methods and interaction during the lectures; level of dialogue with the audience; level of communication with students; fairness and neutrality in giving assessment marks (a quality system is in place at the university, and students at the end of each school year evaluate their teaching staff, their training and the teaching and assessment methods) etc.

The mentioned aspects in measuring professionalism among university teachers' have been elaborated a scale appraised by the students under a five-degree scale (from "completely agree" to "completely disagree"). The students shared the following answers:

1. Completely agree $(18 \%)$

2. Agree (29\%)

3. Indifferent $(13 \%)$

4. Disagree (22\%)

5. Completely disagree $(8 \%)$

It is noticed by the results that most of the respondents (47\%) highly evaluated teaching skills and involvement of their university teachers (Graph 1).

\section{Graph 1. Student evaluation of the level of professionalism of university lecturers}

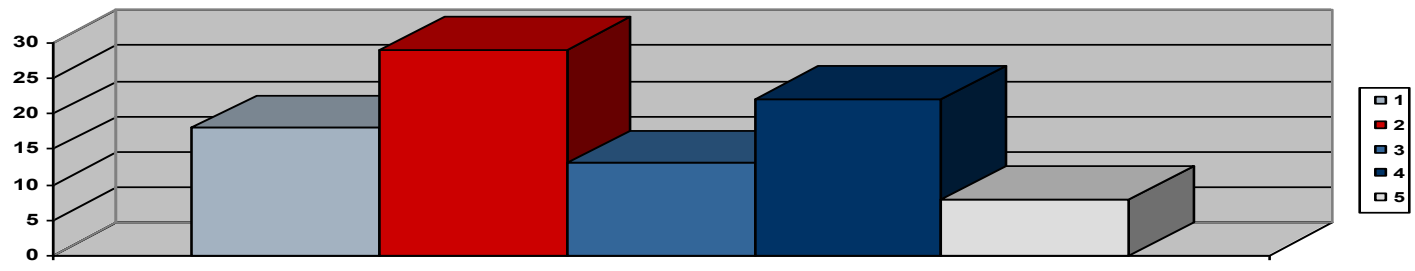


By demonstrating a critical approach towards the teaching process, the students from South-West University (SWU) have overtly offered their stance and motivation to raise their personal demands towards teachers' performance and skills. Approximately $1 / 3$ of the inquired students declared that lecturers are not unbiased in assessment and do not treat all students equally. According to some of the respondents, the lecturers are not prone to interactive teaching and learning methods; also, the study revealed that teachers do not maintain an open dialogue with students. This shows that the requirements of the teachers themselves need to be increased to their work, to increase reflexivity and to consider a more diverse and creative approach.

As a continuation of the topic of the professors' professionalism are also the results of Study of the Institute for Economic Studies, Bulgarian Academy of Sciences (Zareva et al, 2014). The study analyzes the state of higher education and the quality of training that is being maintained. The interdisciplinary study (2012-2013) reveals that $31 \%$ of the academic staff gives a poor mark to Bulgarian higher education. In contrast, $80.6 \%$ of the students define Bulgarian tertiary education as 'good', 'very good' and 'excellent'.

Only $51 \%$ of university teachers believe that Bulgarian higher education is competitive in Europe. More critical in this respect are teachers from private universities. Possible remedies for solving the problems in this sphere, in respondents' opinion, are:

- Achieving an optimal balance between state governance and the autonomy of the HEIs

- Upgrading financial and regulatory framework of higher education

- Linking education with the strategic priorities for economic development and strengthening the link higher education institutions - employers

- Encouragement of business enterprises to invest in universities through receiving tax relieves and other stimuli (change in normative framework is needed)

- Contractual relations between universities and employers (or the Chamber of commerce), state administration, scientific institutions, foreign HEIs and foreign organizations

- Introducing tougher criteria for selection of students

- Enhancing internal and external control over the HEIs; enhancing the knowledge, skills and motivation of both faculty and students

- Updating and upgrading technology, learning content and methods for training

- Funding for capable students

- Synchronization of training programs with practice (Zareva et al., 2014, p.123).

The globalization is increasingly demanding the ability to learn and acquire new skills rapidly and to adapt to new challenges and situations. The most important skill in professional aspect at the moment is the "booming" and quickly developed computer industry that is why computer skills are advisable. In general, the students believe that they have to develop and improve their personal skills during the whole life.

\section{The University as an institution for research skills formation}

The characteristics of the successful professional should be adequate to the requirements of the social situation. The increased significance of research work and research skills (Giddens, 2009) stems from their close reference to future professionalism and social status. In this regard, university education has been attaining a crucial role in the developing of research-centered training of students. One of the most important questions is whether research attitudes are inherited or acquired and formed in the process of learning and development. Obviously, the answer to this question is a complex symbiosis of biological and genetic qualities on the one hand and of created abilities and 
skills on the other hand. Young people participating in the discussions have expressed the view that personal talents and predispositions have to be taken into account, the role of the family as a factor in the formation of research qualities is crucial, but also the educational institutions have a significant impact in the process. In this connection, the role of the university as an institution, which forms the research skills of the students, is growing.

In five focus groups conducted in 2015 at the South-West University under the project „Cultural universals in the academic environment”, students shared that important skills the researcher should possess are:

- Intellectual capabilities;

- Self-improvement;

- Creativity;

- Thoroughness;

- Inspiration.

Participants in the group discussions focused on the creativity as an important skill; they say, "The researcher is the person who has to offer solutions, get out of difficulties, and deal with complex situations". In this sense, creativity becomes the decisive ability of the modern researcher. Educational institutions are largely responsible for developing this skill.

In addition the students participating in the survey (carried out in 2013) declared that: "Education has to develop creative attitudes": $86.0 \%$ of the respondents expressed agreement with that statement: 1 - fully agree $61.5 \% ; 2$ - agree: $24.5 \% ; 3$ - neither agree, nor disagree: 11.5\%; 4 disagree: $1.5 \% ; 5$ - fully disagree: $0 \% ; 6$ - don't know 1\% (Graph. 2).

\section{Graph. 2 Education has to develop creative attitudes}
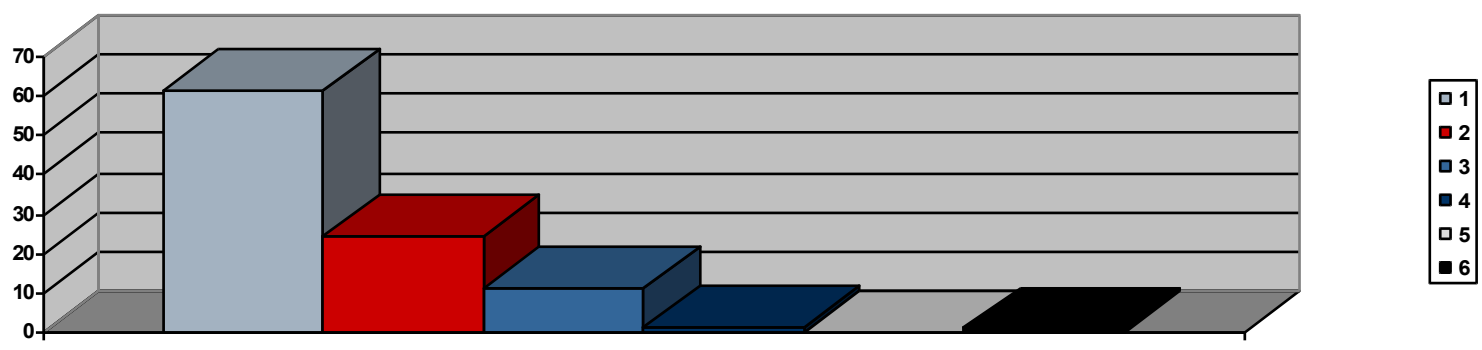

Formation of creativity is related to the study contents that are taught in university, to the specific rules and values in organizational aspect, to the contacts and sub-cultures, which university develops and draws individuals into different relations; university forms the research skills through the basic agents of its impact - professors and lecturers. All those components accumulate definite experience in themselves and they become bearers of particular purpose and engagement devoted to shaping in accordance with the social pattern which determines them. That is important, because through the inclusion of students into research activities:

a) increases the acquired qualification and professional skills;

b) gets students near to laboratories and the processes of constructing knowledge;

c) contributes to acquiring competence through their inclusion into diverse activities ("learning by doing");

d) creates attitude towards learning and adoption of new possibilities. 
According to the students involved in the focus groups, research is related to the development of intellectual skills and qualifications; so students should become more active and interested in training; to apply in practice the matter for instruction at lectures and seminars, to learn new things and turn into a corrective of lecturers' work, through pose the questions and asking for additional specifications.

Creativity and research activity implies complex personal development as from the point of view of obtaining specific skills and competence, as well as concerning qualities necessary for the construction of general attitude towards knowledge and research. Here are some of the qualities, promoted by research activities:

- Criticism and self-reflection.

- Openness to changes.

- Aptitude towards perfection.

- Ambition and active approach

- Teamwork.

It can be noticed that creativity as an aspect of research ability is associated mainly with activities bearing in them the store of a specialized teaching activity, understood as part of professional occupation with research. At the same time, however, along with that conception, shared among students, one has to bear in mind that the research activity is formed through routine and everyday training practices at classrooms and auditoriums as well, which is connected with assigning specific tasks at lectures, seminars, and exercises, literary studies on a definite topic, elaboration of term papers, making presentations, writing of reports and of essays.

Another way to formation research abilities in a university environment is teamwork i. e. "the possibility to discuss different things with the other young people during the classes", "the appearance in front of the other students", "field work". It was observed that the majority of students find attractive the social aspects of university work, namely possibilities for discussions, for establishing of contacts, so that sociability might be considered one of the motivations for including students in different leadership activities.

At every one of the indicated activities, implemented within the framework of training and assigned to students by their lecturers a specific research effort, connected with theoretical and exploratory work, with coordination of the team and distribution of the engagements of every one of the members, making of generalizations and presenting the results from theoretical and/or practical work are presumed. Those are all the important everyday efforts, which are necessary, and the students perceive them as various aspects of training.

That is why it is important to accentuate on the fact that the formation of research abilities is connected with the quality of education, the preparation of lecturers themselves, their participation in different scientific nets, with lecturers and students readiness to work together.

\section{Ph.D. students}

The topic for the formation of research activity was also developed by the project carried out in 2017 in which we asked PH.D. students: How the university should develop research skills? Shared opinions pointed at:

- Inclusion in research projects;

- Participation in conferences and roundtables;

- Writing articles on different topics;

- Elaboration of creative presentations; 
All that means that the departments are primarily responsible for the way they develop the students' skills. In this context is the issue of the autonomy of Ph.D. students to make decisions relating to their work. It was discussed the choosing the title of the Ph.D. thesis. The topic is of significant importance because it assures that the research potential of the scholar is developed through it. All Ph.D. students who participated in the survey in the Faculty of Philosophy in 2017 confirmed that the topic of their theses and their academic interests coincide. Also, a half of the Ph.D. students shared that their Ph.D. thesis is a continuation of their Master's thesis. This means that there exist succession and continuity in the research work undertaken. This is a prerequisite for deepening the interests in the respective research area but it also means that there is a process of discussing and consideration of the views and plans of the Ph.D. students with respect to support and co-operation from the staff within the various departments in the Faculty of Philosophy.

The attitudes of colleagues and the overall milieu, in which Ph.D. students' training and formation as researchers take place, is significant for the complete research work. In this context, a special role is played by the supervisor who is the direct tutor and advisor of the Ph.D. student, with whom all basic ideas of the thesis are being discussed, and who follows the progress of the research work. 91.5\% of the surveyed Ph.D. students in 2017 have stated that they receive full support from their supervisor.

Regarding support from the department, $91.5 \%$ expressed the opinion that they receive support from the department in which their Ph.D. training takes place.

In this sense, we can summarize that Ph.D. students at the Faculty of Philosophy, SWU in the current moment have the support, co-operation for work and achieving their goals. This cooperation comes from both the colleagues and the educational institution itself as an intellectual milieu and incentives for research work.

\section{The Role of the family}

One of the important topics studied during the survey of 2017 was connected to the support received by the Ph.D. students from their family, and friends. The family has a strong impact on dispositions towards life, future, self-image, and work. It creates a specific environment and the total set of conditions related to understanding and care (Coleman 1988).

Family background can also result in contextual differences that may affect achievement and motivation. All $\mathrm{Ph}$. D. students in the surveys of 2017 declare that they have support from their families which itself turns into an important element of the ongoing work on the thesis connected to the co-operation of the family in an emotional, social, and economic plan directed to the future development of the Ph.D. students.

Young people's opinion in the survey revealed a clear relationship between family/ parent support and student achievements. In other words, parents who are actively involved in their children's education and provide a stimulating learning environment at home can help their children develop feelings of competence, control, curiosity, and positive attitudes about academics.

It is necessary to emphasize that "significant others" have a special place in the personal formation. These are:

- The family, as financial and emotional support. Family background can also result in contextual differences that may affect achievements and success.

- The role of the teachers and the educational environment and their impact and the formation of habits and skills.

- The influence of friends and informal environment as a source of support and information. 
- The role of the institution - with the emphasis on the formal side as organizing courses and training.

The "middle class" families are more likely to raise their children to choose and focus on the exact sphere in education, and also of the importance of education in general. As a result, the respondents have demonstrated one very positive attitude towards research and education. It seems like students that came from poor regions are more motivated to study and to engage in research work, because this will help them to "escape" from the "village" or "small town" and to find a better job in the big cities.

According to the respondents, "Every skill has a positive influence". Social skills such as "self-confidence", "self-direction" and "risk-taking" are also increasingly important, because people are expected to be able to behave much more autonomously. "Learning how to learn", "to adapt", " to change" and "to make sense of the vast information flows" are now generic skills that everyone should acquire: "It is important to be able to communicate with people and to understand others". What is important to the respondents lies in the opportunities to develop, participate in life, and find a good environment to be successful.

Some of the young females set the topic for the role of a woman: whether she wants to find a better and well-paid job and she could have the ability to combine professional realization and motherhood. It turns out that gender and the role of motherhood and the relationship with the children remains an eternal theme and can become a problem for the young families and the professional choice of women.

\section{Discussion and Conclusions}

One of the substantial conclusions of the article is that the quality of education, the professionalism of the teachers, the methods of evaluation are not sufficiently appreciated by the students, both nationally and locally. It can be said that the formation of different skills related to the realization of young people is a very responsible process that takes place in the educational system. Furthermore, the development of creative skills for research and activity is always the result of various efforts. In the course of this article, the issue of the attitude of young people towards research, participation, maintenance of sustainable interest in science was discussed. The selection of young people who have a creative attitude, curiosity, interest in the new, thoroughness and author's approach is of great importance. Equally important, however, is the problem of ethics in science. The organization of continuous control and further training and education of young researchers and Ph.D. students in the spirit of scientific ethics is essential.

Challenges to university education in view of providing research skills to young people are connected with:

- Curricula and study programmes, which have to stimulate more creativity and individual approach, and to correspond to person-centered pedagogy.

- Curricula have to show higher mobility and to include more free-chosen disciplines.

- The opening of universities towards older generations, which might turn the universities into real "life-long learning institutions". It is necessary in connection with that distance training forms to be developed further on.

- The activation of project work at universities level as well as an accent on assigning different creative tasks to students in the process of training.

University education is an environment of intellectual interaction; it has a central role in delivering key skills to students, as it is research-centered and focused on attaining knowledge and qualification. 
To summarize, the future of the Bulgarian higher education is expected to refer to developing of prioritized academic disciplines and relevant learning content, as well as to target career orientation and investment in scientific research and innovation.

$\mathrm{Ph}$.D. programs in the Bulgarian conditions are an important factor for the formation of academic staff. They are a period of several years during which Ph.D. students develop their research skills connected to analyticism, creative thinking, sharing ideas, discussions, conducting empirical work. It is namely this period, which is important for the future research work, and a more active and responsible attitude is needed in an institutional plan to the development of Ph.D. students because the future of science depends on their qualities and responsibilities.

\section{References}

1. Aleamoni, Lawrence M., 1981. Student Ratings of Instruction. In: Jason Millman, ed. Handbook of Teacher Evaluation. Beverly Hills, CA: SAGE Publications.

2. Brown, S., Rust, C., and Gibbs, G., 1994. Strategies for Diversifying Assessment in higher education. Oxford: Oxford Centre for Staff De velopment.

3. Coleman, J.S., 1988. Social Capital in the Creation of Human Capital. American Journal of Sociology, 94, pp.95-121.

4. Durkheim, E.,1956. Education and Sociology, New York: Free Press.

5. Ferragina, E., 2012. Social Capital in Europe: A Comparative Regional Analysis. Cheltenham, UK: Edward Elgar.

6. Furst-Bowe, J., 2011. Systems Thinking: Critical to Quality Improvement in Higher Education (Guest Commentary). Quality Approaches in Higher Education, 2(2), pp.2-4.

7. Giddens, A., 2009. Sociology. $6^{\text {th }}$ edition. Revised and updated with P.W. Sutton. Cambridge, UK; Malden, MA: Polity Press.

8. Nightingale, P., Wiata, I.T., Toohey, S., Ryan, G., Hughes, C., Magin, D., 1996. Assessing Learning in Universities. Sydney: University of New South Wales Press.

9. Royal, K., 2011. Understanding Reliability in Higher Education. Student Learning Outcomes Assessment. Quality Approaches in Higher Education, 2(2), pp.8-16.

10. Zareva, I., Matev, M., and Kirova, A., 2014, Higher education in Bulgaria. Economic, social and gender dimensions. Sofia: Akademichno izdatelstvo "Prof. Marin Drinov" (Marin Drinov Academic Publishing House). 